\title{
Hanford 100-D Area Biostimulation Treatability Test Results
}
MJ Truex
M Oostrom
VR Vermeul
DR Newcomer
BG Fritz
FJ Brockman
RD Mackley
CL Bilskis
DP Mendoza
SS Hubbard
RP Elmore JE Peterson
AV Mitroshkov
$\mathrm{KH}$ Williams
DS Sklarew
E Gasperikova
CD Johnson
J Ajo-Franklin

September 2009

Pacific Northwest NATIONAL LABORATORY

Proudly Operated by Battelle Since 1965 


\title{
DISCLAIMER
}

This report was prepared as an account of work sponsored by an agency of the United States Government. Neither the United States Government nor any agency thereof, nor Battelle Memorial Institute, nor any of their employees, makes any warranty, express or implied, or assumes any legal liability or responsibility for the accuracy, completeness, or usefulness of any information, apparatus, product, or process diselosed, or represents that its use would not infringe privately owned rights. Reference berein to any specific commercial product, process, or service by trade name, trademark, manufacturer, or otherwise does not necessarily constitute or imply its endorsement, recommendation, or favoring by the United States Government or any agency thereof, or Battelle Memorial Institute. The views and opinions of authors expressed herein do not necessarily state or reflect those of the United States Government or any agency thereof.

\author{
PACIFIC NORTHWEST NATIONAL LABORATORY \\ operated by \\ BATTELLE \\ for the \\ UNITED STATES DEPARTMENT OF ENERGY \\ under Contract DE-AC0 -76RLO1830 \\ Printed in the United States of America \\ Available to DOE and DOE contractors from the \\ Ofice af Srientifie und Technieal Inforumetion, \\ P.O. Box 62, Oak Ridge, TN 37831-0062; \\ ph: (865) 576-8401 \\ fax: (865) $576-5728$ \\ email: reports adonis.osti.gov \\ Available to the public from the National Technical Information Serviee, \\ U.S. Department of Commerce, 5285 Port Royal Rd., Springfield, VA 22161 \\ ph: $(800)$ 553-6847 \\ fas: $(703)$ 605-6900 \\ email: ordersantis.fedworld.gov \\ online ordering: http://www.ntis.gov/ordering.htm
}

This document was printed on recycled paper.

$(9 / 2003)$ 


\section{Hanford 100-D Area Biostimulation Treatability Test Results}

$\begin{array}{ll}\text { MJ Truex } & \text { M Oostrom } \\ \text { VR Vermeul } & \text { DR Newcomer } \\ \text { BG Fritz } & \text { FJ Brockman } \\ \text { RD Mackley } & \text { CL Bilskis } \\ \text { DP Mendoza } & \text { SS Hubbard } \\ \text { RP Elmore } & \text { JE Peterson }^{(a)} \\ \text { AV Mitroshkov } & \text { KH Williams } \\ \text { DS Sklarew } & \text { E Gasperikova } \\ \text { CD } \\ \text { CD Johnson } & \text { J Ajo-Franklin }^{(a)}\end{array}$

September 2009

Prepared for

the U.S. Department of Energy

under Contract DE-AC05-76RL01830

Pacific Northwest National Laboratory

Richland, Washington 99352

(a) Lawrence Berkeley National Laboratory, Berkeley, California. 


\section{Executive Summary}

Pacific Northwest National Laboratory conducted a treatability test designed to demonstrate that in situ biostimulation can be applied to help meet cleanup goals in the Hanford Site 100-D Area. In situ biostimulation has been extensively researched and applied for aquifer remediation over the last 20 years for various contaminants. In situ biostimulation, in the context of this project, is the process of amending an aquifer with a substrate that induces growth and/or activity of indigenous bacteria for the purpose of inducing a desired reaction. For application at the 100-D Area, the purpose of biostimulation is to induce reduction of chromate, nitrate, and oxygen to remove these compounds from the groundwater. The in situ biostimulation technology is intended to provide supplemental treatment upgradient of the In Situ Redox Manipulation (ISRM) barrier previously installed in the Hanford 100-D Area and thereby increase the longevity of the ISRM barrier. Substrates for the treatability test were selected to provide information about two general approaches for establishing and maintaining an in situ permeable reactive barrier based on biological reactions, i.e., a biobarrier. These approaches included 1) use of a soluble (miscible) substrate that is relatively easy to distribute over a large areal extent, is inexpensive, and is expected to have moderate longevity; and 2) use of an immiscible substrate that can be distributed over a reasonable areal extent at a moderate cost and is expected to have increased longevity. For the treatability test, molasses was selected to represent a commercially available approach based on a soluble substrate. Emulsified vegetable oil, consisting of the commercially available EOS ${ }^{\circledR} 598$ product (EOS Remediation, LLC.), was selected as the immiscible substrate.

The following conclusions related to the test objectives for the soluble substrate are supported by the

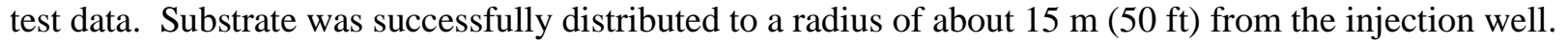
Monitoring data indicate that microbial growth initiated rapidly, and this rapid growth could limit the ability to inject substrate to significantly larger zones from a single injection well. As would be expected, the uniformity of substrate distribution was impacted by subsurface heterogeneity. However, subsequent microbial activity and ability to reduce the targeted species were observed throughout the monitored zone, and low oxygen, nitrate, and chromium concentrations were maintained for the approximately 2-year duration of monitoring. Aquifer permeability reduction within the test zone was moderate and likely due to growth of bacteria. The injected substrate and associated organic degradation products persisted for

about 1 year. Over the second year of barrier monitoring, organic substrate concentrations were low; the continued effectiveness of the treatment zone is attributed to recycling of organic compounds associated with the biomass that was produced during the first year.

The following conclusions related to the test objectives for the immiscible substrate are supported by the test data. Substrate was successfully distributed to a radius of about $8 \mathrm{~m}(25 \mathrm{ft})$ from the injection well. As would be expected, the uniformity of substrate distribution was impacted by subsurface heterogeneity. However, subsequent microbial activity and ability to reduce the targeted species were observed throughout the monitored zone, and low oxygen, nitrate, and chromium concentrations were maintained for the approximately 10-month duration of monitoring. Aquifer permeability reduction within the test zone was moderate and occurred quickly after substrate injection, likely due to physical effects from the presence of immiscible liquid in the aquifer. The monitoring period for the immiscible test was short compared to the expected longevity of the substrate. Therefore, additional monitoring would be necessary to determine the longevity of the treatment. 


\section{Acknowledgments}

Funding for this project was provided by the U.S. Department of Energy Office of Environmental Management (EM-22) Columbia River Protection Supplemental Technologies Project. We thank R. Blaine Rowley and Skip Chamberlain (DOE Headquarters, EM-22), K. Mike Thompson (DOE Richland Operations Office), and Jonathan S. Fruchter (PNNL), for overall management of the EM-22 project and support of this project. We also acknowledge and appreciate the BER Environmental Remediation Science Program support to Susan Hubbard for the column experiments conducted in conjunction with the geophysical field monitoring activities. 


\section{Acronyms and Abbreviations}

$\begin{array}{ll}\text { bgs } & \text { below ground surface } \\ \text { DOE } & \text { U.S. Department of Energy } \\ \text { EBF } & \text { electromagnetic borehole flow meter } \\ \text { EPA } & \text { U.S. Environmental Protection Agency } \\ \mathrm{ft} & \text { foot, feet } \\ \text { gal } & \text { gallon(s) } \\ \text { gpm } & \text { gallons per minute } \\ \text { GPR } & \text { ground-penetrating radar } \\ \text { in. } & \text { inch(es) } \\ \text { ISE } & \text { ion selective electrode } \\ \text { ISRM } & \text { In Situ Redox Manipulation (barrier) } \\ \text { L } & \text { liter(s) } \\ \text { L/min } & \text { liter(s) per minute } \\ \text { m } & \text { meter(s) } \\ \text { MCL } & \text { Maximum Contaminant Level } \\ \text { NIST } & \text { National Institute of Standards and Technology } \\ \text { NTU } & \text { nephelometric turbidity unit(s) } \\ \text { OD } & \text { outside diameter } \\ \text { PNNL } & \text { Pacific Northwest National Laboratory } \\ \text { PV } & \text { pore volume } \\ \text { RCRA } & \text { Resource Conservation and Recovery Act of 1976 } \\ \text { TOC } & \text { total organic carbon }\end{array}$




\section{Contents}

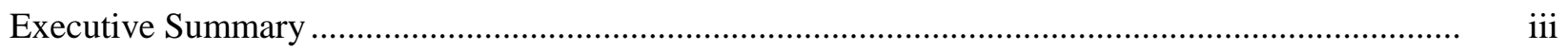

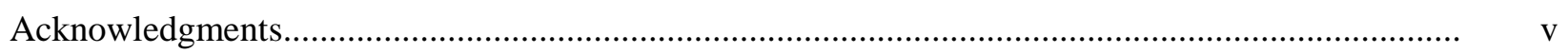

Acronyms and Abbreviations ..................................................................................................... vii

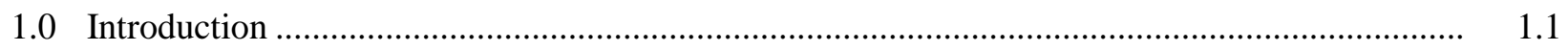

1.1 Site and Waste Stream Summary ............................................................................... 1.1

1.2 Treatment Technology Description................................................................................ 1.1

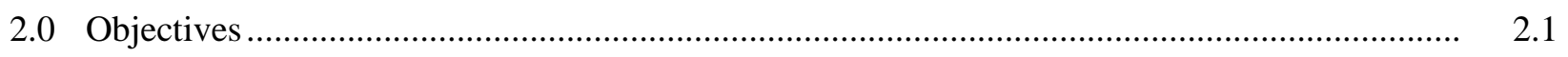

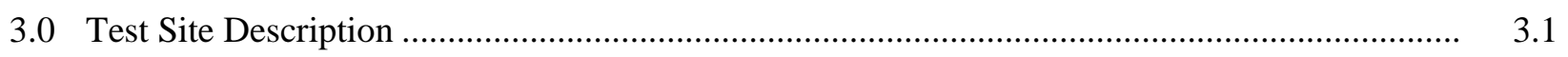

3.1 Test Site Location and Hydrogeologic Setting............................................................. 3.1

3.2 Site-Specific Characterization ................................................................................. 3.4

3.2.1 Hydraulic Properties................................................................................ $\quad 3.7$

3.2.2 Electronic Borehole Flowmeter Summary .......................................................... 3.11

3.2.3 Baseline Water Chemistry ................................................................................ 3.21

3.3 Description of Groundwater Flow System ................................................................ 3.22

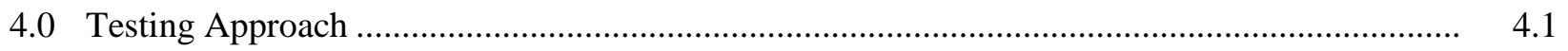

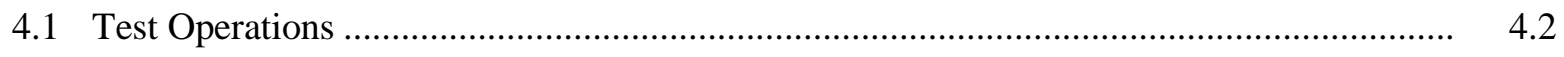

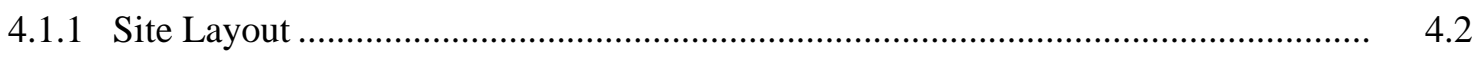

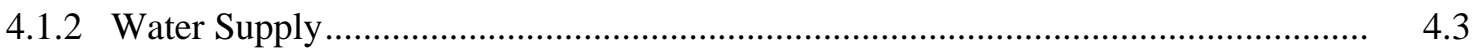

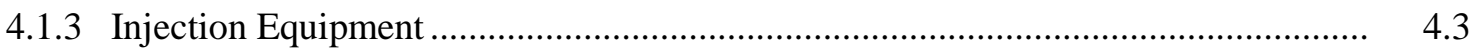

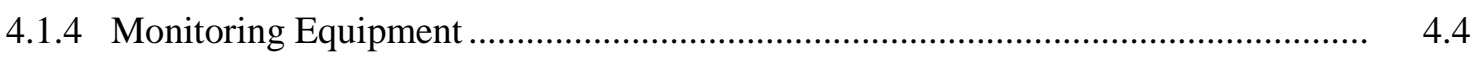

4.1.5 Soluble Substrate Operations ............................................................................. 4.6

4.1.6 Immiscible Substrate Operations..................................................................... 4.7

4.2 Hydraulic Testing to Evaluate Permeability Changes...................................................... 4.8

4.2.1 Hydraulic Slug Testing Methods.............................................................................. 4.8

4.2.2 Geophysical Testing Methods ........................................................................ 4.11

4.3 Test Data Collection and Management .................................................................... 4.20

4.4 Deviations from the Treatability Test Plan .................................................................... 4.21

5.0 Results for the Soluble Substrate Test ..........................................................................

5.1 Injection Description and Results ....................................................................... 5.1

5.2 Process Monitoring Results....................................................................................... 5.8

5.3 Performance Monitoring Results ................................................................................. 5.9

5.3.1 Water Chemistry for Target Compounds ......................................................... 5.9

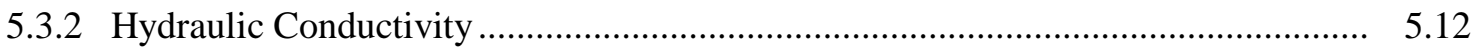

5.3.3 Performance Assessment...................................................................................... 5.14

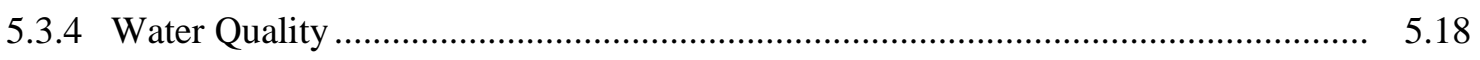

5.4 Summary Comparison of Laboratory Microcosm and Field Test Results .......................... 5.20 
5.5 Description of Results Relative to Field Test Objectives.............................................. 5.22

6.0 Results for the Immiscible Substrate Test ....................................................................

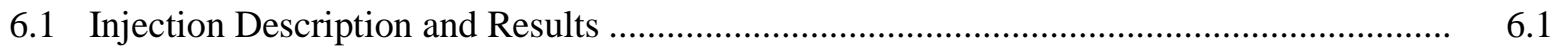

6.2 Performance Monitoring Results ............................................................................. 6.7

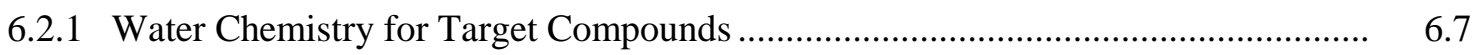

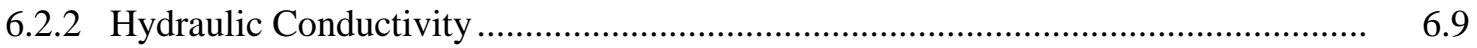

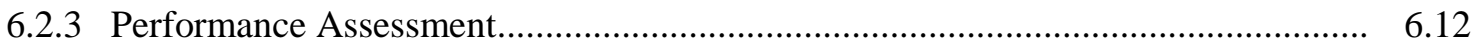

6.2.4 Water Quality ........................................................................................ 6.16

6.3 Summary of Laboratory Emulsion Experiments............................................................. 6.18

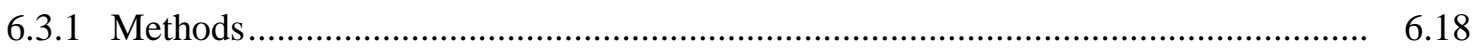

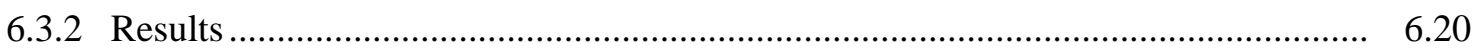

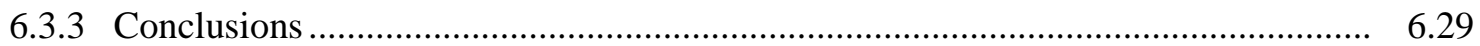

6.4 Description of Results Relative to Field Test Objectives................................................. 6.30

7.0 Conclusions and Recommendations .............................................................................. 7.1

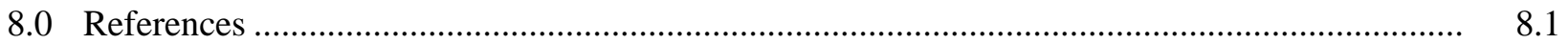

Appendix A - Borehole Logs and Well Completion Diagrams for the Test Site Wells..................... A.1

Appendix B - Gradient Direction and Magnitude in the 100-D Area During the Field Test.............. B. B.1

Appendix C - Geophysical Methods Background.......................................................................... C.1

Appendix D - Field Test Data ......................................................................................... D. D.

Appendix E - Organic Compound Concentration Data Plots for the Soluble Substrate Test ............. E. E.1

Appendix F - Detailed Slug Testing Results .................................................................................. F.1 


\section{Figures}

3.1 Test Location and Recent Chromate Concentration Data for the 100-D Area

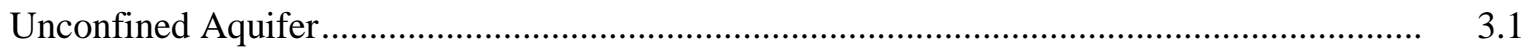

3.2 Test Location and Nitrate Concentration Data for the 100-D Area Unconfined Aquifer........................................................................................................... $\quad 3.2$

3.3 100-D Area Hydrogeologic Cross Section of the Uppermost Aquifer ................................... 3.3

3.4 Site Wells and Location of Geologic Cross Section............................................................ 3.4

3.5 Cross Section View of the Field Test Site .........................................................................

3.6 Top of Underlying Confining Unit ...............................................................................

3.7 Saturated Thickness in the Ringold Formation .................................................................. 3.7

3.8 Recovery Responses for August 2008 Constant-Rate Test in Well 199-D5-108e ................... 3.9

3.9 Neuman Type-Curve Analysis of Pressure Recovery from Well 199-D5-115 for August 2008 Constant-Rate Injection Test in Well 199-D5-108 ...................................... 3.10

3.10 Neuman Type-Curve Analysis of Pressure Recovery from Well 199-D5-116 for August 2008 Constant-Rate Injection Test in Well 199-D5-108_..................................... 3.10

3.11 Neuman Type-Curve Analysis of Pressure Recovery from Well 199-D5-117 for August 2008 Constant-Rate Injection Test in Well 199-D5-108...................................... 3.11

3.12 Electromagnetic Borehole Flowmeter General Configuration ............................................... 3.12

3.13 Electromagnetic Borehole Flowmeter Calibration Results ................................................ 3.13

3.14 Ambient and Dynamic Vertical Flow Profiles, Well 199-D5-107 ....................................... 3.16

3.15 Normalized Hydraulic Conductivity Profile, Well 199-D5-107 ............................................ 3.16

3.16 Ambient and Dynamic Vertical Flow Profiles, Well 199-D5-109 ......................................... 3.17

3.17 Normalized Hydraulic Conductivity Profile, Well 199-D5-109 ........................................... 3.17

3.18 Ambient and Dynamic Vertical Flow Profiles, Well 199-D5-110 ......................................... 3.18

3.19 Normalized Hydraulic Conductivity Plot, Well 199-D5-110 ................................................. 3.19

3.20 Ambient and Dynamic Vertical Flow Profiles, Well 199-D5-111 ......................................... 3.20

3.21 Normalized Hydraulic Conductivity Profile, Well 199-D5-111 ............................................ 3.20

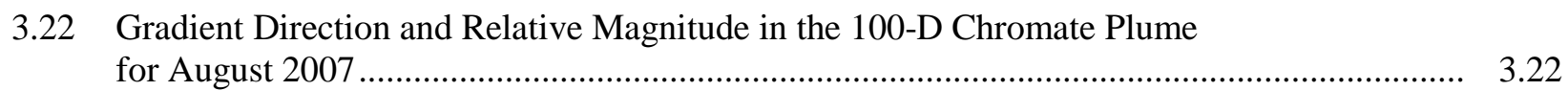

3.23 Gradient Magnitude and Direction from Triangulation Analysis with Wells 199-D5-43, 199-D5-20, and 199-D5-38 and River Stage Data.................................... 3.24

4.1 Conceptual Layout of Test Cells .................................................................................

$4.2 \quad$ Well Layout for the Soluble Substrate Field Test ................................................................

4.3 Well Layout for the Immiscible Substrate Test..................................................................

4.4 Injection Manifold with the Make-Up Water and all Other Necessary Components................ $\quad 4.4$

4.5 Groundwater Sample Acquisition System......................................................................... 4.5

4.6 Slug Test Response for Well 199-D5-109 Showing an Example of the "Double-Straight Line" Effect Observed on Semi-Log Plots for Wells Screened Across the Water Table...................................................................................... 4.10

4.7 Geophysical Measurement Columns Used in the Laboratory Experiments ............................ 4.13 
4.8 Geochemical Analysis of Effluent Fluid Samples from the Molasses

Experimental Column Study.

4.9 Geophysical Responses Associated with Molasses Flow-Through Biostimulation Column Experiment

4.10 Results of Vegetable Oil Biostimulation Flow-Through Column Experiments

5.1 Pressure Recovery Response in Observation Well 199-D5-110 Following the September 2007 Molasses Injection

5.2 Pressure Response at Injection and Monitoring Wells During the Molasses Injection Period

5.3 Flow Rate of Injected Solution and Molasses During the Injection Period

5.4 Operational Parameters Measured at Injection Well 199-D5-107 During the Injection Phase of the Test

5.5 Operational Parameters Measured at Monitoring Well 199-D5-109 During Injection in 199-D5-107

5.6 Operational Parameters Measured at Monitoring Well 199-D5-110 During Injection in 199-D5-107

5.7 Operational Parameters Measured at Monitoring Well 199-D5-111 During Injection in 199-D5-107

5.8 Operational Parameters Measured at Monitoring Well 199-D5-112 During Injection in 199-D5-107

5.9 Operational Parameters Measured at Monitoring Well 199-D5-113 During Injection in 199-D5-107

5.10 Nitrate Concentrations over the Duration of the Test.

5.11 Nitrite Concentrations over the Duration of the Test

5.12 Total Chromium Concentrations from Laboratory Analysis.

5.13 Chromate Concentrations Using Spectrophotometric Analysis ....

5.14 Baseline Radar Imaging and ‘Difference’ Radar Imaging

5.15 Bromide Concentrations over the Duration of the Test.

5.16 TOC Concentrations over the Duration of the Test

5.17 Glucose Concentrations over the Duration of the Test.

5.18 Acetate Concentrations over the Duration of the Test.

$5.19 \mathrm{pH}$ over the Duration of the Test.

5.20 Sulfate Concentrations over the Duration of the Test

5.21 Iron Concentrations over the Duration of the Test

5.22 Methane Concentrations over the Duration of the Test

5.23 Arsenic Concentrations During the Test

5.24 Barium Concentrations During the Test.

5.25 Selenium Concentrations During the Test.

5.26 Denitrification Observed When Microcosm was Spiked with Nitrate While Acetate Concentration was Greater Than $30 \mathrm{mM}$

5.27 Denitrification Observed When Microcosm was Spiked with Nitrate While Acetate Concentration was Less Than $5 \mathrm{mM}$. 
6.1 Flow Rate of Injected Solution and Emulsified Oil During the Injection Period..................... 6.2

6.2 Injection Pressure During Emulsified Oil Injection .......................................................... 6.2

6.3 Pressure Response at Injection and Monitoring Wells During the Injection Period ................. 6.3

6.4 Operational Parameters Measured at Injection Well 199-D5-108 During

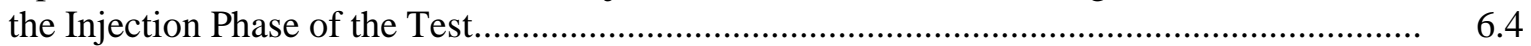

6.5 Operational Parameters Measured at Monitoring Well 199-D5-114 During

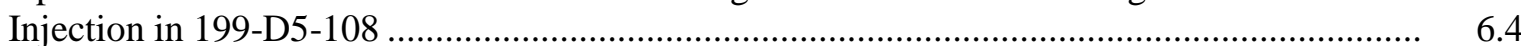

6.6 Operational Parameters Measured at Monitoring Well 199-D5-115 During

Injection in 199-D5-108

6.7 Operational Parameters Measured at Monitoring Well 199-D5-116 During

Injection in 199-D5-108

6.8 Operational Parameters Measured at Monitoring Well 199-D5-117 During I njection in 199-D5-108

6.9 Operational Parameters Measured at Monitoring Well 199-D5-118 During Injection in 199-D5-108

6.10 Nitrate Concentrations over the Duration of the Test...........................................................

6.11 Nitrite Concentrations over the Duration of the Test ...........................................................

6.12 Total Chromium Concentrations over the Duration of the Test ............................................

6.13 Electrical Resistivity Tomagraphy Inversions Showing Electrical Conductivity Along Two Transects

6.14 Baseline Radar Tomogram and Difference Tomograms Indicating Change in Dielectric Constant Post-Injection Along Transect 118-115............................................ 6.12

6.15 Bromide Concentrations over the Duration of the Test...................................................... 6.13

6.16 TOC Concentrations over the Duration of the Test........................................................... 6.13

6.17 Acetate Concentrations over the Duration of the Test.............................................................. 6.14

6.18 Propionate Concentrations over the Duration of the Test ...................................................... 6.14

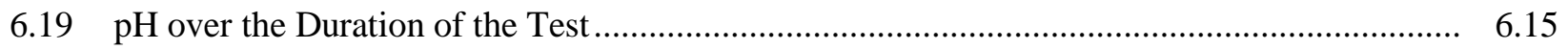

6.20 Sulfate Concentrations over the Duration of the Test ........................................................

6.21 Arsenic Concentrations During the Test ........................................................................... 6.17

6.22 Barium Concentrations During the Test............................................................................... 6.17

6.23 Selenium Concentrations During the Test............................................................................. 6.18

1.24 Comparison of Simulated and Observed Volatile Solids Concentrations for Experiment A1.

1.25 Comparison of Simulated and Observed Volatile Solids Concentrations for Experiment A2.....

1.26 Comparison of Simulated and Observed Volatile Solids Concentrations for

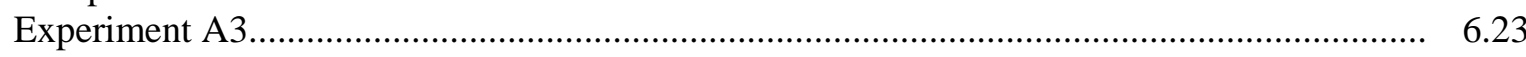

1.27 Comparison of Simulated and Observed Volatile Solids Concentrations for Experiment B1

1.28 Comparison of Simulated and Observed Volatile Solids Concentrations for Experiment B2. 
1.29 Comparison of Simulated and Observed Sediment Volatile Solids Concentrations

after Completion of Experiment B3 …............................................................................. 6.26

1.30 Comparison of Simulated and Observed Volatile Solids Concentrations for

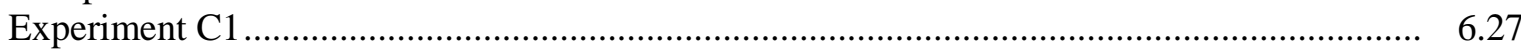

1.31 Comparison of Simulated and Observed Volatile Solids Concentrations for Experiment C2.

1.32 Comparison of Simulated and Observed Sediment Volatile Solids Concentrations after Completion of Experiment C3

\section{Tables}

3.1 Hydraulic Property Estimates from August 2008 Constant-Rate Test in Well 199-D5-108

3.2 Summary of Pertinent Well Information

3.3 Summary of EBF Survey Information

3.4 Baseline Water Chemistry at the Upgradient Background Well 199-D5-40

3.5 Groundwater Hydraulic Information for the Monitoring Set of Wells 199-D5-43, 199-D5-20, and 199-D5-38.

4.1 Field Parameter Monitoring Electrode Specifications

4.2 Slugging Rod Information .....

4.3 Tomographic Data Acquisition Schedule, Molasses Field Experiment....

4.4 Tomographic Data Acquisition Schedule, Vegetable Oil Field Experiment

4.5 Summary of Sampling for the Soluble Substrate Test.

4.6 Summary of Sampling for the Immiscible Substrate Test

4.7 Comparison of Actual and Planned Sampling

5.1 Total Organic Carbon Concentrations at the End of the Substrate Injection Period.

5.2 Permeability Change Results Based on Slug Testing

$5.3 \mathrm{pH}$ Response over One Month of Fermentation with Molasses and Bicarbonate Buffer Added as Specified in the Table

5.4 Biobarrier Scale-Up Information

6.1 Total Organic Carbon Concentrations at the End of the Substrate Injection Period.

6.2 Permeability Change Results Based on Slug Testing

1.3 Emulsion Column Experiments Overview

1.4 Overview of Parameter Values for the Three Laboratory Sands 


\subsection{Introduction}

Pacific Northwest National Laboratory (PNNL) conducted a treatability test designed to demonstrate that in situ biostimulation can be applied to help meet cleanup goals in the 100-D Area of the U.S. Department of Energy (DOE) Hanford Site. This test is part of a strategy to couple multiple technologies to accelerate cleanup of chromium-contaminated groundwater in the 100 Area at the Hanford Site. The in situ biostimulation concept for this treatability test is intended to provide supplemental treatment upgradient of the In Situ Redox Manipulation (ISRM) barrier by reducing the concentration of the primary oxidizing species in groundwater (i.e., nitrate and dissolved oxygen) and chromate, thereby increasing the longevity of the ISRM barrier.

\subsection{Site and Waste Stream Summary}

The Hanford Site in southeastern Washington was established in 1943 to produce plutonium for nuclear weapons using reactors and chemical processing plants. The 100 Area of the Hanford Site is situated along the Columbia River and includes nine deactivated DOE nuclear reactors used for plutonium production between 1943 and 1987. Operations at the Hanford Site now are focused on environmental restoration and waste management. In November 1989, the U.S. Environmental Protection Agency (EPA) designated the 100 Area of the Hanford Site a Superfund site and placed it on the National Priorities List because of soil and groundwater contamination from previous operations at the nuclear facilities. To organize cleanup efforts under Superfund, contaminated areas at the nine deactivated reactors were subdivided into operable units.

The 100-HR-3 Operable Unit is in the north-central part of the Hanford Site along a section of the Columbia River known as the Hanford Reach. This operable unit includes the groundwater underlying the 100-D and 100-H reactor areas and the 600 Area between them. The 100-D Area is the site of two deactivated reactors: the D Reactor, which operated from 1944 to 1967, and the DR Reactor, which operated from 1950 to 1965. The H Reactor operated from 1949 to 1965.

During reactor operations, hexavalent chromium, or chromate, in the form of sodium dichromate $\left(\mathrm{Na}_{2} \mathrm{CrO}_{7}\right)$ was used as an anticorrosion agent in the reactor cooling water. Large volumes of reactor cooling water containing sodium dichromate and short-lived radionuclides were discharged to retention basins for ultimate disposal in the Columbia River through outfall pipelines. Liquid wastes from other reactor operations (e.g., decontamination, water treatment) also contained significant quantities of hexavalent chromium. These wastes were discharged to the soil column at cribs, trenches, and french drains or leaked from storage facilities. Contaminant plumes in groundwater have resulted from these former waste disposal practices. Groundwater contamination in the 100-D Area is the focus of this treatability test.

\subsection{Treatment Technology Description}

In situ biostimulation has been researched extensively and applied for aquifer remediation over the last 20 years for various contaminants. In situ biostimulation, in the context of this project, is the process of amending an aquifer with a substrate that induces growth and/or activity of indigenous bacteria to induce a desired reaction. For application at the 100-D Area, the purpose of biostimulation is to induce reduction of chromate, nitrate, and oxygen to remove these compounds from the groundwater. Chromate 
can be biologically reduced to insoluble chromium (III) (e.g., Alam et al. 2006), and in situ chromate reduction has been demonstrated recently using polylactate as a substrate at the 100-H Area of Hanford (Faybishenko et al. 2008; Hubbard et al. 2008). Nitrate can be biologically reduced using a variety of organic substrates including vegetable oil (e.g., Hunter 2001), and in situ nitrate reduction has been demonstrated at the Hanford Site (e.g., Hooker et al. 1998). Biological nitrate reduction occurs as a stepwise process in which the initial intermediate degradation product is nitrite. Under some conditions, nitrite concentrations can accumulate during nitrate reduction, and nitrite must be monitored as a potential unwanted product of nitrate reduction. The final desired product of biological nitrate reduction is nitrogen gas. Dissolved oxygen is readily reduced by a wide variety of bacteria in the presence of a wide variety of organic substrates. These reductive processes are induced by introduction of an organic substrate and the resultant biological processes create geochemically reduced conditions in the aquifer (e.g., a low oxidation-reduction potential).

For implementation of an in situ permeable reactive barrier based on biological reactions, i.e., a biobarrier, a wide variety of available organic substrates are potentially suitable for establishing anaerobic conditions (AFCEE 2004) and thereby reducing dissolved oxygen, nitrate, and chromate. Substrates for the treatability test were selected to provide information about two general approaches for establishing and maintaining an in situ biobarrier. These approaches included 1) use of a soluble (miscible) substrate that is relatively easy to distribute over a large areal extent, is inexpensive, and is expected to have moderate longevity; and 2) use of an immiscible substrate that can be distributed over a reasonable areal extent at a moderate cost and is expected to have increased longevity.

Soluble (miscible) substrates, typically organic acids or sugars, offer the potential for distributing substrate large distances from an injection well. Although consumption of soluble substrates may be relatively rapid, biomass produced from consumption of the substrate can provide long-term reducing conditions as the biomass decays (Sleep et al. 2005; Yang and McCarty 2000). Reduction of sediment iron or sulfate by bacteria may also create additional long-term reducing capacity. Molasses was selected for use in the treatability test (Truex et al. 2007). Molasses has a high solubility and low cost and is representative of the type of secondary waste substrates that may be available to minimize the long-term cost of the barrier (e.g., carbohydrate wastes). Use of molasses is a commercially available approach for field-scale biostimulation (ARCADIS 2009) and has shown favorable results to support anaerobic bioremediation (Borden and Rodriguez 2006) and chromate reduction (Gemoets et al. 2003).

Immiscible substrates can maintain reducing conditions over a long period because the substrate consumption is controlled by the rate of dissolution (AFCEE 2004). The immiscible substrate can be injected into an aquifer as a separate phase or as an emulsion. However, injection of a separate phase can cause significant hydraulic conductivity reduction and cannot distribute substrate very far from the injection well (Coulibaly and Borden 2004). Use of stable emulsions offers the potential for distribution over a larger areal extent, and the distributed substrate at a weight percentage on the order of $1 \%$ will cause minimal reduction in hydraulic conductivity (Hunter 2001, 2005; Coulibaly and Borden 2004). Because of the large areal extent necessary for full-scale application in the 100-D Area, the treatability test focused on immiscible substrates that can be delivered as an emulsion rather than other immiscible substrates (Truex et al. 2007). Soybean oil can be effectively emulsified (Coulibaly and Borden 2004) and is currently a commercially available bioremediation substrate. A recent study of slow-release substrates for anaerobic bioremediation showed favorable results for soybean oil (Borden and Rodriguez 2006). Hunter $(2001,2005)$ has shown effective denitrification using soybean oil and that the tested emulsifier does not significantly inhibit denitrification (Hunter 2005). The commercially available 
EOS ${ }^{\circledR} 598$ soybean oil emulsion was selected for the treatability test (EOS Remediation, LLC, www.eosremediation.com). Soybean oil releases long-chain fatty acids and glycerol to the groundwater and these compounds are subsequently degraded producing other daughter products that can be degraded further to support maintaining anaerobic conditions (Borden and Rodriguez 2006). The overall reactions in the groundwater are controlled by rate of dissolution, hydrolysis, and associated solubility for the oil. Because mass transfer processes control the reactions and longevity of the reducing conditions, biomass yield and decay are not as important as they are for the soluble substrates.

An extensive data set for a polylactate substrate is available for use in establishing a biobarrier (Faybishenko et al. 2008; Hubbard et al. 2008). However, the substrates selected for this treatability test offer alternatives to polylactate that have the potential for a larger areal extent of distribution from an injection well, with an expected similar ability for in situ reduction of dissolved oxygen, nitrate, and chromate. Other potential injectable substrates, such as whey (soluble and particulate), chitin (particulate), and others, may also offer performance characteristics similar to those of the tested substrates but were not directly evaluated in this treatability testing effort. 


\subsection{Objectives}

The 100-D Biostimulation Field Test was conducted to evaluate whether an effective in situ permeable reactive barrier based on biological reactions, i.e., a biobarrier, can be installed by injecting either 1) a soluble substrate, i.e., one that is microbially degraded over a relatively short time frame when compared to the desired life span of the barrier, or 2) an immiscible substrate, i.e., one that slowly dissolves and releases substrate for microbial reactions over a long period. Molasses was selected as the soluble substrate, and emulsified vegetable oil was selected as the immiscible substrate for the field test.

Specific objectives to be addressed in the field test are as follows:

- Determine the effective radius of treatment.

- Evaluate the uniformity of substrate distribution.

- Identify operational needs for injection.

- Induce fermentation reactions and reducing conditions and grow biomass.

- Minimize permeability changes due to growth of biomass (assessed through comparison of pre- and post-hydraulic test results).

- Quantify the ability to obtain and maintain low oxygen and nitrate/nitrite concentrations (limit primary electron acceptor flux) and determine longevity of treatment.

- Quantify the ability to obtain and maintain low chromate concentrations (augment chromate treatment) and determine longevity of treatment.

- Compile information required for full-scale design, including a description of the injection process and treatment performance. 


\subsection{Test Site Description}

The test site location, hydrogeologic setting, and groundwater flow system are described in the following sections.

\subsection{Test Site Location and Hydrogeologic Setting}

The treatability test site is located in the southwestern portion of the 100-D Area within the chromate and nitrate plumes (Figure 3.1 and Figure 3.2, respectively). Although this location is not within the highest concentration portion of the chromium plume, trend data at this location indicate that chromium concentrations (200-400 ppb) are sufficient to meet treatability test objectives. As shown in Figure 3.2, this location is also well within the 45-mg/L nitrate contour. The selected test site location is approximately $300 \mathrm{~m}$ upgradient of the existing ISRM barrier. Based on pump-and-treat system capture zone analysis (DOE 2006), the test site is not within the capture zone of well D5-39, the closest pumping well.

The general hydrogeologic setting of the groundwater 100-HR-3 Operable Unit (encompassing the 100-D and 100-H Areas) is described in Lindsey and Jaeger (1993); summaries of the conceptual site models for groundwater contamination in each of these areas are presented in Peterson et al. (1996). The unsaturated (vadose) zone in the 100-D Area lies in the Hanford formation and the upper portion of the Ringold Formation (Figure 3.3). The unconfined aquifer is composed of sandy gravel to silty sandy

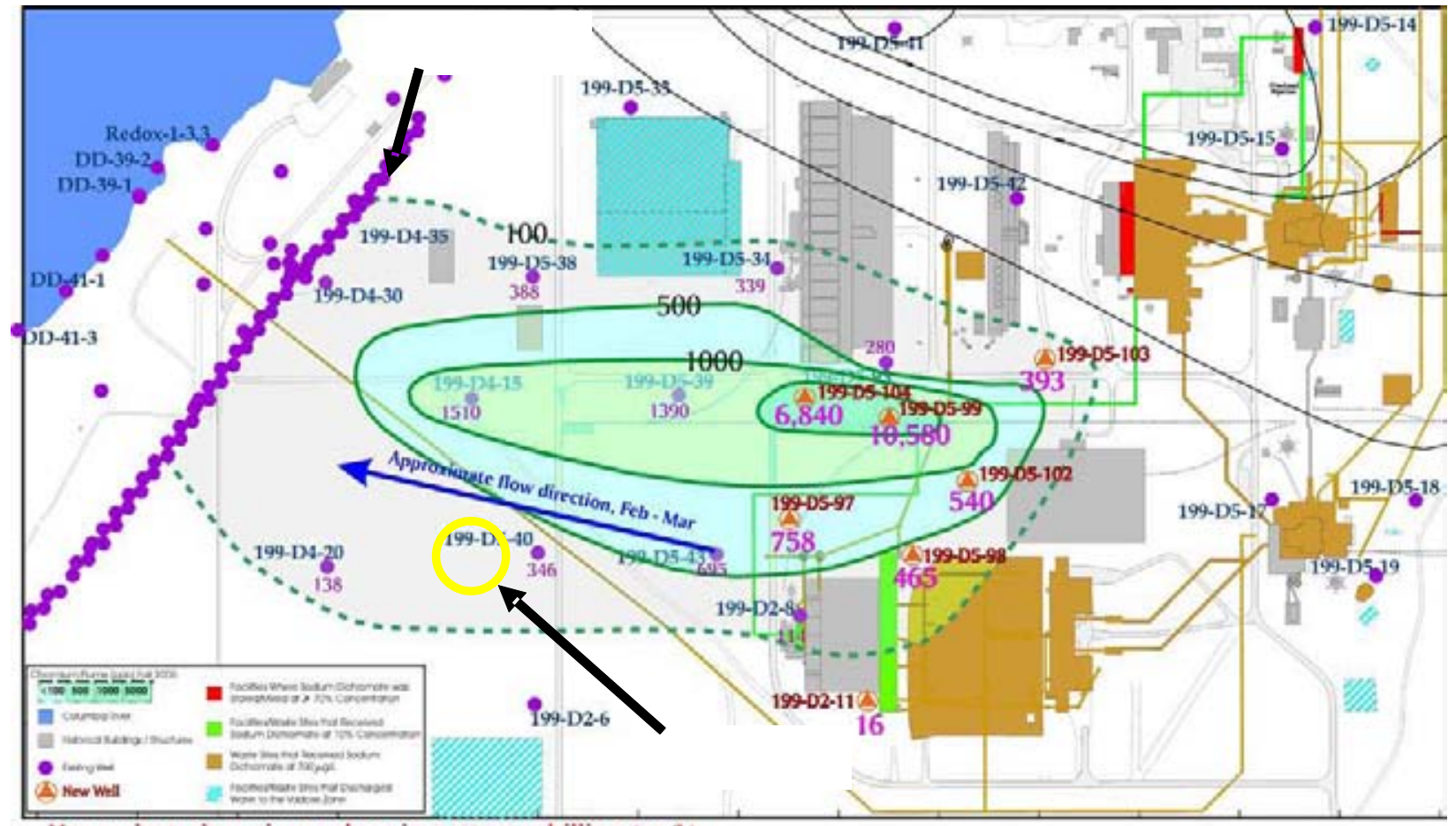

Hexavalent chromium values in parts per billion (ug/L)

Figure 3.1. Test Location and Recent Chromate Concentration Data for the 100-D Area Unconfined Aquifer (personal communication, Scott Petersen, May 3, 2007) 


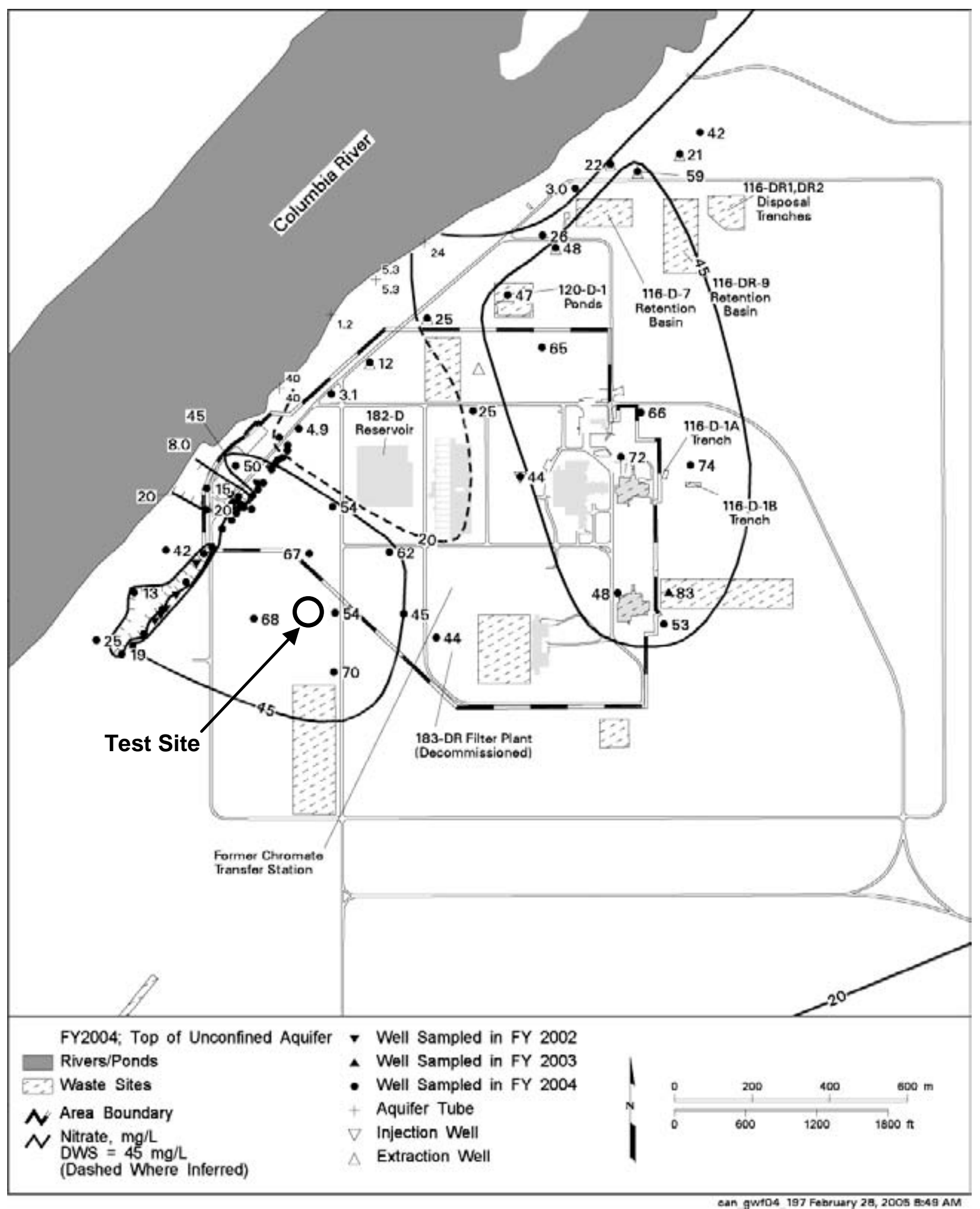

Figure 3.2. Test Location and Nitrate Concentration Data for the 100-D Area Unconfined Aquifer 


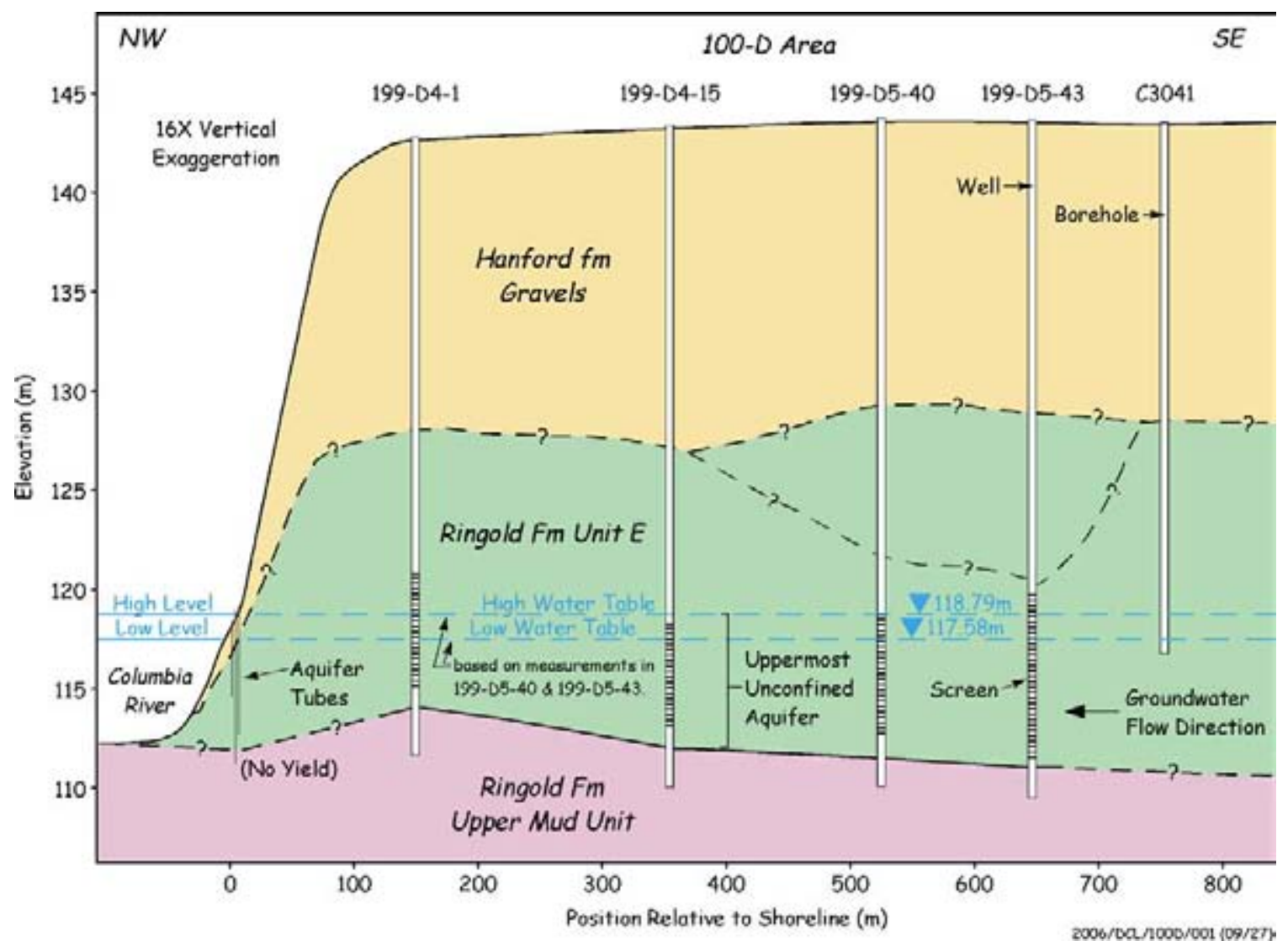

Figure 3.3. 100-D Area Hydrogeologic Cross Section of the Uppermost Aquifer

gravel, 3 to 9 m thick, which corresponds to Ringold Formation Unit E. Depth to the water table ranges from less than $1 \mathrm{~m}$ near the river to $\sim 25 \mathrm{~m}$ farther inland. The base of the unconfined aquifer is a fine-grained silty sand to clay overbank interval, designated the Ringold Formation Upper Mud Unit, which is $~ 15$-m thick and generally dips to the west. The deeper Ringold Formation is believed to comprise more layers of clay, silt, and sand based on interpolations between wells elsewhere in the 100 Areas (Hartman 1999).

In the 100-D Area, chromium is the major contaminant of concern in groundwater and flows toward the Columbia River from multiple source areas through the uppermost unconfined aquifer. At the proposed test site location, the unconfined aquifer is contained within the lower Ringold Formation Unit $\mathrm{E}$ and is approximately 6.8 to $5.8 \mathrm{~m}$ thick (depending on fluctuations occurring in the elevation of the Columbia River); the water table is $\sim 25 \mathrm{~m}$ below ground surface (bgs). Groundwater in the unconfined aquifer generally flows northwest and discharges into the Columbia River. Physical property analyses (porosity, bulk density, and particle size distribution by sieve analysis) were previously conducted on 15 split tube samples collected during drilling of ISRM wells. Particle size ranged from $65 \%$ to $85 \%$ gravel, $14 \%$ to $31 \%$ sand, and less than $6 \%$ fines (silt/clay). Porosity ranged from $5 \%$ to $23 \%$ with a mean of $14 \%$. Bulk density ranged from 2.1 to $2.4 \mathrm{~g} / \mathrm{cm}^{3}$ with a mean of $2.3 \mathrm{~g} / \mathrm{cm}^{3}$ (Williams et al. 2000). 


\subsection{Site-Specific Characterization}

Site-specific characterization data were collected at the field test site as a baseline for interpreting the field test results. During well installation, borehole logs were prepared and used to generate a geologic cross section of the area (Figure 3.4 and Figure 3.5). Isopach maps showing the top of the underlying confining unit (Figure 3.6) and the saturated thickness of the Ringold formation (Figure 3.7) were prepared and indicate relatively constant elevations across the test area. Detailed borehole logs and well completion diagrams are shown in Appendix A.

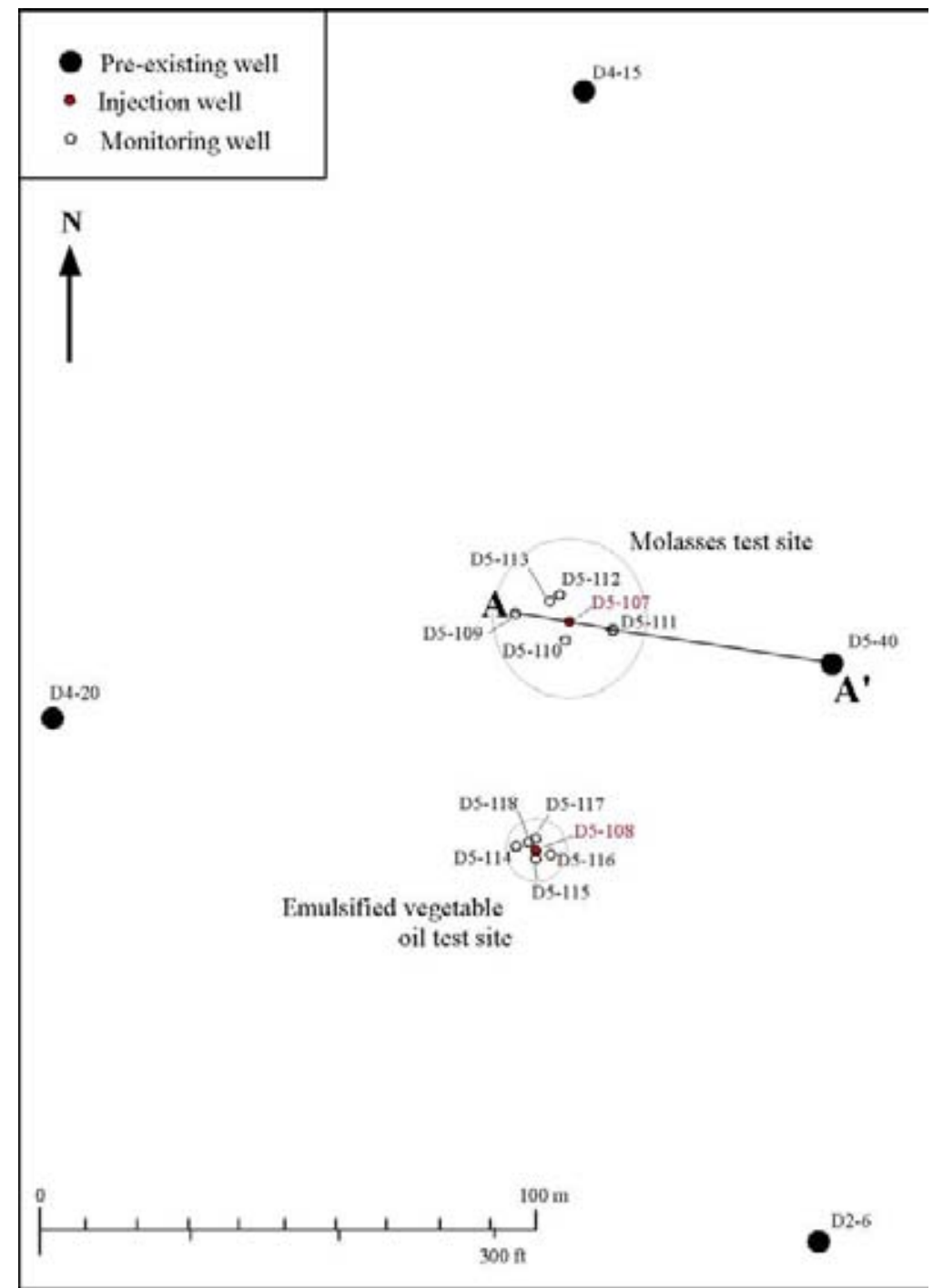

Figure 3.4. Site Wells and Location of Geologic Cross Section 


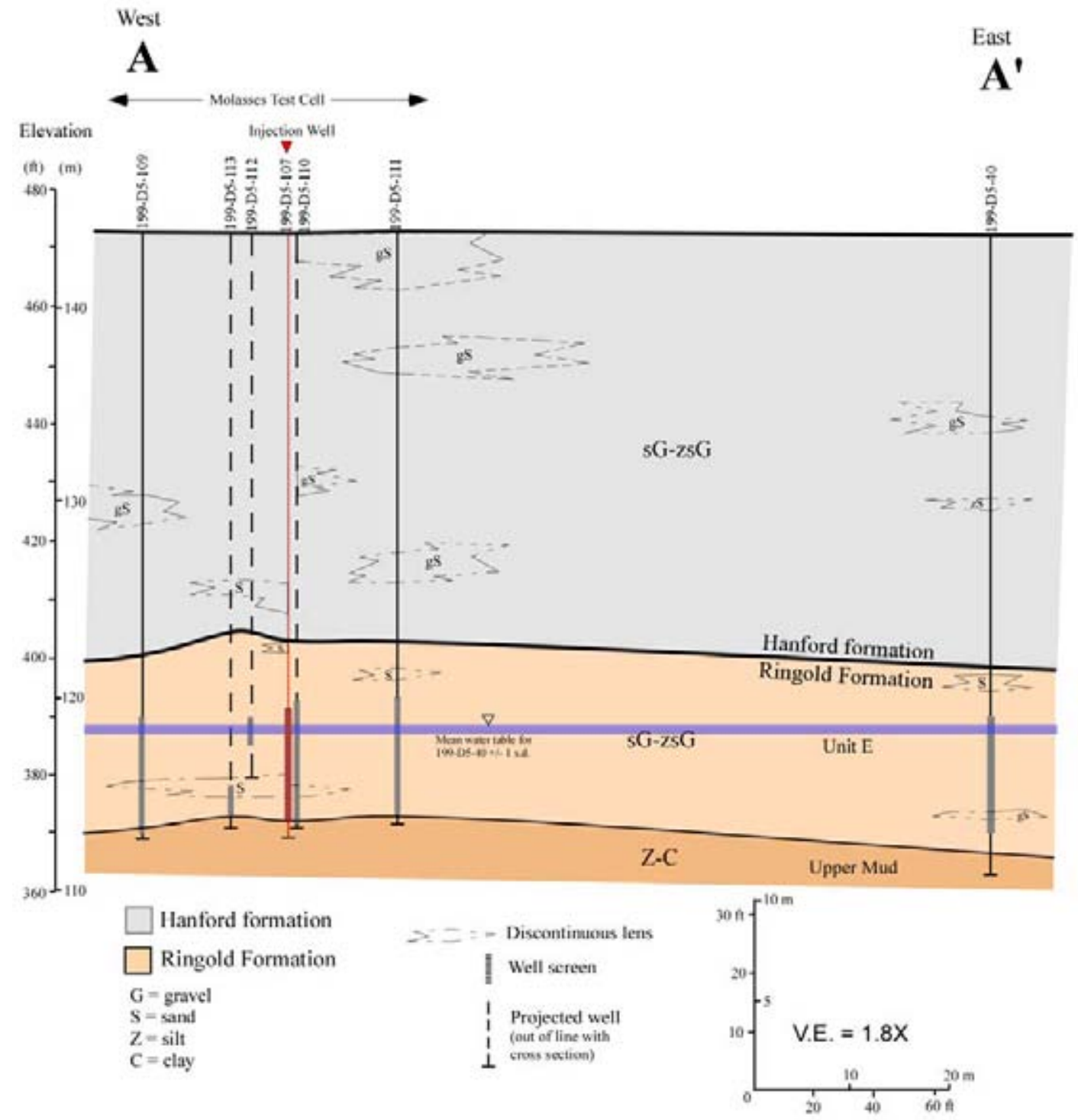

Figure 3.5. Cross Section View of the Field Test Site (see Figure 3.4 for location) 


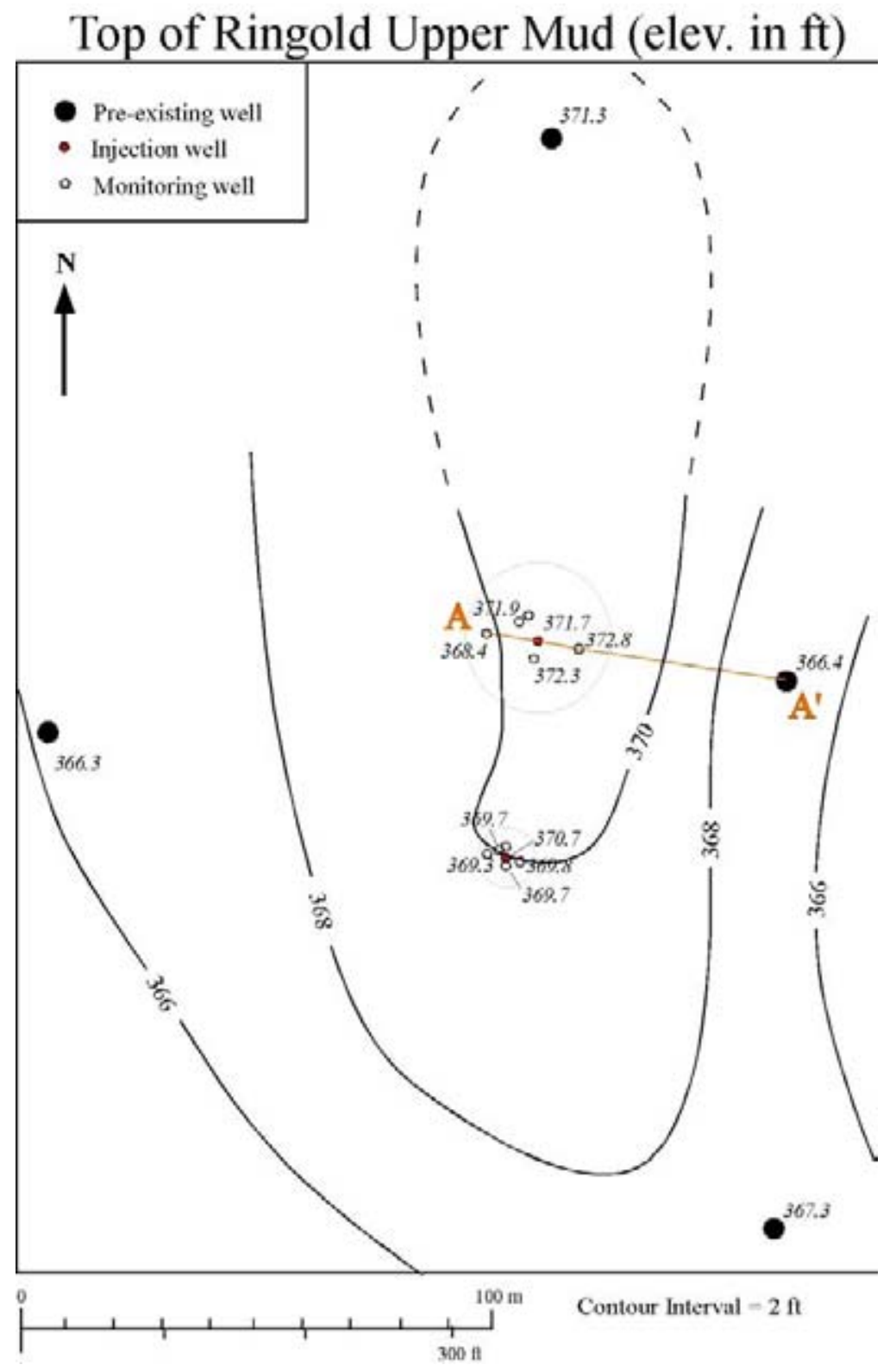

Figure 3.6. Top of Underlying Confining Unit 


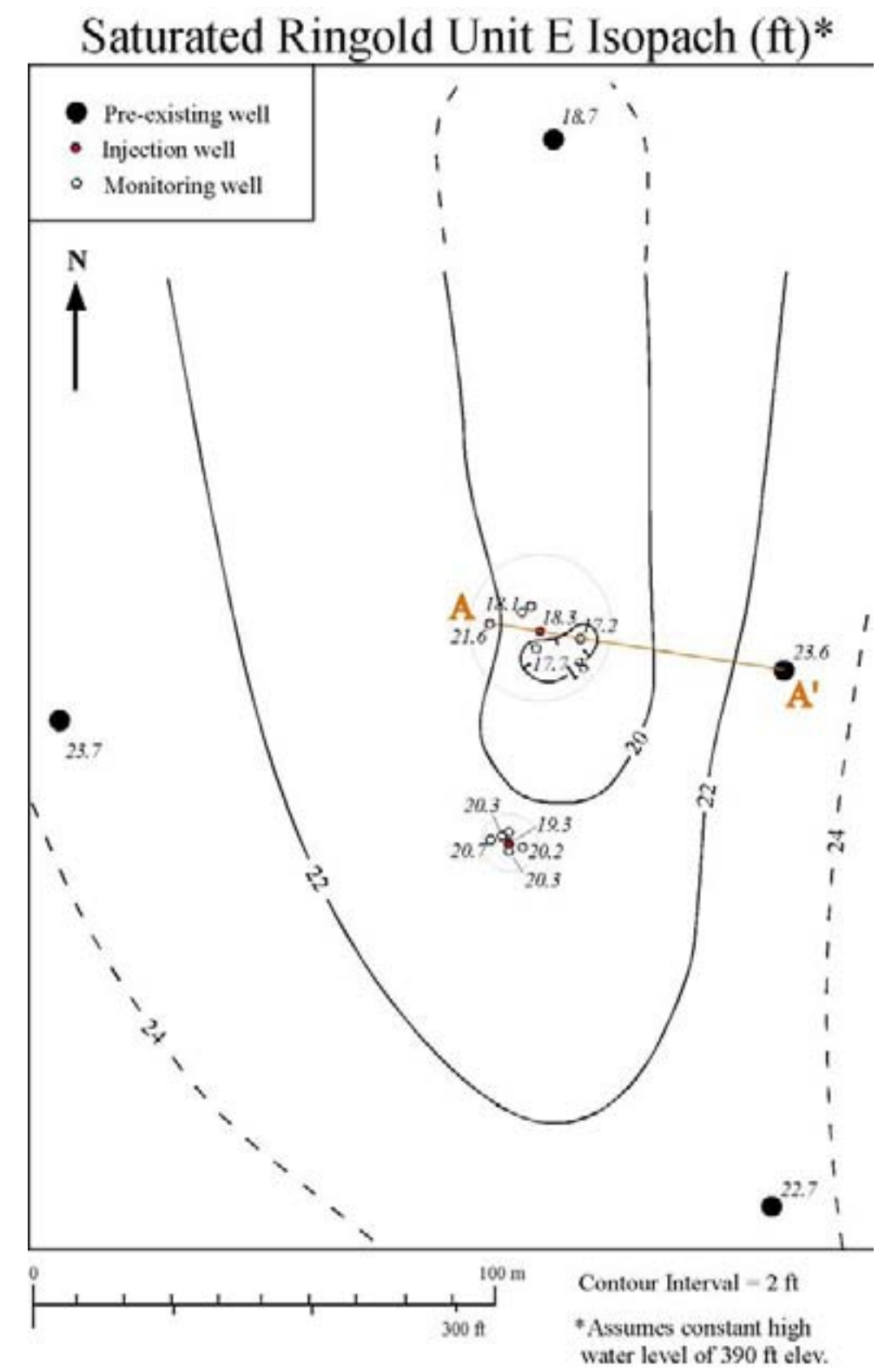

Figure 3.7. Saturated Thickness in the Ringold Formation

\subsubsection{Hydraulic Properties}

The horizontal hydraulic conductivity in the test area was estimated from a constant rate injection test at the immiscible substrate test site. The constant-rate injection test was performed in well 199-D5-108 for a duration of 360 minutes (6 hours), followed by a recovery monitoring period of several days to obtain site-specific aquifer properties. The pressure recovery data from the test were analyzed to provide an estimated average horizontal hydraulic conductivity of $27.4 \mathrm{~m} /$ day (90 ft/day). 


\subsubsection{Test Configuration}

Based upon the expected specific capacity of the stress well, the injection rate for the test was specified as $150 \mathrm{~L} / \mathrm{min}$ (40 gpm). About 70 minutes into the test, the flow rate was adjusted to a new target rate of $130 \mathrm{~L} / \mathrm{min}$ (35 gpm) in order to maintain more stable flows. Flows were held at this rate for the remainder of the test and fluctuated by less than 2 gpm.

Flow rates were measured using a turbine flowmeter and recorded manually in a field record book. Pressure responses were monitored in the stress well and neighboring monitoring wells using sensors (Model PT2X, Instrumentation Northwest, Kirkland, Washington) with ranges of 5 and 15 psig (0.1\% accuracy). These same sensors were installed over the life of the treatability study to provide continuous water-level monitoring data. Manual water-level measurements and depths to bottom for each well were taken at the time of testing using an "e-tape" instrument traceable to standards established by the National Institute of Standards and Technology (NIST).

Five observation wells were used to monitor the pressure response during the test and estimate hydraulic properties of the aquifer. The radial distance between these wells and the stress well ranged between 1.8 and $5.4 \mathrm{~m}$ (5.9 and $17.6 \mathrm{ft}$ ). The stress well and three of the observation wells were fully screened wells. The other two wells were screened in the lower and upper portion of the aquifer, respectively.

\subsubsection{Analytical Methods}

A comparison of the pressure buildup and recovery data revealed similar patterns. The recovery data were selected for analysis because they provided a smoother, less noisy signal of the pressure response. Prior to analysis, the recovery data were transformed into Agarwal-equivalent drawdown and time, which allows recovery data to be analyzed as an equivalent drawdown (or pressure buildup) response (Agarwal 1980).

Hydraulic properties were estimated using a type-curve fitting method according to the analytical solution of Neuman $(1972,1974,1975)$ for an unconfined aquifer with delayed gravity response (specific yield). The analysis also assumes the aquifer is homogeneous, of infinite areal extent, and of uniform thickness, and ignores well-bore storage effects. The pressure response and response derivative data were used for the curve fits. Anisotropy $(\mathrm{Kr} / \mathrm{Kz})$ and specific yield (Sy) were prescribed in the analysis at values of 0.1 and 0.15 , respectively. Transmissivity (T) and storativity (S) were varied until a satisfactory fit to the data could be made. The analysis assumed the observation wells were fully penetrating and ignored the effects of partial penetration. The analyses were performed using the aquifer testing analysis software package AQTESOLV (HydroSOLVE, Inc., Reston, Virginia). 


\subsubsection{Results}

The pressure responses followed a typical delayed-response pattern associated with delayed yield in an unconfined aquifer (Figure 3.8). Pressure responses ranged from 0.15 to $0.5 \mathrm{~m}$ ( 0.5 to $1.7 \mathrm{ft}$ ) near the end of the test within the five observation wells. The pressure responses in wells 199-D5-114 and -118 were not used for the analysis for three reasons:

1. The pressure responses show a late time curvature, suggesting a delayed hydraulic response at these locations indicative of poor hydraulic connection or some other formational heterogeneity (e.g., due to the observation well being located in low-permeability material).

2. Data from substrate injection showed only small amounts of substrate delivery to these wells compared to other wells within the radius of influence of the injection. This result is also indicative of poor hydraulic connection with the injection well.

3. The analytical solution assumes the entire area of influence is homogeneous and does not address varying pressure responses due to heterogeneities.

For these reasons, only the pressure responses from the wells 199-D5-115, -116, and -117 were quantitatively fit with type-curves to obtain hydraulic property estimates.

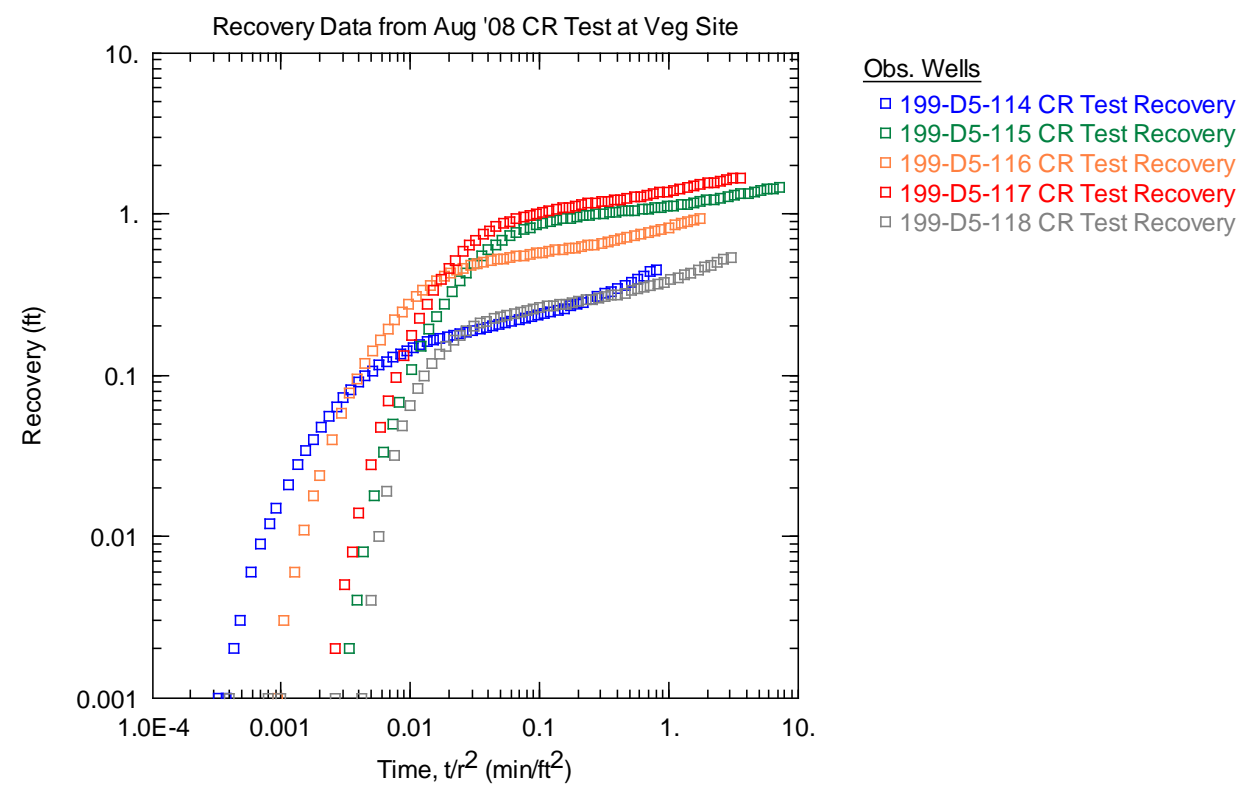

Figure 3.8. Recovery Responses for August 2008 Constant-Rate Test in Well 199-D5-108. Recovery displacement is shown as a function of time divided by the square of radial distance $\left(\mathrm{t} / \mathrm{r}^{2}\right)$.

The average transmissivity $(\mathrm{T})$ estimate obtained from type-curve fits to the recovery data for wells 199-D5-115, -116, and -117 was $160 \mathrm{~m}^{2} /$ day (1,735 ft²/day) (Table 3.1). Individual type-curve fits to the data are shown in Figures 3.9 through 3.11. The average aquifer thickness (b) within the emulsified vegetable oil test site at the time of the constant-rate test was $5.9 \mathrm{~m}(19.3 \mathrm{ft})$. This calculation is based on the measured well water levels and the borehole geologic logs for the stress well and the five neighboring observation wells. The average hydraulic conductivity $(\mathrm{K}=\mathrm{T} / \mathrm{b})$ estimate is $27.4 \mathrm{~m} /$ day $(90 \mathrm{ft} / \mathrm{day})$

(Table 3.1). 
Table 3.1. Hydraulic Property Estimates from August 2008 Constant-Rate Test in Well 199-D5-108

\begin{tabular}{lccc}
\hline Well & Storativity, S & $\begin{array}{c}\text { Transmissivity, } \mathrm{T} \\
\left(\mathrm{ft}^{2} / \text { day) }\right.\end{array}$ & $\begin{array}{c}\text { Hydraulic } \\
\text { Conductivity, K } \\
\text { (ft/day) }\end{array}$ \\
\hline 199-D5-115 & 0.008 & 1,830 & 95 \\
199-D5-116 & 0.010 & 2,100 & 109 \\
199-D5-117 & 0.010 & 1,275 & 66 \\
Avg. & 0.009 & 1,735 & 90 \\
St. Dev & 0.001 & 421 & 22 \\
\hline
\end{tabular}

Notes: Specific yield (Sy) and anisotropy $(\mathrm{Kr} / \mathrm{Kz})$ were prescribed at values of 0.15 and 0.1 , respectively. The average aquifer thickness (b) of the six wells in the test cluster at the time of testing was $19.3 \mathrm{ft}$.

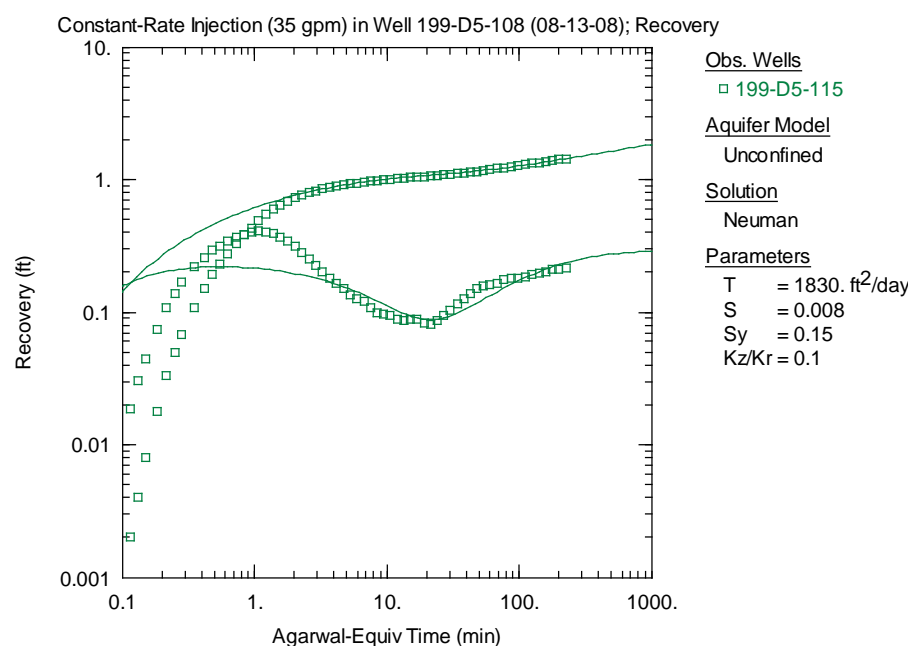

Figure 3.9. Neuman Type-Curve Analysis of Pressure Recovery from Well 199-D5-115 for August 2008 Constant-Rate Injection Test in Well 199-D5-108

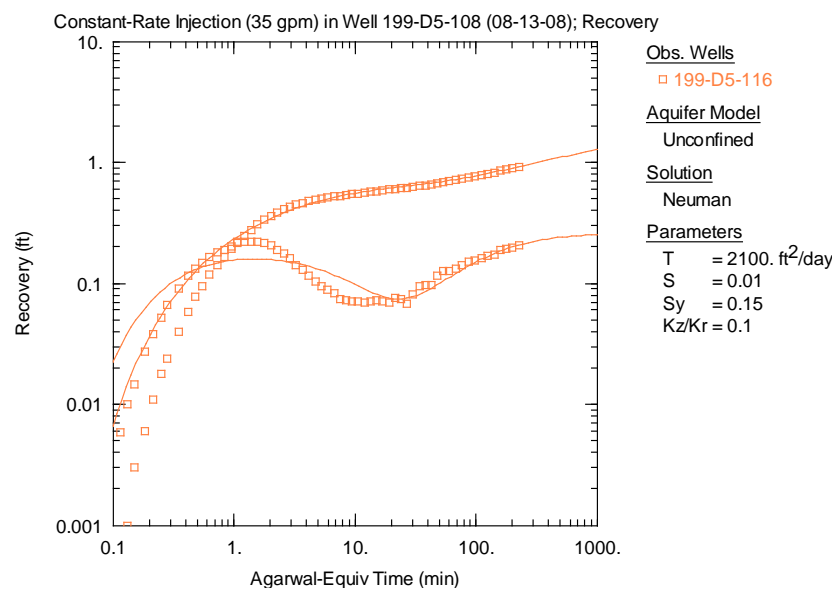

Figure 3.10. Neuman Type-Curve Analysis of Pressure Recovery from Well 199-D5-116 for August 2008 Constant-Rate Injection Test in Well 199-D5-108 


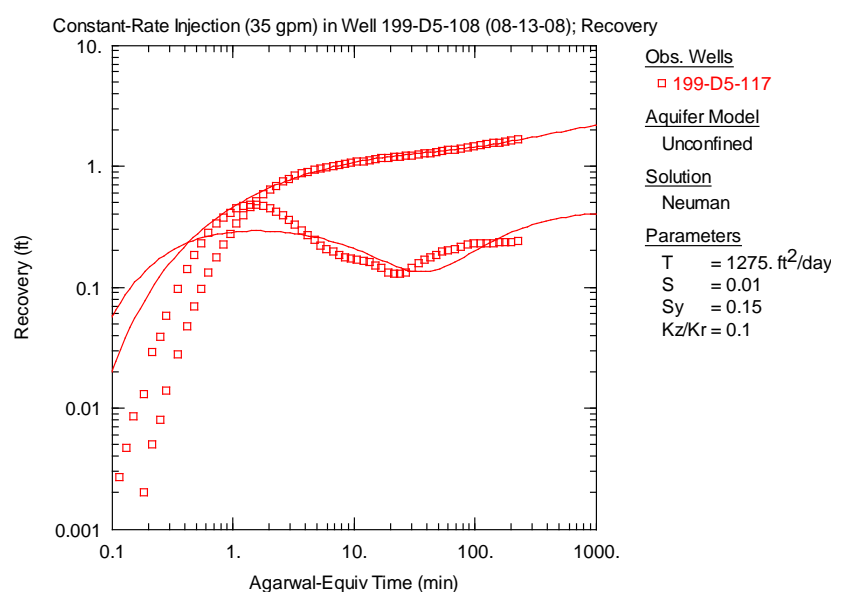

Figure 3.11. Neuman Type-Curve Analysis of Pressure Recovery from Well 199-D5-117 for August 2008 Constant-Rate Injection Test in Well 199-D5-108

\subsubsection{Electronic Borehole Flowmeter Summary}

The purpose of the electronic borehole flowmeter survey was to characterize the distribution of vertical flow conditions and inferred vertical hydraulic conductivity distribution in the aquifer at the soluble substrate test cell. Electromagnetic borehole flowmeter (EBF) surveys are effective for measuring the vertical groundwater flow velocity distribution in wells. The vertical groundwater-flow velocity measurements can be used to infer the vertical distribution of lateral groundwater flow into a well.

\subsubsection{Electromagnetic Borehole Flowmeter Survey Description}

The theory that governs the operation of the EBF is Faraday's Law of Induction, which states that the voltage induced by a conductor moving at right angles through a magnetic field is directly proportional to the velocity of the conductor moving through the field. Flowing water is the conductor, the electromagnet generates a magnetic field, and the electrodes are used to measure the induced voltage. For sign convention, upward flow represents a positive voltage signal and downward flow represents a negative voltage signal. More detailed descriptions of the EBF instrument system and field test applications are provided in Young et al. (1998).

The concept of the field test design is illustrated in Figure 3.12. The EBF probe consisted of an electromagnet and two electrodes 180 degrees apart inside a hollow cylinder. The inside diameter (ID) of the hollow cylinder was $2.5 \mathrm{~cm}$ (1 in.) and the outside diameter (OD) of the probe cylinder was just under $5.1 \mathrm{~cm}$ (2 in.). The probe (serial number FMT0605, Quantum Engineering Corporation, Loudon, Tennessee) is capable of measuring flow ranging from $0.04 \mathrm{~L} / \mathrm{min}(0.01 \mathrm{gpm})$ to $40 \mathrm{~L} / \mathrm{min}(10.6 \mathrm{gpm})$.

The probe was connected to an electronics box at the surface with a jacketed cable. The electronics attached to the electrodes transmit a voltage signal directly proportional to the velocity of water acting as the conductor. A computer was used to record the voltage signal and convert the signal to a flow rate measurement. 


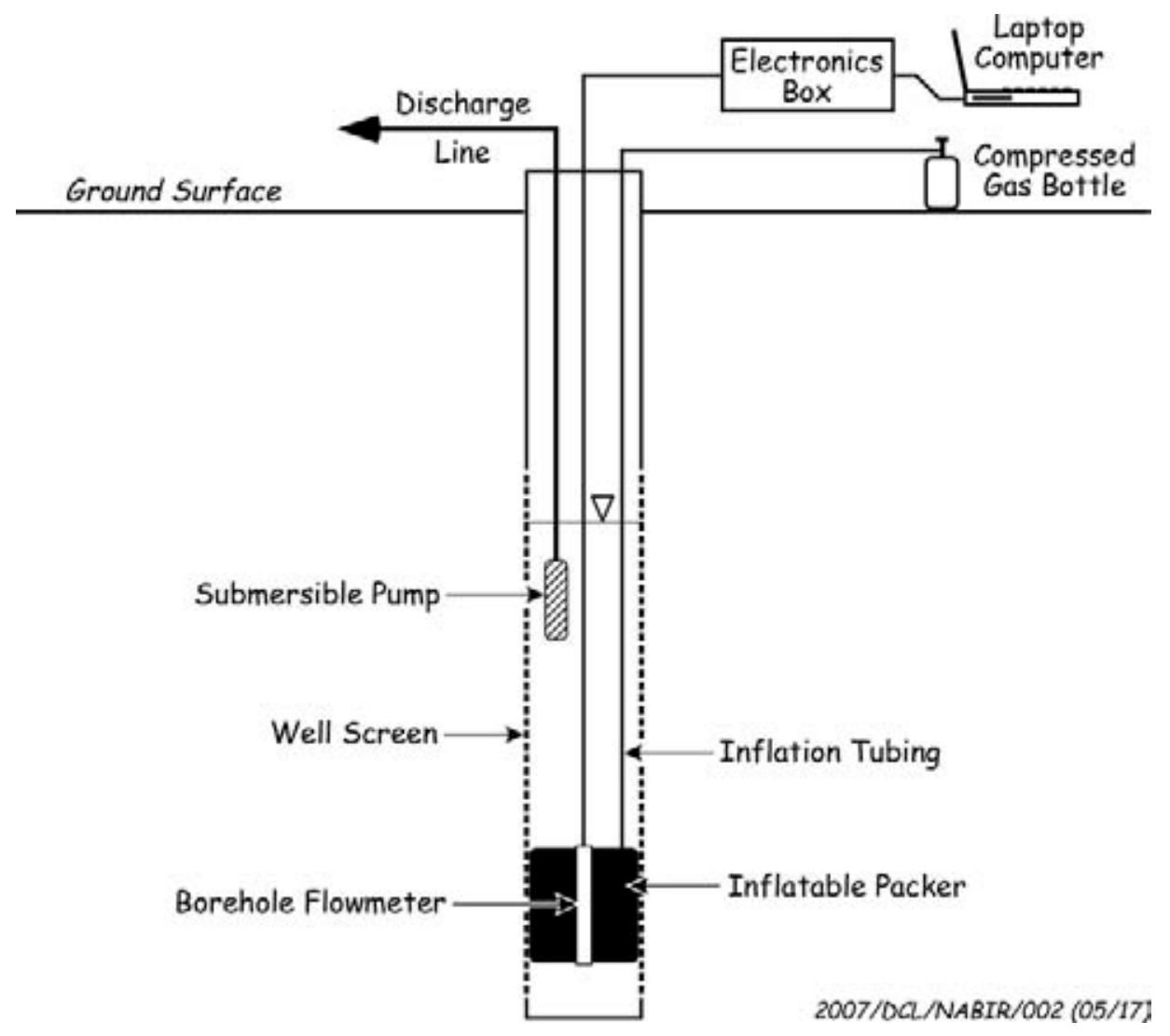

Figure 3.12. Electromagnetic Borehole Flowmeter General Configuration

For the PVC wire-wrap well screens, an inflatable packer was used to minimize bypass flow between the probe and the well screen (Figure 3.12). The inflatable packer consists of a rubber sleeve attached to a stainless steel assembly and is sealed with hose clamps. The EBF probe cylinder was mounted inside the stainless steel assembly. The packer and all fittings were checked for gas leaks at the surface before flowmeter profiling began. At each prescribed depth, inflation of the packer was controlled using compressed nitrogen gas, a regulator, and inflation tubing. After the packer was inflated, the packer seal was checked by pulling the cable for tension. Flow conditions were allowed to re-establish for several minutes due to disturbances caused by movement of the packer/probe assembly. After the flow measurement was recorded, the packer was deflated using a vented valve. The probe was raised (or lowered) very slowly to the next depth, and the measurement procedure was repeated.

\subsubsection{Data Acquisition and Reporting}

Both ambient and dynamic (i.e., pump-induced) flowmeter tests were performed in four wells at the soluble substrate test cell. Ambient flowmeter measurements were acquired every 0.6 to $1.5 \mathrm{~m} \mathrm{(2} \mathrm{to} 5 \mathrm{ft}$ ) over the saturated well-screen sections. Dynamic flowmeter measurements were acquired at 0.3-m (1-ft) intervals and at known depths of well-screen solid joints. The locations of the well-screen joints were based on well completion log information (i.e., tubular goods tally) and confirmed in the field by feeling the resistance during raising and lowering of the packer/probe assembly. The purpose of measuring flow at the well-screen joints is to correct for bypass flow between the inflated packer and the well screen. All flowmeter measurements were referenced to the top of the outer protective casing. 
During the dynamic flowmeter tests, pumping was extracted from the well and discharged to a portable tank. The discharge rate was $1.89 \mathrm{~L} / \mathrm{min}(0.50 \mathrm{gpm})$ for all four wells tested and was held constant during each dynamic test. Each well was pumped $\sim 10$ to 15 minutes to allow flow conditions to reach near-equilibrium before recording the EBF measurements. The discharge rate was measured and recorded periodically with a calibrated in-line flowmeter. After near-equilibrium conditions were established, EBF measurements were made in succession from bottom to top of the saturated well-screen section. Zero-flow point measurements taken at the bottom of the well provide a reference for the survey measurements.

\subsubsection{Electromagnetic Borehole Flowmeter Calibration}

The EBF probe was calibrated according to the manufacturer's calibration procedure described in Young et al. (1998). Calibration of the instrument was performed over a range of flow rates comparable to flow rates measured in the field. The calibration procedure consisted of establishing a constant uniform flow rate through a vertical PVC pipe containing the EBF probe and comparing the flowmeter measurements (in voltage output) with flow rate measurements at the PVC pipe outlet. Flow rates were maintained at a constant rate by using a power supply box with controller and a $12-\mathrm{V}$ pump. A linear regression plot of the calibration measurements yielded a slope of $3.561 \mathrm{~L} / \mathrm{min} / \mathrm{V}(0.9408 \mathrm{gpm} / \mathrm{V}$ (Figure 3.13).

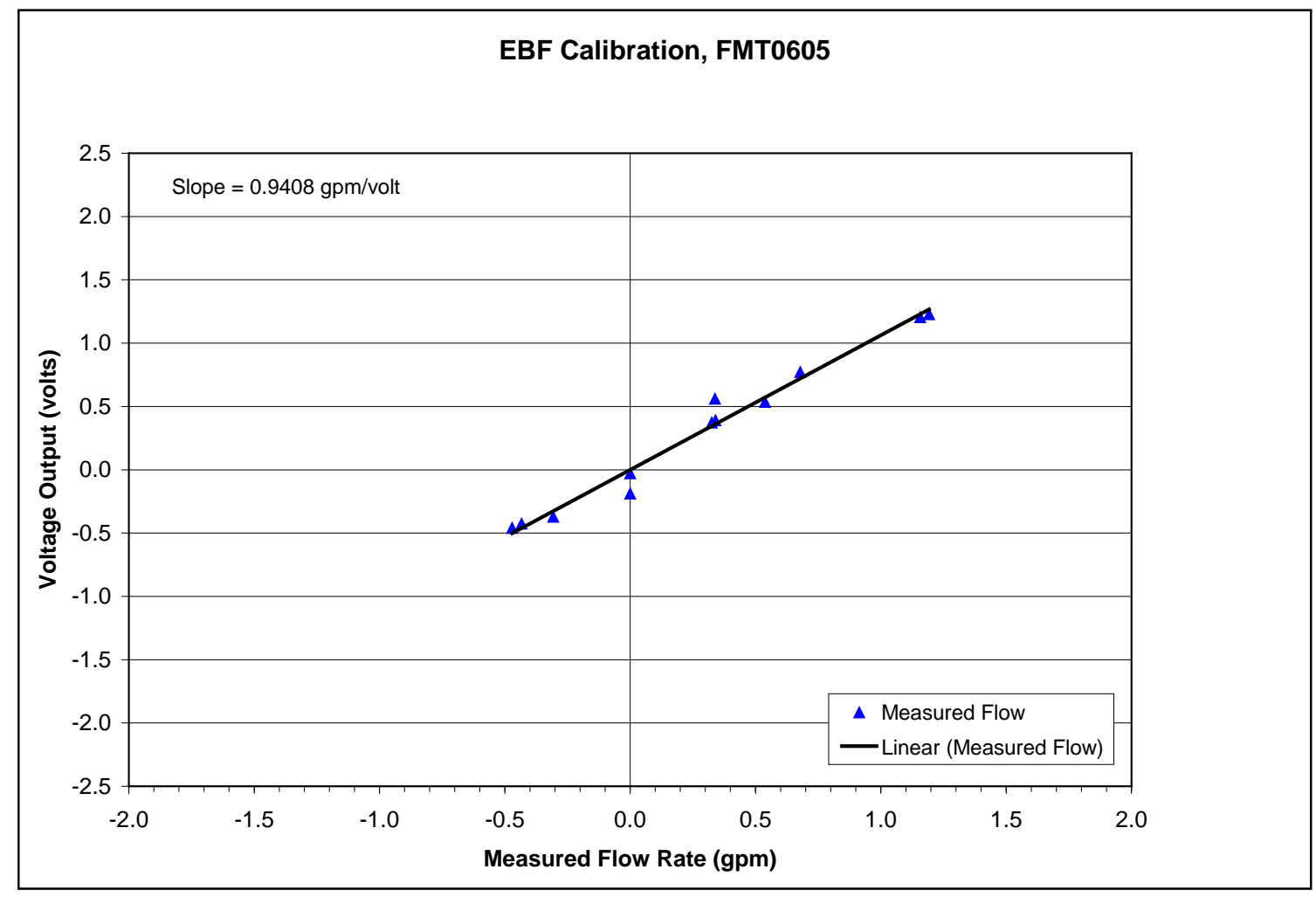

Figure 3.13. Electromagnetic Borehole Flowmeter Calibration Results 


\subsubsection{Electromagnetic Borehole Flowmeter Survey Analyses}

For the EBF survey analysis, it is assumed that the aquifer within the well-screen section is composed of a series of horizontal layers, possessing layer-specific hydraulic properties. Under ambient flow conditions (i.e., non-pumping), the difference between two successive well-screen depth measurements is the portion of ambient flow, $\Delta \mathrm{q}_{\mathrm{i}}$, entering the well screen between depths where the flow measurements were taken. These two depths are assumed to bound layer $i(I=1,2, \ldots, n)$. The portion of flow, $\Delta \mathrm{Q}_{\mathrm{i}}$, entering the well screen between these successive depths under pump-induced conditions is calculated in the same manner. Ambient-flow survey-profile information is used to correct dynamic flowmeter survey results for background vertical-gradient conditions.

The analytical method used for calculating the vertical distribution of relative hydraulic conductivity from dynamic EBF surveys is summarized in Molz et al. (1994) and Boman et al. (1997). Briefly stated, assuming that a constant pumping rate and pseudo-steady-state conditions are reached during pumping, the normalized relative hydraulic conductivity, $\mathrm{K}_{\mathrm{r}}$, for each ith layer within the aquifer can be calculated as follows:

$$
K_{r}=\frac{K_{i}}{K_{\text {avg }}}=\frac{\left(\Delta Q_{i}-\Delta q_{i}\right) / \Delta z_{i}}{\sum_{i}\left(\Delta Q_{i}-\Delta q_{i}\right) / \sum z_{i}} ; i=1,2, \ldots, n
$$

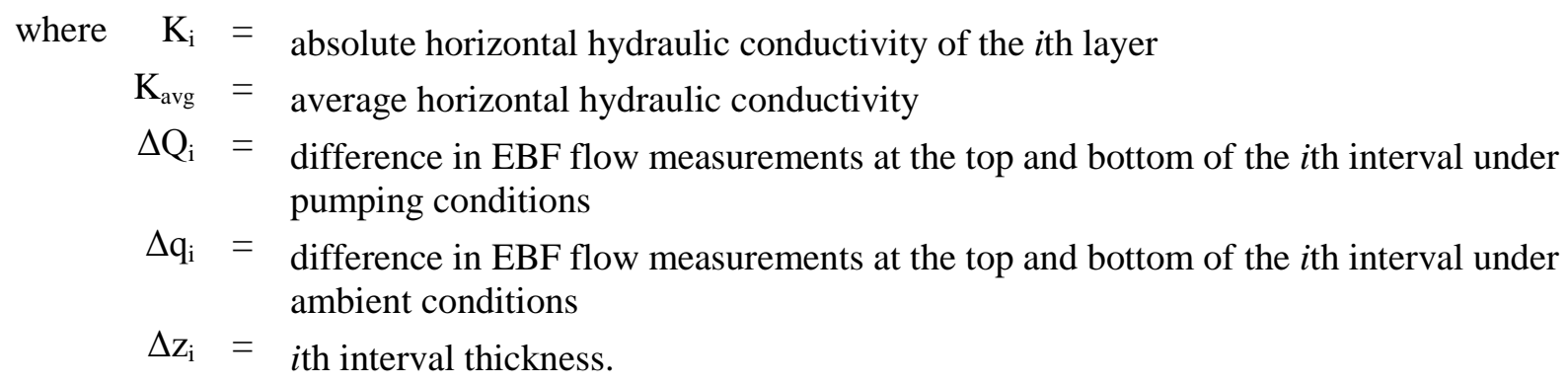

As indicated in Equation (3.1), the normalized relative hydraulic-conductivity value can be determined directly from measuring specific depth inflow rates as it relates to total flow pumped from the entire test interval. An absolute or actual hydraulic-conductivity-value depth profile (i.e., $\mathrm{K}_{\mathrm{i}}$ versus depth), however, can be developed if an estimate of $\mathrm{K}_{\mathrm{avg}}$ has been determined from a standard hydrologic test method (e.g., constant-rate pumping test). This can be derived by calculating the dimensional values of $\mathrm{K}_{\mathrm{i}}$ for each ith depth interval by multiplying the net dynamic flowmeter test discharge result relationship (indicated in Equation [3.1]) by the previously determined $\mathrm{K}_{\mathrm{avg}}$ value.

\subsubsection{Electromagnetic Borehole Flowmeter Survey Results}

Ambient and dynamic EBF surveys were performed in four wells at the biostimulation site. A summary of the pertinent well information is provided in Table 3.2. The following sections provide a description of the flowmeter survey performed at each well and analysis results for the saturated wellscreen sections profiled. All depths in the following sections are referenced to ground surface. A summary of the EBF survey information is provided in Table 3.3. 
Table 3.2. Summary of Pertinent Well Information

\begin{tabular}{lccccc}
\hline Well Number & $\begin{array}{c}\text { Pre-Survey } \\
\text { Static Depth to } \\
\text { Water (ft bgs) }\end{array}$ & $\begin{array}{c}\text { Pump-Induced } \\
\text { Depth to Water } \\
\text { (ft bgs) }\end{array}$ & $\begin{array}{c}\text { Depth to Top of } \\
\text { Well-Screen } \\
\text { Section (ft bgs) }\end{array}$ & $\begin{array}{c}\text { Depth to Bottom } \\
\text { of Well-Screen } \\
\text { Section (ft bgs) }\end{array}$ & $\begin{array}{c}\text { Measured Depth } \\
\text { to Bottom of } \\
\text { Well (ft bgs) }\end{array}$ \\
\hline 199-D5-107 & 84.02 & 84.16 & 82.3 & 102.3 & 102.7 \\
199-D5-109 & 83.94 & 83.95 & 82.8 & 102.8 & 103.1 \\
199-D5-110 & 84.17 & 84.24 & 80.5 & 100.5 & 101.0 \\
199-D5-111 & 84.09 & 84.17 & 80.1 & 100.1 & 100.6 \\
\hline
\end{tabular}

Table 3.3. Summary of EBF Survey Information

\begin{tabular}{|c|c|c|c|c|c|c|}
\hline \multirow[b]{2}{*}{ Well Number } & \multirow[b]{2}{*}{ Survey Date(s) } & \multirow[b]{2}{*}{$\begin{array}{c}\text { Well Screen } \\
\text { ID (in.) }\end{array}$} & \multirow[b]{2}{*}{$\begin{array}{l}\text { Well Screen } \\
\text { Type }\end{array}$} & \multicolumn{3}{|c|}{ EBF Tests Performed } \\
\hline & & & & Ambient & Dynamic & $\begin{array}{l}\text { Discharge } \\
\text { Rate (gpm) }\end{array}$ \\
\hline 199-D5-107 & Sept. 21, 2007 & 6 & 20 Slot PVC & $\mathrm{X}$ & $\mathrm{X}$ & 0.50 \\
\hline 199-D5-109 & Sept. 24, 2007 & 4 & 20 Slot PVC & $\mathrm{X}$ & $\mathrm{X}$ & 0.50 \\
\hline 199-D5-110 & Sept. 21-22, 2007 & 4 & 20 Slot PVC & $\mathrm{X}$ & $\mathrm{X}$ & 0.50 \\
\hline 199-D5-111 & Sept. 22, 2007 & 4 & 20 Slot PVC & $\mathrm{X}$ & $\mathrm{X}$ & 0.50 \\
\hline
\end{tabular}

Well 199-D5-107. Ambient and dynamic flowmeter surveys were performed on September 21, 2007. The ambient and dynamic flow profiles are shown in Figure 3.14. Ambient measurements ranged from less than detection (i.e., $<0.04 \mathrm{~L} / \mathrm{min}[<0.01 \mathrm{gpm}]$ ) to $0.34 \mathrm{~L} / \mathrm{min}(0.09 \mathrm{gpm})$ in the upward direction. The net dynamic flow measurements indicate a generally uniform flow profile over a depth of 25.7 to $30.5 \mathrm{~m}$ (84.2 to $100 \mathrm{ft}$ ) bgs of the saturated well-screen section. Dynamic flow measurements indicate little flow contribution within the bottom $\sim 0.6 \mathrm{~m}$ ( $\sim 2 \mathrm{ft}$ ) of the well screen, which is consistent with the Ringold Formation upper mud unit encountered at a depth of $30.8 \mathrm{~m}$ (101 ft) bgs. Bypass flow between the packer/probe assembly and the well screen was estimated to be $\sim 13 \%$ of the net dynamic vertical flow. Bypass flow through the sand-pack material surrounding the well screen was estimated to be $~ 30 \%$ of the net flow. A depiction of the inferred normalized hydraulic conductivity profile is shown in Figure 3.15. 


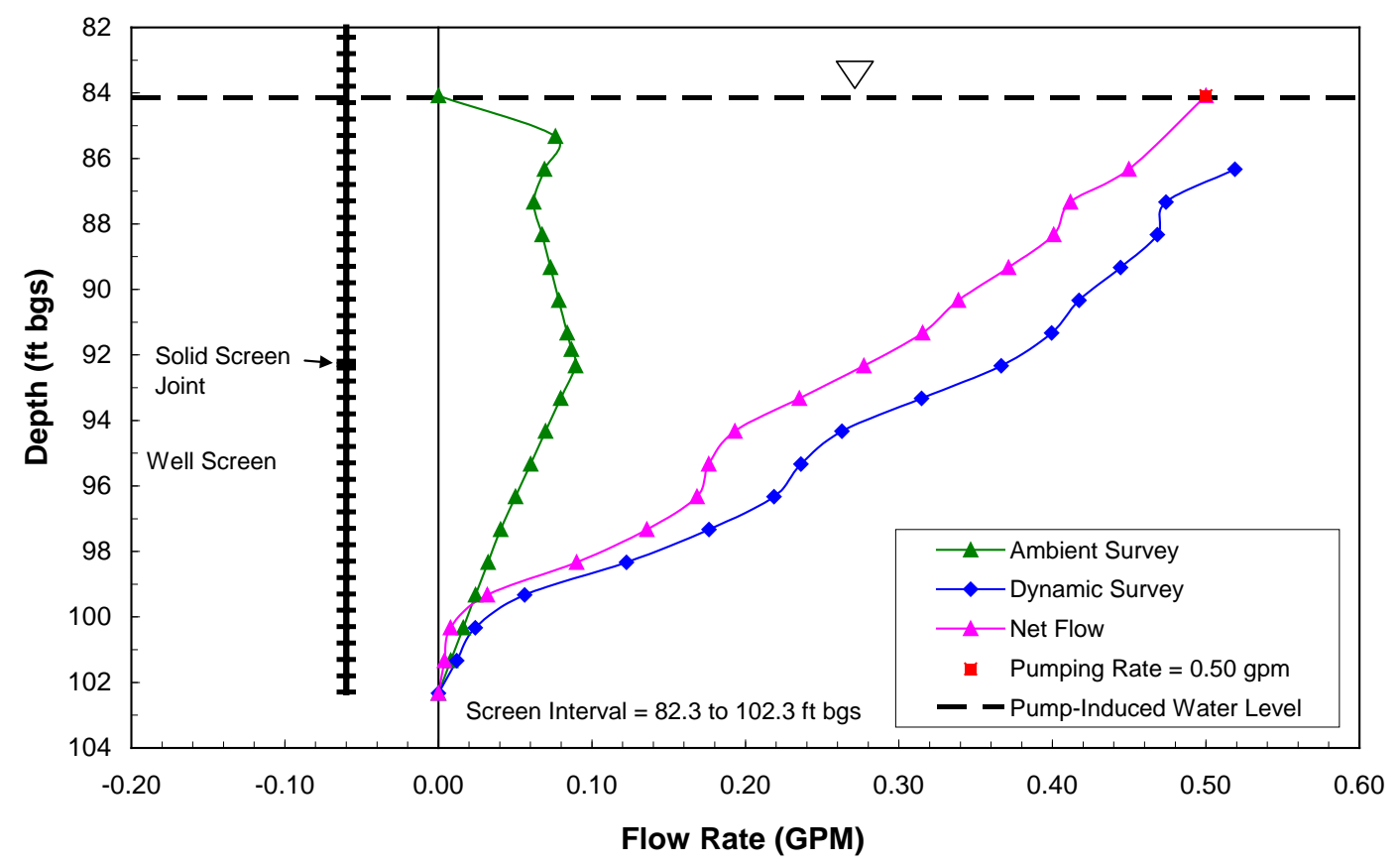

Figure 3.14. Ambient and Dynamic Vertical Flow Profiles, Well 199-D5-107

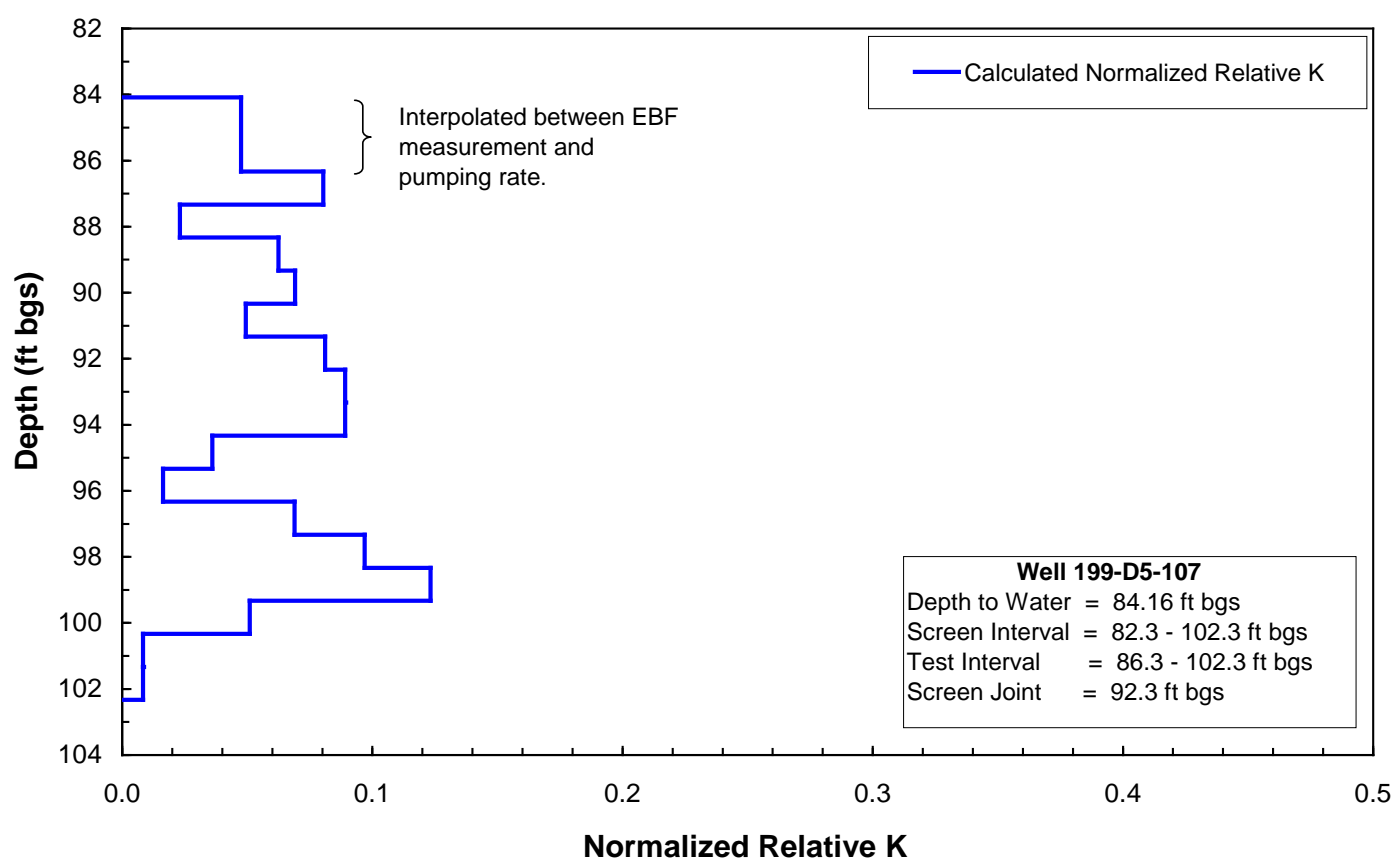

Figure 3.15. Normalized Hydraulic Conductivity Profile, Well 199-D5-107

Well 199-D5-109. Ambient and dynamic flowmeter surveys were performed on September 24, 2007. The ambient and dynamic flow profiles are shown in Figure 3.16. Ambient measurements ranged from less than detection (i.e., $<0.04 \mathrm{~L} / \mathrm{min}[<0.01 \mathrm{gpm}]$ ) in the middle portion of the well screen to $0.26 \mathrm{~L} / \mathrm{min}$ (0.07 gpm) upward flow in the upper portion of the well screen. The net dynamic flow measurements indicate a sharp increase in flow contribution between a depth of 29.4 to $30.0 \mathrm{~m}$ (96.4 and $98.4 \mathrm{ft}$ ) bgs. This 0.6-m (2-ft) depth interval is a high permeable zone that indicates a high relative hydraulic 
conductivity. The middle portion of the well-screen section between a depth of 27.9 to $29.4 \mathrm{~m}$ (91.4 and $96.4 \mathrm{ft}$ ) bgs contributes little or no flow over this interval. The dynamic flow profile shows generally uniform flow above $27.9 \mathrm{~m}$ (91.4 ft) bgs. Bypass flow between the packer/probe assembly and the well screen was calculated to be $\sim 7 \%$ of the measured dynamic vertical flow. Bypass flow through the sandpack material surrounding the well screen was estimated to be $\sim 18 \%$ of the net flow. A depiction of the inferred normalized hydraulic conductivity profile is shown in Figure 3.17.

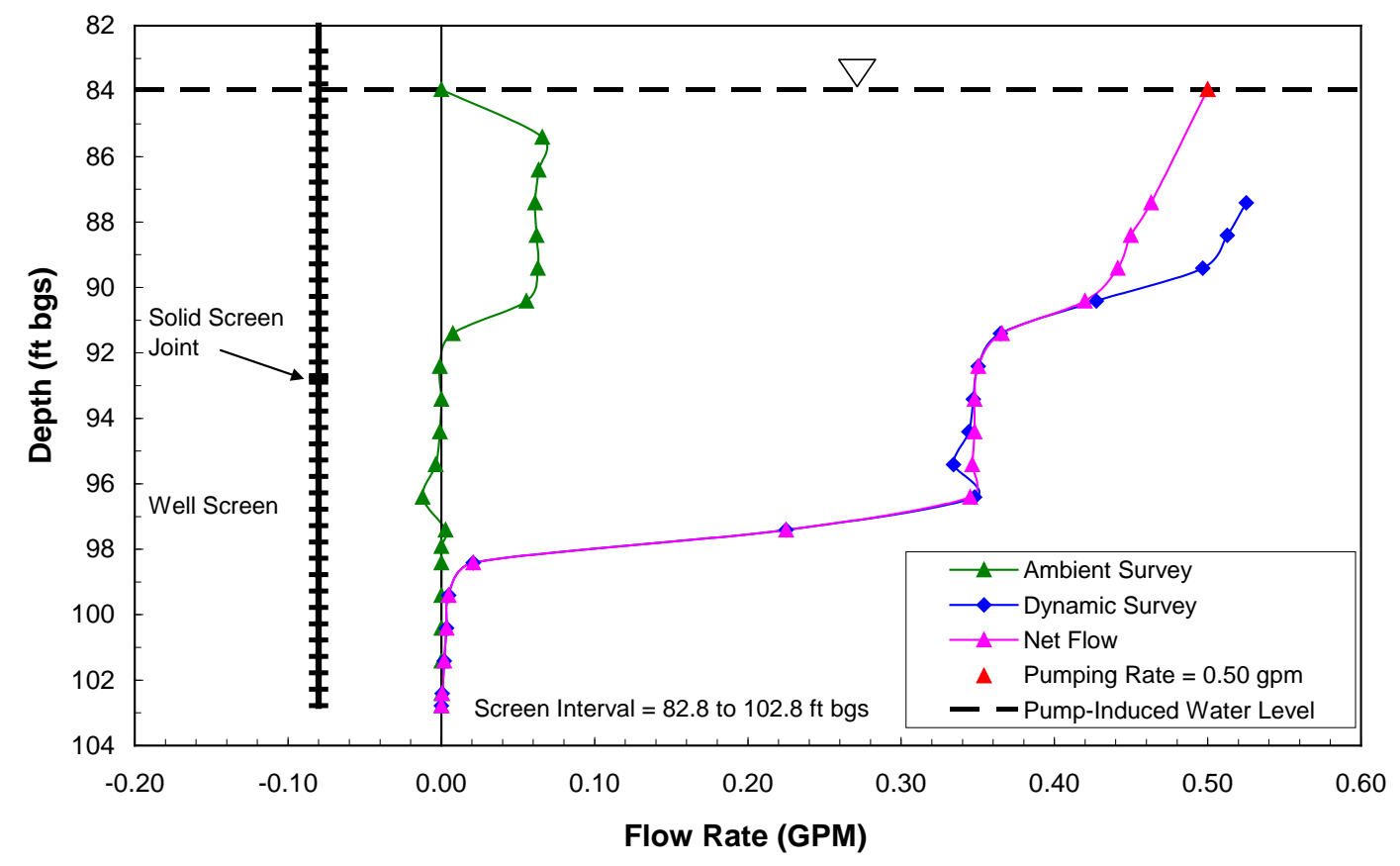

Figure 3.16. Ambient and Dynamic Vertical Flow Profiles, Well 199-D5-109

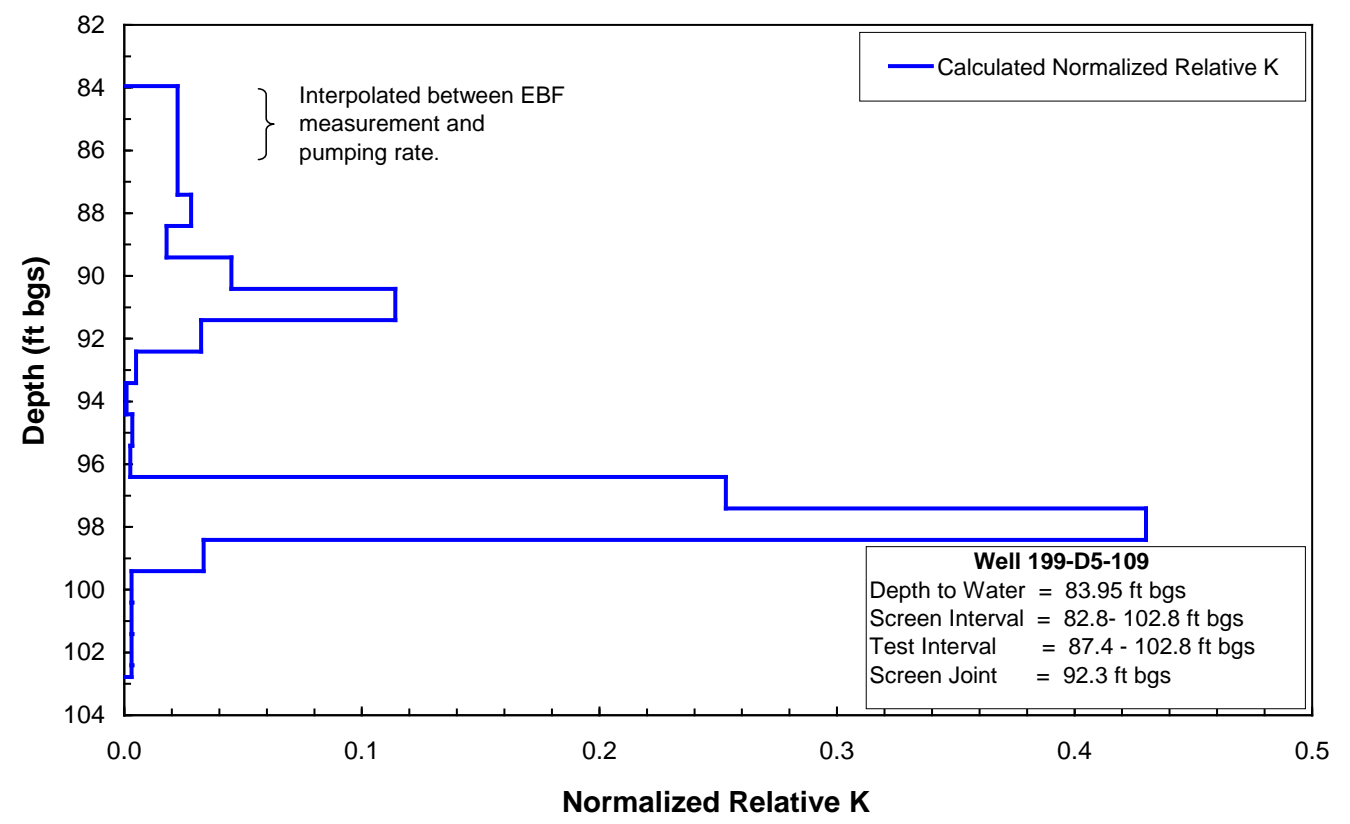

Figure 3.17. Normalized Hydraulic Conductivity Profile, Well 199-D5-109 


\section{Well 199-D5-110}

Ambient and dynamic flowmeter surveys were performed on September 21-22, 2007. The ambient and dynamic flow profiles are shown in Figure 3.18. Ambient flow measurements were uniform over the saturated well-screen section, with values ranging from 0.23 to $0.26 \mathrm{~L} / \mathrm{min}(0.06$ to $0.07 \mathrm{gpm})$ upward flow. Net dynamic flow measurements also show a generally uniform contribution of flow over a depth of $\sim 27.4$ to $30.2 \mathrm{~m}$ bgs ( $\sim 90$ to $99 \mathrm{ft}$ bgs) with lower contributions from the lower and upper part of the saturated well-screen section. The normalized hydraulic conductivity profile indicates the highest permeable zone at a depth of 28.8 to $29.4 \mathrm{~m}$ bgs (94.6 to $96.6 \mathrm{ft}$ bgs). Bypass flow between the packer/probe assembly and the well screen was estimated to be $\sim 7 \%$ of the net dynamic vertical flow. Bypass flow through the sand-pack material surrounding the well screen was estimated to be $\sim 32 \%$ of the net flow. A depiction of the inferred normalized hydraulic conductivity profile is shown in Figure 3.19.

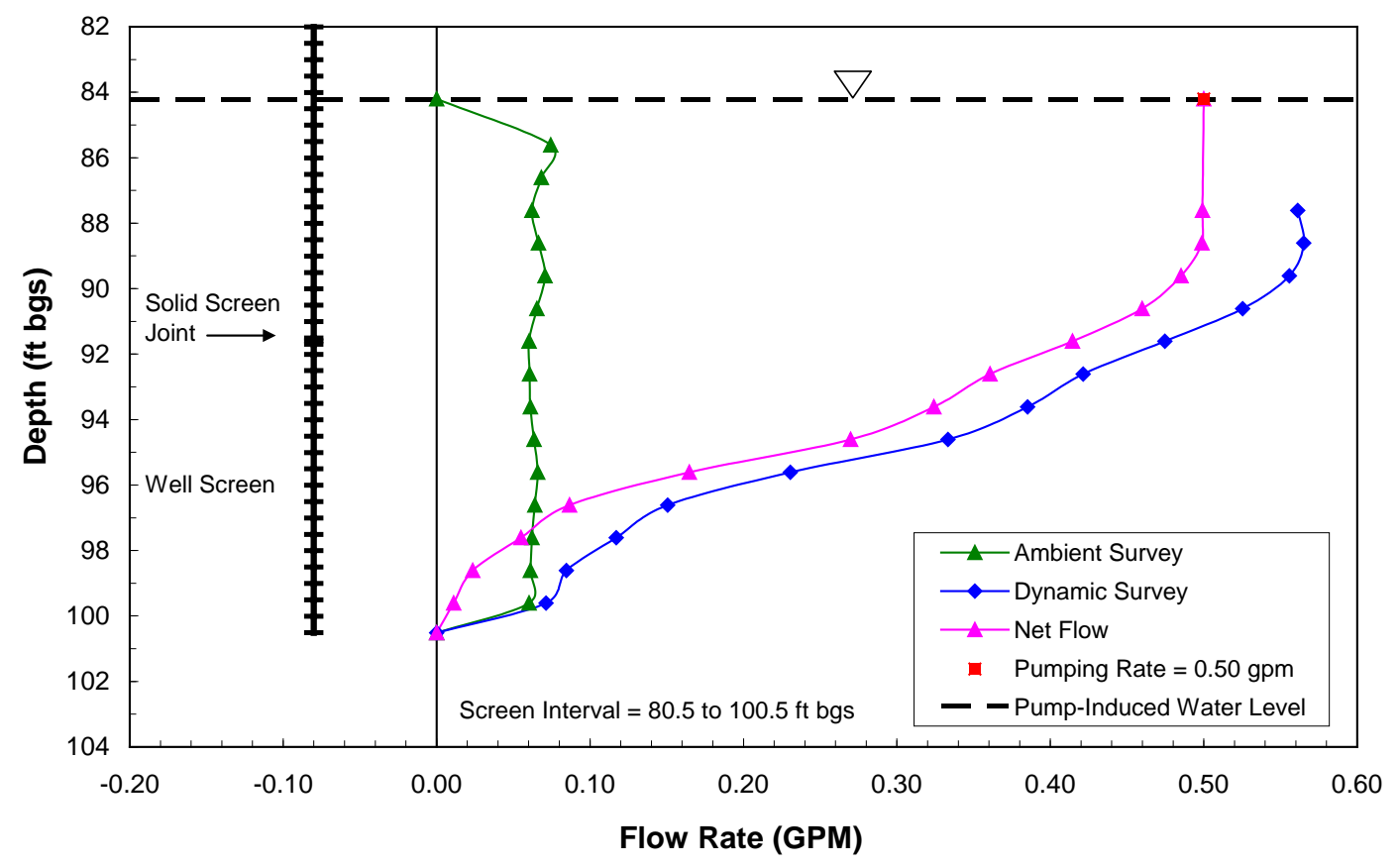

Figure 3.18. Ambient and Dynamic Vertical Flow Profiles, Well 199-D5-110 


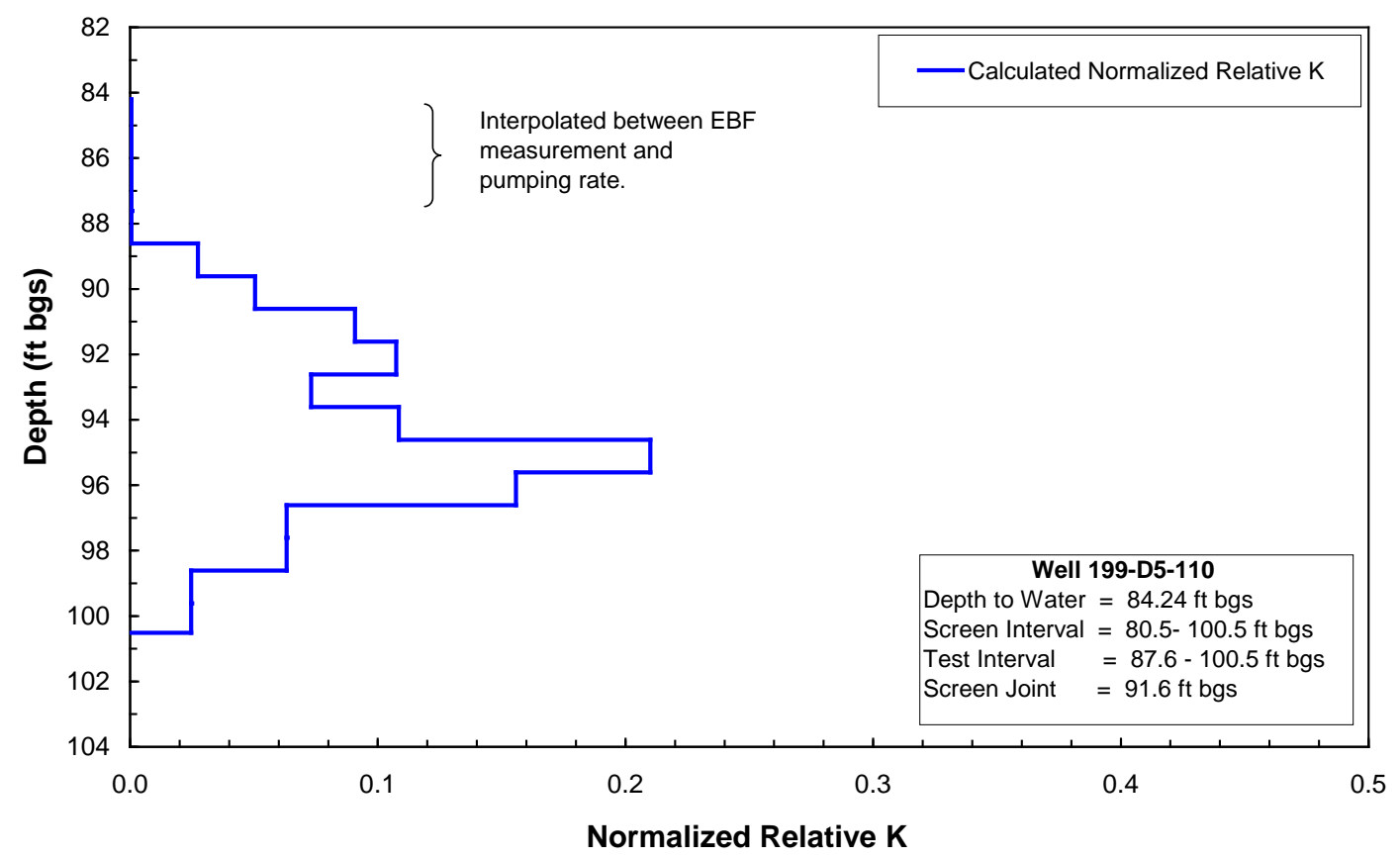

Figure 3.19. Normalized Hydraulic Conductivity Plot, Well 199-D5-110

Well 199-D5-111. Ambient and dynamic flowmeter surveys were performed on September 22, 2007. The ambient and dynamic flow profiles are shown in Figure 3.20. Ambient flow measurements were close to or below the detection limit (i.e., $0.04 \mathrm{~L} / \mathrm{min}[0.01 \mathrm{gpm}]$ ) of the instrument, indicating little or no ambient flow. The net dynamic flow measurements indicate a generally uniform flow profile over a depth of 27.3 to $30.5 \mathrm{~m}$ (89.6 to $100.1 \mathrm{ft}$ ) bgs and a slightly lower, but uniform flow profile above $27.3 \mathrm{~m}$ (89.6 ft) bgs. The normalized hydraulic conductivity profile indicates a thin, slightly higher permeable zone occurring at a depth of $\sim 27.4 \mathrm{~m}(\sim 90 \mathrm{ft})$ bgs. Bypass flow between the packer/probe assembly and the well screen was estimated to be $\sim 12 \%$ of the net dynamic vertical flow. A depiction of the inferred normalized hydraulic conductivity profile is shown in Figure 3.21. 


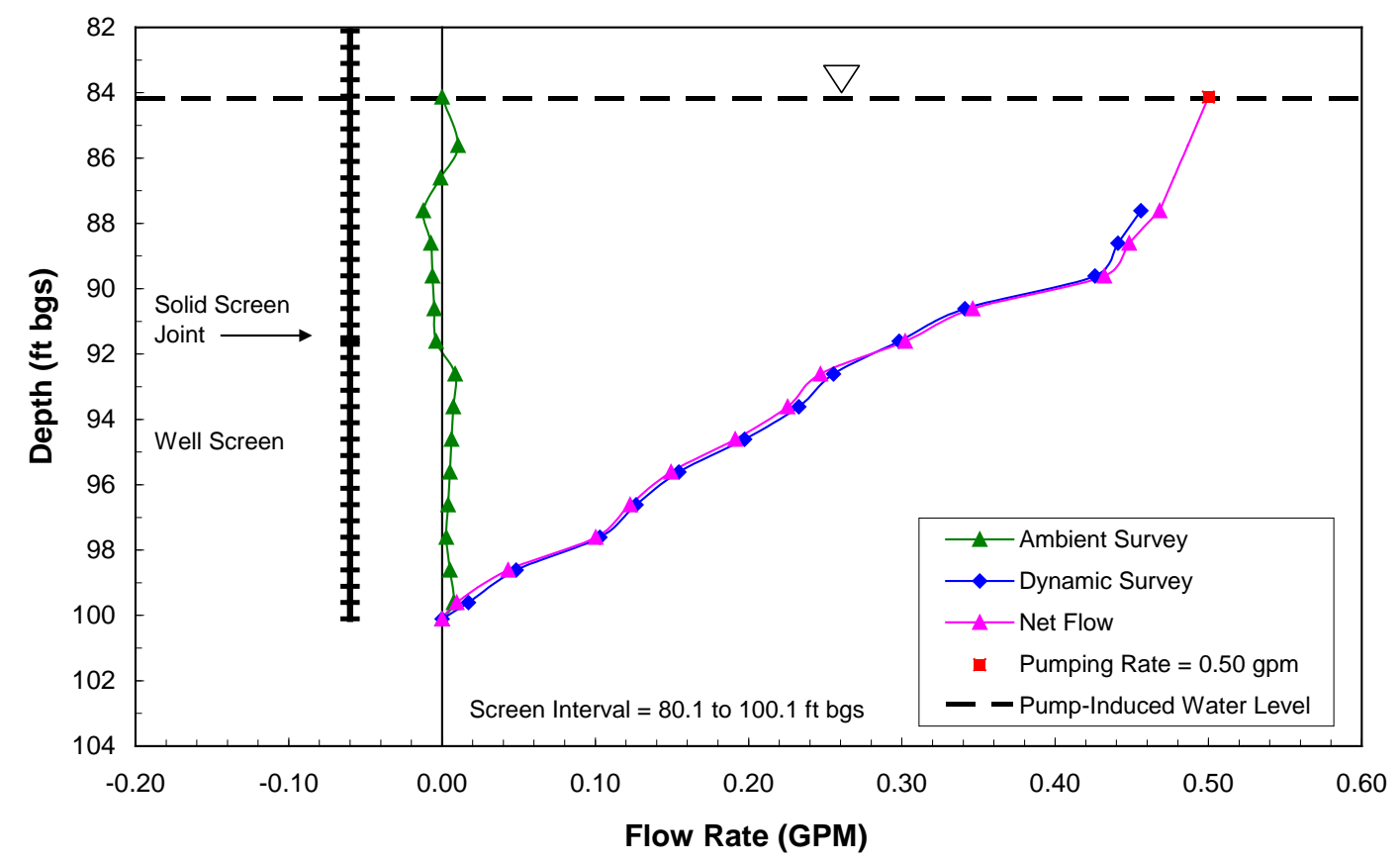

Figure 3.20. Ambient and Dynamic Vertical Flow Profiles, Well 199-D5-111

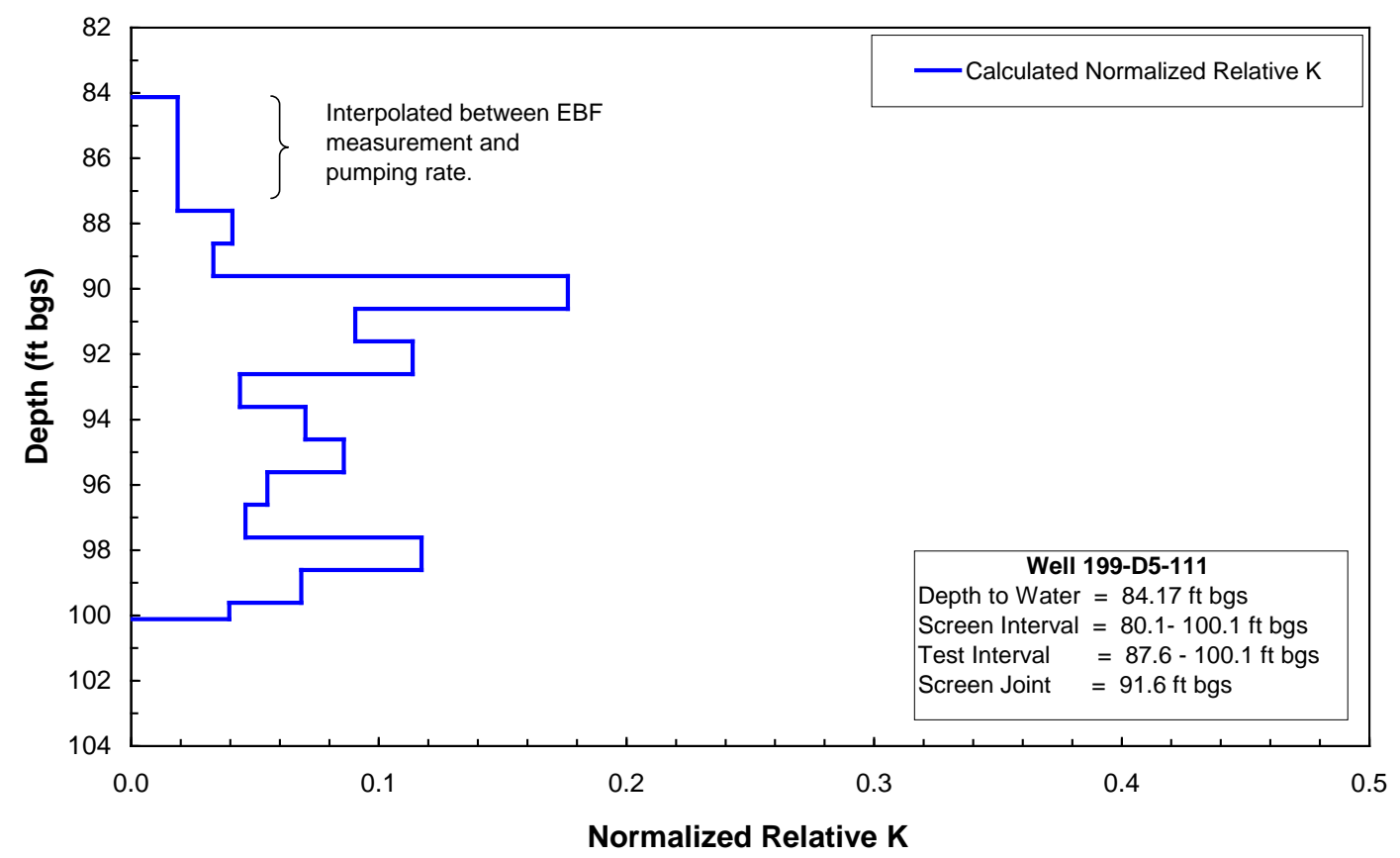

Figure 3.21. Normalized Hydraulic Conductivity Profile, Well 199-D5-111 


\subsubsection{Summary}

Analysis results indicate generally uniform lateral flow and relative hydraulic conductivity distribution for saturated well-screen sections in the three wells 199-D5-107, 199-D5-110, and 199-D5-111 surveyed. Analysis results for the fourth well, 199-D5-109, indicate a significantly increased lateral flow and relative hydraulic conductivity over a 0.6-m (2-ft) interval within the lower part of the well-screen section.

\subsubsection{Baseline Water Chemistry}

Baseline water chemistry data were collected prior to any injection activity. These data are listed in Table 3.4.

Table 3.4. Baseline Water Chemistry at the Upgradient Background Well 199-D5-40. Average of two sampling events in September 2007.

\begin{tabular}{lcl}
\hline \multicolumn{1}{c}{ Constituent } & Concentration $^{(\mathrm{a})}$ & $\mathrm{Units}$ \\
\hline Chromate & 70.0 & $\mu \mathrm{g} / \mathrm{L}$ \\
Chromium & 80.3 & $\mu \mathrm{g} / \mathrm{L}$ \\
Nitrate & 61.5 & $\mathrm{mg} / \mathrm{L}$ \\
Nitrite & 0.2 & $\mathrm{mg} / \mathrm{L}$ \\
Dissolved oxygen & 5.6 & $\mathrm{mg} / \mathrm{L}$ \\
Aluminum & $100 \mathrm{U}$ & $\mu \mathrm{g} / \mathrm{L}$ \\
Antimony & $500 \mathrm{U}$ & $\mu \mathrm{g} / \mathrm{L}$ \\
Arsenic & 1.5 & $\mu \mathrm{g} / \mathrm{L}$ \\
Barium & 98.1 & $\mu \mathrm{g} / \mathrm{L}$ \\
Bismuth & $500 \mathrm{U}$ & $\mu \mathrm{g} / \mathrm{L}$ \\
Boron & $250 \mathrm{U}$ & $\mu \mathrm{g} / \mathrm{L}$ \\
Cadmium & 0.2 & $\mu \mathrm{g} / \mathrm{L}$ \\
Calcium & 87307 & $\mu \mathrm{g} / \mathrm{L}$ \\
Cobalt & $250 \mathrm{U}$ & $\mu \mathrm{g} / \mathrm{L}$ \\
Copper & 52.2 & $\mu \mathrm{g} / \mathrm{L}$ \\
Iron & 50.0 & $\mu \mathrm{g} / \mathrm{L}$ \\
Lead & 53.3 & $\mu \mathrm{g} / \mathrm{L}$ \\
Magnesium & 18579 & $\mu \mathrm{g} / \mathrm{L}$ \\
Manganese & $25 \mathrm{U}$ & $\mu \mathrm{g} / \mathrm{L}$ \\
Molybdenum & 1.2 & $\mu \mathrm{g} / \mathrm{L}$ \\
Phosphorus & $1250 \mathrm{U}$ & $\mu \mathrm{g} / \mathrm{L}$ \\
Potassium & 4971 & $\mu \mathrm{g} / \mathrm{L}$ \\
Selenium & 4.4 & $\mu \mathrm{g} / \mathrm{L}$ \\
Silicon & 13628 & $\mu \mathrm{g} / \mathrm{L}$ \\
Silver & 0.03 & $\mu \mathrm{g} / \mathrm{L}$ \\
Sodium & 11701 & $\mu \mathrm{g} / \mathrm{L}$ \\
Sulfur & 43849 & $\mu \mathrm{g} / \mathrm{L}$ \\
Zinc & 894 & $\mu \mathrm{g} / \mathrm{L}$ \\
Zirconium & $25 \mathrm{U}$ & $\mu \mathrm{g} / \mathrm{L}$ \\
Bromide & 0.3 & $\mathrm{mg} / \mathrm{L}$ \\
Chloride & 26.0 & $\mathrm{mg} / \mathrm{L}$ \\
Phosphate & 0.1 & $\mathrm{mg} / \mathrm{L}$ \\
Sulfate & 136.5 & $\mathrm{mg} / \mathrm{L}$ \\
TOC & 3.3 & $\mathrm{mg} / \mathrm{L}$ \\
\hline (a) & &
\end{tabular}

(a) A "U" designation indicates the analyte was below the detection limit. The number next to the symbol is the detection limit. 


\subsection{Description of Groundwater Flow System}

The hydraulic gradient at and surrounding the field test site was evaluated over time using hydraulic-head triangulation. Figure 3.22 shows the gradient magnitude and direction in August 2007 over an areal extent on the scale of the 100-D Area chromate plume. A series of these figures depicting the gradient magnitude and direction monthly for the period from August 2007 through June 2009 are included in Appendix B. The central triangle in the plume area formed by wells 199-D5-43, -20, and -38 (hereafter, central triangle) was used as the primary indicator of flow in the vicinity of the field test site. Table 3.5 shows the average monthly gradient magnitude and net direction for the central triangle January 2007 through June 2009. Figure 3.23 shows the gradient magnitude and direction for the central triangle plotted with the river stage data over a period of about 2 years. These data show a consistent annual pattern of groundwater flow toward the river for about 10 months and flow for about 2 months which is diverted by high river stages such that flow in the central triangle is more parallel with the direction of river flow.

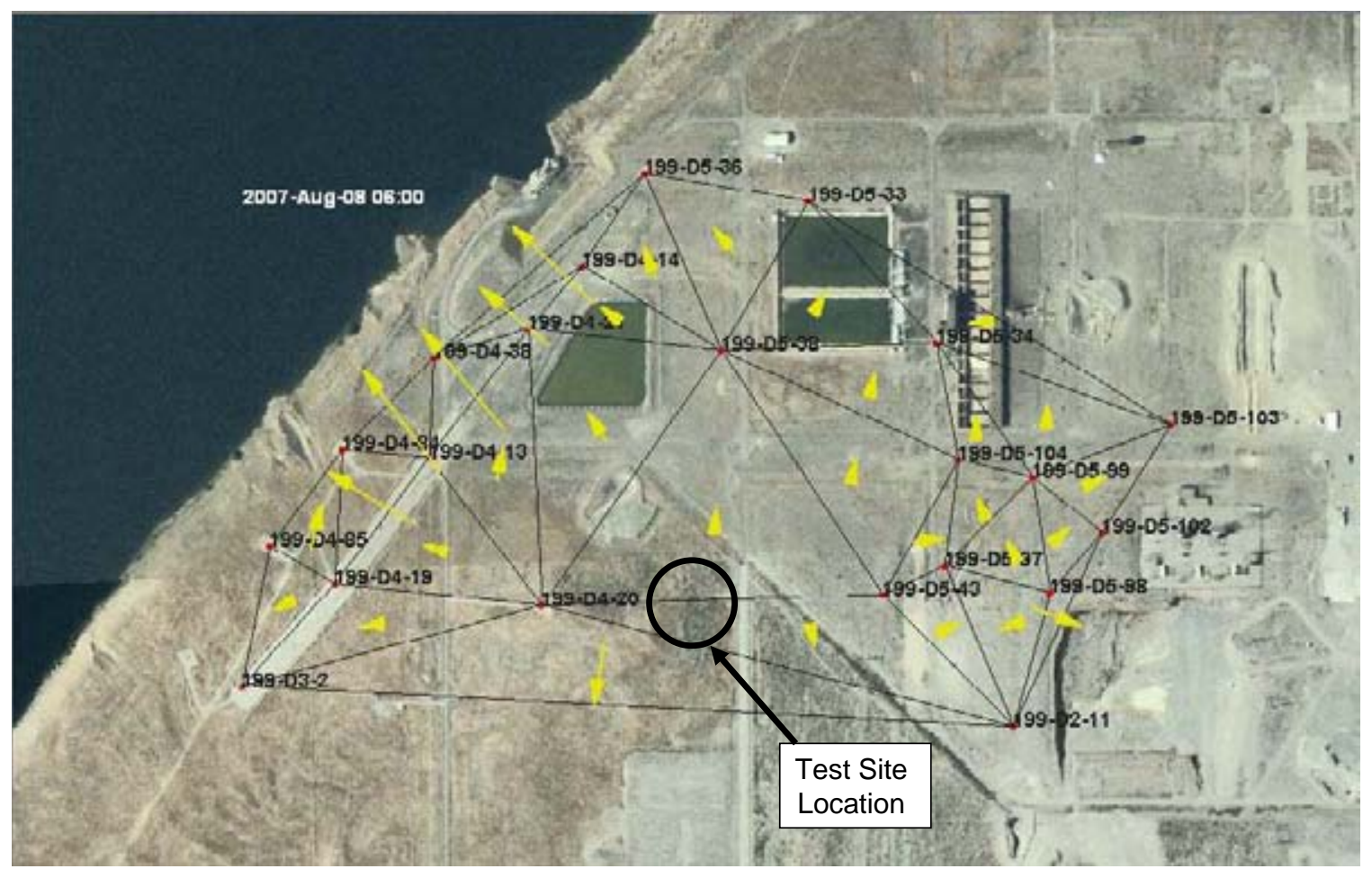

Figure 3.22. Gradient Direction and Relative Magnitude in the 100-D Chromate Plume for August 2007

Groundwater movement through the test area was estimated using the gradient information in Table 3.5 and the hydraulic properties identified for the site (hydraulic conductivity of $27.4 \mathrm{~m} /$ day and porosity of 0.14, see Sections 3.1 and 3.2). This analysis estimates that, over a period of about 10 months each year, the groundwater moves toward the river (directional azimuth of between $280^{\circ}$ and $10^{\circ}$ ) at a rate of about $38 \mathrm{~m} /$ year (125 ft/year). The remainder of the year, the groundwater moves about $8 \mathrm{~m} /$ year (26 ft/year) to the northeast, generally parallel with the direction of river flow. 
Table 3.5. Groundwater Hydraulic Information for the Monitoring Set of Wells 199-D5-43, 199-D5-20, and 199-D5-38

\begin{tabular}{lccccc}
\hline & $\begin{array}{c}\text { Average } \\
\text { Hydraulic } \\
\text { Gradient } \\
(\mathrm{m} / \mathrm{m})\end{array}$ & $\begin{array}{c}\text { Net } \\
\text { Direction } \\
\text { (azimuth) }\end{array}$ & $\begin{array}{c}\text { Percentage of } \\
\text { Data Missing } \\
\text { for the Period }\end{array}$ & $\begin{array}{c}\text { Groundwater } \\
\text { Velocity } \\
(\mathrm{m} / \text { day) }\end{array}$ & $\begin{array}{c}\text { (a) } \\
\text { Distance in } \\
(\mathrm{m})\end{array}$ \\
\hline July 2007 & 0.00043 & $25.3^{\circ}$ & 0.0 & 0.0842 & 2.525 \\
August 2007 & 0.00041 & $354.3^{\circ}$ & 0.0 & 0.0802 & 2.407 \\
September 2007 & 0.00061 & $315.4^{\circ}$ & 0.0 & 0.1194 & 3.582 \\
October 2007 & 0.00098 & $309.8^{\circ}$ & 0.0 & 0.1918 & 5.754 \\
November 2007 & 0.00090 & $300.2^{\circ}$ & 0.0 & 0.1761 & 5.284 \\
December 2007 & 0.00058 & $291.4^{\circ}$ & 0.0 & 0.1135 & 3.405 \\
January 2008 & 0.00041 & $294.3^{\circ}$ & 0.0 & 0.0802 & 2.407 \\
February 2008 & 0.00044 & $317.1^{\circ}$ & 0.0 & 0.0861 & 2.583 \\
March 2008 & 0.00052 & $313.1^{\circ}$ & 0.1 & 0.1018 & 3.053 \\
April 2008 & 0.00054 & $309.9^{\circ}$ & 0.0 & 0.1057 & 3.171 \\
May 2008 & 0.00034 & $353.1^{\circ}$ & 0.0 & 0.0665 & 1.996 \\
June 2008 & 0.00103 & $76.5^{\circ}$ & 0.0 & 0.2016 & 6.048 \\
July 2008 & 0.00097 & $61.0^{\circ}$ & 0.0 & 0.1898 & 5.695 \\
August 2008 & 0.00072 & $356.5^{\circ}$ & 0.0 & 0.1409 & 4.227 \\
September 2008 & 0.00091 & $324.0^{\circ}$ & 0.0 & 0.1781 & 5.343 \\
October 2008 & 0.00115 & $313.1^{\circ}$ & 0.0 & 0.2251 & 6.752 \\
November 2008 & 0.00103 & $310.5^{\circ}$ & 0.0 & 0.2016 & 6.048 \\
December 2008 & 0.00071 & $313.5^{\circ}$ & 10.5 & 0.1390 & 4.169 \\
January 2009 & 0.00050 & $320.2^{\circ}$ & 26.4 & 0.0979 & 2.936 \\
February 2009 & 0.00045 & $316.2^{\circ}$ & 6.2 & 0.0881 & 2.642 \\
March 2009 & 0.00069 & $304.6^{\circ}$ & 0.1 & 0.1350 & 4.051 \\
April 2009 & 0.00062 & $304.7^{\circ}$ & 0.0 & 0.1213 & 3.640 \\
May 2009 & 0.00026 & $332.0^{\circ}$ & 66.4 & 0.0509 & 1.527 \\
(a) Calcus & 0.00036 & $74.2^{\circ}$ & 8.2 & 0.0705 & 2.114 \\
\hline
\end{tabular}

(a) Calculated linear velocity using a hydraulic conductivity of $27.4 \mathrm{~m} /$ day, the tabulated gradient, and a porosity of 0.14 . 


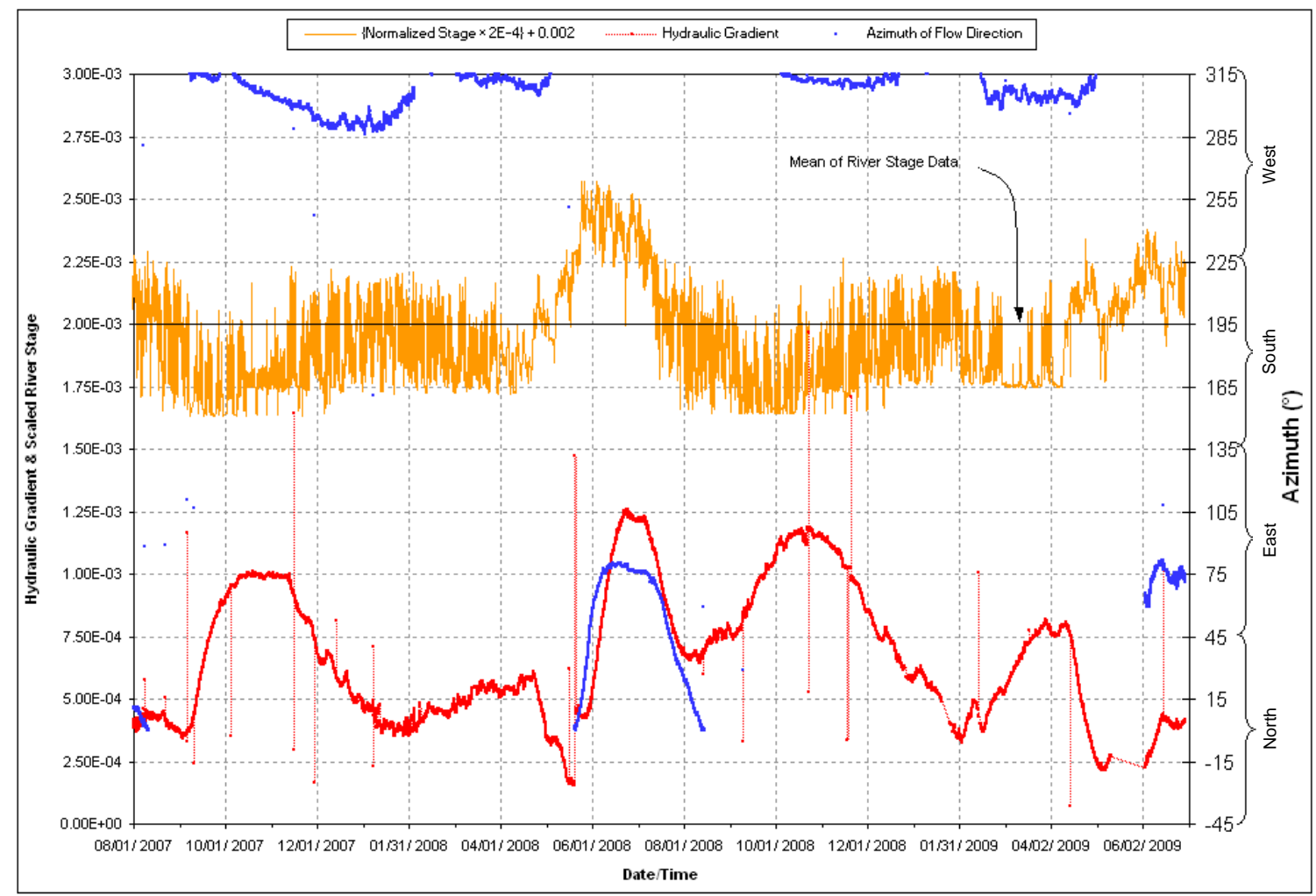

Figure 3.23. Gradient Magnitude and Direction from Triangulation Analysis with Wells 199-D5-43, 199-D5-20, and 199-D5-38 and River Stage Data 


\subsection{Testing Approach}

The treatability test was conducted according to the treatability test plan (Truex et al. 2007). Two test cells were installed at the test site, each consisting of an injection well surrounded by monitoring wells (Figure 4.1). The test cells were located such that existing well 199-D5-40 could be used as an upgradient, unimpacted monitoring location for both test cells. During well installation, sediment samples were collected and used in laboratory microcosm studies to confirm that the substrates induce chromate, nitrate, and dissolved oxygen reduction and for bench-scale studies of emulsion transport. Site characterization information were used to refine the field test design. Field test operations were conducted by injecting the substrate using process water from the 100-D Area pressurized water supply as the carrier solution. The injected water/substrate displaced chromate- and nitrate-contaminated groundwater during the injection. However, this displacement was used to assist in evaluating the longevity of the treatment. Because chromate and nitrate were initially absent in the treatment area, the injection and monitoring locations were used to evaluate the breakthrough of chromate and nitrate at these locations as a means to assess when the reductive capacity was exhausted.

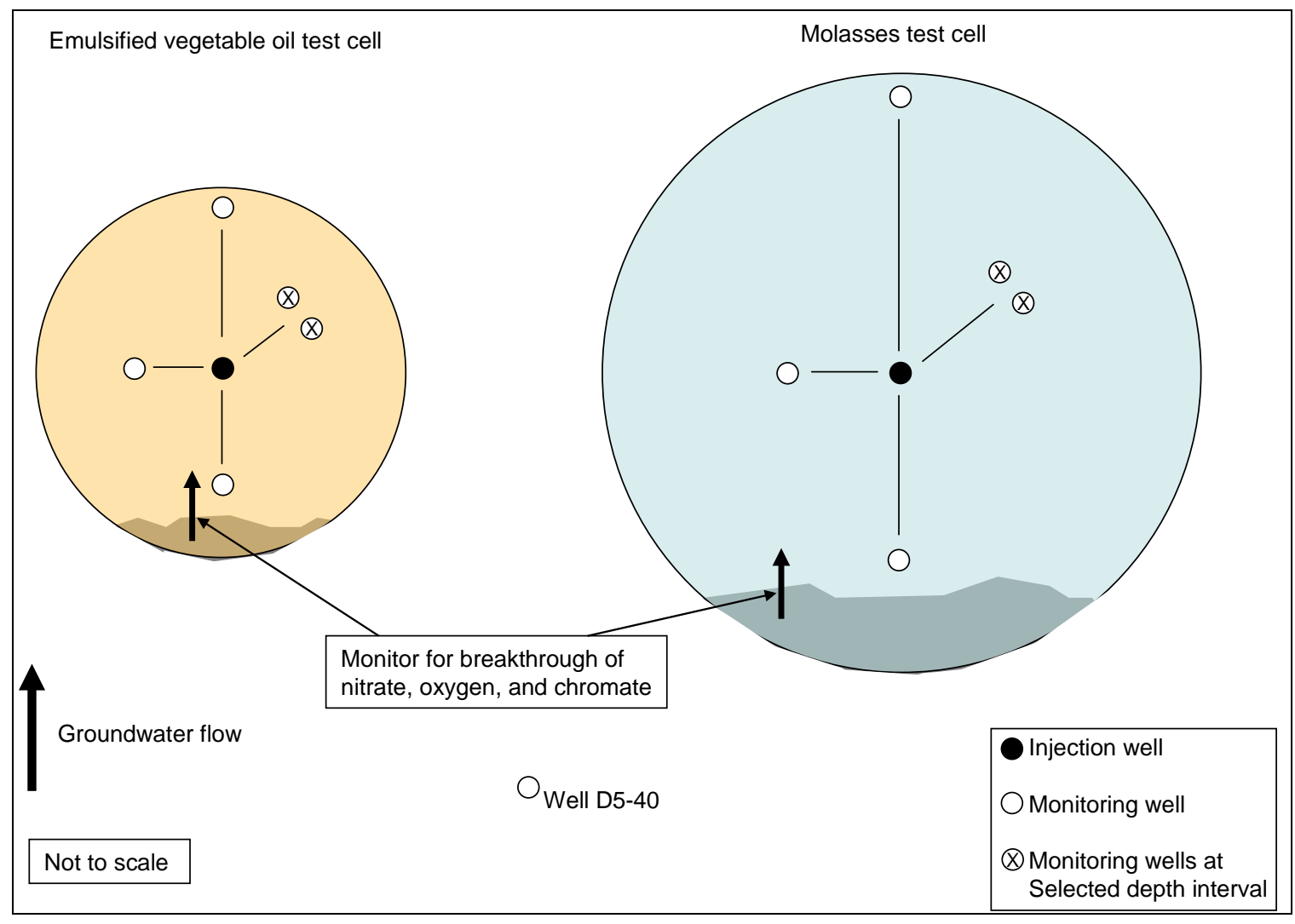

Figure 4.1. Conceptual Layout of Test Cells

This monitoring process is shown conceptually on Figure 4.1. These data address the effectiveness and implementability objectives for the test. Distribution of the substrates was assessed using geophysical methods and through monitoring of groundwater total organic carbon, turbidity, and a conservative tracer at the monitoring locations during and just after injection. These data and the 
operational aspects of the test address the implementability objectives for the test. The design and operational aspects of conducting the test in conjunction with the performance and distribution data were used to evaluate system scale-up and estimate cost for full-scale application, thereby addressing the cost objective of the test.

Through testing of the two different types of potential substrates (immiscible and soluble), the treatability test was intended to enable evaluation of how each substrate performs under field conditions (e.g., in the presence of field-scale heterogeneities) at the large scale necessary for a biobarrier to provide supplemental treatment upgradient of the ISRM barrier. The following sections summarize the test operations, hydraulic testing approach, data collection and management, and deviations from the test plan.

\subsection{Test Operations}

\subsubsection{Site Layout}

The test site is located just south of the 100-D reactor complex. Figure 4.2 and Figure 4.3 show the well layout for the soluble substrate and immiscible substrate tests, respectively. The field site included an exclusion zone during active chemical injection operations where no unauthorized personnel were allowed. The area contained sampling lines, cabling for water level measurement, sampling pump control lines, and the make-up water feed line. The laboratory trailer was located just outside this exclusion zone. The sampling manifold and other sampling equipment were located in the laboratory trailer. All waterlevel monitoring transducer cabling was routed into this trailer for real-time observations during testing. The process trailer was located in the exclusion zone and contained the water and chemical injection piping and control systems. Two 1,890-L (500-gal) tanks were located outside the exclusion zone for purge water storage.

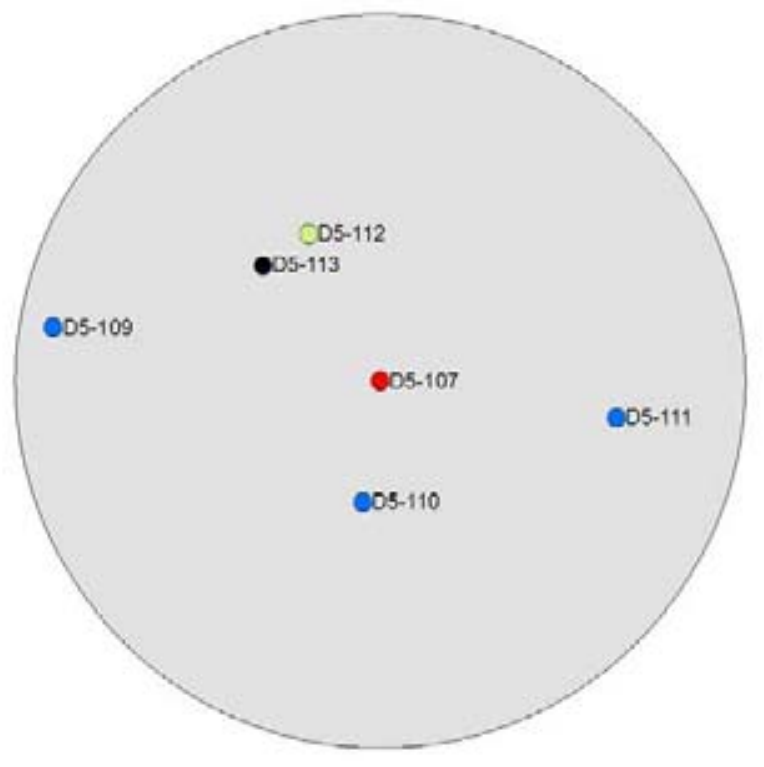

\section{Legend}

- Fully-Screened Injection Well

- Fully-Screened Monitoring Well

- Lower-Zone Monitoring Well

- Upper-Zone Monitoring Well

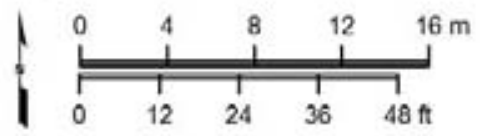

Figure 4.2. Well Layout for the Soluble Substrate Field Test 


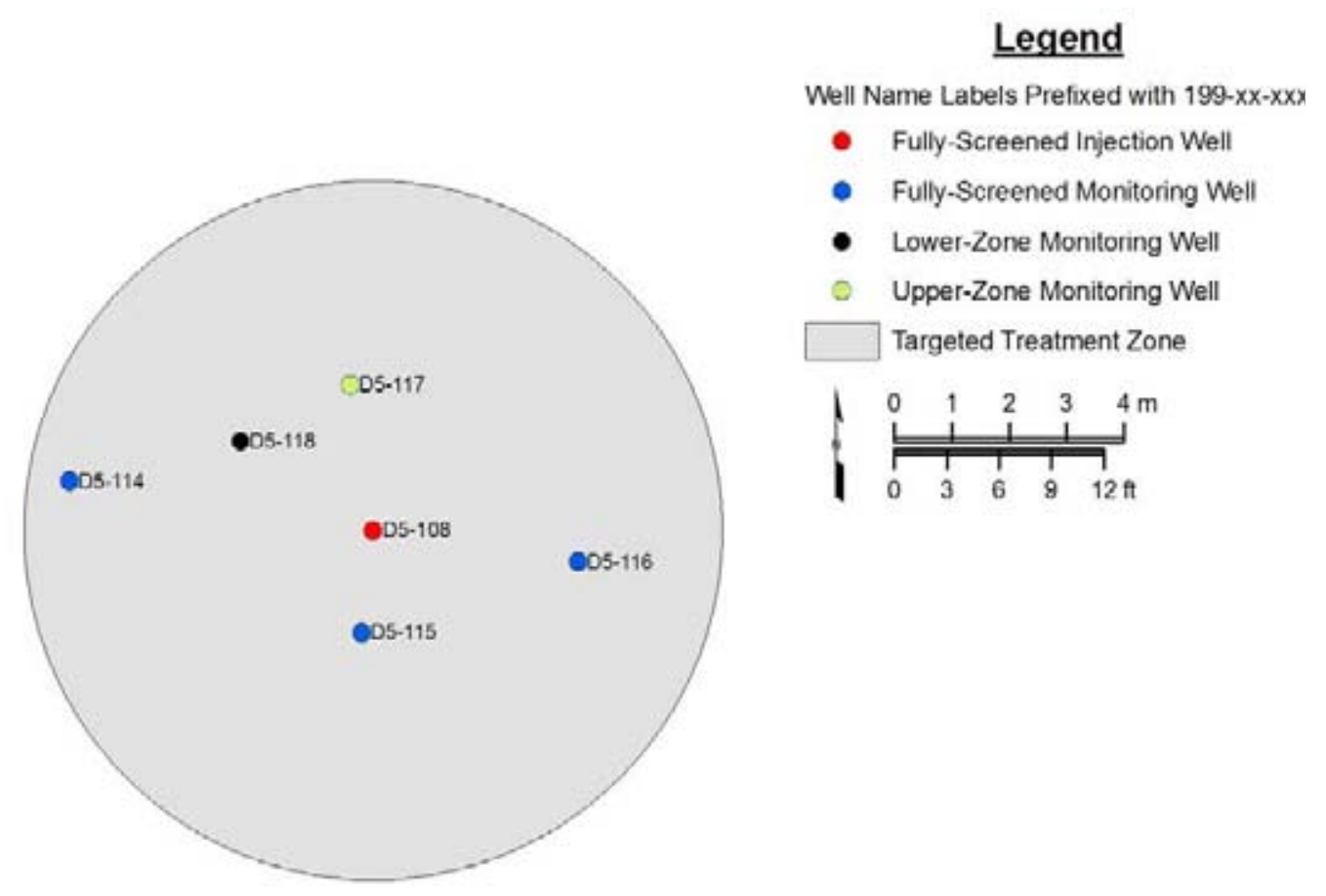

Figure 4.3. Well Layout for the Immiscible Substrate Test

\subsubsection{Water Supply}

Process water for the injections was obtained from the 100-D Area water supply system. The closest available access point was located approximately $200 \mathrm{~m}$ north of the injection site. A backflow preventer was installed to prevent any inadvertent siphoning of injection process water back into the water supply piping system. The water was routed to the test site through 7.6-cm (3-in.) lay-flat hose. The pressure loss through the hose was small enough that the pressurized water supply had sufficient capacity to achieve the specified flow rate.

\subsubsection{Injection Equipment}

Process water was routed into the injection manifold located inside the process trailer. The injection manifold (Figure 4.4) consisted of 5-cm (2-in.) stainless steel piping, valving, a pump, and flow rate monitoring equipment. For the soluble substrate test, the tracer solution also included a nitrogen nutrient. The manifold was used for diversion/shutoff and flow control of the process water and for dilution of the concentrated feed stock solutions to achieve the desired injection concentrations. The tracer and substrate solutions were fed into the manifold system using a chemical metering pump (Model QD, Fluid Metering, Inc., Syosset, New York) and double-diaphragm pump (Sandpiper, Warren Rupp, Mansfield, Ohio), respectively. Flow rate of the tracer was maintained with manual adjustments as necessary. The substrate feed rate was controlled by manually adjusting the stroke rate of the double diaphragm pump. The feed rate was monitored and recorded using a Campbell CR10X data logger (Campbell Scientific, Logan, Utah). The process water and total solution feed rates were measured with stainless steel turbine flowmeters (FTB-900, Omega Scientific, Stamford, Connecticut) and recorded with a Campbell CR10X data logger. The solution feed rate was also monitored on a qualitative basis using an in-line rotameter (Model 7500, King Instrument Company, Garden Grove, California). 


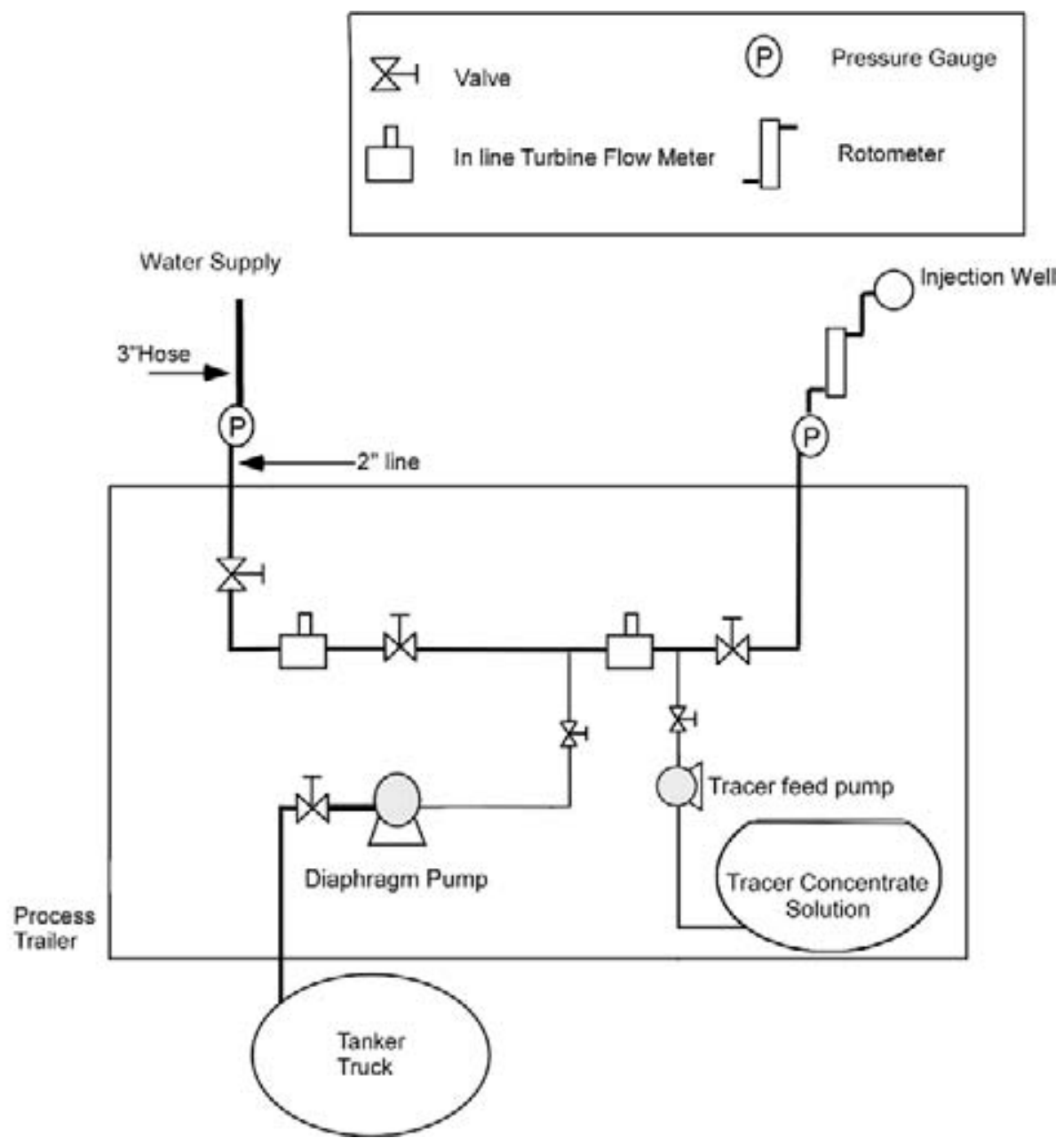

Figure 4.4. Injection Manifold with the Make-Up Water and all Other Necessary Components

Two pressure gauges were located in the system; one at the inlet and one at the outlet of the injection manifold (Figure 4.4). The injection well was outfitted with an injection pipe consisting of $32 \mathrm{~m} \mathrm{(105 \textrm {ft } )}$ of 5-cm (2-in.) schedule 40 PVC pipe with the bottom section capped. Holes were drilled into the pipe over a $6.1-\mathrm{m}(20-\mathrm{ft})$ interval corresponding to the screened interval of the injection well.

\subsubsection{Monitoring Equipment}

Dedicated Grundfos Redi-flow2 sampling pumps (Instrumentation Northwest, Kirkland, Washington) capable of providing sample flows rates up to $7.6 \mathrm{~L} / \mathrm{min}(2 \mathrm{gpm})$ were installed in all site monitoring wells. The sample tubing (0.95-cm [0.375-in.] polyethylene) from each of these sampling pumps was routed inside the laboratory trailer and connected to a sampling manifold. A single variable-frequency power supply (Redi-flo VFD, Instrumentation Northwest) provided power for the sampling pumps. A multichannel interface (pump switchbox) was used to allow a single power supply/controller arrangement to provide power to all sampling pumps.

A sampling manifold was used to collect samples from the various monitoring wells. This approach routes all sample streams into a central manifold for monitoring field parameters (in a flow-through monitoring assembly) and collecting groundwater samples (Figure 4.5). The advantage of this type of 
system is that all field parameter measurements are made using a single set of electrodes, which improves data quality and comparability of spatially distributed measurements. Consistent labeling between the sampling manifold and pump switch box simplified selection of the well to be sampled and reduced the chance of operator error during the frequent sampling associated with the injection tests. To further help reduce the potential for collecting sample from the wrong well, the pump switch box included a series of low-voltage light-emitting diode indicator lights on the sample manifold. When a pump was turned on, a light came on to indicate which pump was operating and which valve on the manifold should be opened.

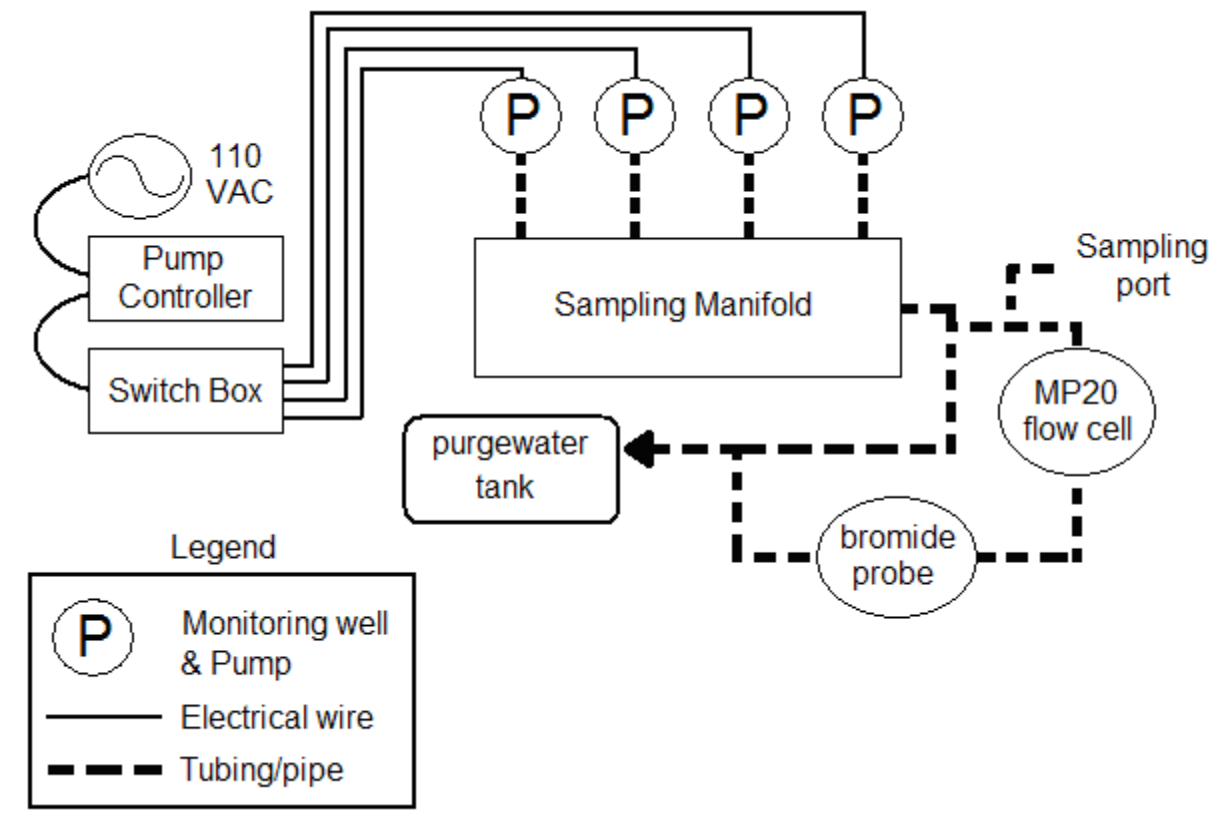

Figure 4.5. Groundwater Sample Acquisition System

Field parameters (specific conductance, temperature, dissolved oxygen, $\mathrm{pH}$, and oxidation reduction potential) were monitored using an MP20 flow cell (QED Environmental Systems, Ann Arbor, Michigan). The flow-through nature of the flow cell assembly minimizes the amount of dead space within the monitoring chamber.

To monitor real-time tracer arrivals, bromide ion selective electrodes (ISE) were used in a flowthrough assembly for pumped samples and in selected monitoring wells for downhole measurements. The ISE probe (TempHion, Instrumentation Northwest) was plumbed in series with the MP20 flow cell, providing real-time estimates of bromide concentration in the field. Prior to sampling, it was determined that the housing for the bromide probe required a 3.78-L (1-gal) purge volume for readings to stabilize. ISE measurements were logged using a Campbell Scientific CR10X data logger programmed to record data at a frequency ranging from 5 to 30 minutes.

Purge rates during groundwater sampling were maintained at $3.78 \mathrm{~L}(1 \mathrm{gal})$ per minute to minimize drawdown in the monitoring wells and, based on volumetric calculations and field observations, it was determined that a 2-minute purge time was sufficient to ensure adequate purging of the sample lines, manifold, and flow cells. During field operations, flow cell readings generally stabilized in less than 1 minute, indicating that the 2-minute purge time was adequate. The sensors used to measure field parameters during this test meet the specifications shown in Table 4.1. 
Table 4.1. Field Parameter Monitoring Electrode Specifications

\begin{tabular}{llll}
\hline \multicolumn{1}{c}{ Parameter } & \multicolumn{1}{c}{ Manufacturer/Model No. } & \multicolumn{1}{c}{ Range } & Accuracy \\
\hline $\mathrm{pH}$ & QED/MP20 & 2 to $12 \mathrm{pH}$ units & $\pm 0.2 \mathrm{pH}$ \\
$\begin{array}{l}\text { Oxidation reduction } \\
\text { potential }\end{array}$ & QED/MP20 & -999 to $999 \mathrm{mV}$ & $\pm 25 \mathrm{mV}$ \\
Temperature & QED/MP20 & 5 to $50^{\circ} \mathrm{C}$ & $\pm 0.2^{\circ} \mathrm{C}$ \\
Specific conductance & QED/MP20 & 0 to $100 \mathrm{mS} / \mathrm{cm}$ & $\pm 1 \%$ \\
Dissolved oxygen & QED/MP20 & 0 to $50 \mathrm{mg} / \mathrm{L}$ & $\pm 0.2 \mathrm{mg} / \mathrm{L}$ \\
Bromide & Instrumentation Northwest/ & Calibrate to specified range & $\pm 5 \%$ of range \\
& TempHion & & \\
\hline
\end{tabular}

\subsubsection{Soluble Substrate Operations}

Pretest Monitoring. Before the test injection, hydraulic testing and baseline aqueous sampling were conducted. Hydraulic testing included slug and slug interference testing, electronic borehole flowmeter testing in each fully screened well, and a geophysical survey. Additional pretest monitoring included water-level measurements at test cell wells and other selected locations, to determine hydraulic gradients. Baseline aqueous monitoring included analyses for total organic carbon (TOC), organic acids, nitrate, nitrite, sulfate, chromate, major cations and anions, metals covered by the Resource Conservation and Recovery Act of 1976 (RCRA), and dissolved oxygen concentration. Baseline monitoring was performed in all test cell monitoring and injection wells and at well 199-D5-40, the upgradient monitoring well.

Substrate Injection. The substrate injection was conducted using process water injected at approximately 40 gpm amended with approximately $40 \mathrm{~g} / \mathrm{L}$ molasses, $100 \mathrm{mg} / \mathrm{L}$ ammonium chloride, and $100 \mathrm{mg} / \mathrm{L}$ sodium bromide. Samples of the injected solution and at the test cell monitoring wells were collected periodically during injection and were analyzed for bromide, TOC, organic acids, nitrate, nitrite, sulfate, and chromate. At the end of the substrate injection, process water was injected for approximately an hour to clear the injection system of substrate and flush the wellbore. The decline in hydraulic head at the monitoring locations was monitored after injection flow was terminated to provide data to help evaluate hydraulic properties of the test zone. After the injection was completed, the injection system was disconnected and the injection well was converted to a monitoring location. Details of the sampling schedule are included in Section 4.3.

Process Monitoring. Process monitoring was conducted after injection to assess the formation of a reducing barrier. Samples were collected at each well in the test cell weekly for 8 weeks and analyzed for TOC, organic acids, nitrate, nitrite, sulfate, chromate, oxygen, oxidation reduction potential, bromide, and $\mathrm{pH}$. To assess the impact of the injected solutions, slug tests and additional geophysical surveys were conducted during the process monitoring phase. Details of the sampling schedule are included in Section 4.3.

Performance Monitoring. After the process monitoring phase was completed, the test cell was monitored to assess its performance as a reducing barrier. The goal of this monitoring phase was to evaluate the conditions within the reducing zone and to determine when nitrate, chromate, and oxygen 
breakthrough occurs as an indication of barrier longevity. This performance monitoring consisted of samples collected periodically for 21 months at each well in the test cell and at the upgradient monitoring well (199-D5-40). Samples were analyzed for TOC, organic acids, bromide, nitrate, nitrite, sulfate, chromate, total chromium, oxygen, oxidation reduction potential, and $\mathrm{pH}$. Additionally, major cations and anions, RCRA metals, and methane were monitored for comparison to the baseline water quality determined in the pretest monitoring. Details of the sampling schedule are included in Section 4.3.

\subsubsection{Immiscible Substrate Operations}

Pretest Monitoring. Before the test injection, hydraulic testing and baseline aqueous sampling were conducted. Hydraulic testing included slug and slug interference testing, electronic borehole flowmeter testing in each fully screened well, an injection/recovery test, and a geophysical survey. Additional pretest monitoring included water-level measurements at test cell wells and other selected locations, to determine hydraulic gradients. Baseline aqueous monitoring included analyses for TOC, organic acids, nitrate, nitrite, sulfate, chromate, major cations and anions, metals covered by RCRA, and dissolved oxygen concentration. Baseline monitoring was performed in all test cell wells and at well 199-D5-40, the upgradient monitoring well. A short-duration injection test using process water was conducted with monitoring of the pressure buildup and recovery after injection to help estimate the bulk hydraulic properties for the test cell.

Substrate Injection. The substrate injection was conducted over a period of 17 hours using process water injected at approximately $40 \mathrm{gpm}$ amended with approximately $60 \mathrm{~g} / \mathrm{L}$ emulsion (EOS ${ }^{\circledR} 598$ product) and $100 \mathrm{mg} / \mathrm{L}$ sodium bromide. Emulsion amendment was not continuous during this time but occurred in seven discrete pulses, with a total emulsion injection time of 10.5 hours. Samples of the injected solution and at the test cell monitoring wells were collected periodically during injection and were analyzed for bromide, TOC, nitrate, nitrite, sulfate, and chromate. At the end of the substrate injection, process water was injected for approximately 3 hours to clear the injection system of substrate. After the injection was completed, the injection system was disconnected and the injection well was converted to a monitoring location. Details of the sampling schedule are included in Section 4.3.

Process Monitoring. Reporting for the process monitoring was combined with that for the performance monitoring phase for the immiscible substrate injection because of the similar monitoring frequency.

Performance Monitoring. After injection, the test cell was monitored to assess its performance as a reducing barrier. The goal of this monitoring was to evaluate the conditions within the reducing zone and to determine when nitrate, chromate, and oxygen breakthrough occurs as an indication of barrier longevity. This performance monitoring consisted of samples collected periodically for 10 months at each well in the test cell and at the upgradient monitoring well (199-D5-40). Samples were analyzed for TOC, bromide, nitrate, nitrite, sulfate, chromate, total chromium, oxygen, oxidation reduction potential, and $\mathrm{pH}$. Additionally, major cations and anions, RCRA metals, and methane were monitored for comparison to the baseline water quality determined in the pretest monitoring. To assess the impact of the injected solutions on geohydrologic properties, slug tests and additional geophysical surveys were conducted during the process monitoring phase. Details of the sampling schedule are included in Section 4.3. 


\subsection{Hydraulic Testing to Evaluate Permeability Changes}

Permeability changes due to the injected materials and biomass production were evaluated using slug testing and geophysical testing. The two techniques are described in Sections 4.2.1 and 4.2.2, respectively.

\subsubsection{Hydraulic Slug Testing Methods}

A series of slug tests was performed in 10 of the 12 wells located within the molasses and emulsified vegetable oil treatment test sites to evaluate changes in aquifer hydraulic properties after bioremediation treatment. The two upper-zone monitoring wells, 199-D5-112 and 199-D5-117, were not tested because they did not contain sufficient water column for slug testing. Baseline slug tests were conducted in August 2007 prior to any injection treatment activities. Post-treatment slug tests were performed in the molasses well cluster in two separate campaigns, once in November 2007 and again in November 2008. In the emulsified vegetable oil well cluster, post-treatment slug testing was performed once in November 2008. The responses from the pre- and post-treatment slug tests were then used to evaluate changes in formation permeability.

\subsubsection{Well Development}

Insufficiently developed wells may have a low-K skin around the screen. This negatively impacts the slug test response, and the K estimate will be biased low. Well development was performed by the drilling contractor in two separate phases using a double-disc surge block. During well completion, surging was performed within 3-m (10-ft) intervals for a minimum of 1 hour per interval, with development considered complete when the filter pack sand had finished settling. Fines pulled into the well during surging were then bailed/pumped out of the wellbore. After well completion, additional surging was performed within the screened interval until minimal fines were detected. The wells were then pumped at flow rates up to $130 \mathrm{~L} / \mathrm{min}$ (35 gpm) with a submersible pump until turbidity levels were below 5 NTU.

Based on reproducibility in the slug test results, it appears that the wells were sufficiently developed prior to performing the pre-treatment slug tests. Changes in the response between repeat tests can indicate a dynamic skin effect, which is indicative of the need for additional development in the well (Butler 1998). Except for the post-treatment tests in the two injection wells (199-D5-107 and 199-D5-108), no dynamic skins were observed. It should be noted that, although the absence of dynamic skin does provide indication that the well has been developed to the extent possible for stress levels comparable to that provided by the slug tests, it does not provide confirmation that no skin exists.

\subsubsection{Field Methods}

Slug testing was performed using three different slugging rods of known dimensions. The 6-in.diameter injection wells were slug-tested using 3- and 4.5-in.-OD slugging rods, and the 4-in.-diameter wells were tested with 2- and 3-in.-OD rods. Table 4.2 contains summary information for the different slugging rods used. For each test, the slugging rod was rapidly submerged into the water column within the test well, creating falling-head conditions. Water levels were allowed to recover to static conditions after the slug-injection test. The slugging rod was then rapidly withdrawn from the water column, 
creating a rising-head test. As time permitted, many of the wells were tested using multiple slugging rods of different volumes, to vary the initial stress level as well as to repeat tests with the same slugging rod. Butler (1998) recommends doing this to identify non-ideal test conditions such as changing effective screen length and dynamic skin effects. In general, the responses were reproducible and independent of magnitude of initial stress.

Table 4.2. Slugging Rod Information

\begin{tabular}{cccc}
\hline & & \multicolumn{2}{c}{$\begin{array}{c}\text { Theoretical Initial Stress }\left(\mathrm{H}_{\mathrm{o}}^{*}\right) \text {, } \\
\mathrm{ft} \text { of } \mathrm{H}_{2} \mathrm{O}\end{array}$} \\
\cline { 3 - 4 } $\begin{array}{c}\text { Outside Diameter, } \\
\text { in. }\end{array}$ & Volume, $\mathrm{ft}^{3}$ & 6-in. Well & 4-in. Well \\
\hline 2.0 & 0.13 & Not used & 1.50 \\
3.0 & 0.33 & 1.68 & 3.77 \\
4.5 & 0.74 & 3.77 & Not used \\
\hline
\end{tabular}

Pressure responses were monitored in the stress well and neighboring monitoring wells for each test using sensors (Model PT2X, Instrumentation Northwest, Kirkland, Washington) with ranges of 5 and 15 psig (0.1\% accuracy). Manual water-level measurements and depths to bottom for each well were taken at the beginning and end of each day of testing using an "e-tape” instrument traceable to standards established by NIST. It was noted that no wells experienced any significant infilling with fine-grained material as a result of the slug-testing activities, providing further indication that the wells were effectively development prior to slug testing.

\subsubsection{Wells Screened Across the Water Table}

Most of the wells within the test sites are screened across the water table and exhibited associated impacts to the early-time responses. The highly permeable filter pack sand and the surrounding developed zone act as an effectively larger well casing, resulting in an observed initial stress $\left(\mathrm{H}_{0}\right)$ that is lower than expected based on the volume of the slugging rod and the nominal well casing radius. In situations such as these, where the filter pack material and surrounding developed zone have a higher $\mathrm{K}$ than the undisturbed aquifer material, the slug test response has a characteristic "double straight-line" pattern on a semi-log plot (Bouwer 1989). This type of response is characterized by an initially steeper section of data indicative of the high-K filter pack (inner zone), followed by a flatter formational response in later time (outer zone). An example of this is illustrated in Figure 4.6. 


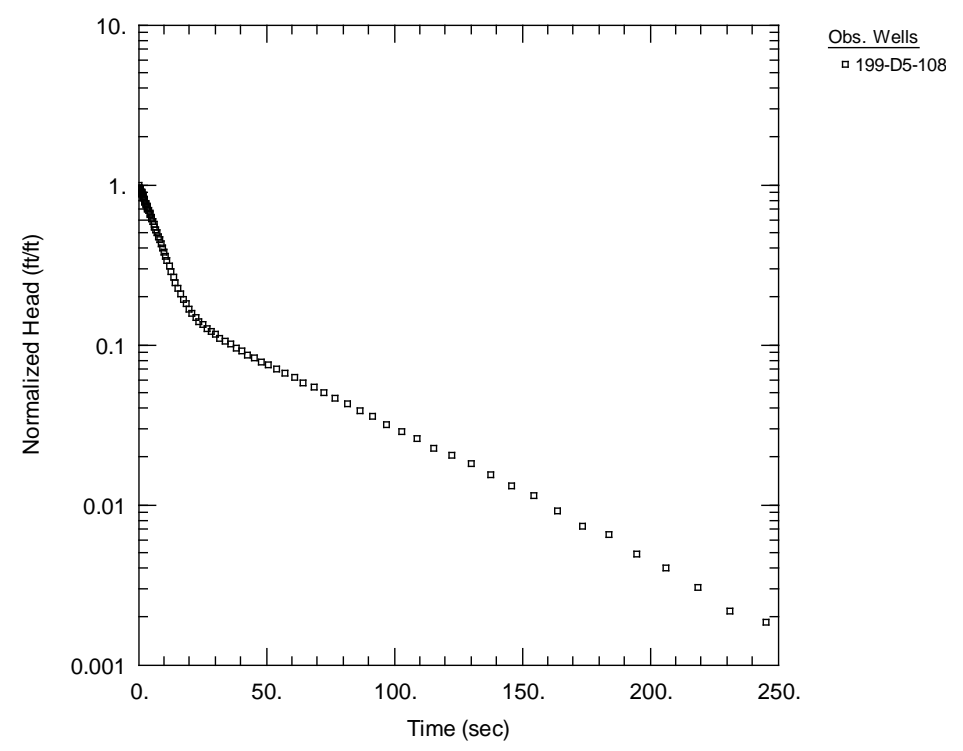

Figure 4.6. Slug Test Response for Well 199-D5-109 (August 2007) Showing an Example of the "Double-Straight Line" Effect (Bouwer 1989) Observed on Semi-Log Plots for Wells Screened Across the Water Table

The combination of being screened across the water table and having a highly permeable filter pack has the effect of increasing the effective radius of the well. This results in the observed initial stress $\left(\mathrm{H}_{0}\right)$ being lower than the theoretical initial stress $\left(\mathrm{H}_{\mathrm{o}}{ }^{*}\right)$ calculated from the slugging rod volume and nominal well casing radius $\left(\mathrm{r}_{\mathrm{c}}\right)$. The additional pore volume of the filter pack increases the effective casing volume. Butler (1998) recommends empirically calculating the $r_{c}$ term for each response with a massbalance approach:

$$
r_{e}=r_{c} \sqrt{\frac{H_{o}^{*}}{H_{o}}}
$$

For wells screened across the water table, the effective casing radius $\left(\mathrm{r}_{\mathrm{e}}\right)$ was calculated using Equation (4.1) and used in place of the nominal casing radius $\left(\mathrm{r}_{\mathrm{c}}\right)$ in the analytical models. The inner and outer zone portions of the slug test responses were analyzed separately by the methods detailed below in an effort to address the heterogeneous responses in wells screened across the water table (Bouwer 1989; Butler 1998; Spane and Newcomer 2008).

\subsubsection{Analytical Methods}

The slug test responses were analyzed with standard methods for estimating aquifer hydraulic properties in unconfined aquifers. Although considerable effort was made in the field to initiate each slug test instantaneously, some of the very early-time ( $\mathrm{t} \leq 5$ seconds) data required minimal processing prior to analysis due to signal noise or the effects of non-instantaneous slug withdrawal. This involved the translation and projection of time and initial stress $\left(\mathrm{H}_{0}\right)$ according to the approach described in Butler (1998). 
For wells screened across the water table, the inner/outer zone responses were analyzed using the type-curve model of Hyder et al. (1994), commonly referred to as the KGS model (Butler 1998), as well as the straight-line method of Bouwer and Rice (1976). Both methods are appropriate for over-damped responses such as those observed. Due to its empirical nature and analytical simplicity, the Bouwer and Rice (1976) method is very commonly used. However, the KGS type-curve method avoids some of the weaknesses and limitations inherent in the Bouwer and Rice (1976) method (Butler 1998). Estimates were made using both methods to provide comparison and a range of values, but the results from the KGS model are considered more representative, given the non-ideal test conditions and heterogeneous (inner vs. outer zone) responses associated with being screened across the water table.

The over-damped responses observed in the two lower-zone monitoring wells (199-D5-113 and 199-D5-118) followed a more typical (homogeneous) pattern because they were not screened across the water table. For these two wells, the entire response was fit by a single straight line (Bouwer and Rice) or curve (KGS model) rather than separate inner/outer zone analyses.

Slug-test responses in well 199-D5-109 showed very rapid responses (recovery in less than a few seconds) that were critically damped. Critically damped responses are identified by a characteristic concave-downward pattern on a semi-log plot (Butler 1998). In critically damped responses, the initial portion of the data is affected by inertial effects of the water column as water flows rapidly into the well bore from a highly permeable formation. Using the Bouwer and Rice and KGS methods on critically damped responses can lead to incorrect K estimates. Accordingly, these responses were analyzed also using the Springer and Gelhar (1991) high-K variant of the Bouwer and Rice method in which the inertial effects of water are addressed.

Slug tests impart a more localized stress to the aquifer than other larger-scale hydraulic characterization methods such as tracer and constant-rate pumping tests. Near-well conditions have a large influence on slug test responses, as mentioned earlier. For this and other reasons (e.g., anisotropy and heterogeneity) K estimates from slug tests should be considered "lower bound" (Butler 1998) K estimates for the formation. Results from the constant-rate pumping test conducted in August 2008 are more representative of the large-scale aquifer at the site. However, pre- and post-treatment slug testing using consistent field and analytical methods provides an assessment tool for evaluating potential changes in permeability within the treatment zone.

All slug test responses were analyzed using the aquifer testing analysis software package AQTESOLV (HydroSOLVE, Inc.).

\subsubsection{Geophysical Testing Methods}

Time-lapse geophysical data sets have the potential to provide information about the distribution of amendments injected into the subsurface for remediation purposes. The ability to geophysically distinguish pore fluid replacement by an injected amendment at the field scale is a function of many factors, including the geophysical contrast between the pore fluid and the injected amendment, the additional impact on the geophysical signature by biogeochemical transformations that occur as a response to the biostimulation, and scaling factors. Through linking laboratory and field-scale investigations, Hubbard et al. (2008) illustrated the potential of time-lapse geophysical methods for imaging the spatiotemporal distribution of an injected polylactate as well as remediation-induced biogeochemical transformations at the $\mathrm{Cr}(\mathrm{VI})$-contaminated Hanford 100-H site. 
Laboratory and field experiments have been performed at the Hanford 100-D site to determine the utility of geophysical methods for assessing 1) the effective radius and 2) the uniformity of the injected soluble substrate (molasses) and immiscible substrate (emulsified vegetable oil). In addition to addressing the objectives of the project, the study also focused on identifying which geophysical method (or suite of methods) was most useful for imaging the two different amendments.

A very brief background of the different geophysical methods that were used for this study and petrophysical relationships that can be used to interpret geophysical measurements in terms of amendment distribution is provided in Appendix C. The following paragraphs briefly review the geophysical methods as well as laboratory and field experimental approaches that were employed for the treatability test.

\subsubsection{Laboratory Experiments}

The laboratory experiments consisted of obtaining seismic, radar, and complex electrical measurements of the individual fluid components (water and amendments) as well as performing flowthrough column experiments wherein bioremediation was induced via introduction of the different amendments in saturated sediments. Although the primary objective was to document the geophysical signature of the initial phase of the experiment — the pore water replacement with the amendment — the geophysical signatures at later times were also recorded to assess if subsequent biogeochemical reactions are also likely to influence the geophysical signatures.

The experimental electrical conductivity fluid component measurements for the treatability test were (in microsiemens per meter) groundwater $\sim 22$, molasses $=246$, and vegetable oil $=30.4$. The experimental dielectric constant values for the fluid components were groundwater $=80$, molasses $=79.7$, and vegetable oil $=3$. These batch measurements suggest that pore water replacement by vegetable oil should be detectable using radar time-lapse methods, and that electrical methods should be able to track the pore water replacement of both molasses and vegetable oil, with the molasses providing the most significant contrast.

The molasses and vegetable oil flow-through column biostimulation experiments were conducted over approximately 1 month using acrylic columns. For each experiment, separate columns were instrumented with different types of sensors for making radar, seismic, and complex electrical measurements (Figure 4.7). The columns were carefully packed using sieved, predominantly quartz sand sediments that had been recently retrieved from the Ringold Formation in the 100-Area. Microbial inoculation was not performed; instead, the biostimulation experiments relied on the ability of the attached community to utilize the introduced substrate. To circumvent environmental health and safety issues associated with using $\mathrm{Cr}(\mathrm{VI})$-contaminated groundwater from the 100-D site for the column experiments, a synthetic groundwater was made using a recipe that replicated the Hanford 100-D geochemistry less the $\mathrm{Cr}(\mathrm{VI})$.

The synthetic groundwater was introduced from the same influent vessel to the base of all columns. To facilitate comparison between the geophysical signatures over time in these different-width columns, the flow rates during the vegetable oil experiment were adjusted so that the pore water velocities would be similar to each other and to flow rates at the Hanford 100-D site. A rate of $0.034 \mathrm{~mL} / \mathrm{min}$ was used for the wider time domain reflectometry (TDR) column; a flow rate of $0.765 \mathrm{~mL} / \mathrm{min}$ was used for the other smaller-diameter columns (electrical, seismic, and geochemical). 

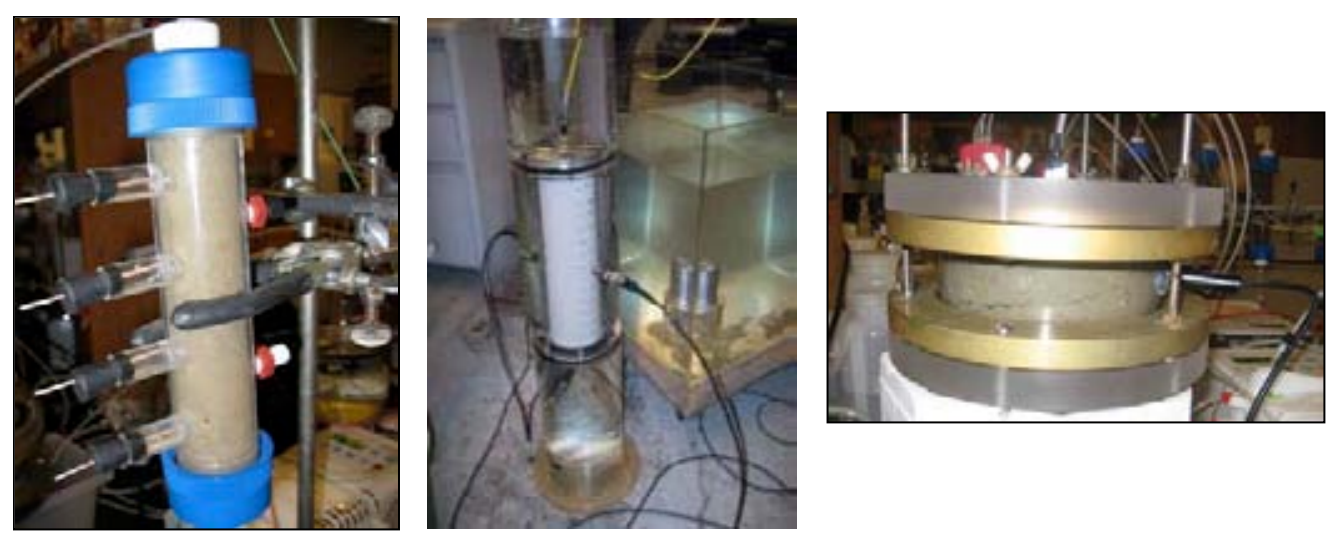

Figure 4.7. Geophysical Measurement Columns Used in the Laboratory Experiments. Left: complex resistivity, four-electrode column. Middle: seismic column. Right: time domain reflectometry column.

After the columns were flushed for several days with the synthetic groundwater, store-bought molasses and ammonium (60 mg/L) were injected into the columns intended for testing the geophysical response of the miscible substrate. Ammonium was added as a readily available supply of nitrogen for cell growth (and, once oxidized to $\mathrm{NO}_{3}$, to mimic the concentration in the 100-D groundwater). Molasses injection proceeded for 5 days, followed by continuous flushing with synthetic groundwater for almost 2 months.

Synthetic groundwater was also flushed through the columns intended for testing the geophysical response to the vegetable oil. Flushing occurred for several days, followed by introduction of the EOS 598 emulsion, which proceeded for 12 days. Continuous flushing with synthetic groundwater proceeded after the amendment introduction for almost 2 months. For the molasses and vegetable oil column experiments, effluent samples were analyzed for organic carbon, chloride, nitrate, and sulfate at 1- to 2-day intervals during the initiation of the experiments and less frequently thereafter. The molasses effluent samples were also assessed for bromide concentrations. Total organic carbon was measured as acetate using an ion chromatograph, and anions were measured using ion chromotography.

Geophysical measurements were made before, during, and after amendment introduction. Electrical conductivity measurements were made using a YSI Model 35 conductance meter, dielectric constant measurements were made using a Trase TDR system with 8-cm prongs, and seismic measurements were made using two fluid-coupled 1,000-kHz piezoelectric transducers at three locations along the column length. The column geophysical measurements were interpreted to obtain estimates of geophysical attributes as a function of time relative to amendment injection. The TDR waveform amplitudes were analyzed using the tangent method to estimate dielectric constant. Seismic velocity and amplitudes were determined for each of the three locations using the first arrival time and the maximum peak-to-peak voltage surrounding that first arrival, respectively, following Peterson et al. (1985). Electrical phase, imaginary conductivity, and real conductivity measurements were assessed over the acquisition frequency range. These measurements were subsequently interpreted in terms of Cole-Cole parameters of chargeability and time constant, following the stochastic method given by Chen et al. (2008). 
Geochemical analyses of aqueous effluent samples are shown in Figure 4.8; the geophysical attributes associated with the molasses flow-through experiments are shown in Figure 4.9. On all graphs, the shaded region indicates the duration of the molasses injection. Comparison of the organic carbon and bromide measurements suggested that the molasses remained in the column slightly longer than the conservative tracer. Analysis of the geophysical signatures suggested that

- Electrical conductivity is significantly increased and tracks the organic carbon.

- The Cole-Cole electrical parameters (tau and chargeability) indicate the leading and trailing edges of the injectate 'plume.'

- The molasses severely attenuates the seismic amplitudes.

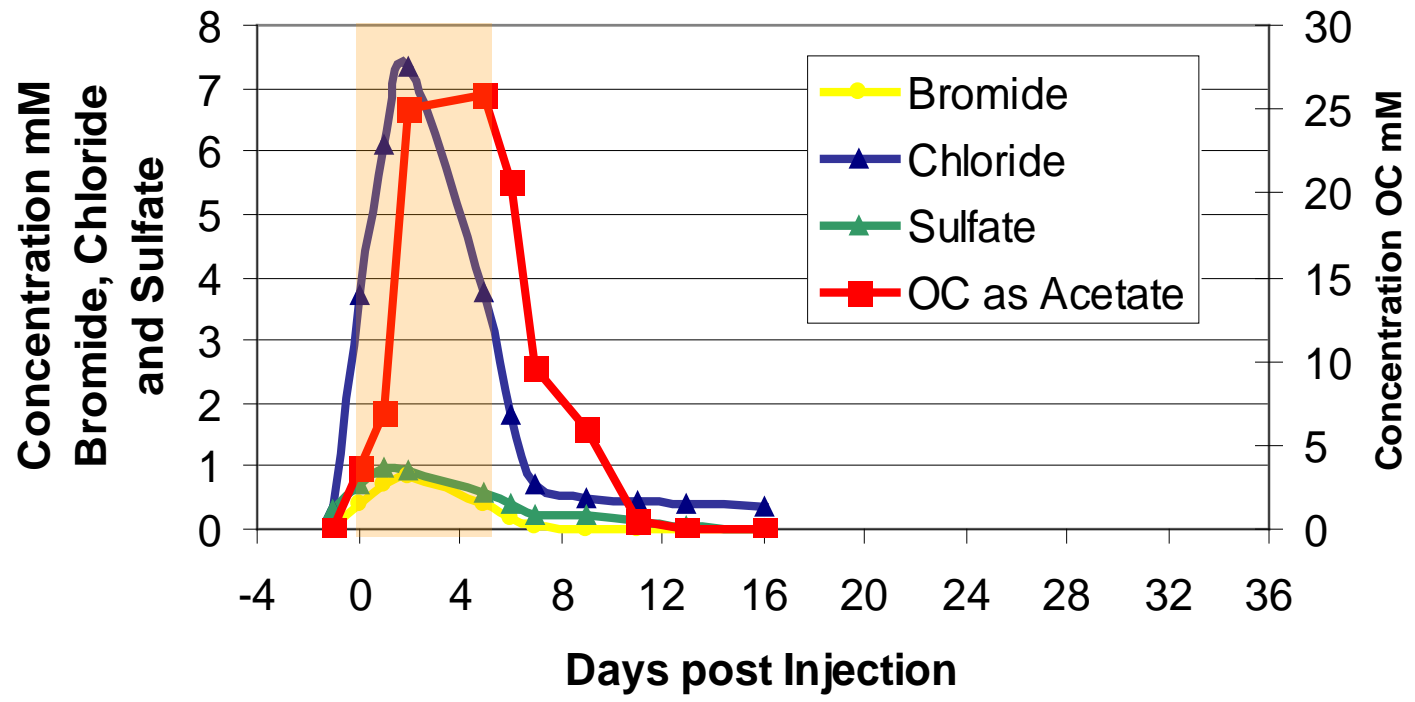

Figure 4.8. Geochemical Analysis of Effluent Fluid Samples from the Molasses Experimental Column Study. The shaded region represents the duration of the molasses injection. The large chloride spike is associated with the store-bought molasses. Comparison of the bromide and organic carbon signatures suggest that the residence time of the molasses in the system is just slightly longer than that of the conservative tracer. 


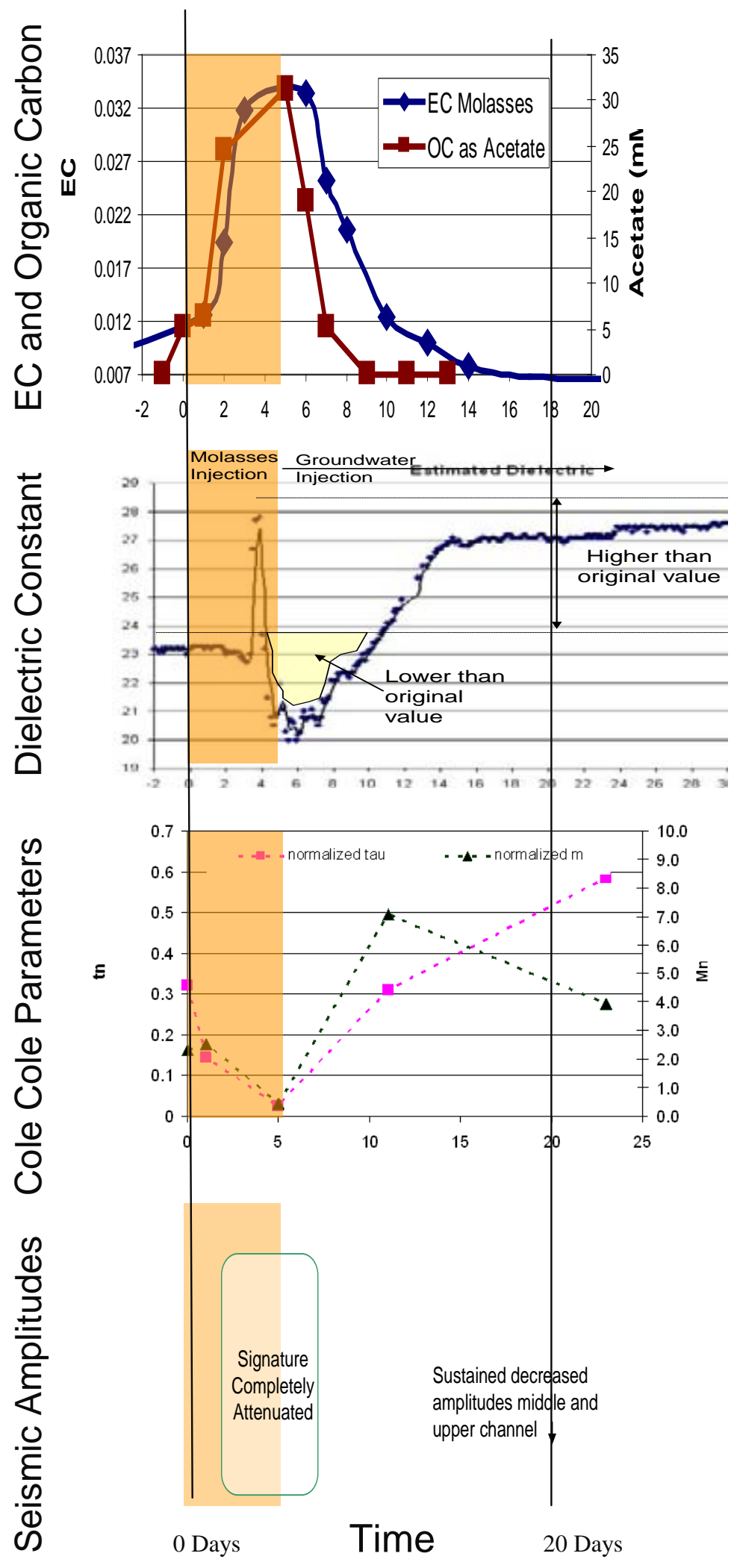

Figure 4.9. Geophysical Responses Associated with Molasses Flow-Through Biostimulation Column Experiment 
The dielectric constant changes after the molasses is almost through the system: it initially increases, then decreases, and then increases again to 20\% higher than baseline. Because the dielectric constant of the molasses (79) is very similar to that of water (80), and because the changes occur after the amendment has passed through the system, the dielectric changes are interpreted as a response to remediation-induced biogeochemical transformations rather than the pore fluid replacement with the amendment. In particular, we interpret the decrease to be due to the formation of nitrogen/ $\mathrm{CO}_{2}$ gas bubbles (which were visible during the laboratory experiment). The increase in dielectric constant at later times could be caused by an increased grain dielectric constant or to enhanced porosity (refer to Appendix C).

These laboratory experiments suggest that the electrical methods should provide excellent information about the molasses distribution, and that the presence of the amendment should severely attenuate the seismic signature. Although time-lapse radar methods are not expected to be able to track the amendment, they should respond to subsequent biogeochemical transformations.

Geochemical and geophysical analyses of the vegetable oil column experiments are shown in Figure 4.10. The shaded portion indicates the period during which vegetable oil was introduced into the flow-through column; the saturating fluid during other times is the synthetic groundwater. Different from the miscible amendment, some of the largest geophysical responses lag in time behind the amendment pulse, suggesting that some of the amendment remains in the system, as would be expected. Analysis of the geophysical responses suggests that the pore fluid replacement by the vegetable oil leads to

- a decrease in electrical conductivity

- a change in Cole-Cole parameters, including a sustained increase in normalized tau and decrease in normalized chargeability after vegetable oil was introduced

- a decrease in seismic velocity

- an initial increase in dielectric constant and then an approximately $11 \%$ decrease in dielectric constant in later times as groundwater $(\mathrm{k}=80)$ was replaced by vegetable oil $(\mathrm{k} \sim 3)$.

These experiments suggest that all three geophysical methods should provide information about the vegetable oil distribution. 


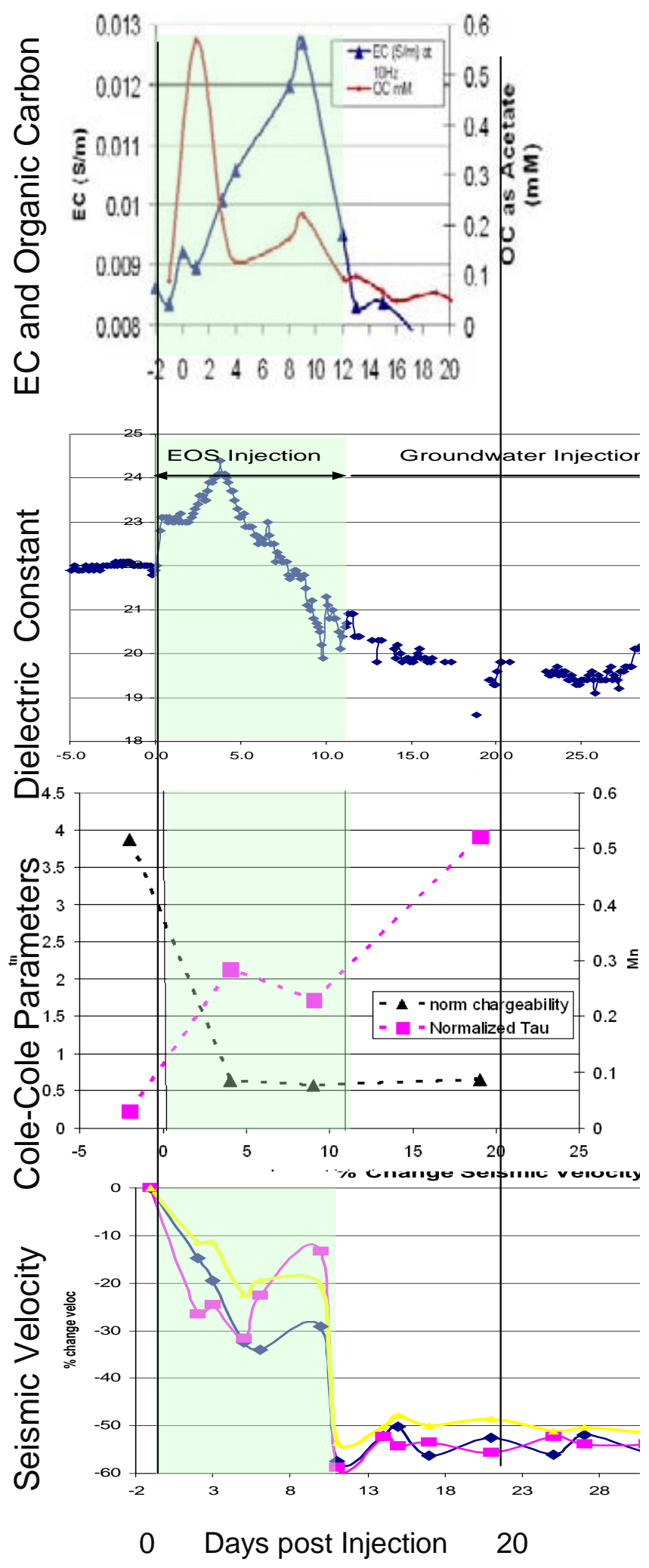

Figure 4.10. Results of Vegetable Oil Biostimulation Flow-Through Column Experiments. The green shaded area indicates the duration of the vegetable oil injection into the column. 


\subsubsection{Field Data Acquisition and Inversion}

Tomographic ground-penetrating radar (GPR), electrical time domain reflectometer (TDR), and seismic data were collected between several of the monitoring wellbores at both the miscible and immiscible test cells following the acquisition schedules shown in Table 4.3 and Table 4.4.

Table 4.3. Tomographic Data Acquisition Schedule, Molasses Field Experiment

\begin{tabular}{|c|c|c|c|c|c|}
\hline Date & Well Pair & GPR & Seismic & ERT & Comments \\
\hline 5-Sep-07 & $111-107$ & $\mathrm{X}$ & $\mathrm{X}$ & & ERT failed \\
\hline \multirow[t]{6}{*}{ 'Baseline’ } & $110-107$ & $\mathrm{X}$ & $\mathrm{X}$ & & \\
\hline & 109-107 & $\mathrm{X}$ & $\mathrm{X}$ & & \\
\hline & $113-107$ & $\mathrm{X}$ & $\mathrm{X}$ & & \\
\hline & $113-110$ & $\mathrm{X}$ & $\mathrm{X}$ & & \\
\hline & $109-113$ & $\mathrm{X}$ & $\mathrm{X}$ & & \\
\hline & $111-110$ & $\mathrm{X}$ & $\mathrm{X}$ & & \\
\hline 26-Sept-07 & Mol. Injection Initiated & & & & \\
\hline \multirow[t]{2}{*}{ 10-Oct-07 } & $109-113$ & $\mathrm{X}$ & $\mathrm{X}$ & & Seismic attenuated \\
\hline & All Others & $\mathrm{X}$ & $\mathrm{X}$ & & GPR \& seismic attenuated \\
\hline \multirow[t]{3}{*}{ 13-Nov-07 } & $113-107$ & $\mathrm{X}$ & $\mathrm{X}$ & & Seismic attenuated \\
\hline & $109-113$ & $\mathrm{X}$ & $\mathrm{X}$ & & Seismic attenuated \\
\hline & All Others & $\mathrm{X}$ & $\mathrm{X}$ & & GPR \& seismic attenuated \\
\hline \multirow[t]{3}{*}{ 25-Apr-08 } & $113-107$ & $\mathrm{X}$ & $\mathrm{X}$ & & Seismic attenuated \\
\hline & $109-113$ & $\mathrm{X}$ & $\mathrm{X}$ & & Seismic attenuated \\
\hline & All Others & $\mathrm{X}$ & $\mathrm{X}$ & & GPR \& seismic attenuated \\
\hline \multirow[t]{2}{*}{ 20-Aug-08 } & $109-113$ & $\mathrm{X}$ & $\mathrm{X}$ & & Seismic attenuated \\
\hline & All Others & $\mathrm{X}$ & $\mathrm{X}$ & & GPR \& seismic attenuated \\
\hline \multirow[t]{4}{*}{ 5-May-09 } & $113-107$ & $\mathrm{X}$ & $\mathrm{X}$ & & Seismic attenuated \\
\hline & $109-113$ & $\mathrm{X}$ & $\mathrm{X}$ & & Seismic attenuated \\
\hline & $110-107$ & $\mathrm{X}$ & $\mathrm{X}$ & & Seismic attenuated \\
\hline & All Others & $\mathrm{X}$ & $\mathrm{X}$ & & GPR \& seismic attenuated \\
\hline
\end{tabular}

Radar tomographic data were collected using a PulseEKKO 100 system, with 100-MHz central frequency antennas and a transmitter and receiver spacing of $0.125 \mathrm{~m}$ in the wellbores. Radar data were collected from several meters above the water table through the saturated intervals. Radar travel time and amplitude picking, pre-inversion quality control steps, and inversion procedures were performed following Peterson (2001). The changes in radar attributes as a function of time were determined by inverting the differences in the travel times and amplitudes between the baseline and subsequent data sets instead of differencing the inverted velocity or attenuation values. This approach tends to minimize error associated with borehole and station effects and also may minimize mathematical error because only one inversion procedure is performed. Estimates of radar velocity (and changes in velocity) were converted to dielectric constant estimates as described in Appendix C.

Seismic tomographic data were collected in only the saturated section using a Geometrics Geode seismic system, an LBNL piezoelectric source, and an ITI hydrophone sensor string that was lowered down the wellbores. The central frequency of the pulse was $4000 \mathrm{~Hz}$ with a bandwidth from approximately 1000 to $7000 \mathrm{~Hz}$. The source and geophone spacing in the wellbores was $0.125 \mathrm{~m}$. Travel times and associated amplitudes were picked for all source-receiver pairs and inverted for seismic velocity and amplitude (or associated changes) using a 0.25 -m by 0.25 -m discretization, following Peterson et al. (1985). 
Table 4.4. Tomographic Data Acquisition Schedule, Vegetable Oil Field Experiment

\begin{tabular}{|c|c|c|c|c|c|}
\hline Date & Well Pair & GPR & Seismic & ERT & Comments \\
\hline \multirow[t]{7}{*}{ 5-Sep-07 } & $114-108$ & $\mathrm{X}$ & $\mathrm{X}$ & & \\
\hline & 116-108 & $\mathrm{X}$ & $\mathrm{X}$ & & \\
\hline & $118-115$ & $\mathrm{X}$ & $\mathrm{X}$ & & \\
\hline & 118-116 & $\mathrm{X}$ & $\mathrm{X}$ & & \\
\hline & $115-114$ & $\mathrm{X}$ & $\mathrm{X}$ & & \\
\hline & $115-116$ & $\mathrm{X}$ & $\mathrm{X}$ & & \\
\hline & $115-108$ & $\mathrm{X}$ & $\mathrm{X}$ & & \\
\hline 10-Oct-07 & 118-115 & $\mathrm{X}$ & & & \\
\hline \multirow{9}{*}{ 14-Nov-07 } & 114-108 & & $\mathrm{X}$ & & \\
\hline & 116-108 & & $\mathrm{X}$ & & \\
\hline & 118-108 & & $\mathrm{X}$ & & \\
\hline & $118-115$ & $\mathrm{X}$ & $\mathrm{X}$ & & \\
\hline & $118-116$ & & $\mathrm{X}$ & & \\
\hline & $115-114$ & & $\mathrm{X}$ & & \\
\hline & $115-116$ & & $\mathrm{X}$ & & \\
\hline & $118-114$ & & $\mathrm{X}$ & & \\
\hline & $115-108$ & & $\mathrm{X}$ & & \\
\hline \multirow[t]{6}{*}{ 18-Aug-08 } & $118-115$ & $\mathrm{X}$ & $\mathrm{X}$ & $\mathrm{X}$ & Considered as \\
\hline & $118-116$ & $\mathrm{X}$ & $\mathrm{X}$ & $\mathrm{X}$ & Baseline \\
\hline & $115-114$ & $\mathrm{X}$ & $\mathrm{X}$ & $\mathrm{X}$ & Measurements \\
\hline & $115-116$ & $\mathrm{X}$ & $\mathrm{X}$ & $\mathrm{X}$ & \\
\hline & $118-114$ & $\mathrm{X}$ & $\mathrm{X}$ & $\mathrm{X}$ & \\
\hline & $116-114$ & $\mathrm{X}$ & $\mathrm{X}$ & $\mathrm{X}$ & \\
\hline 20-Aug-08 & Vegetable Oil Injected & & & & \\
\hline \multirow[t]{6}{*}{ 22-Aug-08 } & $118-115$ & $\mathrm{X}$ & $\mathrm{X}$ & $\mathrm{X}$ & \\
\hline & $118-116$ & $\mathrm{X}$ & $\mathrm{X}$ & $\mathrm{X}$ & \\
\hline & $115-114$ & $\mathrm{X}$ & $\mathrm{X}$ & $\mathrm{X}$ & \\
\hline & $115-116$ & $\mathrm{X}$ & $\mathrm{X}$ & $\mathrm{X}$ & \\
\hline & $118-114$ & $\mathrm{X}$ & $\mathrm{X}$ & $X$ & \\
\hline & $116-114$ & $\mathrm{X}$ & $\mathrm{X}$ & $\mathrm{X}$ & \\
\hline \multirow[t]{6}{*}{ 25-Aug-08 } & $118-115$ & $\mathrm{X}$ & $\mathrm{X}$ & $\mathrm{X}$ & \\
\hline & 118-116 & $\mathrm{X}$ & $\mathrm{X}$ & $\mathrm{X}$ & \\
\hline & $115-114$ & $\mathrm{X}$ & $\mathrm{X}$ & $\mathrm{X}$ & GPR failed \\
\hline & $115-116$ & $\mathrm{X}$ & $\mathrm{X}$ & $\mathrm{X}$ & GPR failed \\
\hline & $118-114$ & $\mathrm{X}$ & $\mathrm{X}$ & $X$ & \\
\hline & $116-114$ & $\mathrm{X}$ & $\mathrm{X}$ & $\mathrm{X}$ & GPR failed \\
\hline \multirow[t]{6}{*}{ 19-Nov-08 } & $118-115$ & $\mathrm{X}$ & $\mathrm{X}$ & $\mathrm{X}$ & \\
\hline & $118-116$ & $\mathrm{X}$ & $\mathrm{X}$ & $X$ & Seismic attenuated \\
\hline & $115-114$ & $X$ & $\mathrm{X}$ & $\mathrm{X}$ & \\
\hline & $115-116$ & $\mathrm{X}$ & $\mathrm{X}$ & $\mathrm{X}$ & \\
\hline & $118-114$ & $\mathrm{X}$ & $\mathrm{X}$ & $\mathrm{X}$ & Seismic attenuated \\
\hline & $116-114$ & $\mathrm{X}$ & $\mathrm{X}$ & $X$ & Seismic attenuated \\
\hline \multirow[t]{6}{*}{ 6-Мау-09 } & $118-115$ & $\mathrm{X}$ & $\mathrm{X}$ & $\mathrm{X}$ & Seismic attenuated \\
\hline & $118-116$ & $\mathrm{X}$ & $\mathrm{X}$ & $\mathrm{X}$ & Seismic attenuated \\
\hline & $115-114$ & $\mathrm{X}$ & $\mathrm{X}$ & $\mathrm{X}$ & Seismic attenuated \\
\hline & $115-116$ & $\mathrm{X}$ & $\mathrm{X}$ & $\mathrm{X}$ & Seismic attenuated \\
\hline & $118-114$ & $\mathrm{X}$ & $\mathrm{X}$ & $\mathrm{X}$ & Seismic attenuated \\
\hline & $116-114$ & $\mathrm{X}$ & $\mathrm{X}$ & $\mathrm{X}$ & Seismic attenuated \\
\hline
\end{tabular}

Electrical data were collected using an MPT/ERT2004 system (Multi-Phase Technologies, LLC, Sparks, Nevada) using 15 electrodes per well, each separated by $0.4 \mathrm{~m}$. Inversions were performed using EarthImager software (Advanced Geosciences, Inc., Austin, Texas) to yield estimates of electrical conductivity. 
Results of the field investigation are reported along with the other field data in Sections 5 (soluble substrate) and 6 (immiscible substrate).

\subsection{Test Data Collection and Management}

Data were collected during the injection, process monitoring, and performance monitoring phases of the field test according to the treatability test plan (Truex et al. 2007). Specific sampling dates and analytes are listed in Table 4.5 (soluble substrate) and Table 4.6 (immiscible substrate). There were no data quality issues that impacted interpretation of the results as presented in this report. Appendix D lists the field test data and data validation reports to support the results reported herein.

Table 4.5. Summary of Sampling for the Soluble Substrate Test

\begin{tabular}{|c|c|c|}
\hline Testing Phase & Sample Date & Analytes \\
\hline Pre-test & $09 / 10 / 07$ & $\mathrm{~A}, \mathrm{C}, \mathrm{M}, \mathrm{O}, \mathrm{T}$ \\
\hline Pre-test & 09/17/07 & A,C,M,O,T \\
\hline Pre-test & 09/25/07 & $\mathrm{A}, \mathrm{C}, \mathrm{M}, \mathrm{O}, \mathrm{T}$ \\
\hline Injection & 09/26/07 & A,B,T (multiple events) \\
\hline Injection & 09/27/07 & A,B,T (multiple events) \\
\hline Injection & 09/28/07 & A,B,T (multiple events) \\
\hline Injection & 09/29/07 & A,B,T (multiple events) \\
\hline Process monitoring & $10 / 03 / 07$ & $\mathrm{~A}, \mathrm{~B}, \mathrm{C}, \mathrm{O}, \mathrm{T}$ \\
\hline Process monitoring & $10 / 09 / 07$ & $\mathrm{~A}, \mathrm{~B}, \mathrm{C}, \mathrm{O}, \mathrm{T}$ \\
\hline Process monitoring & $10 / 17 / 07$ & $\mathrm{~A}, \mathrm{~B}, \mathrm{C}, \mathrm{O}, \mathrm{T}$ \\
\hline Process monitoring & $10 / 24 / 07$ & $\mathrm{~A}, \mathrm{~B}, \mathrm{C}, \mathrm{O}, \mathrm{T}$ \\
\hline Process monitoring & $10 / 31 / 07$ & $\mathrm{~A}, \mathrm{~B}, \mathrm{C}, \mathrm{O}, \mathrm{T}$ \\
\hline Process monitoring & $11 / 08 / 07$ & $\mathrm{~A}, \mathrm{~B}, \mathrm{C}, \mathrm{O}, \mathrm{T}$ \\
\hline Process monitoring & $11 / 15 / 07$ & $\mathrm{~A}, \mathrm{~B}, \mathrm{C}, \mathrm{O}, \mathrm{T}$ \\
\hline Process monitoring & $11 / 20 / 07$ & $\mathrm{~A}, \mathrm{~B}, \mathrm{C}, \mathrm{O}, \mathrm{T}$ \\
\hline Process monitoring & $11 / 28 / 07$ & $\mathrm{~A}, \mathrm{~B}, \mathrm{C}, \mathrm{O}, \mathrm{T}$ \\
\hline Performance monitoring & $12 / 05 / 07$ & A,C,M,Me,O,T \\
\hline Performance monitoring & $12 / 18 / 07$ & A,C,M,Me,O,T \\
\hline Performance monitoring & 01/08/08 & A,C,M,Me,O,T \\
\hline Performance monitoring & 01/30/08 & A,C,M,Me,O,T \\
\hline Performance monitoring & 02/13/08 & A,C,M,Me,O,T \\
\hline Performance monitoring & 02/27/08 & A,C,M,Me,O,T \\
\hline Performance monitoring & 03/19/08 & A,C,M,Me,O,T \\
\hline Performance monitoring & 04/15/08 & A,C,M,Me,O,T \\
\hline Performance monitoring & 05/13/08 & A,C,M,Me,O,T \\
\hline Performance monitoring & 07/09/08 & A,C,M,Me,O,T \\
\hline Performance monitoring & 09/18/08 & A,C,M,Me,O,T \\
\hline Performance monitoring & 01/07/09 & A,C,M,Me,O,T \\
\hline Performance monitoring & 03/11/09 & A,C,M,Me,O,T \\
\hline Performance monitoring & 06/22/09 & A,C,M,Me,O,T \\
\hline \multicolumn{3}{|c|}{$\begin{array}{l}\mathrm{A}=\text { anions, } \mathrm{B}=\text { bromide, } \mathrm{C}=\text { hexavalent chromium, } \mathrm{M}=\text { metals, } \mathrm{Me}=\text { methane, } \mathrm{O}=\text { organic acids } \\
\text { total organic carbon. } \\
\text { Field parameters were collected at all sample events. } \\
\text { Note: There are some differences in sampling at individual wells; see Appendix } \mathrm{D} \text { for full details. }\end{array}$} \\
\hline
\end{tabular}


Table 4.6. Summary of Sampling for the Immiscible Substrate Test

\begin{tabular}{lcl}
\hline \multicolumn{1}{c}{ Testing Phase } & Sample Date & \multicolumn{1}{c}{ Analytes } \\
\hline Pre-Test & $08 / 05 / 08$ & A,B,C,T \\
Pre-Test & $08 / 12 / 08$ & A,B,C,T \\
Injection & $08 / 20 / 08$ & A,B,T \\
Injection & $08 / 21 / 08$ & A,B,T \\
Performance monitoring & $09 / 08 / 08$ & A,B,C,M,O,T \\
Performance monitoring & $10 / 10 / 08$ & A,B,C,M,O,T \\
Performance monitoring & $12 / 19 / 08$ & A,B,C,M,O,T \\
Performance monitoring & $03 / 11 / 09$ & A,B,C,M,O,T \\
Performance monitoring & $06 / 22 / 09$ & A,B,C,M,O,T \\
\hline A = anions, B = bromide, C = hexavalent chromium, M = metals, Me= methane, \\
O = organic acids, T = total organic carbon. \\
Field parameters were collected at all sample events. \\
Note: There are some differences in sampling at individual wells; see Appendix D \\
for full details.
\end{tabular}

\subsection{Deviations from the Treatability Test Plan}

The treatability test plan includes provisions for a final test design phase with corresponding laboratory experimentation. Thus, there are minor difference between the treatability test plan and the final test implementation because the field design was refined based on characterization information collected at the field test site and from laboratory study results. Minor adjustments were made to the sampling schedule outlined in the treatability test plan in response to observed response and based on analyses conducted as part of the final design effort for the test. Performance of the immiscible substrate test was delayed by 1 year to accommodate additional time for test design and the corresponding laboratory tests for emulsion injection. In particular for the immiscible substrate test, sampling frequencies were reduced based on the anticipation of slower temporal changes in parameters. Additionally, some analytes were mistakenly missed, notably the baseline samples for the immiscible substrate test cell. Table 4.7 summarizes the differences between the planned and actual sampling and analysis schedule. 
Table 4.7. Comparison of Actual and Planned Sampling

\begin{tabular}{|c|c|c|c|c|}
\hline \multirow[b]{2}{*}{ Parameter } & \multirow[b]{2}{*}{ Monitoring Phase } & \multirow[b]{2}{*}{ Test Plan Sampling Frequency } & \multicolumn{2}{|c|}{ Actual Sampling } \\
\hline & & & Soluble Substrate & Immiscible Substrate \\
\hline \multirow{2}{*}{$\begin{array}{l}\text { Major cations: Al, } \\
\text { As, B, Ba, Bi, Ca, } \\
\text { Co, Fe, K, Mg, Mn, } \\
\text { Ni, Zn, Zr, P, Sr, } \\
\text { Na, Si, S, Sb }\end{array}$} & Pretest monitoring & 1,2 , and 3 weeks before injection & Same & None \\
\hline & $\begin{array}{l}\text { Performance } \\
\text { monitoring }\end{array}$ & 1,6 , and 12 months after injection & More sampling events & More sampling events \\
\hline \multirow{2}{*}{$\begin{array}{l}\text { RCRA/Trace } \\
\text { metals: Cr, Cu, As, } \\
\text { Se, Mo, Ag, Cd, } \\
\text { Pb, }{ }^{238} \mathrm{U}\end{array}$} & Pretest monitoring & 1,2 , and 3 weeks before injection & Same & None \\
\hline & $\begin{array}{l}\text { Performance } \\
\text { monitoring }\end{array}$ & 1,6 , and 12 months after injection & More sampling events & More sampling events \\
\hline \multirow[t]{2}{*}{ Anions: $\mathrm{Cl}^{-}, \mathrm{PO}_{4}^{3-}$} & Pretest monitoring & 1,2 , and 3 weeks before injection & Same & None \\
\hline & $\begin{array}{l}\text { Performance } \\
\text { monitoring }\end{array}$ & 1,6 , and 12 months after injection & More sampling events & More sampling events \\
\hline Methane & $\begin{array}{l}\text { Performance } \\
\text { monitoring }\end{array}$ & 1,6 , and 12 months after injection & More sampling events & None \\
\hline \multirow{4}{*}{$\begin{array}{l}\text { Total organic } \\
\text { carbon }\end{array}$} & Pretest monitoring & 1,2 , and 3 weeks before injection & Same & Only 2 events \\
\hline & $\begin{array}{l}\text { Substrate } \\
\text { injection }\end{array}$ & $\begin{array}{l}\text { Every } 4 \text { hours in injection line } \\
\text { (soluble), every } 2 \text { hours in } \\
\text { injection line (immiscible), every } \\
4 \text { hours starting } 8 \text { hours before } \\
\text { expected arrival at monitoring } \\
\text { wells (soluble), every } 2 \text { hours } \\
\text { starting } 4 \text { hours before expected } \\
\text { arrival at monitoring wells } \\
\text { (immiscible) }\end{array}$ & Comparable & Only at end \\
\hline & $\begin{array}{l}\text { Process } \\
\text { monitoring }\end{array}$ & Weekly for 8 weeks after injection & Same & Less frequent \\
\hline & $\begin{array}{l}\text { Performance } \\
\text { monitoring }\end{array}$ & $\begin{array}{l}\text { Twice per month after end of } \\
\text { process monitoring stage }\end{array}$ & $\begin{array}{l}\text { Sampling frequency } \\
\text { reduced to enable } \\
\text { sampling over a longer } \\
\text { total duration }\end{array}$ & Less frequent \\
\hline \multirow[t]{4}{*}{$\mathrm{NO}_{2}^{-}, \mathrm{NO}_{3}^{-}, \mathrm{SO}_{4}^{2-}$} & Pretest monitoring & 1,2 , and 3 weeks before injection & Same & Only 2 events \\
\hline & $\begin{array}{l}\text { Substrate } \\
\text { injection }\end{array}$ & $\begin{array}{l}\text { Every } 4 \text { hours in injection line } \\
\text { (soluble), every } 2 \text { hours in } \\
\text { injection line (immiscible), every } \\
4 \text { hours starting } 8 \text { hours before } \\
\text { expected arrival at monitoring } \\
\text { wells (soluble), every } 2 \text { hours } \\
\text { starting } 4 \text { hours before expected } \\
\text { arrival at monitoring wells } \\
\text { (immiscible) }\end{array}$ & Comparable & Comparable \\
\hline & $\begin{array}{l}\text { Process } \\
\text { monitoring }\end{array}$ & Weekly for 8 weeks after injection & Same & Less frequent \\
\hline & $\begin{array}{l}\text { Performance } \\
\text { monitoring }\end{array}$ & $\begin{array}{l}\text { Twice per month after end of } \\
\text { process monitoring stage }\end{array}$ & $\begin{array}{l}\text { Sampling frequency } \\
\text { reduced to enable } \\
\text { sampling over a longer } \\
\text { total duration }\end{array}$ & Less frequent \\
\hline
\end{tabular}


Table 4.7. (contd)

\begin{tabular}{|c|c|c|c|c|}
\hline \multirow[b]{2}{*}{ Parameter } & \multirow[b]{2}{*}{ Monitoring Phase } & \multirow[b]{2}{*}{ Test Plan Sampling Frequency } & \multicolumn{2}{|c|}{ Actual Sampling } \\
\hline & & & Soluble Substrate & Immiscible Substrate \\
\hline \multirow[t]{4}{*}{$\mathrm{Cr}^{+6}$} & Pretest monitoring & 1 , 2, and 3 weeks before injection & Same & Only 2 events \\
\hline & $\begin{array}{l}\text { Substrate } \\
\text { injection }\end{array}$ & $\begin{array}{l}\text { Every } 4 \text { hours in injection line } \\
\text { (soluble), every } 2 \text { hours in } \\
\text { injection line (immiscible), every } \\
4 \text { hours starting } 8 \text { hours before } \\
\text { expected arrival at monitoring } \\
\text { wells (soluble), every } 2 \text { hours } \\
\text { starting } 4 \text { hours before expected } \\
\text { arrival at monitoring wells } \\
\text { (immiscible) }\end{array}$ & Comparable & Comparable \\
\hline & $\begin{array}{l}\text { Process } \\
\text { monitoring }\end{array}$ & Weekly for 8 weeks after injection & Same & Less frequent \\
\hline & $\begin{array}{l}\text { Performance } \\
\text { monitoring }\end{array}$ & $\begin{array}{l}\text { Twice per month after end of } \\
\text { process monitoring stage }\end{array}$ & $\begin{array}{l}\text { Sampling frequency } \\
\text { reduced to enable } \\
\text { sampling over a longer } \\
\text { total duration }\end{array}$ & Less frequent \\
\hline \multirow[t]{4}{*}{ Bromide } & Pretest monitoring & 1,2 , and 3 weeks before injection & Same & Only 2 events \\
\hline & $\begin{array}{l}\text { Substrate } \\
\text { injection }\end{array}$ & $\begin{array}{l}\text { Every } 4 \text { hours in injection line } \\
\text { (soluble), every } 2 \text { hours in } \\
\text { injection line (immiscible), every } \\
4 \text { hours starting } 8 \text { hours before } \\
\text { expected arrival at monitoring } \\
\text { wells (soluble), every } 2 \text { hours } \\
\text { starting } 4 \text { hours before expected } \\
\text { arrival at monitoring wells } \\
\text { (immiscible) }\end{array}$ & Comparable & Comparable \\
\hline & $\begin{array}{l}\text { Process } \\
\text { monitoring }\end{array}$ & Weekly for 8 weeks after injection & Same & Less frequent \\
\hline & $\begin{array}{l}\text { Performance } \\
\text { monitoring }\end{array}$ & $\begin{array}{l}\text { Twice per month after end of } \\
\text { process monitoring stage }\end{array}$ & $\begin{array}{l}\text { Sampling frequency } \\
\text { reduced to enable } \\
\text { sampling over a longer } \\
\text { total duration }\end{array}$ & Less frequent \\
\hline \multirow[t]{4}{*}{ Organic Acids } & Pretest monitoring & 1 , 2, and 3 weeks before injection & Same & None \\
\hline & $\begin{array}{l}\text { Substrate } \\
\text { injection }\end{array}$ & End of substrate injection & Same & Same \\
\hline & $\begin{array}{l}\text { Process } \\
\text { monitoring }\end{array}$ & Weekly for 8 weeks after injection & Same & Less frequent \\
\hline & $\begin{array}{l}\text { Performance } \\
\text { monitoring }\end{array}$ & $\begin{array}{l}\text { Twice per month after end of } \\
\text { process monitoring stage }\end{array}$ & $\begin{array}{l}\text { Sampling frequency } \\
\text { reduced to enable } \\
\text { sampling over a longer } \\
\text { total duration }\end{array}$ & Less frequent \\
\hline
\end{tabular}




\subsection{Results for the Soluble Substrate Test}

Results for the field test are presented for the injection, process monitoring, and performance monitoring phases of the test in the following sections. The supporting laboratory test results are also summarized. The overall results are then presented and discussed with respect to each of the test objectives.

\subsection{Injection Description and Results}

The concept for the substrate injection process was to obtain an injection radius of about $15 \mathrm{~m} \mathrm{(50 \textrm {ft } )}$ with a uniform molasses concentration of about $40 \mathrm{~g} / \mathrm{L}$. Process water was used as the carrier medium for the substrate. An injection flow rate was selected so the substrate would be delivered over a period of about 3 days. This injection period minimized the possibility of accumulating excessive biomass near the injection well during the injection process. Laboratory tests showed that the lag time before significant microbial growth occurred was on the order of 5 days. A tracer was injected with the substrate to help identify the injection front and for subsequent monitoring of injection solution elution from the test zone.

The injection pressures monitored within the injection wellbore during substrate injection were higher than anticipated based on the observed pressure response during developmental pumping and an initial injection test using only water. The viscosity of the injected solution was 1.5 to $2 \mathrm{cP}$. Thus, only a small increase in the injection pressure was the result of the somewhat higher viscosity of the molasses-water mixture. It is likely the largest percentage of the increase resulted from incomplete dissolution of the concentrated molasses feed stock that may have initially caused temporary plugging in the injection well. During the first 24 hours of the test, the molasses feed was periodically stopped for short periods of time to allow process water only to pass through the well screen. Each time this operation was performed, injection pressures quickly decreased to below critical levels (i.e., pressures had built up to the point where water in the well bore was near ground surface) and a sustained reduction in injection pressure was realized. This response is consistent with the hypothesis that a film of molasses had accumulated in the screen openings, and potentially further out into the filter pack, thus increasing the pressure drop across this near-well zone. Injecting process water would dissolve any molasses accumulation on the screen. After about 24 hours of injection, the injection pressures stabilized (Figure 5.1), and the injection flow rate could be more readily maintained (Figure 5.2).

After injection was terminated, water levels did not begin recovering toward static conditions for about 25 minutes. A representative recovery response for the observation wells, as seen in well 199-D5110, is shown in Figure 5.3. The late-time pressure response is about three times lower than predicted (solid blue type curve in Figure 5.3). This delay in pressure recovery is likely associated with recharge of an unknown volume of molasses solution that leaked into the overlying, more permeable Hanford formation during the injection period. Pressures reached as high as $35 \mathrm{psi}$ (80 $\mathrm{ft}$ of water buildup) in the injection well during molasses injection. These relatively high pressures could have compromised the bentonite seal and formed preferential vertical pathways along the borehole/filter pack interface, allowing a portion of the injection stream to leak up through the annular space into the more permeable Hanford formation sediments. This volume of water would have drained vertically following the termination of the test, causing the observed delay in recovery to pre-test static conditions - analogous to well-bore storage effects, but on a larger scale and less predictable. The magnitude of this effect was not significant enough to prevent distribution of the molasses in the test cell and subsequent functioning as a permeable reactive barrier. However, the effect should be considered when applying this technology elsewhere. 


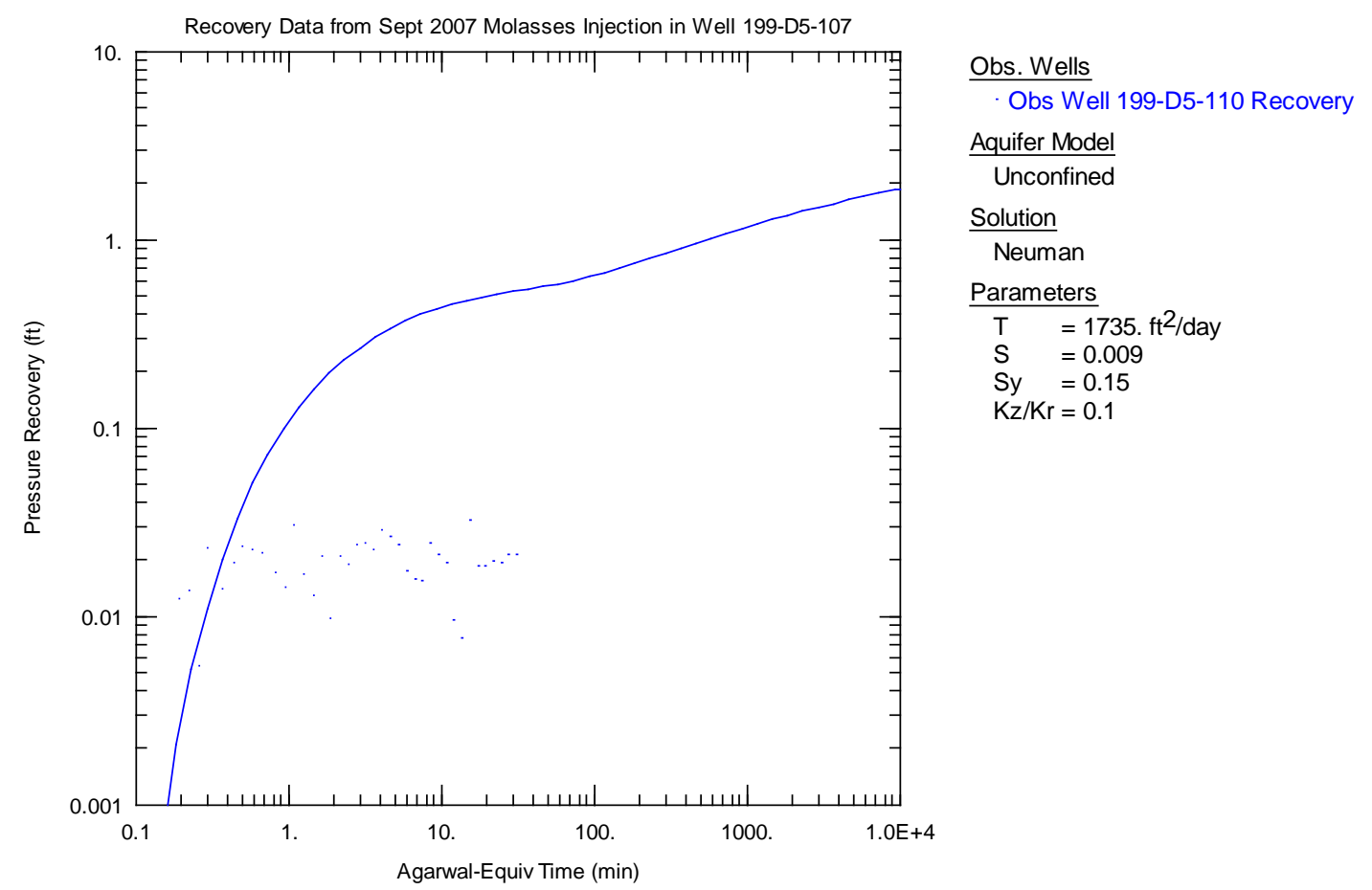

Figure 5.1. Pressure Recovery Response in Observation Well 199-D5-110 Following the September 2007 Molasses Injection

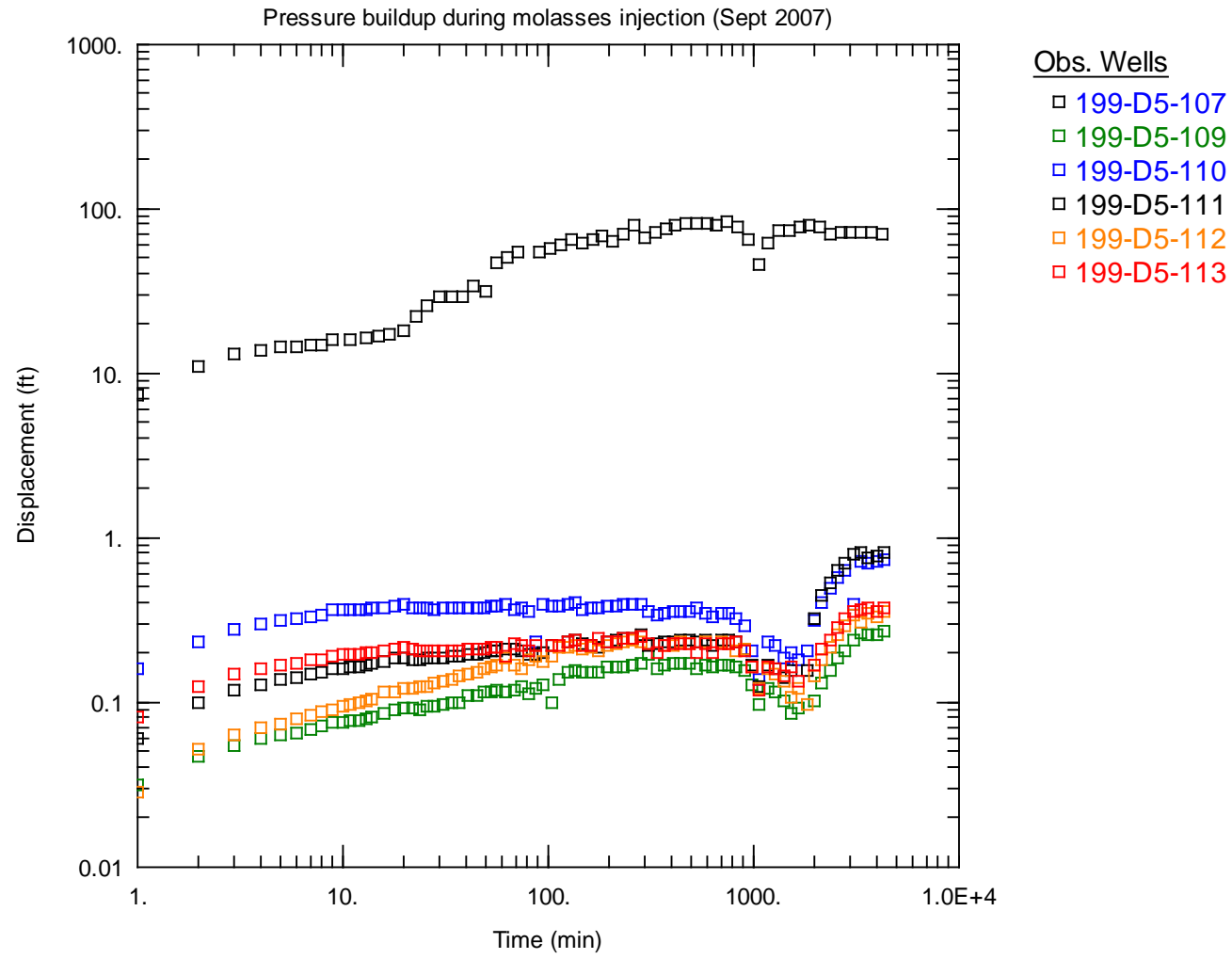

Figure 5.2. Pressure Response at Injection and Monitoring Wells During the Molasses Injection Period 


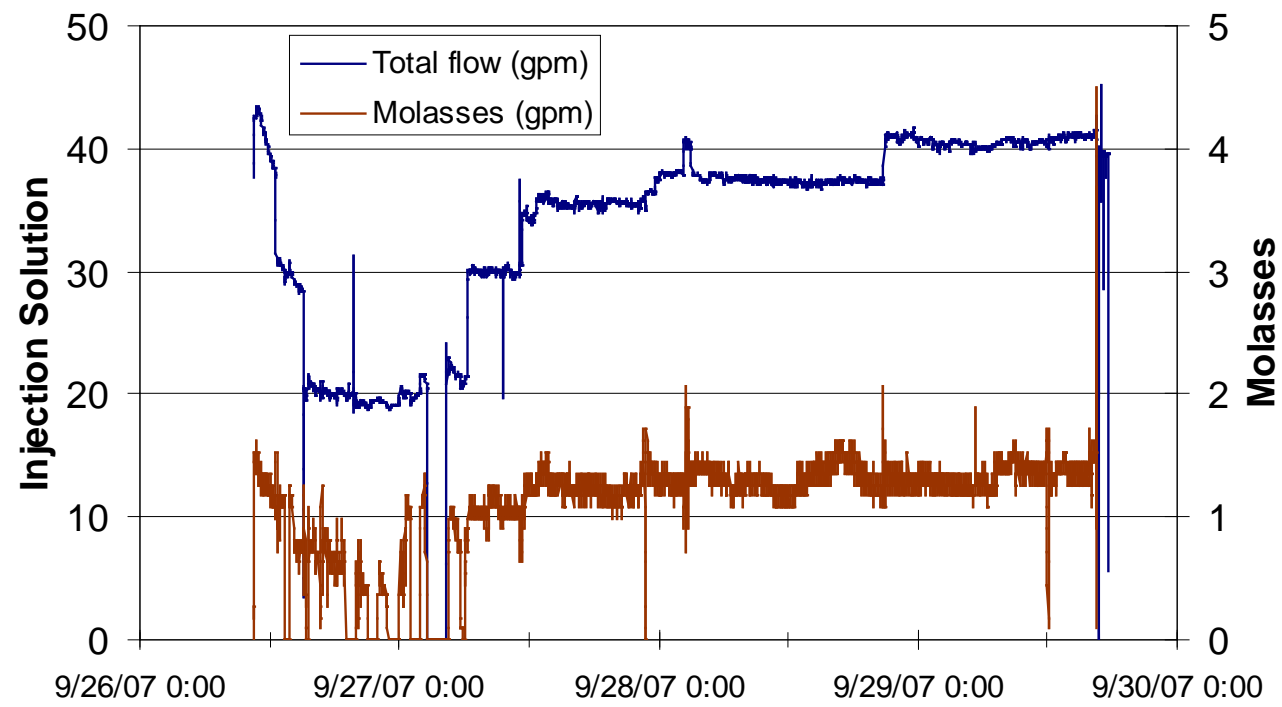

Figure 5.3. Flow Rate of Injected Solution and Molasses During the Injection Period

The following parameters describe the injection process.

- The average injection flow rate (water and all solutes) was approximately $125 \mathrm{~L} / \mathrm{min}$ (33 gpm).

- The average molasses injection flow rate was approximately $4.2 \mathrm{~L} / \mathrm{min}(1.1 \mathrm{gpm})$.

- Approximately 19,300 L (5,100 gal) of molasses were injected.

- The total injection volume was about 594,000 L (157,000 gal).

- The average molasses concentration during injection was about $44 \mathrm{~g} / \mathrm{L}$.

- The injection duration was 3.25 days.

- Based on the injected volume, estimated aquifer properties (5.6-m [18-ft] thick at the time of injection with a porosity of 0.14 ), and an idealized radial geometry, the nominal injection radius was $15 \mathrm{~m}$ $(50 \mathrm{ft})$.

- About $9400 \mathrm{~L}$ (2,500 gal) of water were injected after the molasses injection was terminated, to flush the injection system, injection wellbore, and filter pack.

- About 625 L (165 gal) of sodium bromide tracer solution were injected, resulting in an average solution concentration of $69 \mathrm{mg} / \mathrm{L}$ as bromine, based on the measured concentration in the stock solution, the volume of stock solution injected, and the total solution (i.e., water and molasses) volume injected.

- About 625 L (165 gal) of ammonium chloride solution were injected, resulting in an average solution concentration of $171 \mathrm{mg} / \mathrm{L}$ based on the measured concentration in the stock solution, the volume of stock solution injected, and the total solution (i.e., water and molasses) volume injected.

- Injection pressure was variable throughout the injection but was typically about 25 psi. 
Primary data collected to monitor substrate injection are depicted in Figures 5.4 through 5.9. Note that the tracer and TOC concentration data, which are metrics for the quantity of solution and substrate respectively, follow similar breakthrough curves at each monitoring location, indicating there was no significant retardation of the injected substrate. These figures also show that the oxidation reduction potential dropped quickly with substrate injection. These data, along with the organic acid data presented later, suggest that substrate utilization by the in situ microbial population begins quickly and, subsequently, injection for a longer duration could be problematic because of the potential for excessive biomass formation near the injection well. Under the radial flow system created by this single-well injection, substrate flow is directed outward from the point of injection with flow velocities decreasing with radial distance. The well hydraulics associated with this radial flow system will place an upper bound on the rate at which fluids can be injected, and at the biostimulation treatability test site, $150 \mathrm{~L} / \mathrm{min}$ (40 gpm) was identified as the maximum rate that could be sustained. Another factor to consider is the volume of water required to increase the injection radius varies with the square of the radius. As an

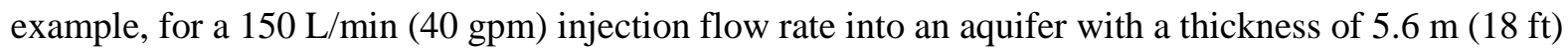
and a porosity of 0.14 , about 3 days are required to inject to a radius of $15 \mathrm{~m}(50 \mathrm{ft})$. However, about 5.25 days would be required to inject to a radius of $20 \mathrm{~m}(66 \mathrm{ft})$. The field test data suggest that injection

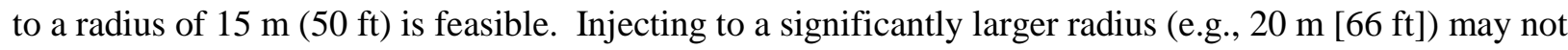
be feasible because of the potential for biofouling.

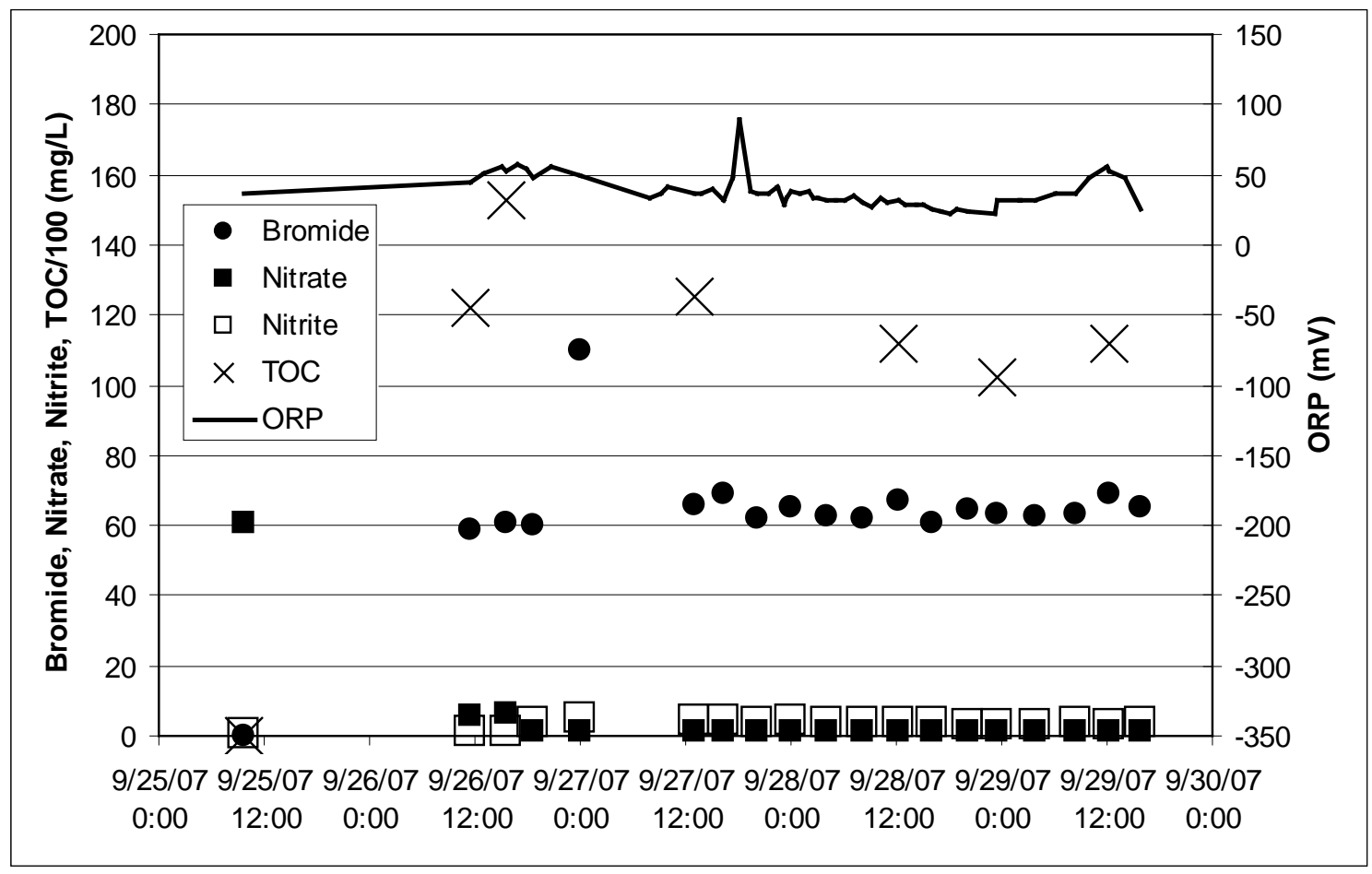

Figure 5.4. Operational Parameters Measured at Injection Well 199-D5-107 During the Injection Phase of the Test 


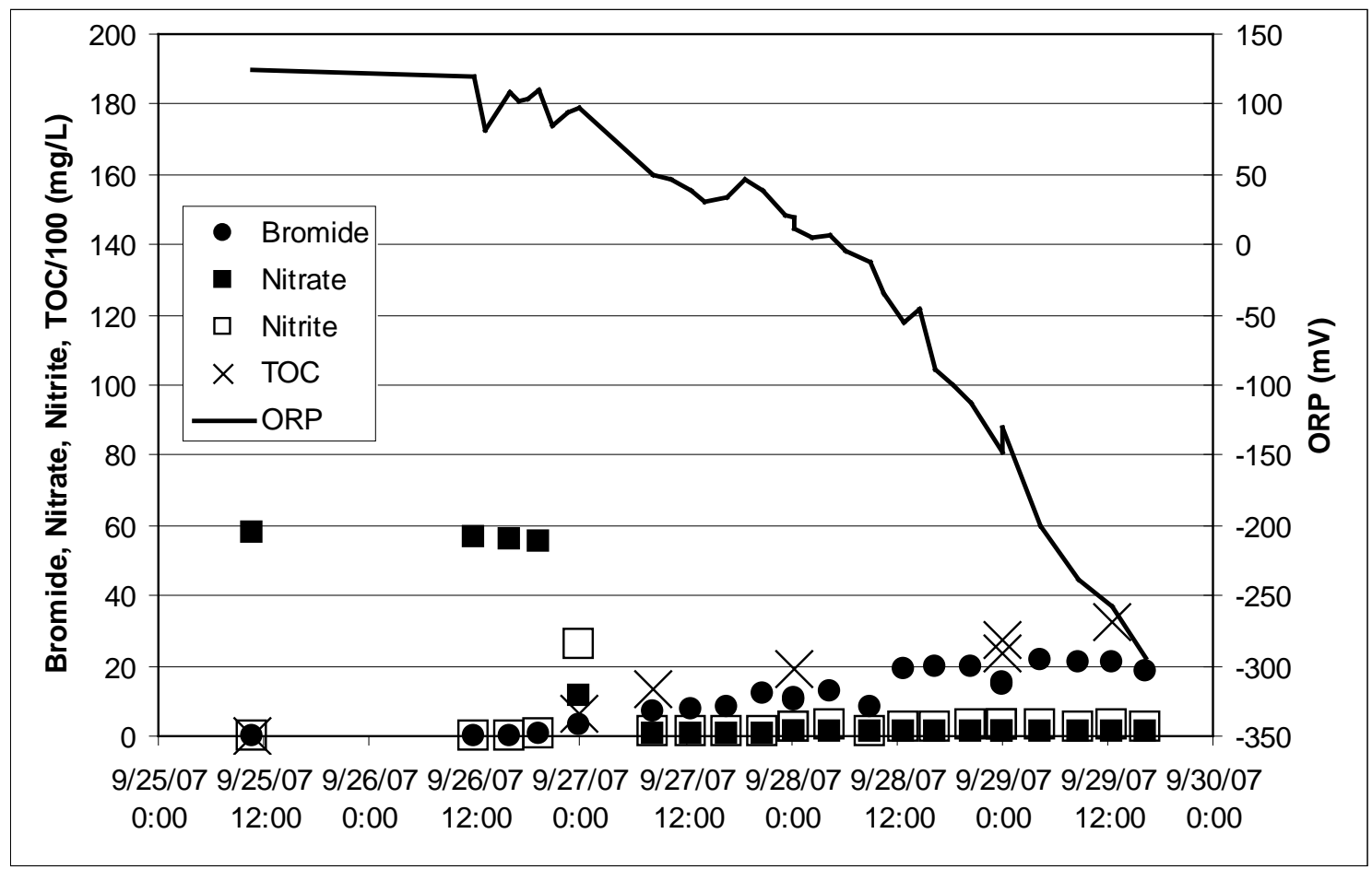

Figure 5.5. Operational Parameters Measured at Monitoring Well 199-D5-109 During Injection in 199-D5-107

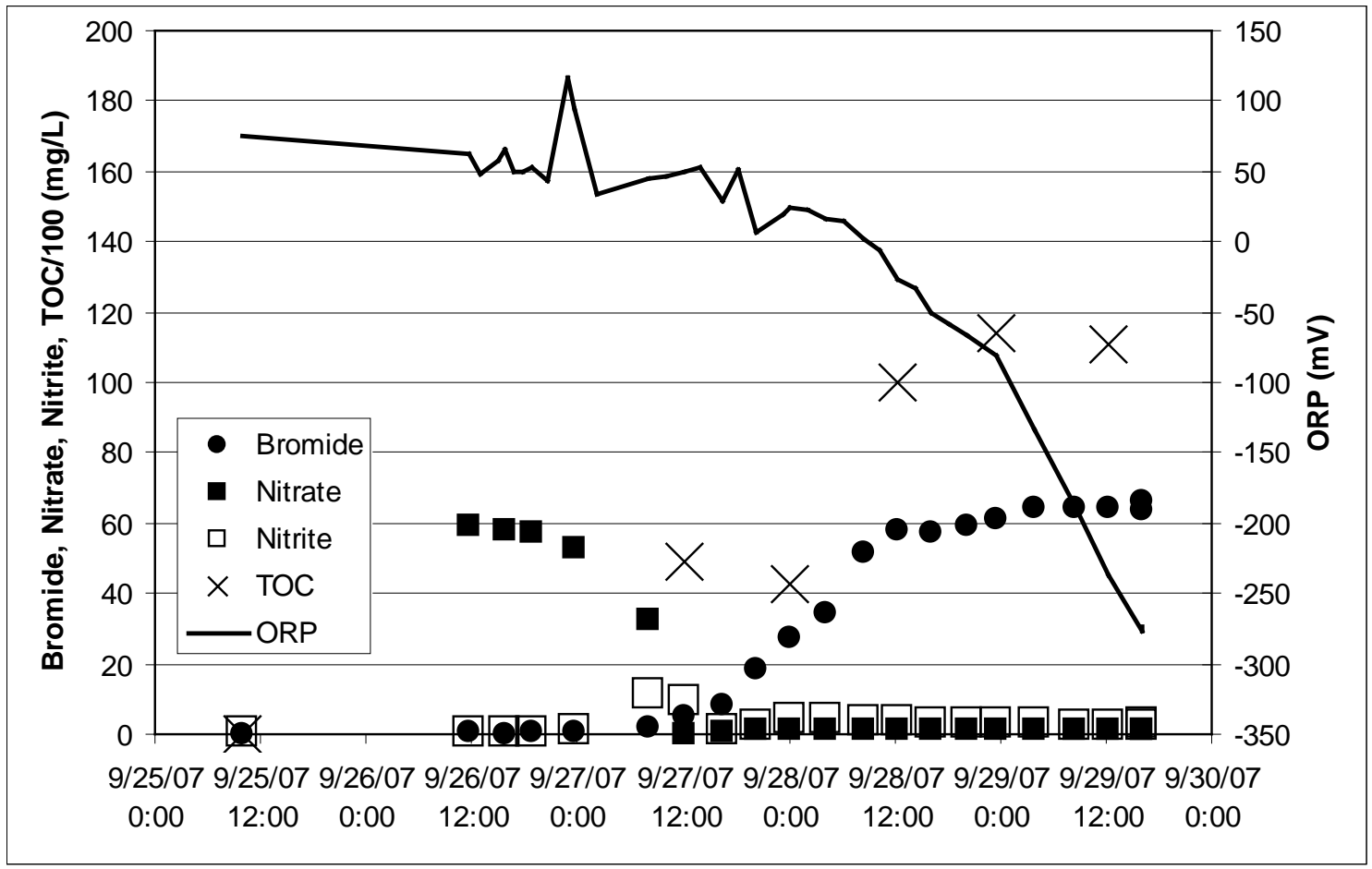

Figure 5.6. Operational Parameters Measured at Monitoring Well 199-D5-110 During Injection in 199-D5-107 


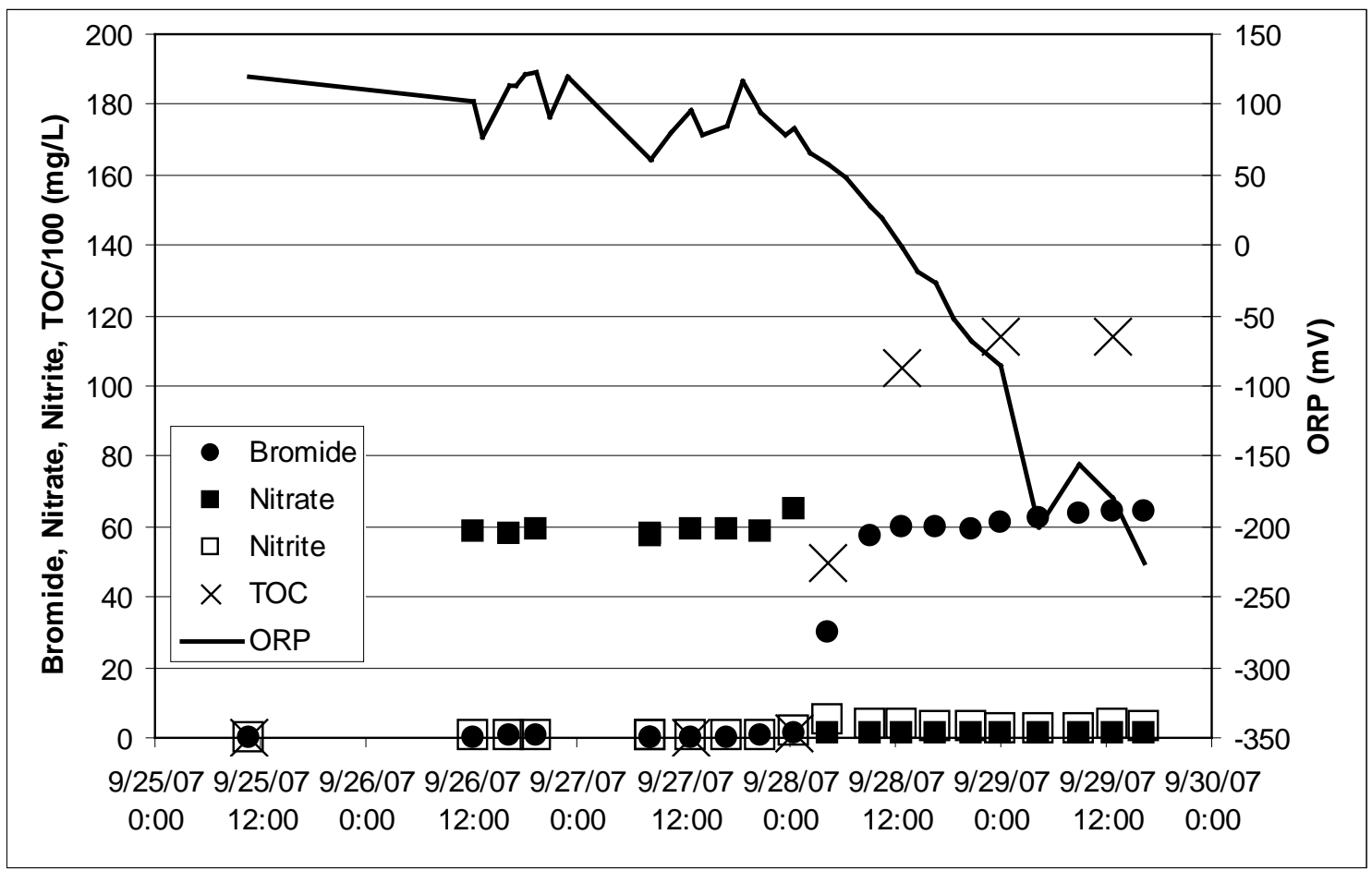

Figure 5.7. Operational Parameters Measured at Monitoring Well 199-D5-111 During Injection in 199-D5-107

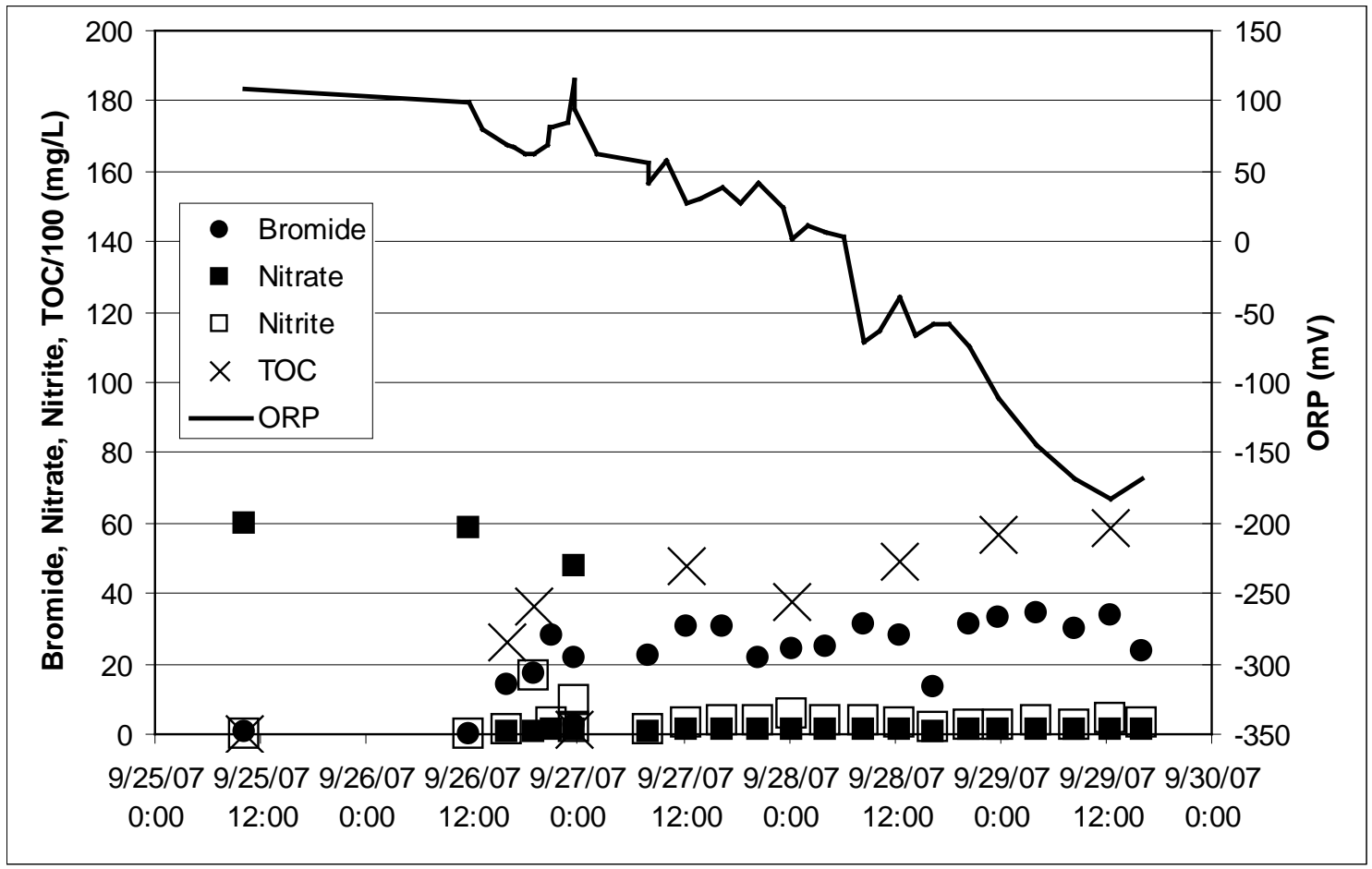

Figure 5.8. Operational Parameters Measured at Monitoring Well 199-D5-112 During Injection in 199-D5-107 


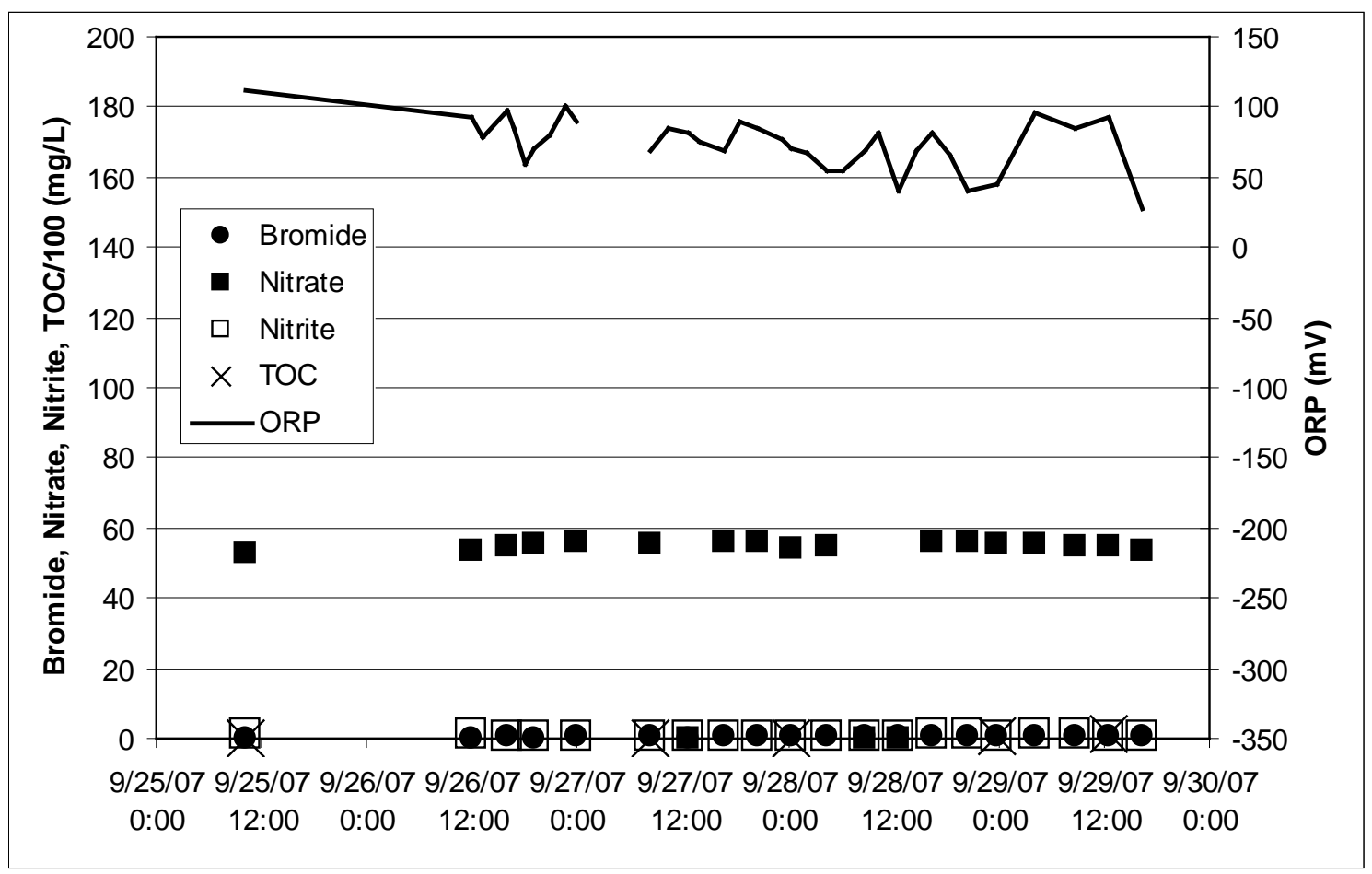

Figure 5.9. Operational Parameters Measured at Monitoring Well 199-D5-113 During Injection in 199-D5-107

Total organic carbon concentrations were monitored intermittently throughout the test, and the measurements collected at the end of the injection process were used to assess the uniformity of substrate distribution. Based on the estimated injection radius of $15 \mathrm{~m}$ (50 ft), monitoring wells 199-D5-110, -111, -112 , and -113 should have had a TOC concentration comparable to the injected concentration by the end of the injection. Well 199-D5-109 should have been just on the fringe of the substrate injection. As shown in Table 5.1, TOC data at monitoring wells 199-D5-110, -111, and -109 are consistent with what would be expected for the substrate injection. Total organic carbon values are lower than expected at monitoring wells 199-D5-112 (upper zone monitoring) and 199-D5-113 (lower zone monitoring). Characterization data showed that the hydraulic conductivity over the screened interval for well 199-D5112 was higher than what was observed at other locations. Substrate arrival data indicate that transport in the direction of wells 199-D5-112 and -113 moved predominantly through the upper, more permeable, zone and was diluted or otherwise diverted by this high-conductivity layer, as indicated by the early tracer arrival that never reached full concentration. Very little substrate appeared in the lower interval at well 199-D5-113, although the TOC concentration did increase by a factor of 10 within a week after injection, possibly because of density sinking of the substrate. This information suggests that heterogeneities in the direction of wells 199-D5-112 and -113 impacted the initial distribution of substrate. Further observations during the process monitoring and performance monitoring phases were used to determine how the variability in substrate injection impacts the ability of the bioremediation zone to reduce oxygen, nitrate, and chromate over time. 
Table 5.1. Total Organic Carbon Concentrations at the End of the Substrate Injection Period

\begin{tabular}{ll}
\hline \multicolumn{1}{c}{ Well } & \multicolumn{1}{c}{ Total Organic Carbon (g/L) } \\
\hline 199-D5-107 (injection well) & 11 \\
199-D5-109 & 2.7 \\
$199-D 5-110$ & 11 \\
$199-D 5-111$ & 11 \\
$199-D 5-112$ & 6 \\
199-D5-113 & 0.1 (rising to 1.5 shortly after injection terminated) \\
\hline
\end{tabular}

In summary, the dissolved substrate (molasses) injection provided a large ( 15 -m radius) zone of substrate distributed around the injection well. Operations were relatively simple, although management of the injection pressure was initially problematic. While there was no apparent biofouling during injection (i.e., the injection mound did not continue to build significantly over time), there are indications that microbial activity had begun. Thus, it is likely that injection to larger radial distances (e.g., $20 \mathrm{~m}$ [66 ft]) may not be possible without use of a groundwater recirculation process capable of significantly enhancing interwell groundwater flow rates during an injection.

\subsection{Process Monitoring Results}

The goals of the process monitoring phase were 1) to assess the anticipated fermentation process induced by the injection of substrate, and 2) to evaluate the "drift" of the substrate and fermentation products downgradient because of the natural groundwater flow. At the end of the substrate injection phase, a suite of analytes was collected to define the starting conditions. These analytes then were monitored weekly over the next 8 weeks. Key analytes are

- organic acids (fermentation products)

- anions including chromate, nitrate, nitrite, sulfate, and bromide (tracer)

- TOC

- field parameters, including $\mathrm{pH}$, specific conductance, dissolved oxygen, and oxidation-reduction potential.

In summary, results from process monitoring indicate that fermentation was rapidly induced through injection of the substrate and much longer than the 8-week process monitoring period. Thus, results of the process monitoring phase are combined with the performance monitoring phase. For reference, Appendix E contains plots of the organic acid concentrations and geochemical indicators during the first 8 weeks of monitoring. 


\subsection{Performance Monitoring Results}

Performance monitoring results with respect to the targeted treatment compounds, hydraulic properties, and overall biogeochemical conditions are presented in this section.

\subsubsection{Water Chemistry for Target Compounds}

Nitrate, dissolved oxygen, and chromate were the target compounds for treatment in the biobarrier. In summary, low concentrations of nitrate, nitrite, and oxygen were maintained throughout the test duration. Chromium and chromate concentrations, while variable during the period where significant organic acids were present in the test zone, were significantly lower than the background concentrations.

\subsubsection{Nitrate/Nitrite}

Data indicate that nitrate concentration within the test cell remained below $2 \mathrm{mg} / \mathrm{L}$ over a duration of 600 days, except for a short period (approximately 3 months) in which concentrations reached up to $10 \mathrm{mg} / \mathrm{L}$ at well 199-D5-112. For the duration of the test, nitrite concentrations were generally $2 \mathrm{mg} / \mathrm{L}$ or lower. As demonstrated in laboratory experiments, the site microbial population is capable of full denitrification without significant buildup of nitrite as an intermediate compound. Details of the results over the test period are depicted in Figure 5.10 and Figure 5.11.

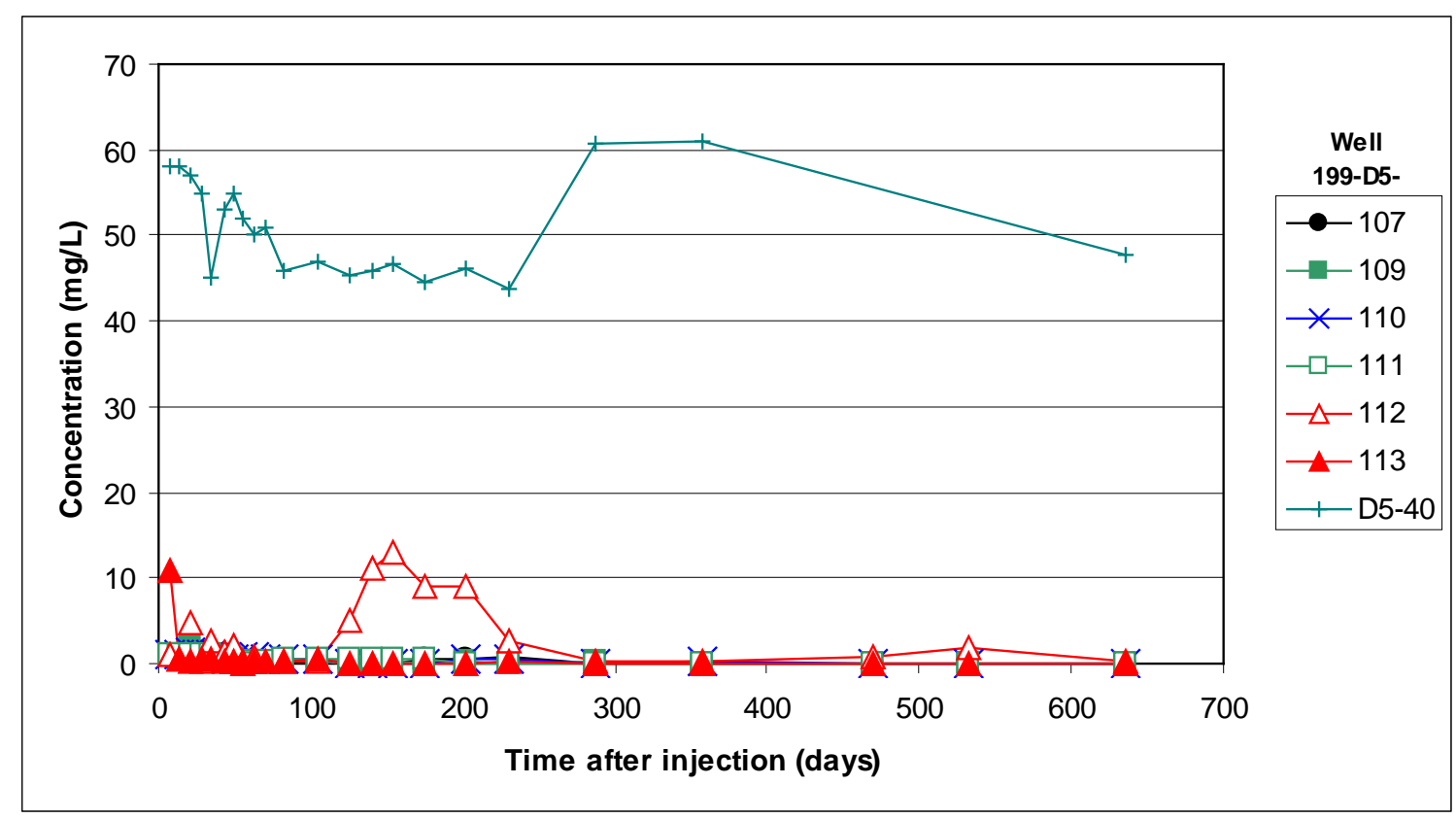

Figure 5.10. Nitrate Concentrations over the Duration of the Test 


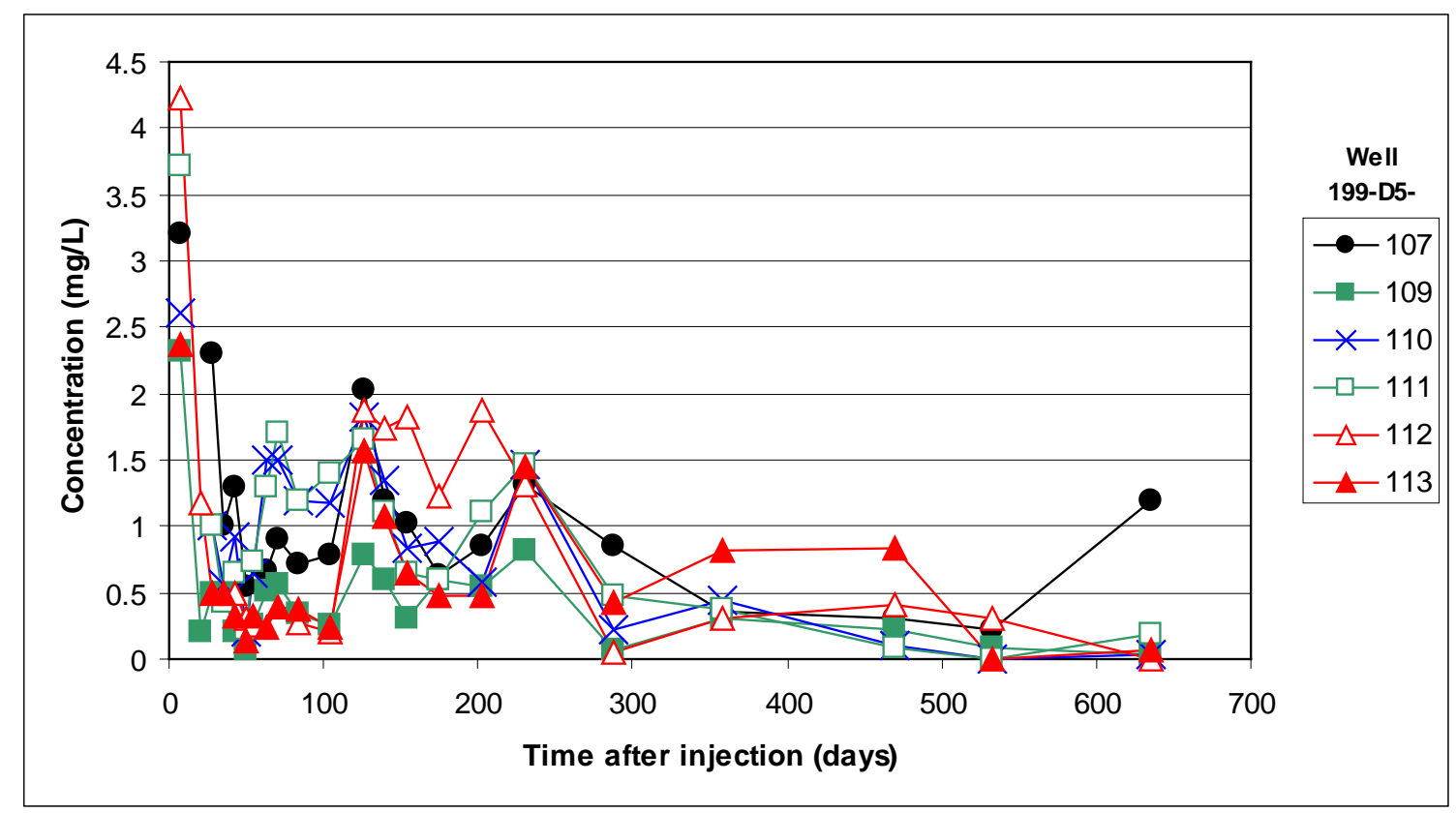

Figure 5.11. Nitrite Concentrations over the Duration of the Test

\subsubsection{Dissolved Oxygen}

Data indicate that dissolved oxygen concentration within the test cell remained below $1 \mathrm{mg} / \mathrm{L}$ over the duration of the test at all wells.

\subsubsection{Chromate/Chromium}

Chromate reduction in the test cell was monitored using the measurements of hexavalent chromium (chromate, $\mathrm{Cr}^{6+}$ ) in the form of the water soluble chromate ion (from onsite spectrophotometric analysis) and total chromium (from laboratory ICP-MS analysis) in water samples. The data indicate that both hexavalent chromium and total chromium concentrations in the test cell were significantly lower than background upgradient concentrations in well 199-D5-40 except for a period from day 50 to 140 where hexavalent chromium measurements varied dramatically from below detection to above $250 \mu \mathrm{g} / \mathrm{L}$. During this time period of variation in the data, the $\mathrm{pH}$ at all wells in the test cell was below $\mathrm{pH} 6$ and ranged as low as $\mathrm{pH} 4$ due to the presence of organic acids. In contrast, the $\mathrm{pH}$ at the background upgradient well 199-D5-40 did not vary significantly (range of 7.1 to 8). Over the same time interval, there were no organic acids present and the hexavalent chromium concentrations at this well remained relatively stable with values between 80 and $140 \mu \mathrm{g} / \mathrm{L}$. The hexavalent chromium concentrations were stable again, and generally below detection, after day 140 throughout the remainder of the test when $\mathrm{pH}$ was generally above $\mathrm{pH} 6$ at most wells and the organic acid concentration had declined substantially. Details of the results over the test period are depicted in Figure 5.12 and Figure 5.13. 


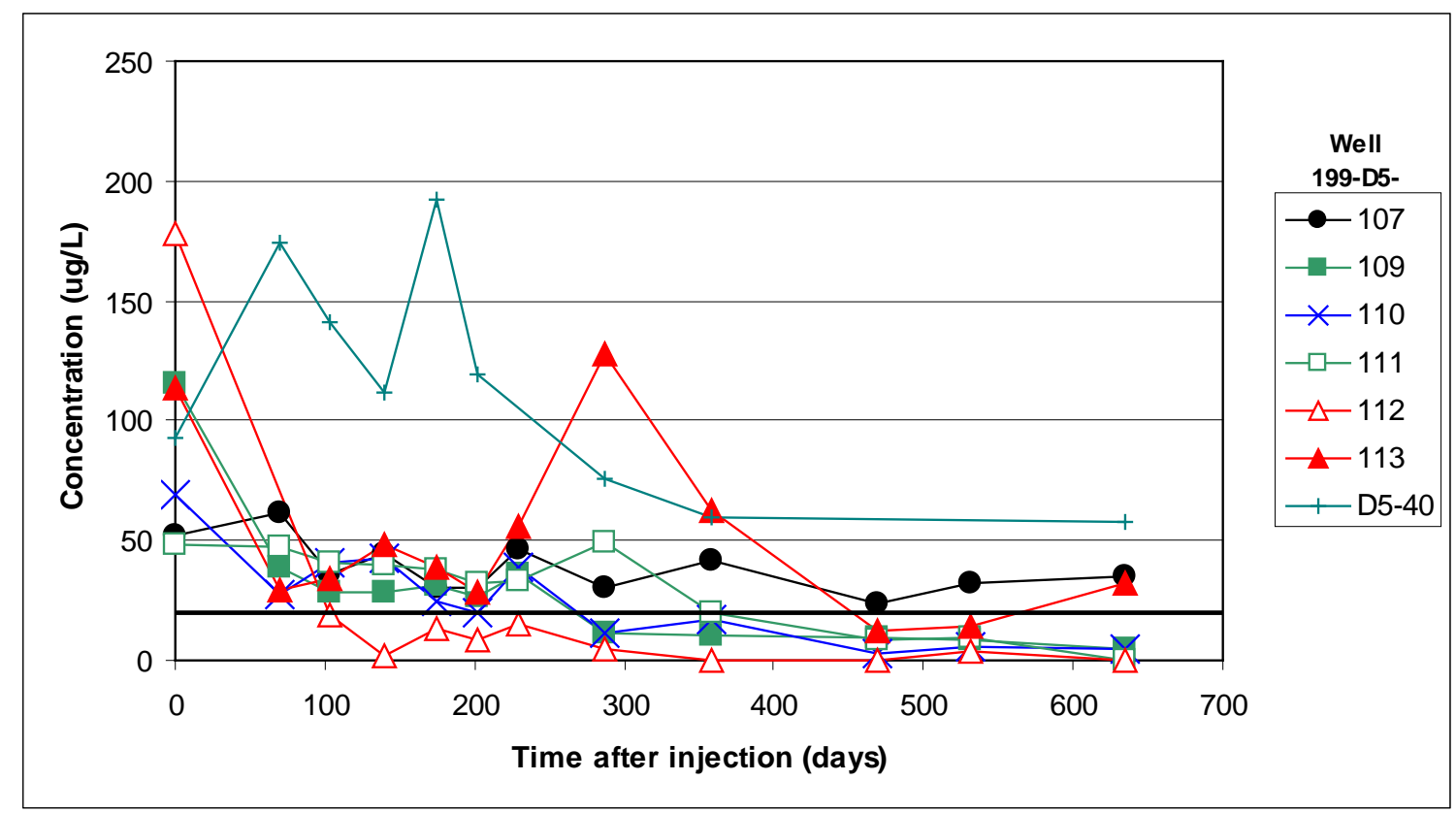

Figure 5.12. Total Chromium Concentrations from Laboratory Analysis (ICP-MS). The target contaminant level for chromate in the Hanford 100-D groundwater is $22 \mu \mathrm{g} / \mathrm{L}$.

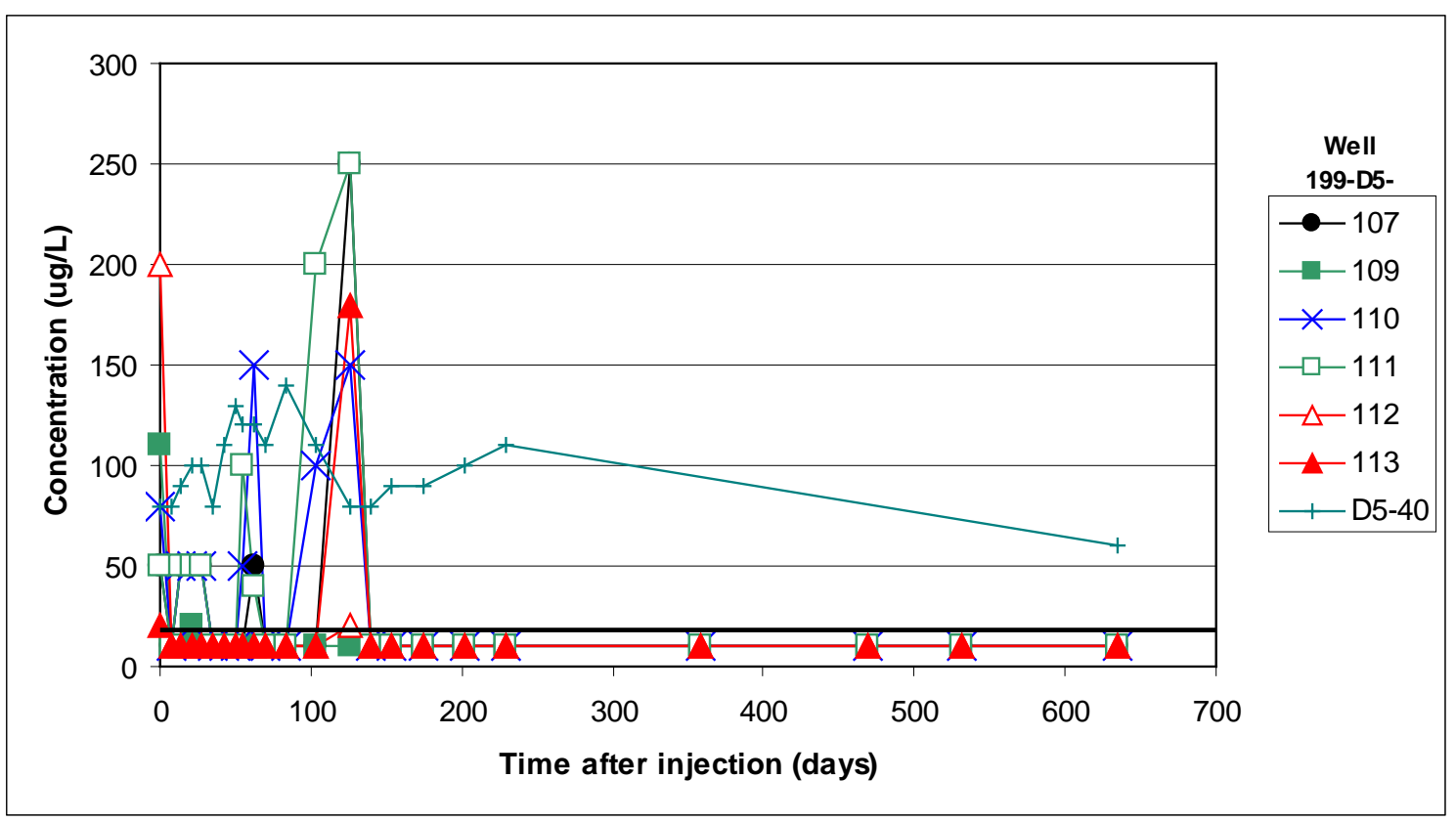

Figure 5.13. Chromate Concentrations Using Spectrophotometric Analysis (field test kit). The target contaminant level for chromate in the Hanford 100-D groundwater is $22 \mu \mathrm{g} / \mathrm{L}$. Data below the detection limit are plotted at the detection limit for the method. 


\subsubsection{Hydraulic Conductivity}

Hydraulic conductivity was assessed through hydraulic slug testing, geophysical testing, and bromide elution.

\subsubsection{Hydraulic Slug Test Results}

Hydraulic slug testing was conducted prior to injection (August 2007), in November 2007 approximately 60 days after substrate injection, and again in November 2008 approximately 420 days after injection. Table 5.2 shows the results of these tests in terms of the relative hydraulic conductivity of the post-injection tests compared to the pre-injection test. These results show minimal impact from injection of the substrate in the short term. Over the longer term, permeability was reduced, likely due to biomass growth. By the November 2008 test, chemical data show that the organic compound concentrations in the test cell are very low. Thus, the biomass concentration would be expected to slowly decline over time and lead to increased permeability back toward the baseline value. Full details of the hydraulic slug testing are shown in Appendix F.

Table 5.2. Permeability Change Results Based on Slug Testing

\begin{tabular}{ccc}
\hline & \multicolumn{2}{c}{$\begin{array}{c}\text { Permeability Change } \\
\left(\mathrm{K}_{\text {post }} / \mathrm{K}_{\text {pre }}\right)^{(\mathrm{a})}\end{array}$} \\
\cline { 2 - 3 } Well Name & Post 1 & Post 2 \\
\hline 199-D5-109 & 1.20 & 0.02 \\
199-D5-110 & 0.99 & 0.28 \\
199-D5-111 & 1.08 & 0.23 \\
199-D5-113 & 0.75 & 0.55 \\
\hline
\end{tabular}

(a) Post 1 is based on data for the pre-injection result (August 2007) and post-injection result conducted November 2007. Post 2 is based on data for the pre-injection result (August 2007) and post-injection result conducted November 2008.

\subsubsection{Geophysical Testing Results}

Although electrical methods are expected to be the most useful for imaging molasses distribution, the baseline electrical data acquisition failed. Additionally, the attenuation of the seismic amplitudes was so severe that the quality of the post-injection datasets was unusable; this seismic response was expected based on the laboratory response and indicates that all well pair directions were impacted by the injected molasses. However, some of the pre- and post-injection radar tomograms had acceptable data quality. Where acceptable, radar travel times were used to estimate velocity and dielectric constant distribution (see Appendix C). Figure 5.14 shows a baseline radar dielectric constant transect and an associated change in dielectric constant at 2 months post injection. Comparison of the dielectric constant transect with the wellbore geological and hydraulic conductivity flowmeter data suggests that the radar is useful for delineating the hydrological heterogeneity of the injection zone. Comparison of the change in dielectric with the baseline illustrates the impact of heterogeneity on the system: at 2 months post injection, the dielectric has increased $\sim 10 \%$ in the most permeable zone. The geophysical imaging 
suggested that the molasses was distributed a minimum of $16 \mathrm{~m}$ from the injection well. Heterogeneity significantly influenced the amendment distribution, with more amendment traveling through the more permeable zones.

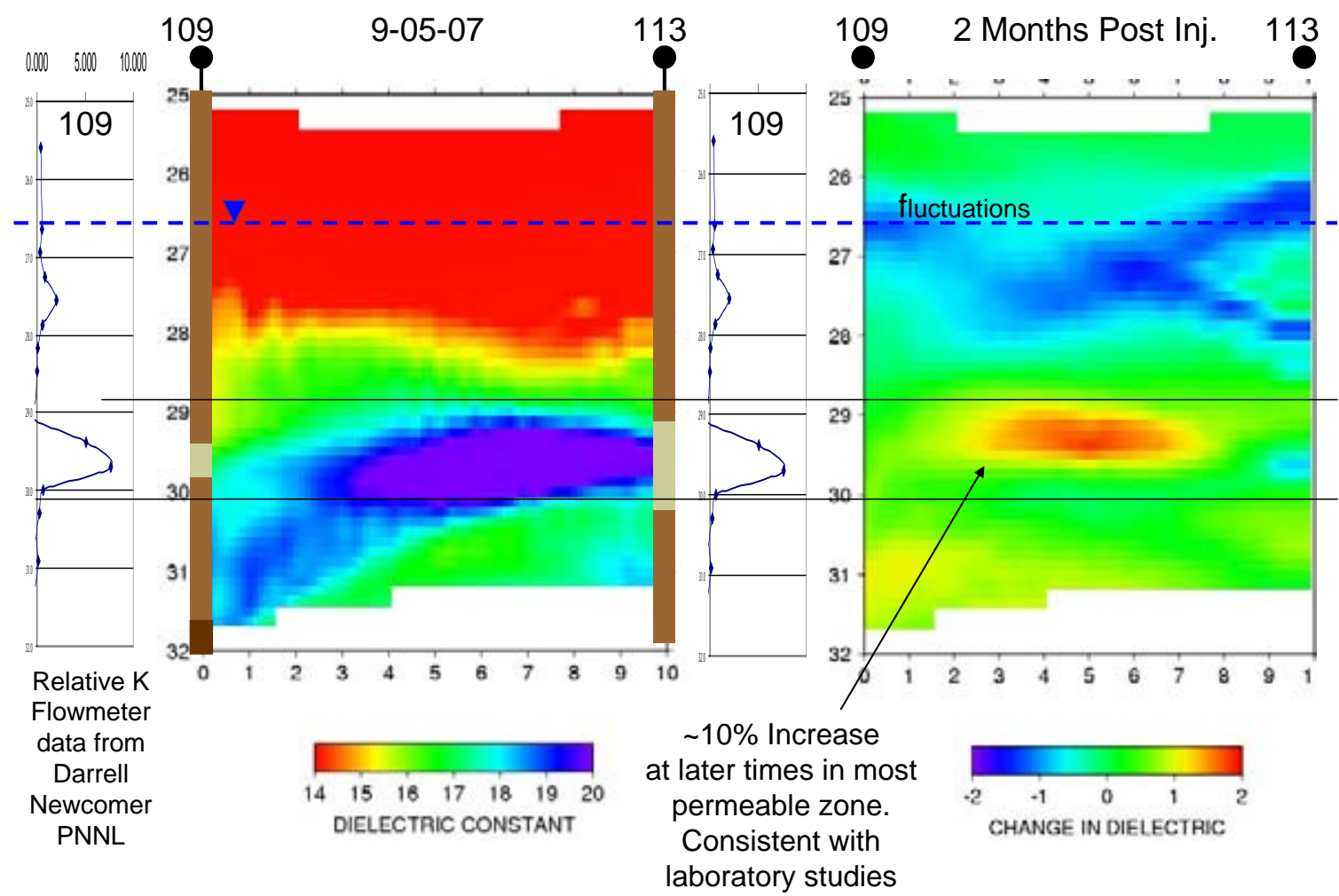

Figure 5.14. Baseline Radar Imaging (left) and 'Difference' Radar Imaging (right). Shown are 1) the favorable comparison of the radar tomogram with the geological and hydrological wellbore data and 2) the influence of heterogeneity on the amendment distribution and subsequent biogeochemical transformations. Decreases in dielectric constant near the water table are likely due to water table fluctuations.

\subsubsection{Bromide Elution}

The elution of bromide that was injected with the substrate was used to evaluate groundwater movement through the test cell. Assessment of the bromide response is complicated by the uneven initial distribution (Figure 5.15). Initial bromide concentration at monitoring wells 199-D5-110 and -111 were comparable to the injected bromide concentration. At these wells, bromide was eluted to approximately half the initial concentration within 70 days. Subsequently, the rate of bromide elution decreased substantially. These results are consistent with hydraulic slug testing data showing that the hydraulic conductivity remained comparable to pre-injection values through November 2007 ( 60 days), and then decreased less than half of the pre-injection valued by November 2008 ( $\sim 20$ days). Bromide data at the injection well (199-D5-107) and well 199-D5-113 show an increase of bromide concentrations as groundwater redistributed the injected solution within the test cell. These data also indicate that groundwater flux at these locations is slow and/or being fed by an upgradient source of injected solution or potentially through drainage from the unsaturated zone. Both of these wells represent locations where 
the hydraulic conductivity is expected to be low. The injection well would be expected to have the largest growth of biomass in the test cell and consequently the most significant biomass-related decrease in hydraulic conductivity. Well 199-D5-113 is screened within a low permeability region of the test cell.

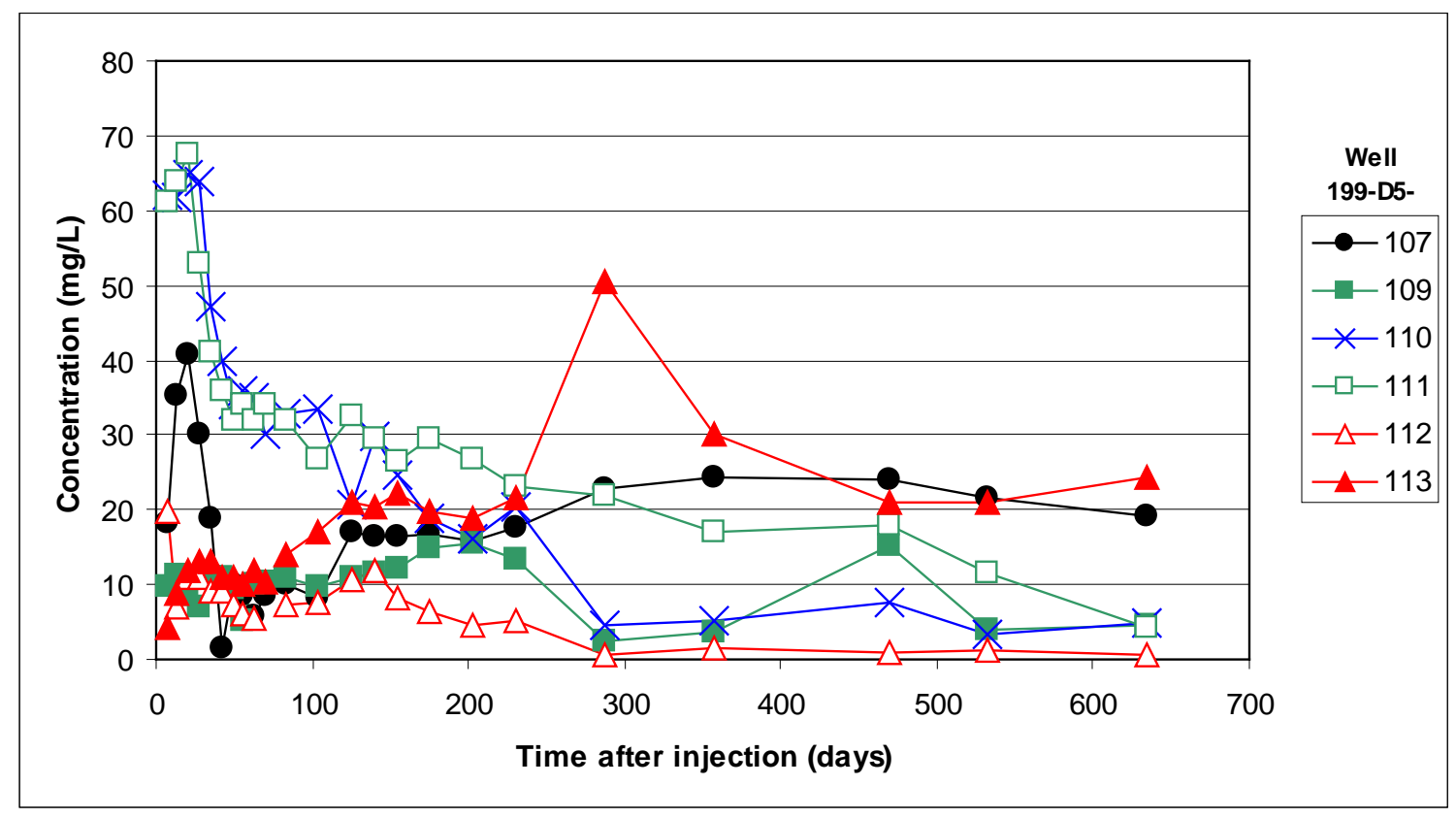

Figure 5.15. Bromide Concentrations over the Duration of the Test

\subsubsection{Performance Assessment}

The soluble substrate biobarrier maintained low nitrate, nitrite, dissolved oxygen and chromium concentrations over the duration of the monitoring period. During this time, conditions within the test cell changed in response to the addition of the substrate and associated biogeochemical reactions that were induced. Figures 5.16 through 5.22 show the trends in primary biogeochemical parameters, including TOC, glucose, acetate, $\mathrm{pH}$, sulfate, iron, and methane.

Addition of molasses as a soluble substrate induced fermentation to organic acids (see Appendix E). These reactions resulted in decreased total organic carbon and glucose concentrations with time. Acetate concentration increased initially and then declined. The groundwater $\mathrm{pH}$ declined and then increased again over the same time interval as the acetate concentration changes as would be expected due to the presence of organic acids at relatively high concentrations. These $\mathrm{pH}$ changes were greater than expected based on the laboratory buffering tests conducted prior to the field test. However, the overall performance of the biobarrier did not appear to be significantly diminished due to the transient low $\mathrm{pH}$ conditions.

Biological activity also included sulfate reduction, iron reduction, and methanogenesis. These biological processes began occurring several months after substrate injection. Neither process was observed in the relatively short term laboratory tests that were conducted prior to the field test. Sulfate and iron reduction processes create reduced species that have reductive capacity to help maintain the targeted reducing conditions within the biobarrier and may increase the overall effectiveness and longevity of the biobarrier. 


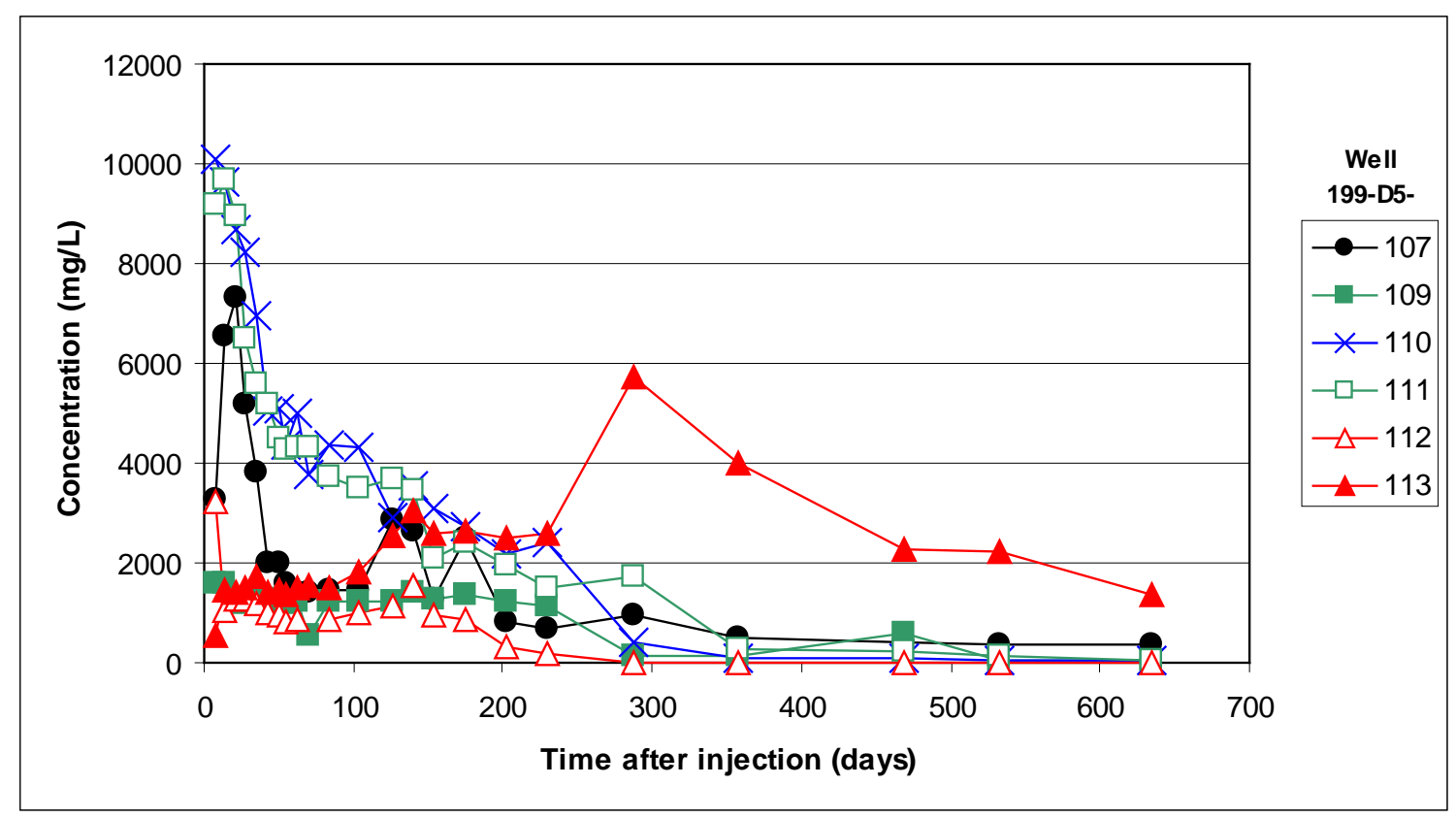

Figure 5.16. TOC Concentrations over the Duration of the Test

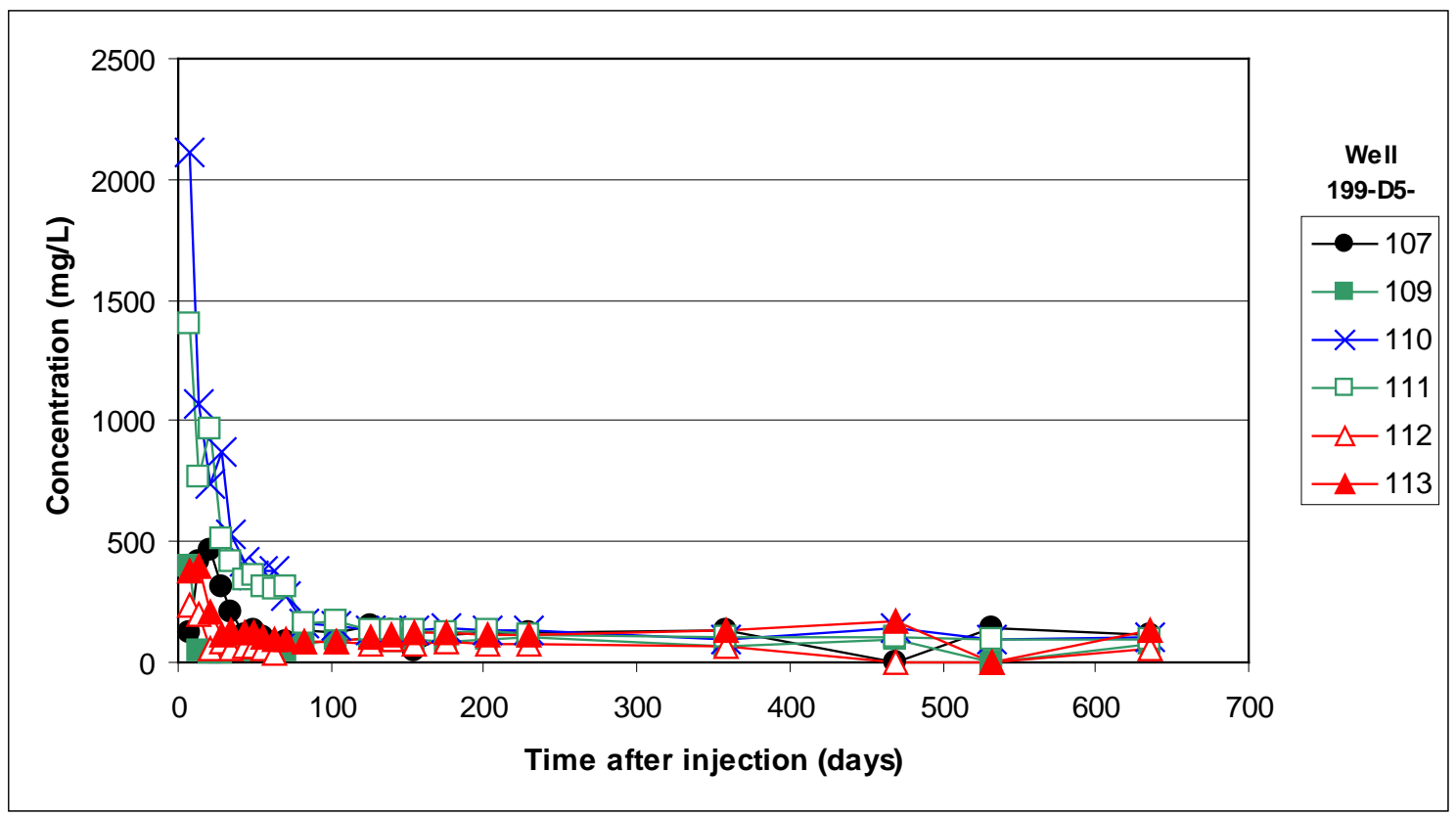

Figure 5.17. Glucose Concentrations over the Duration of the Test 


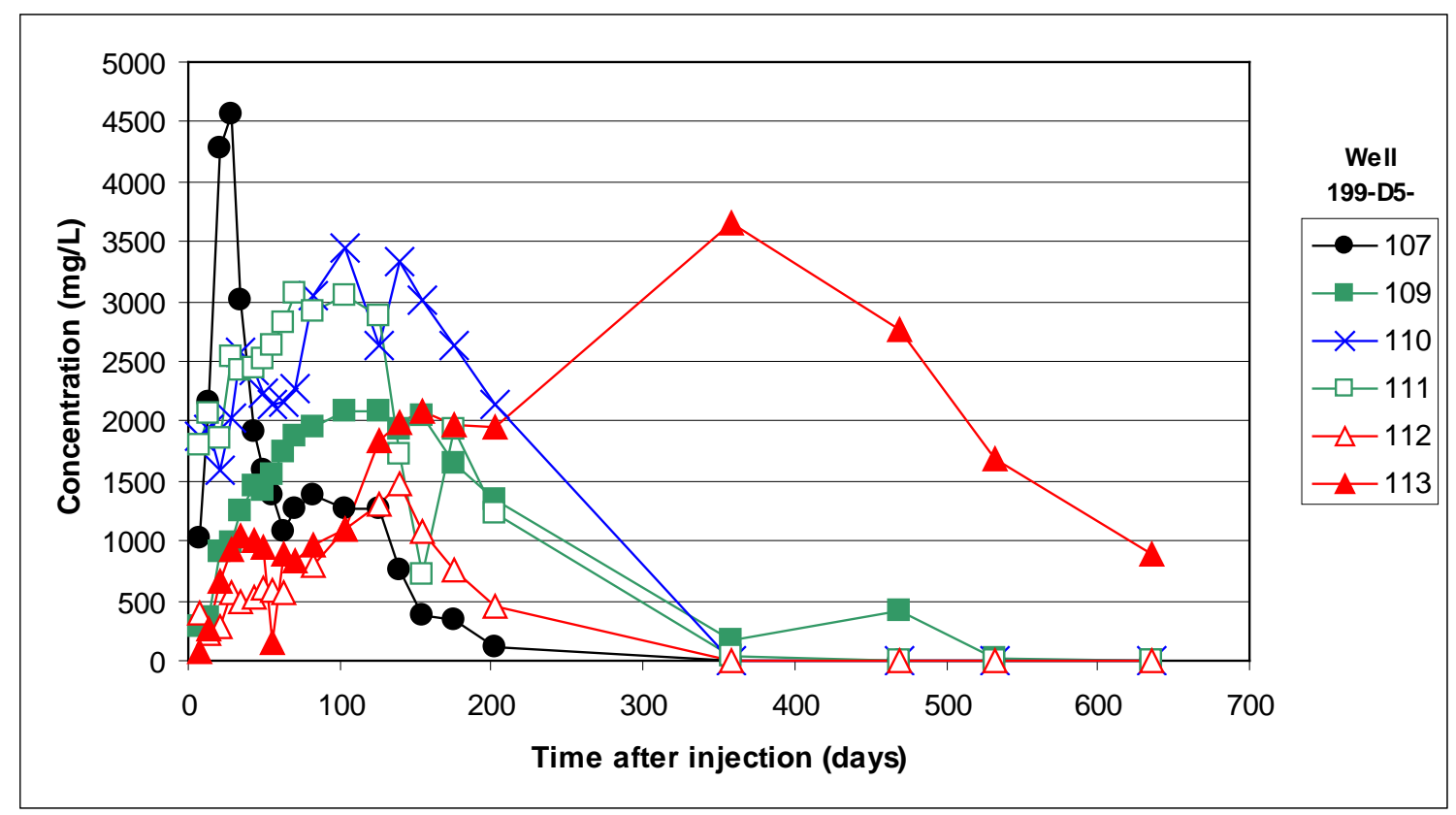

Figure 5.18. Acetate Concentrations over the Duration of the Test

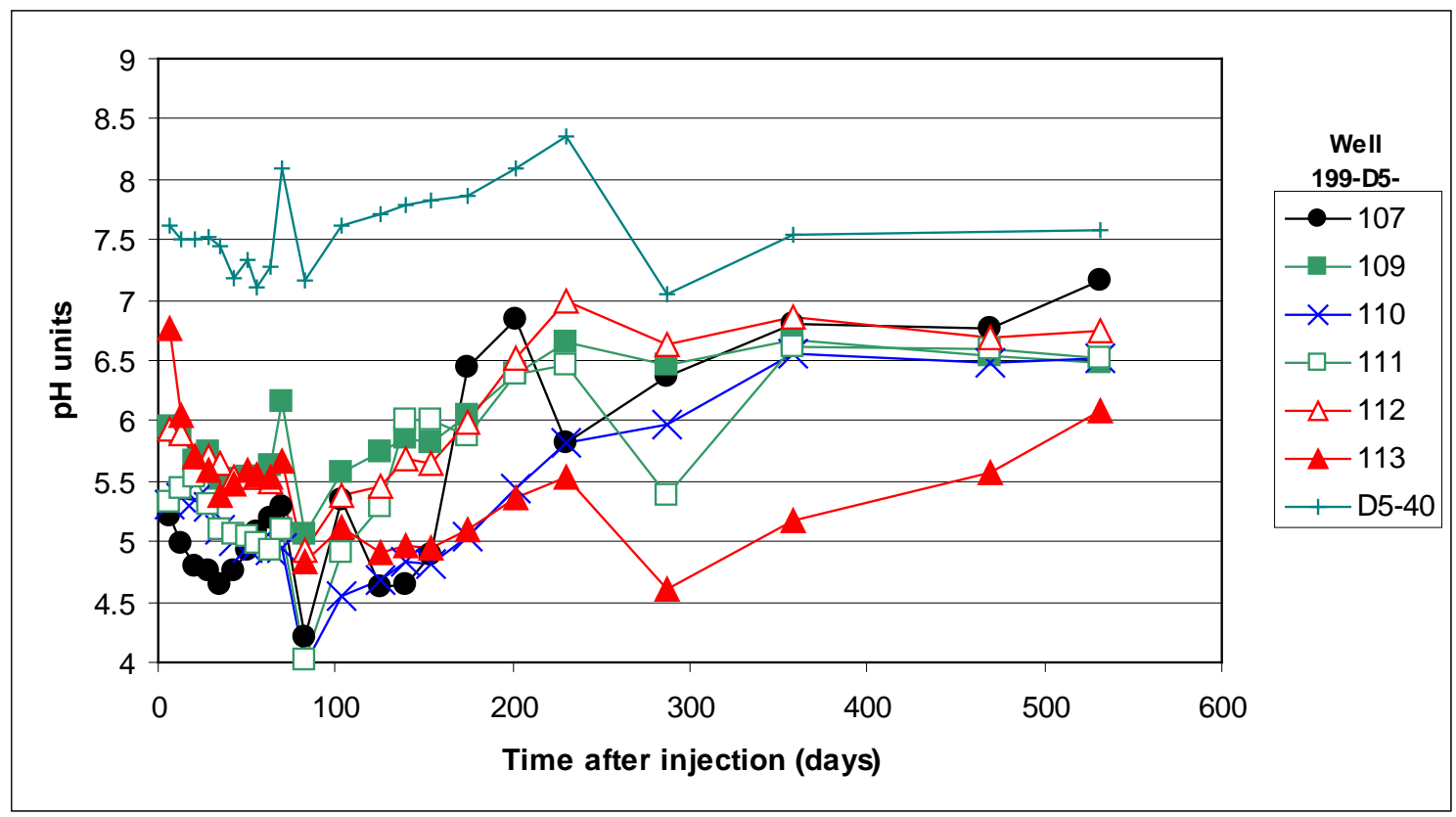

Figure 5.19. $\mathrm{pH}$ over the Duration of the Test. Data are not available for the last sampling time (day 635). Data for day 532 for well 199-D5-40 are also not available. The plotted point at day 532 is the average $\mathrm{pH}$ over the duration of the test at well 199-D5-40. 


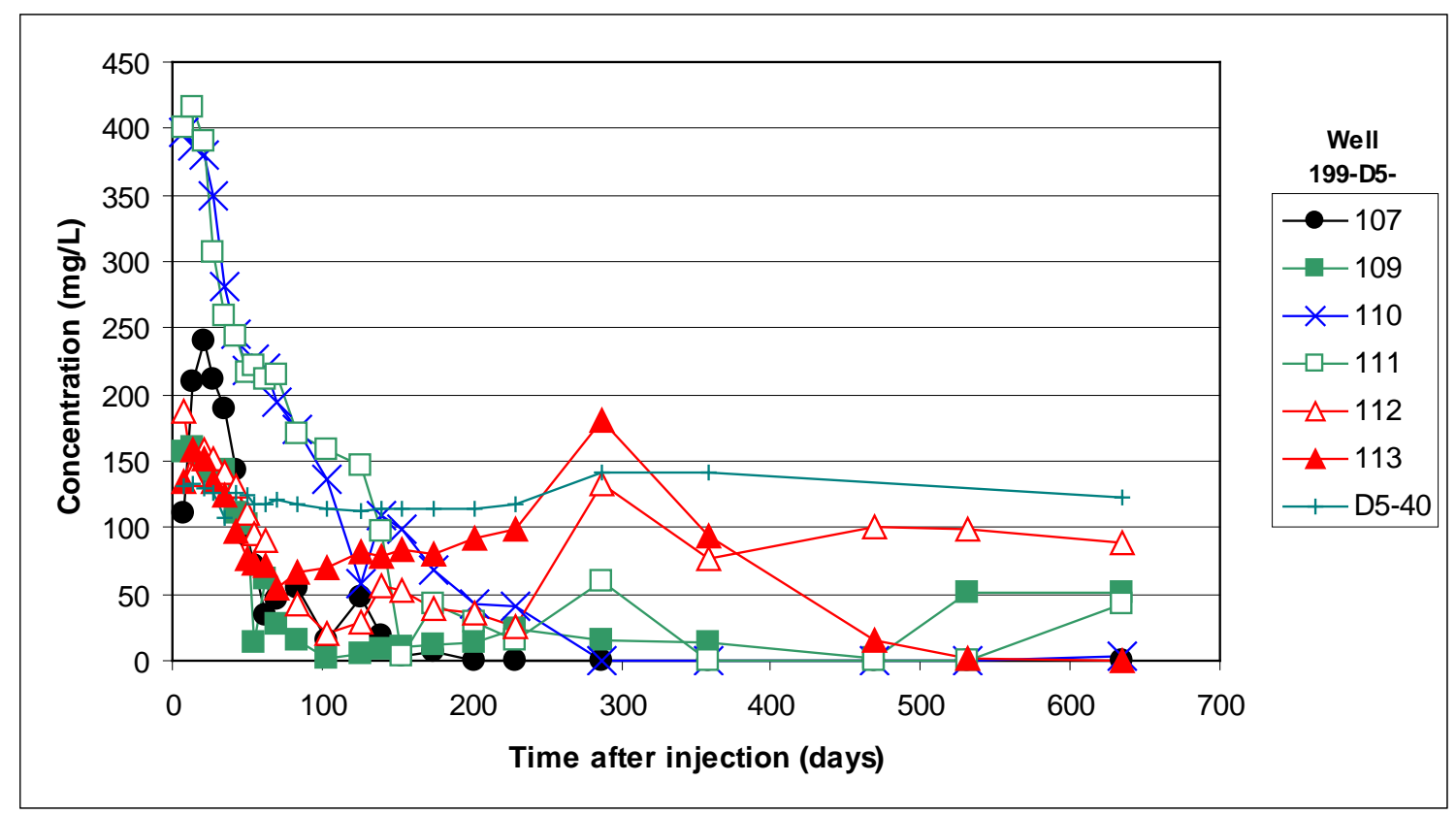

Figure 5.20. Sulfate Concentrations over the Duration of the Test

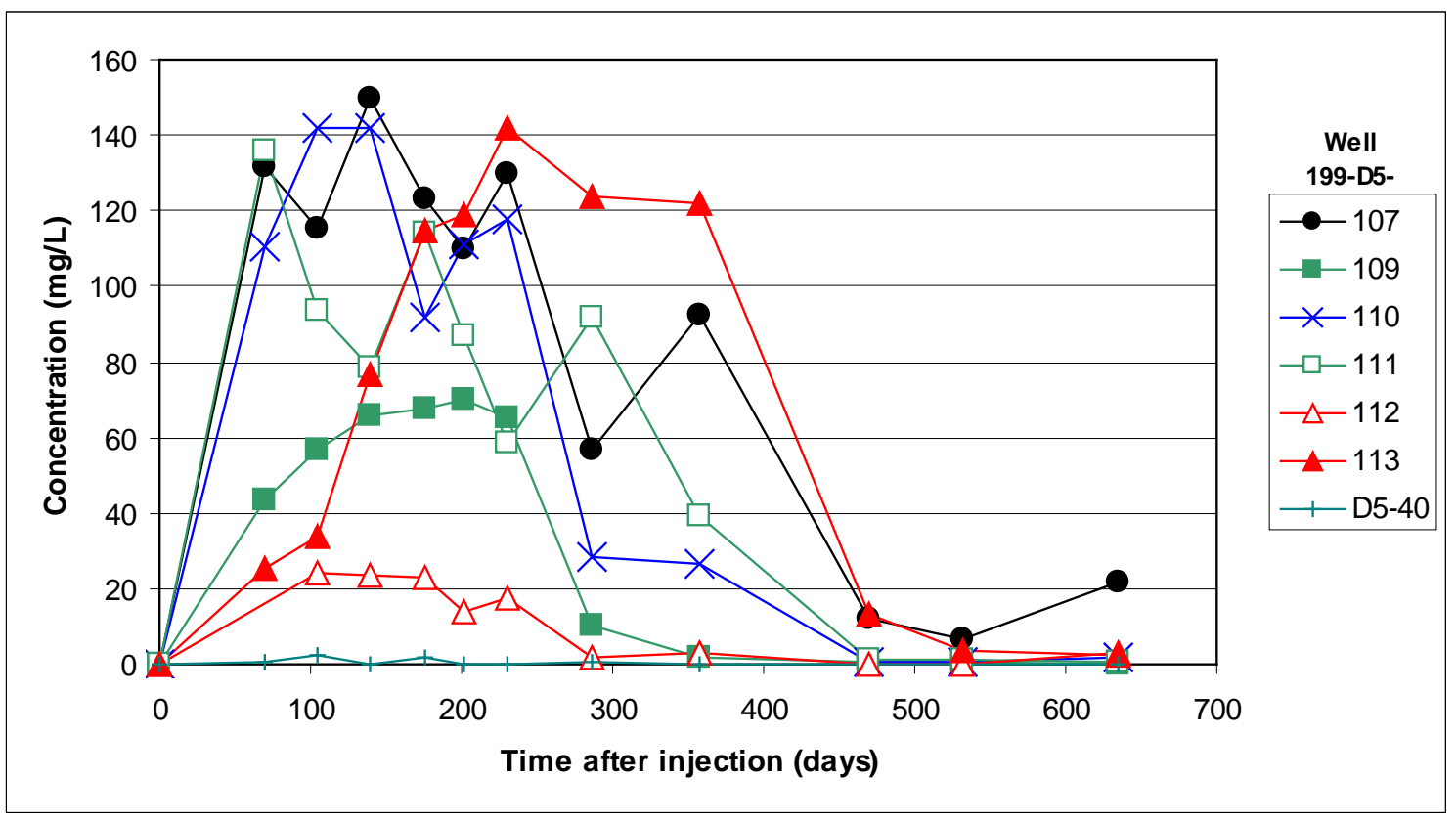

Figure 5.21. Iron Concentrations over the Duration of the Test 


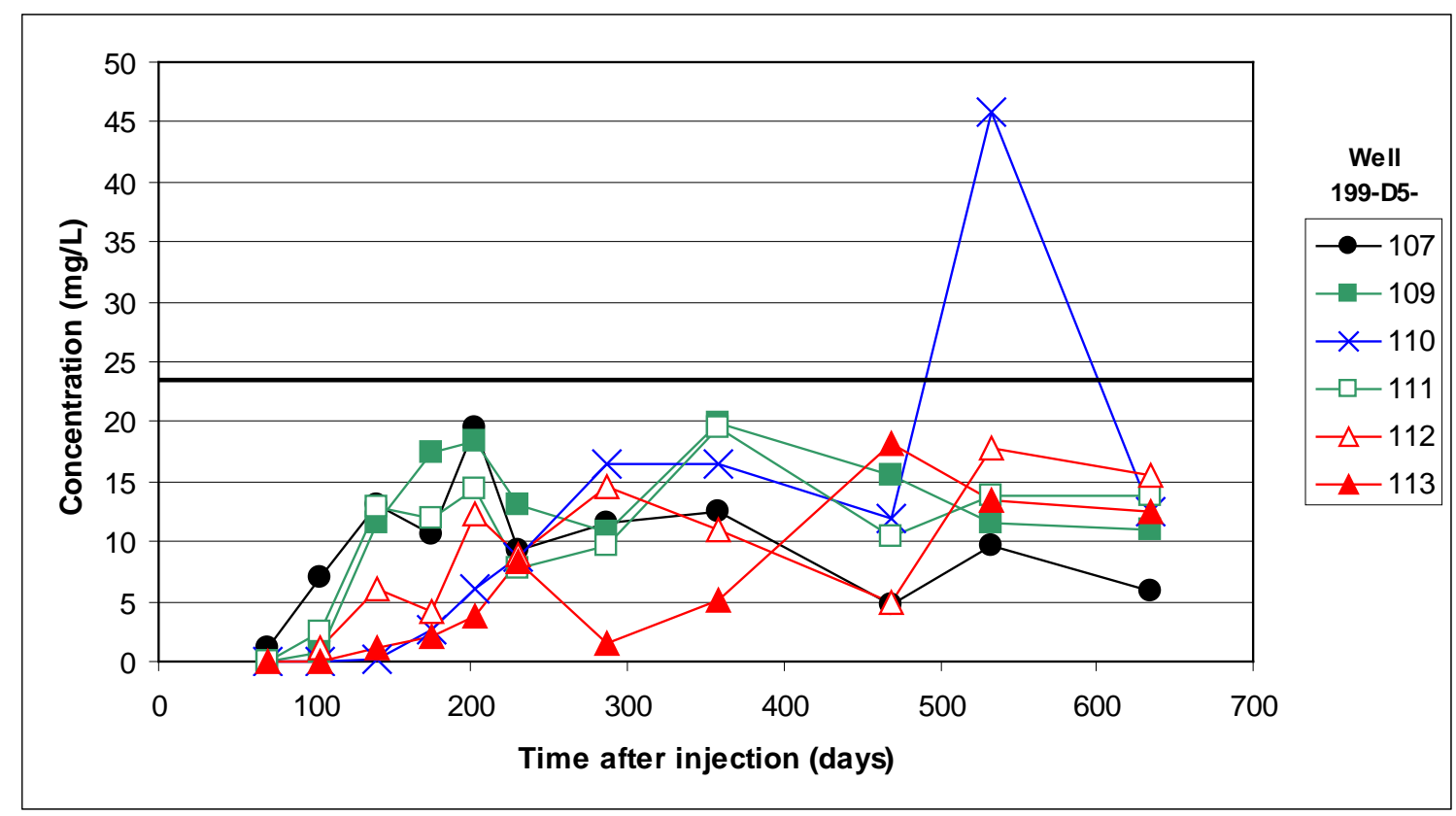

Figure 5.22. Methane Concentrations over the Duration of the Test

By about 300 days after substrate injection, the soluble substrate and associated organic degradation products are essentially depleted. Continued performance of the biobarrier in terms of reducing nitrate, nitrite, dissolved oxygen, and chromate after this time is associated with the presence of reduced iron and sulfur species and cryptic growth of biomass as discussed in the test plan (Truex et al. 2007). It should also be noted that the apparent performance in terms of groundwater constituent reduction is affected by the rate at which constituents are carried into the test cell. Because the hydraulic conductivity was decreased within the test cell, the flow rate through the test cell is slower than initially and the biogeochemical data would therefore evolve more slowly than initially. Although the reduction in hydraulic conductivity was moderate, full scale application of a biobarrier must consider changes to the flow field and associated solute flux through the biobarrier. The decreased flow rate and the continued reductive conditions throughout the duration of the test suggest that continued monitoring would be needed to fully determine the capacity and longevity of the induced biobarrier.

\subsubsection{Water Quality}

Within the test cell, water quality was negatively impacted by an increase in the concentration of metals and organic constituents and a decrease in the $\mathrm{pH}$, oxidation-reduction potential, and dissolved oxygen concentration. These changes were expected due to the imposed anaerobic conditions required for biological treatment of dissolved oxygen, nitrate, and chromate. Although the concentration of most metals increased, only three, arsenic, barium, and selenium, increased to concentrations consistently above the maximum contamination level. The concentration profiles for these metals are shown in Figures 5.23 through 5.25. The concentration of lead increased to above the maximum contamination level for one sample in well 199-D5-111 and one sample in well 199-D5-113. A biobarrier design requires a downgradient portion of the aquifer where these water quality impacts can recover and this type of recovery region would need to be considered as part of determining the location for biobarrier application. 


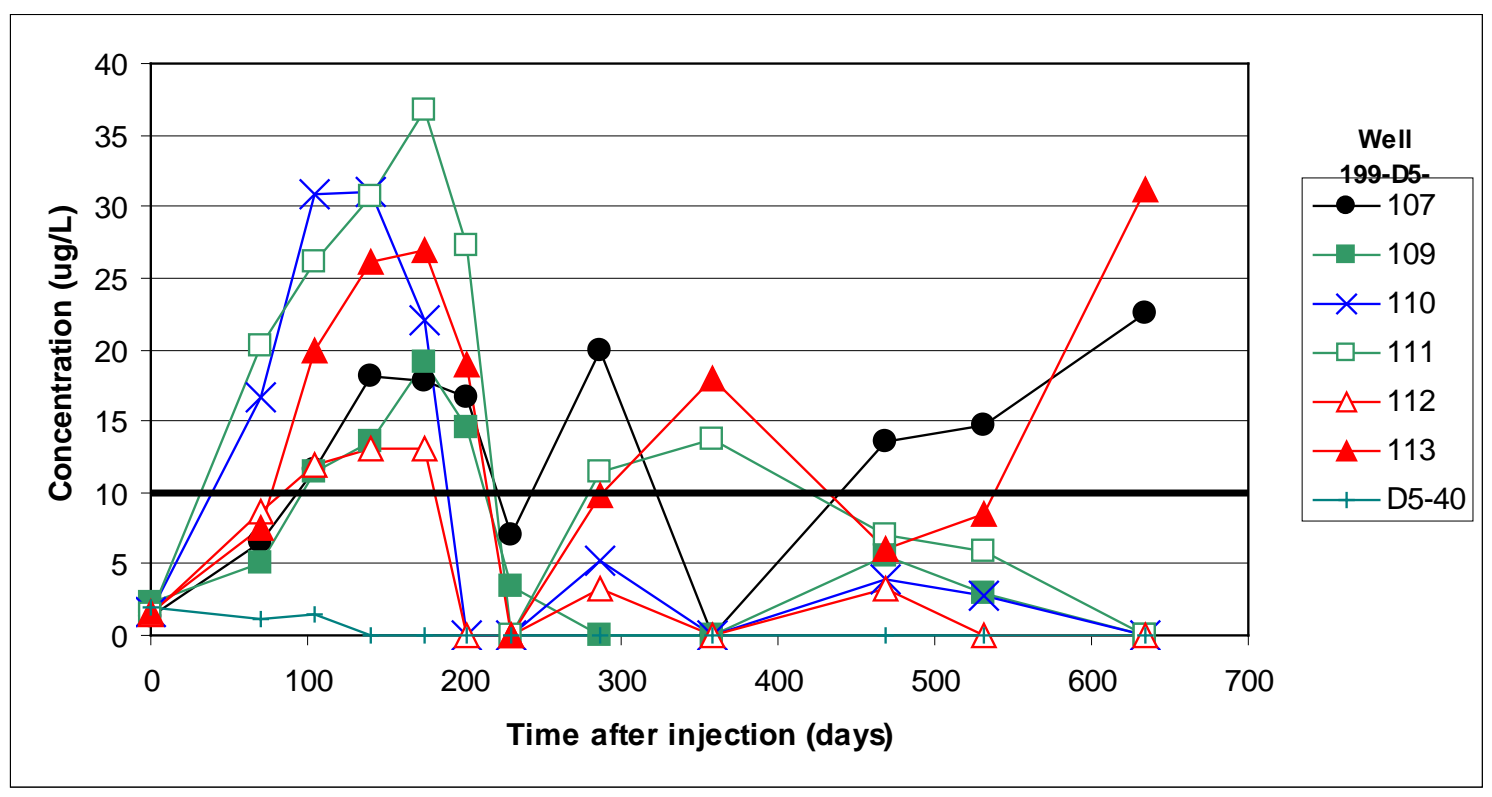

Figure 5.23. Arsenic Concentrations During the Test. The drinking water Maximum Contaminant Level (MCL) for arsenic is $10 \mu \mathrm{g} / \mathrm{L}$.

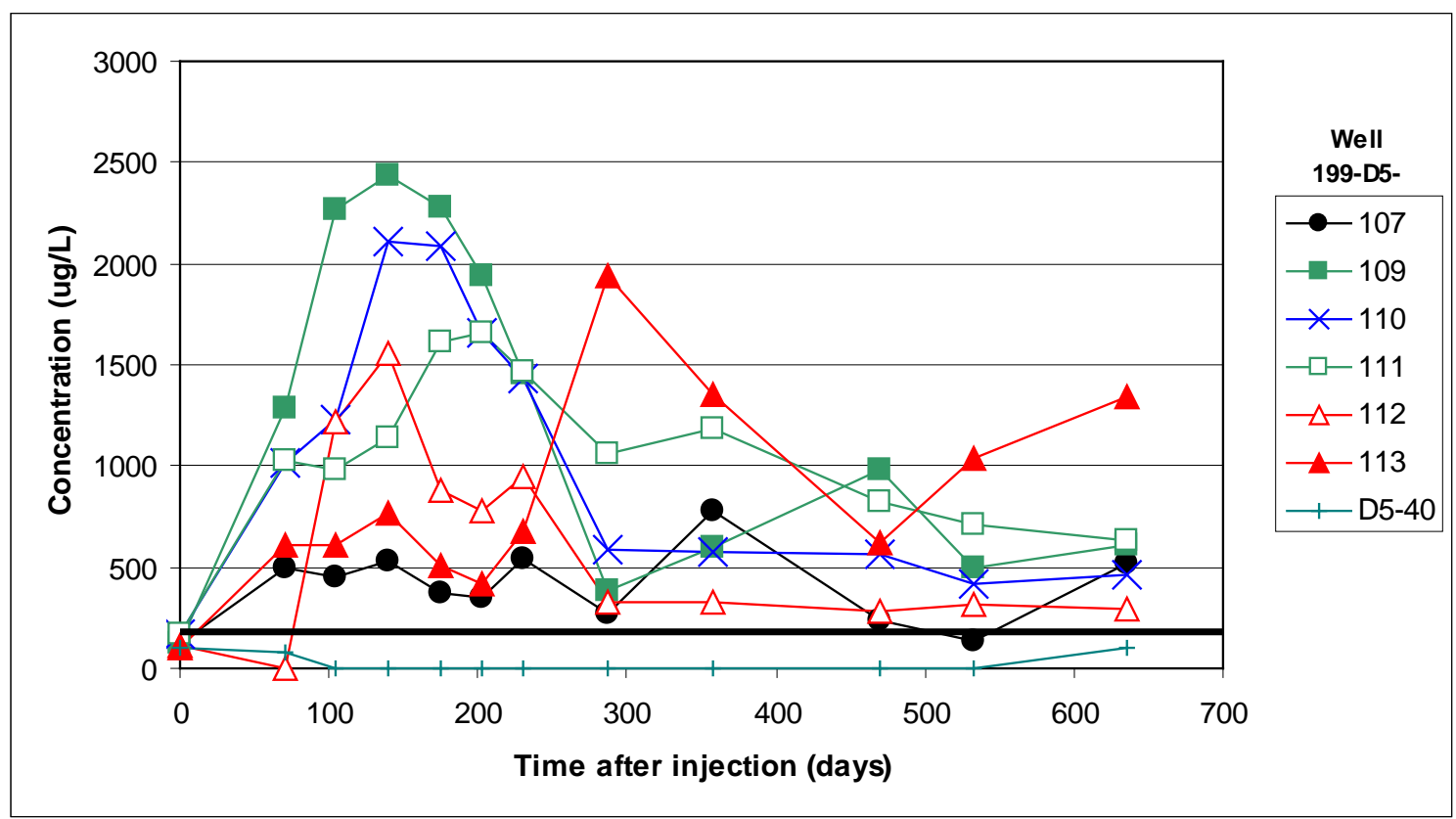

Figure 5.24. Barium Concentrations During the Test. The drinking water Maximum Contaminant Level (MCL) for barium is $200 \mu \mathrm{g} / \mathrm{L}$. 


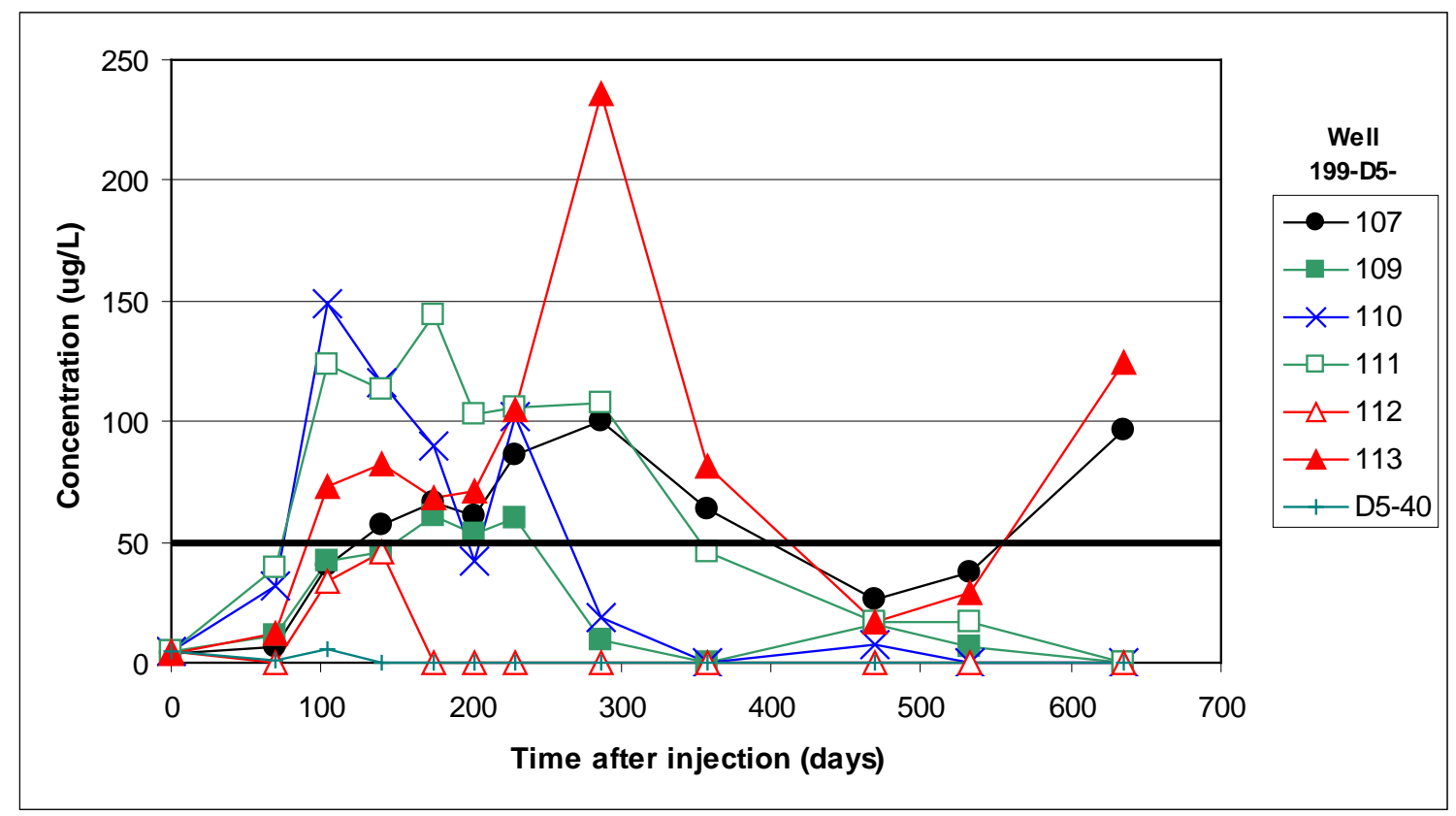

Figure 5.25. Selenium Concentrations During the Test. The drinking water Maximum Contaminant Level (MCL) for selenium MCL is $50 \mu \mathrm{g} / \mathrm{L}$.

\subsection{Summary Comparison of Laboratory Microcosm and Field Test Results}

Laboratory microcosm tests showed that dominant products of substrate fermentation varied based on the initial substrate concentration. At an initial substrate concentration similar to the concentration injected at the field test site, the primary products of fermentation included succinate, lactate, propionate, acetate, formate, ethanol, and butyrate, with acetate dominating at the end of the fermentation period. A similar mixture of fermentation products was observed during field test.

Laboratory experiments also evaluated whether additional buffering capacity would be needed during substrate injection. Table 5.3 shows the $\mathrm{pH}$ changes occurring as a function of added bicarbonate buffer. Based on these results, no additional buffering was added during substrate injection because it was interpreted that the buffering available in the sediment was sufficient. However, the $\mathrm{pH}$ drop observed in the field was larger than expected and generally lowered the $\mathrm{pH}$ by $2 \mathrm{pH}$ units during fermentation. The $\mathrm{pH}$ remained low for several months and then increased again toward neutral. The $\mathrm{pH}$ drop in some of the microcosm experiments conducted after the buffering experiment was also on the order of $2 \mathrm{pH}$ units; however, fermentation and subsequent denitrification were still observed. It is likely the presence of carbonate minerals as buffering materials may be heterogeneously distributed, and the overall buffering capacity was different from what was observed in the initial buffer tests. 
Table 5.3. pH Response over One Month of Fermentation with Molasses (45 g/L) and Bicarbonate Buffer Added as Specified in the Table

\begin{tabular}{lcccc} 
& \multicolumn{4}{c}{ Bicarbonate Buffer Concentrations and Resulting pHs } \\
& $1 \mathrm{mM}$ & $30 \mathrm{mM}$ & $100 \mathrm{mM}$ & $300 \mathrm{mM}$ \\
\hline Initial $\mathrm{pH}$ & 6.8 & 6.8 & 7.6 & 9 \\
Final pH & 6.5 & 6.5 & 7.5 & 8 \\
\hline
\end{tabular}

Figure 5.26 and Figure 5.27 show typical responses for nitrate reduction in microcosm experiments. Note that denitrification occurs without significant production of a nitrite intermediate product. Similar results were observed during the field test where data suggested that nitrate reduction occurred and nitrite concentrations remained very low. Figure 5.26 and Figure 5.27also show no sulfate reduction in the microcosm experiments over a period of about 75 days. In the field, sulfate reduction and methane production was initiated 3-4 months after substrate injection.

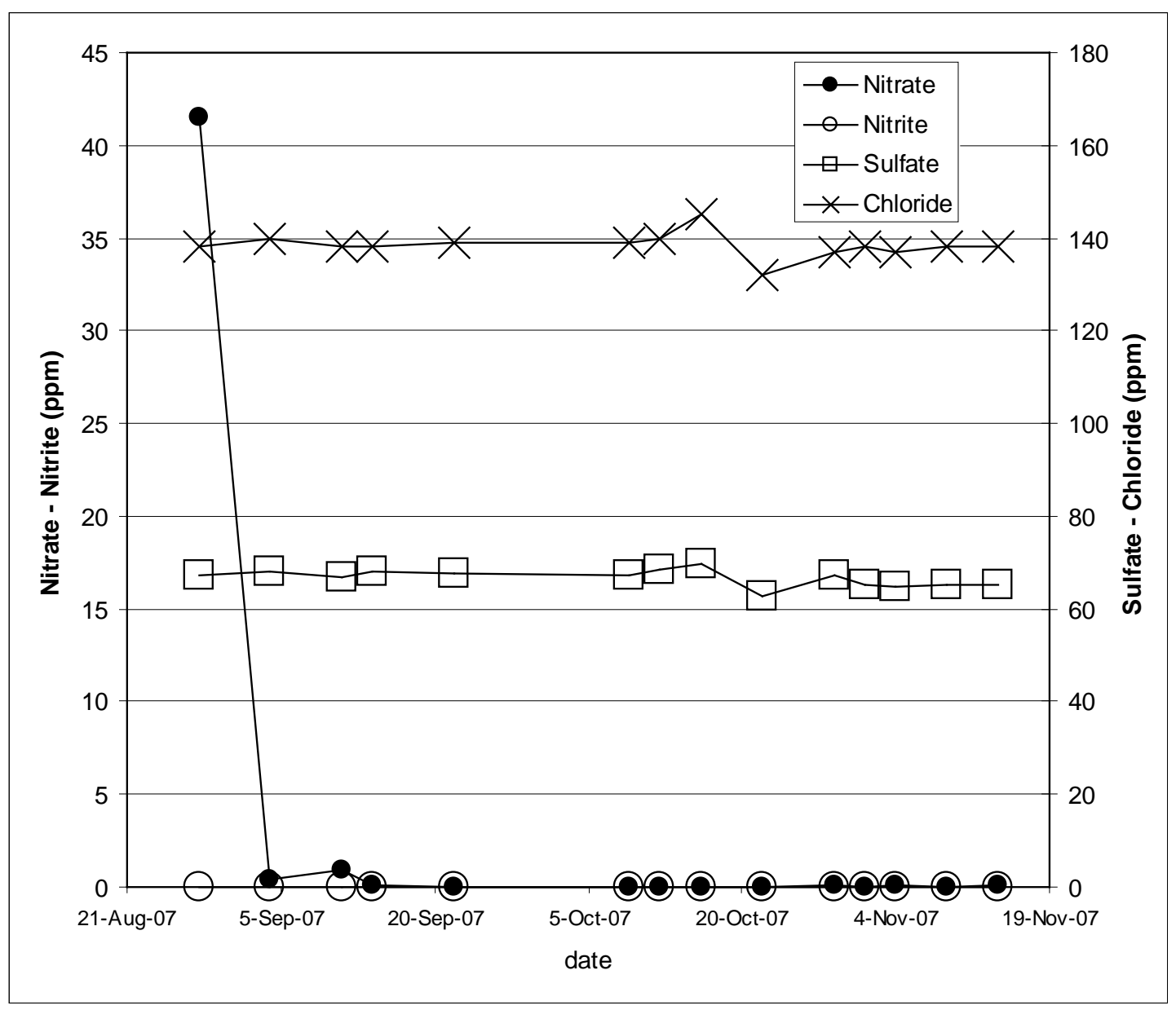

Figure 5.26. Denitrification Observed When Microcosm was Spiked with Nitrate While Acetate Concentration (the dominant remaining organic acid) was Greater Than $30 \mathrm{mM}$. Sulfate reduction was not observed over a period of about 75 days. 


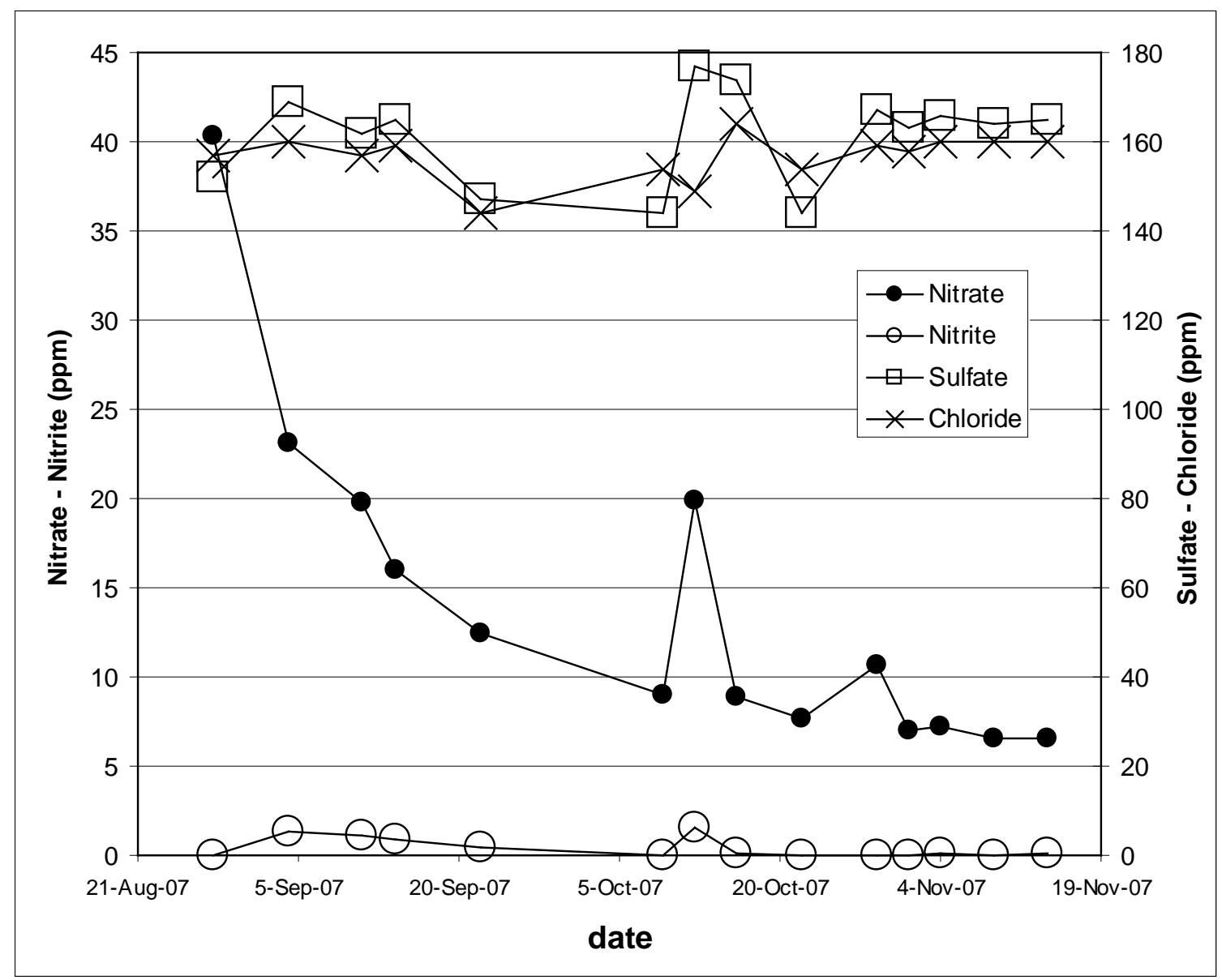

Figure 5.27. Denitrification Observed When Microcosm was Spiked with Nitrate While Acetate Concentration (the dominant remaining organic acid) was Less Than $5 \mathrm{mM}$. Sulfate reduction was not observed over a period of about 75 days.

\subsection{Description of Results Relative to Field Test Objectives}

The following is a summary of the field test results with respect to the objectives of the field test.

- Determine the effective radius of injection.

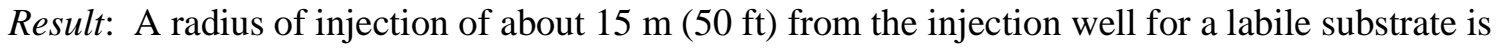
obtainable. It is unlikely that a radius greater than $20 \mathrm{~m}$ (66 ft) could be obtained because of the rapid initiation of microbial reactions and potential for associated biomass buildup near the injection well. However, hydraulic properties would need to be evaluated at any proposed implementation location to determine if a higher injection rate, and thus a larger radial extent of treatment for a given time period, could be sustained. Additionally, use of a groundwater recirculation process that was able to significantly enhance interwell groundwater flow rates during an injection may also enable larger well spacing during full-scale deployment of the technology. 
- Evaluate the uniformity of substrate distribution.

Result: Uniformity of substrate injection is, as expected, dependent on formational heterogeneities within and beyond the targeted treatment zone. However, the field test injection was able to distribute substrate to all of the monitoring locations, although at different concentrations. Subsequent microbial activity and treatment of the target compounds over a period of about 2 years was observed at all locations.

- Identify operational needs for injection.

Result: Relatively simple operations with the use of process water and substrate supplied in a tanker truck were demonstrated during the injection. One problem encountered was the initial injection pressure increase, which most likely resulted from accumulation of molasses or solids from the molasses tanker on the injection well screen or within the filter pack material. A mitigation approach was developed during the treatability test (i.e., short pulses of process water were used to dissolve molasses buildup on the screen openings), and similar approaches may be required during full-scale deployment of the technology.

- Induce fermentation reactions and reducing conditions and grow biomass.

Result: Process monitoring data showed that fermentation reactions and associated reducing conditions occurred at all of the monitoring locations. Direct in situ biomass measurement is not possible, but indirect measurements suggest that biomass was produced and helped facilitate treatment of target compounds and maintenance of reducing conditions for about 1 year after the introduced substrate and associated fermentations products were depleted, for a total treatment duration of about 2 years and potentially longer.

- Minimize permeability changes resulting from biomass increases.

Result: Comparison of pre- and post-injection hydraulic conductivity measurements results show minimal impact from injection of the substrate in the short term. Over the longer term, permeability was reduced, likely due to biomass growth. At most locations, moderate permeability reductions ranging from 0.23 to 0.55 of the initial value were observed. However, at one well, permeability was reduced to 0.02 of the initial value.

- Quantify the ability to obtain and maintain low oxygen and nitrate/nitrite concentrations (limit primary electron acceptor flux) and determine longevity of treatment.

Result: Low oxygen, nitrate, and nitrite concentrations were maintained over the duration of the test ( $\sim 2$ years) with indications that the treatment duration will be longer than 2 years.

- Quantify the ability to obtain and maintain low chromate concentrations (augment chromate treatment) and determine longevity of treatment.

Result: Low total chromium and chromate concentrations were maintained over the duration of the test ( 2 years), with indications that the treatment duration will be longer than 2 years.

- Quantify the water quality impacts of the treatment. 
Result: Within the test cell, water quality was negatively impacted by an increase in the concentration of metals and organic constituents and a decrease in the $\mathrm{pH}$, oxidation-reduction potential, and dissolved oxygen concentration. These changes were expected due to the imposed anaerobic conditions required for biological treatment of dissolved oxygen, nitrate, and chromate. A biobarrier design requires a downgradient portion of the aquifer where these water quality impacts can recover, and this type of recovery region would need to be considered as part of determining the location for biobarrier application.

- Compile information for full-scale design considering the injection process, biobarrier performance, hydrogeology, and electron flux information at 100-D.

Result: Table 5.4 shows the information available from this treatability test that is suitable for use to support design and cost estimation in a feasibility study.

Table 5.4. Biobarrier Scale-Up Information

\begin{tabular}{|c|c|c|}
\hline Item & Value & Comment \\
\hline Substrate loading & $6.7 \mathrm{~kg} / \mathrm{m}^{3}$ & $\begin{array}{l}\text { Lower substrate loading may be } \\
\text { appropriate for volumetric bioremediation } \\
\text { of chromate or for shorter periods of } \\
\text { barrier effectiveness. }\end{array}$ \\
\hline Substrate cost & $0.21 \$ / \mathrm{kg}$ & Treatability test cost \\
\hline Nutrient loading & $4 \mathrm{mg} / \mathrm{m}^{3}$ & $\begin{array}{l}\text { May not be necessary in all } \\
\text { bioremediation applications }\end{array}$ \\
\hline Nutrient cost & $5 \$ / \mathrm{kg}$ & $\begin{array}{l}\text { Treatability test cost for ammonium } \\
\text { chloride (may not be needed for some } \\
\text { sites) }\end{array}$ \\
\hline $\begin{array}{l}\text { Injection well spacing } \\
\text { (perpendicular to flow) }\end{array}$ & $30 \mathrm{~m}$ & $\begin{array}{l}\text { Based on 15-m radius of influence. Full- } \\
\text { scale spacing may need to consider } \\
\text { overlapping of substrate injection zones. } \\
\text { Potentially, larger spacing could be } \\
\text { obtained with a groundwater recirculation } \\
\text { system and may be appropriate, } \\
\text { depending on relative cost of recirculation } \\
\text { design versus a single well injection } \\
\text { design. }\end{array}$ \\
\hline $\begin{array}{l}\text { Operational labor for } \\
\text { injection }\end{array}$ & 250 hours of labor time & Labor for injection during the test \\
\hline Monitoring frequency & Quarterly to semiannually & $\begin{array}{l}\text { Based on the timeframe of observed } \\
\text { changes during the test. }\end{array}$ \\
\hline $\begin{array}{l}\text { Frequency of substrate } \\
\text { injection }\end{array}$ & $\begin{array}{l}\text { Every } 2 \text { years (observed performance } \\
\text { over test duration) } \\
\text { Every } 3-4 \text { years (estimated based on } \\
\text { performance observed over 2-year } \\
\text { period) }\end{array}$ & $\begin{array}{l}\text { Barrier performance did not diminish over } \\
\text { the 2-year testing period. Groundwater } \\
\text { flow conditions should also be considered } \\
\text { in determining the frequency of } \\
\text { reinjection. }\end{array}$ \\
\hline
\end{tabular}


Table 5.4. (contd)

\begin{tabular}{|c|c|c|}
\hline Item & Value & Comment \\
\hline \multirow[t]{10}{*}{$\begin{array}{l}\text { Primary injection } \\
\text { equipment and cost }\end{array}$} & $\begin{array}{l}\text { Substrate feed pump (air-driven } \\
\text { diaphragm pump) - } \$ 2,500\end{array}$ & \multirow{10}{*}{$\begin{array}{l}\text { Equipment used during the test and } \\
\text { nominal cost. Injection system design } \\
\text { and construction cost is not included. } \\
\text { These costs would be best estimated by } \\
\text { the contractor performing the scale-up } \\
\text { injections. }\end{array}$} \\
\hline & Nutrient feed pump (peristaltic) - $\$ 500$ & \\
\hline & Feedwater pump (centrifugal) - \$500 & \\
\hline & $\begin{array}{l}\text { Substrate flowmeter (pulse counter) - } \\
\$ 1,000\end{array}$ & \\
\hline & Nutrient flowmeter (turbine) - \$800 & \\
\hline & Feedwater flowmeter (turbine) - $\$ 1,000$ & \\
\hline & In-line mixer - $\$ 100$ & \\
\hline & $\begin{array}{l}\text { Data logger for flowmeters and feed } \\
\text { pump - } \$ 3,000\end{array}$ & \\
\hline & Hose for feedwater - $\$ 10 / \mathrm{ft}$ & \\
\hline & $\begin{array}{l}\text { Hardware for injection well piping - } \\
\$ 400\end{array}$ & \\
\hline
\end{tabular}




\subsection{Results for the Immiscible Substrate Test}

\subsection{Injection Description and Results}

The concept for the immiscible substrate injection process was to obtain an injection radius of about

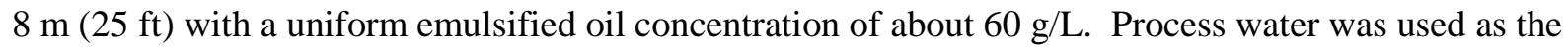
carrier medium for the substrate. Emulsion properties were carefully controlled to enable distribution to the target radius and to achieve a targeted oil concentration within the biobarrier. A tracer was injected with the substrate to help identify the injection front and for subsequent monitoring of injection solution elution from the test zone.

Injection flow rate of process water and emulsified oil are shown in Figure 6.1. The pressure response in the injection well and the surrounding monitoring wells during injection are shown in Figure 6.2 and Figure 6.3. The following parameters describe the details of the injection process.

- The average injection flow rate (water and all solutes) was approximately $147 \mathrm{~L} / \mathrm{min}$ (38.7 gpm).

- The average emulsified oil injection flow rate while oil injection was occurring was approximately 8.6 L/min (2.3 gpm). The average oil injection flow rate during the overall oil injection phase was $5.3 \mathrm{~L} / \mathrm{min}(1.4 \mathrm{gpm})$.

- Approximately 5,560 L (1470 gal) of emulsified oil were injected.

- The total injection volume was about $157,700 \mathrm{~L}$ (41,700 gal), including periods in which only process water was injected but not including process water injection before or after the oil injection phase.

- The average emulsified oil concentration during periods with oil injection was about $60 \mathrm{~g} / \mathrm{L}$.

- The injection duration of the oil phase was 17.4 hours, although the total duration of emulsified oil pulses was 10.7 hours.

- Based on the injected volume, estimated aquifer properties (5.6-m [18-ft] thick at the time of injection with a porosity of 0.14 ), and an idealized radial geometry, the nominal injection radius was $8 \mathrm{~m}$ $(25 \mathrm{ft})$.

- About 30,600 L (8,100 gal) of water were injected after the emulsified oil injection was terminated, to flush the injection system, injection wellbore, and filter pack.

- About $67 \mathrm{~L}$ (17.7 gal) of concentrated sodium bromide tracer solution were injected (187 g/L $\left.\mathrm{Br}^{-}\right)$, resulting in an average solution concentration of $75 \mathrm{mg} / \mathrm{L}$ as bromine, based on the concentrations measured in the injection well during injection.

- Injection pressure was variable throughout the injection, ranging from 3 to 17 psi.

The injection pressures monitored within the injection wellbore during substrate injection were higher than anticipated, based on the observed pressure response during developmental pumping and an initial injection test using only water. Pressure buildup was mitigated by pulse injection of the emulsion. 


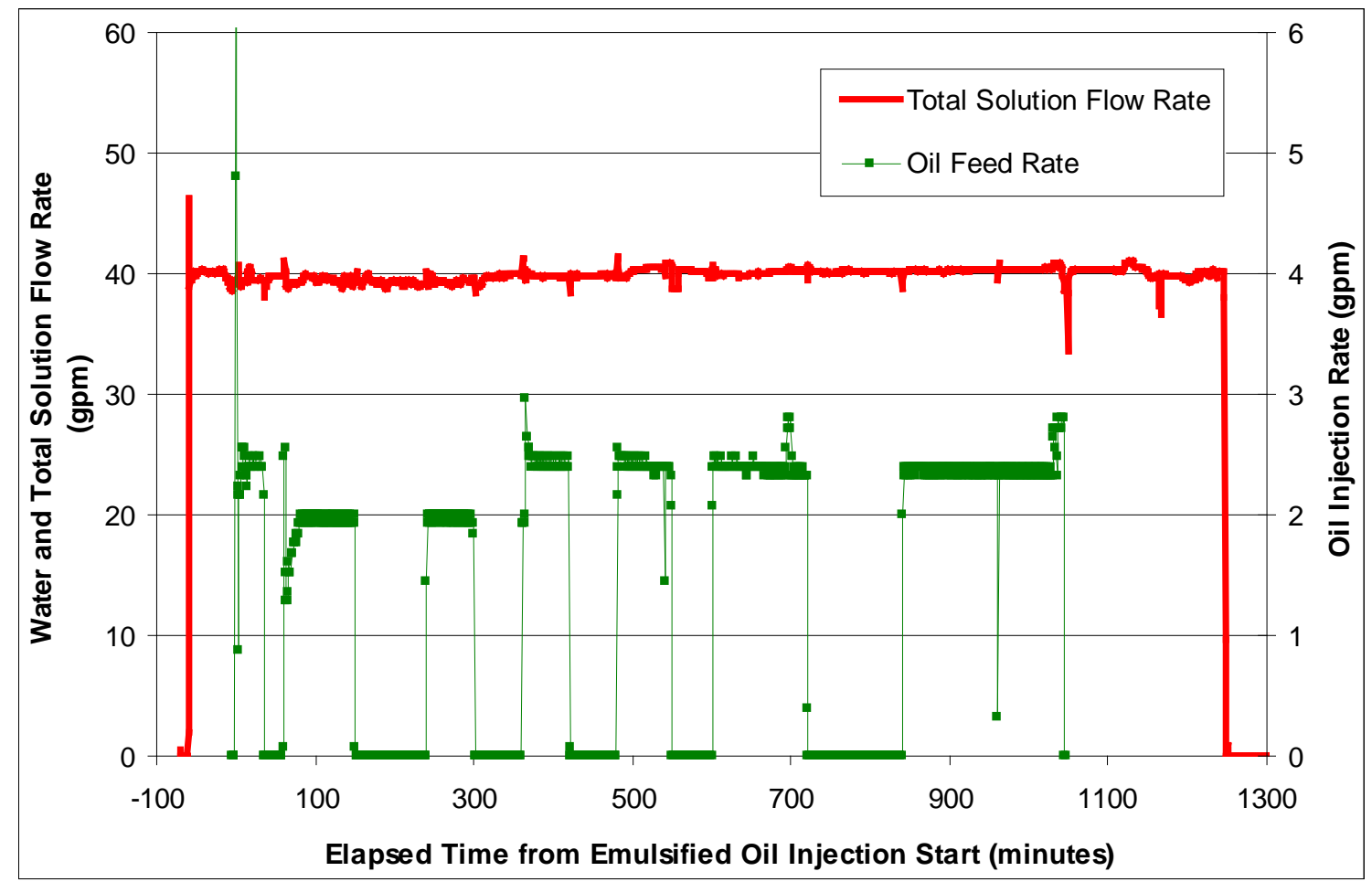

Figure 6.1. Flow Rate of Injected Solution and Emulsified Oil During the Injection Period

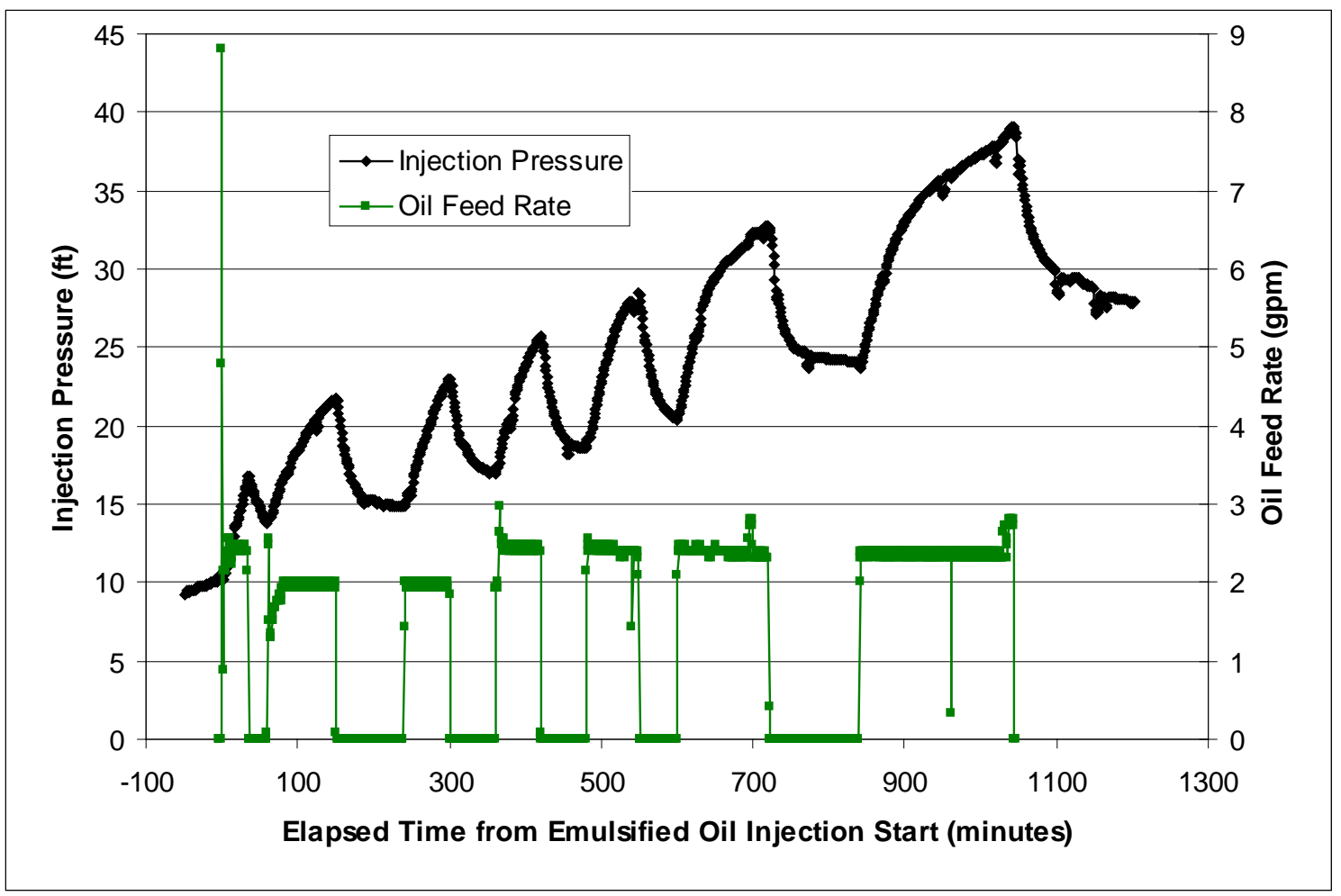

Figure 6.2. Injection Pressure (well 199-D5-108) During Emulsified Oil Injection 


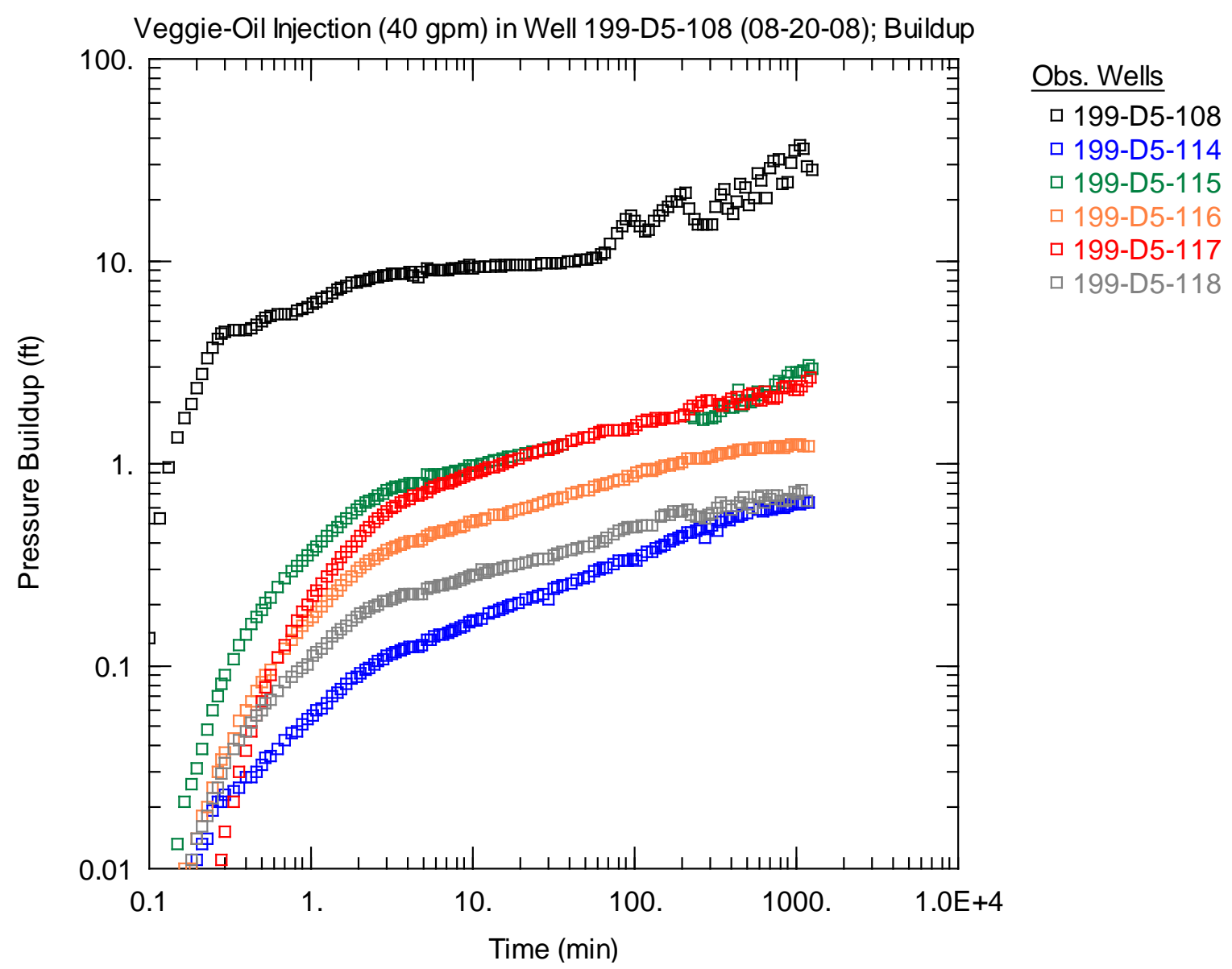

Figure 6.3. Pressure Response at Injection and Monitoring Wells During the Injection Period. Here elapsed time is from the start of water injection. Oil injection began 60 minutes after the start of water injection.

Primary data collected to monitor substrate injection are depicted in Figures 6.4 through 6.9. 


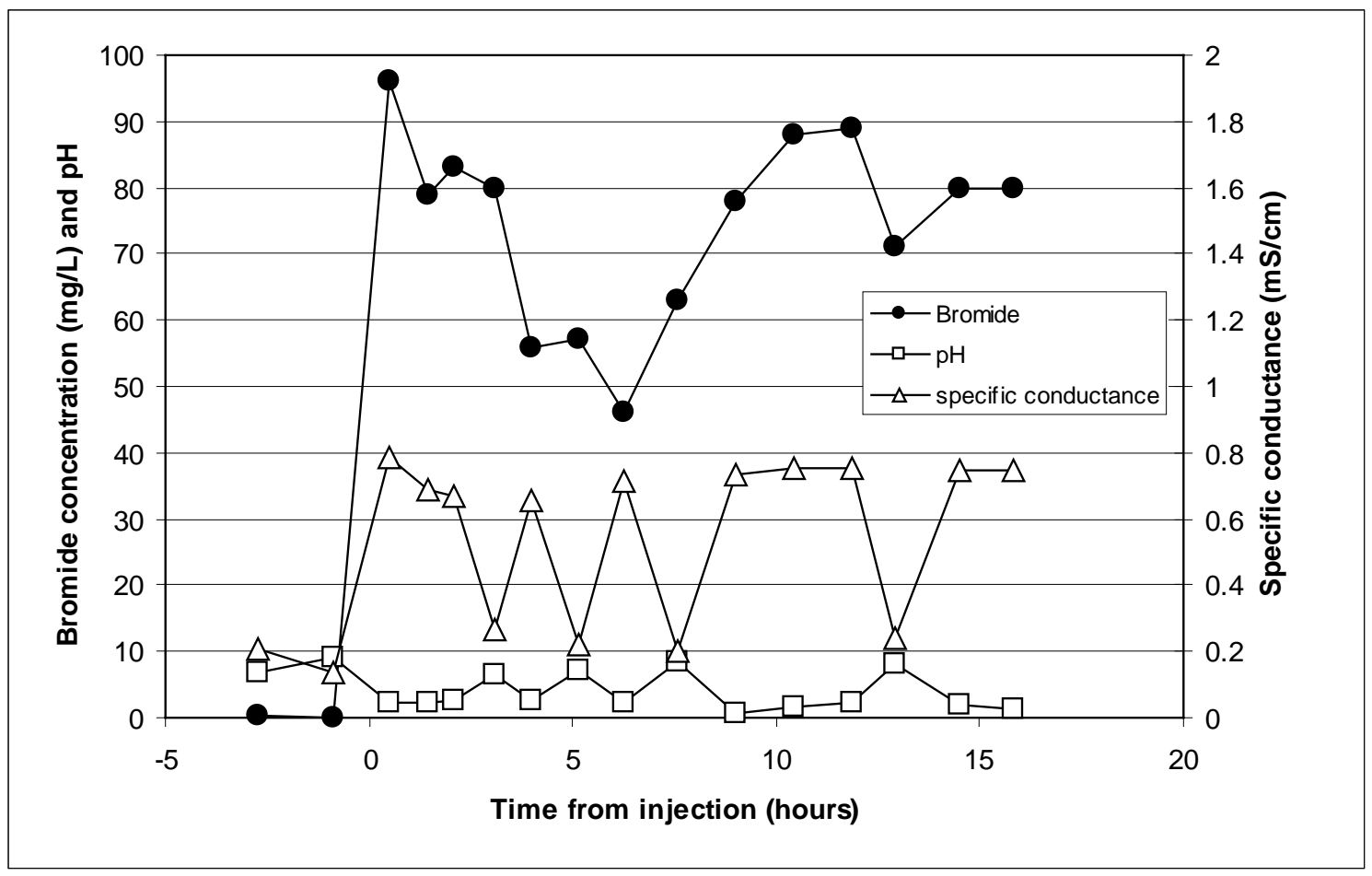

Figure 6.4. Operational Parameters Measured at Injection Well 199-D5-108 During the Injection Phase of the Test

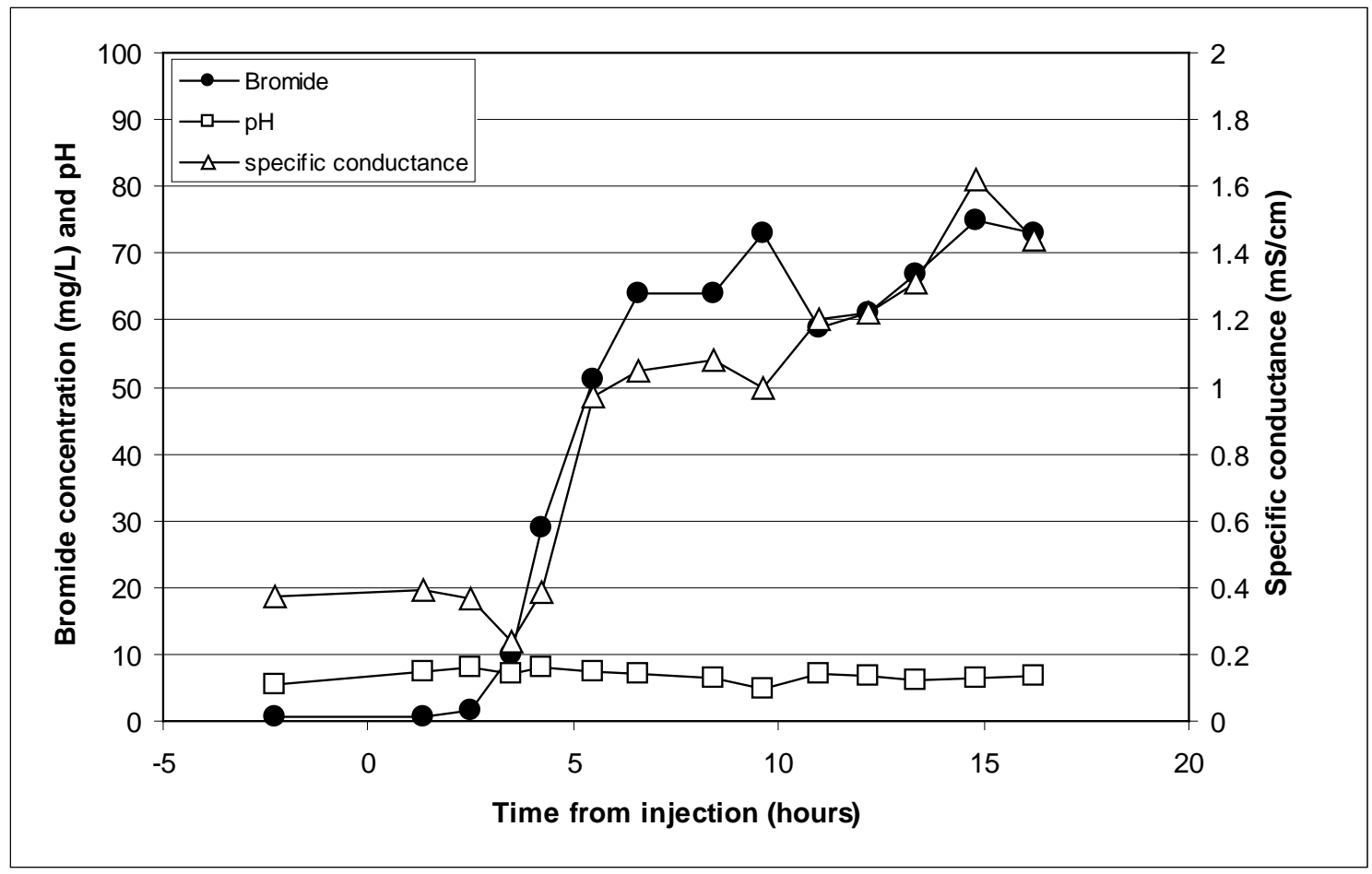

Figure 6.5. Operational Parameters Measured at Monitoring Well 199-D5-114 During Injection in 199-D5-108 


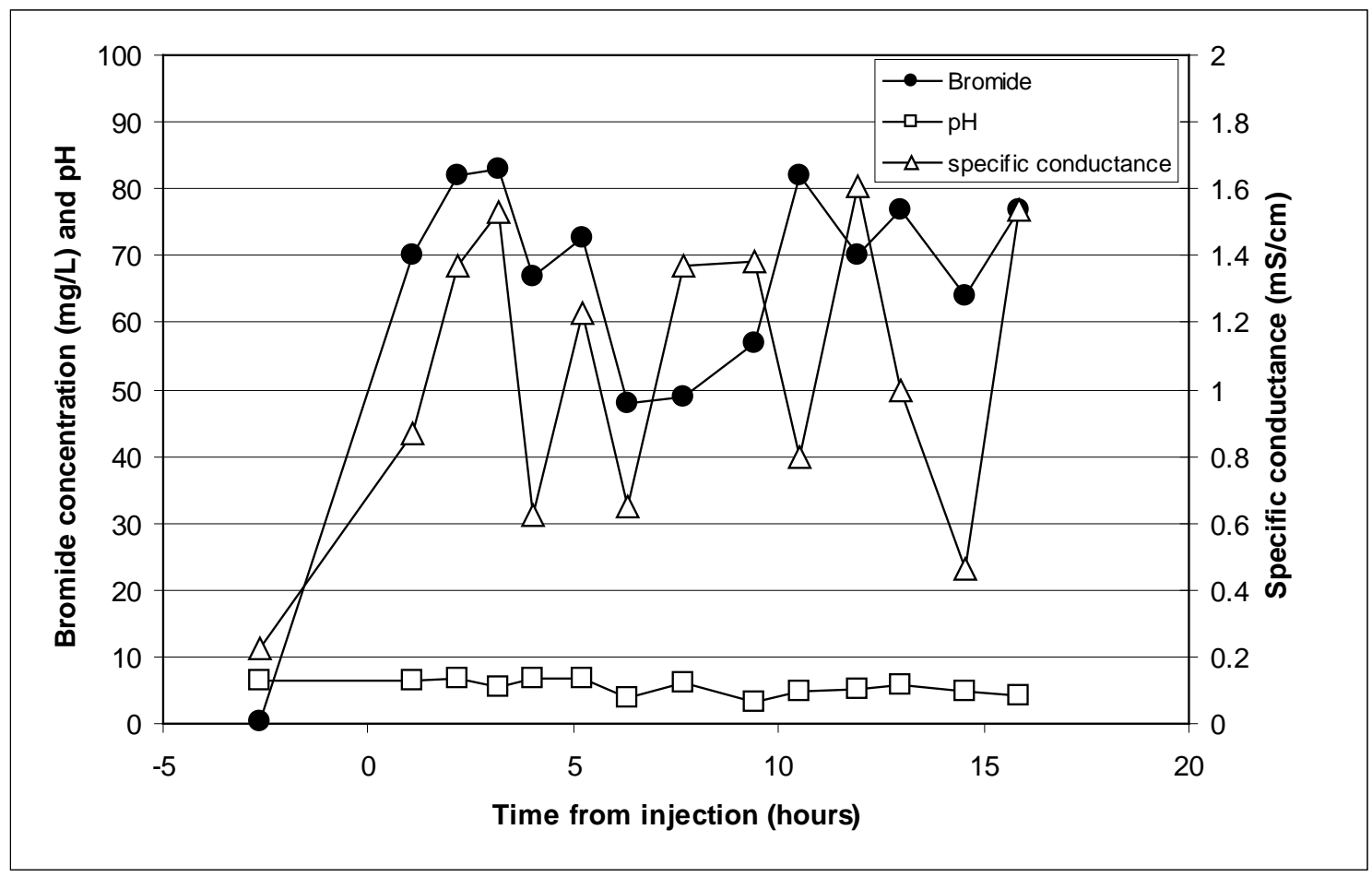

Figure 6.6. Operational Parameters Measured at Monitoring Well 199-D5-115 During Injection in 199-D5-108

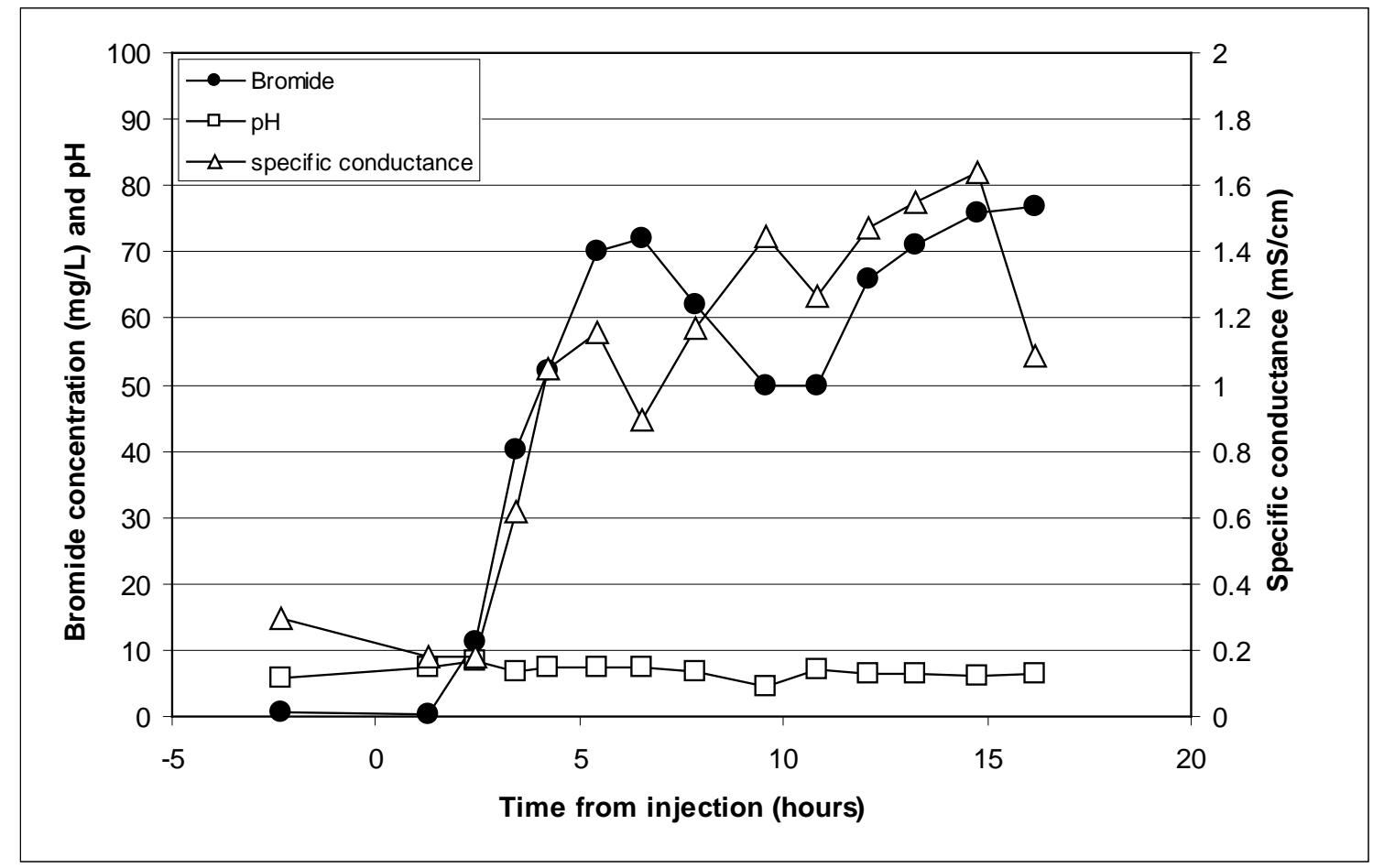

Figure 6.7. Operational Parameters Measured at Monitoring Well 199-D5-116 During Injection in 199-D5-108 


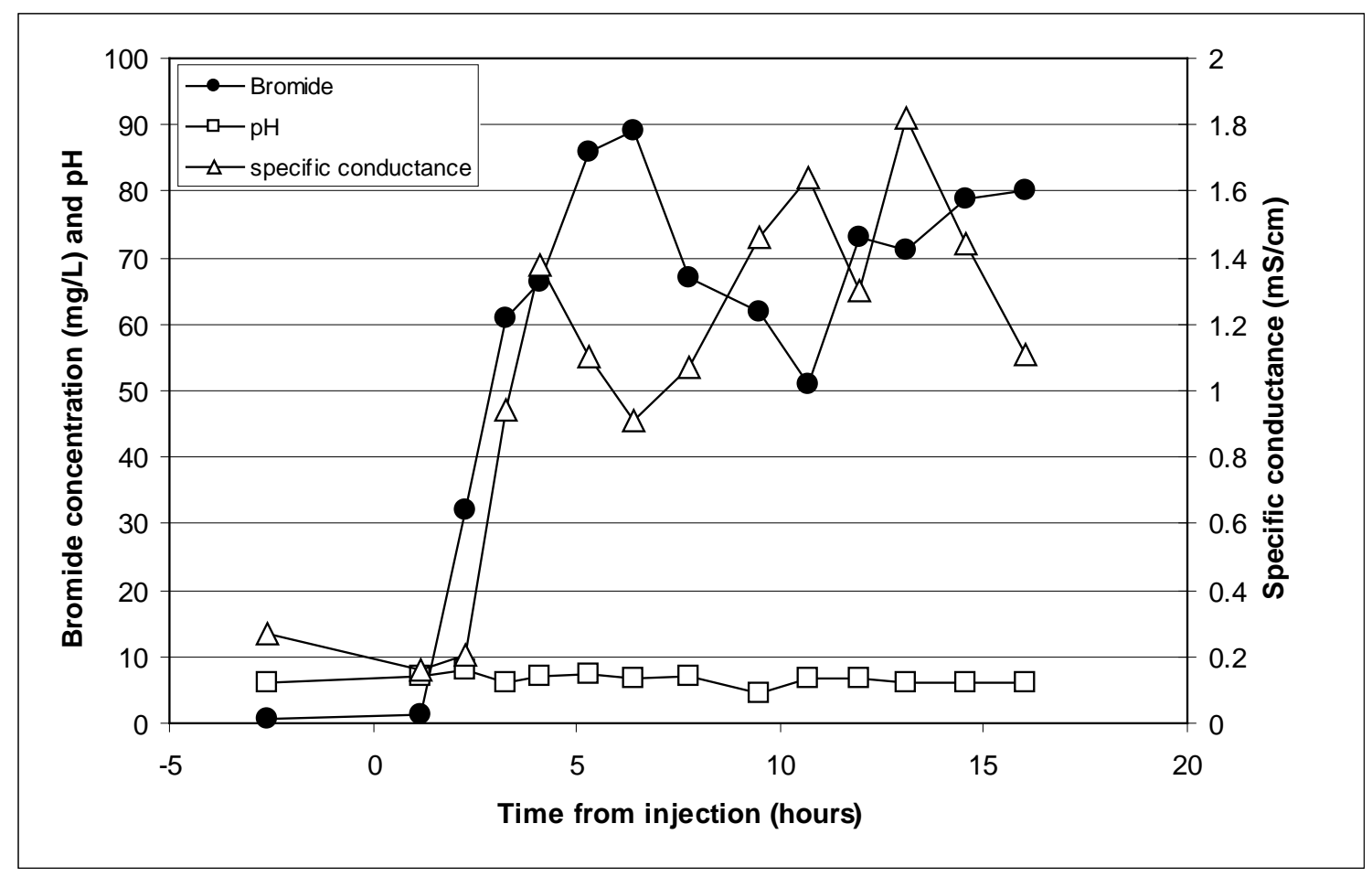

Figure 6.8. Operational Parameters Measured at Monitoring Well 199-D5-117 During Injection in 199-D5-108

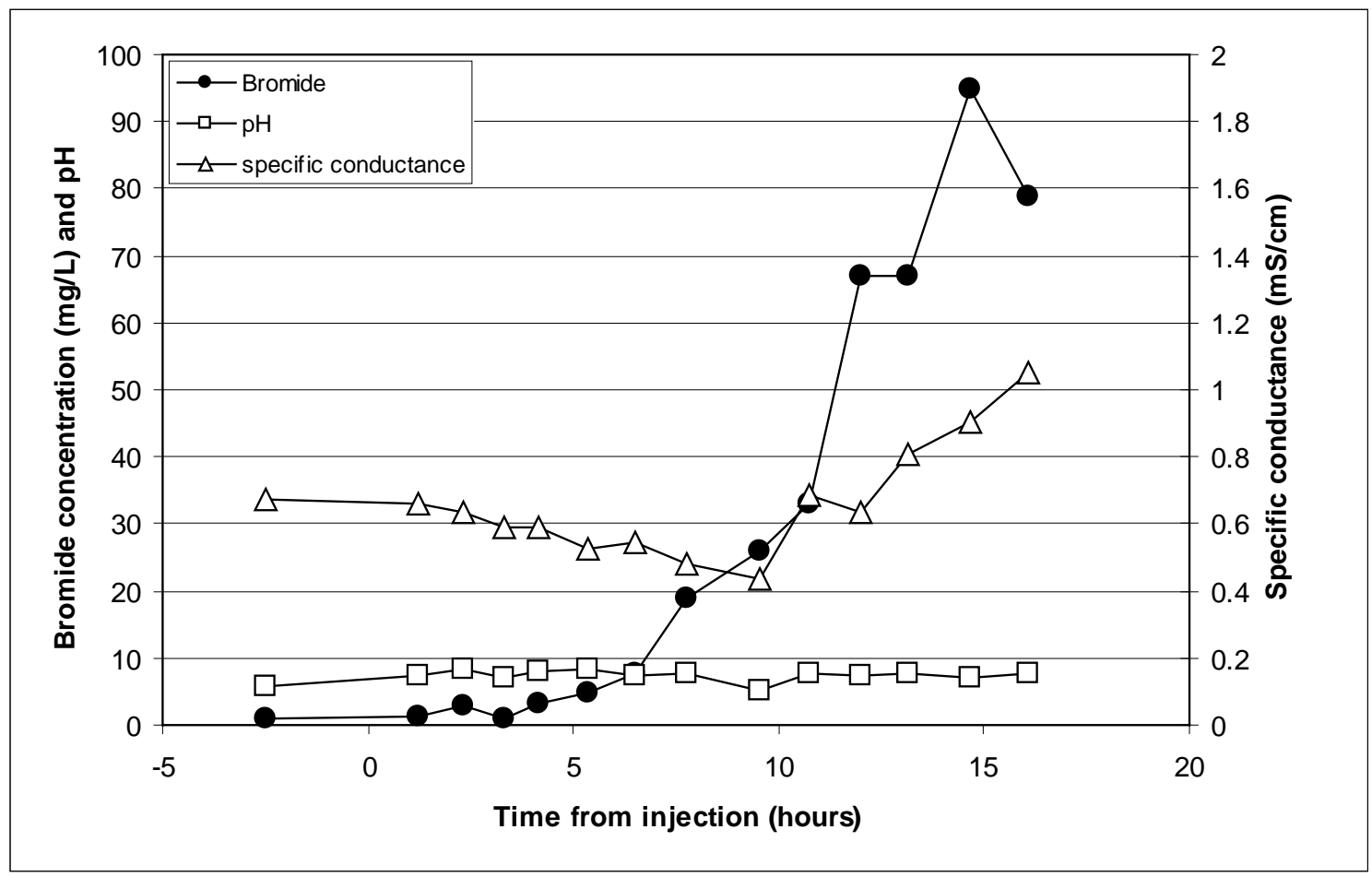

Figure 6.9. Operational Parameters Measured at Monitoring Well 199-D5-118 During Injection in 199-D5-108 
Total organic carbon concentrations measured at the end of the injection process were used to assess the uniformity of substrate distribution. Based on the injected volume and the corresponding estimated

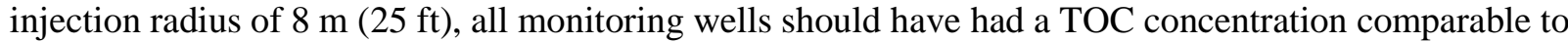
the injected concentration by the end of the injection. As shown in Table 6.1, TOC data at monitoring wells 199-D5-115, and -117 are consistent with what would be expected for the substrate injection. Total organic carbon values are lower than expected at monitoring well 199-D5-116 and significantly lower than expected at wells 199-D5-114 and 199-D5-118 (lower zone monitoring).

Table 6.1. Total Organic Carbon Concentrations at the End of the Substrate Injection Period

\begin{tabular}{lc}
\hline \multicolumn{1}{c}{ Well } & Total Organic Carbon $(\mathrm{g} / \mathrm{L})$ \\
\hline 199-D5-108 (injection well) & $14.8^{(\mathrm{a})}$ \\
199-D5-114 & 0.8 \\
199-D5-115 & 10.2 \\
199-D5-116 & 2.6 \\
199-D5-117 & 12.2 \\
199-D5-118 & 0.6 \\
\hline (a) $\quad$ Average during entire period when oil was injected. \\
\hline
\end{tabular}

In summary, the dissolved emulsified oil injection provided a large ( $~ 8 \mathrm{~m}$ radius) zone of substrate distributed around the injection well. Operations were relatively simple, although pulse injection was necessary to manage injection pressure. It is likely that injection to larger radial distances may be possible.

\subsection{Performance Monitoring Results}

Performance monitoring results with respect to the targeted treatment compounds, hydraulic properties, and overall biogeochemical conditions are presented in this section.

\subsubsection{Water Chemistry for Target Compounds}

Nitrate, dissolved oxygen, and chromate were the target compounds for treatment in the biobarrier. In summary, low concentrations of nitrate, nitrite, chromium and oxygen were maintained throughout the test duration.

\subsubsection{Nitrate/Nitrite}

Data indicate that nitrate concentration within the test cell remained below $1 \mathrm{mg} / \mathrm{L}$ over a duration of 10 months. During this time, nitrite concentrations did not increase to above $1 \mathrm{mg} / \mathrm{L}$. As demonstrated in laboratory experiments, the site microbial population is capable of full denitrification without buildup of nitrite as an intermediate compound. Details of the results over the test period are depicted in Figure 6.10 and Figure 6.11. 


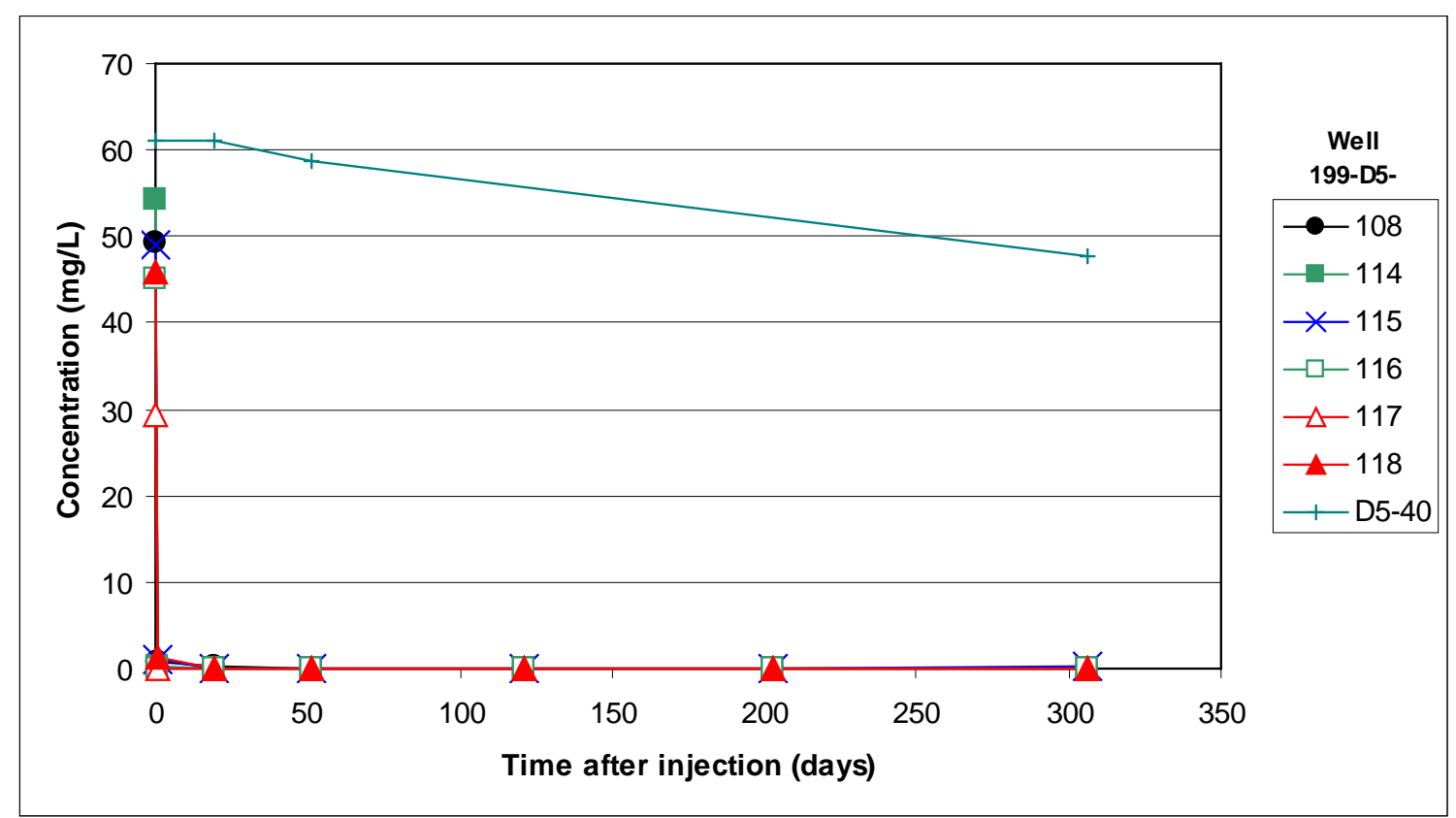

Figure 6.10. Nitrate Concentrations over the Duration of the Test

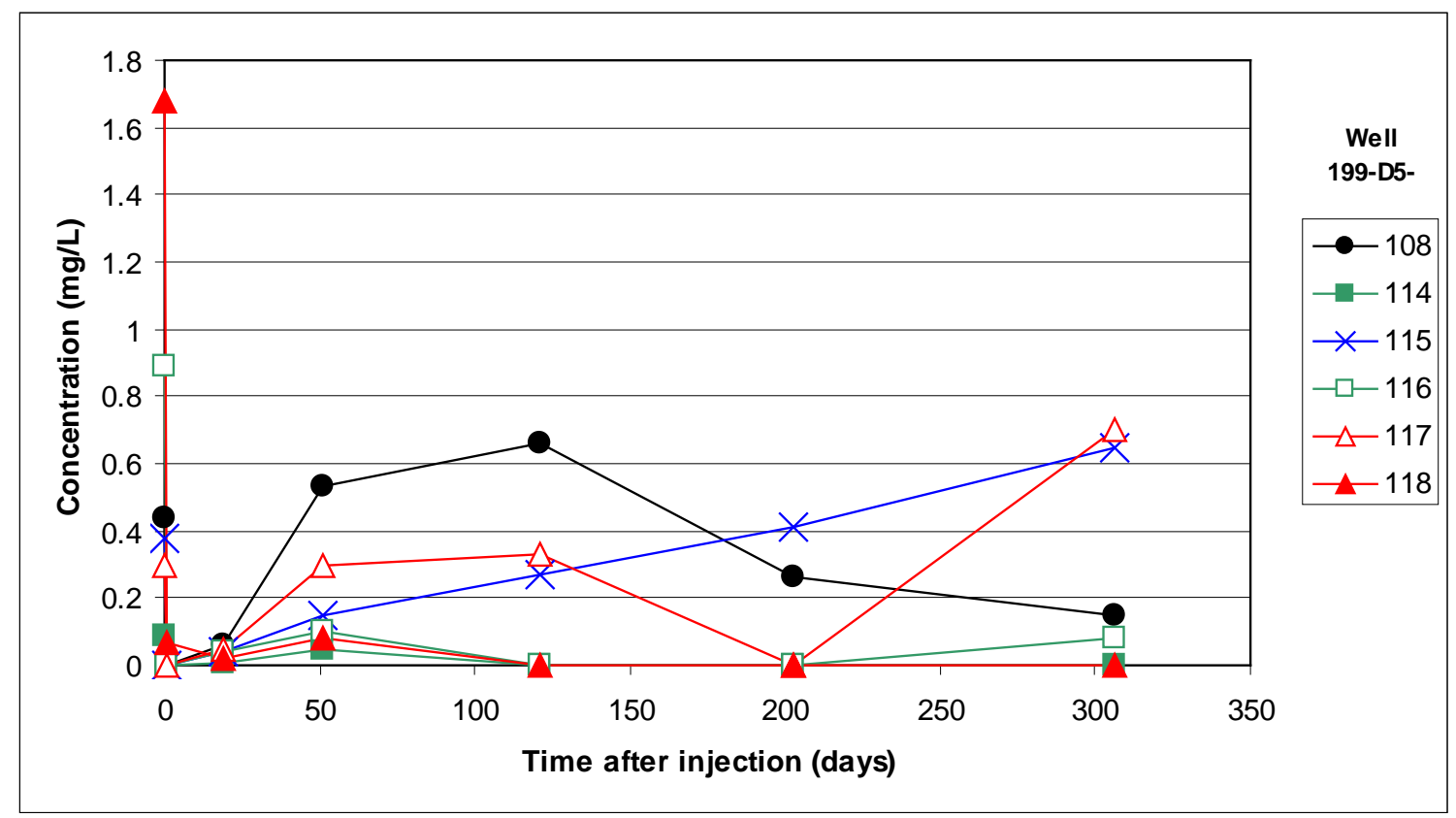

Figure 6.11. Nitrite Concentrations over the Duration of the Test

\subsubsection{Dissolved Oxygen}

Data indicate that dissolved oxygen concentration within the test cell remained below $1 \mathrm{mg} / \mathrm{L}$ over a duration of 10 months at all wells. 


\subsubsection{Chromate/Chromium}

Chromate reduction in the test cell was monitored using measurements of total chromium (from laboratory inductively coupled plasma mass spectrometry analysis) in water samples. The data indicate that total chromium concentrations in the test cell were significantly lower than background upgradient concentrations in well 199-D5-40. Details of the results over the test period are depicted in Figure 6.12.

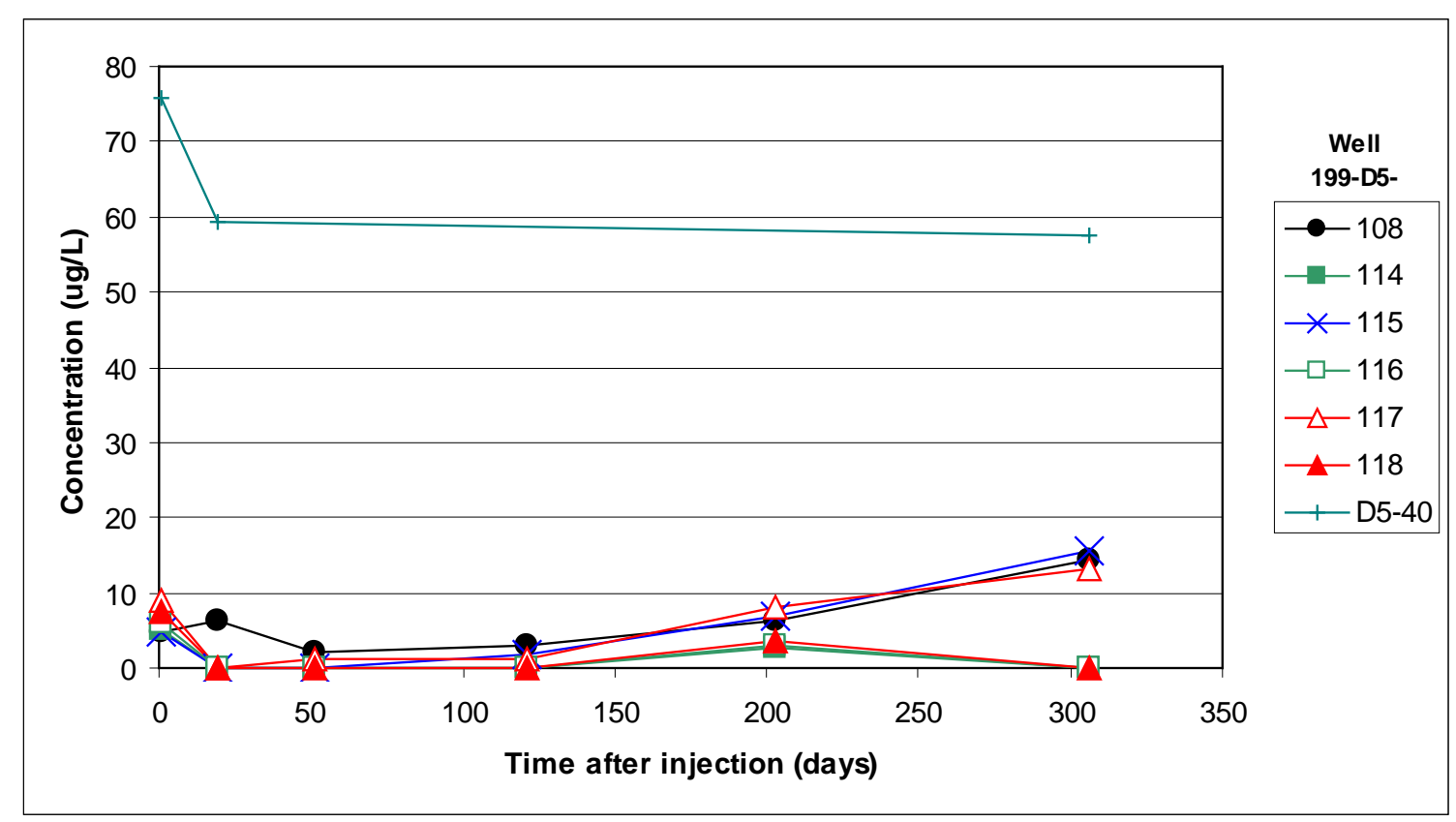

Figure 6.12. Total Chromium Concentrations over the Duration of the Test

\subsubsection{Hydraulic Conductivity}

Hydraulic conductivity was assessed through hydraulic slug testing, geophysical testing, and bromide elution.

\subsubsection{Hydraulic Slug Test Results}

Hydraulic slug testing was conducted prior to injection (August 2007) and in November 2008 approximately 90 days after substrate injection. Table 6.2 shows the results of these tests in terms of the relative hydraulic conductivity of the post-injection test compared to the pre-injection test. In contrast to the molasses injection, permeability in the immiscible substrate test cell changed quickly and appears to be due to the presence of the injected oil rather than due to significant biomass growth. Because of the slow dissolution of substrate over time, additional permeability reduction is not expected. Full details of the hydraulic slug testing are shown in Appendix F. 
Table 6.2. Permeability Change Results Based on Slug Testing

\begin{tabular}{lc}
\hline \multicolumn{1}{c}{ Well Name } & $\begin{array}{c}\text { Permeability Change } \\
\left(\mathrm{K}_{\mathrm{pos}} / \mathrm{K}_{\mathrm{pre}}\right)^{(\mathrm{a})}\end{array}$ \\
\hline 199-D5-114 & 0.57 \\
199-D5-115 & 0.32 \\
199-D5-116 & 0.36 \\
199-D5-118 & 0.70 \\
\hline
\end{tabular}

(a) Results are based on data for the pre-injection result (August 2007) and post-injection result conducted November 2008.

\subsubsection{Geophysical Testing Results}

Time-lapse electrical and radar tomograms associated with the vegetable oil test cell are shown in Figure 6.13 and Figure 6.14, respectively. Comparison of the baseline electrical image (Figure 6.13a) and the one collected 2 days post-injection (Figure 6.13b) shows that there is a 10-70\% decrease in resistivity (or increase in electrical conductivity), which is consistent with the laboratory studies. Both Figure 6.13b and Figure 6.13c illustrate the influence of heterogeneity on the amendment distribution-most of the electrical conductivity changes occurred near the water table and in the unit at $30 \mathrm{~m}$ bgs that is likely more permeable. The time-lapse images show that the amendment becomes more distributed over time: at 2 days after injection, much of the amendment is near the water table and in the presumably higherpermeability zones but is more completely distributed at 2 months post-injection.

The baseline and time-lapse radar tomograms (Figure 6.14b) reveal behavior similar to that observed with the electrical data. Consistent with laboratory experiments, the post-injection images reveal $10 \%$ decreases in dielectric constant. They also show that the amendment appears to be distributed most near the water table and within the unit located at $\sim 30 \mathrm{~m}$ bgs. The seismic data (not shown) were not as useful. On the baseline data, some of the amplitudes near the water table were attenuated (likely due to trapped gas associated with a fluctuating water table), and the amplitudes on the data sets collected post-injection were also attenuated, likely due to evolved gasses (such as $\mathrm{N}_{2}$ and $\mathrm{CO}_{2}$ ). The geophysical imaging reveals that the radius of influence of the substrate injection extended at least $6 \mathrm{~m}$ from the injection well. 


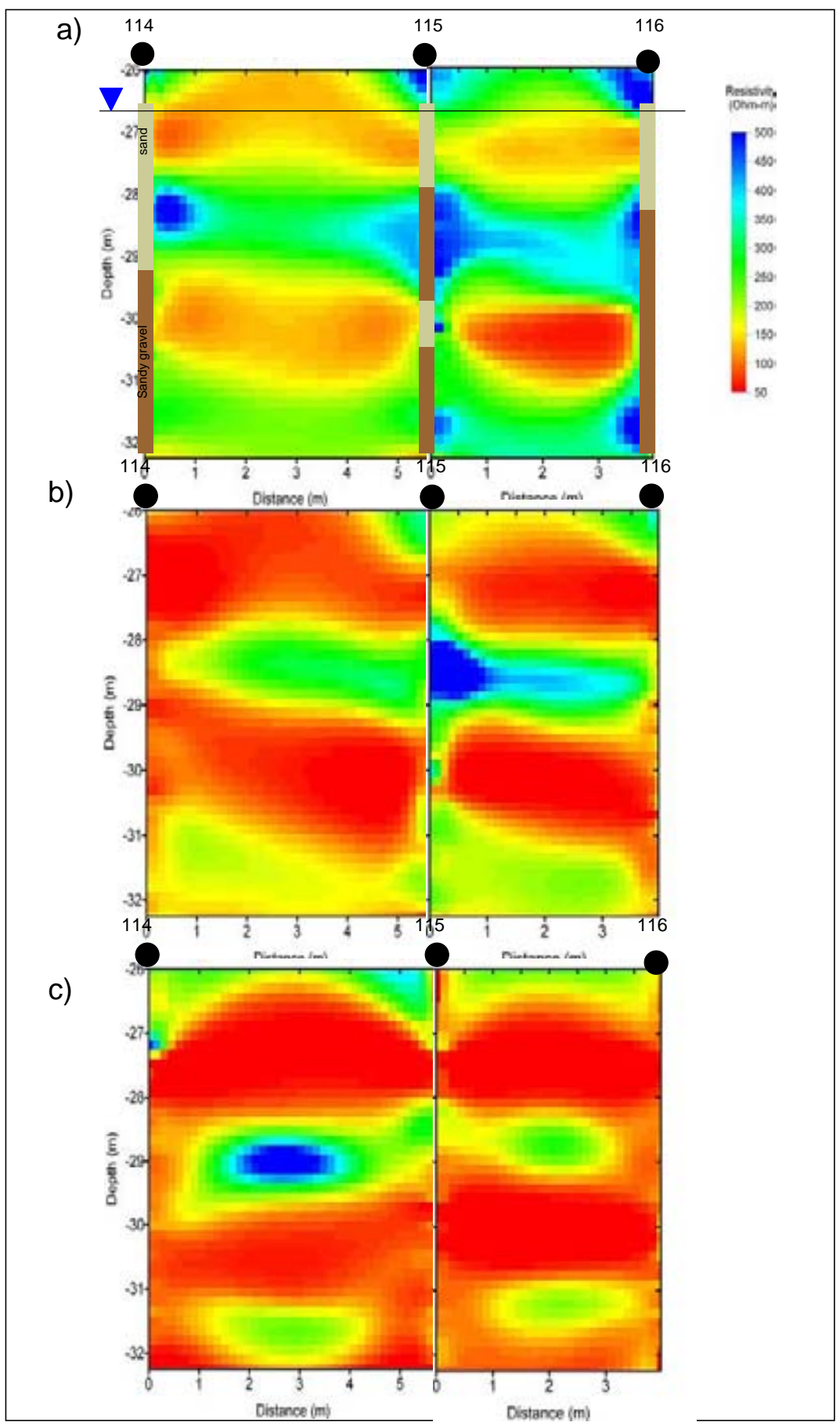

Figure 6.13. Electrical Resistivity Tomagraphy Inversions Showing Electrical Conductivity Along Two Transects (wells 114-115 and 115-116). (a) Prior to injection (August 19, 2008); (b) 2 days post-injection (August 22, 2008); (c) 3 months post-injection (November 18, 2008). 


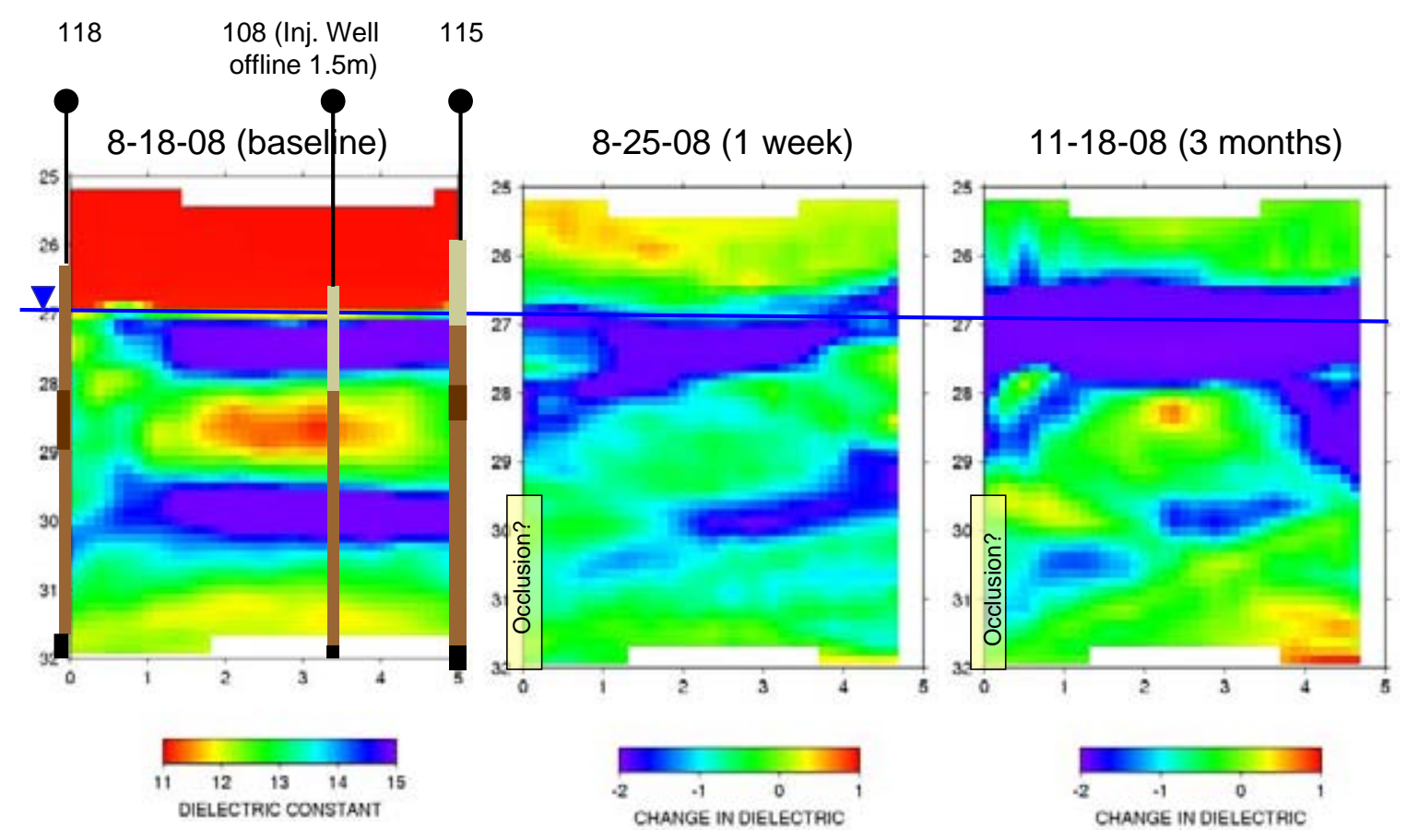

Figure 6.14. Baseline Radar Tomogram (left) and Difference Tomograms (middle and right) Indicating Change in Dielectric Constant Post-Injection Along Transect 118-115

\subsubsection{Bromide Elution}

Bromide concentrations at the test cell monitoring wells show only slow elution where only 2 wells have eluted bromide to concentrations at or below $50 \%$ of the initial concentration through 306 days of monitoring. The two wells showing the greatest elution are the downgradient well, 199-D5-114, with 50\% concentration by day 121 and the upgradient well, 199-D5-116, with 50\% elution by day 306 . Using the hydraulic conductivity reduction measured in the post-injection hydraulic slug test analysis and the average hydraulic gradient over the test duration, the average groundwater movement through the test cell would be about $19.5 \mathrm{~m}$ in 306 days. The average groundwater movement suggests that one pore volume would have moved through the test cell over the 306 day monitoring period whereas the bromide elution data suggest less movement.

\subsubsection{Performance Assessment}

The immiscible substrate biobarrier maintained low nitrate, nitrite, dissolved oxygen and chromium concentrations over the duration of the monitoring period (10 months). During this time, conditions within the test cell changed in response to the addition of the substrate and associated biogeochemical reactions that were induced. Figures 6.15 through 6.20 show the trends in primary biogeochemical parameters, including total organic carbon, acetate, $\mathrm{pH}$, and sulfate. Although all of these changes indicate that appropriate reactions are occurring. The monitoring period is short compared to 1) the time required for groundwater to travel through the test cell and 2) the expected duration of the oil substrate. Both the hydraulic conductivity assessment and bromide elution data suggest that groundwater flow through the test cell is slow. Thus, continued monitoring would be needed to evaluate the capacity and longevity of the induced biobarrier. 


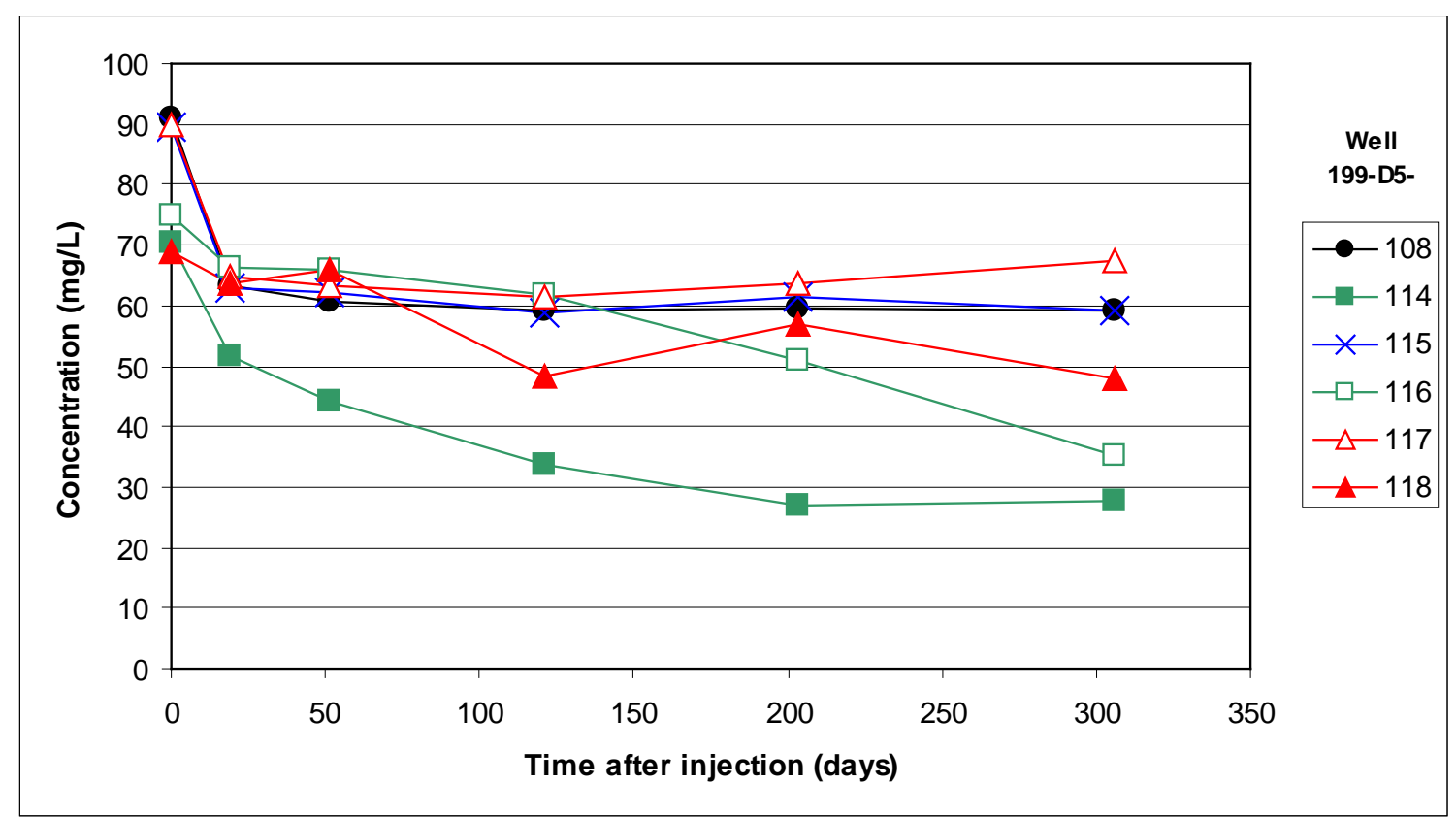

Figure 6.15. Bromide Concentrations over the Duration of the Test

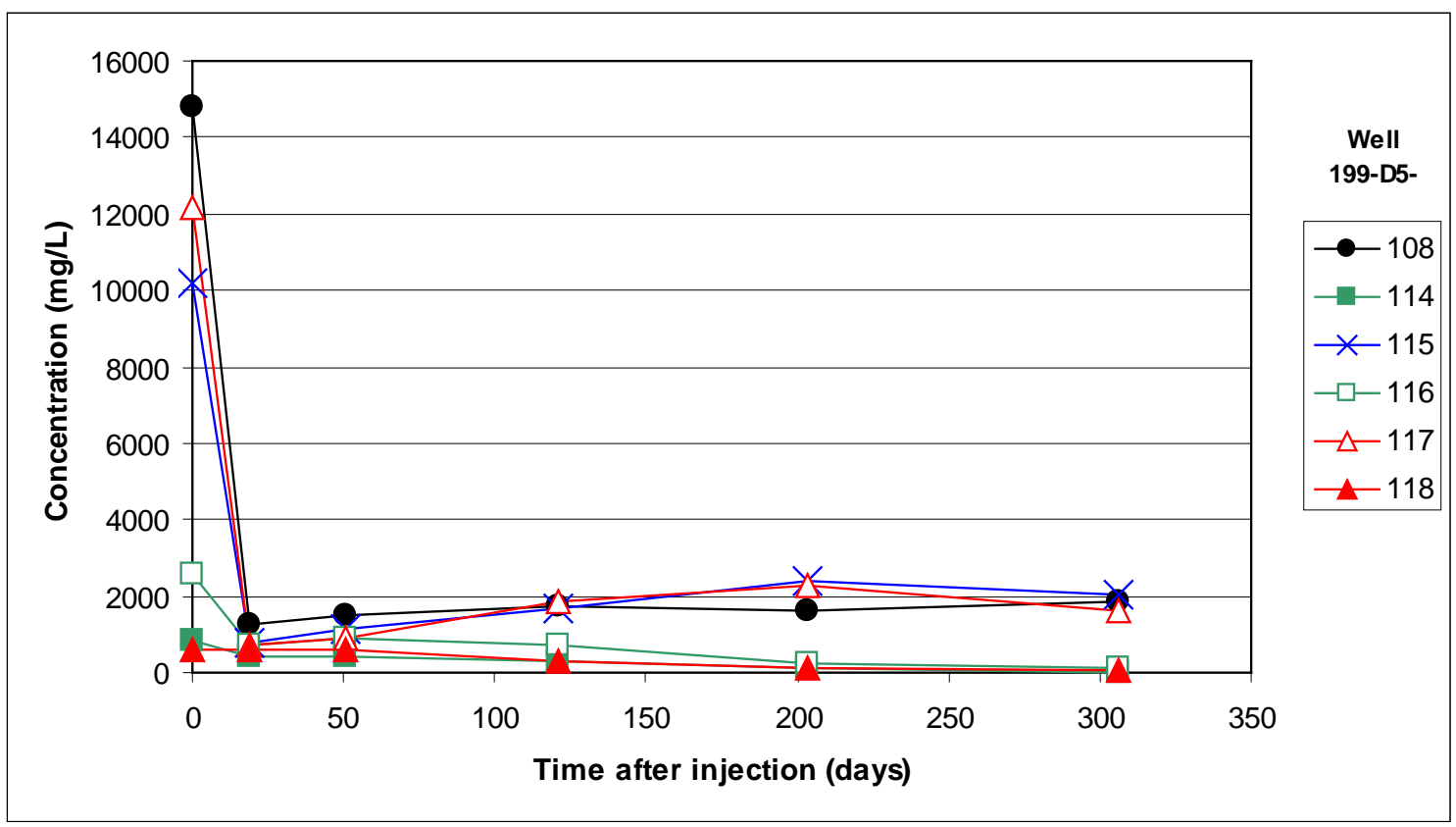

Figure 6.16. TOC Concentrations over the Duration of the Test 


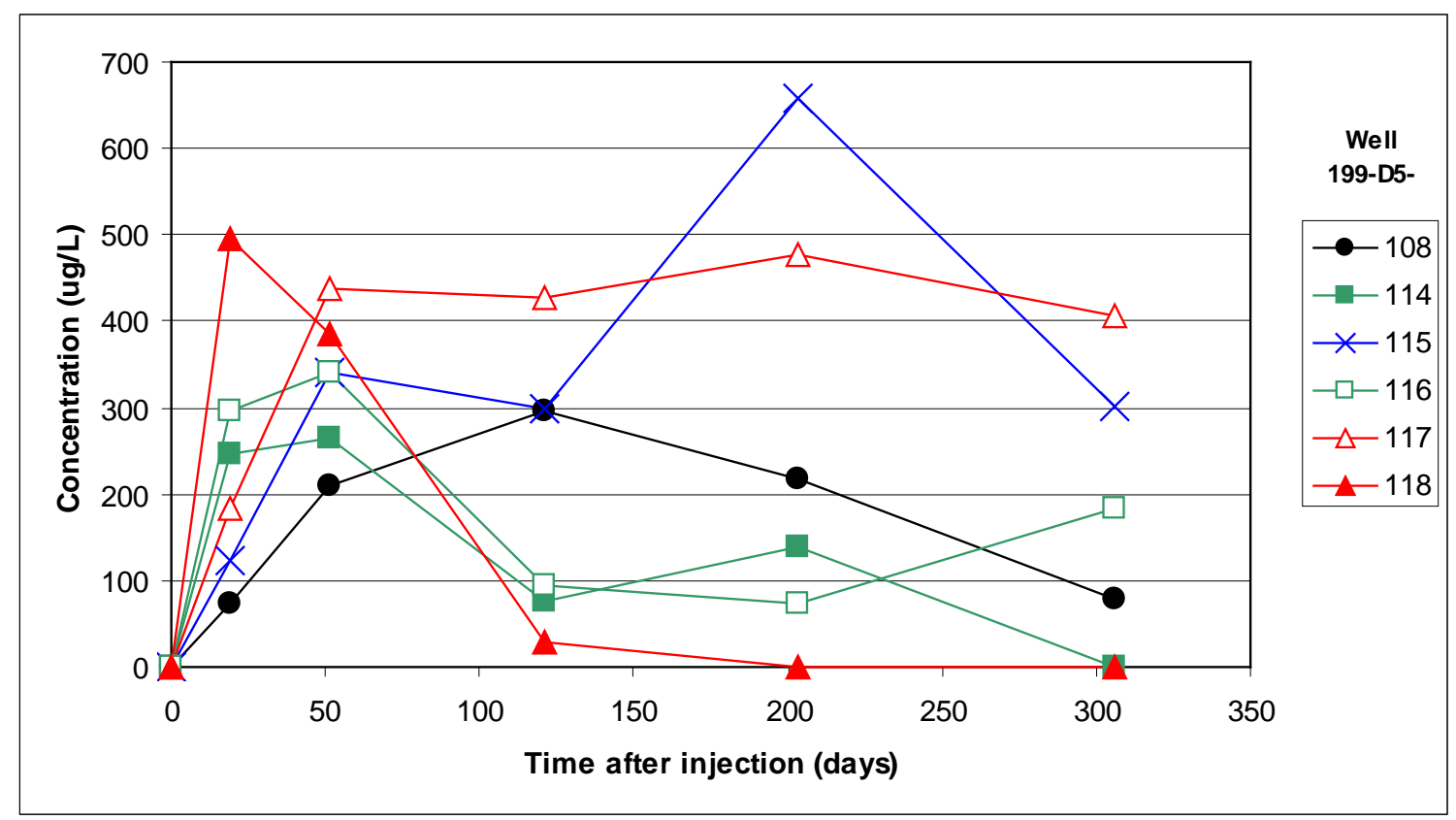

Figure 6.17. Acetate Concentrations over the Duration of the Test

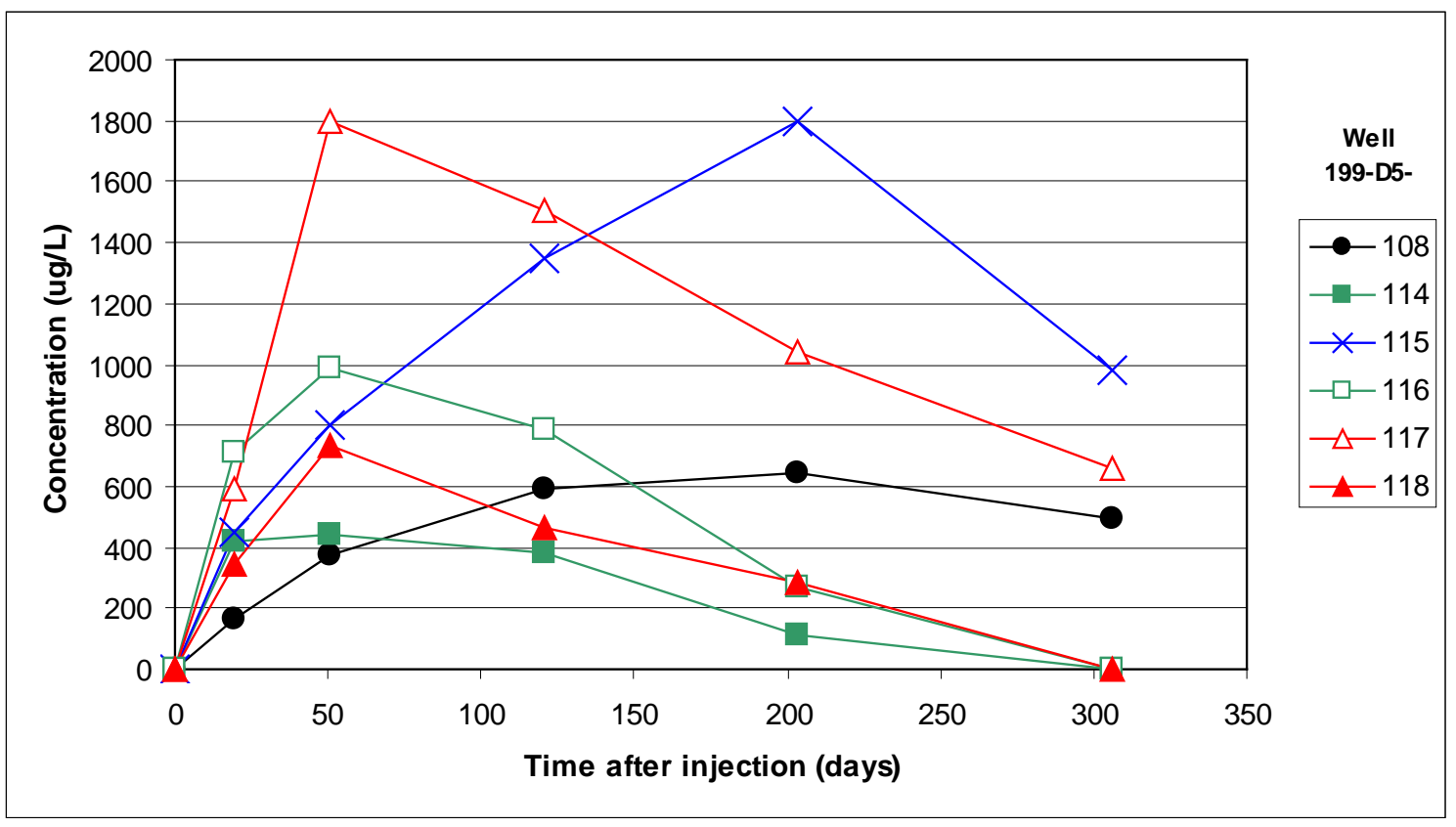

Figure 6.18. Propionate Concentrations over the Duration of the Test 


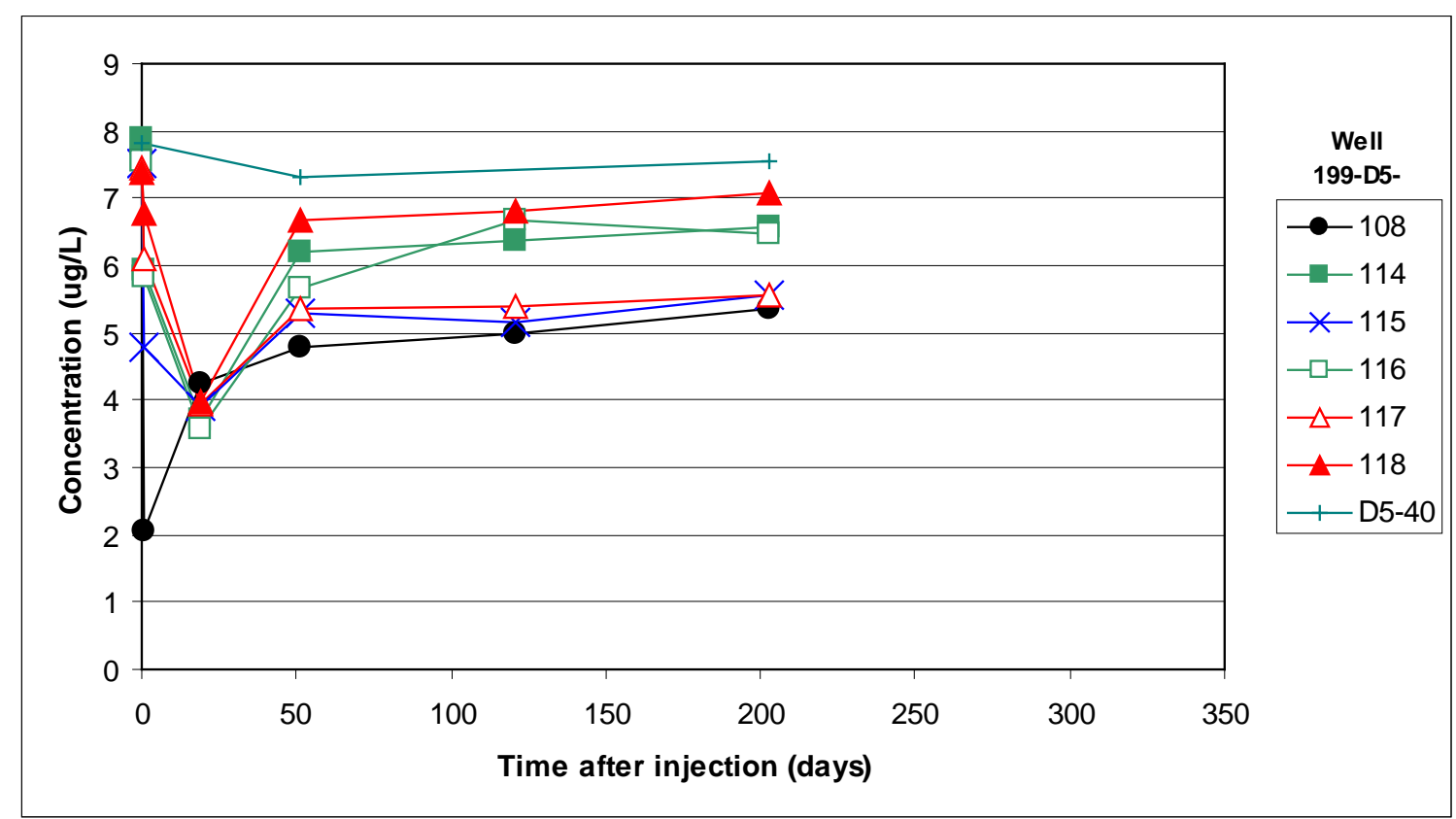

Figure 6.19. $\mathrm{pH}$ over the Duration of the Test. Data are not available for the last sampling time (day 306). Data for day 203 for well 199-D5-40 are also not available. The plotted point at day 203 is the average $\mathrm{pH}$ over the duration of the test at well 199-D5-40.

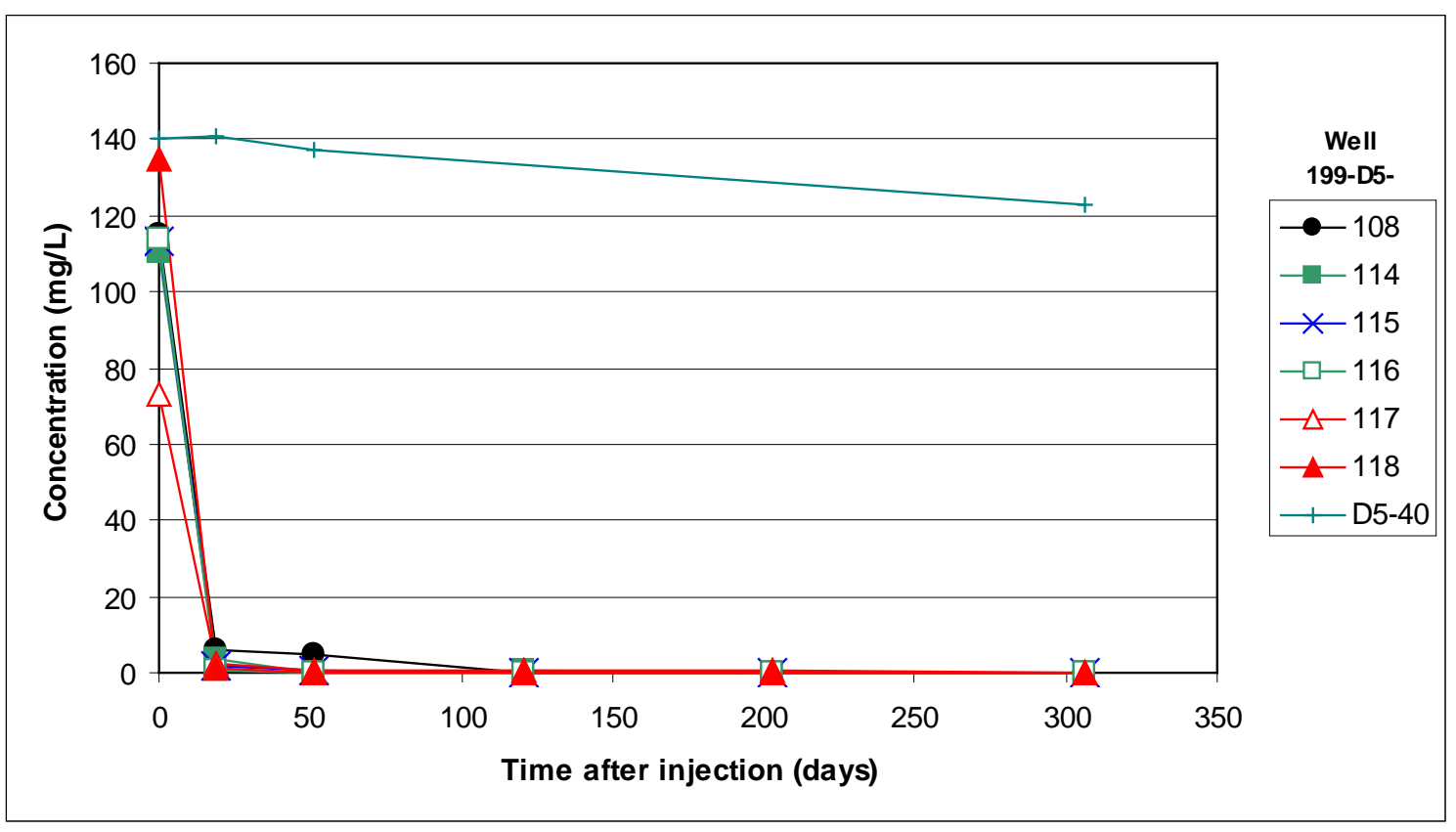

Figure 6.20. Sulfate Concentrations over the Duration of the Test 
Several early trends in the data are noteworthy. The total organic carbon declined rapidly as oil droplets became attached to sediment surfaces. However, the total organic carbon concentrations are then maintained in wells 199-D5-108, -115 , and -117 at nearly $2 \mathrm{~g} / \mathrm{L}$. The total organic carbon concentrations appear to correspond to the summation of propionate and acetate concentrations. These two organic acids are typical fermentation products of lactate. The emulsified oil solution contained $4 \%$ lactic acid. The initial $\mathrm{pH}$ decline was expected due to the acidic nature of the injected solution (i.e., lactic acid). The $\mathrm{pH}$ of the groundwater is beginning to recover, but is slowly evolving, potentially due to the slow groundwater flow conditions.

As with the soluble substrate test cell, the apparent performance in terms of nitrate, dissolved oxygen, and chromate reduction is affected by the rate at which constituents are carried into the test cell. Because the hydraulic conductivity decreased within the test cell, the flow rate through the test cell is slow and the biogeochemical data will therefore evolve slowly. The reduction in hydraulic conductivity occurred rapidly, indicative of a physical effect rather than a biological effect. Full scale application of a biobarrier should consider changes to the flow field and associated solute flux through the biobarrier. The decreased flow rate suggests that continued monitoring would be needed to fully determine the capacity and longevity of the induced biobarrier.

\subsubsection{Water Quality}

Within the test cell, water quality was negatively impact by an increase in the concentration of metals and organic constituents and a decrease in oxidation-reduction potential and dissolved oxygen concentration. These changes were expected due to the imposed anaerobic conditions required for biological treatment of dissolved oxygen, nitrate, and chromate. Although the concentration of most metals increased, only three, arsenic, barium, and selenium, increased to concentrations consistently above the maximum contamination level. The concentration profiles for these metals are shown in Figures 6.21 through 6.23. A biobarrier design requires a downgradient portion of the aquifer where these water quality impacts can recover and this type of recovery region would need to be considered as part of determining the location for biobarrier application. 


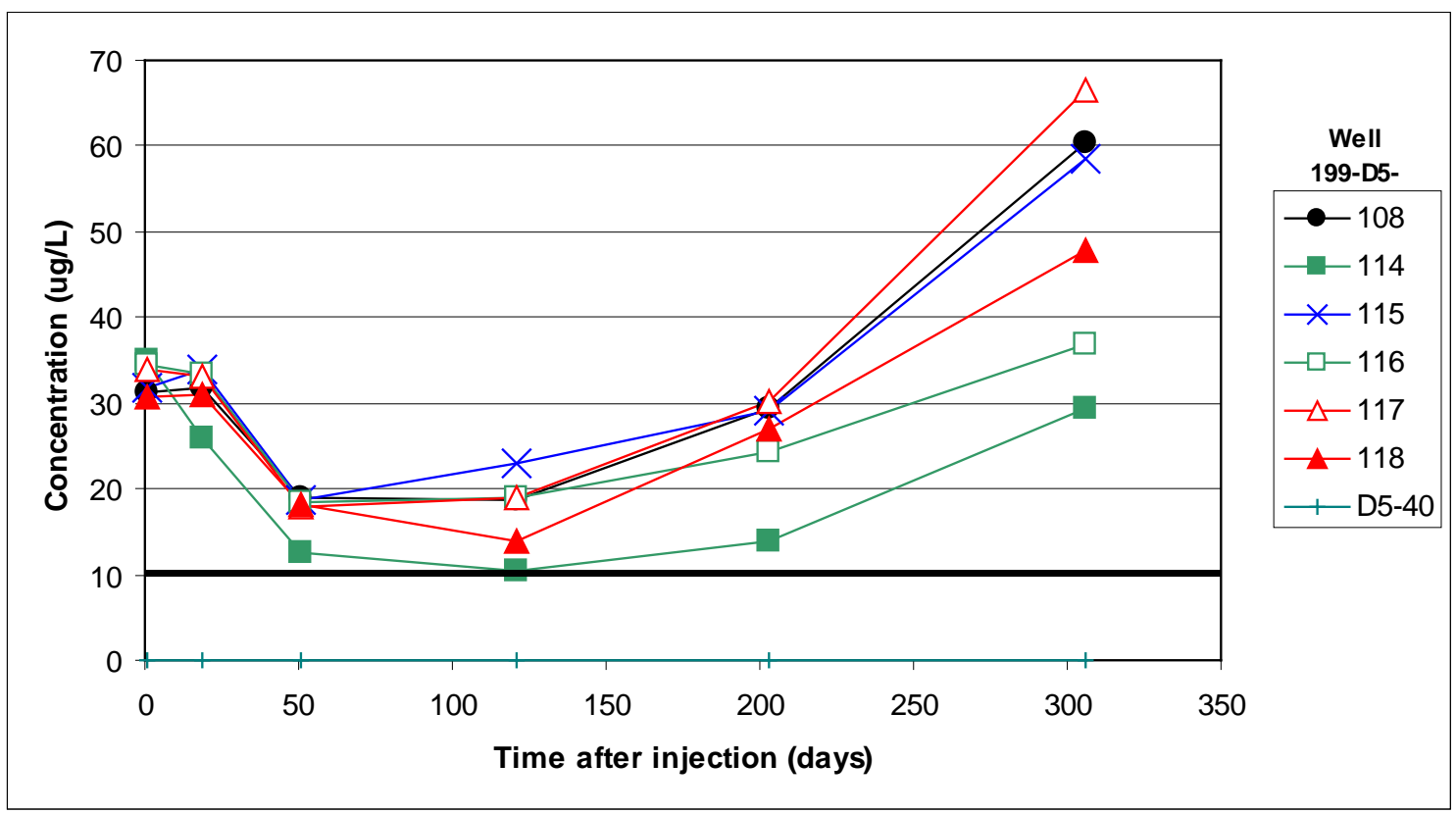

Figure 6.21. Arsenic Concentrations During the Test. The drinking water Maximum Contaminant Level (MCL) for arsenic is $10 \mu \mathrm{g} / \mathrm{L}$.

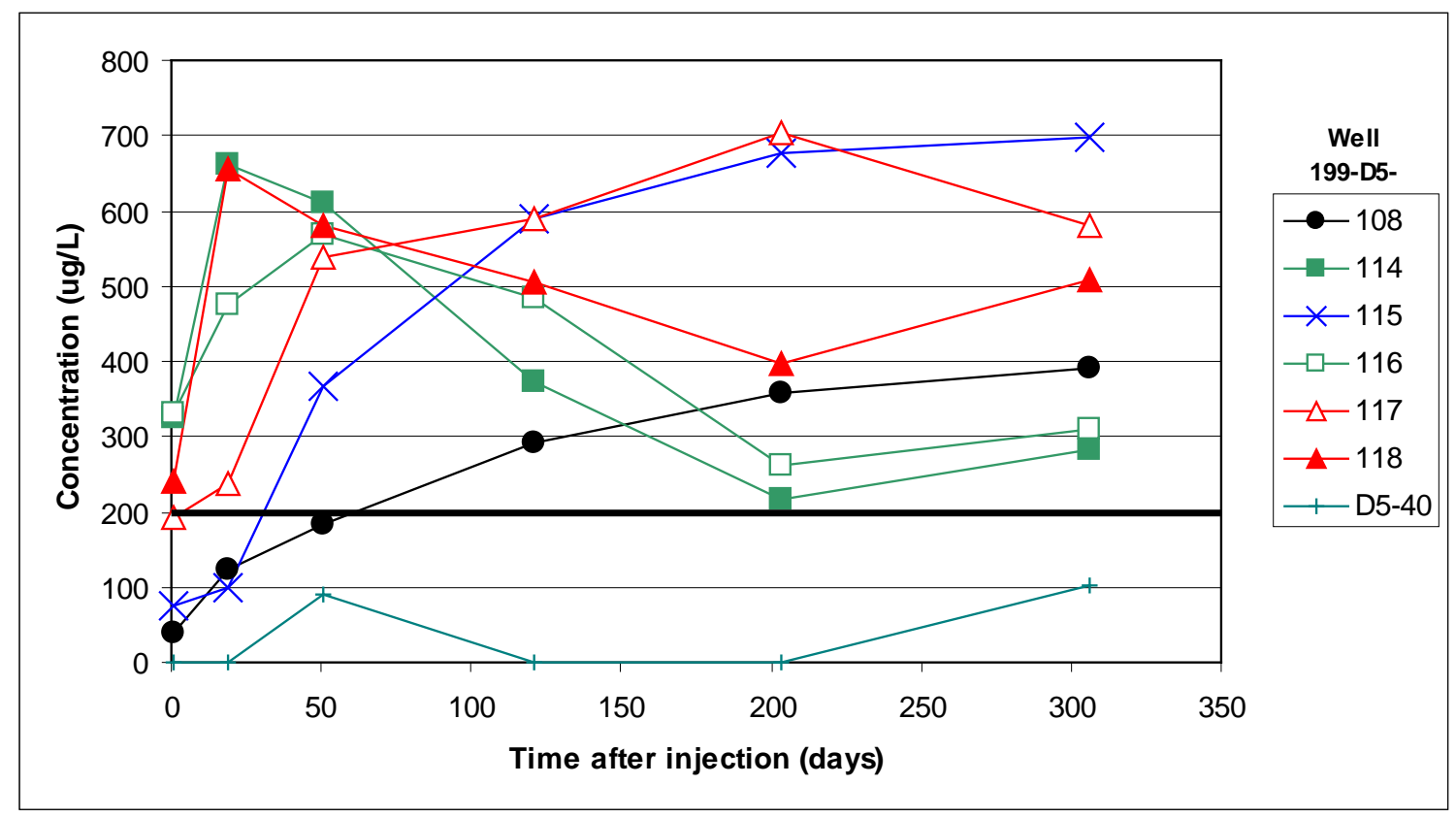

Figure 6.22. Barium Concentrations During the Test. The drinking water Maximum Contaminant Level (MCL) for barium is $200 \mu \mathrm{g} / \mathrm{L}$. 


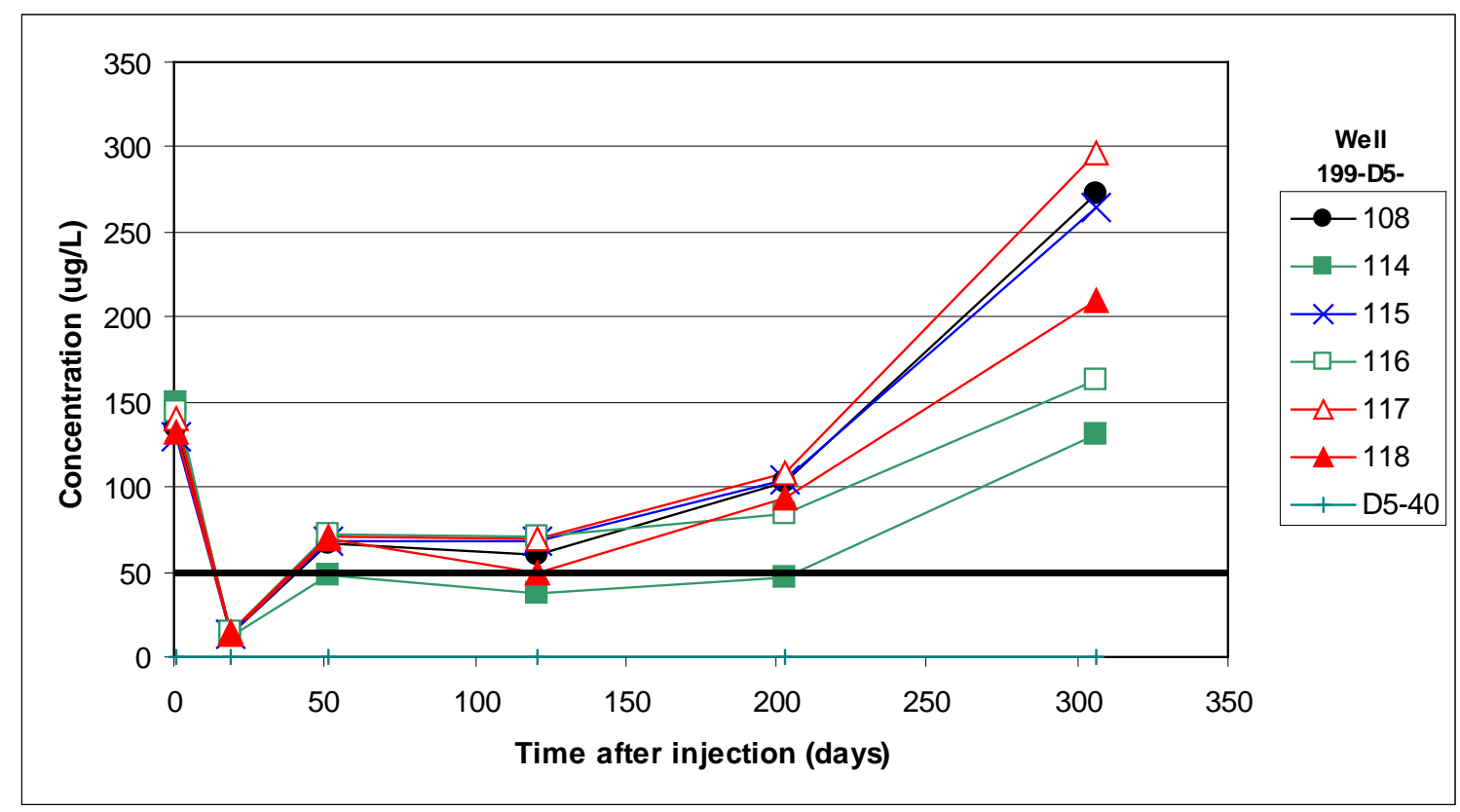

Figure 6.23. Selenium Concentrations During the Test. The drinking water Maximum Contaminant Level (MCL) for selenium is $50 \mu \mathrm{g} / \mathrm{L}$.

\subsection{Summary of Laboratory Emulsion Experiments}

Laboratory experiments were conducted to evaluate the distribution and retention of emulsified oil as a function of sediment properties relevant to the Hanford field test. Emulsified oil offers potential advantages for biobarrier application due to its potential for creating a long-lasting barrier. However, because emulsified oil is a nonaqueous phase substance delivered as small droplets, distribution of emulsified oil within the subsurface is controlled by parameters different from those for distribution of a soluble substrate. In addition, a sufficient quantify of the oil must be delivered and retained within the targeted biobarrier to promote long barrier life and adequate contaminant treatment. Results of the laboratory testing and their relationship to the Hanford field test are presented in the following subsections.

\subsubsection{Methods}

A series of experiments was conducted with three different laboratory-grade Accusands (Table 6.3). Detailed properties of these porous media can be found in Schroth et al. (1996). The 70, 40/50, and 20/30-mesh sands are classified as a fine-, medium-, and coarse-grained sand, respectively. The 1-m-long rectangular columns, with a cross-sectional area of $30 \mathrm{~cm}^{2}$, were packed under saturated conditions to obtain average porosities listed in Table 6.4. Simulations were conducted to help interpret the experimental results using the STOMP code. Details of the simulations are described by Oostrom. ${ }^{1}$

The oil-emulsion used in the experiments had properties similar to those of the emulsion used by Borden (2007). The emulsion (EOS 598, www.EOSRemediation.com) contains 59.8\% by weight emulsified soybean oil, food-grade surfactants (10.1\%), and lactate (4\%). The emulsion was prepared using high-energy mixing with nonionic surfactants to obtain an emulsion with a relatively mean uniform 
droplet size of $1.9 \mu \mathrm{m}$ (standard deviation $=0.8 \mu \mathrm{m}$ ). The statistics of the droplets were determined microscopically using a standard particle analysis technique. For the experiments, the EOS 598 was diluted by a factor 5 , to obtain an injection oil concentration of $0.12 \mathrm{~g} / \mathrm{cm}^{3}$. This concentration was used by Borden (2007) and Coulibaly (2006) in their column experiments. For each sand, three experiments were conducted with injections of $1,0.1$, and 0.05 pore volumes (PVs) of the emulsion, followed a flush of 4 PVs of tapwater. Pore volume values are listed in Table 6.4. The injection rate for all experiments was $10 \mathrm{~cm}^{3} / \mathrm{min}$. Effluent samples were collected every $30 \mathrm{~min}$. After the experiment was completed, the column was immediately divided into 10 -cm-long sections. Three approximately 50 -g samples were obtained from each section, and the oil concentration was determined using high-temperature ignition.

The maximum oil retention, $C_{i m}^{\max }$, for each sand was determined independently by flushing a 30-cmlong, 2.54-cm-internal diameter column with emulsion for 10 PVs, followed by a 10-PV tapwater flush. After the flushes, all the sand in the column was collected, and five approximately 50-g samples were obtained. The samples were first dried, followed by ignition at $550^{\circ} \mathrm{C}$. The gravimetric oil concentrations resulting from this procedure were assumed to be representative of the maximum oil retention and are listed in Table 6.4. The equivalent collector diameter, $d_{c}$, was assumed to be equal to the $d_{10}$ value and was extracted from Schroth et al. (1996). The only parameter not independently obtained was the empty bed collision efficiency, $\alpha$. The value in Table 6.4 was taken from Borden (2007), as it represents an efficiency for similar soybean emulsion in a sandy porous medium.

Table 6.3. Emulsion Column Experiments Overview

\begin{tabular}{ccc}
\hline Experiment & Sand Type (mesh) & $\begin{array}{c}\text { Emulsion Injection } \\
\text { Duration }\end{array}$ \\
\hline A1 & 70 & $1 \mathrm{PV}$ \\
A2 & 70 & $0.1 \mathrm{PV}$ \\
A3 & 70 & $0.05 \mathrm{PV}$ \\
B1 & $40 / 50$ & $1 \mathrm{PV}$ \\
B2 & $40 / 50$ & $0.1 \mathrm{PV}$ \\
B3 & $40 / 50$ & $0.05 \mathrm{PV}$ \\
C1 & $20 / 30$ & $1 \mathrm{PV}$ \\
C2 & $20 / 30$ & $0.1 \mathrm{PV}$ \\
C3 & $20 / 30$ & $0.05 \mathrm{PV}$ \\
\hline
\end{tabular}

Table 6.4. Overview of Parameter Values for the Three Laboratory Sands

\begin{tabular}{lccc}
\hline \multicolumn{1}{c}{ Parameter } & 70 -mesh & $40 / 50$ mesh & 20/30 mesh \\
\hline Porosity & 0.42 & 0.33 & 0.35 \\
Dry bulk density $\left(\mathrm{g} / \mathrm{cm}^{3}\right)$ & 1.54 & 1.78 & 1.72 \\
Pore volume $\left(\mathrm{cm}^{3}\right)$ & 1260 & 990 & 1050 \\
Equivalent collector diameter, $d_{c}(\mathrm{~m})$ & $2.0 \times 10^{-4}$ & $3.1 \times 10^{-4}$ & $6.2 \times 10^{-4}$ \\
Empty bed collision efficiency, $\alpha$ & $2.5 \times 10^{-5}$ & $2.5 \times 10^{-5}$ & $2.5 \times 10^{-5}$ \\
Emulsion mean droplet size, $d_{n}(\mathrm{~m})$ & $1.9 \times 10^{-6}$ & $1.9 \times 10^{-6}$ & $1.9 \times 10^{-6}$ \\
$C_{\text {Maximum oil retention, }}^{\max }(\mathrm{g} / \mathrm{g})$ & 0.0038 & 0.0022 & 0.0010 \\
Emulsion injection concentration $\left(\mathrm{g} / \mathrm{cm}^{3}\right)$ & & & 0.12 \\
Oil density $\left(\mathrm{g} / \mathrm{cm}^{3}\right)$ & 0.95 & 0.95 & 0.12 \\
\hline
\end{tabular}




\subsubsection{Results}

Experimental and simulated results for experiments A1, A2, and A3 in the fine-grained 70-mesh sand are shown in Figures 6.24, 6.25, and 6.26, respectively. For the 1-PV injection (Figure 6.24), emulsion breakthrough concentrations are close to the injection concentration of $0.12 \mathrm{~g} / \mathrm{cm}^{3}$. The sediment concentrations throughout the column are predicted to be at the maximum level. For the listed dry bulk density, the total emulsion mass remaining in the column after flushing amounts to $17.1 \mathrm{~g}$. Because the 1-PV of oil emulsion used for the injection contained $148.8 \mathrm{~g}$ oil, this result is according to expectation. The experimental data follow the trends of the predictions. The observed scatter is consistent with the relatively large errors associated with the ignition method and the relatively low oil concentrations

A reduction of the injected oil volume for experiments A2 and A3 resulted in much smaller emulsion concentration effluent peaks. For these experiments with 0.1- and 0.05-PV injections, almost all the injected oil mass is predicted to remain in the sediment. Again, the experimental data follow the trends predicted by the simulator. For experiment A3, the effluent concentrations were too small for meaningful experimental observation. The sediment concentrations shown in Figure 6.25 indicate that for the 0.05-PV injection, the emulsion volume was barely sufficient to transport out to the top of the column.

Experimental and simulated results for experiments B1, B2, and B3 in the medium-grained 40/50mesh sand are shown in Figures 6.27, 6.28, and 6.29, respectively. The maximum oil retention for this sand is almost a factor of two smaller than for the 70-mesh sand. As a result, compared to the experiments for the 70-mesh sand, more oil was flushed through the columns. The experimental sediment emulsion and breakthrough concentrations are again consistent with the simulated results.

Experimental and simulated results for experiments C1, C2, and C3 in the coarse-grained 20/30-mesh sand are shown in Figures 6.30, 6.31, and 6.32, respectively. For this coarse sand, the maximum oil retention is only about $25 \%$ of the 70 -sand retention. As a result, even for the 0.05 -PV injection, the added emulsion mass is sufficient to maximize the retained oil concentration in the sediment. 


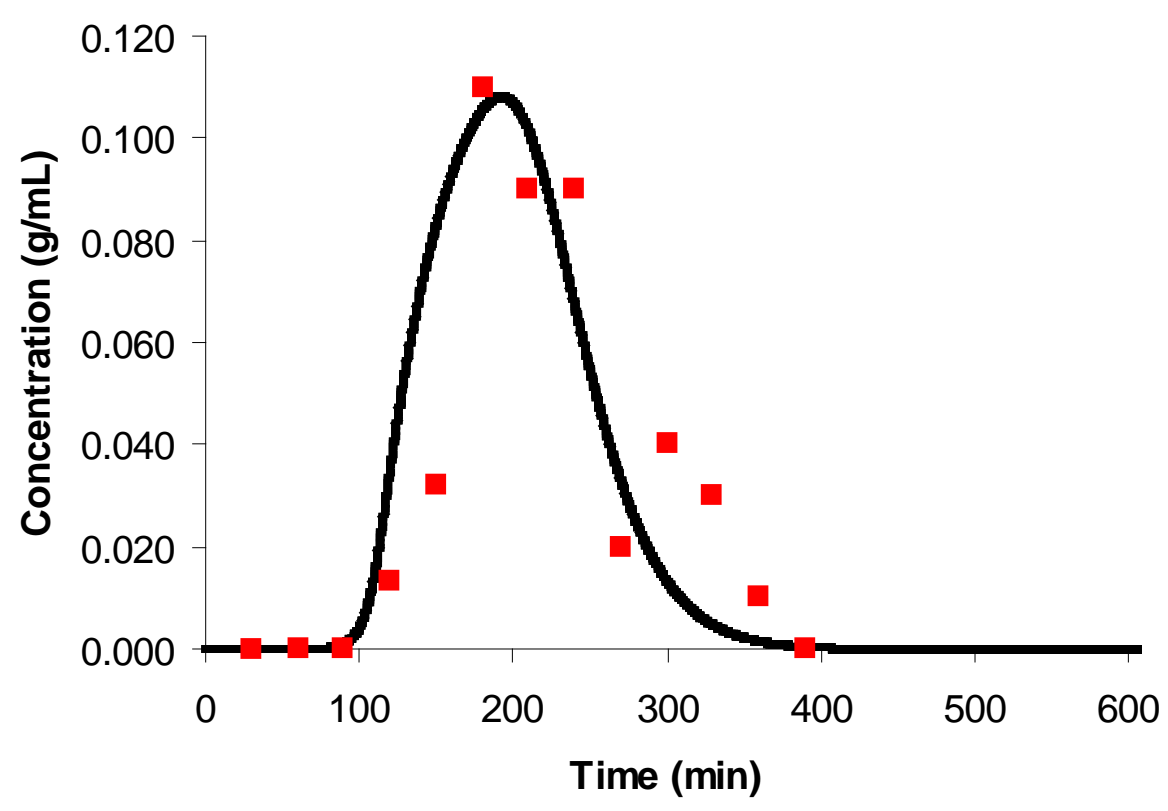

(a)

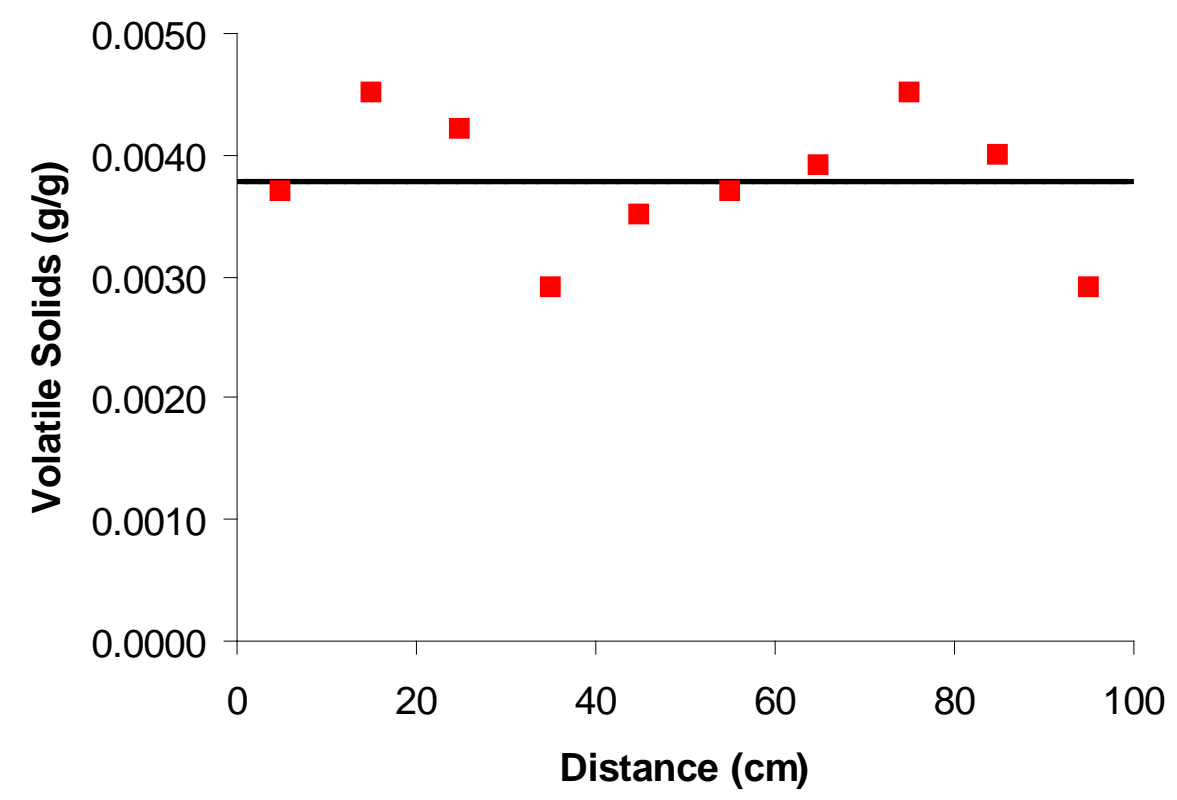

(b)

Figure 6.24. Comparison of Simulated and Observed Volatile Solids Concentrations for Experiment A1. (a) column effluent, and (b) sediment after completion of the experiment. Points represent the experimental data. The solid line represents the simulated values. 


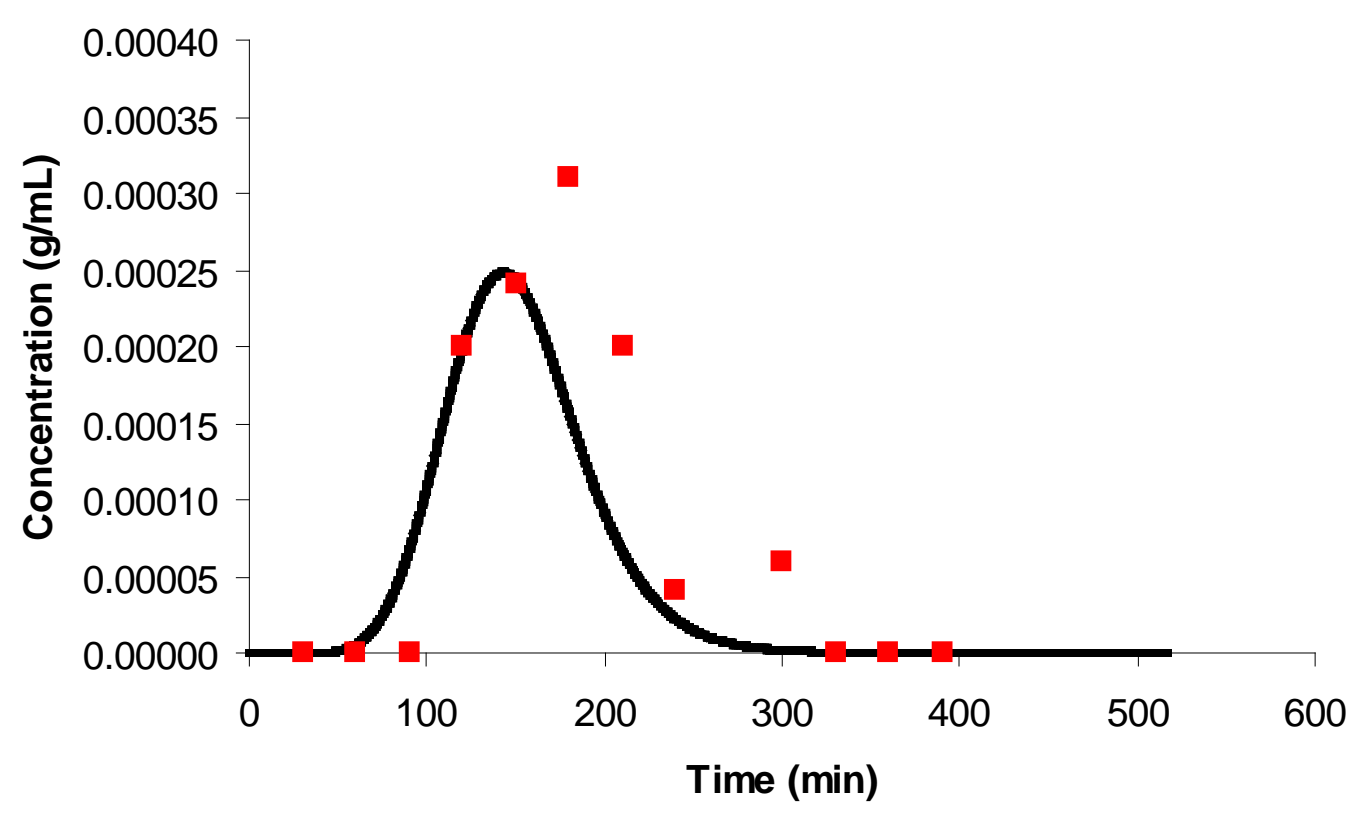

(a)

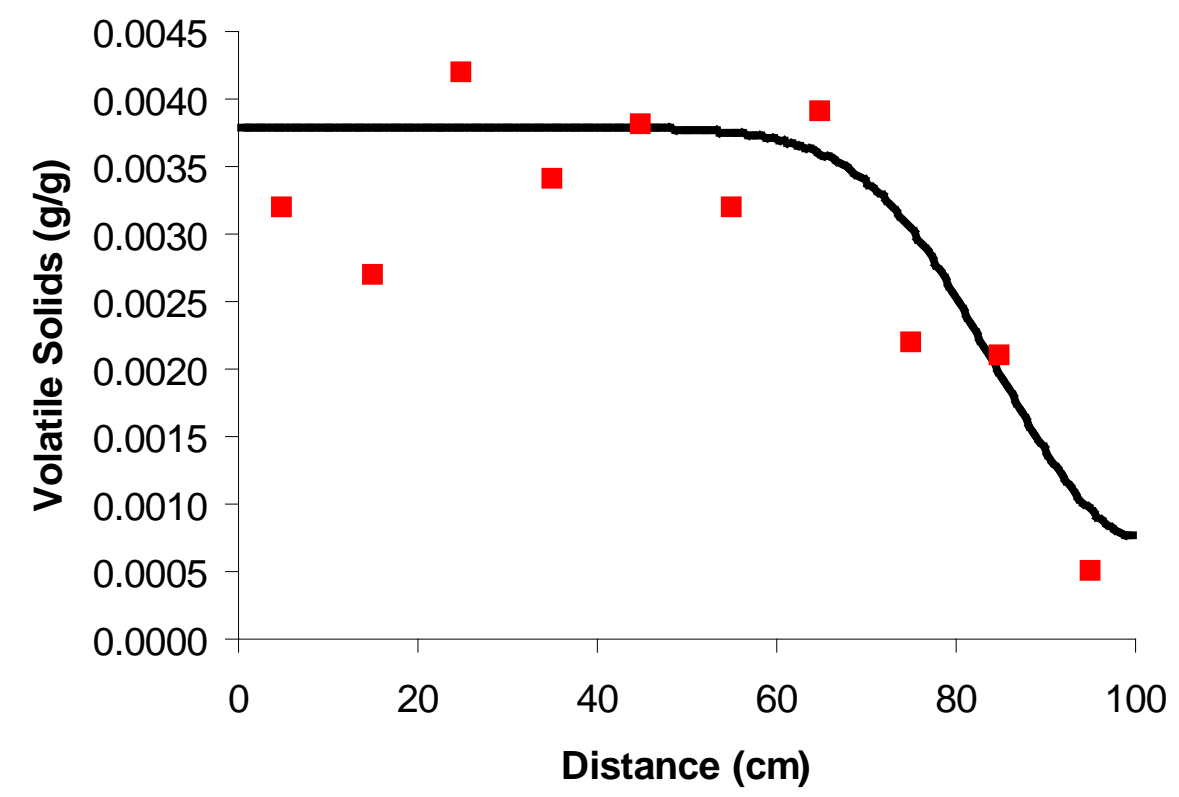

(b)

Figure 6.25. Comparison of Simulated and Observed Volatile Solids Concentrations for Experiment A2. (a) column effluent, and (b) sediment after completion of the experiment. Points represent the experimental data. The solid line represents the simulated values. 


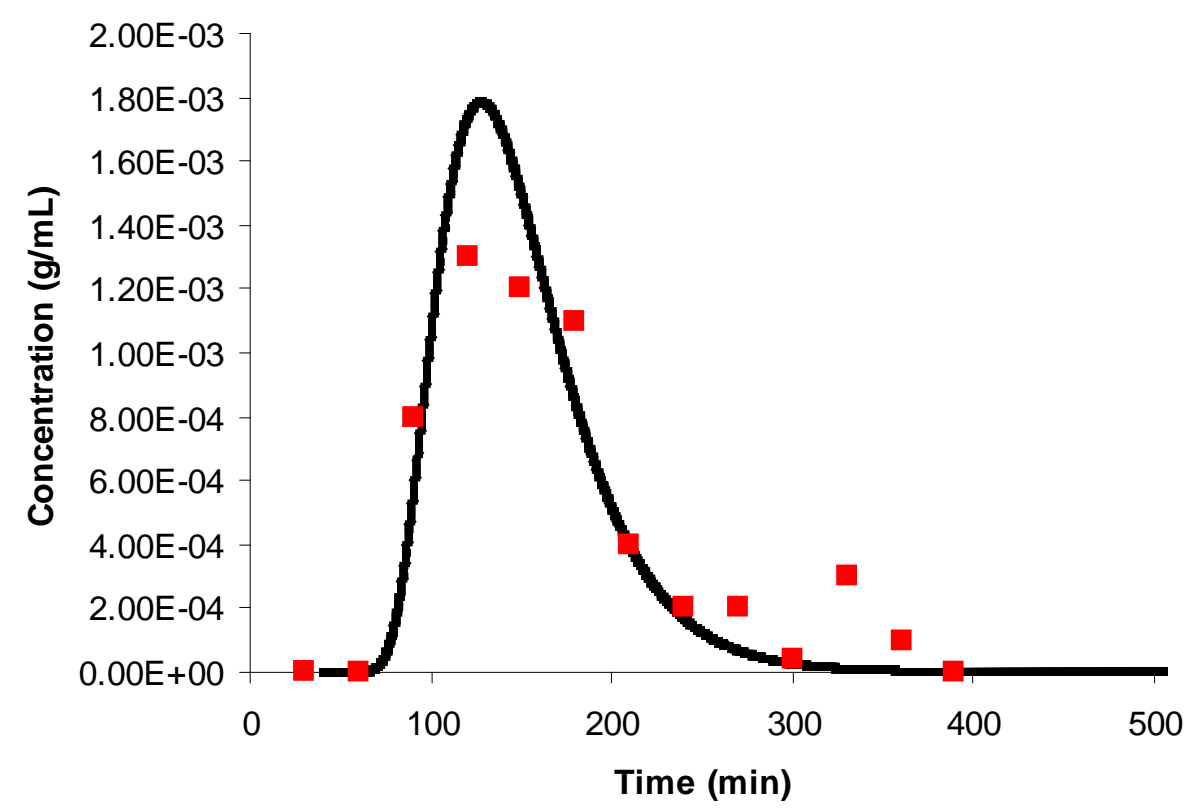

(a)

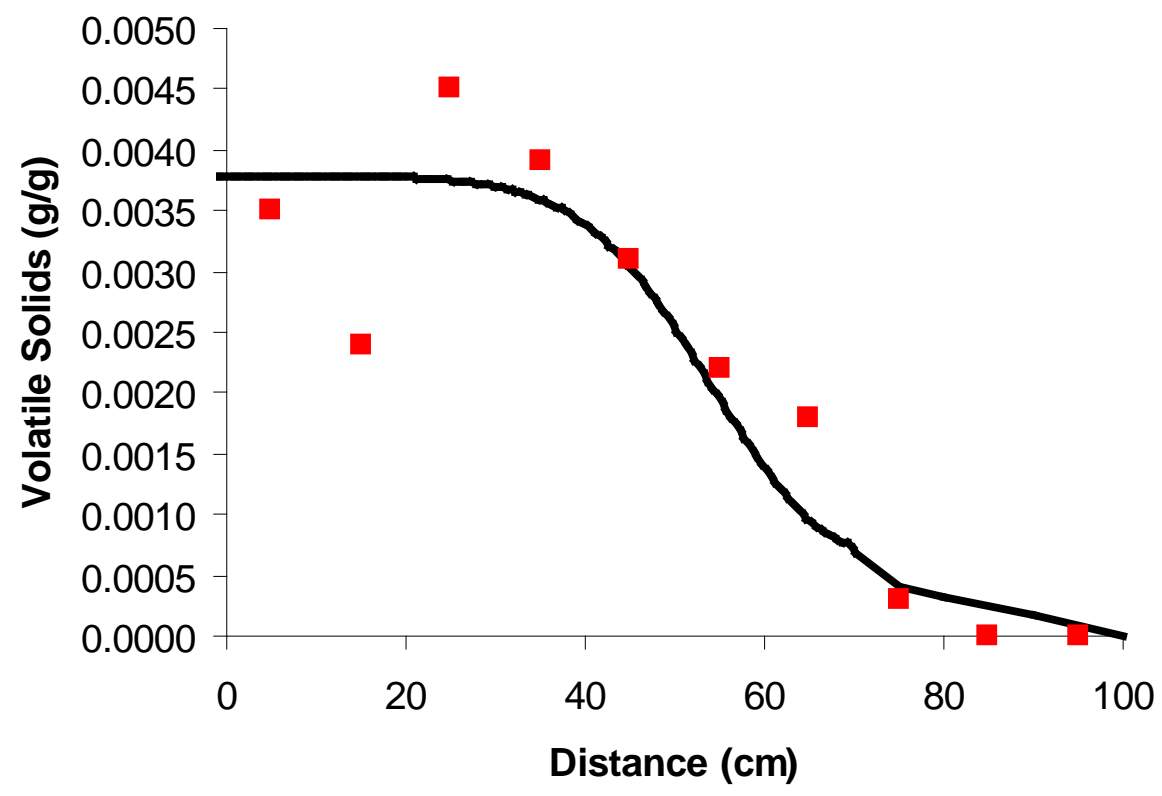

(b)

Figure 6.26. Comparison of Simulated and Observed Volatile Solids Concentrations for Experiment A3. (a) column effluent and (b) sediment after completion of the experiment. Points represent the experimental data. The solid line represents the simulated values. 


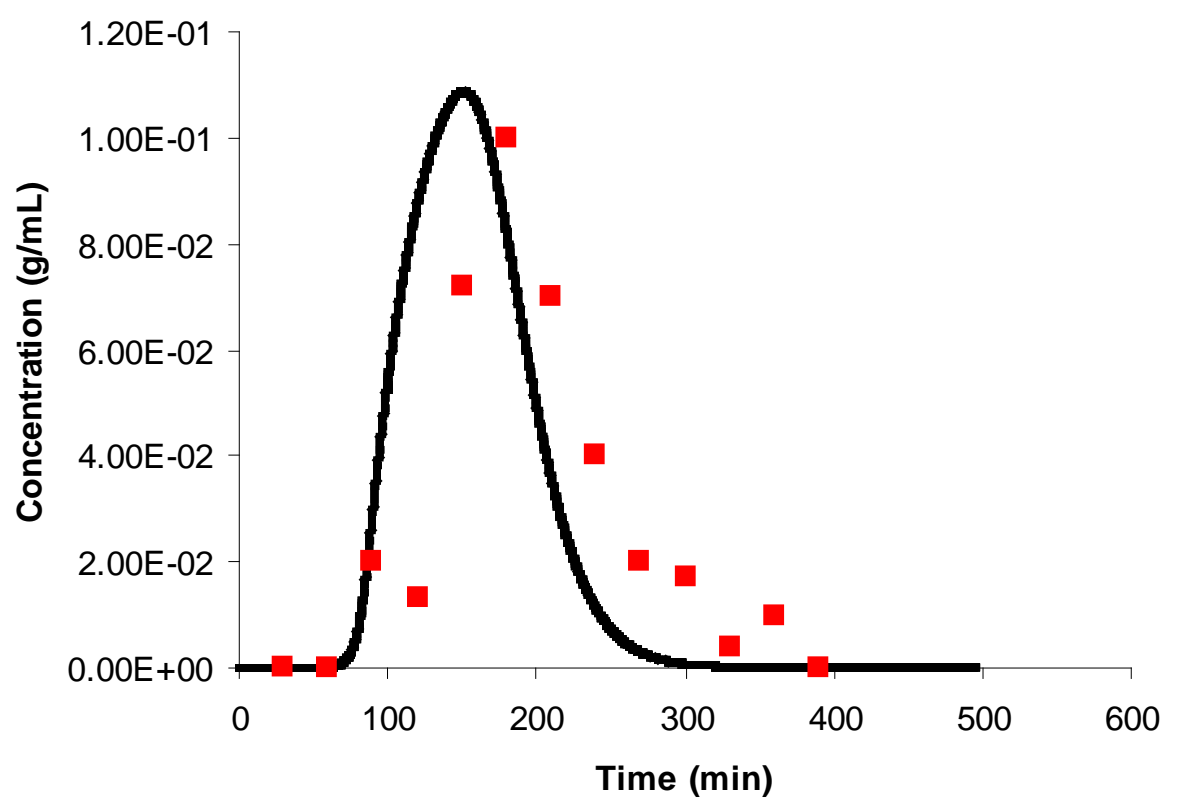

(a)

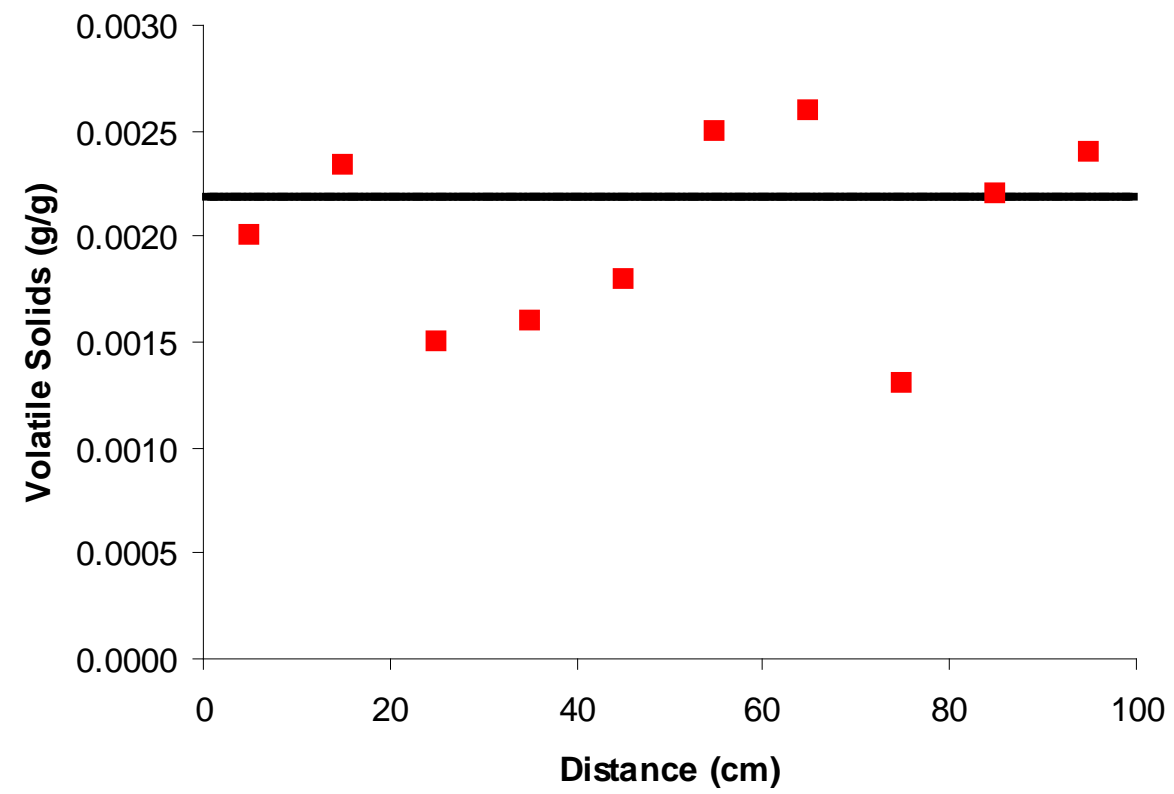

(b)

Figure 6.27. Comparison of Simulated and Observed Volatile Solids Concentrations for Experiment B1. (a) column effluent and (b) sediment after completion of the experiment. Points represent the experimental data. The solid line represents the simulated values. 


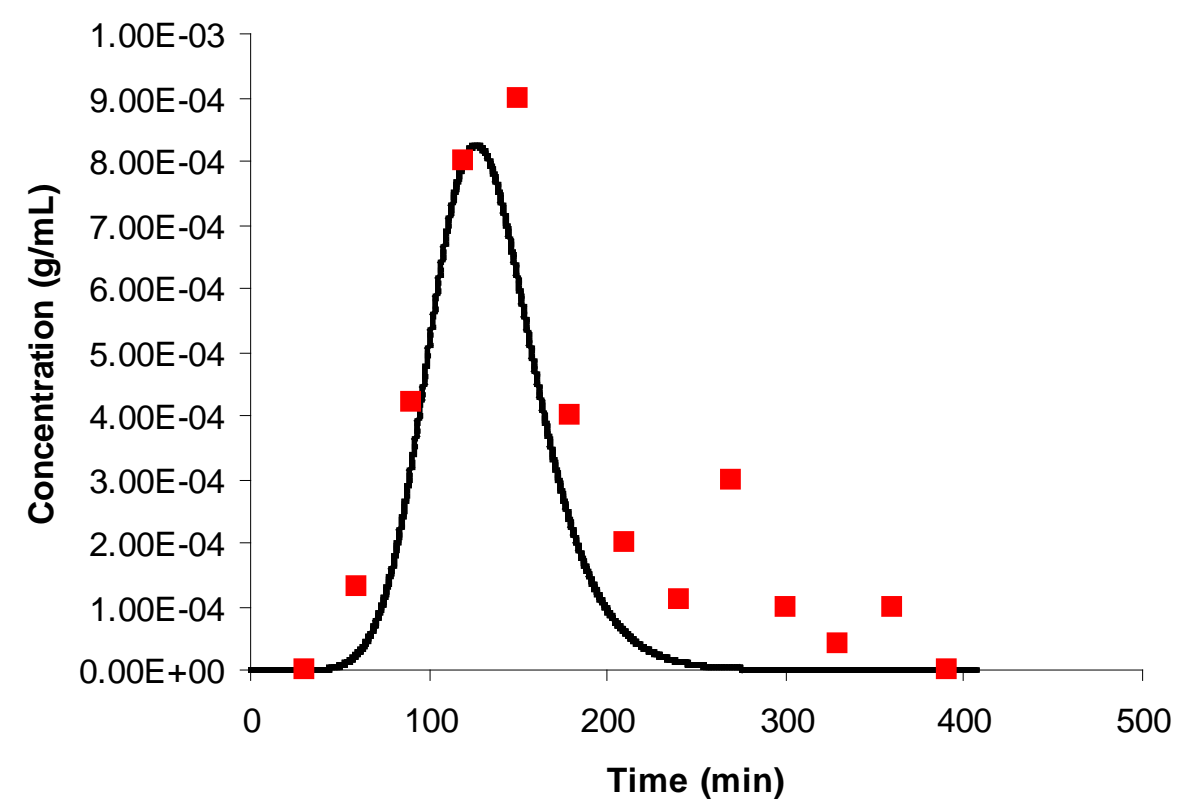

(a)

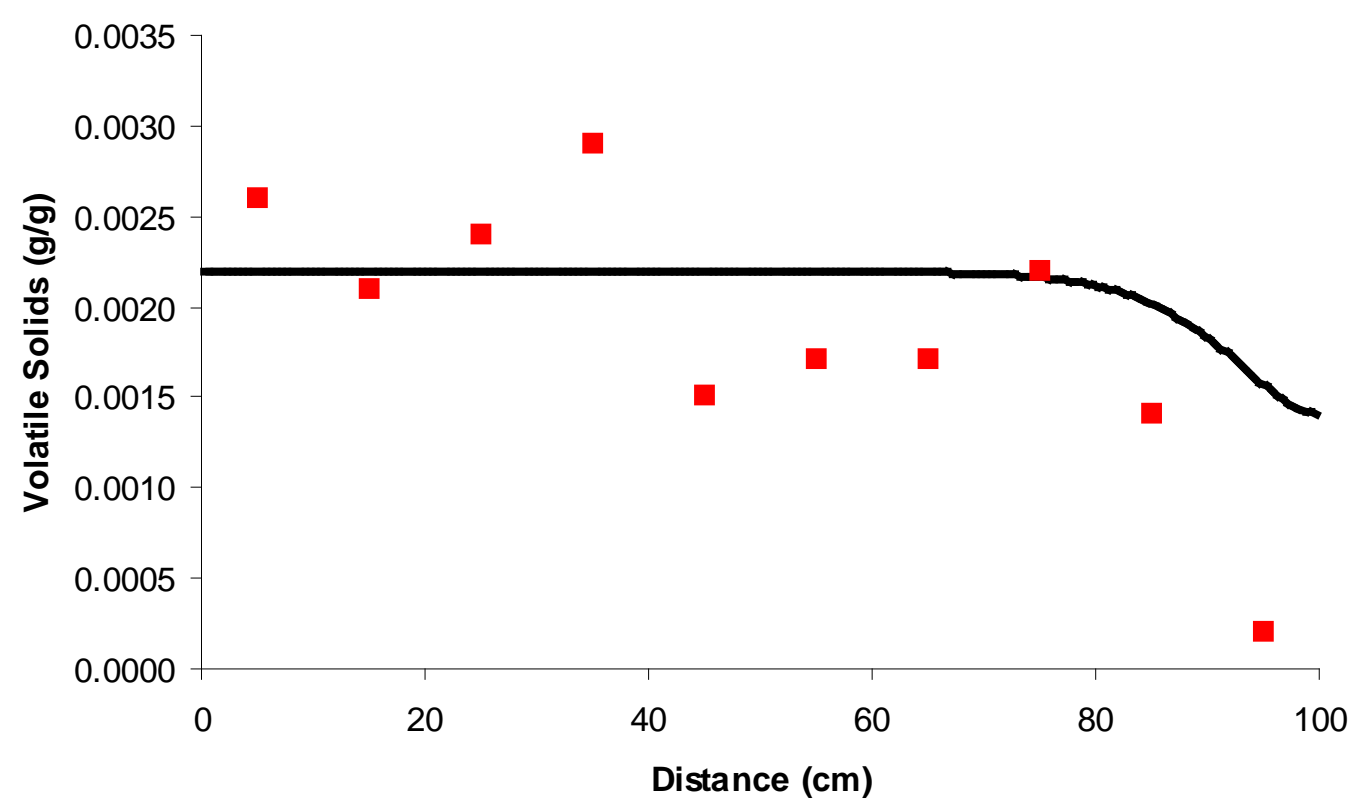

(b)

Figure 6.28. Comparison of Simulated and Observed Volatile Solids Concentrations for Experiment B2. (a) column effluent and (b) sediment after completion of the experiment. Points represent the experimental data. The solid line represents the simulated values. 


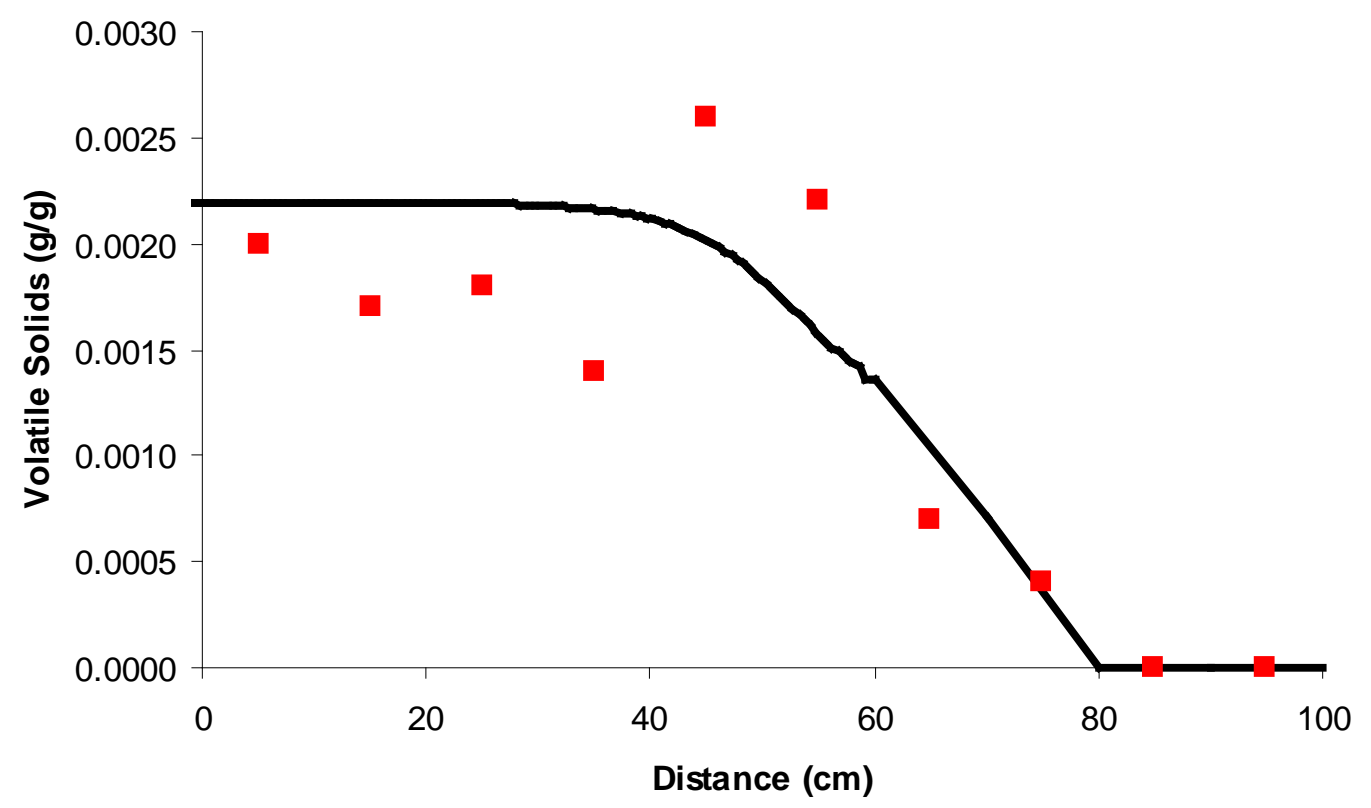

Figure 6.29. Comparison of Simulated and Observed Sediment Volatile Solids Concentrations after Completion of Experiment B3. Points represent the experimental data. The solid line represents the simulated values. 


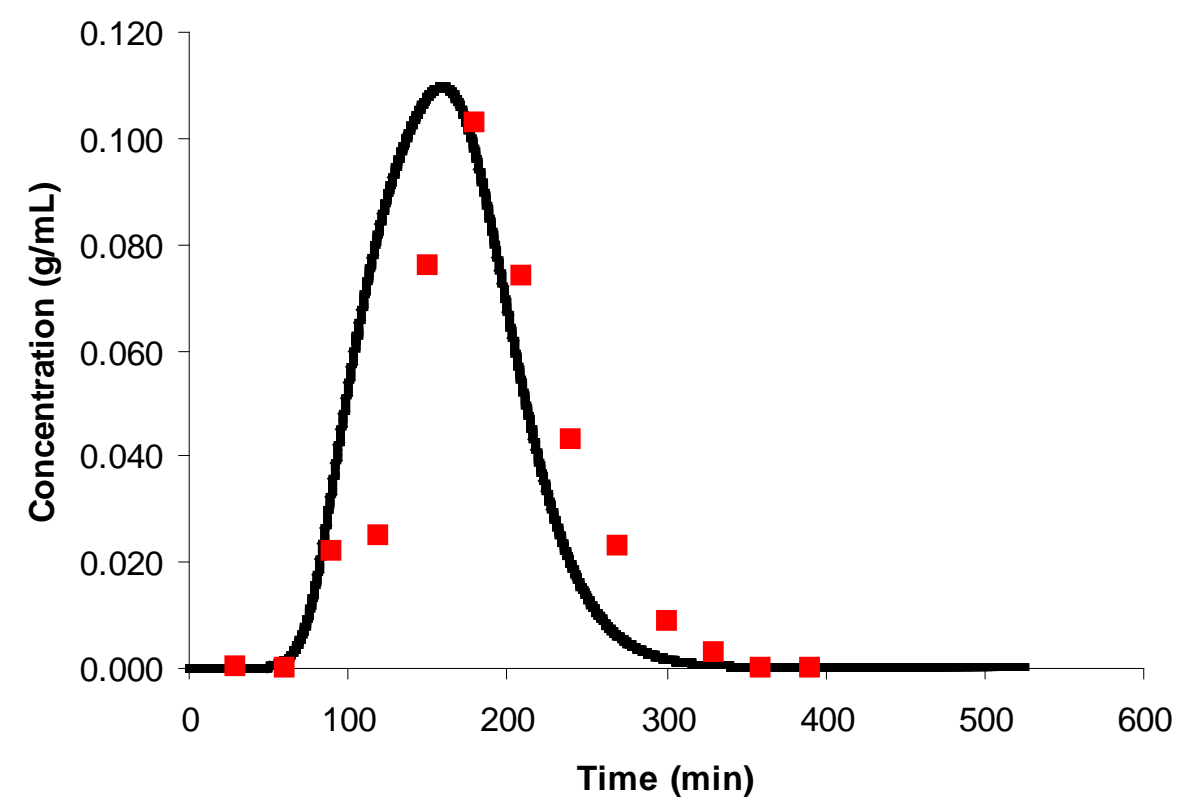

(a)

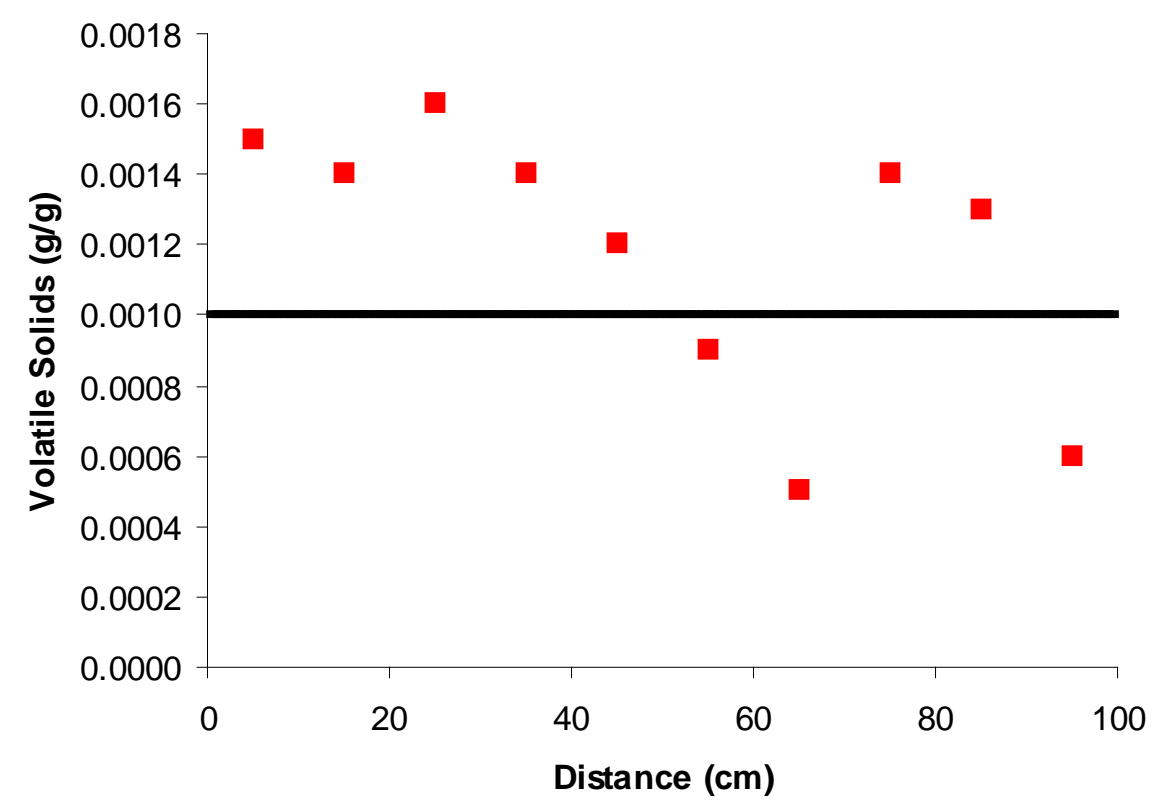

(b)

Figure 6.30. Comparison of Simulated and Observed Volatile Solids Concentrations for Experiment C1. (a) column effluent and (b) sediment after completion of the experiment. Points represent the experimental data. The solid line represents the simulated values. 


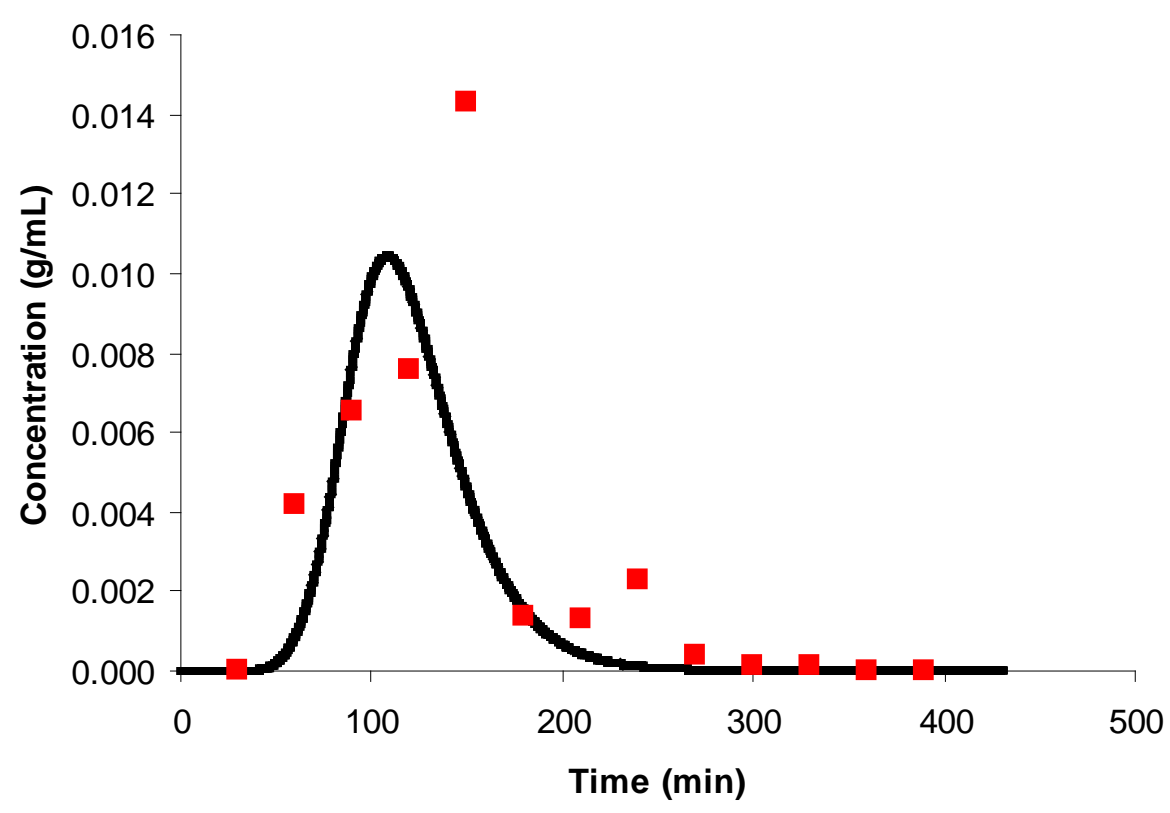

(a)

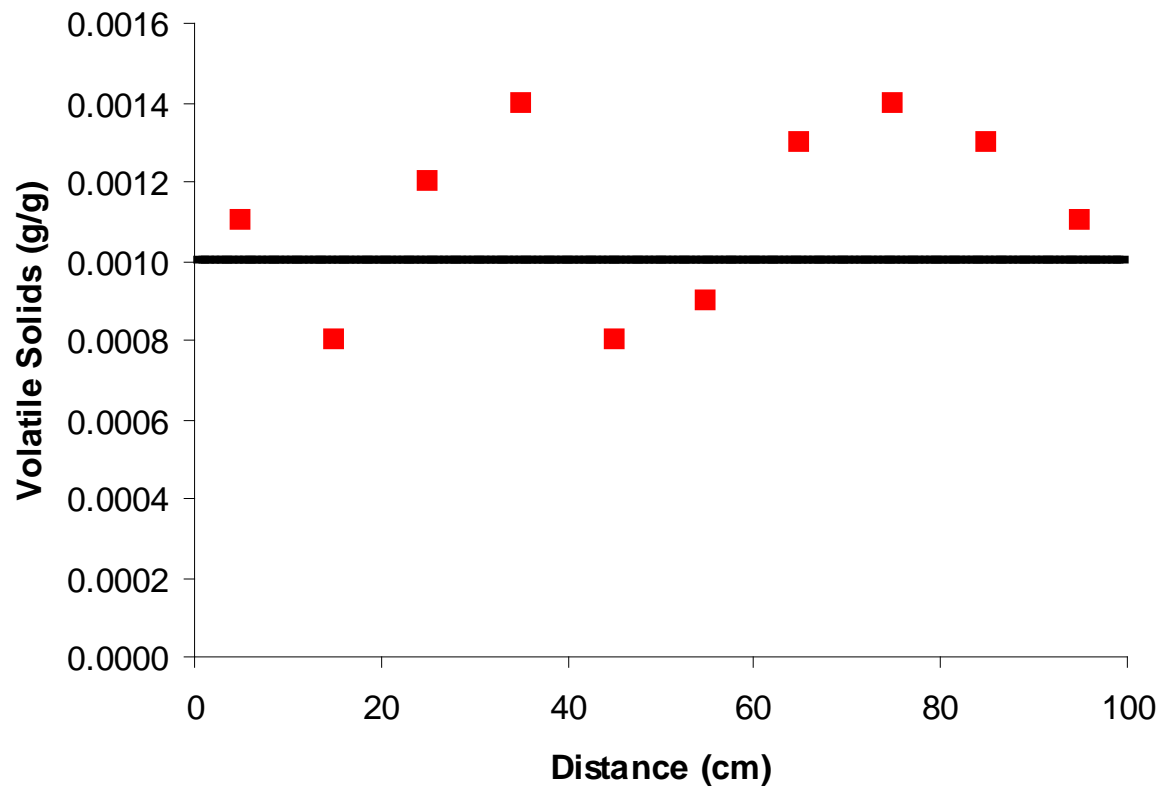

(b)

Figure 6.31. Comparison of Simulated and Observed Volatile Solids Concentrations for Experiment C2. (a) column effluent and (b) sediment after completion of the experiment. Points represent the experimental data. The solid line represents the simulated values. 


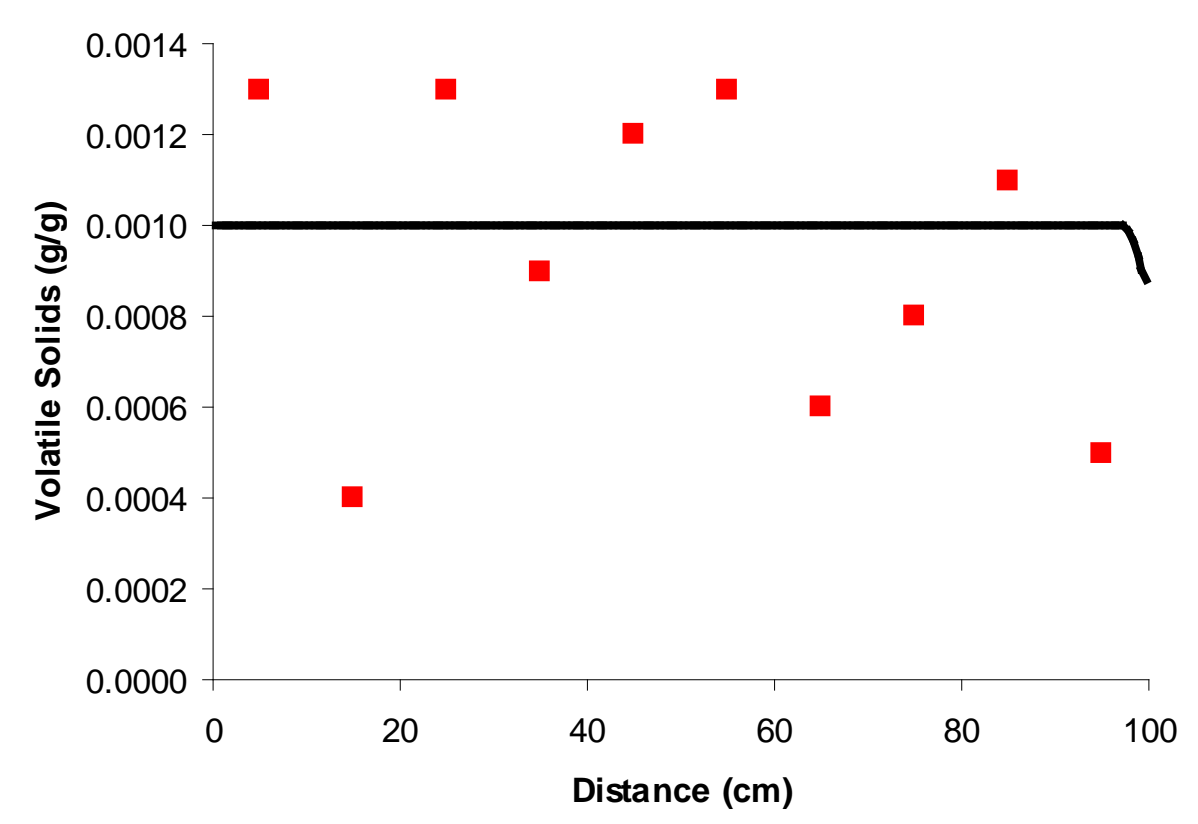

Figure 6.32. Comparison of Simulated and Observed Sediment Volatile Solids Concentrations after Completion of Experiment C3. Points represent the experimental data. The solid line represents the simulated values.

\subsubsection{Conclusions}

As suggested by these results and literature data (e.g., Borden 2007; Coulibaly 2006), transport and retention of emulsified oil is strongly influenced by the relative sediment porous media pore size and oil droplet size. For the Hanford application, the Ringold Formation contains a wide range of sediment particle sizes with the characteristic that the pore spaces between the large particles are filled with small particles. This type of packing is reflected in the relatively low porosities observed in the Ringold Formation. Under these conditions, emulsion transport and retention would be controlled by the small particle sizes and associated small pores. Thus, the target oil retention for the field test was estimated based on the results for the 70 sand.

Additionally, design information from the emulsion supplier (EOS Remediation, LLC) and the results of laboratory testing indicate that transport of the emulsion is significantly hindered as the droplet size of the emulsion increases. In tests with larger droplet sizes, oil transport was minimal in the experimental columns. Thus, results were not depicted. For the field test, emulsion product properties similar to the emulsion properties in the laboratory experiments were desired. An emulsion product delivery specification was used to ensure that the emulsion product was suitable for injection. Optical microscopy of product samples was used to ensure that the emulsified material had a mean droplet size of less than $2.5 \mu \mathrm{m}$ with a standard deviation of less than $1 \mu \mathrm{m}$. The EOS 598 met these specifications on delivery for the field test. 


\subsection{Description of Results Relative to Field Test Objectives}

The following is a summary of the field test results with respect to the objectives of the field test.

- Determine the effective radius of injection.

Result: A radius of injection of about $8 \mathrm{~m}$ (25 ft) from the injection well for the emulsified oil substrate was obtainable. Potentially, a greater injection radius is possible Additionally, use of a groundwater recirculation process that was able to significantly enhance interwell groundwater flow rates during an injection may also enable larger well spacing during full-scale deployment of the technology.

- Evaluate the uniformity of substrate distribution.

Result: Uniformity of substrate injection is, as expected, dependent on formational heterogeneities within and beyond the targeted treatment zone. However, the field test injection was able to distribute substrate to all of the monitoring locations, though at different concentrations. Subsequent microbial activity and treatment of the target compounds over a period of about 10 months was observed at all locations.

- Identify operational needs for injection.

Result: Relatively simple operations with the use of process water and substrate supplied in a tanker truck were demonstrated during the injection. A pulsed injection strategy was used to mitigate pressure buildup during injection, although continuous injection may have been possible.

- Induce fermentation reactions and reducing conditions and grow biomass.

Result: Process monitoring data showed that fermentation reactions and associated reducing conditions occurred at all of the monitoring locations. Direct in situ biomass measurement is not possible, but indirect measurements suggest that biomass was produced and helped facilitate treatment of target compounds and maintenance of reducing conditions.

- Minimize permeability changes resulting from biomass increases.

Result: In contrast to the molasses injection, permeability in the immiscible substrate test cell changed quickly and appears to be due to the presence of the injected oil rather than due to significant biomass growth. Because of the slow dissolution of substrate over time, additional permeability reduction is not expected.

- Quantify the ability to obtain and maintain low oxygen and nitrate/nitrite concentrations (limit primary electron acceptor flux) and determine longevity of treatment.

Result: Low oxygen and nitrate/nitrite concentrations were maintained over the duration of the test ( 10 months) with indications that the treatment duration will be longer. 
- Quantify the ability to obtain and maintain low chromate concentrations (augment chromate treatment) and determine longevity of treatment.

Result: Low total chromium and chromate concentrations were maintained over the duration of the test ( 10 months) with indications that the treatment duration will be longer.

- Quantify the water quality impacts of the treatment.

Result: Within the test cell, water quality was negatively impact by an increase in the concentration of metals and organic constituents and a decrease in the $\mathrm{pH}$, oxidation-reduction potential, and dissolved oxygen concentration. These changes were expected due to the imposed anaerobic conditions required for biological treatment of dissolved oxygen, nitrate, and chromate. A biobarrier design requires a downgradient portion of the aquifer where these water quality impacts can recover and this type of recovery region would need to be considered as part of determining the location for biobarrier application.

- Compile information for full-scale design considering the injection process, biobarrier performance, hydrogeology, and electron flux information at 100-D

Result: Table 6.5 shows the information available from this treatability test that is suitable for use to support design and cost estimation in a feasibility study.

Table 6.5. Biobarrier Scale-Up Information

\begin{tabular}{|c|c|c|}
\hline Item & Value & Comment \\
\hline Substrate loading & $5 \mathrm{~kg} / \mathrm{m}^{3}$ & $\begin{array}{l}\text { Lower substrate loading may be } \\
\text { appropriate for volumetric } \\
\text { bioremediation of chromate or for } \\
\text { shorter periods of barrier } \\
\text { effectiveness. }\end{array}$ \\
\hline Substrate cost & $4.1 \$ / \mathrm{kg}$ & Treatability test cost \\
\hline Nutrient loading & Not applicable & $\begin{array}{l}\text { Deemed unnecessary for the } \\
\text { emulsified oil substrate. }\end{array}$ \\
\hline $\begin{array}{l}\text { Injection well spacing } \\
\text { (perpendicular to flow) }\end{array}$ & $16 \mathrm{~m}$ & $\begin{array}{l}\text { Based on } 8 \text { m radius of influence. } \\
\text { Full-scale spacing may need to } \\
\text { consider overlapping of substrate } \\
\text { injection zones. Potentially, larger } \\
\text { spacing could be obtained with a } \\
\text { longer injection period or with a } \\
\text { groundwater recirculation system } \\
\text { and may be appropriate depending } \\
\text { on relative cost of recirculation } \\
\text { design versus a single well } \\
\text { injection design. }\end{array}$ \\
\hline Operational labor for injection & 90 hours of labor time & Labor for injection during the test \\
\hline Monitoring frequency & Quarterly to semiannually & $\begin{array}{l}\text { Based on the timeframe of } \\
\text { observed changes during the test. }\end{array}$ \\
\hline
\end{tabular}


Table 6.5. (contd)

\begin{tabular}{|c|c|c|}
\hline Item & Value & Comment \\
\hline Frequency of substrate injection & Every 5 years & $\begin{array}{l}\text { Estimated based on design } \\
\text { calculation from emulsion provider. } \\
\text { Barrier performance did not } \\
\text { diminish over the } 10 \text {-month testing } \\
\text { period. Groundwater flow } \\
\text { conditions should be considered in } \\
\text { determining the frequency of } \\
\text { reinjection. }\end{array}$ \\
\hline \multirow[t]{8}{*}{$\begin{array}{l}\text { Primary injection equipment and } \\
\text { cost }\end{array}$} & $\begin{array}{l}\text { Substrate feed pump (air-driven } \\
\text { diaphragm pump) - } \$ 2,500\end{array}$ & \multirow{8}{*}{$\begin{array}{l}\text { Equipment used during the test and } \\
\text { nominal cost. Injection system } \\
\text { design and construction cost is not } \\
\text { included. These costs would be } \\
\text { best estimated by the contractor } \\
\text { performing the scale-up injections. }\end{array}$} \\
\hline & $\begin{array}{l}\text { Feedwater pump (centrifugal) - } \\
\$ 500\end{array}$ & \\
\hline & $\begin{array}{l}\text { Substrate flowmeter (pulse } \\
\text { counter) - } \$ 1,000\end{array}$ & \\
\hline & $\begin{array}{l}\text { Feedwater flowmeter (turbine) - } \\
\$ 1000\end{array}$ & \\
\hline & In-line mixer - $\$ 100$ & \\
\hline & $\begin{array}{l}\text { Data logger for flowmeters \& feed } \\
\text { pump- } \$ 3,000\end{array}$ & \\
\hline & Hose for feedwater- $\$ 10 / \mathrm{ft}$ & \\
\hline & $\begin{array}{l}\text { Hardware for injection well } \\
\text { piping- } \$ 400\end{array}$ & \\
\hline
\end{tabular}




\subsection{Conclusions and Recommendations}

Pacific Northwest National Laboratory conducted a treatability test designed to demonstrate that in situ biostimulation can be applied to help meet cleanup goals in the Hanford Site 100-D Area. The in situ biostimulation technology is intended to provide supplemental treatment upgradient of the In Situ Redox Manipulation (ISRM) barrier previously installed in the Hanford 100-D Area and, thereby increase the longevity of the ISRM barrier. Substrates for the treatability test were selected to provide information about two general approaches for establishing and maintaining an in situ biobarrier. These approaches included 1) use of a soluble (miscible) substrate that is relatively easy to distribute over a large areal extent, is inexpensive, and is expected to have moderate longevity and 2) use of an immiscible substrate that can be distributed over a reasonable areal extent at a moderate cost and is expected to have increased longevity.

The results of the treatability test demonstrate that biostimulation is a viable approach to create a permeable reactive barrier for reducing nitrate, oxygen, and chromate concentrations in the groundwater at the Hanford 100-D Area. A single injection of substrate can create a permeable reactive barrier that lasts at least 2 years and likely longer. It is reasonable to extend these results to support the conclusion that biostimulation is also a viable approach to treating nitrate and chromate within a targeted volume of the aquifer in the Hanford 100-D Area, although the approach to application would likely be somewhat different than the design of the permeable reactive barrier application in the treatability test.

For the soluble substrate test, substrate was successfully distributed and induced a biobarrier that

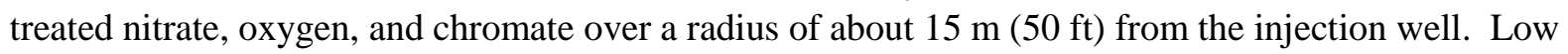
oxygen, nitrate, and chromium concentrations were maintained for the approximately 2-year duration of monitoring. Aquifer permeability reduction within the test zone was moderate and likely due to growth of bacteria. The injected substrate and associated organic degradation products persisted for about 1 year. Over the second year of barrier monitoring, organic substrate concentrations were low; the continued effectiveness of the treatment zone is attributed to recycling of organic compounds associated with the biomass that was produced during the first year. Thus, the soluble substrate approach met the test performance objectives. Scale-up parameters were determined based on the test data and are available for use in subsequent feasibility studies, as needed.

The immiscible substrate was successfully distributed to a radius of about $8 \mathrm{~m}(25 \mathrm{ft})$ from the injection well. Subsequent microbial activity and ability to reduce the targeted species were observed throughout the monitored zone, and low oxygen, nitrate, and chromium concentrations were maintained for the approximately 10-month duration of monitoring. Aquifer permeability reduction within the test zone was moderate and occurred quickly after substrate injection, likely due to physical effects from the presence of immiscible liquid in the aquifer. The monitoring period for the immiscible test was short compared to the expected longevity of the substrate. Initial indications from the immiscible substrate injection are favorable, however, additional monitoring would be necessary to determine the longevity of the treatment and verify acceptable performance relative to all of the test objectives. Scale-up parameters were determined based on the test data and are available for use in subsequent feasibility studies, as needed. 


\subsection{References}

AFCEE. 2004. Principles and Practices of Enhanced Anaerobic Bioremediation of Chlorinated Solvents. Air Force Center for Environmental Excellence, Brooks City-Base, Texas; Naval Facilities Engineering Service Center, Port Hueneme, California; and Environmental Security Technology Certification Program, Arlington, Virginia. Available at http://www.afcee.brooks.af.mil/products/ techtrans/Bioremediation/BIOREMresources.asp (June 20, 2008).

Agarwal RG. 1980. "A New Method to Account for Producing Time Effects when Drawdown Type Curves Are Used to Analyze Pressure Buildup and Other Test Data.” SPE Paper 9289, Society of Petroleum Engineers, Dallas, Texas.

Alam M, A Hossain, D Yonge, B Peyton, and J Petersen. 2006. "Bioreduction of Hexavalent Chromium in Flow-Through Quartz Sand Columns.” J. Environ. Engineering 132(3):358-366.

ARCADIS. 2009. ARCADIS, Denver, Colorado. Available at www.arcadis-us.com (September 14, 2009).

Boman GK, FJ Molz, and KD Boone. 1997. "Borehole Flowmeter Application in Fluvial Sediments: Methodology, Results, and Assessment.” Ground Water 35(3):443-450.

Borden RC. 2007. "Effective Distribution of Emulsified Edible Oil for Enhanced Anaerobic Bioremediation.” Journal of Contaminant Hydrology 94:1-12.

Borden RC and BX Rodriguez. 2006. "Evaluation of Slow Release Substrates for Anaerobic Bioremediation.” Bioremediation J. 10(1-2):59-69.

Bouwer H. 1989. “The Bouwer and Rice Slug Test - An Update.” Ground Water 27(3):304-309.

Bouwer H and RC Rice. 1976. “A Slug Test Method for Determining Hydraulic Conductivity of Unconfined Aquifers with Completely or Partially Penetrating Wells.” Water Resources Research 12(3):423-428.

Butler JJ, Jr. 1998. The Design, Performance, and Analysis of Slug Tests. Lewis Publishers, Boca Raton.

Chen J, A Kemna, and S Hubbard. 2008. "A Comparison Between Gauss-Newton and Markov-Chain Monte Carlo-Based Methods for Inverting Spectral Induced-Polarization Data for Cole-Cole Parameters.” Geophysics 73(6):F247-F259, DOI 10.1190/1.2976115.

Clement TP. "RT3D - A Modular Computer Code for Simulating Reactive Multispecies Transport in 3Dimensional Groundwater Aquifers.” PNNL-SA-28967, Pacific Northwest National Laboratory, Richland, Washington.

Coulibaly KM and RC Borden. 2004. "Impact of Edible Oil Injection on the Permeability of Aquifer Sands.” J. Contam. Hydrol. 71:219-237. 
Coulibaly KM, CM Long, and RC Borden. 2006. “Transport of Edible Oil Emulsions in Clayey-Sands: 1D Column Results and Model Development.” J. Hydrol. Eng. 11:2030-2237.

DOE. 2006. Calendar Year 2005 Annual Summary Report for the 100-HR-3, 100-KR-4, and 100-NR-2 Operable Unit Pump-and-Treat Operations. DOE/RL-2006-08, U.S. Department of Energy, Richland, Washington.

Fang Y, SB Yabusaki, and GT Yeh. 2006. "A General Simulator for Reaction-Based Biogeochemical Processes.” Computers \& Geosciences 32:64-72.

Faybishenko B, TC Hazen PE Long, EL Brodie, ME Conrad, SS Hubbard, N Christensen, D Joyner, SE Borglin, R Chakraborty, KH Williams, JE Peterson, J Chen, ST Brown, TK Tokunaga, J Wan, M Firestone, DR Newcomer, CT Resch, KJ Cantrell, A Willett, and S Koenigsberg. 2008. "In Situ LongTerm Reductive Bioimmobilization of Cr(VI) in Groundwater Using Hydrogen Release Compound.” Environmental Science \& Technology 42(22):8478-8485.

Gemoets J, C Gielen, N Hermans, Y Vermoortel, and M Carpels. 2003. "Evaluation of the Potential for Natural Attenuation and In Situ Bioprecipiation of Chromium in Groundwater.” Paper L-07 in Proceedings of the Seventh International In Situ and On-Site Bioremediation Symposium, Orlando, Florida.

Hartman MJ. 1999. Hanford Site Groundwater: Settings, Sources, and Methods. PNNL-13080, Pacific Northwest National Laboratory, Richland, Washington.

Hubbard SS, K Williams, M Conrad, B Faybishenko, J Peterson, J Chen, P Long, and T Hazen. 2008. "Geophysical Monitoring of Hydrological and Biogeochemical Transformations Associated with Cr(VI) Biostimulation.” Environmental Science and Technology. DOI 10.1021/es071702s.

Hunter WJ. 2001. "Use of Vegetable Oil in a Pilotscale Denitrifying Barrier.” J. Contam. Hydrol. 53:119-131.

Hunter WJ. 2005. "Injection of Innocuous Oil to Create Reactive Barriers for Bioremediation: Laboratory Studies.” J. Contam. Hydrol. 80:31-48.

Lindsey KA and GK Jaeger. 1993. Geologic Setting of the 100-HR-3 Operable Unit, Hanford Site, South-Central Washington. WHC-SD-EN-TI-132, Rev. 0, Westinghouse Hanford Company, Richland, Washington.

Hyder Z, JJ Butler, Jr., CD McElwee, and W Liu. 1994. "Slug Tests in Partially Penetrating Wells.” Water Resources Research 30(11):2945-2957.

Molz FJ, RH Morin, AE Hess, JG Melville, and O Gueven. 1989. “The Impeller Meter for Measuring Aquifer Permeability Variations: Evaluation and Comparison with Other Tests.” Water Resources Research 25(7):1677-1683.

Neuman SP. 1972. "Theory of Flow in Unconfined Aquifers Considering Delayed Response of the Water Table.” Water Resources Research 8(4):1031-1045. 
Neuman SP. 1974. "Effect of Partial Penetration of Flow in Unconfined Aquifer Considering Delayed Gravity Response.” Water Resources Research 10(2):303-312.

Neuman SP. 1975. "Analysis of pumping test data from anisotropic unconfined aquifers considering delayed gravity response.” Water Resources Research 11(2):329-342.

Peterson JE. 2001. "Pre-Inversion Processing and Analysis of Tomographic Radar Data.” Journal of Environ. Engin. Geop. 6(1):1-18.

Peterson JE, B Paullson, and TE McKevilly. 1985. "Applications of Algebraic Reconstruction Techniques to Crosshole Seismic Data.” Geophysics 50(10):1566-1580.

Peterson RE, RF Raidl, and CW Denslow. 1996. Conceptual Site Models for Groundwater Contamination at 100-BC-5, 100-KR-4, 100-HR-3, and 100-FR-3 Operable Units, Hanford Site. BHI-00917, Rev. 0, Bechtel Hanford, Inc., Richland, Washington.

Rajagopalan R and C Tien. 1976. "Trajectory Analysis of Deep-Bed Filtration with the Sphere-in-Cell Porous Media Model.” A.I.C.H.E.J. 22:523-533.

Schroth MH, SJ Ahearn, JS Selker, and JD Istok. 1996. “Characterization of Miller-Similar Silica Sands for Laboratory Hydrologic Studies.” Soil Science Soc. Am. J. 60:1331-1339.

Sleep BE, AJ Brown, and B Sherwood Lollar. 2005. "Long-Term Tetrachloroethene Degradation Sustained by Endogenous Cell Decay.” J. Environ. Eng. Sci. 4:11-17.

Spane FA and DR Newcomer. 2008. Results of Detailed Hydrologic Characterization Tests - Fiscal and Calendar Year 2005. PNNL-17348, Pacific Northwest National Laboraatory, Richland, Washington.

Truex MJ, VR Vermeul, PE Long, FJ Brockman, M Oostrom, S Hubbard, RC Borden, and JS Fruchter. 2007. Treatability Test Plan for an In Situ Biostimulation Reducing Barrier. PNNL-16424, Pacific Northwest National Laboratory, Richland, Washington.

White MD and M Oostrom. 2006. STOMP Subsurface Transport Over Multiple Phases, Version 4.0, User's Guide. PNNL-15782, Pacific Northwest National Laboratory, Richland, Washington.

Williams MD, VR Vermeul, JE Szecsody, and JS Fruchter. 2000. 100-D Area In Situ Redox Treatability Test for Chromate-Contaminated Water. PNNL-13349, Pacific Northwest National Laboratory, Richland, Washington.

Williams KH, D Ntarlagiannis, LD Slater, A Dohnalkova, SS Hubbard, and JF Banfield. 2005. “Geophysical Imaging of Stimulated Microbial Biomineralization.” Environ. Sci. Technol. 39(19):75927600 DOI: 10.1021/es0504035.

Yang Y and PL McCarty. 2000. "Biomass, Oleate, and Other Possible Substrates for Chloroethene Reductive Dehalogenation.” Bioremediation J. 4(2):125-133.

Young SC, HE Julian, HS Pearson, FJ Molz, and GK Boman. 1998. Application of the Electromagnetic Borehole Flowmeter. EPA/600/R-98/058, U.S. Environmental Protection Agency, Ada, Oklahoma. 


\section{Appendix A}

\section{Borehole Logs and Well Completion Diagrams for the Test Site Wells}




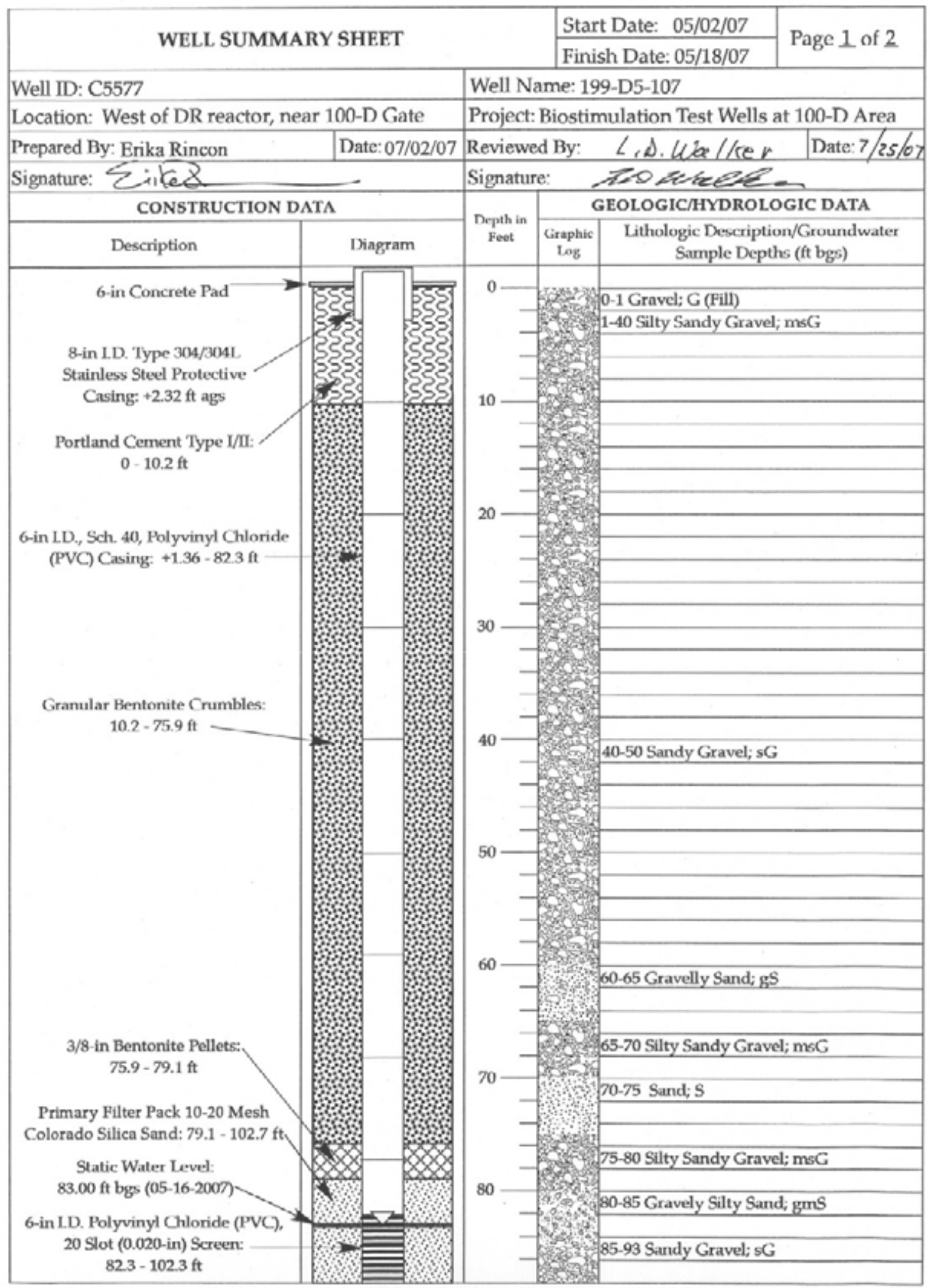




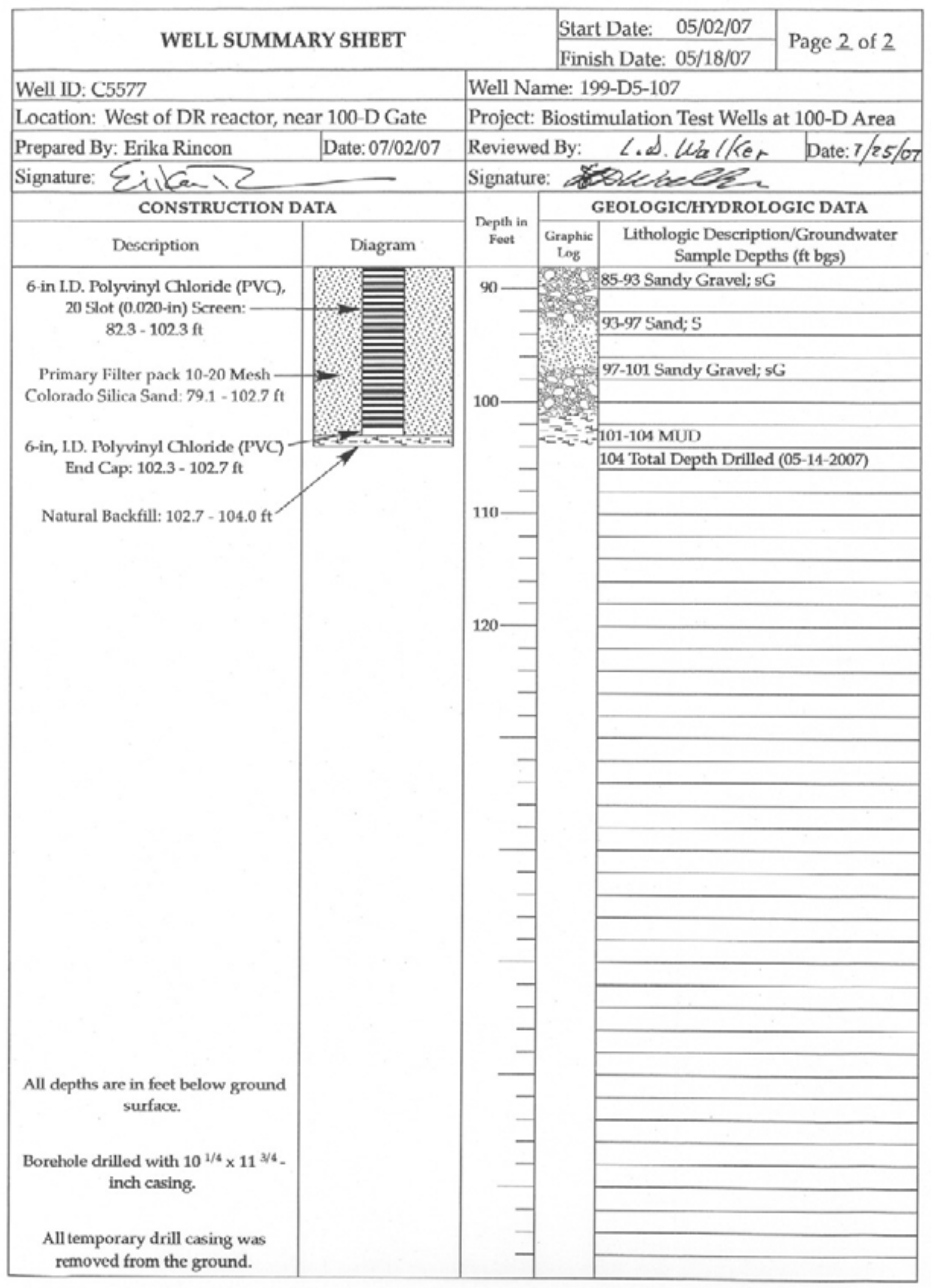




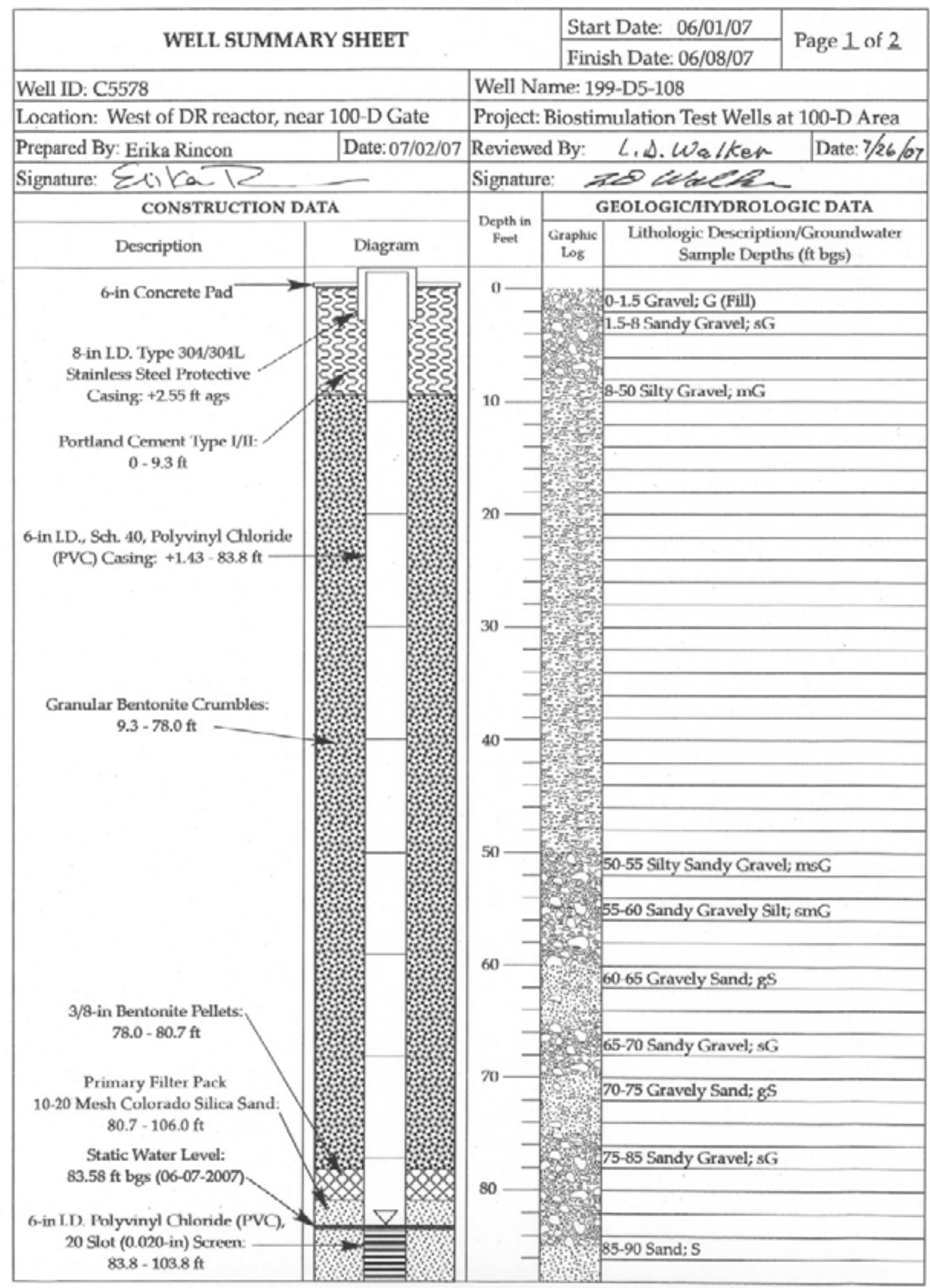




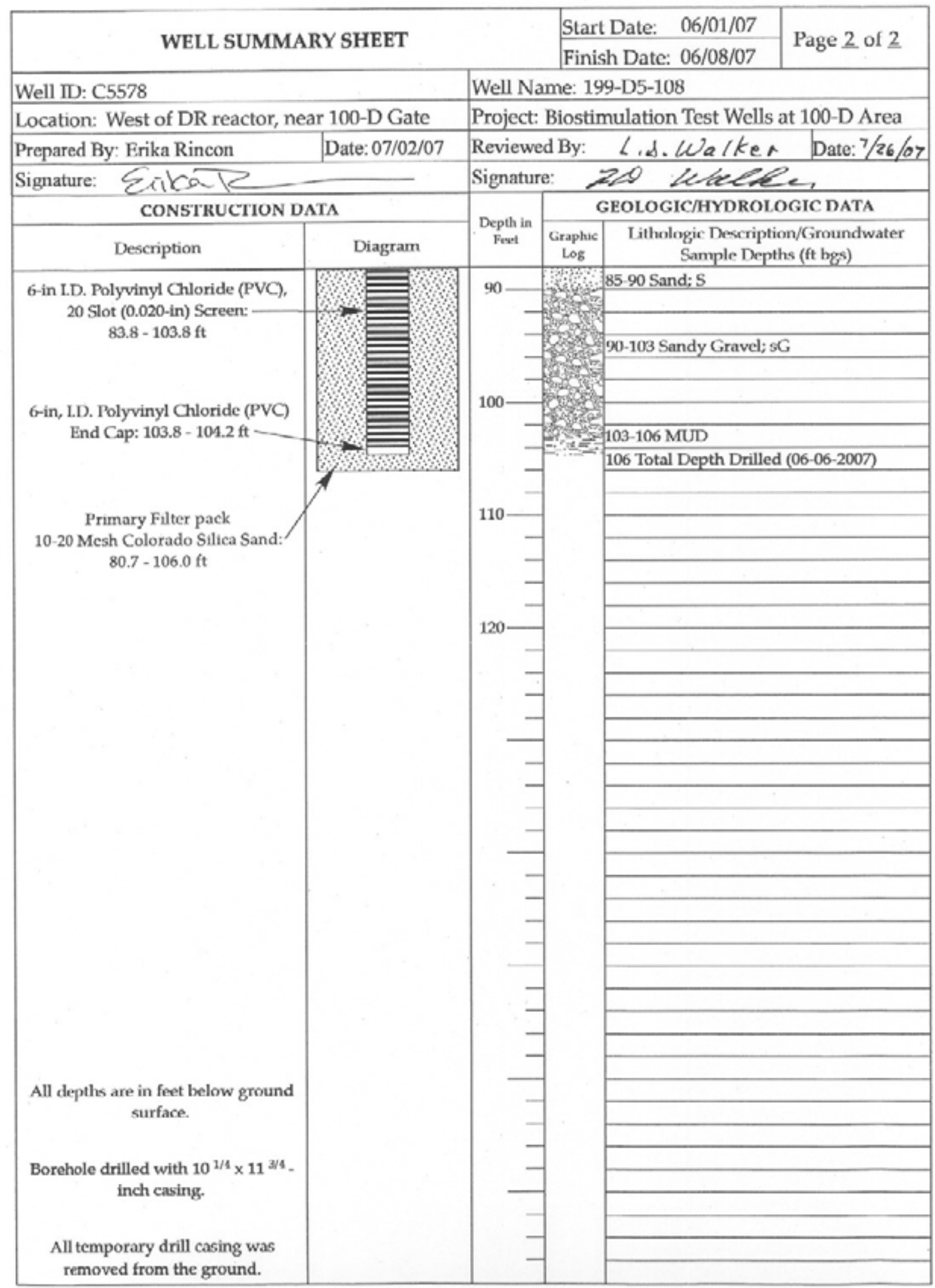




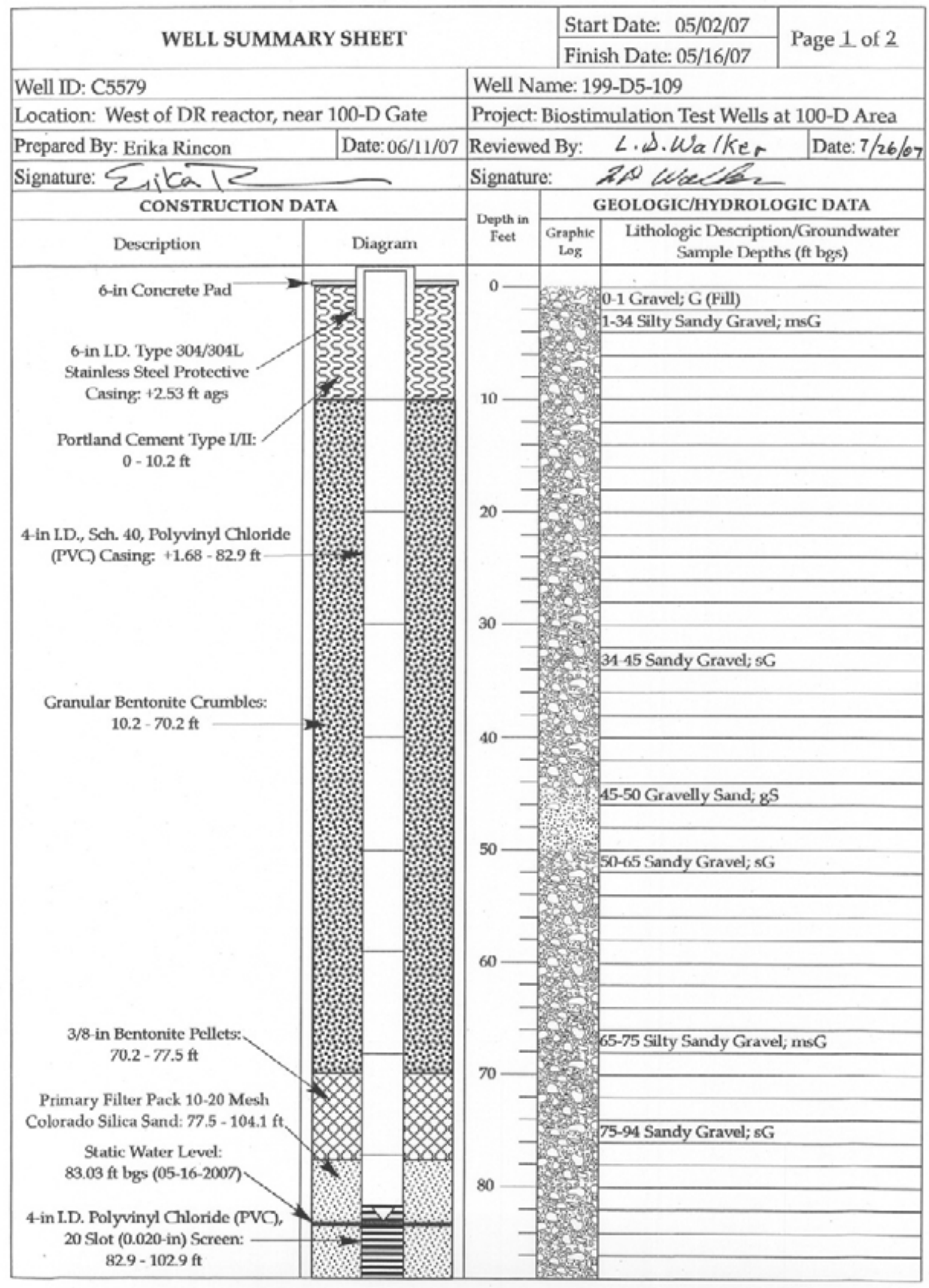




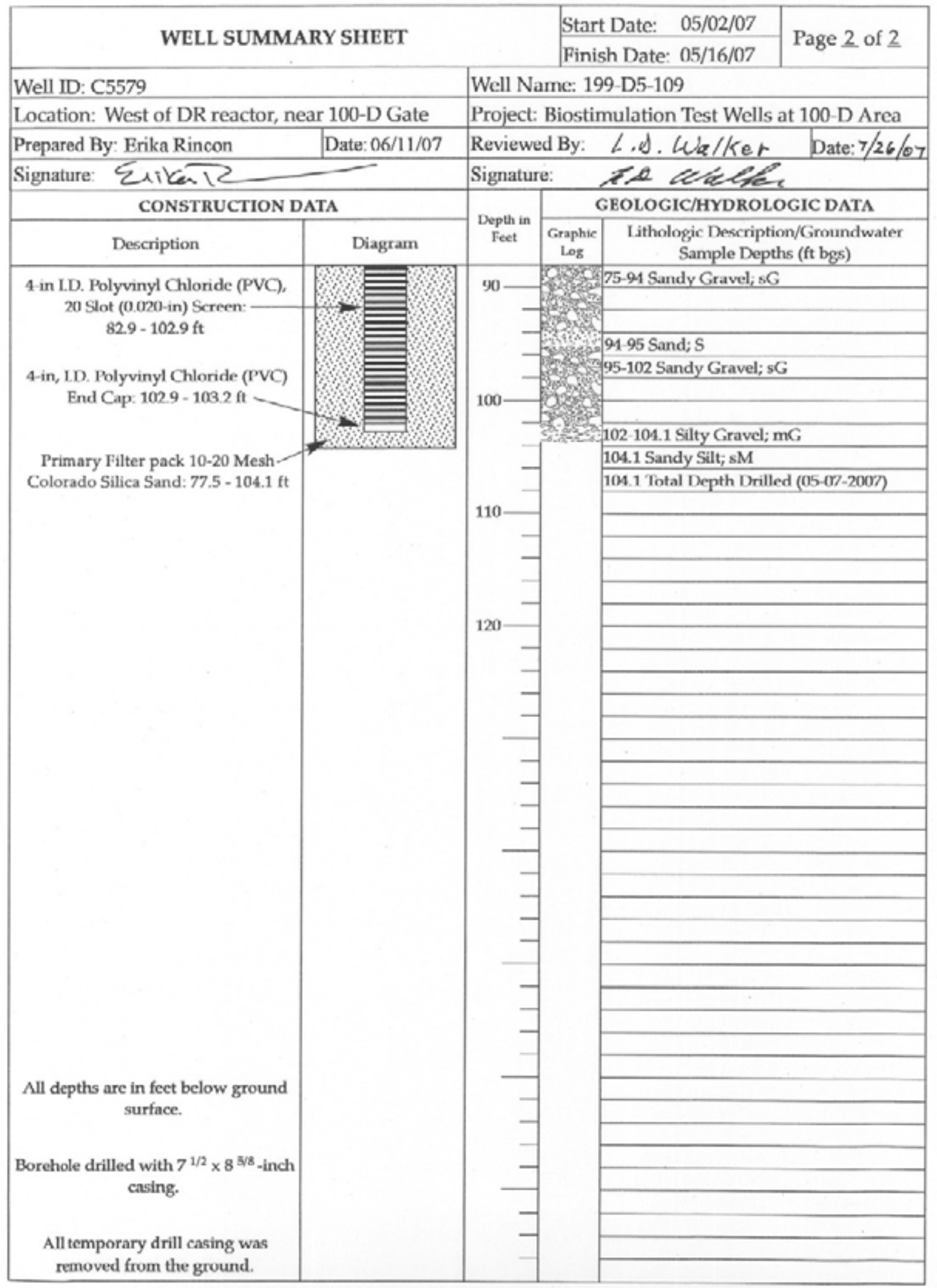




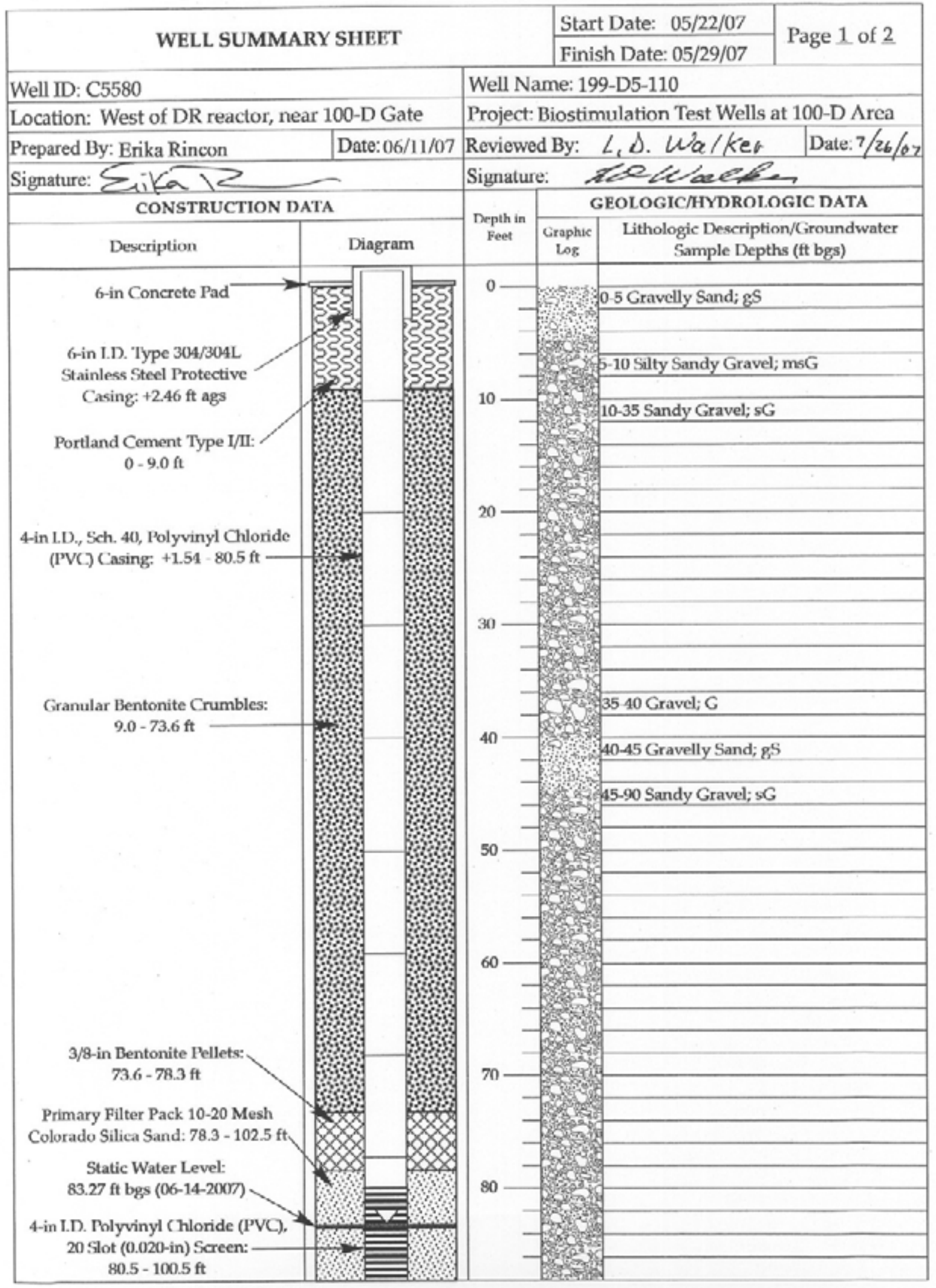




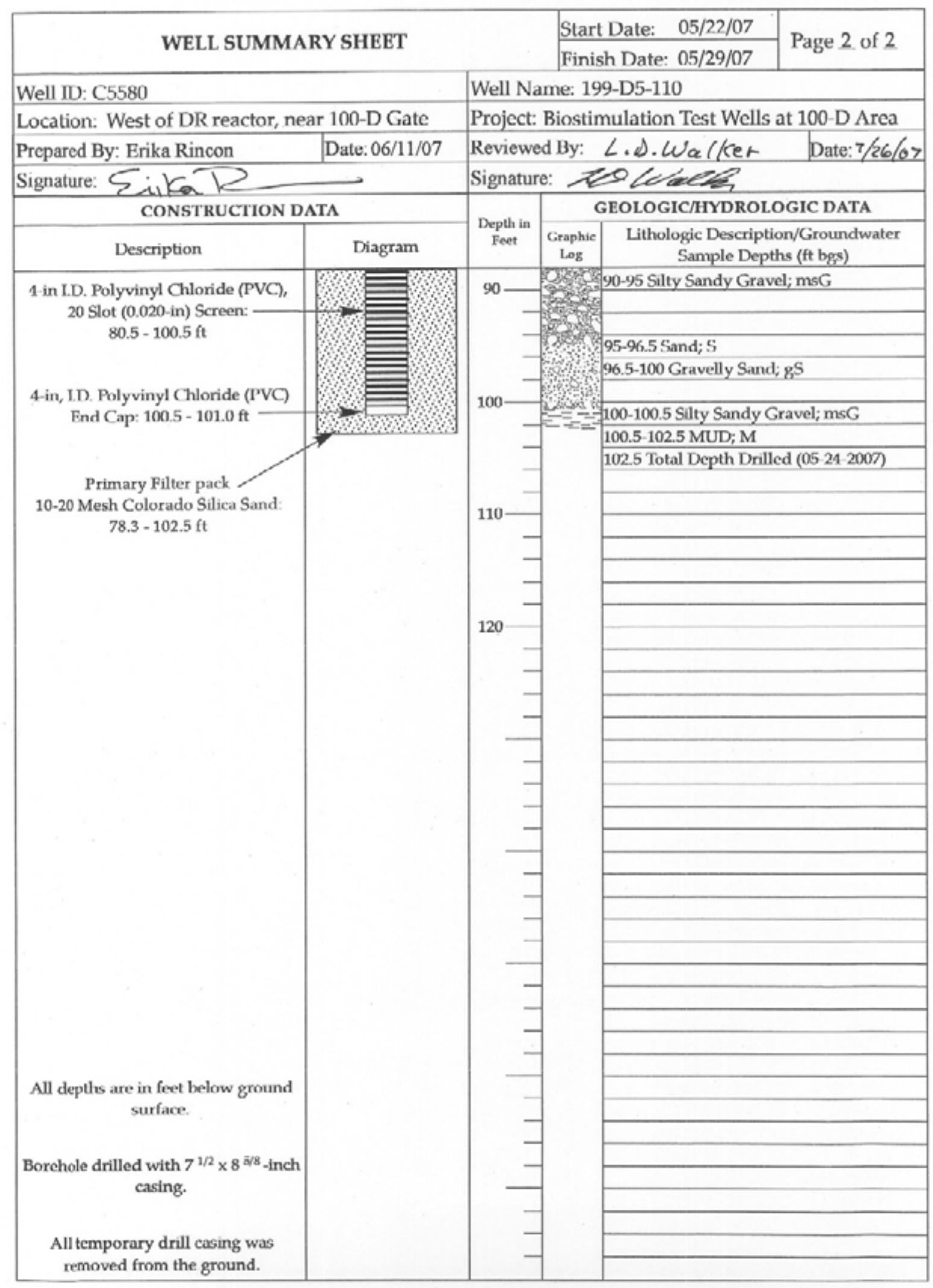




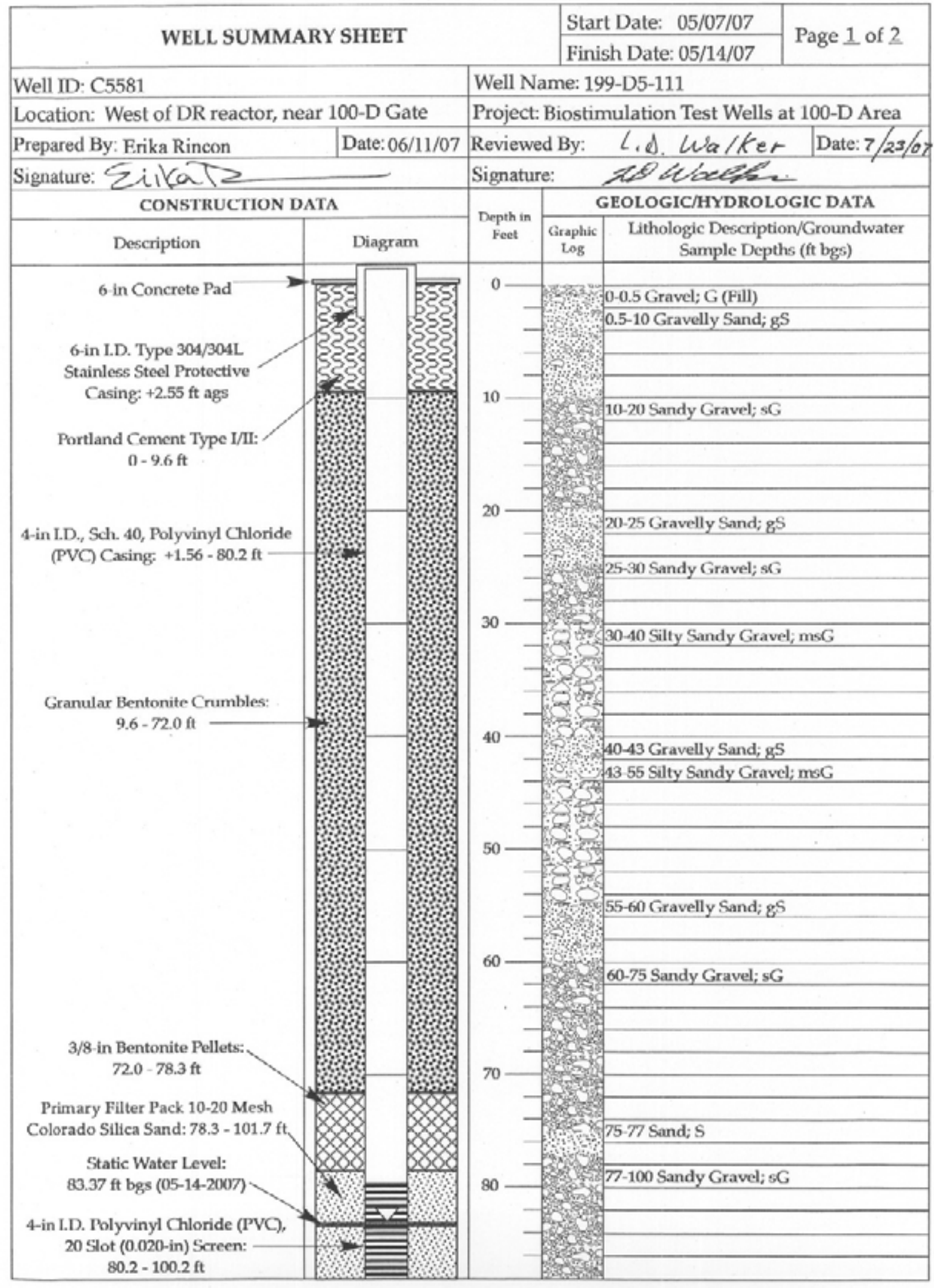




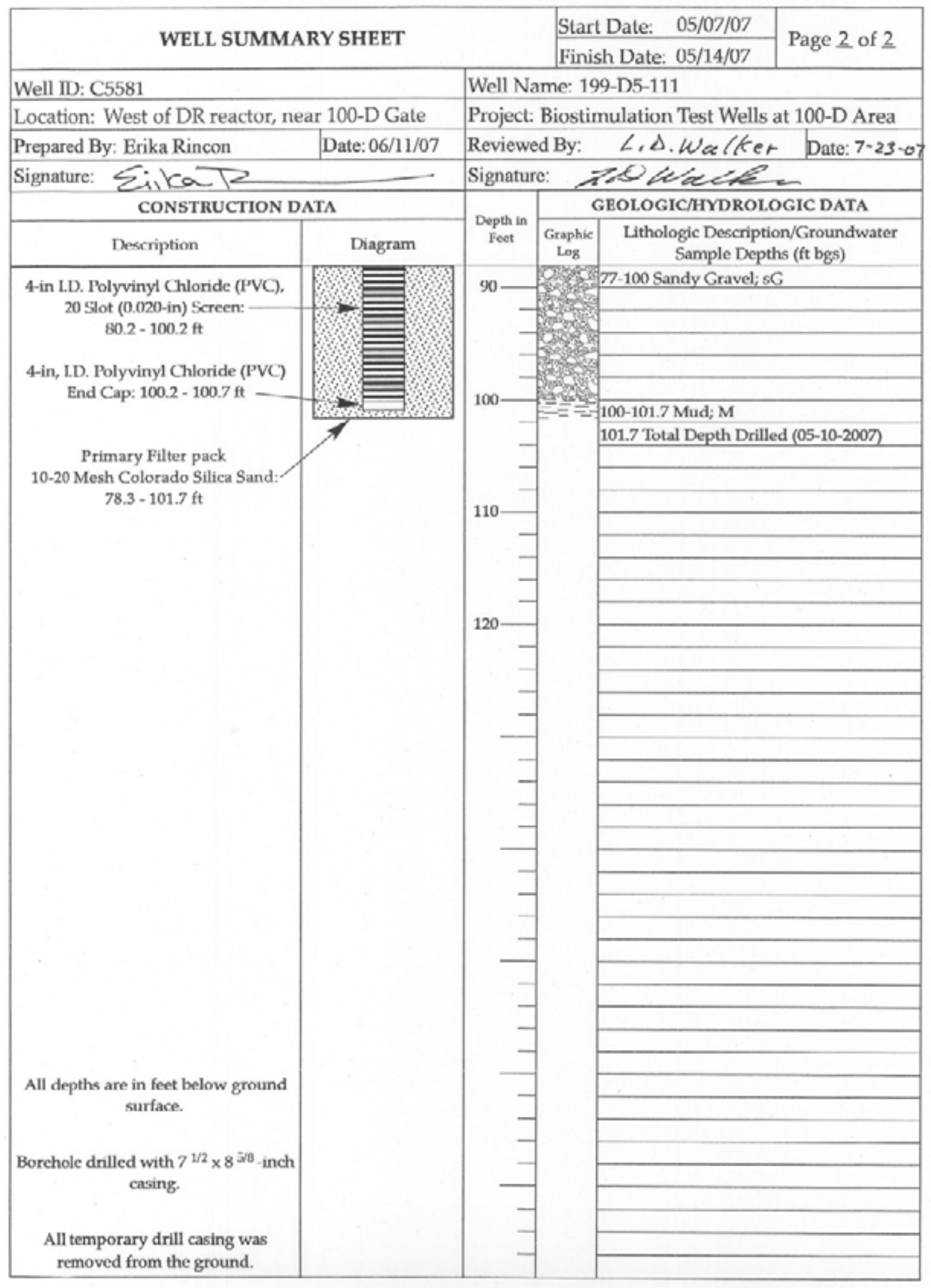




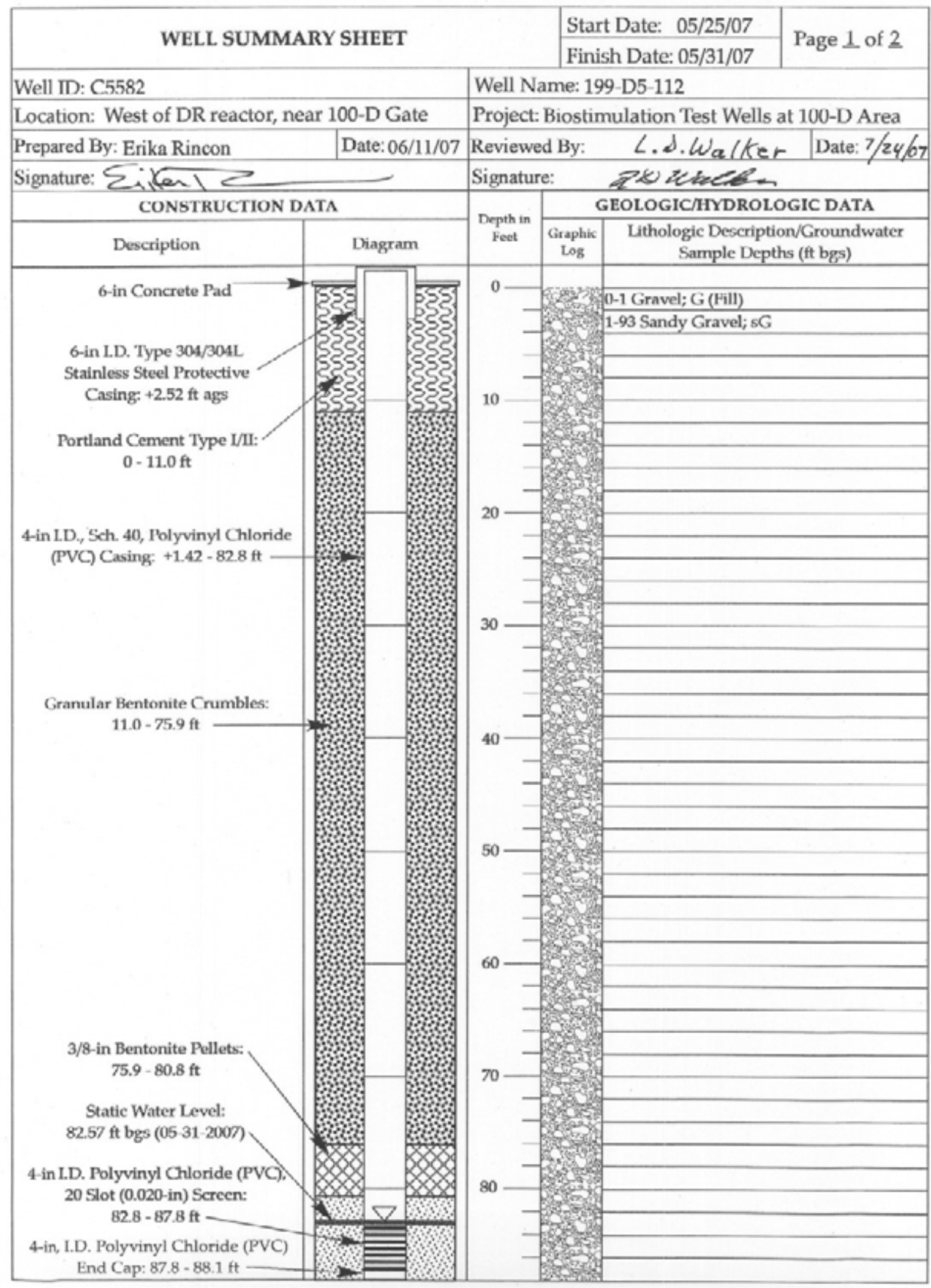




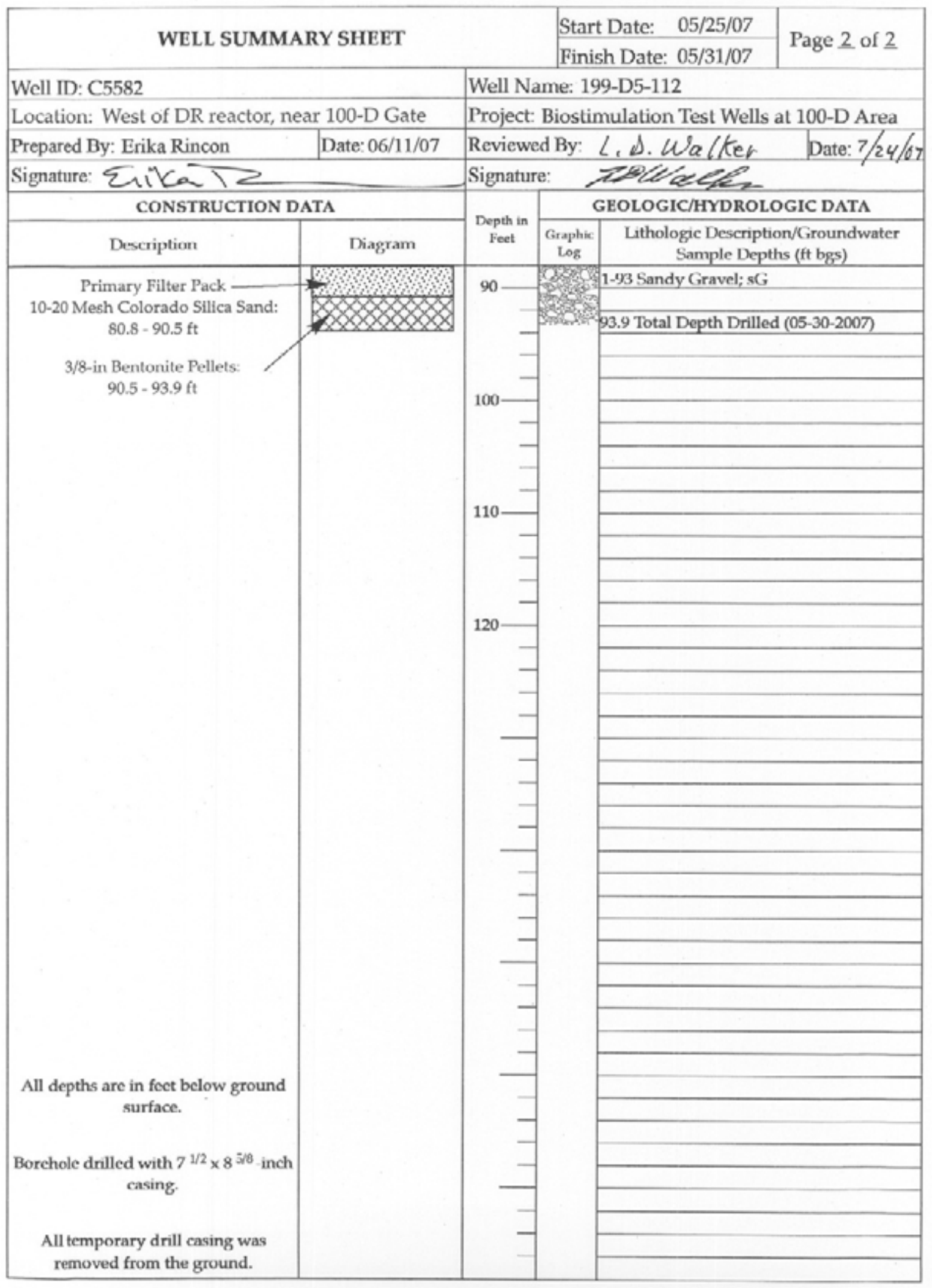




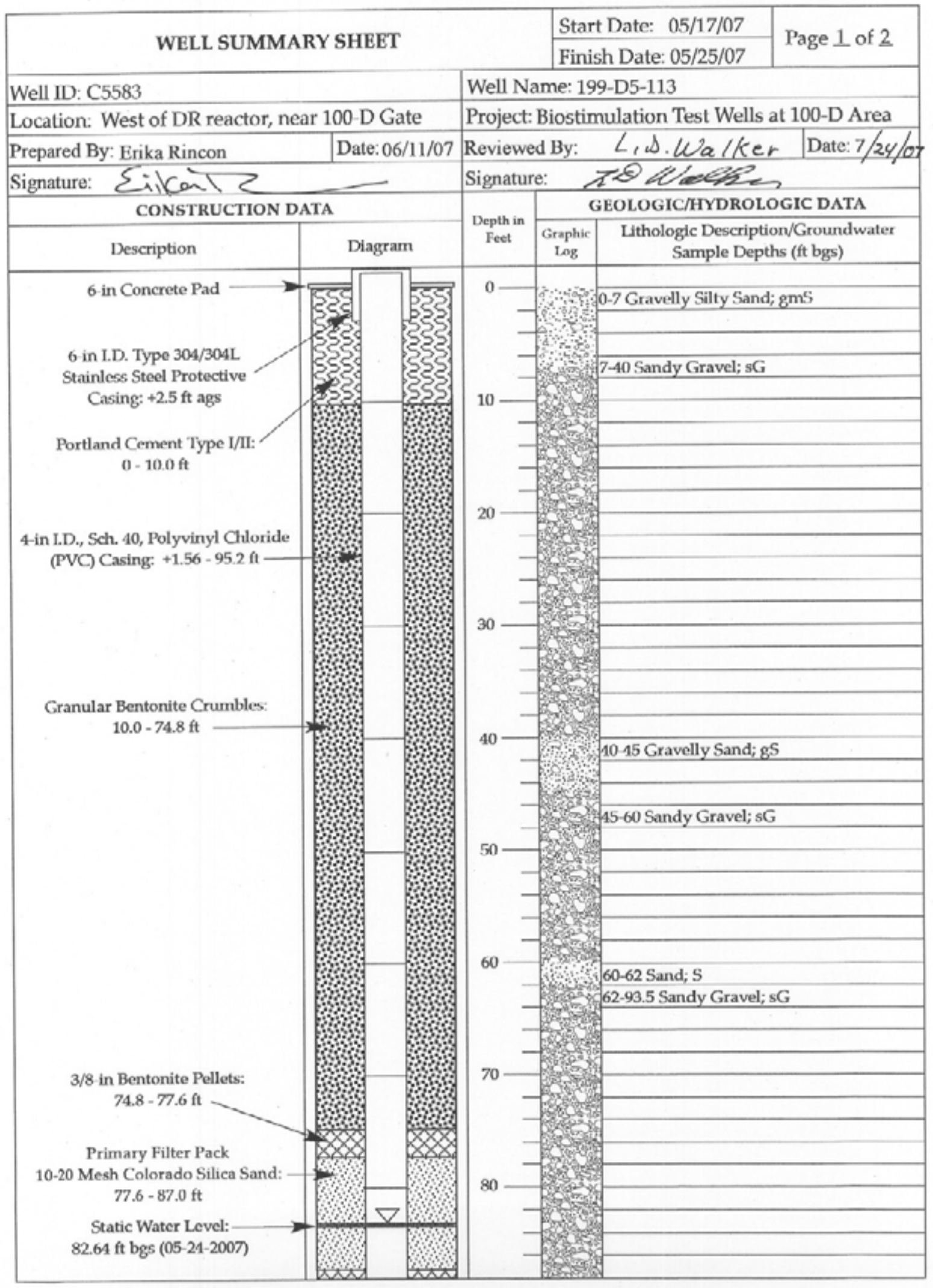




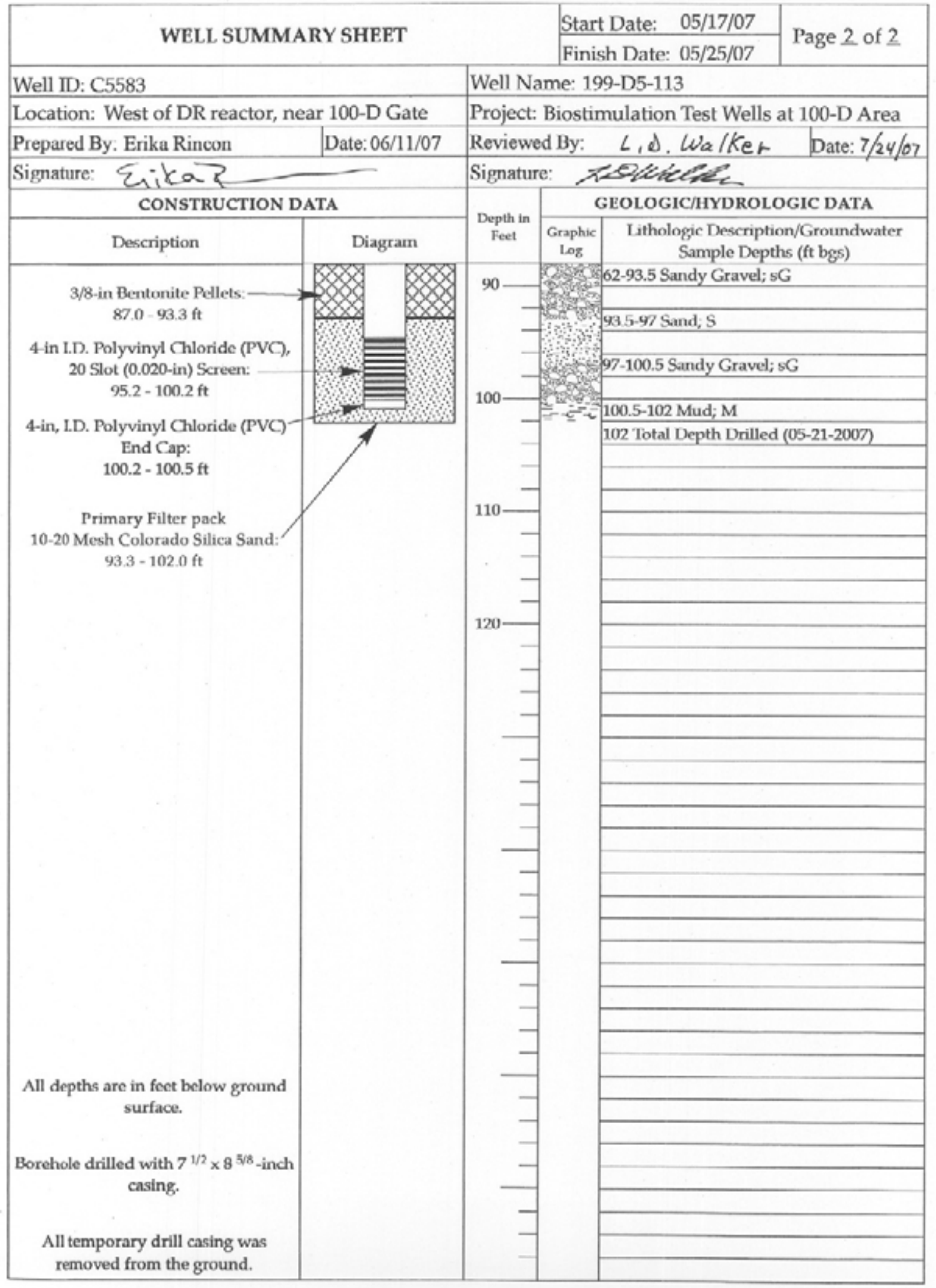




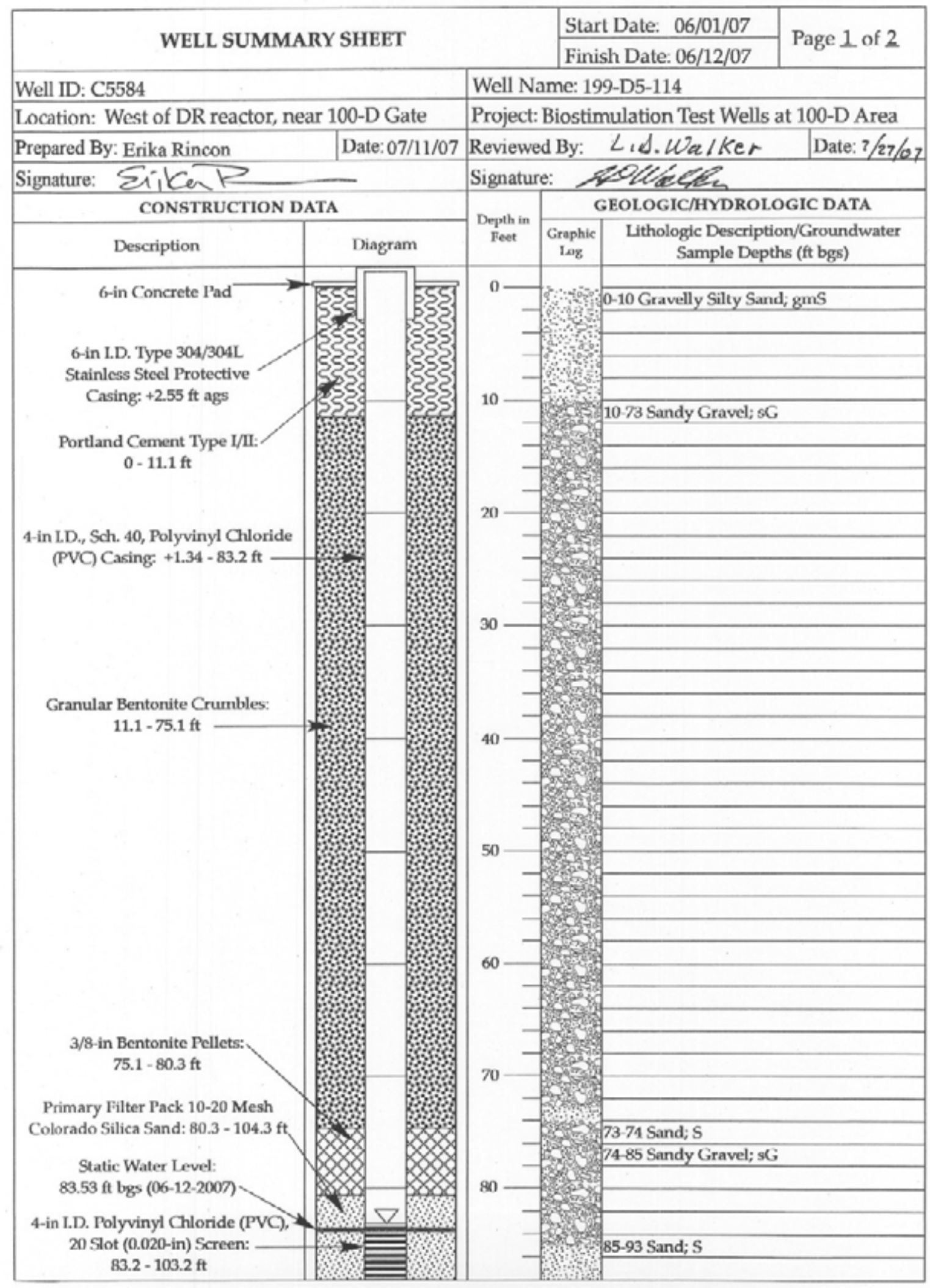




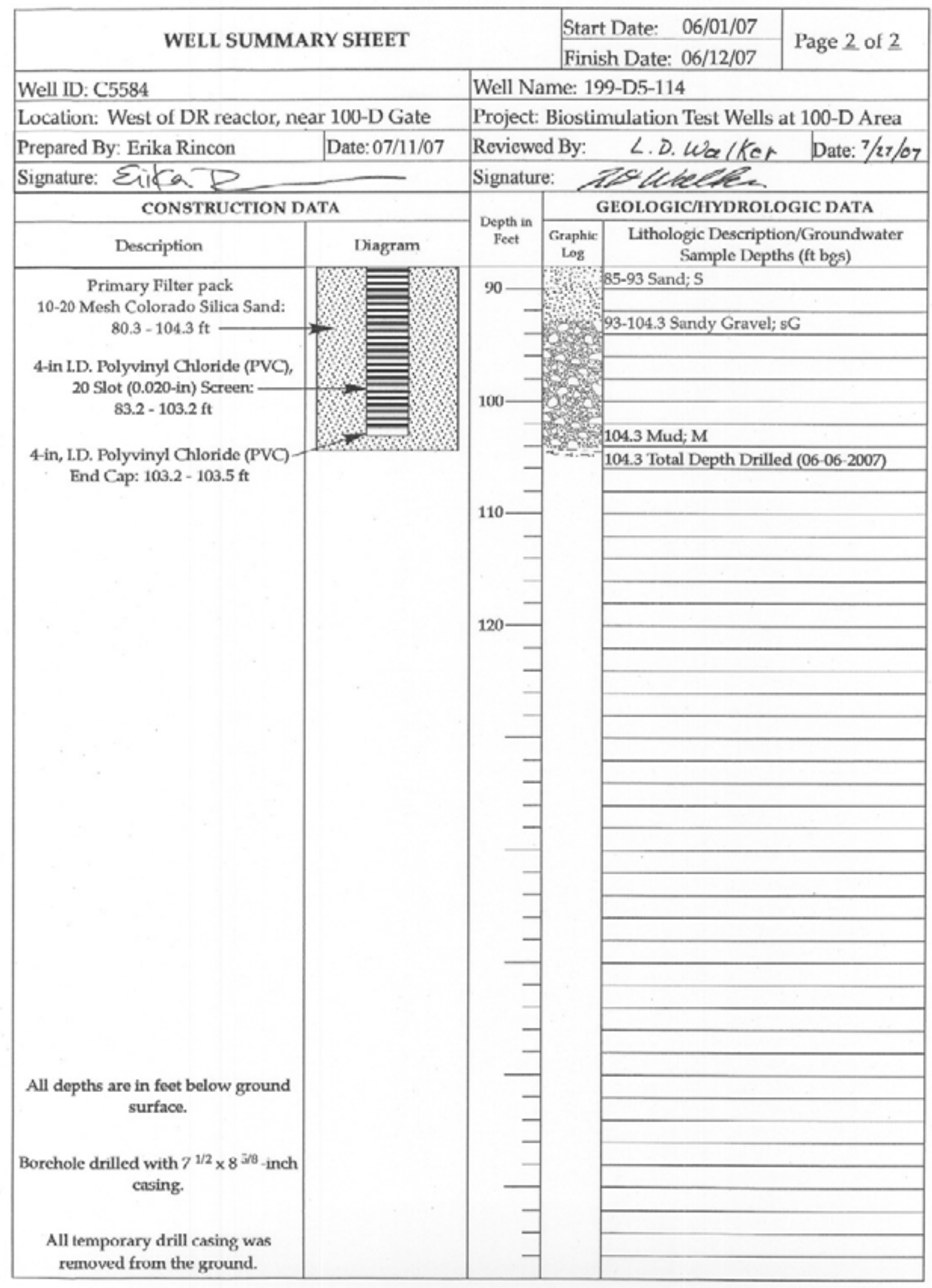




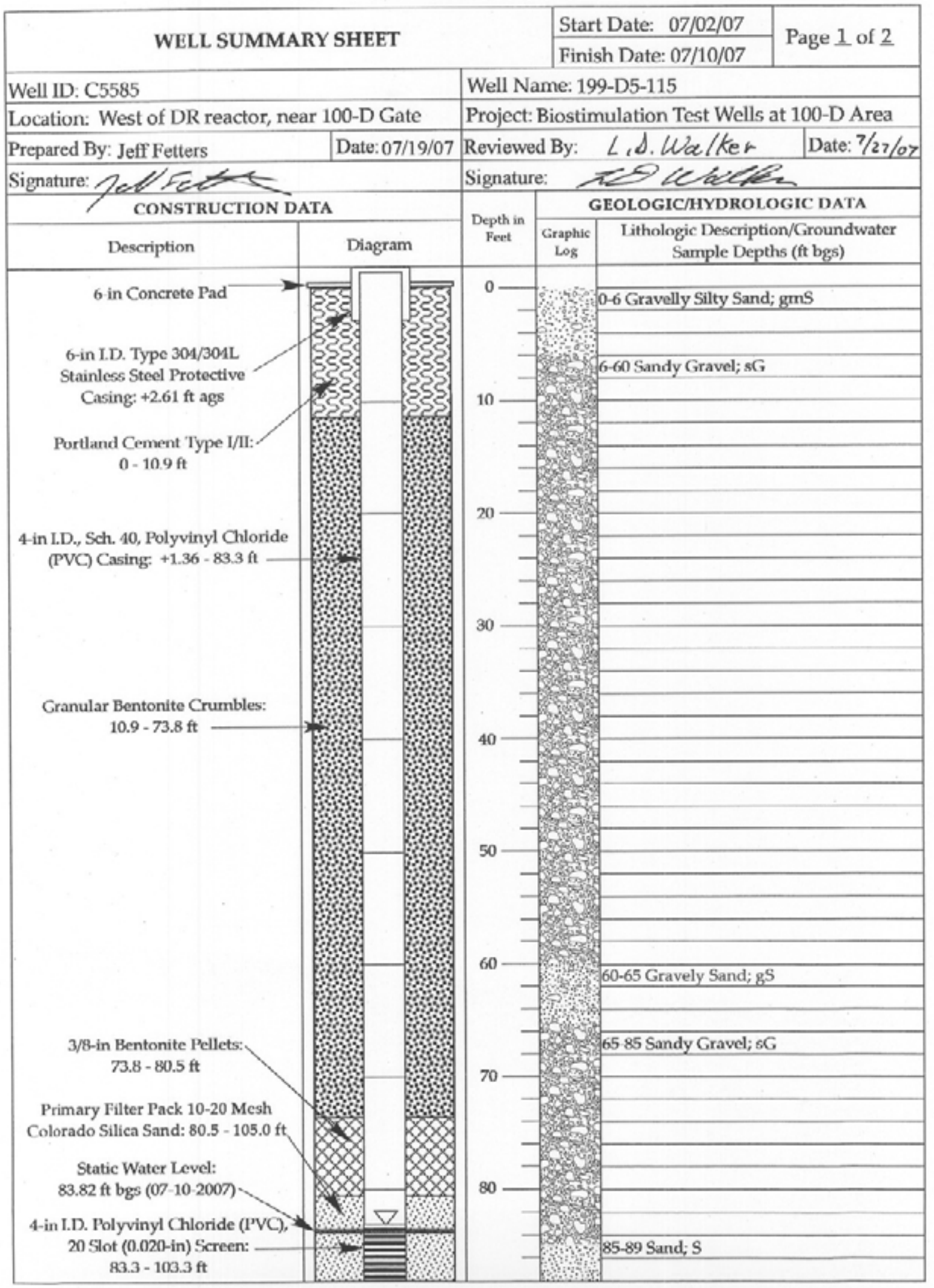




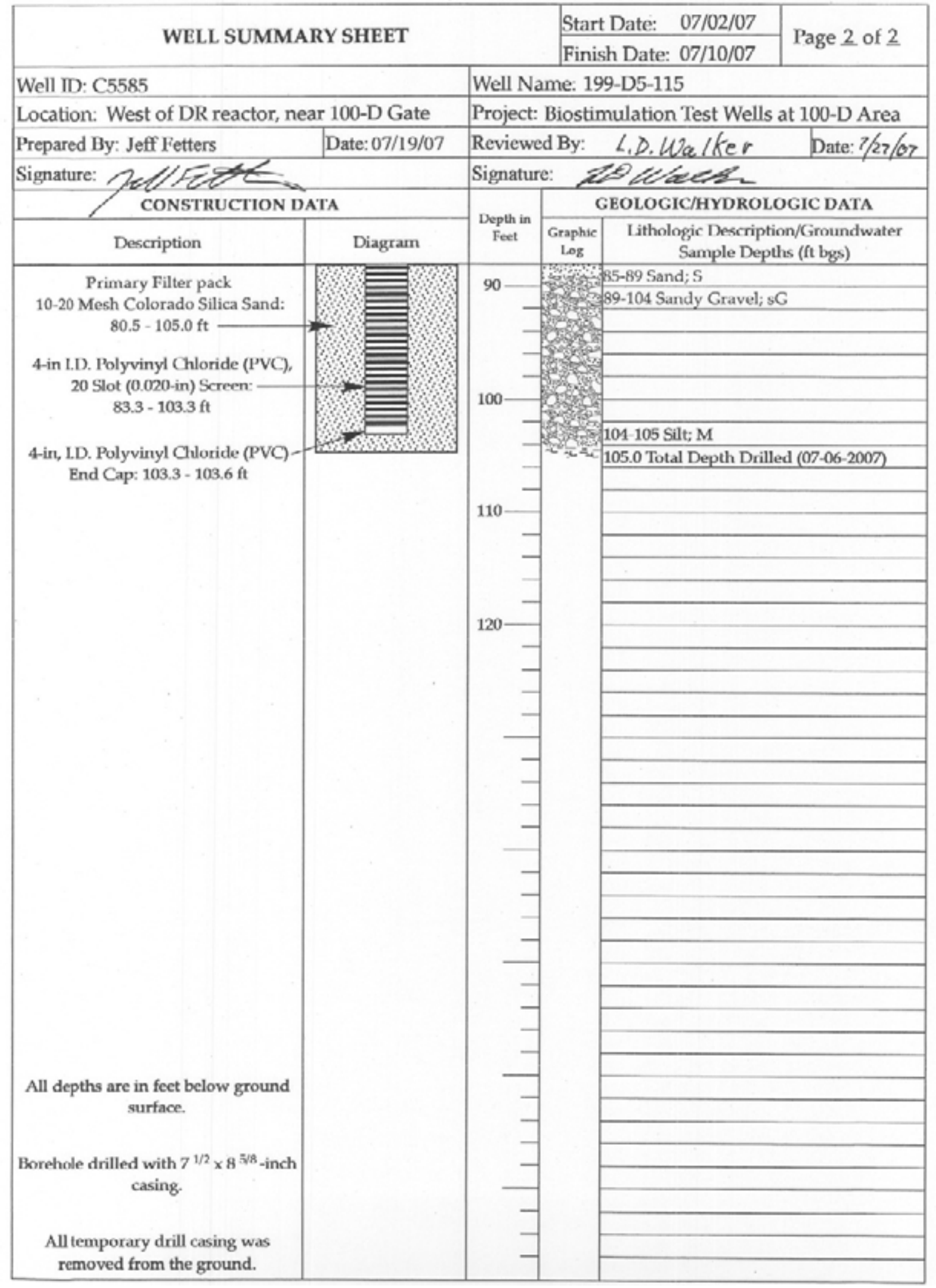




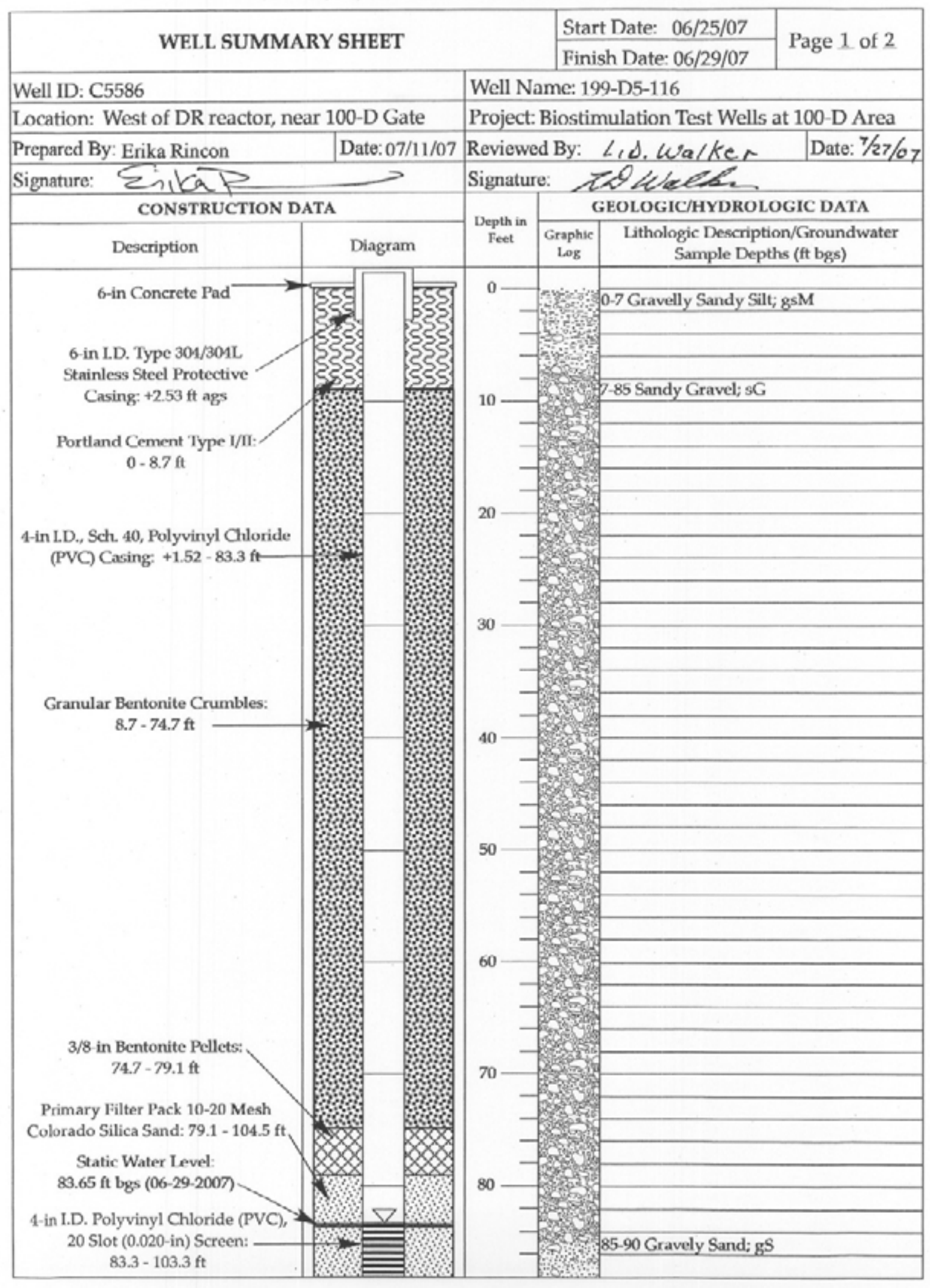




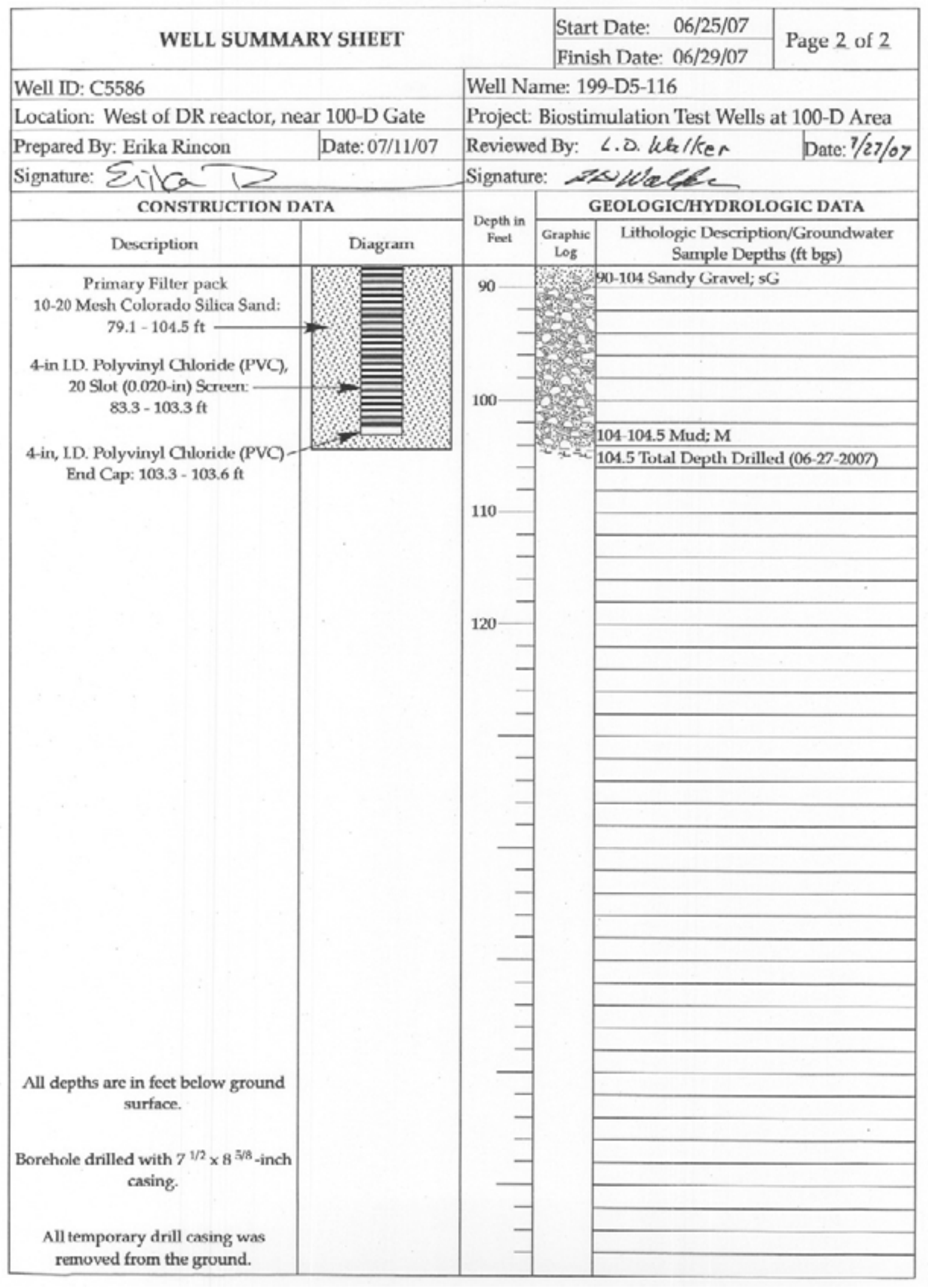




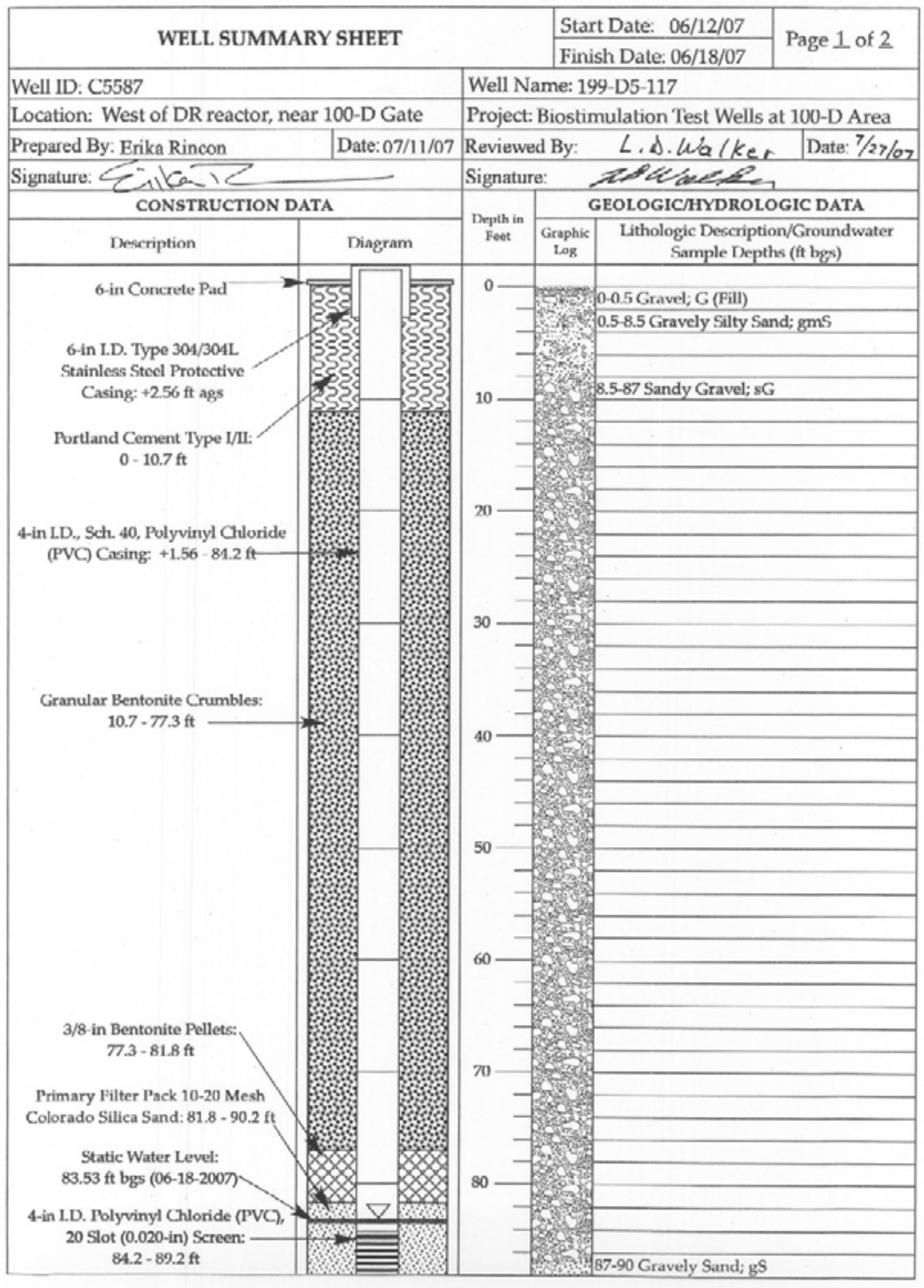




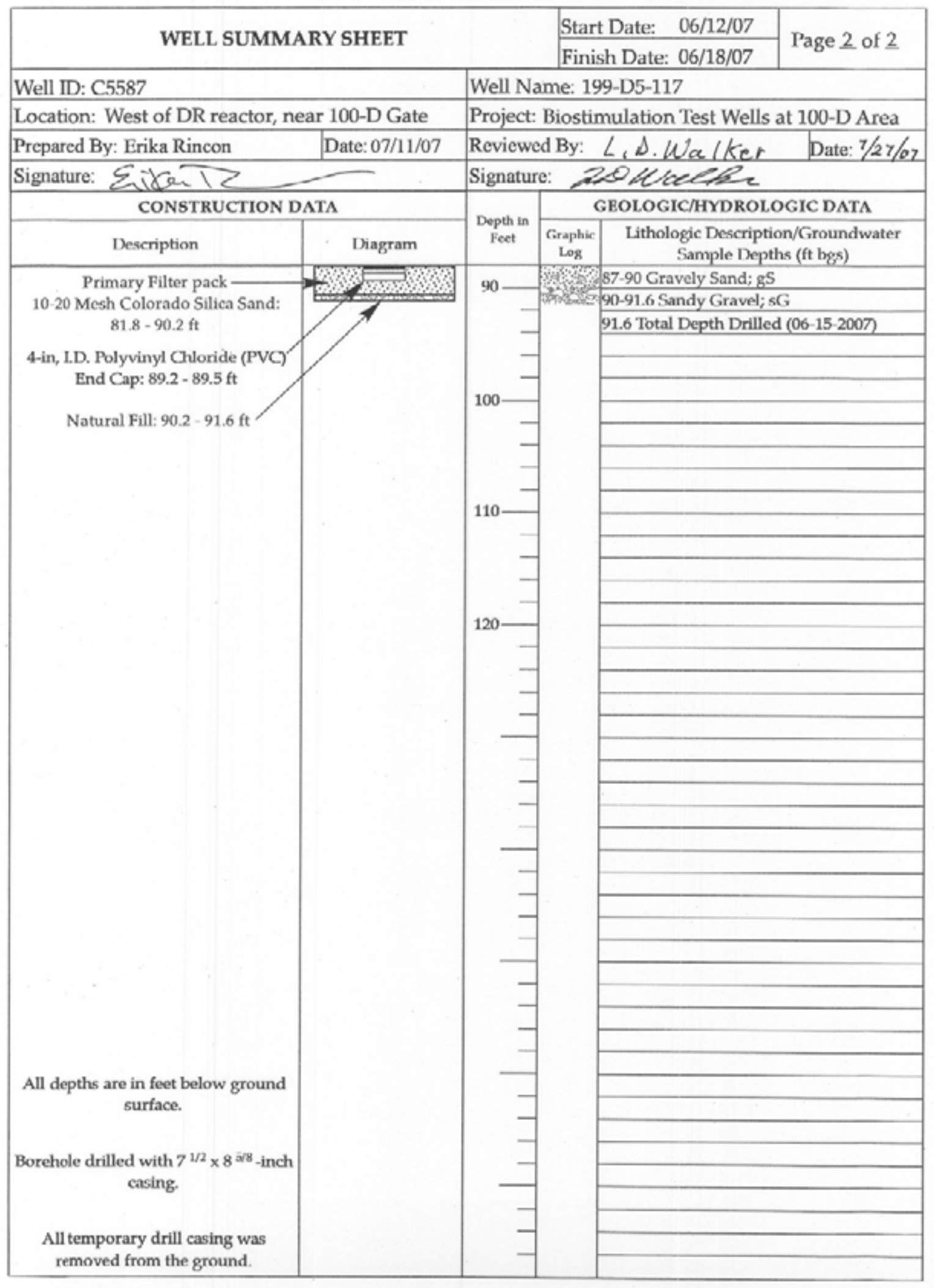




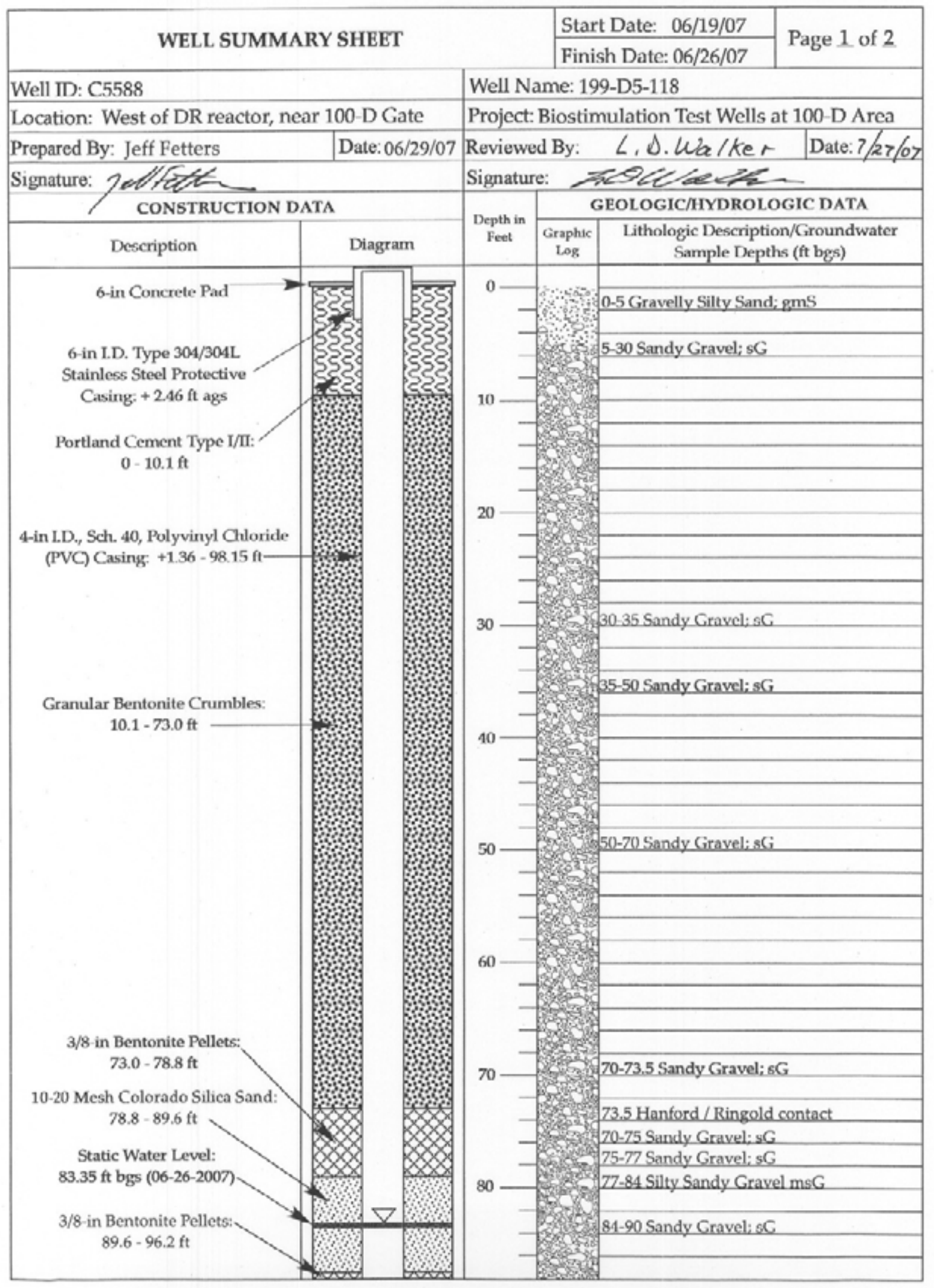




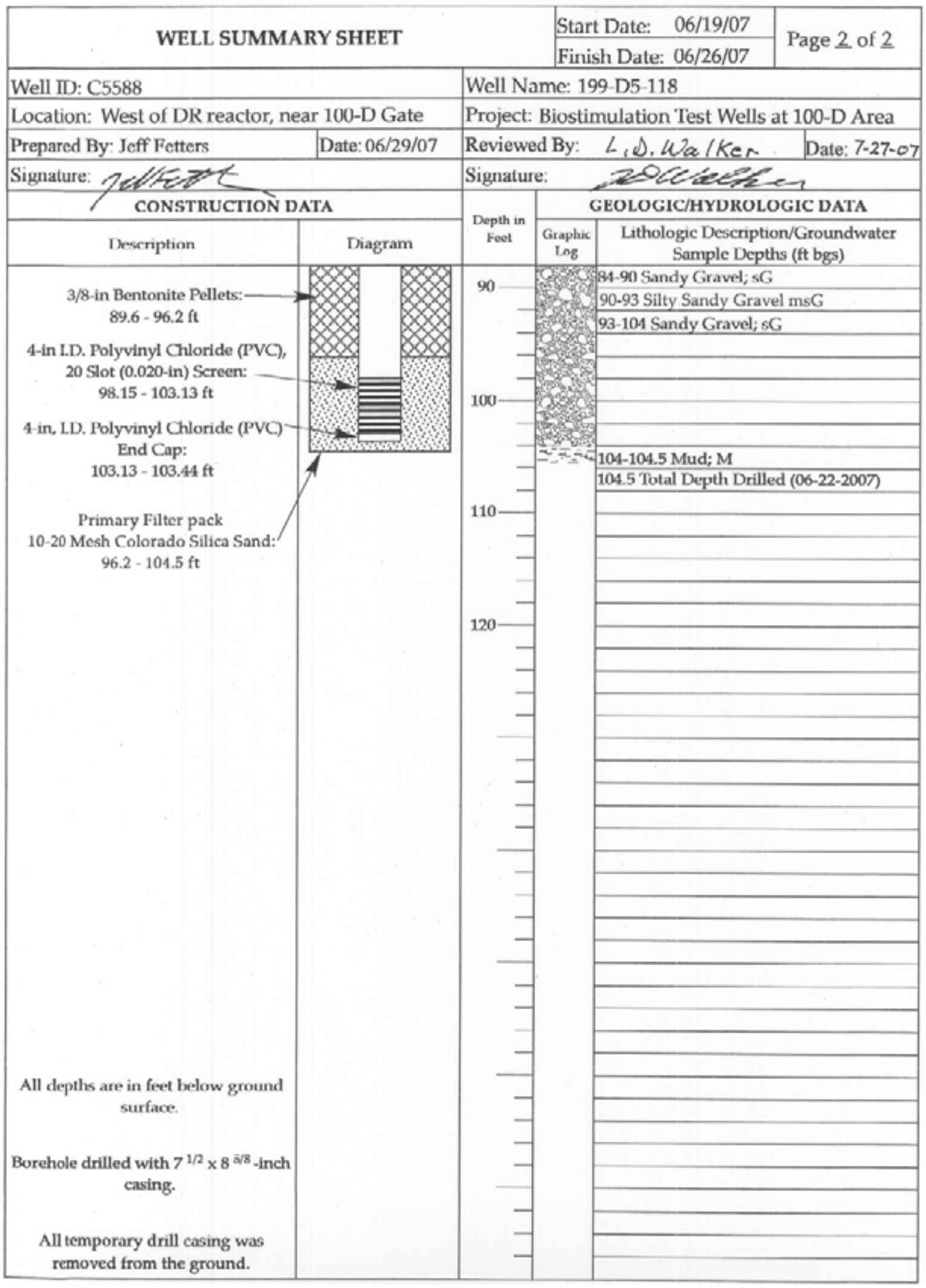




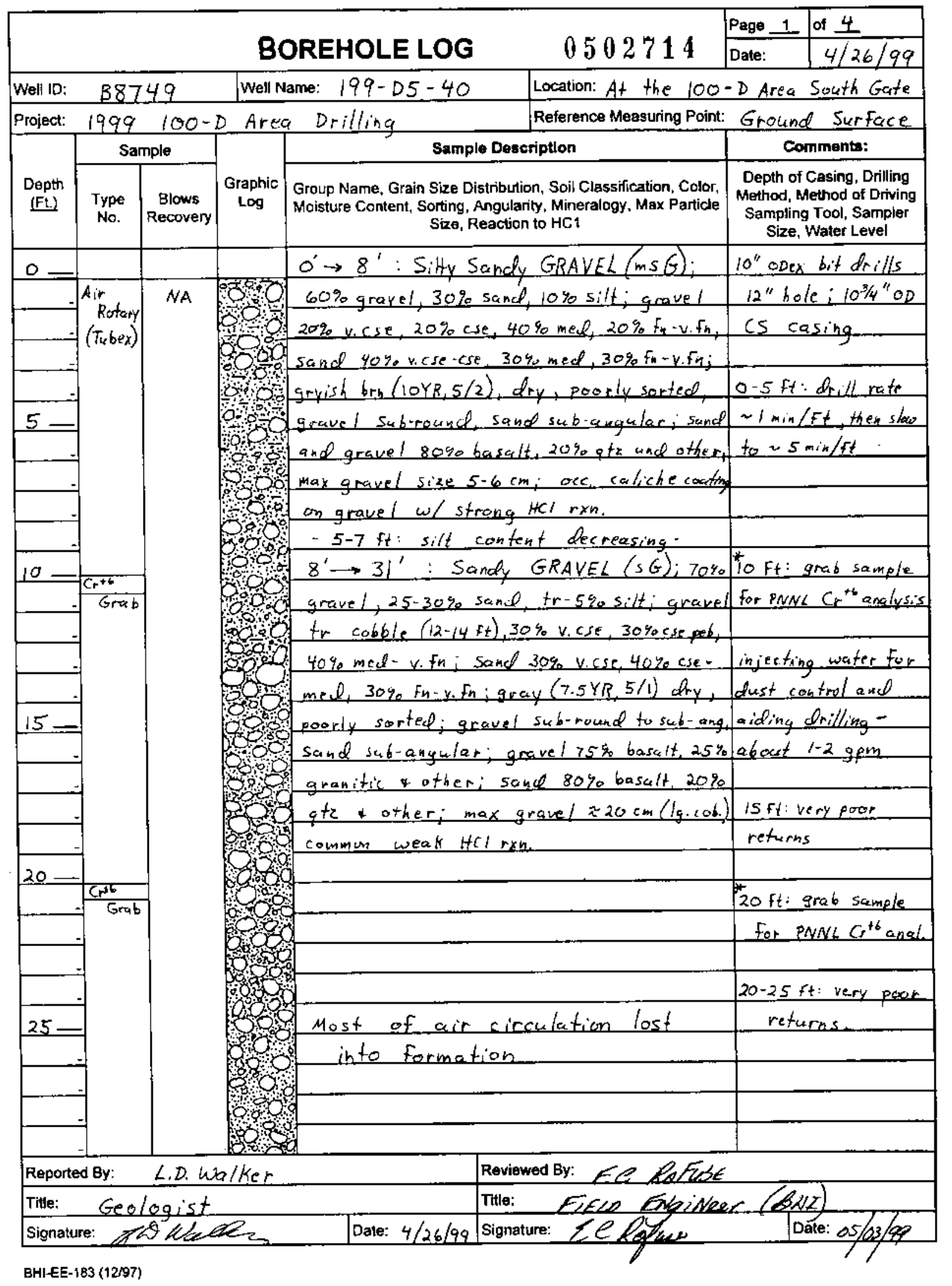




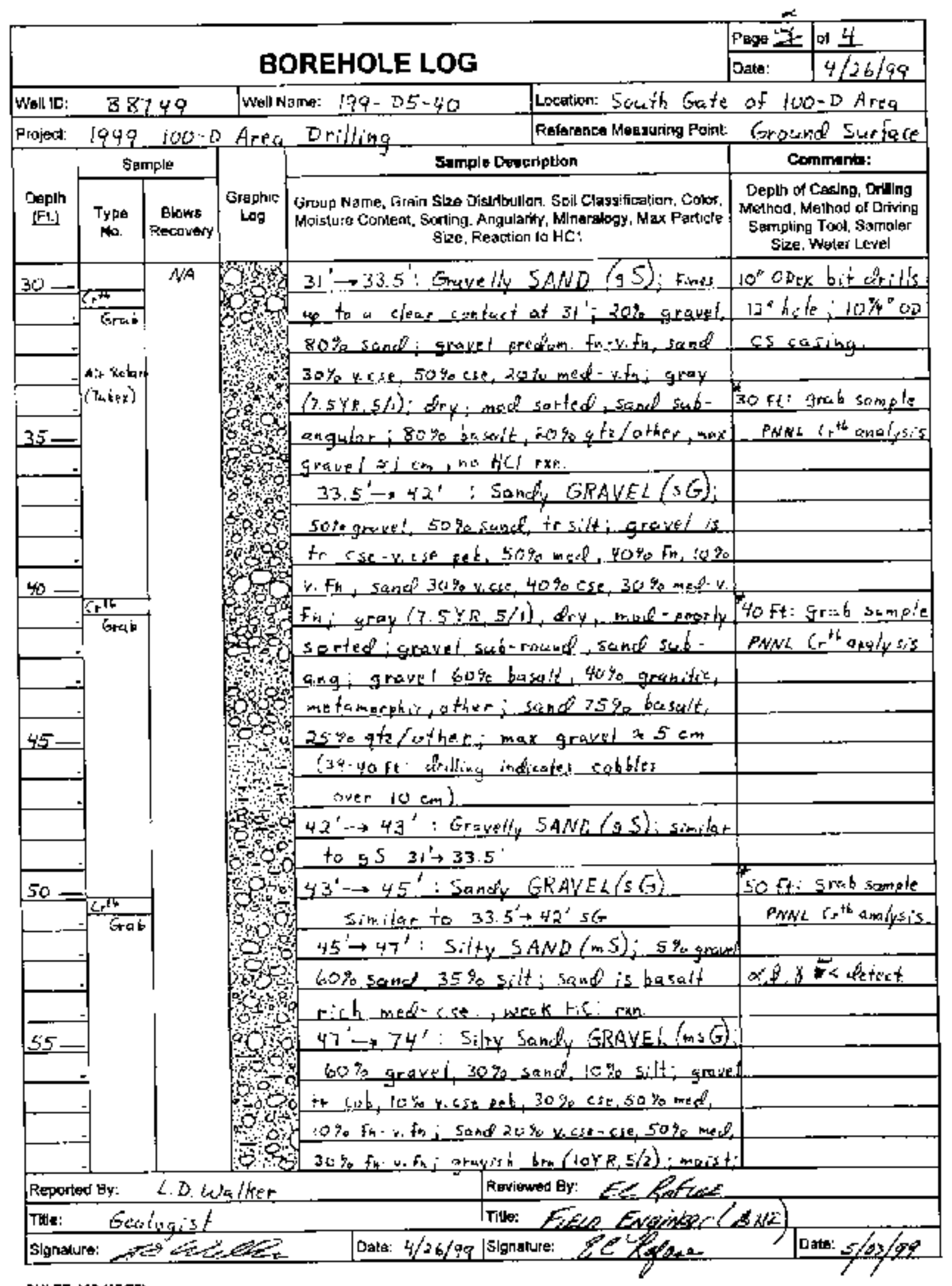

BHI.EE-183 [12/87] 
3

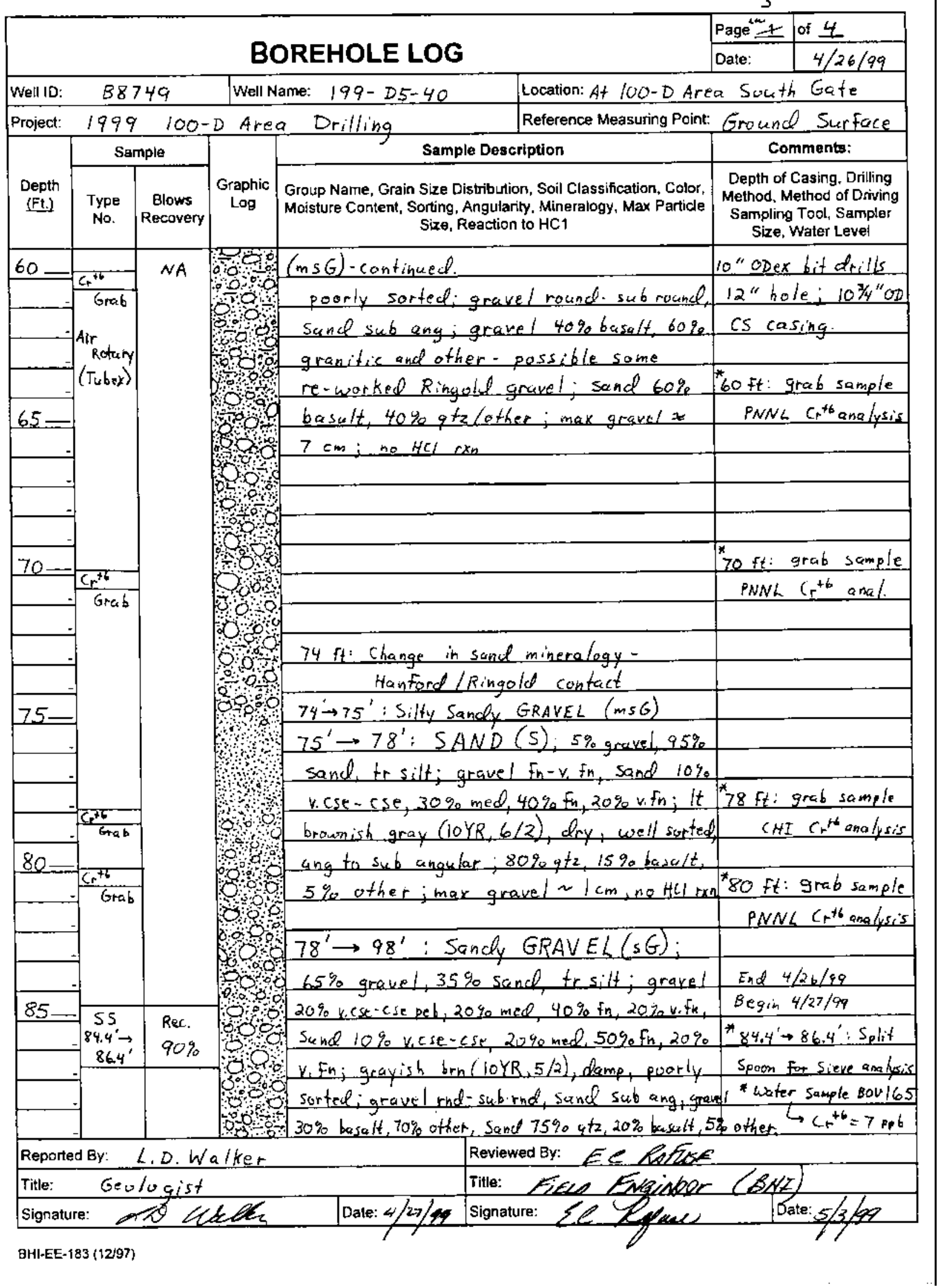




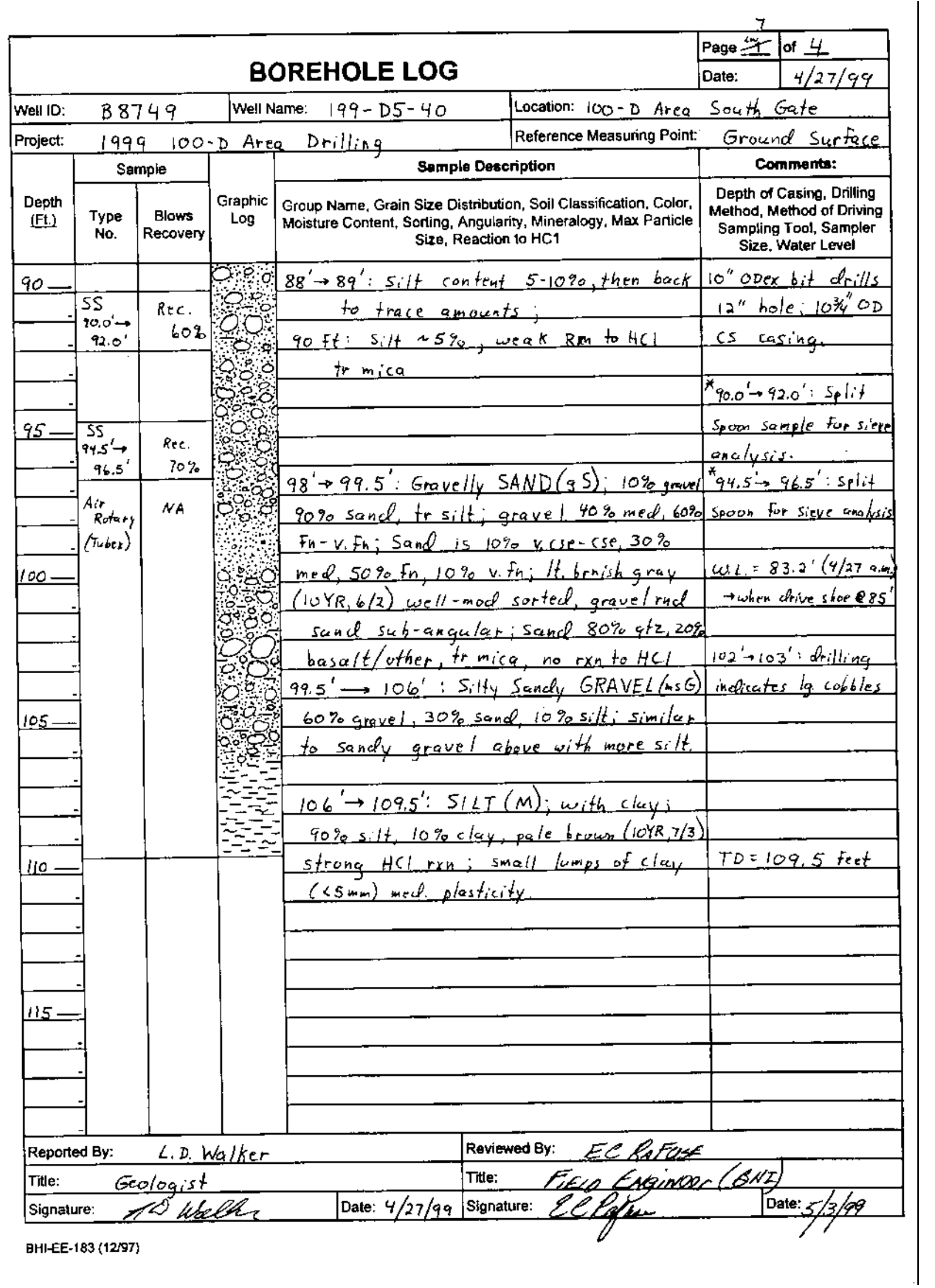




\section{7}

WELL SUMMARY SHEET

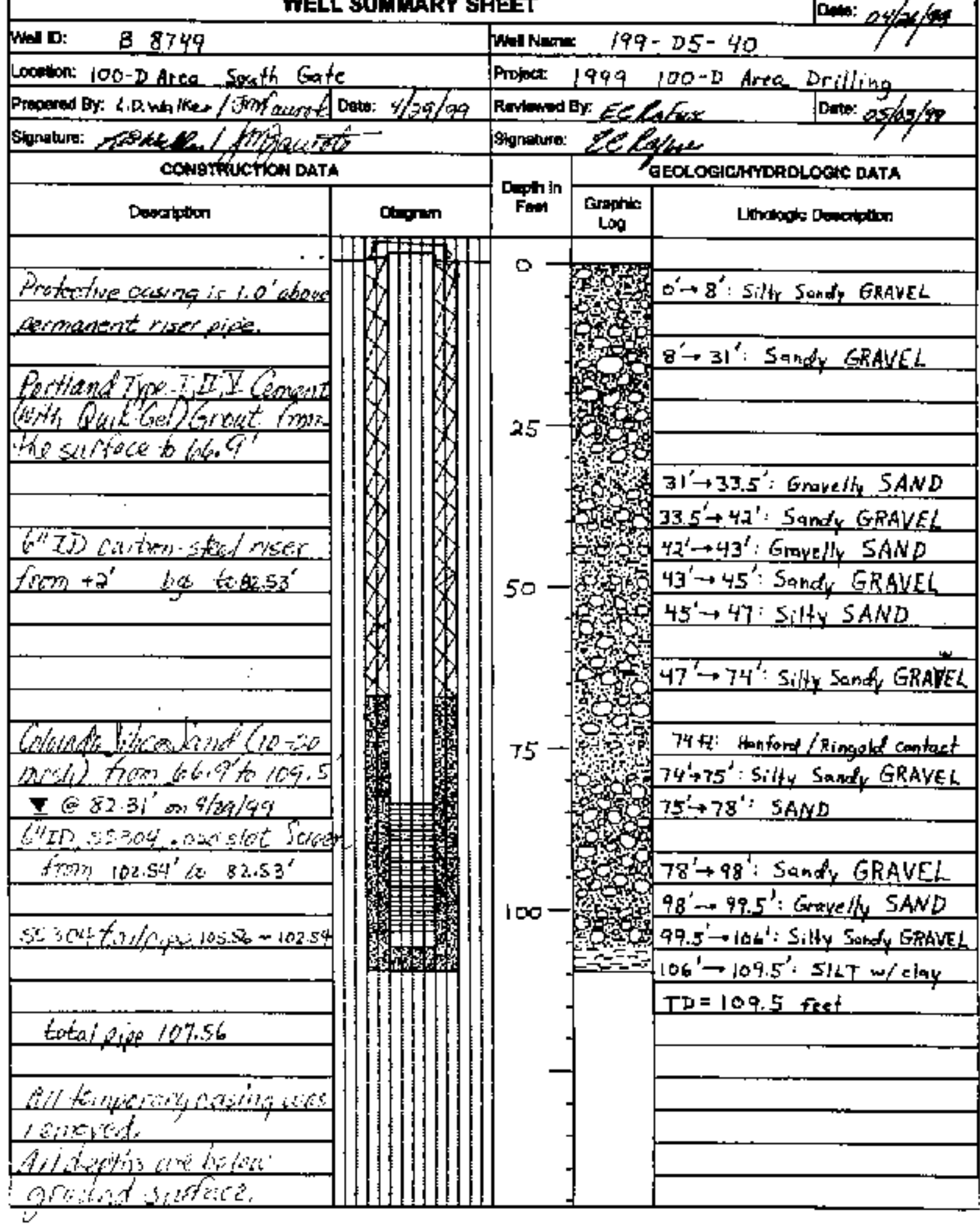




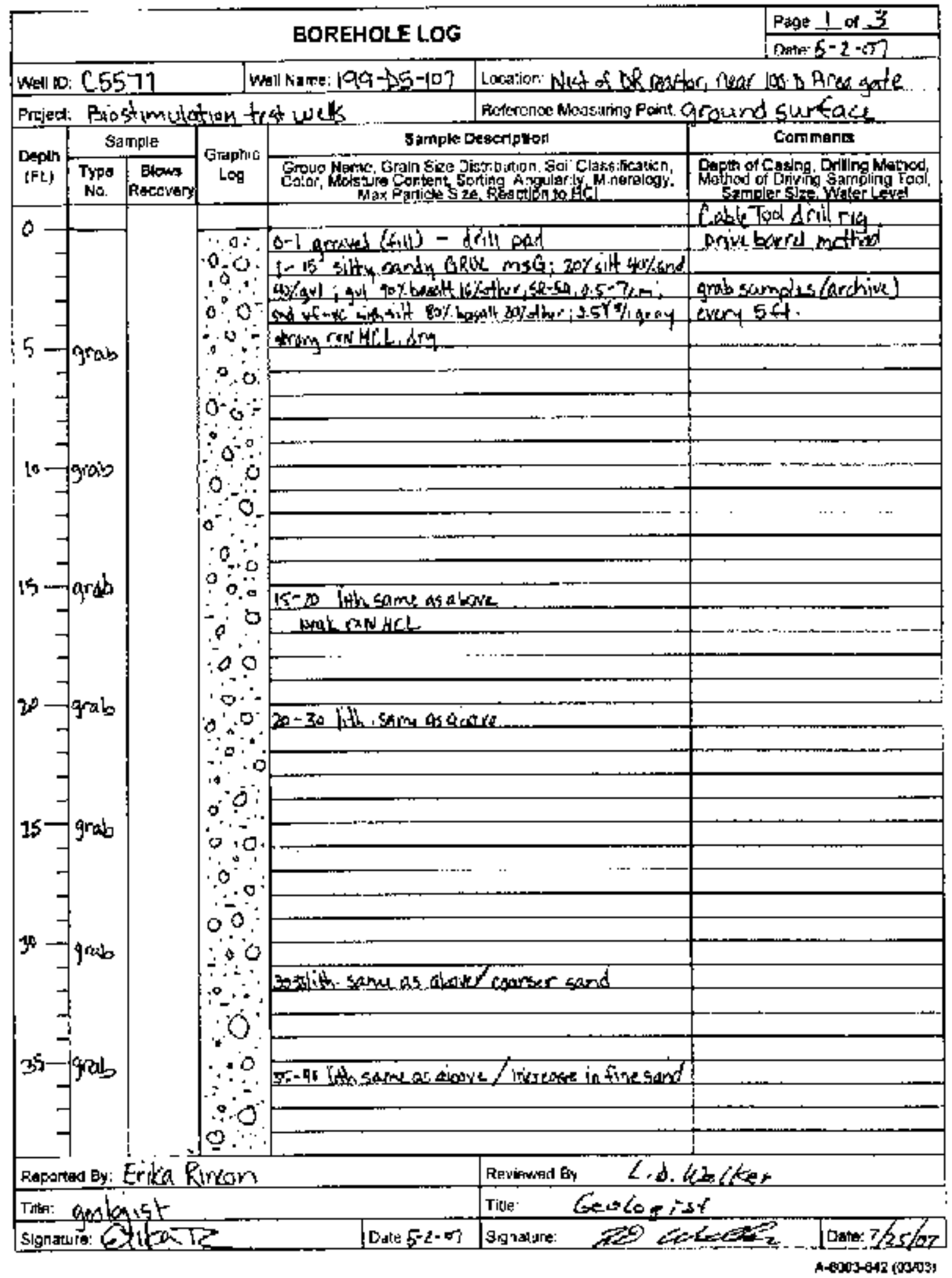




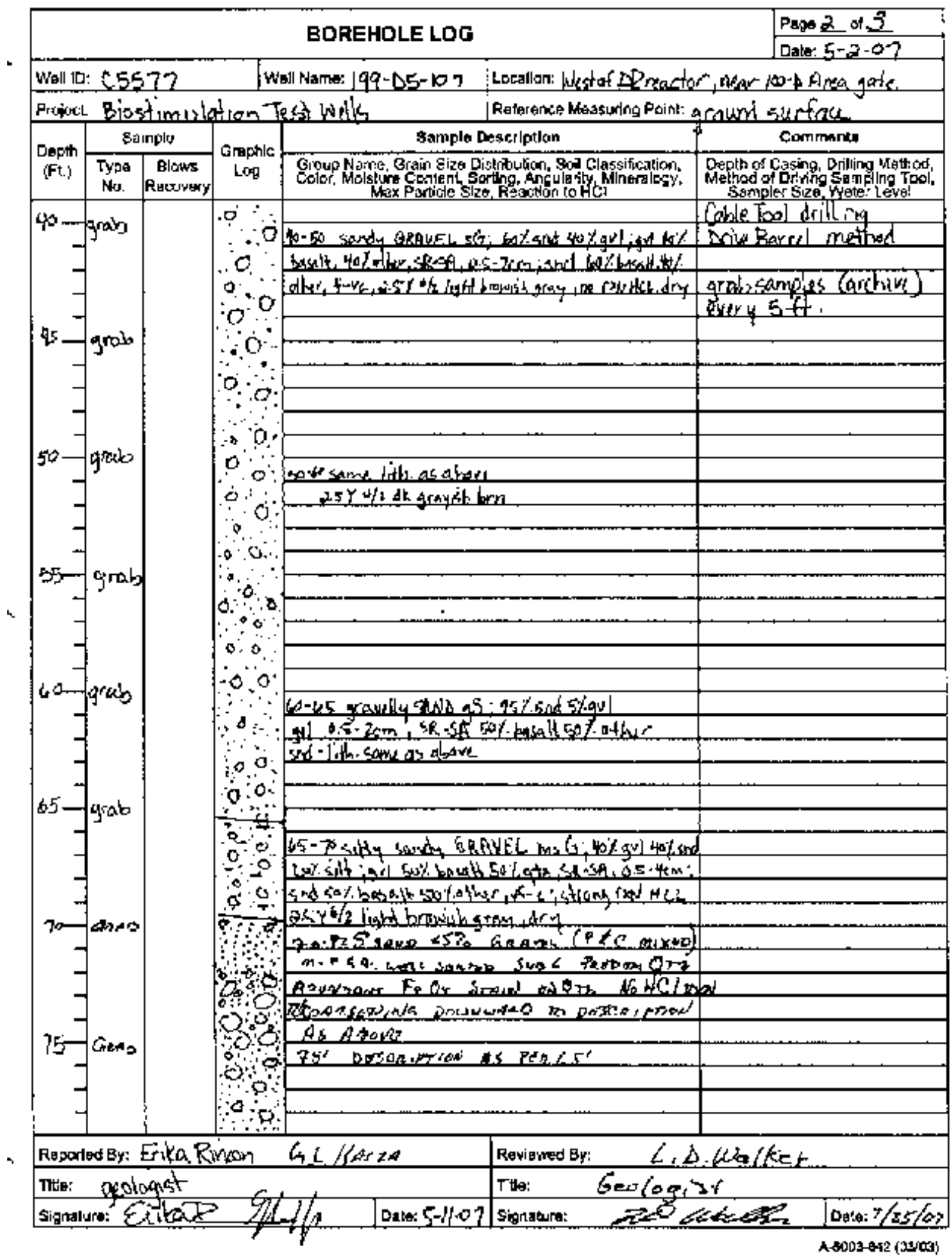




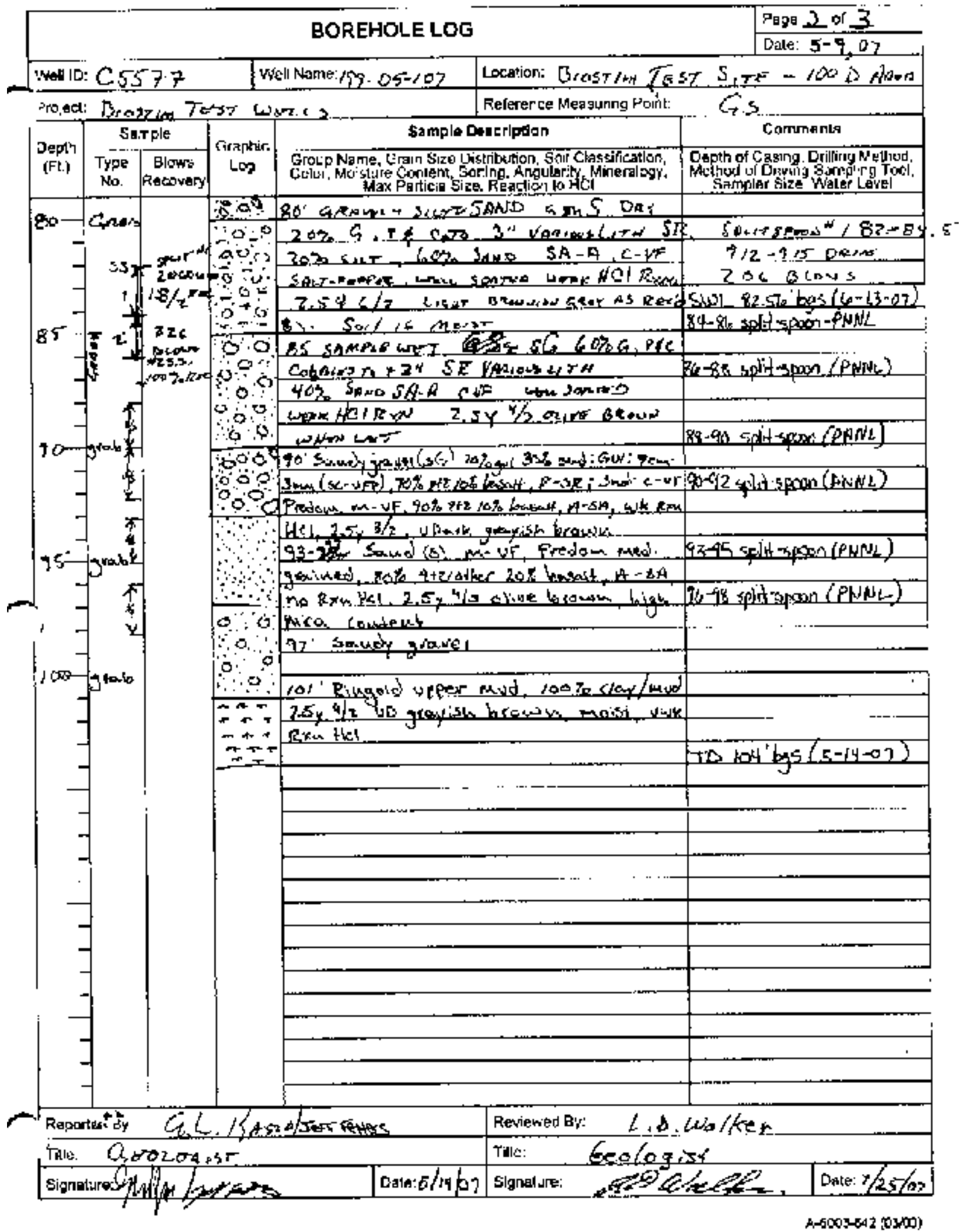




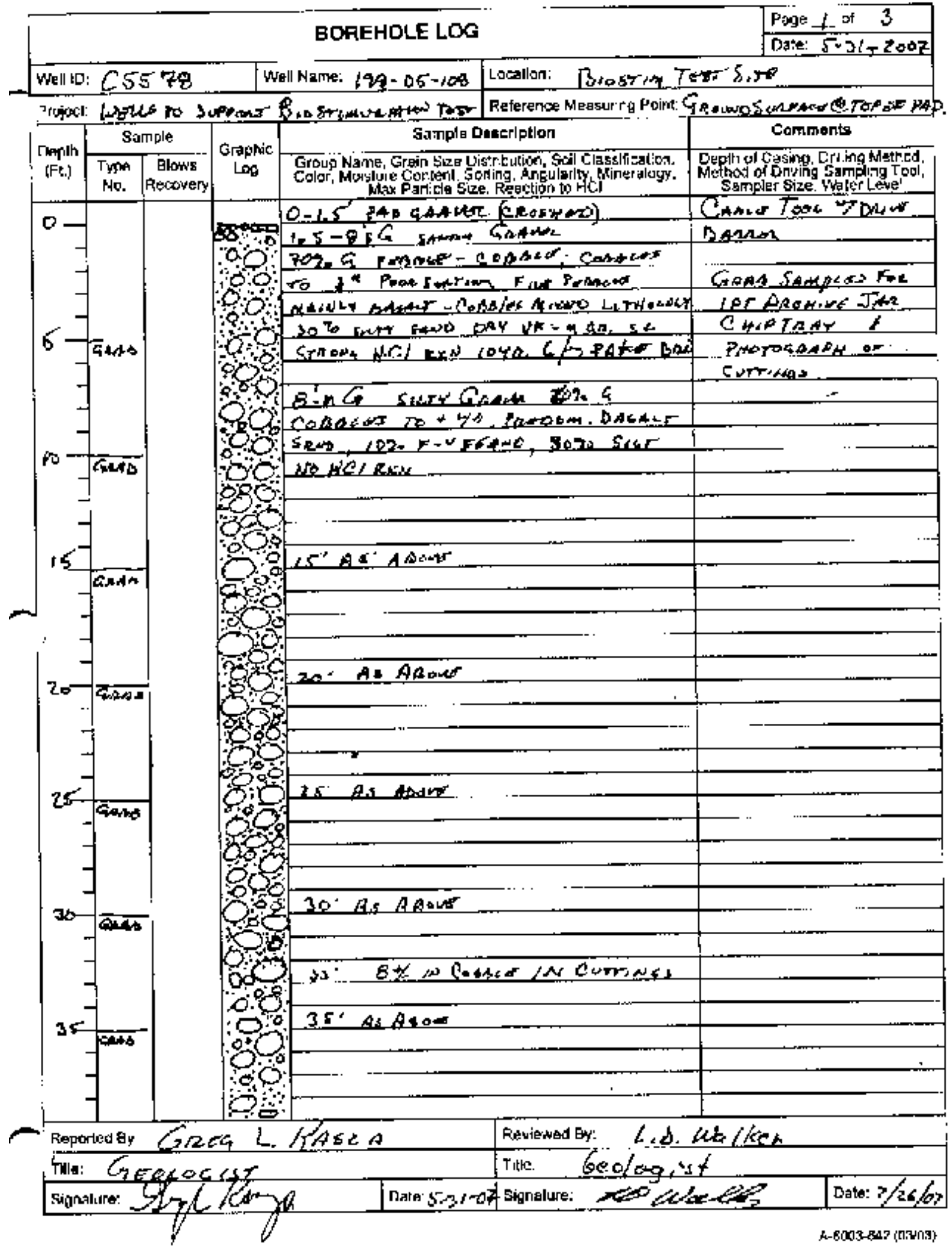




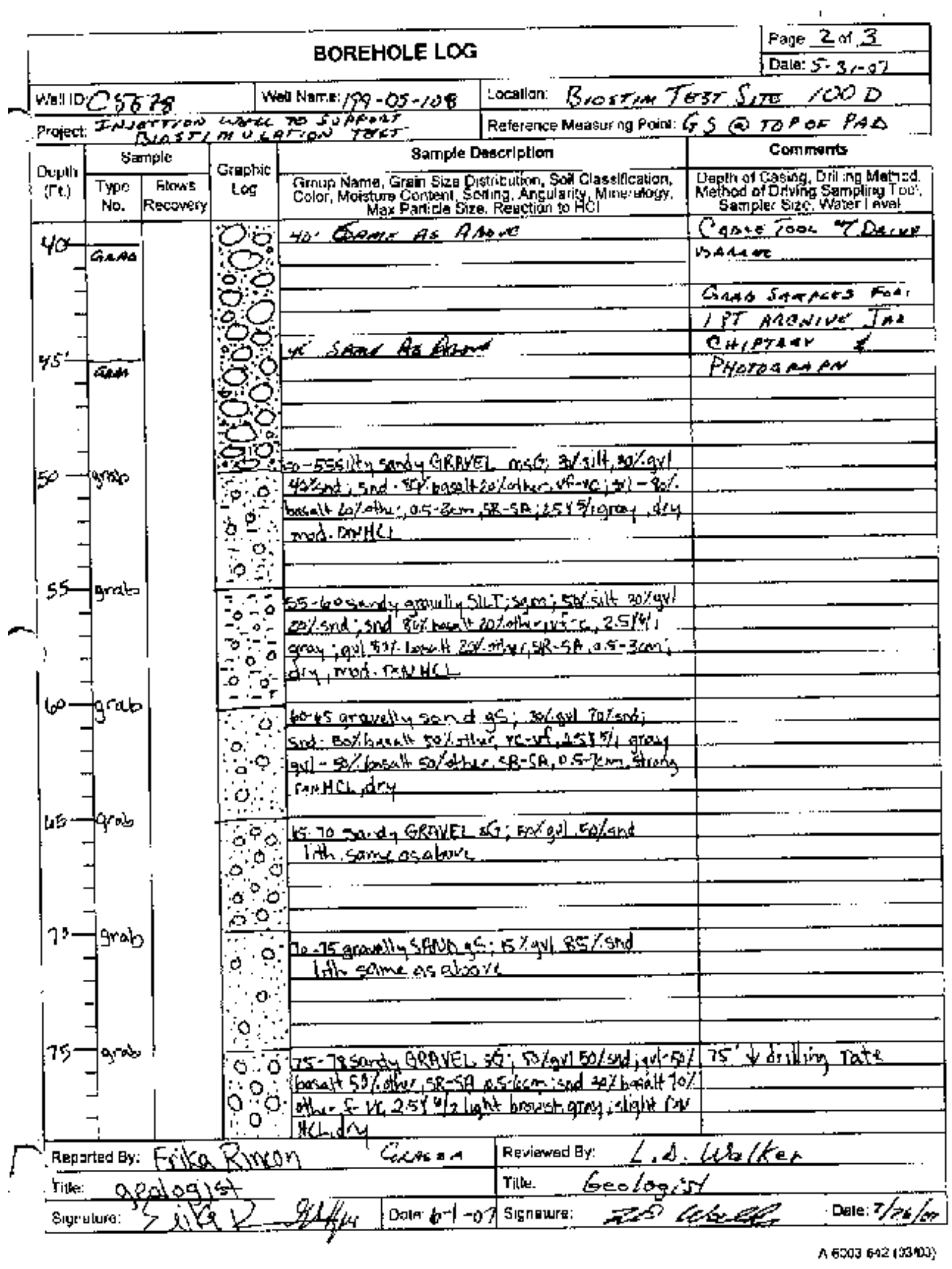




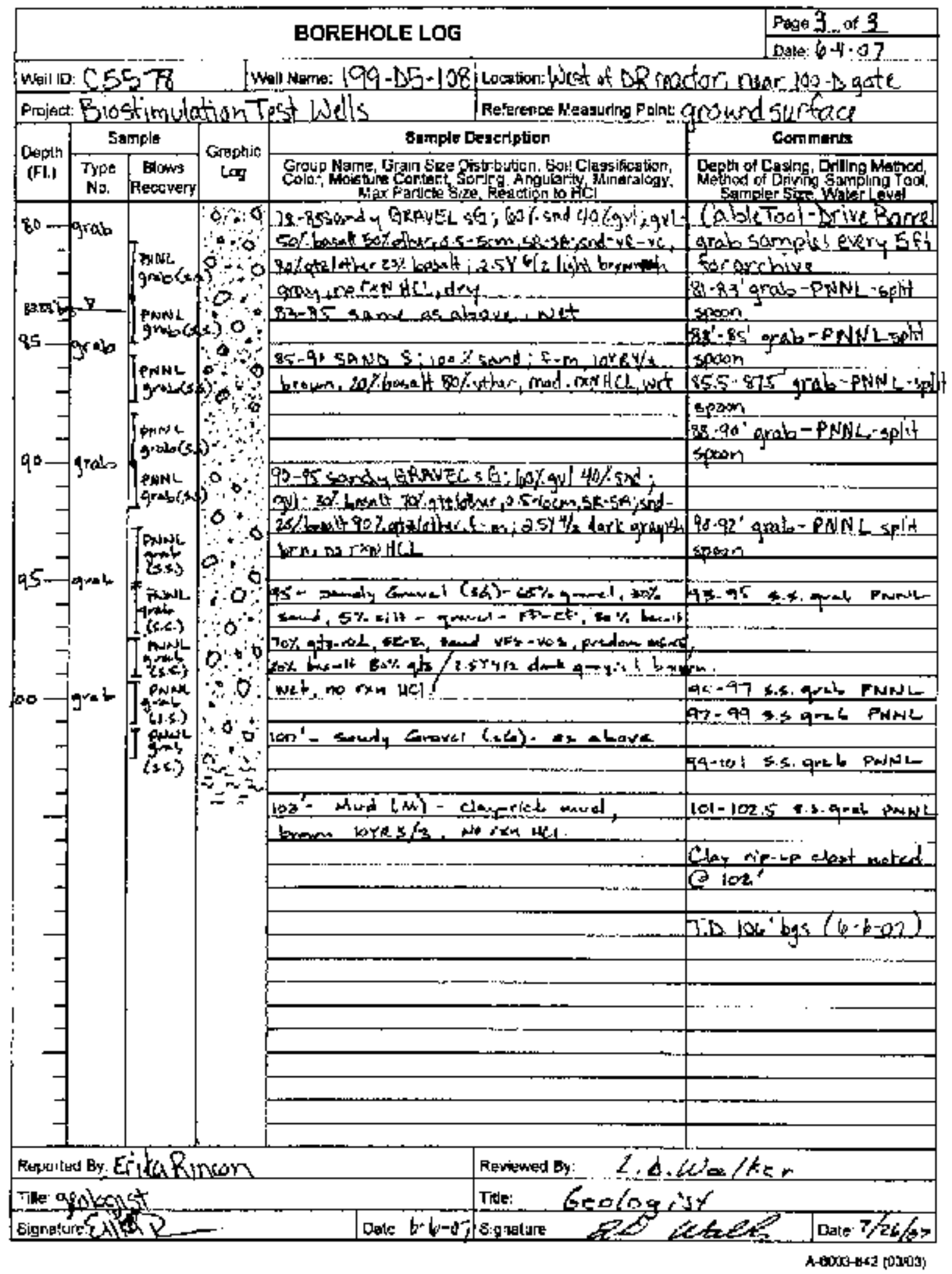




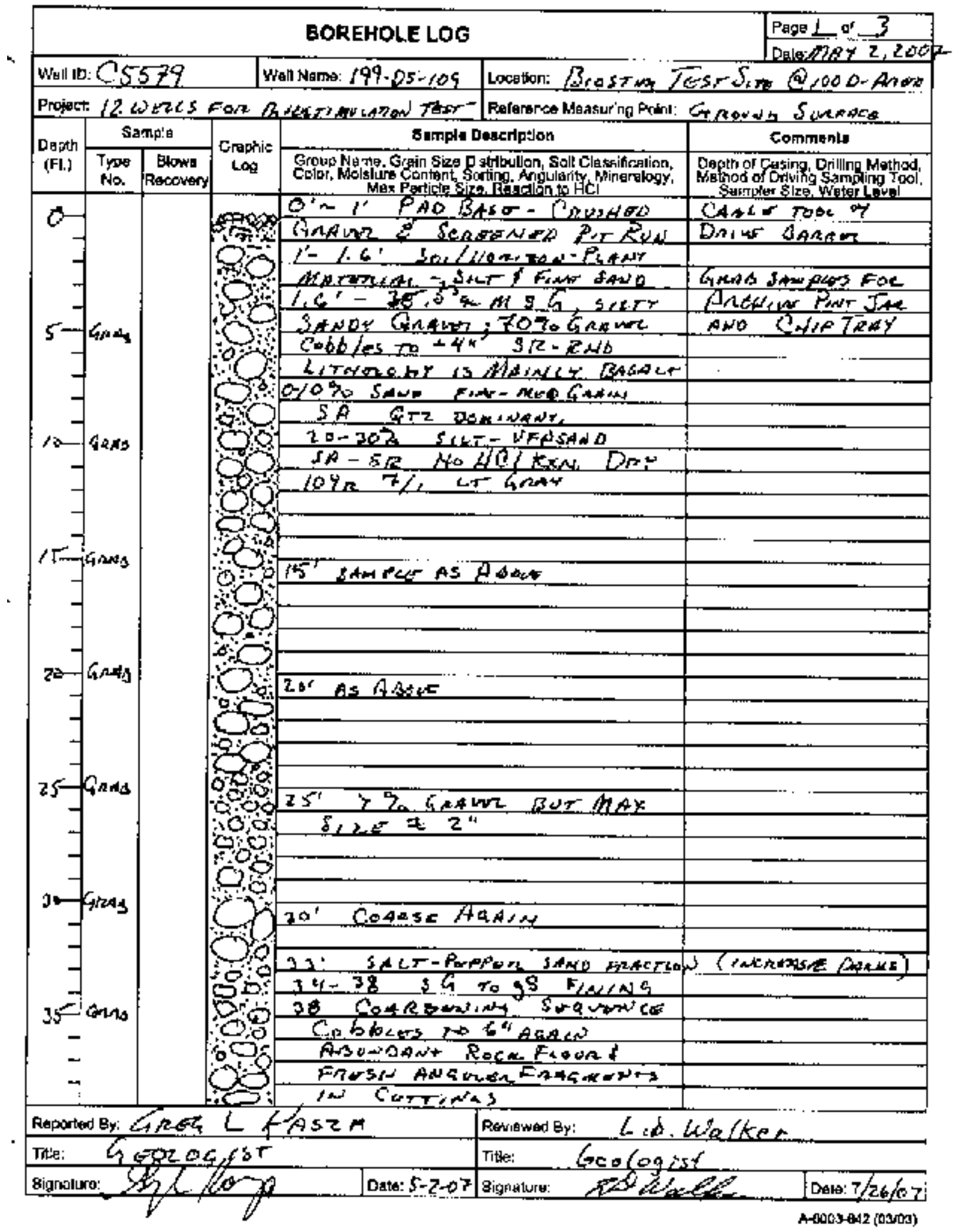




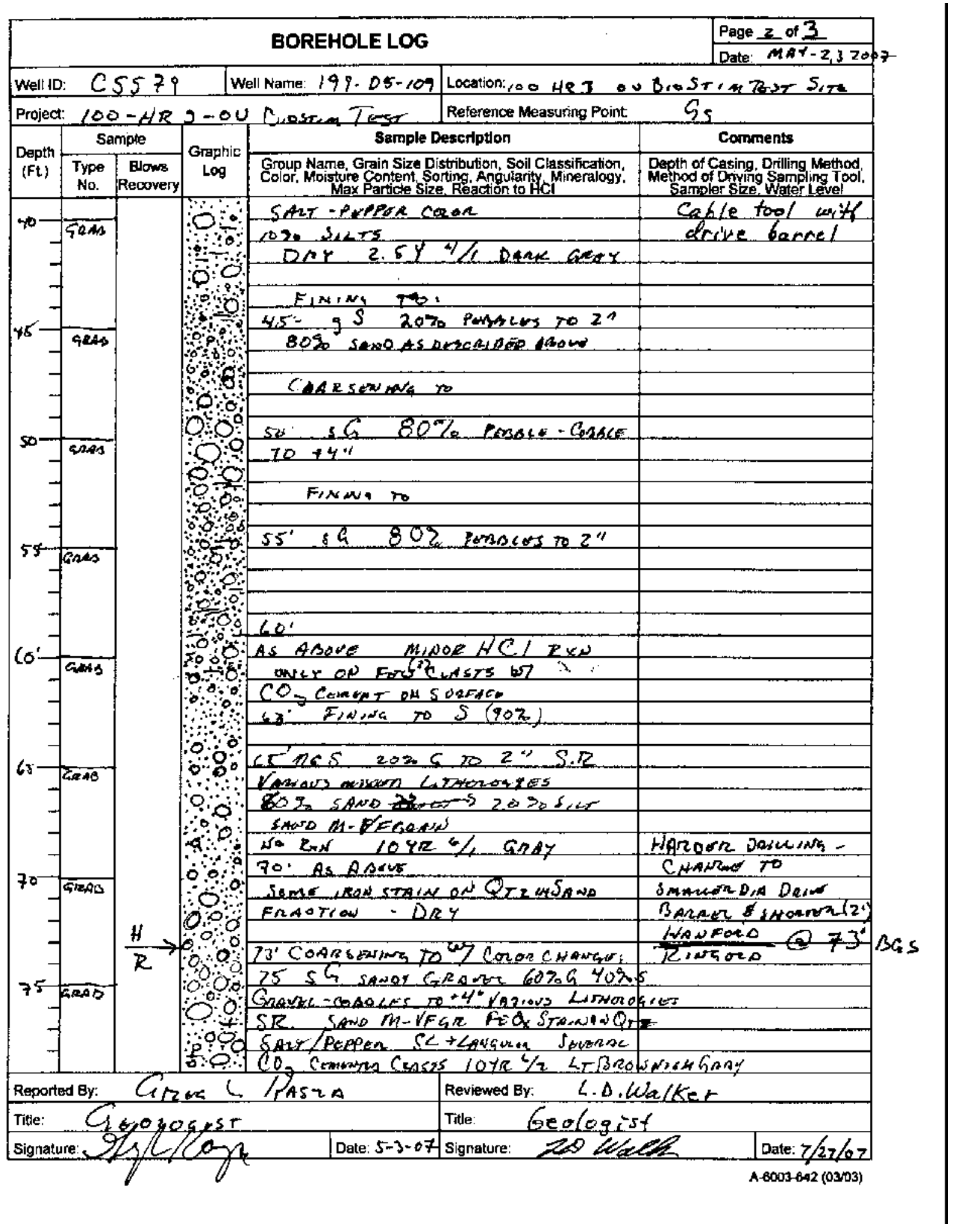




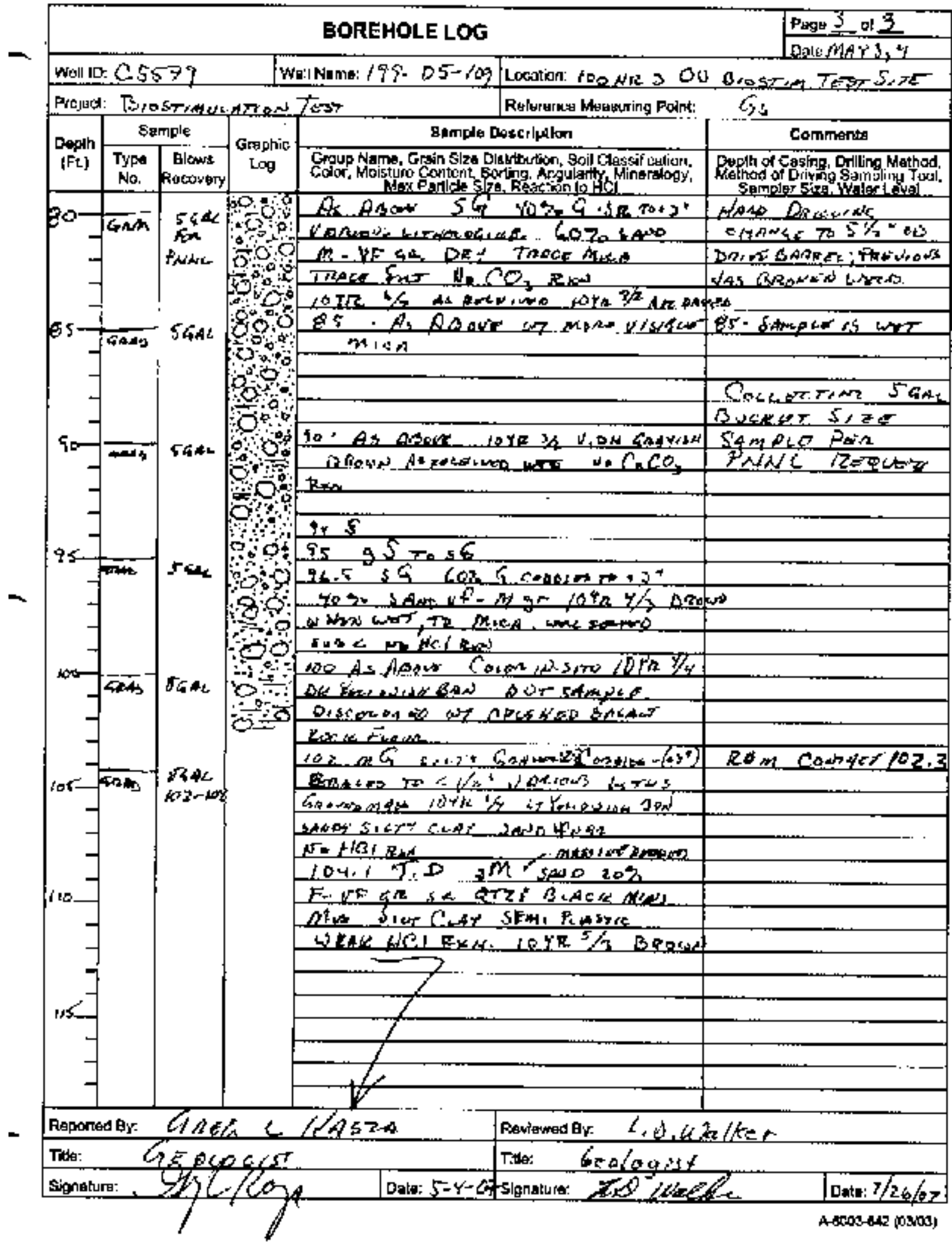




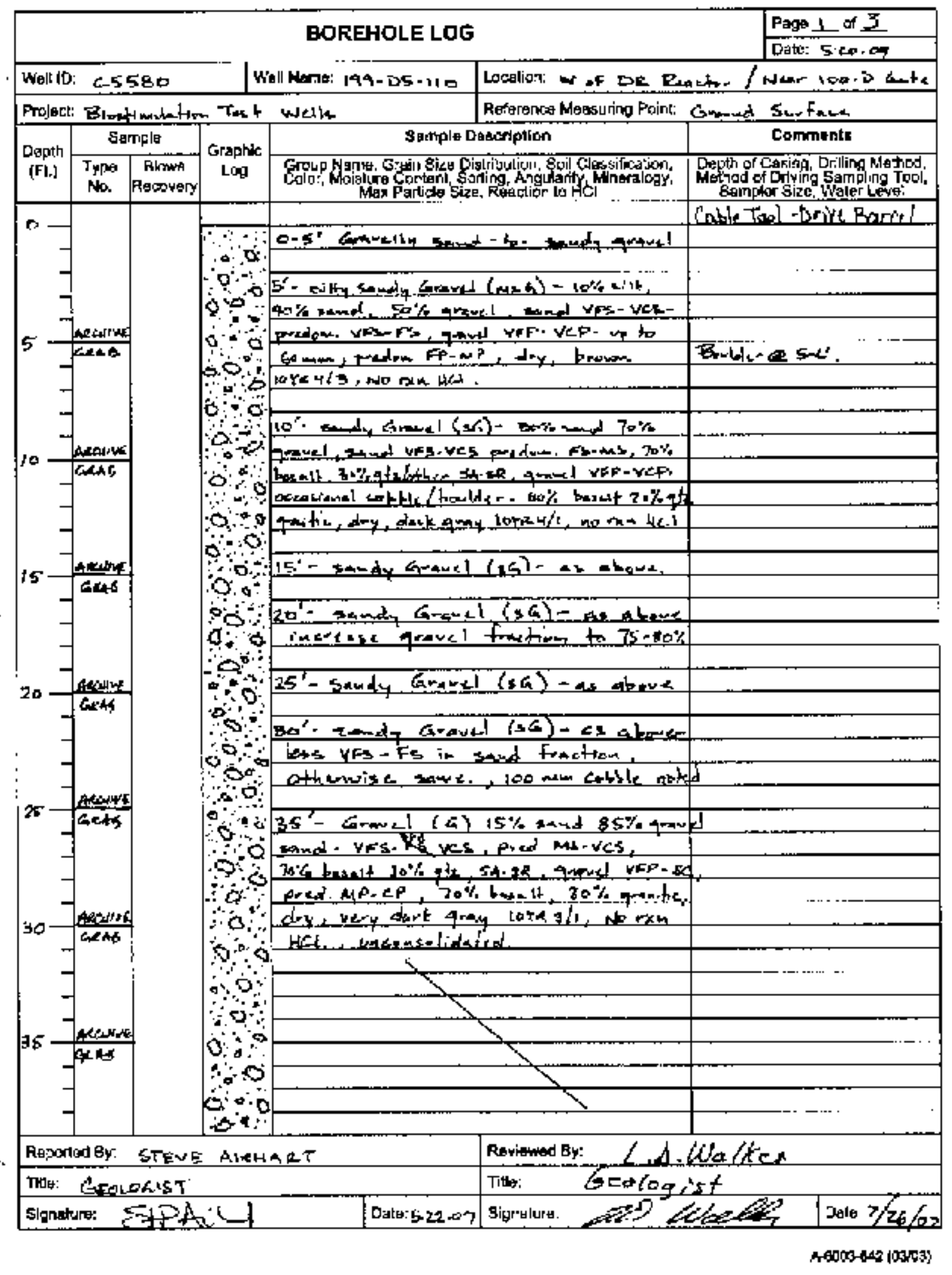




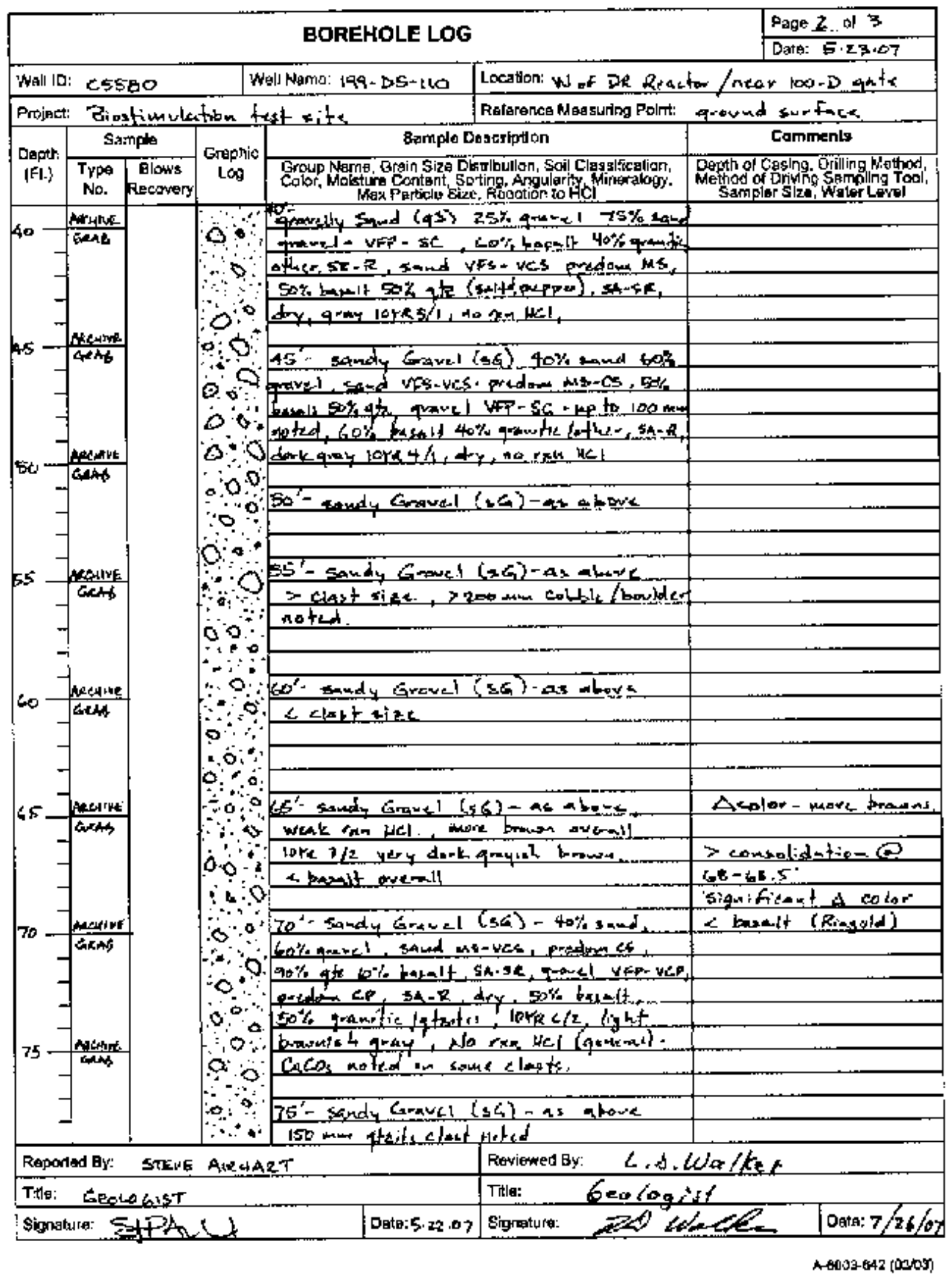




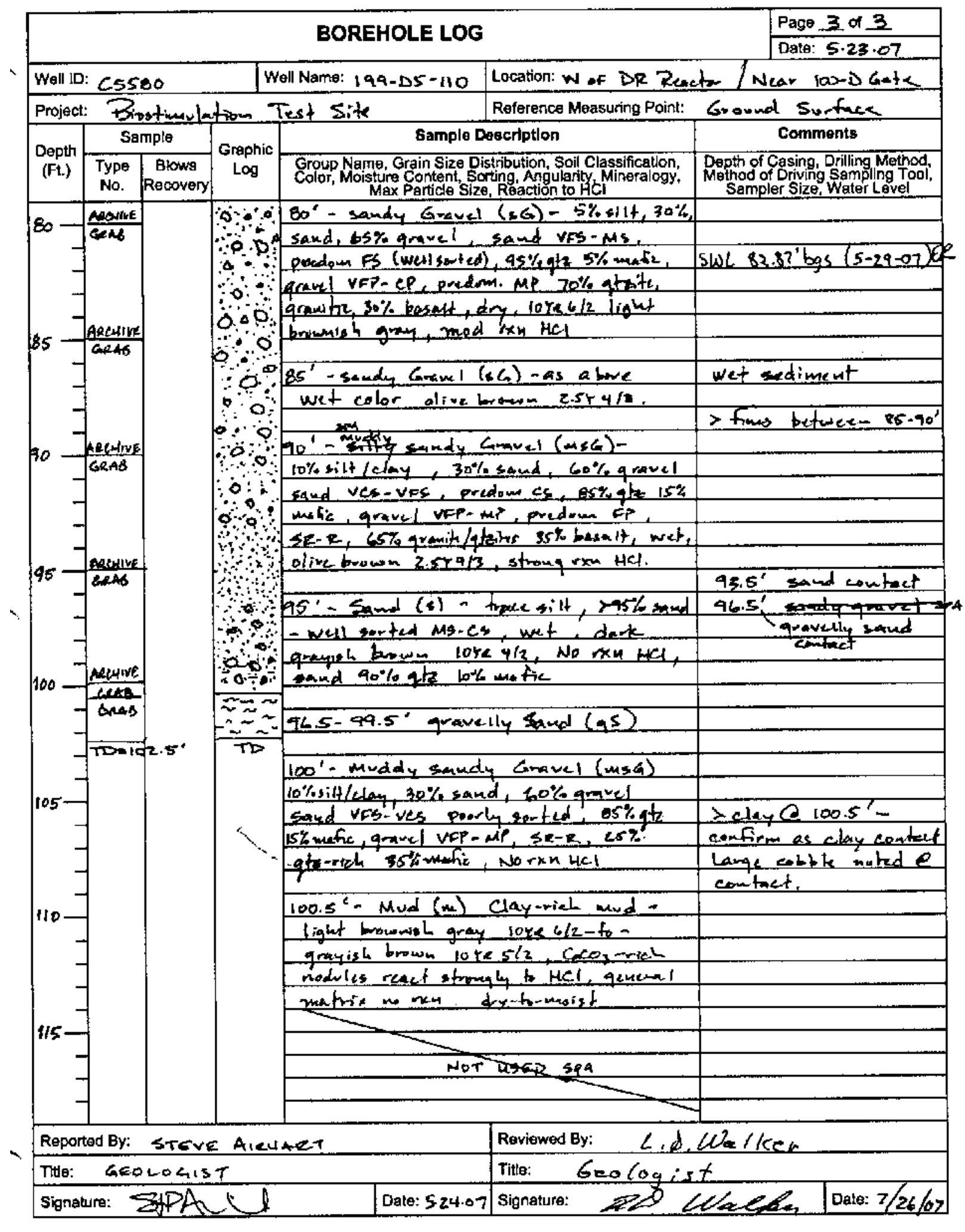

A $5003-642(03 / 03)$ 


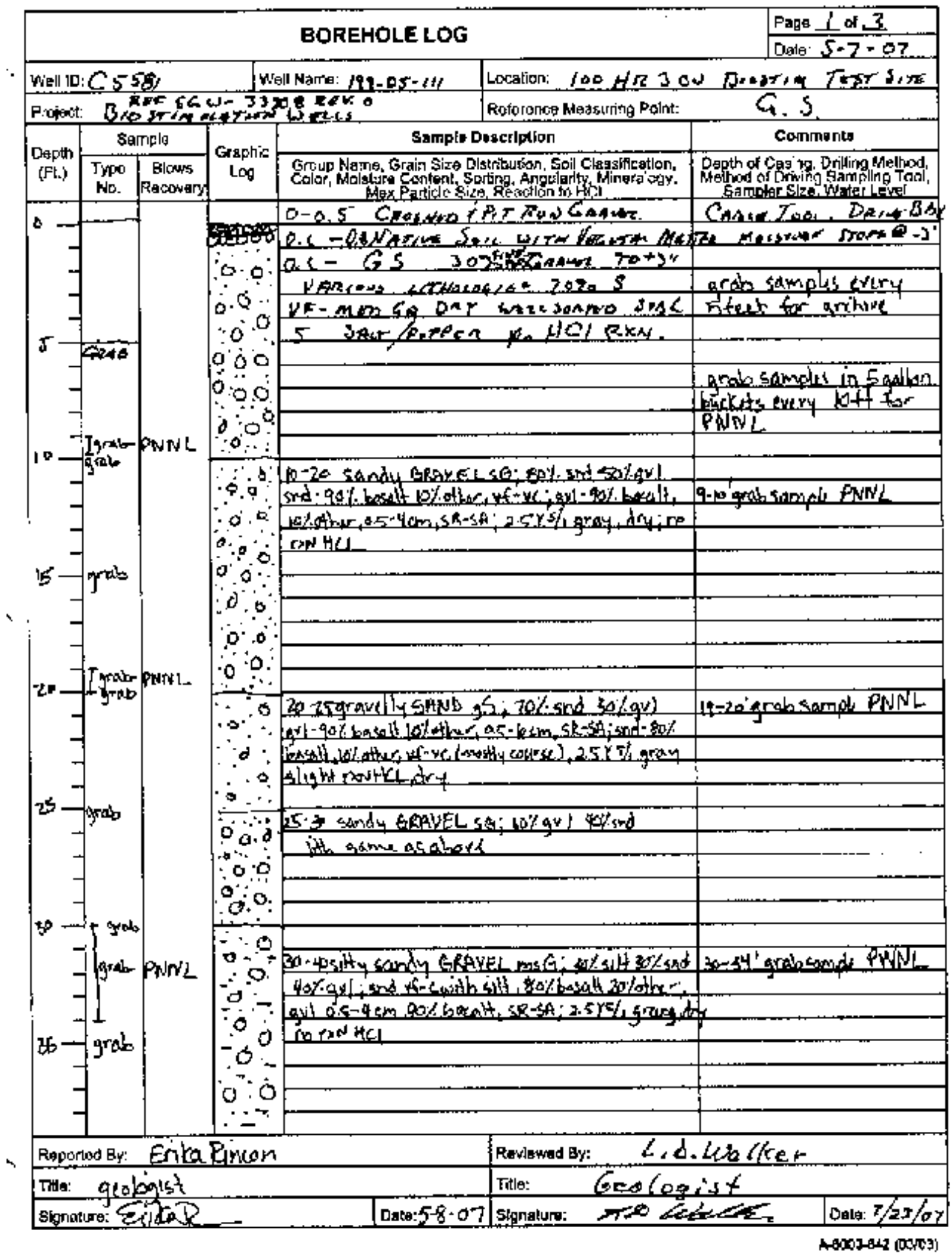




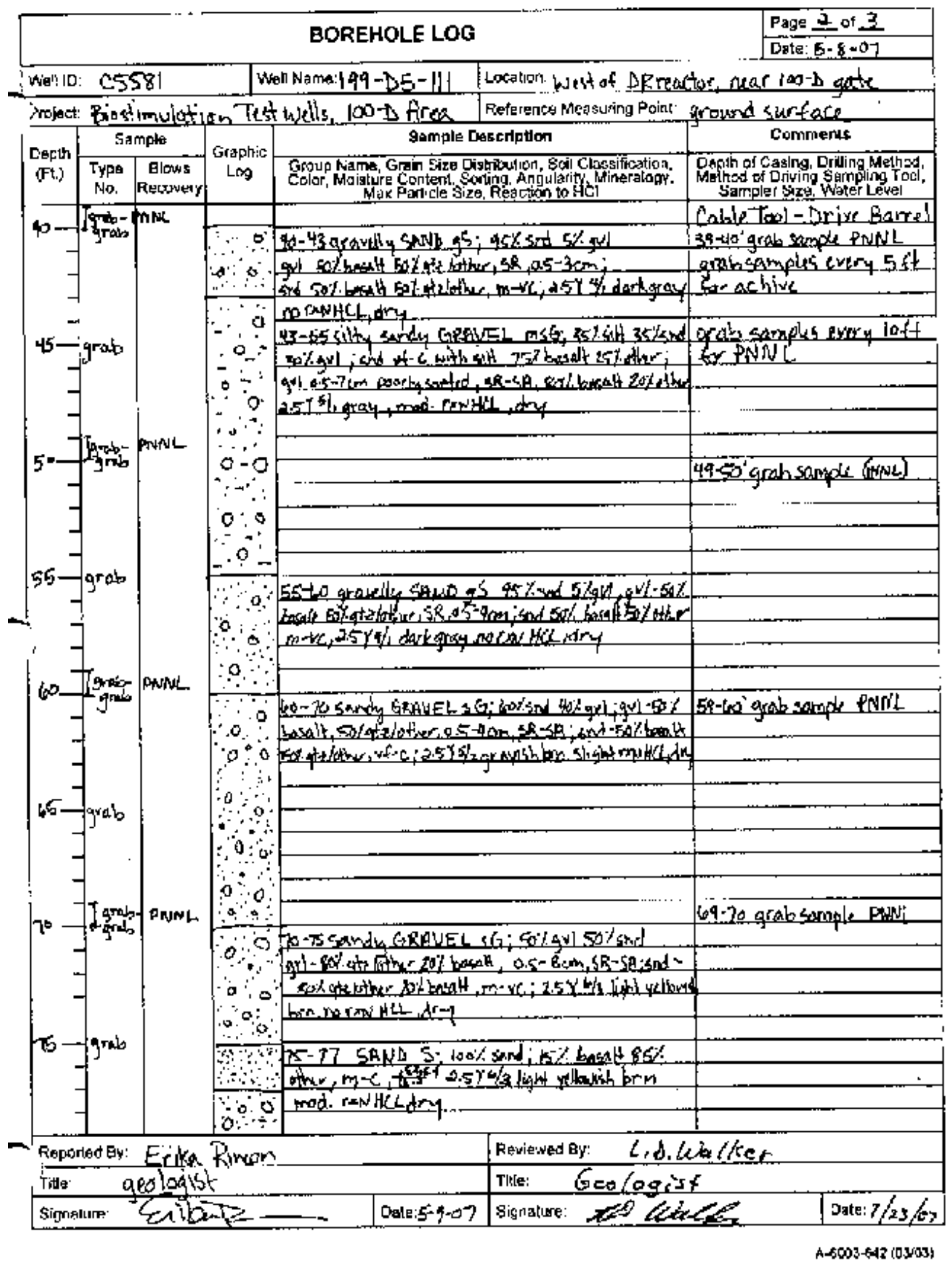




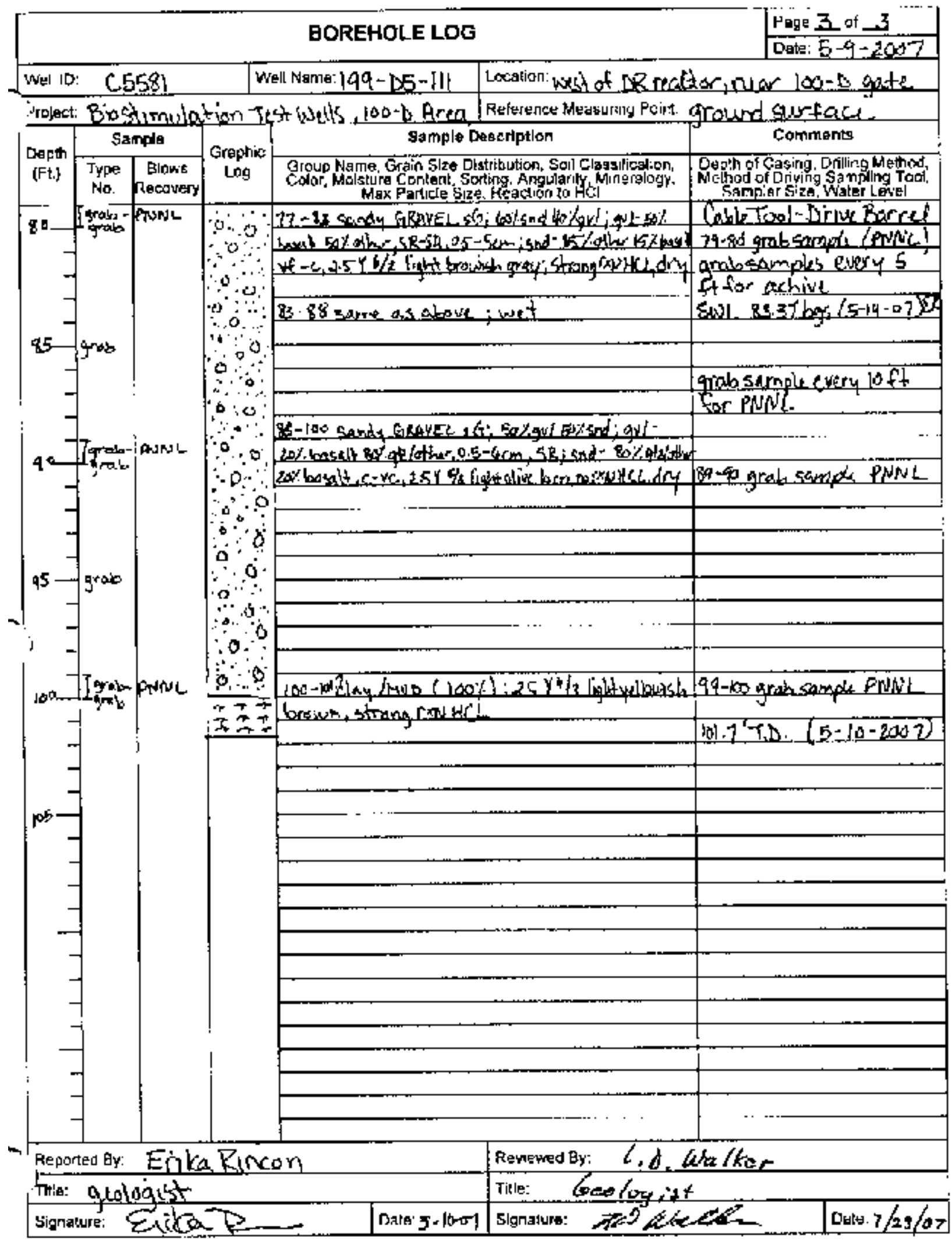




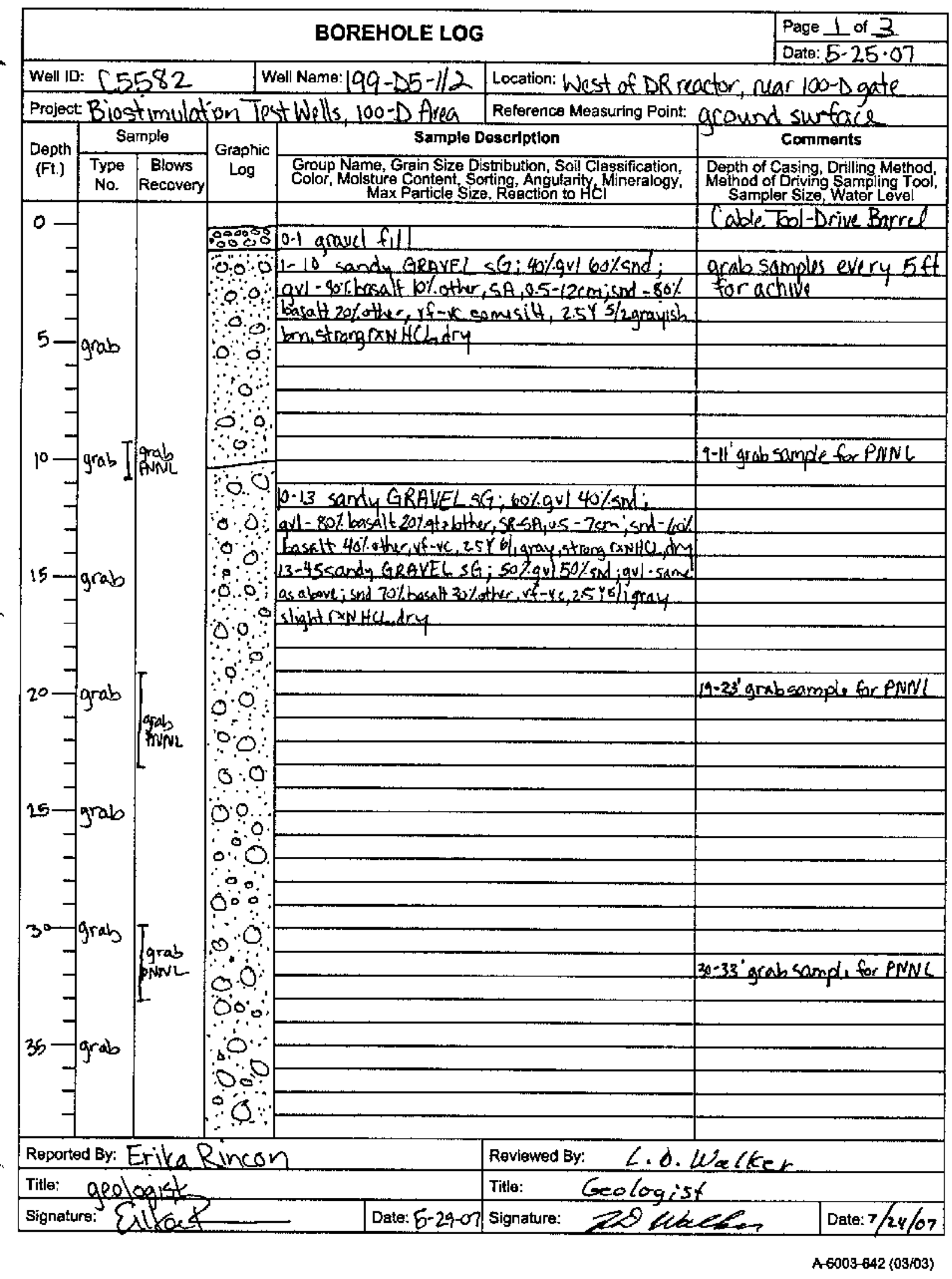




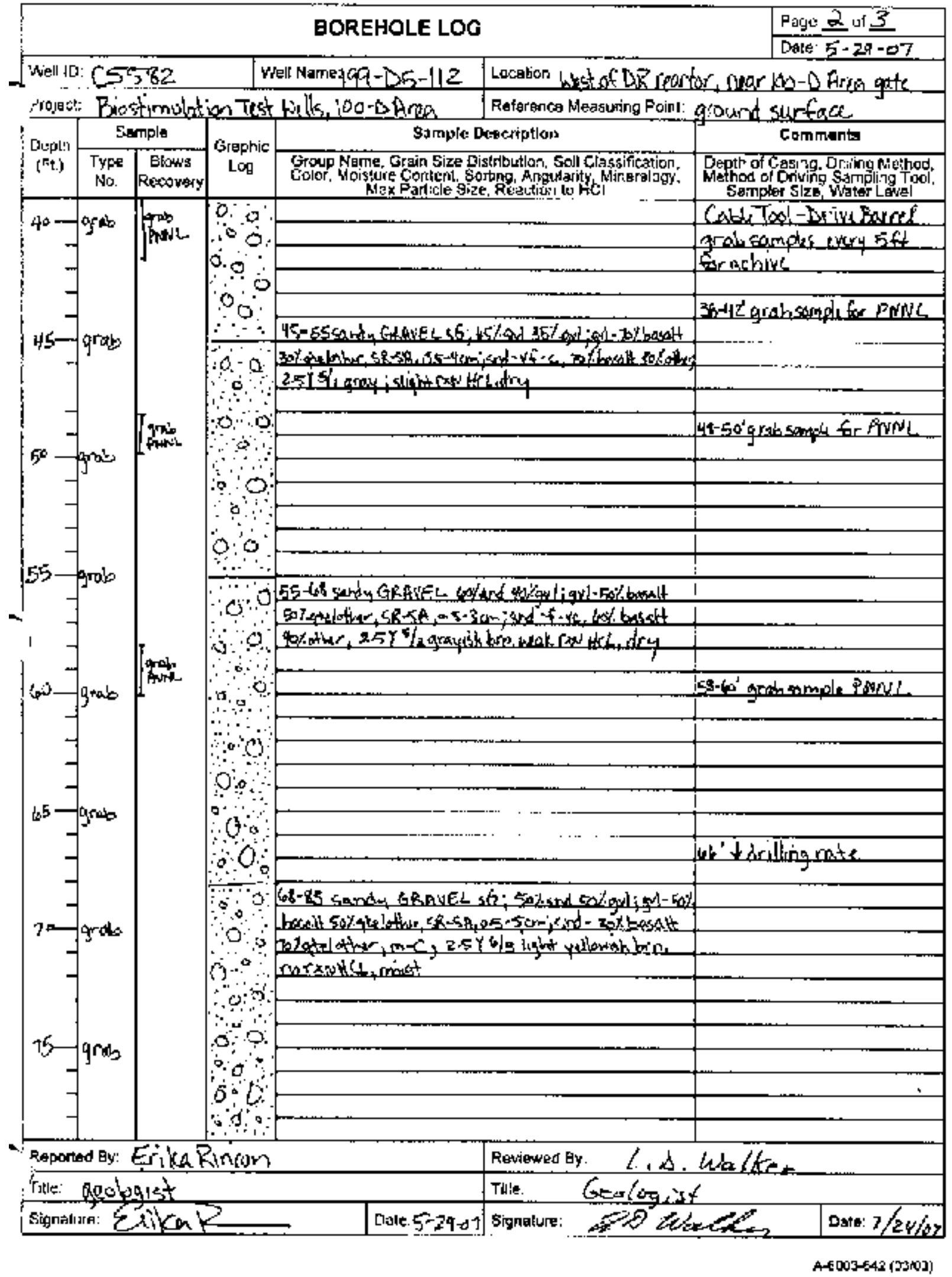




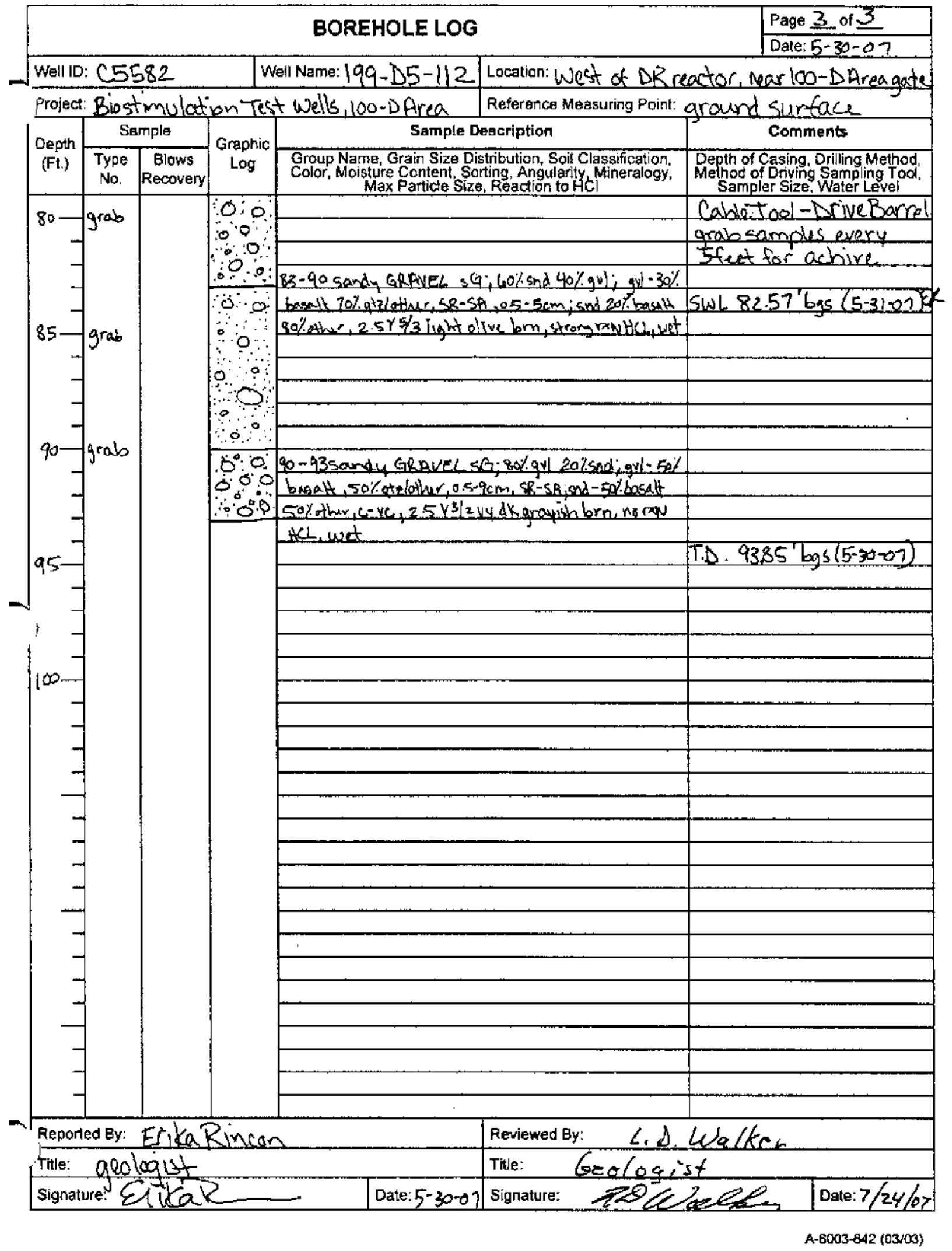




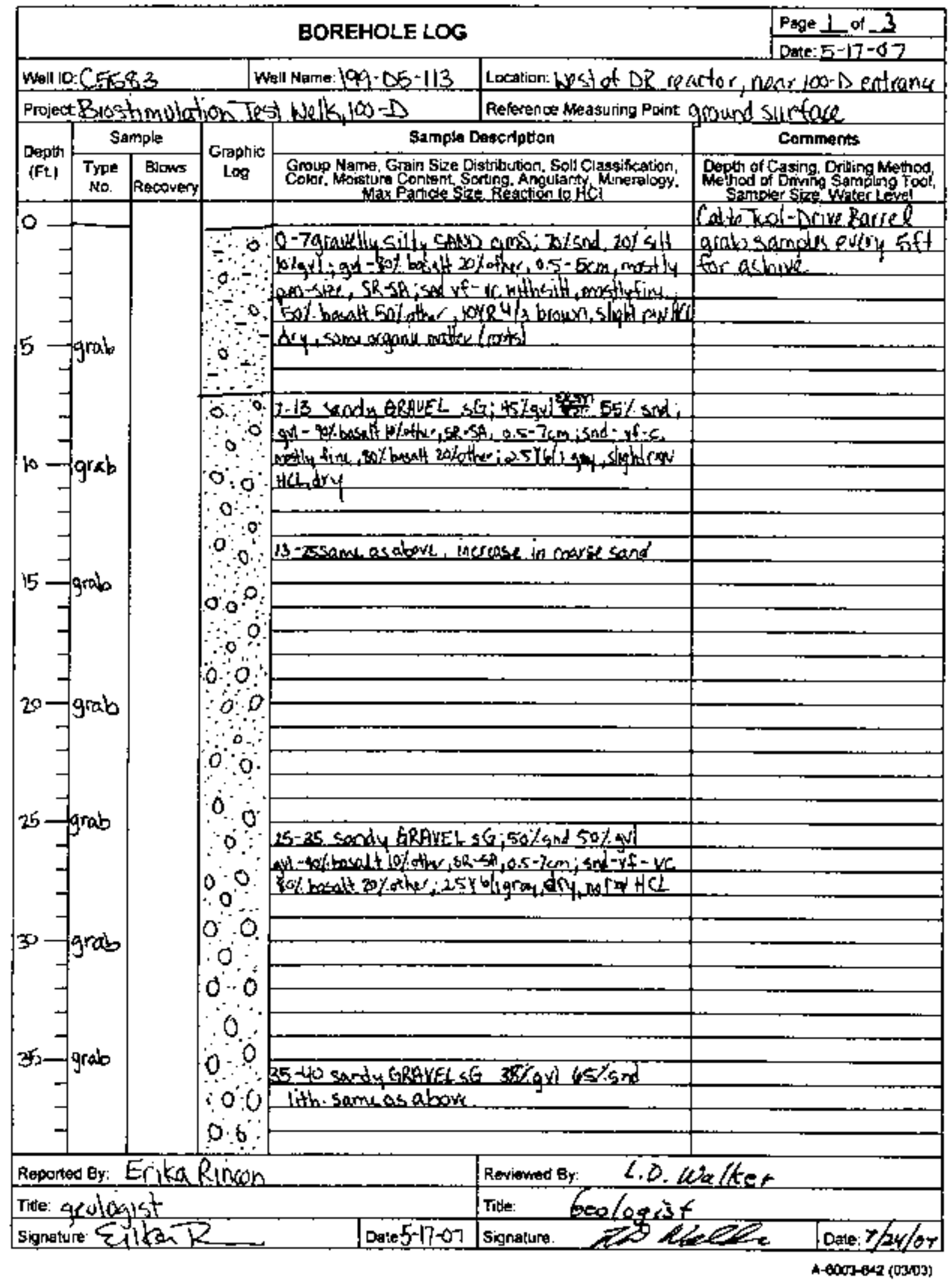




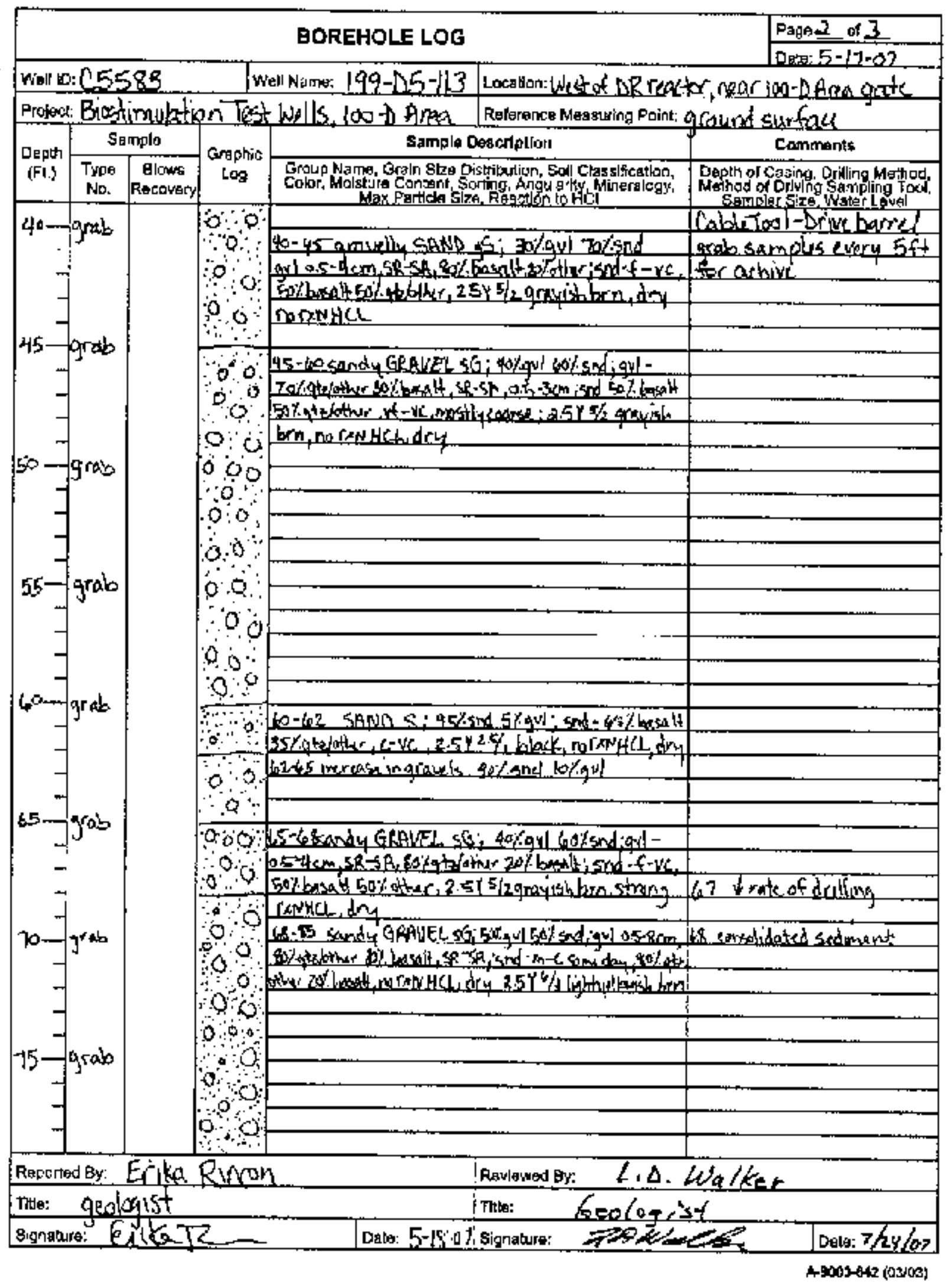




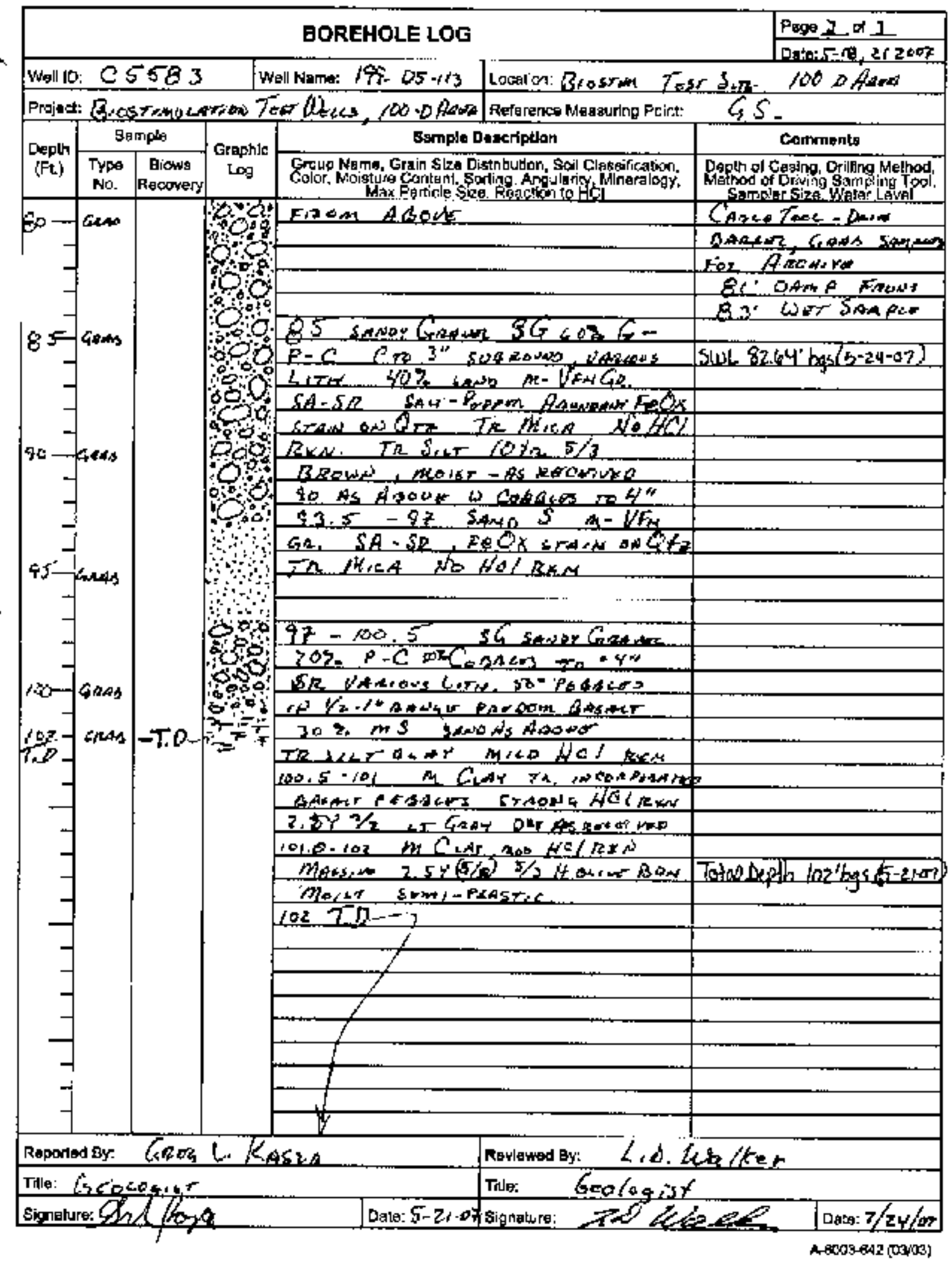




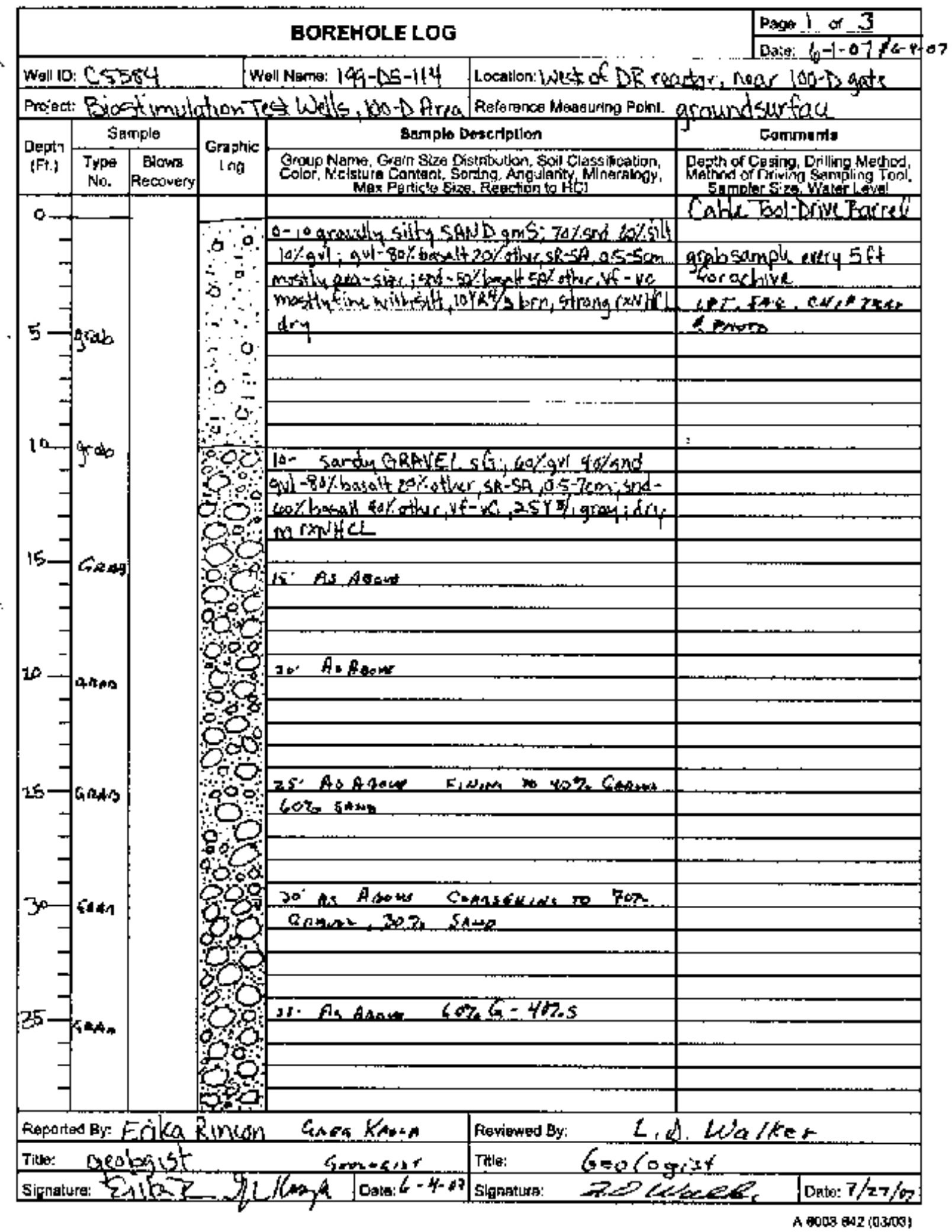




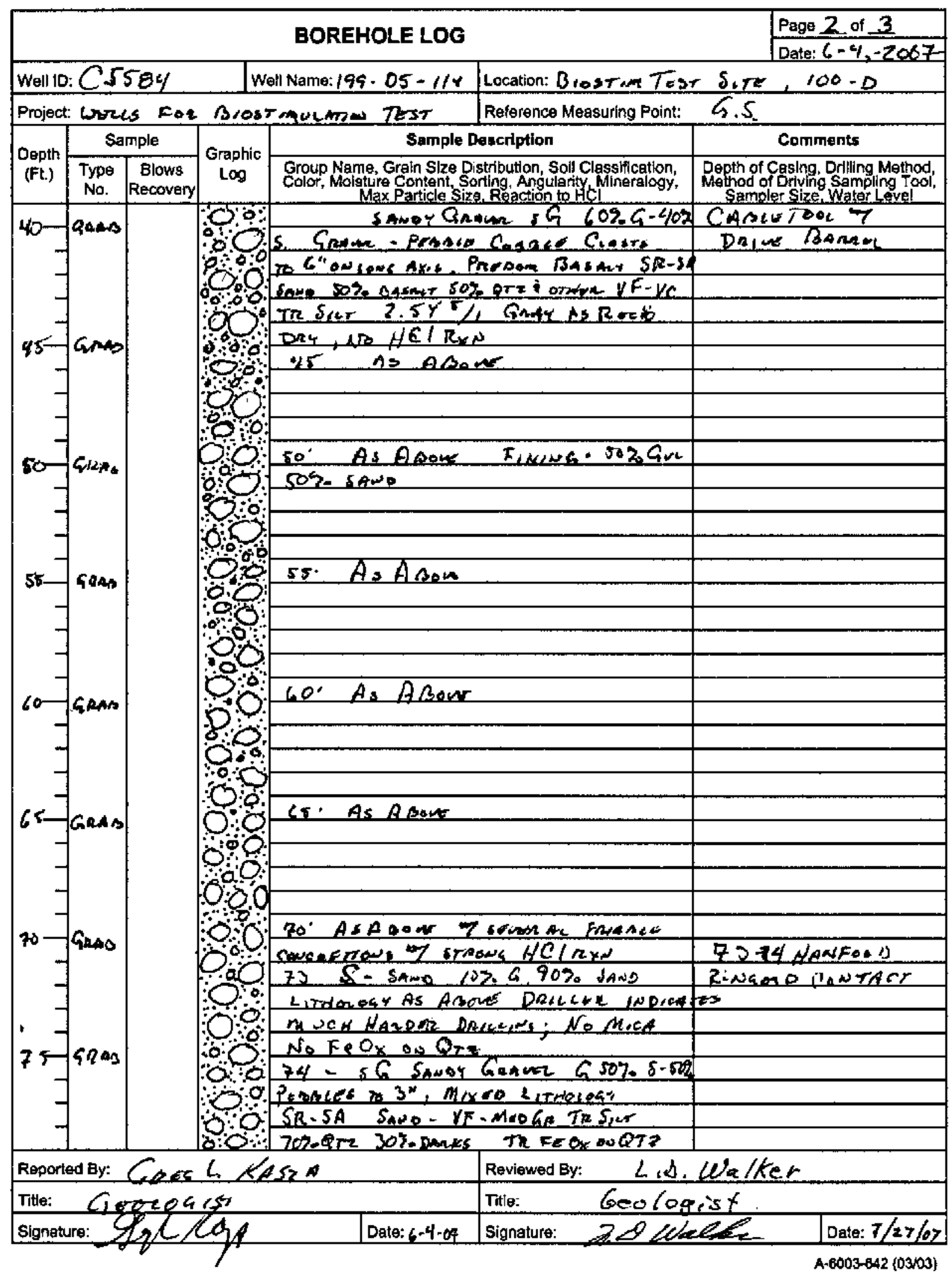




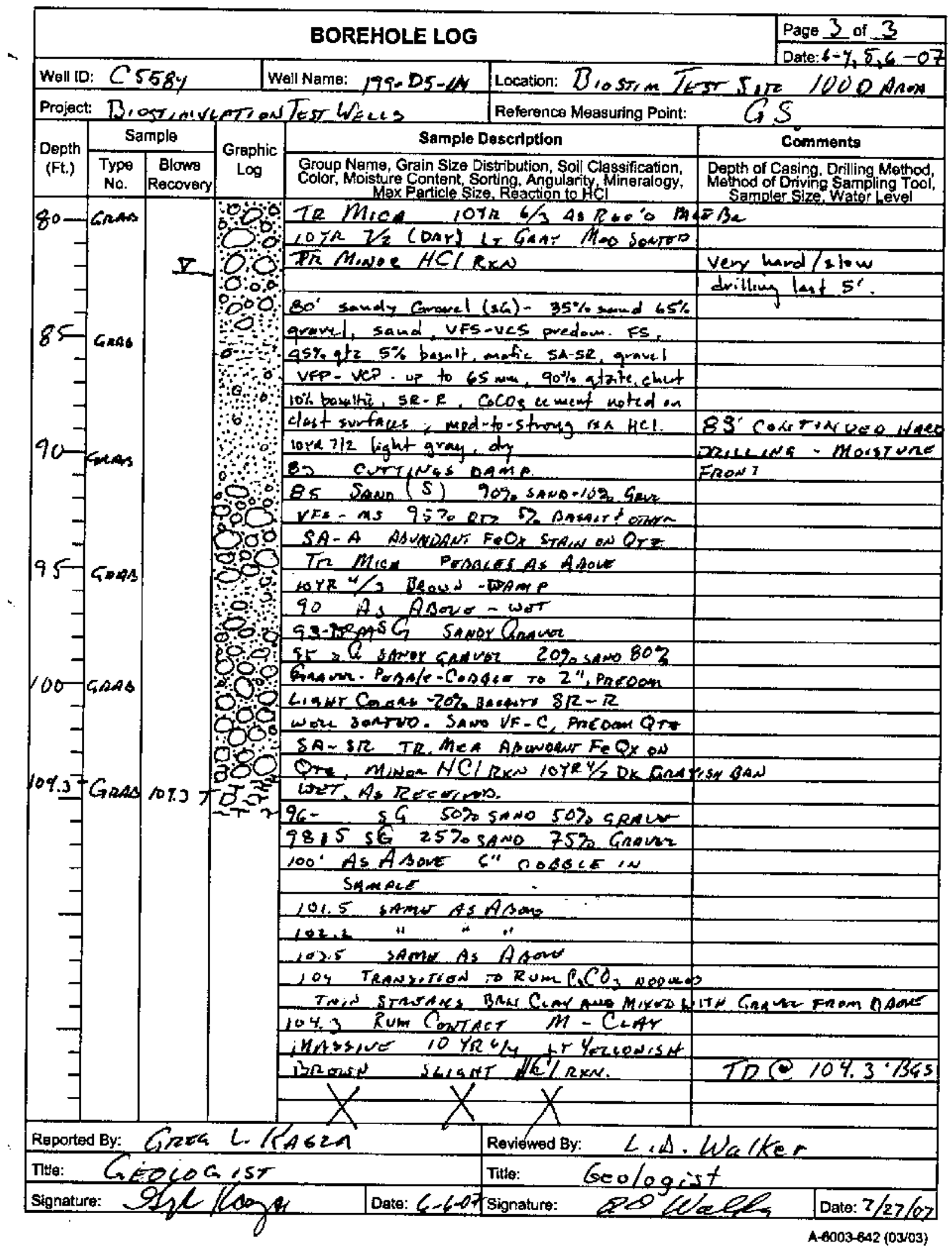




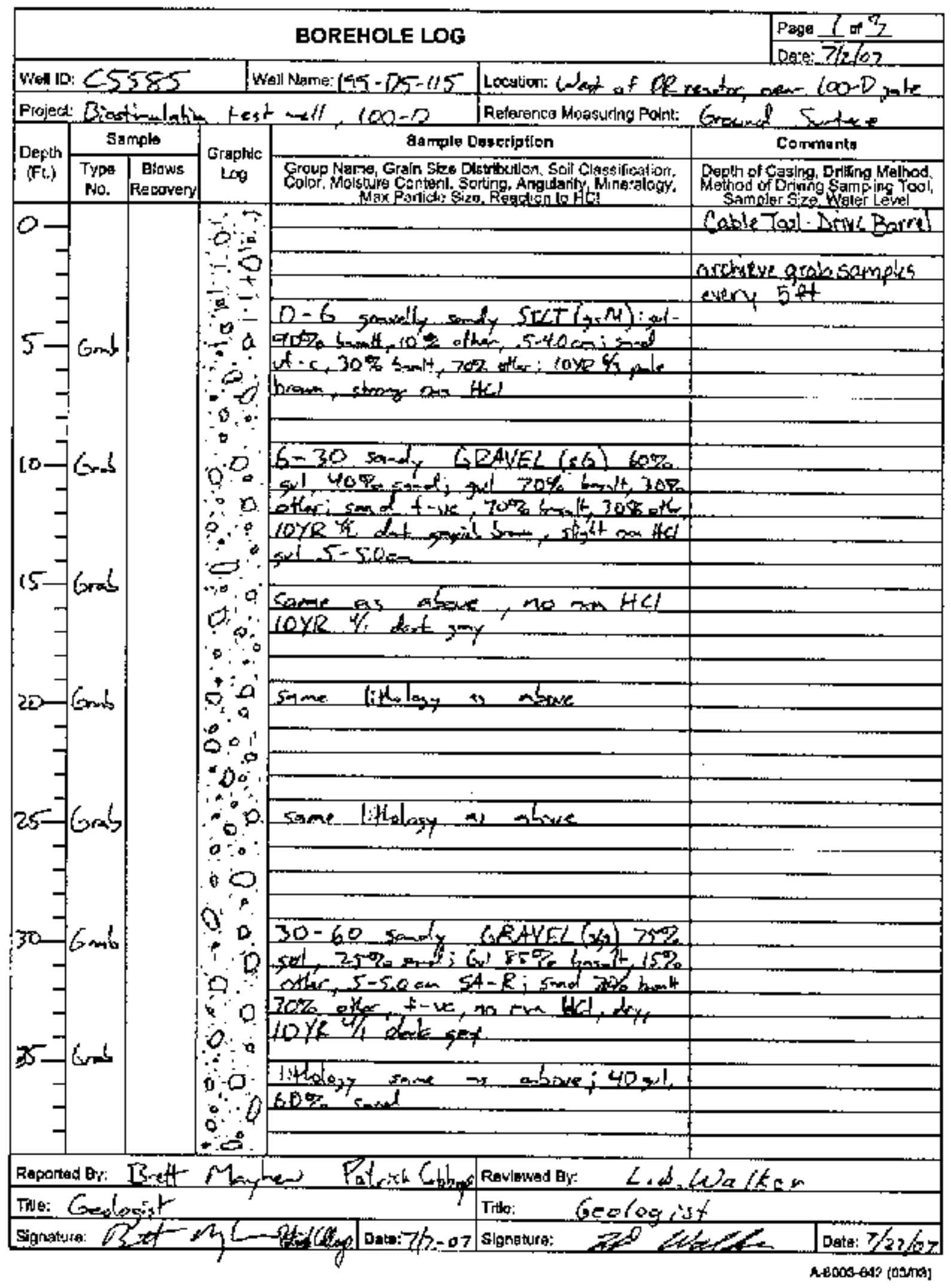




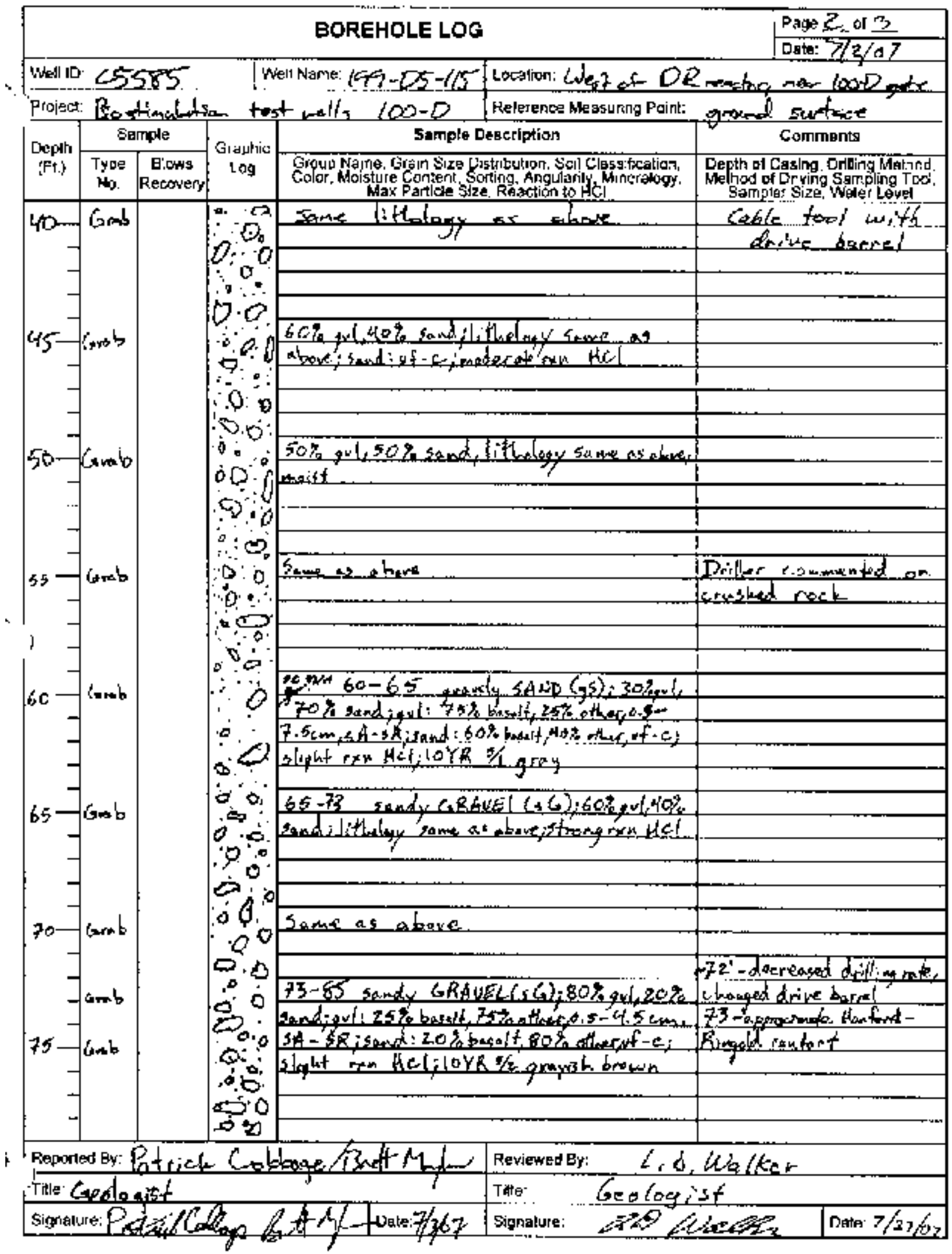




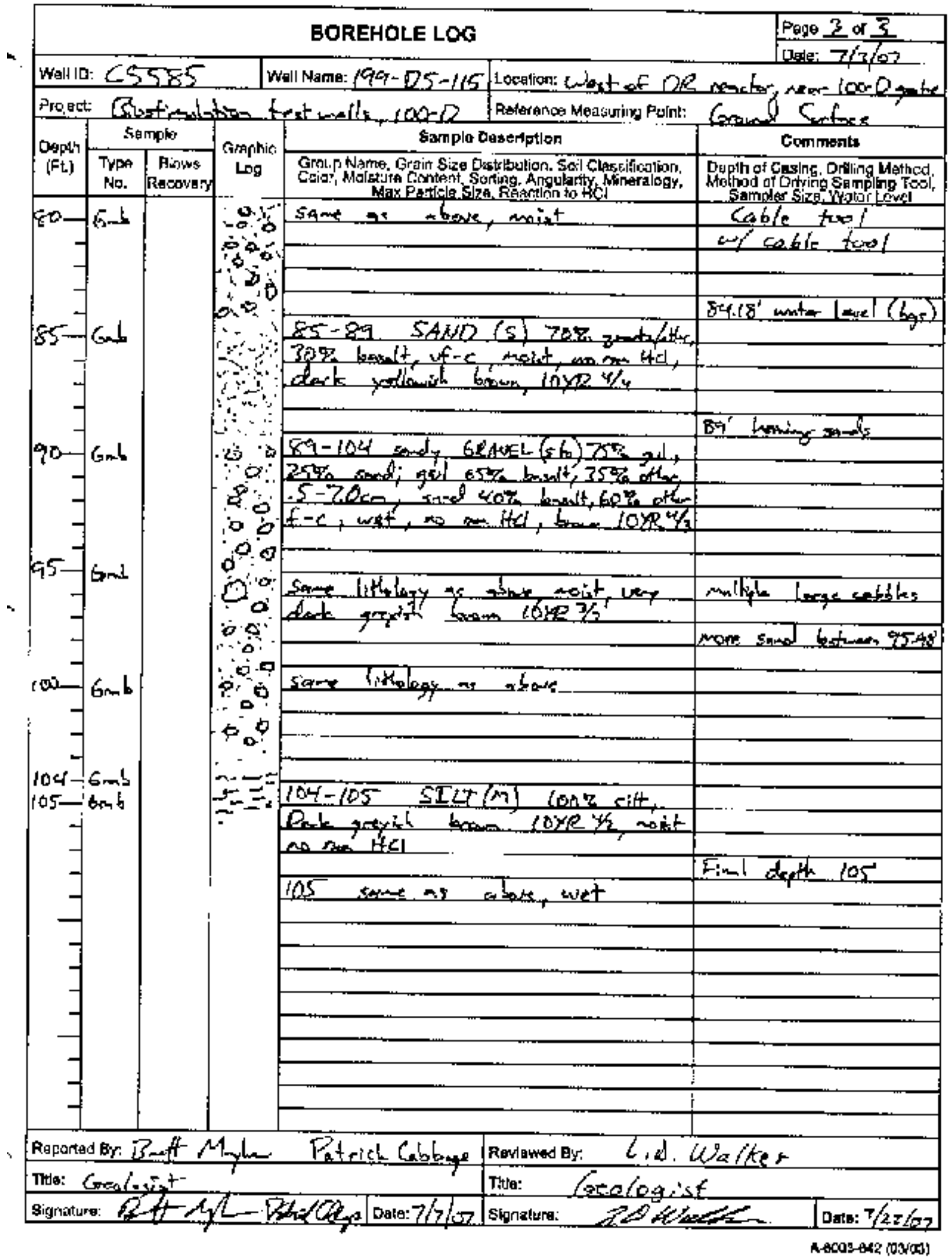




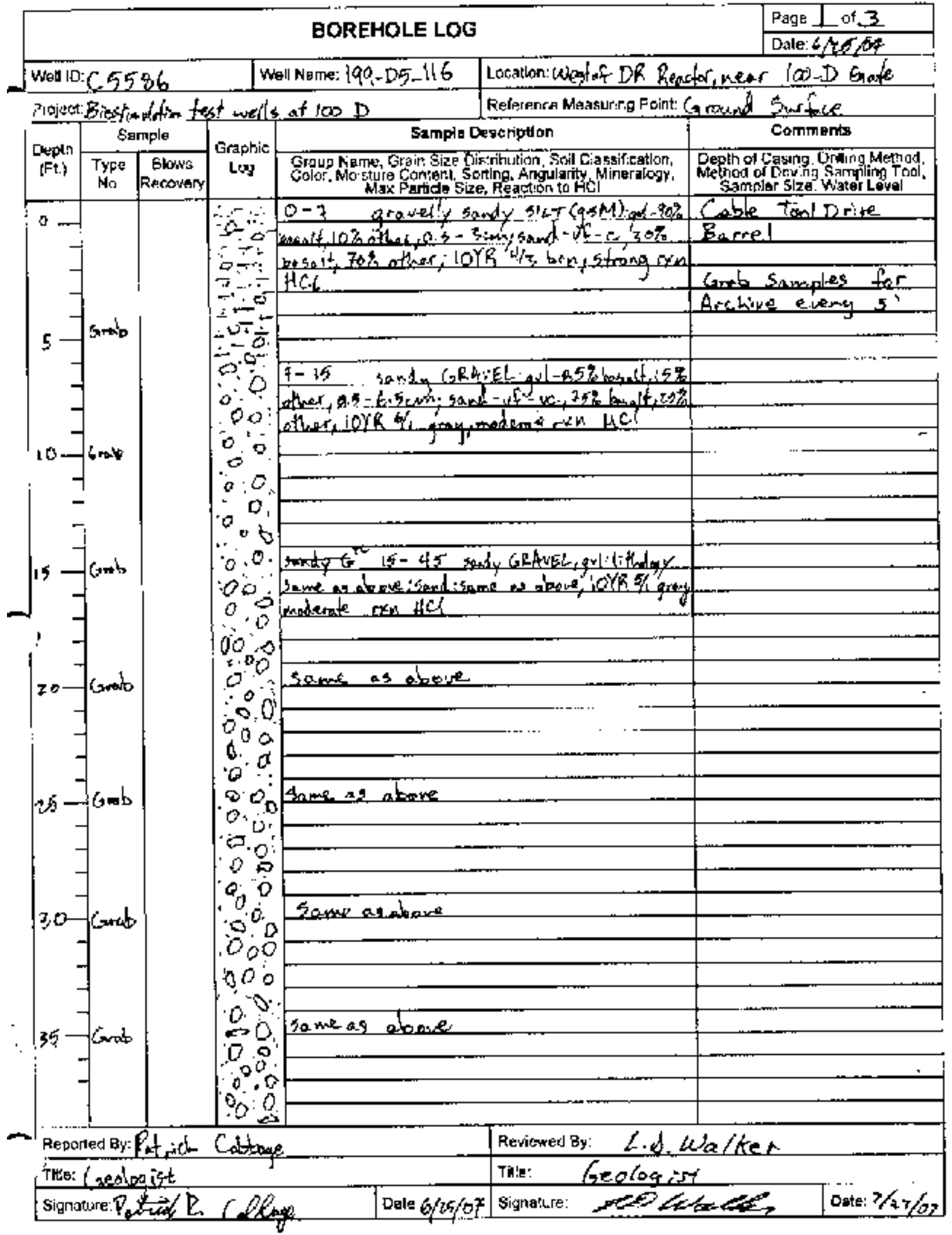




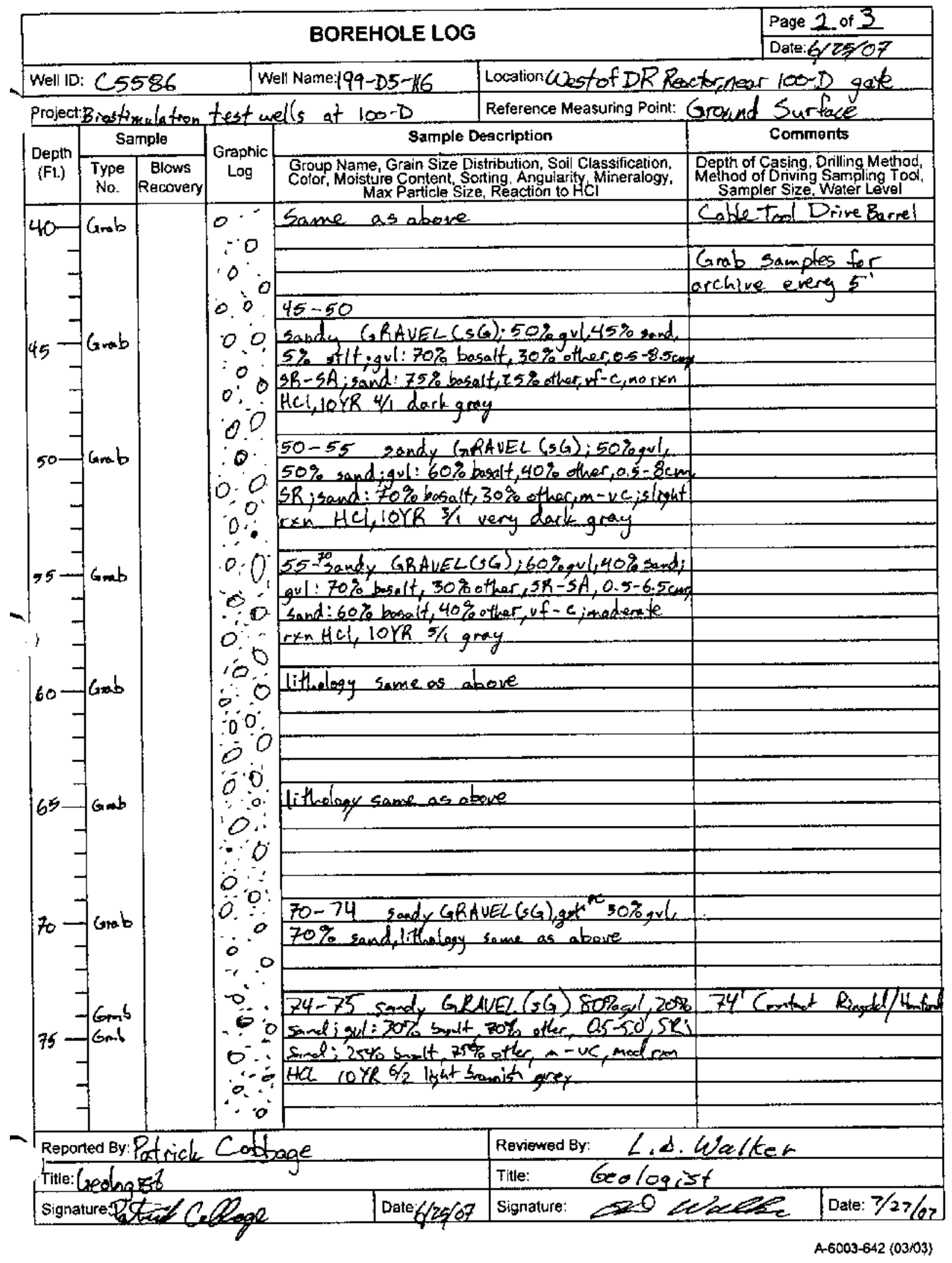




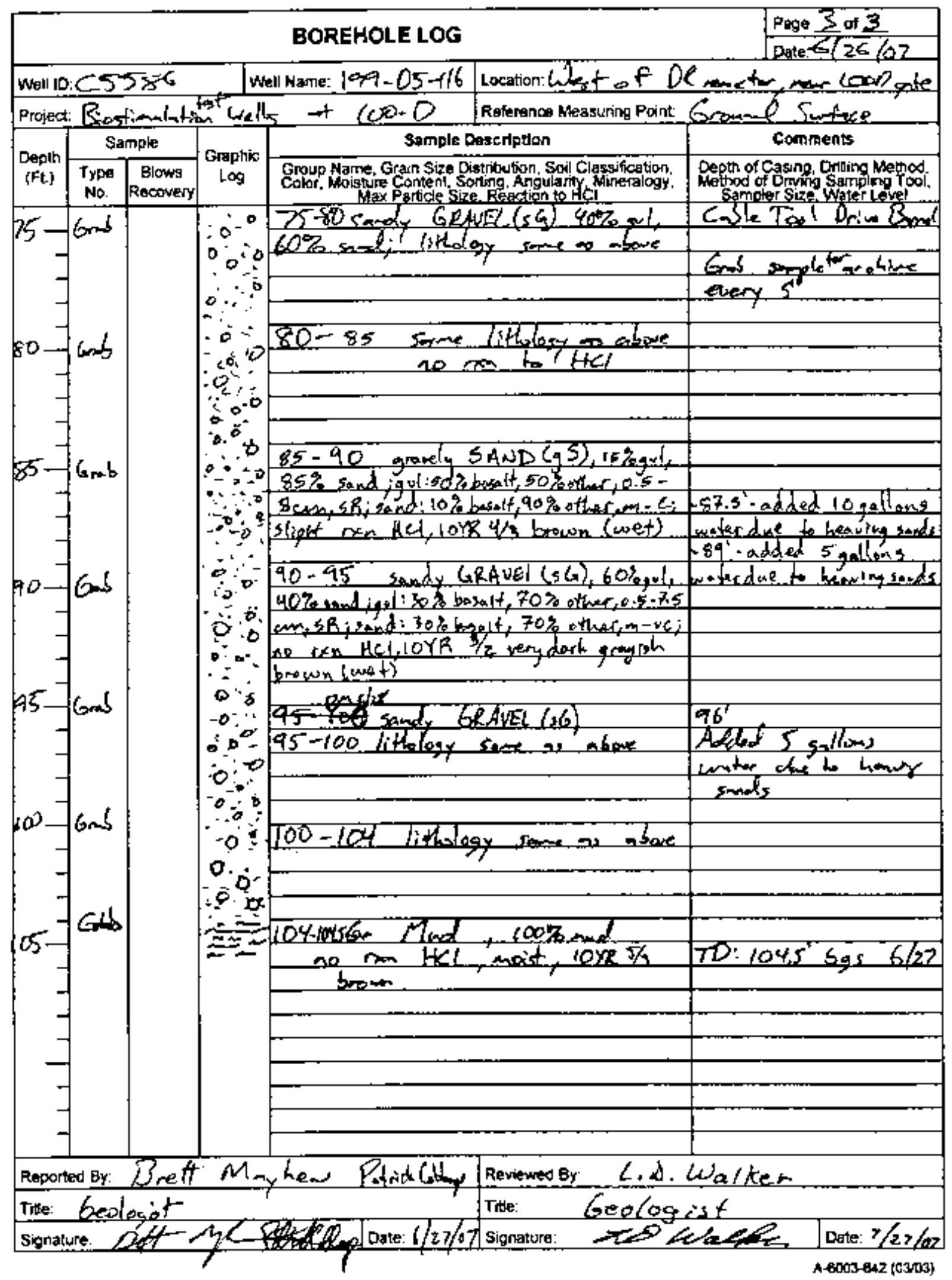




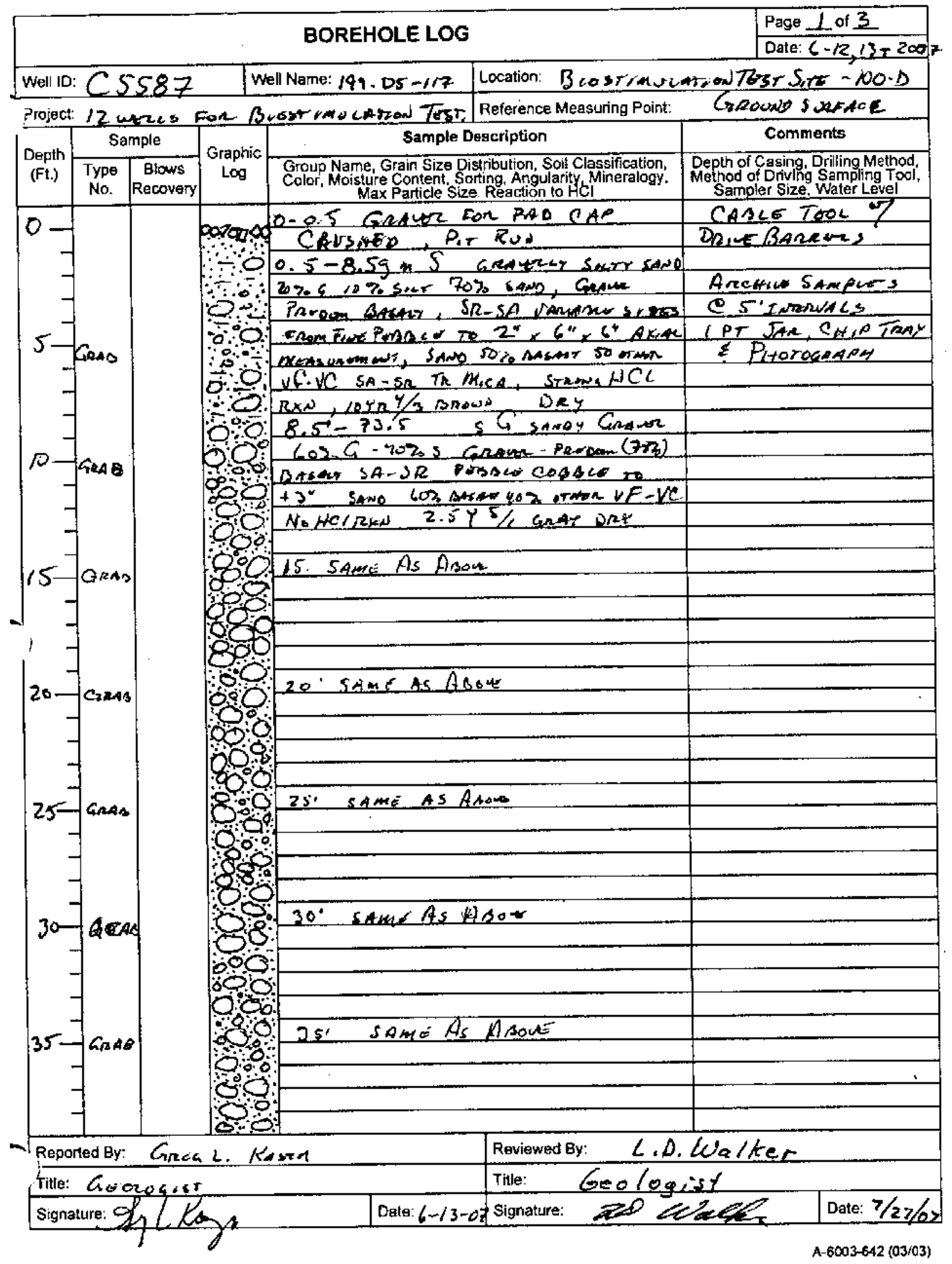




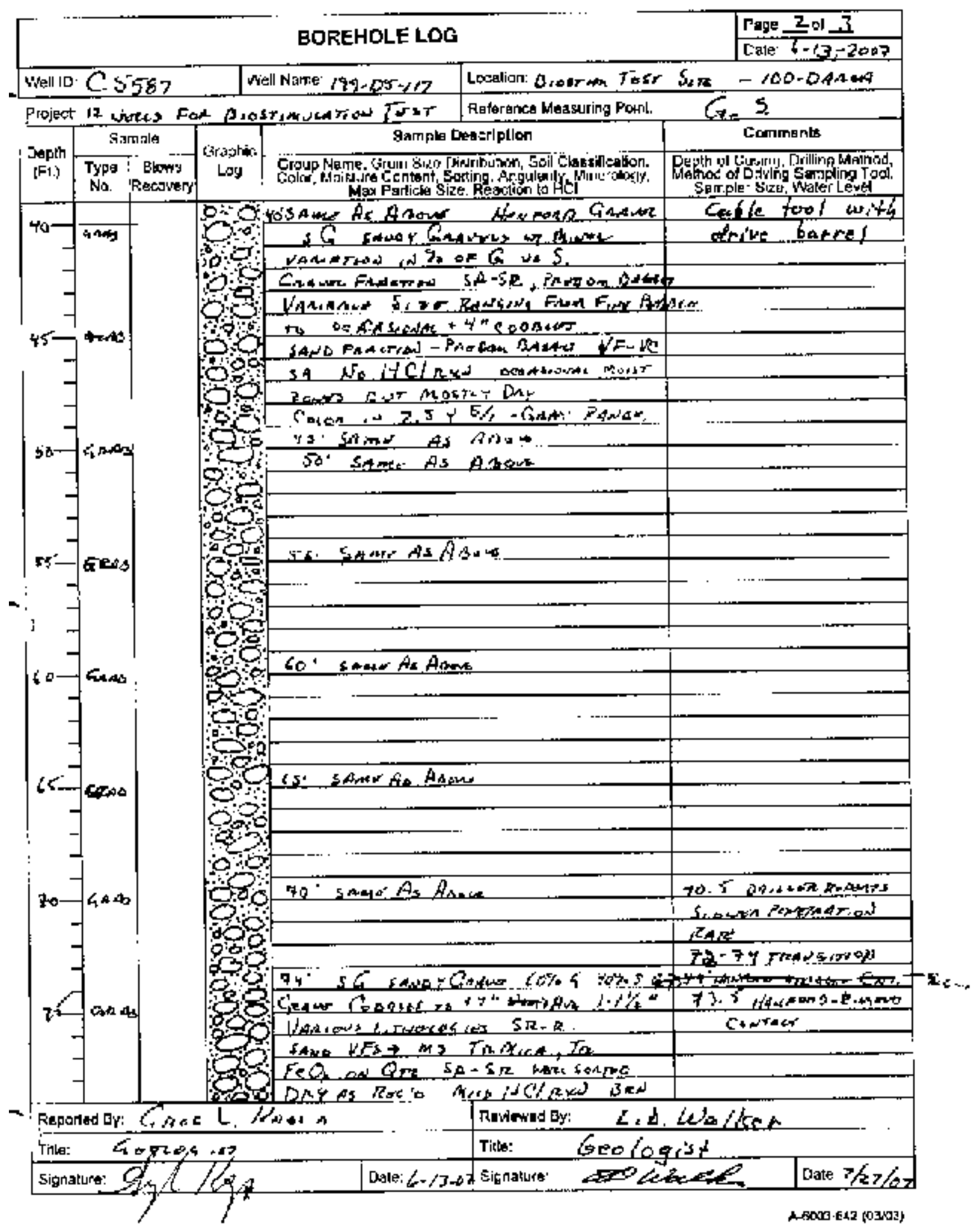




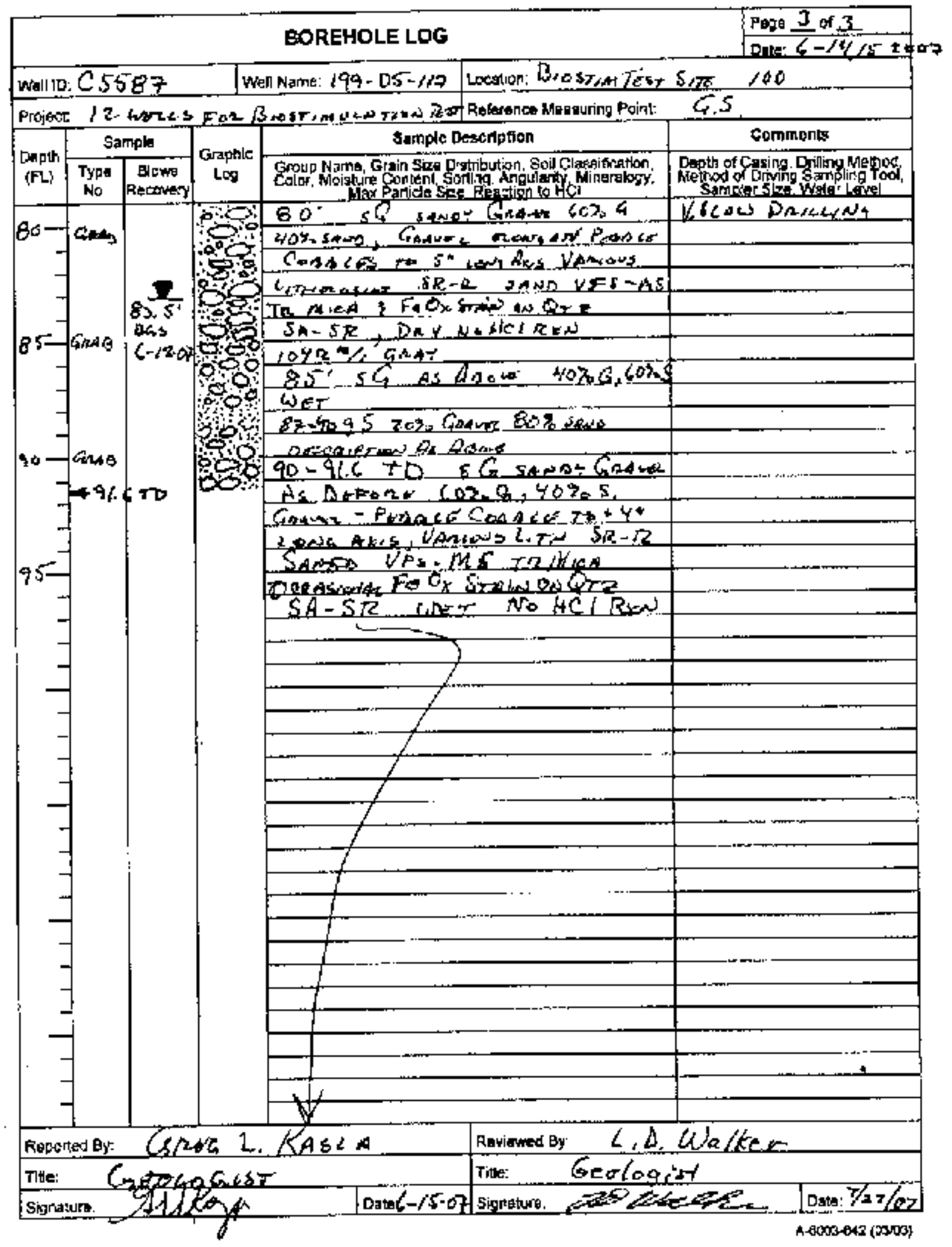




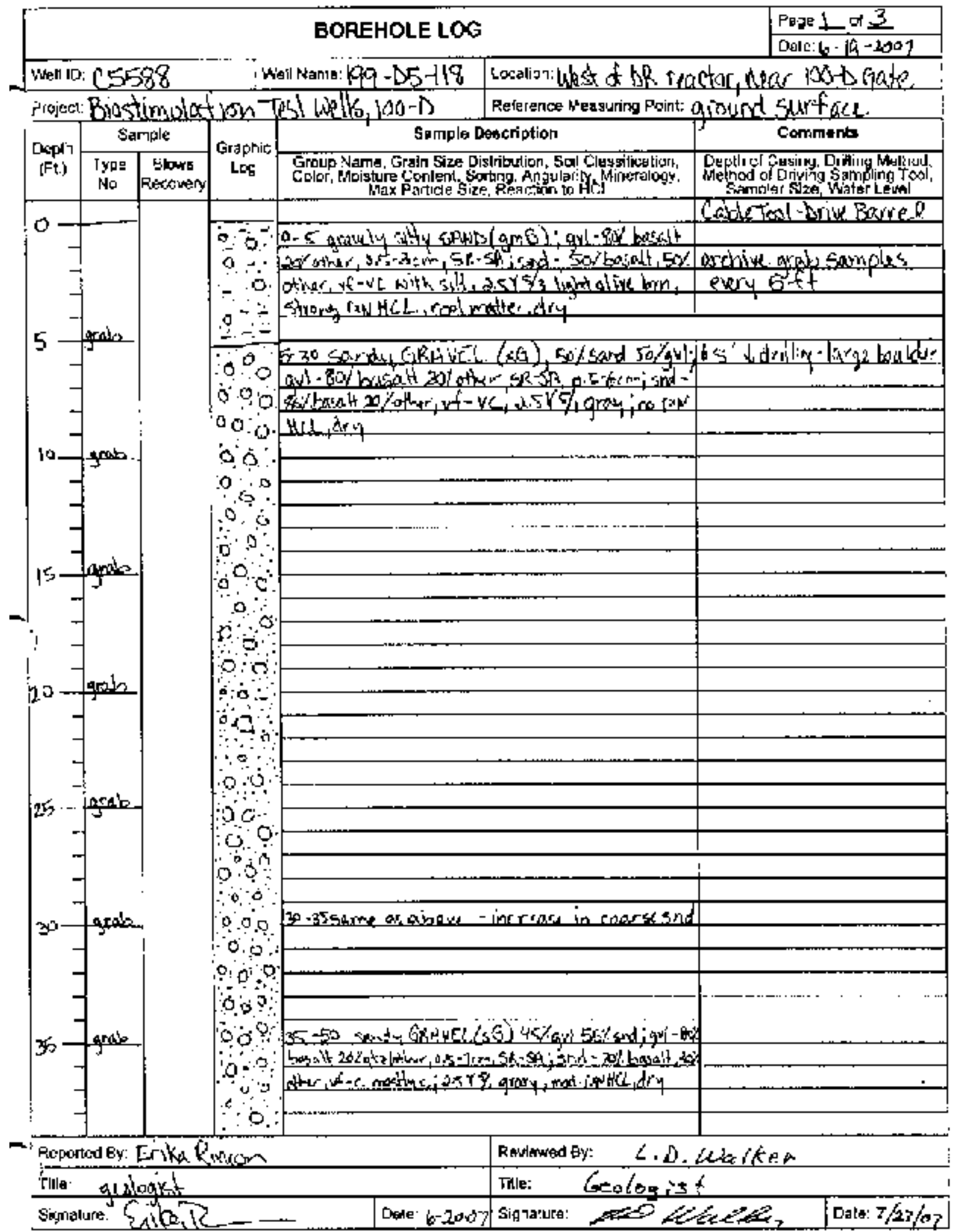




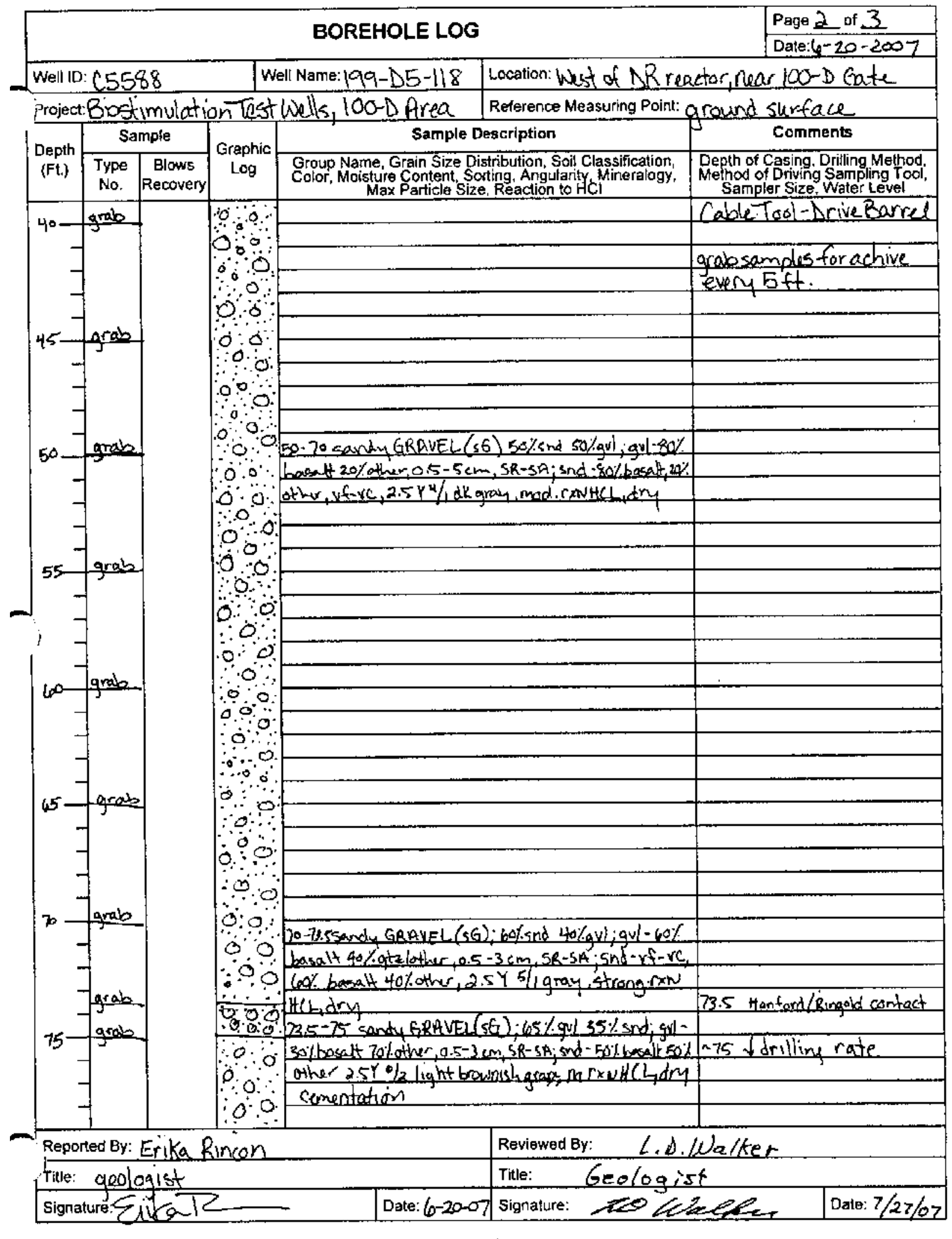

A.6003-642 (03/03) 


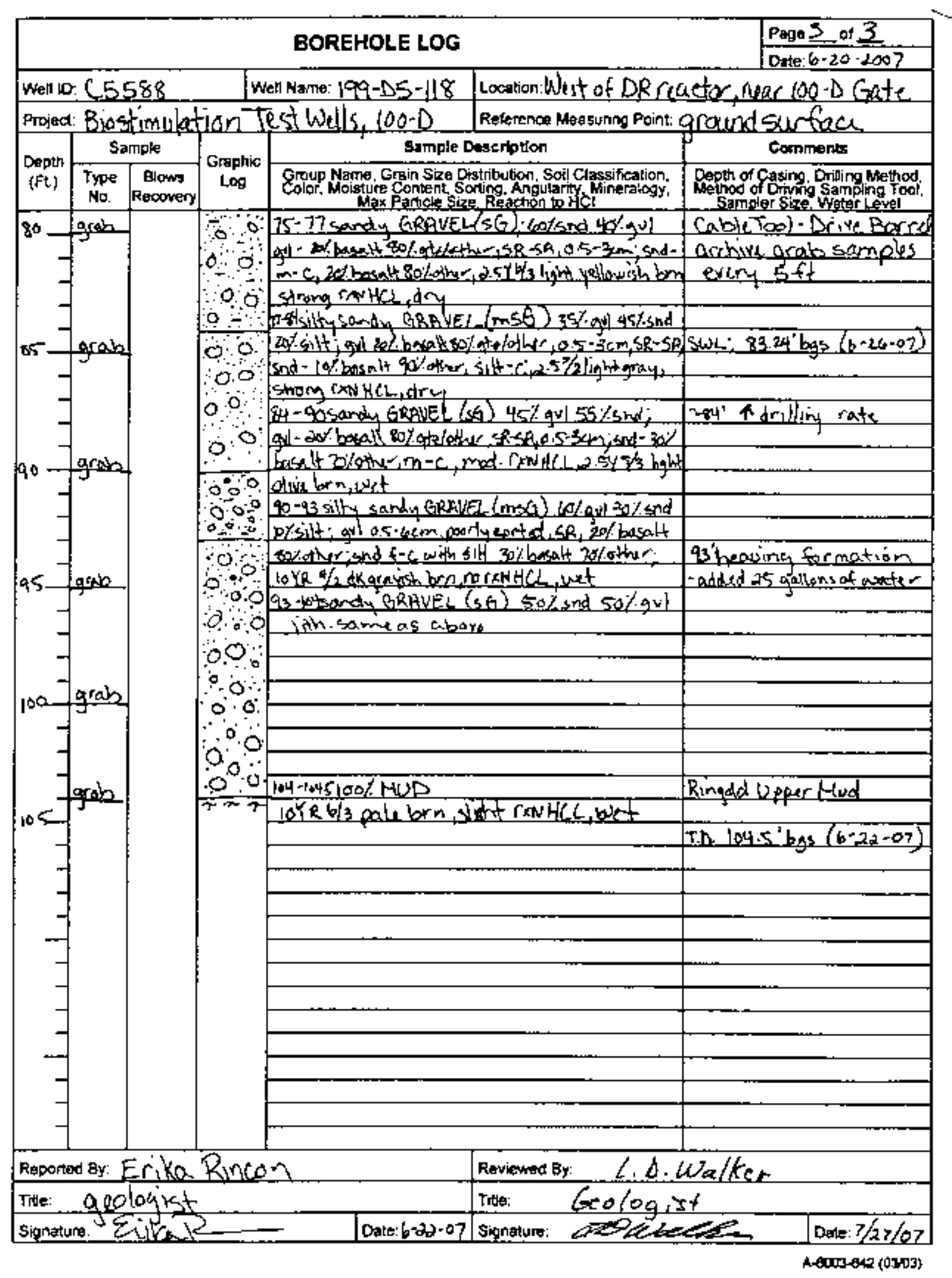


Appendix B

Gradient Direction and Magnitude in the 100-D Area During the Field Test 


\section{Appendix B}

\section{Gradient Direction and Magnitude in the 100-D Area During the Field Test}

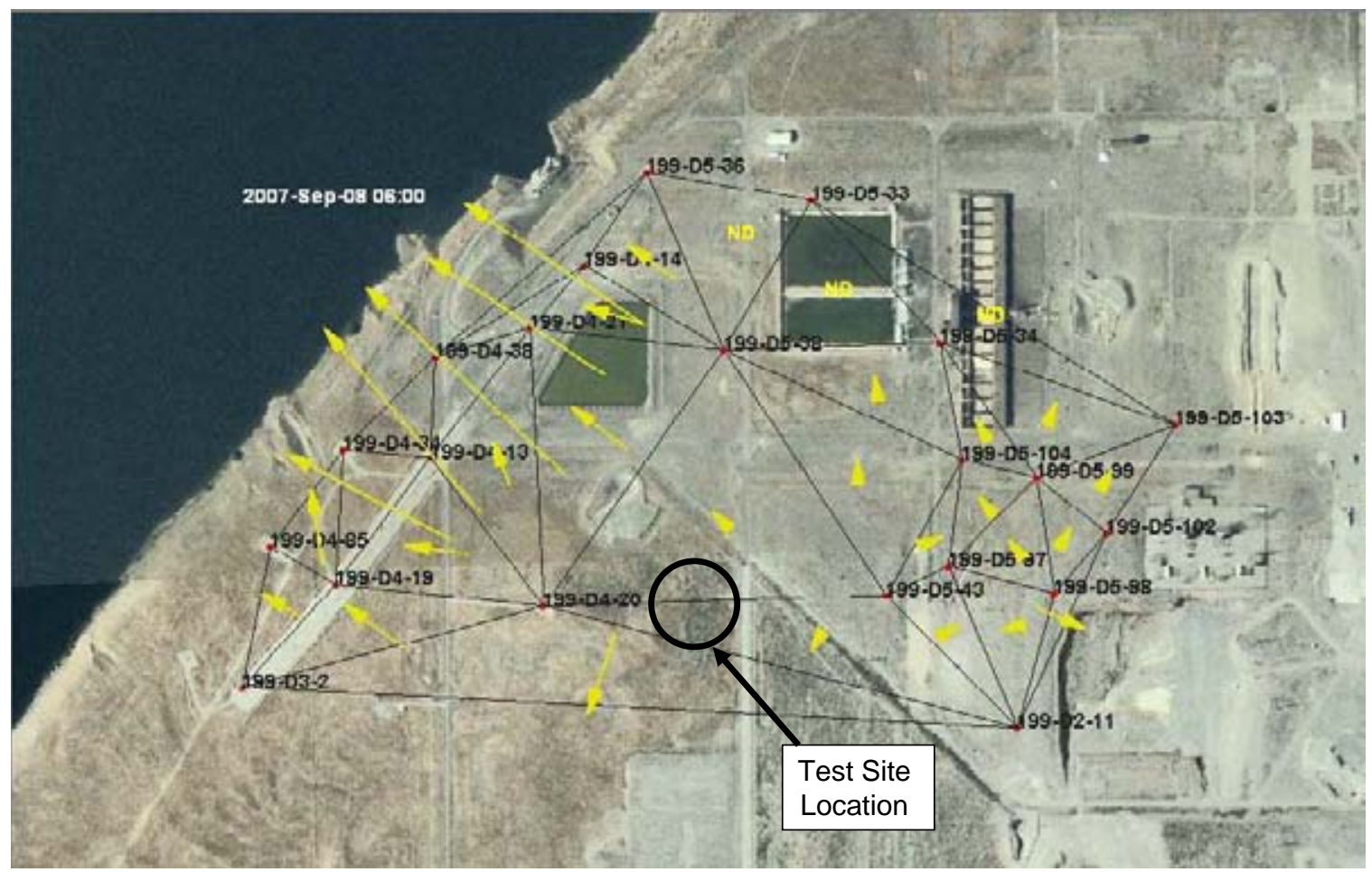

Figure B.1. Gradient Direction and Relative Magnitude in the 100-D Chromate Plume for September 2007 


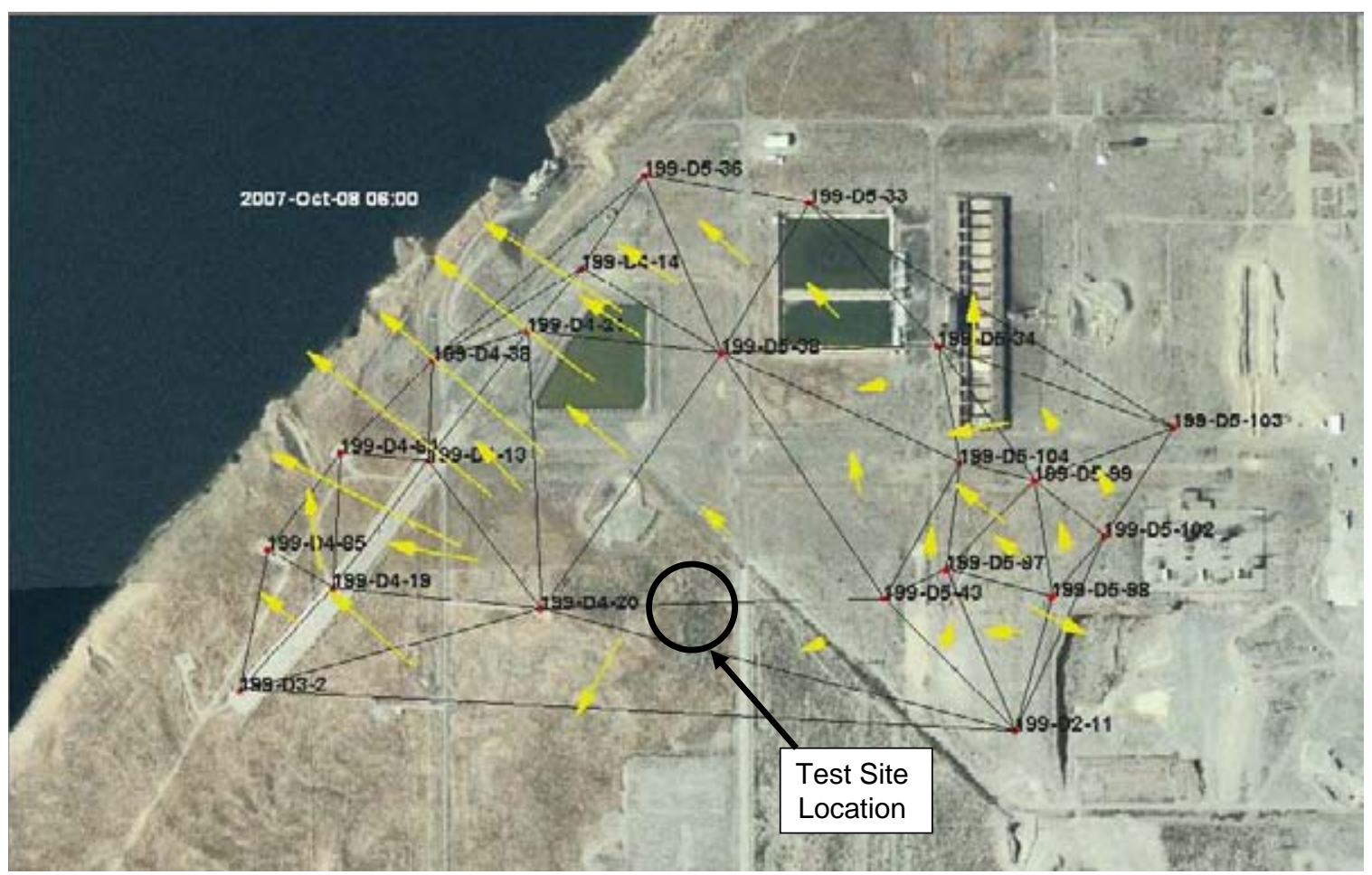

Figure B.2. Gradient Direction and Relative Magnitude in the 100-D Chromate Plume for October 2007

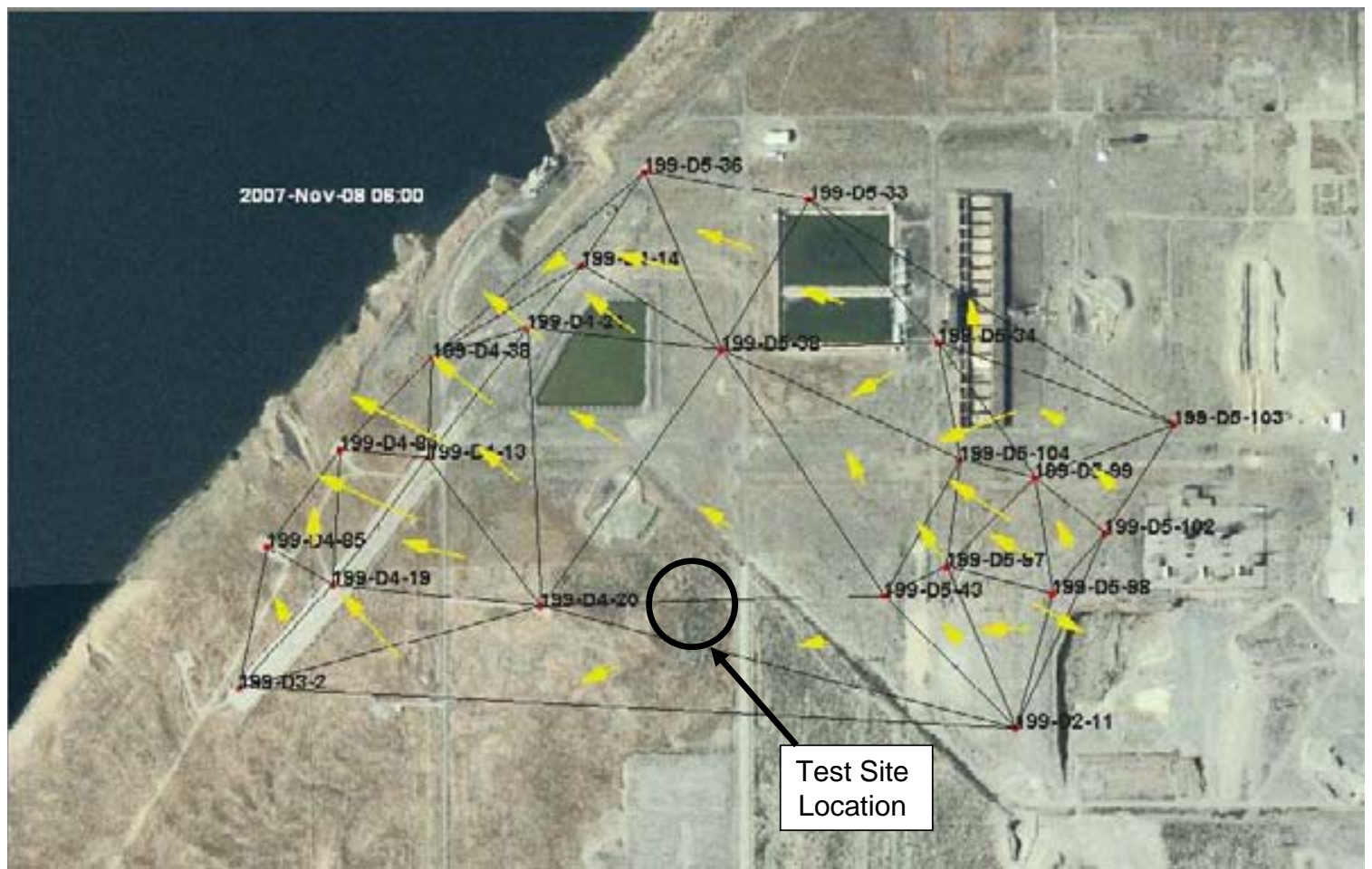

Figure B.3. Gradient Direction and Relative Magnitude in the 100-D Chromate Plume for November 2007 


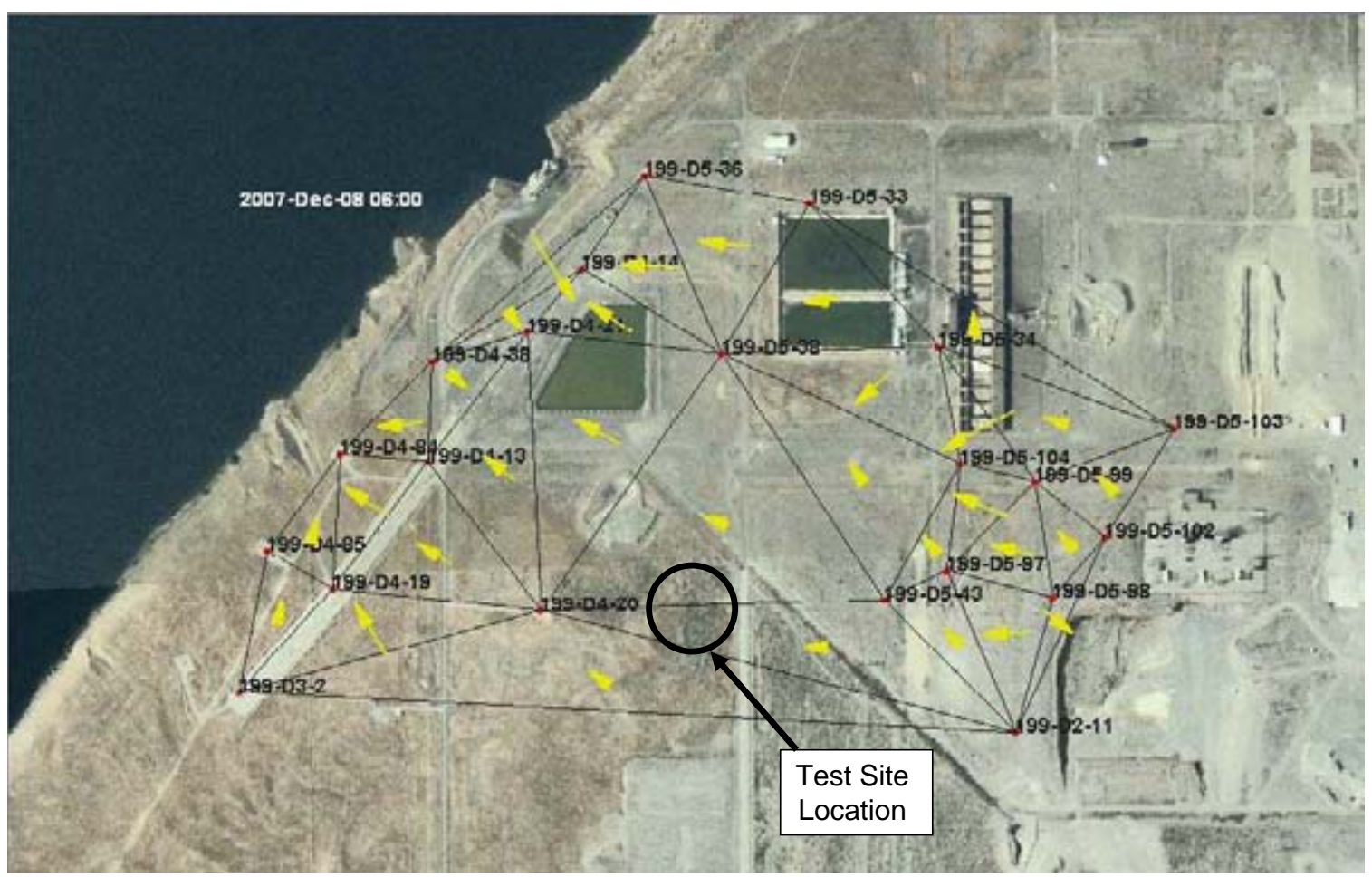

Figure B.4. Gradient Direction and Relative Magnitude in the 100-D Chromate Plume for December 2007

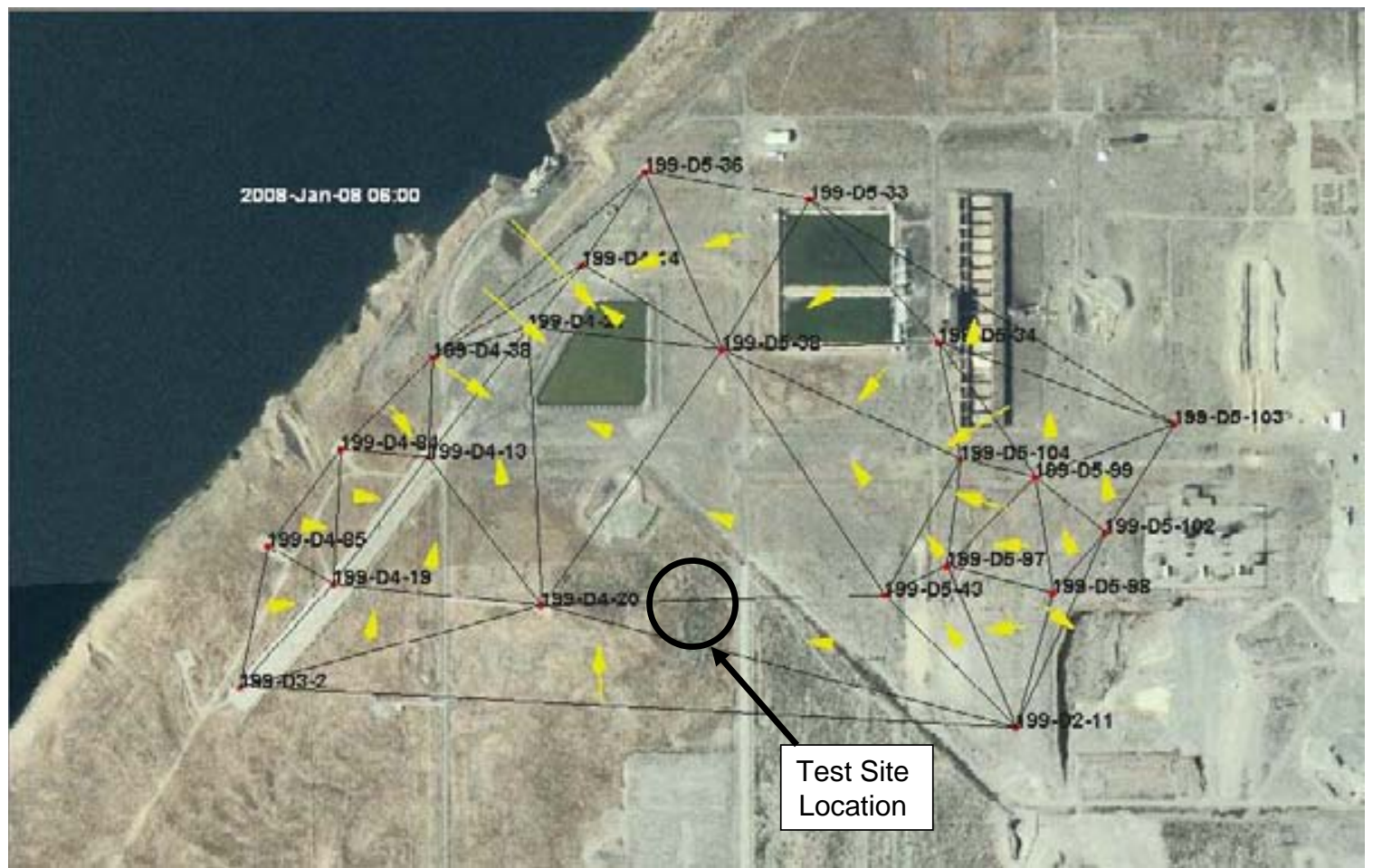

Figure B.5. Gradient Direction and Relative Magnitude in the 100-D Chromate Plume for January 2008 


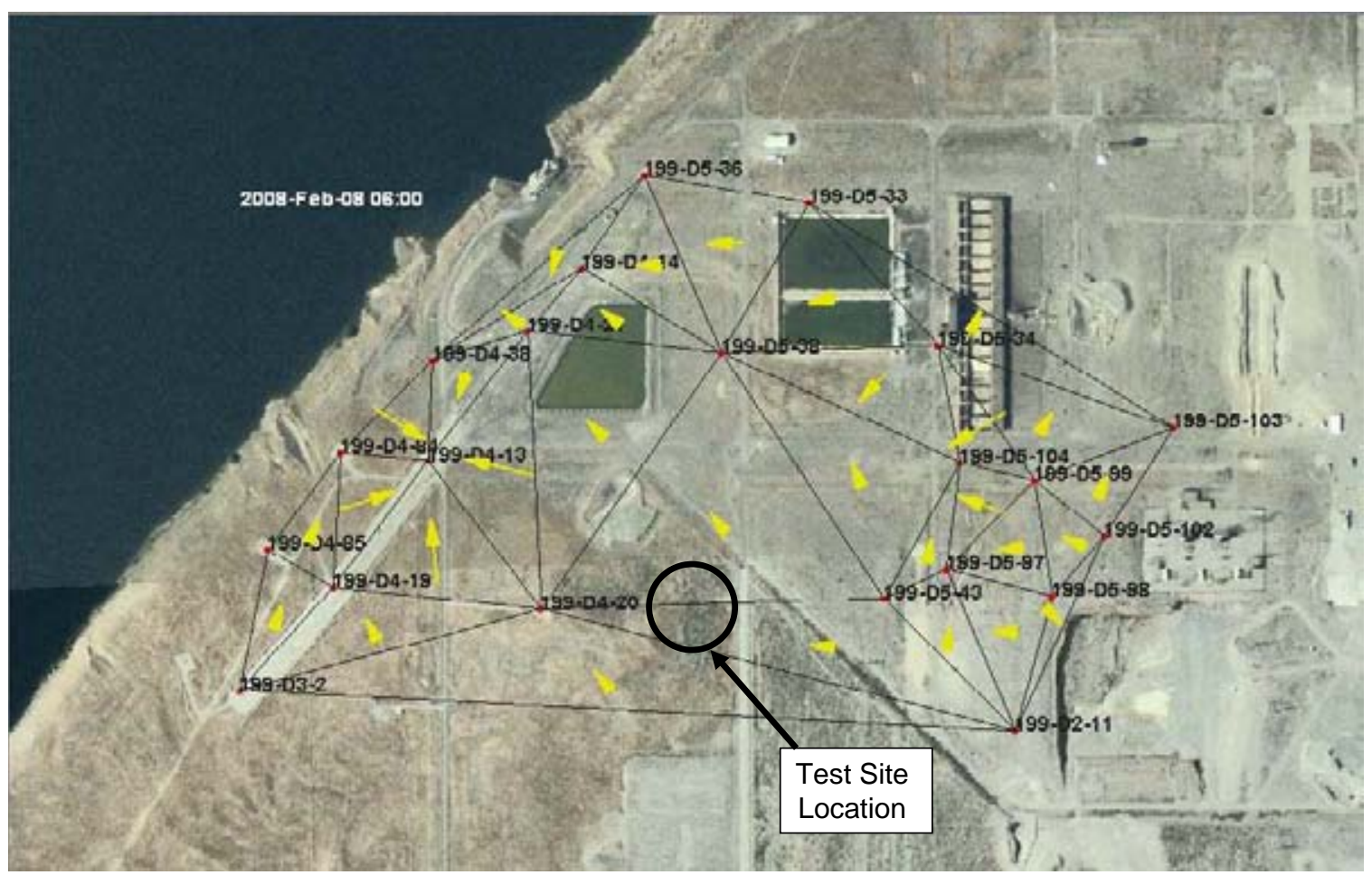

Figure B.6. Gradient Direction and Relative Magnitude in the 100-D Chromate Plume for February 2008

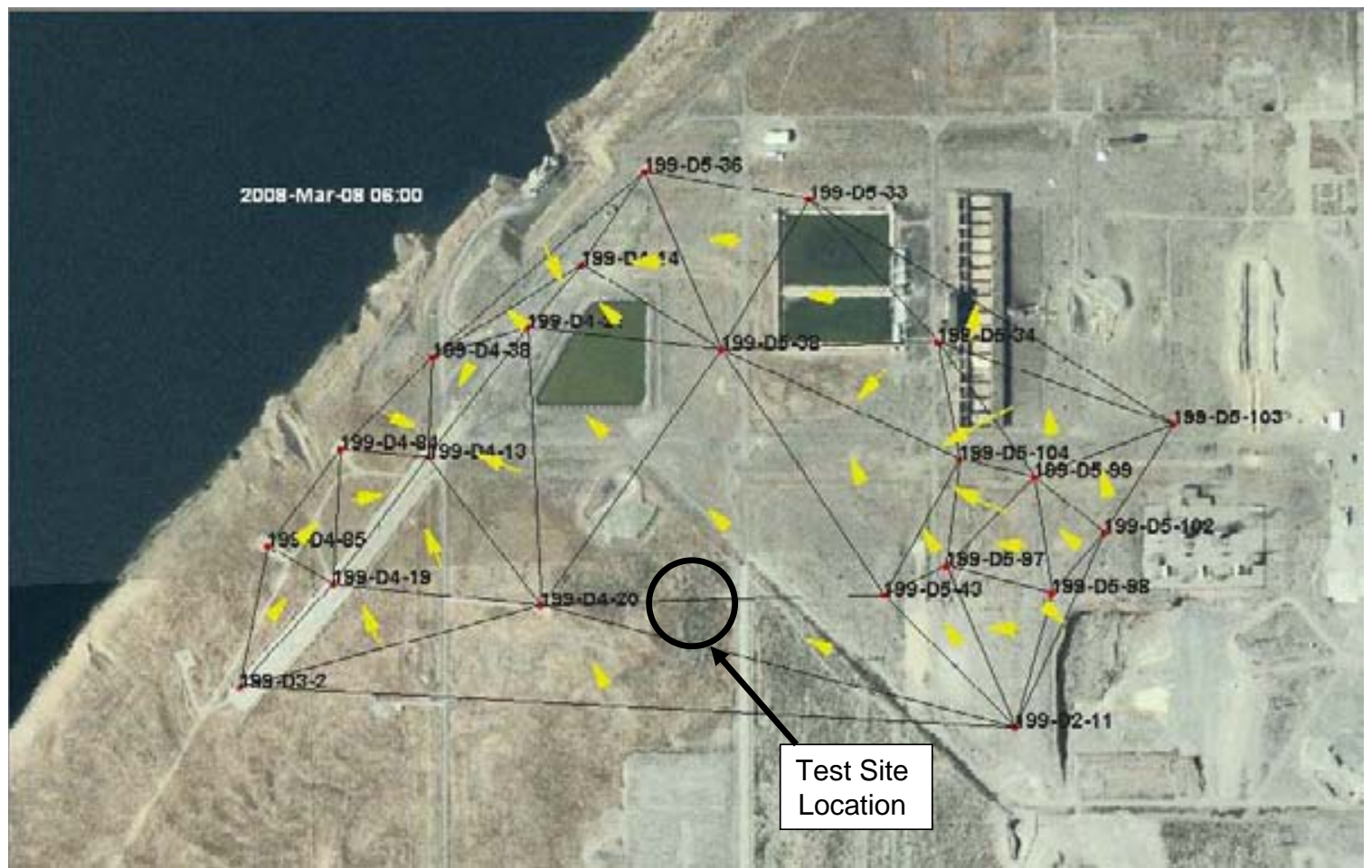

Figure B.7. Gradient Direction and Relative Magnitude in the 100-D Chromate Plume for March 2008 


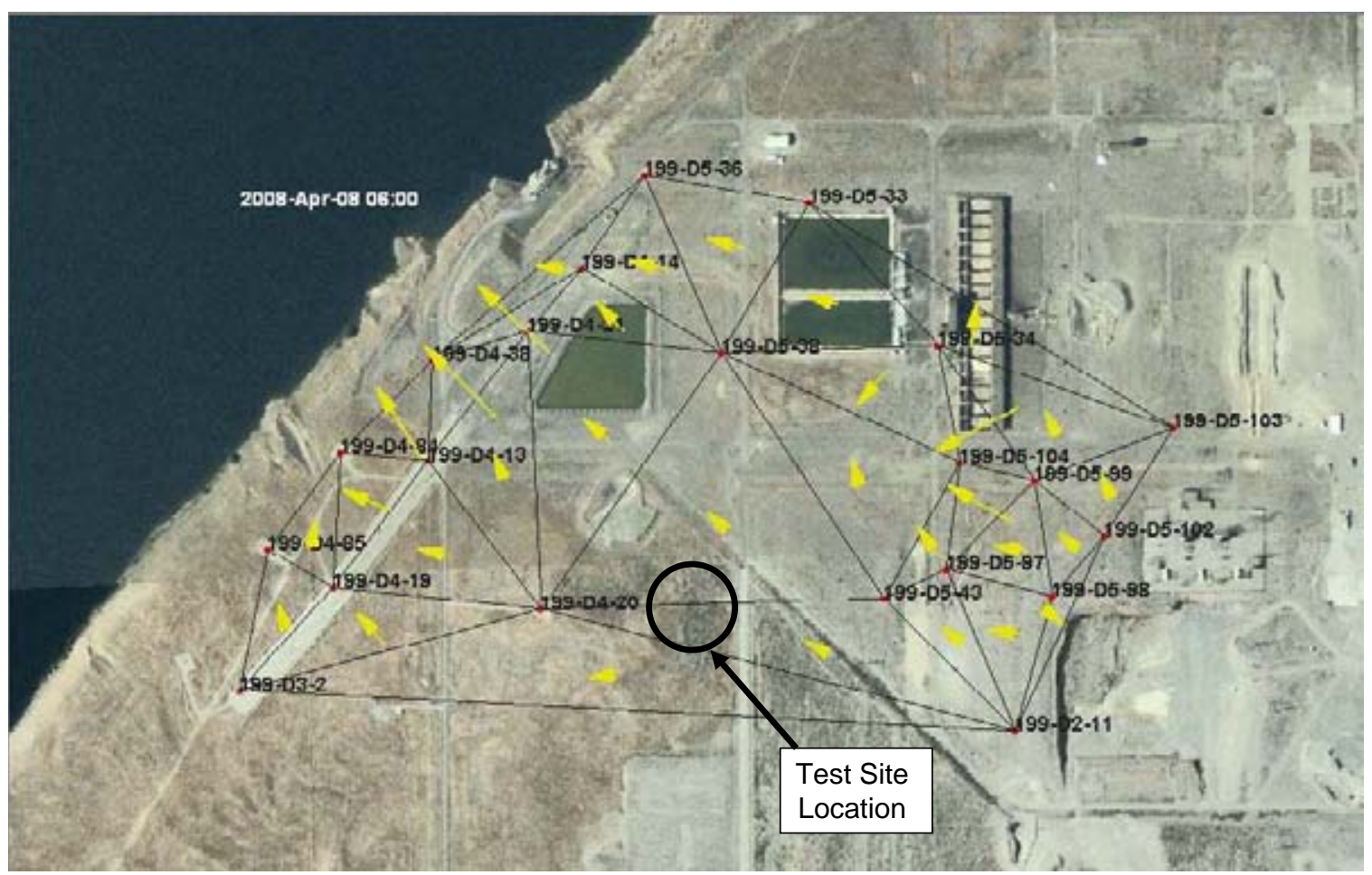

Figure B.8. Gradient Direction and Relative Magnitude in the 100-D Chromate Plume for April 2008

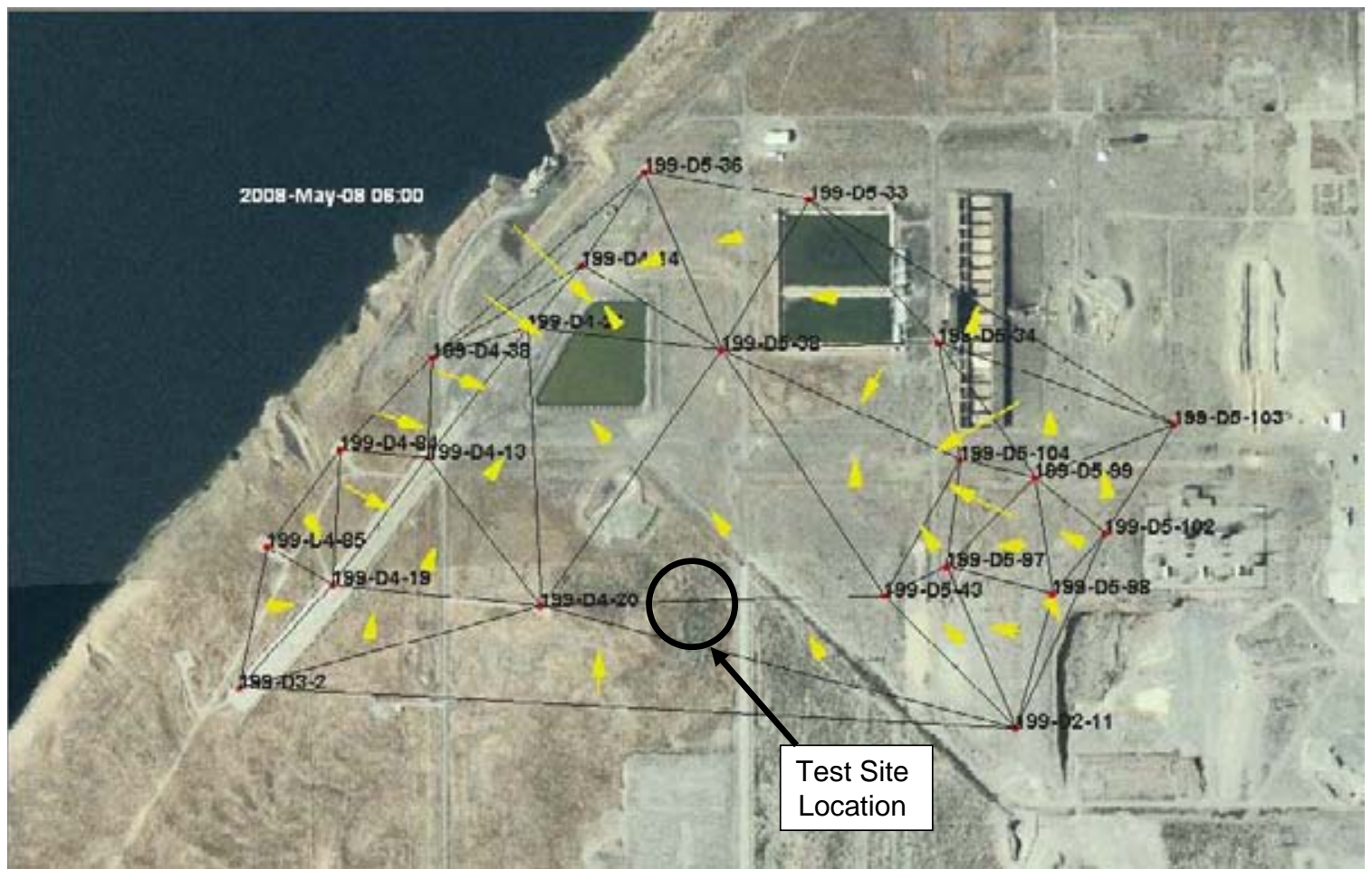

Figure B.9. Gradient Direction and Relative Magnitude in the 100-D Chromate Plume for May 2008 


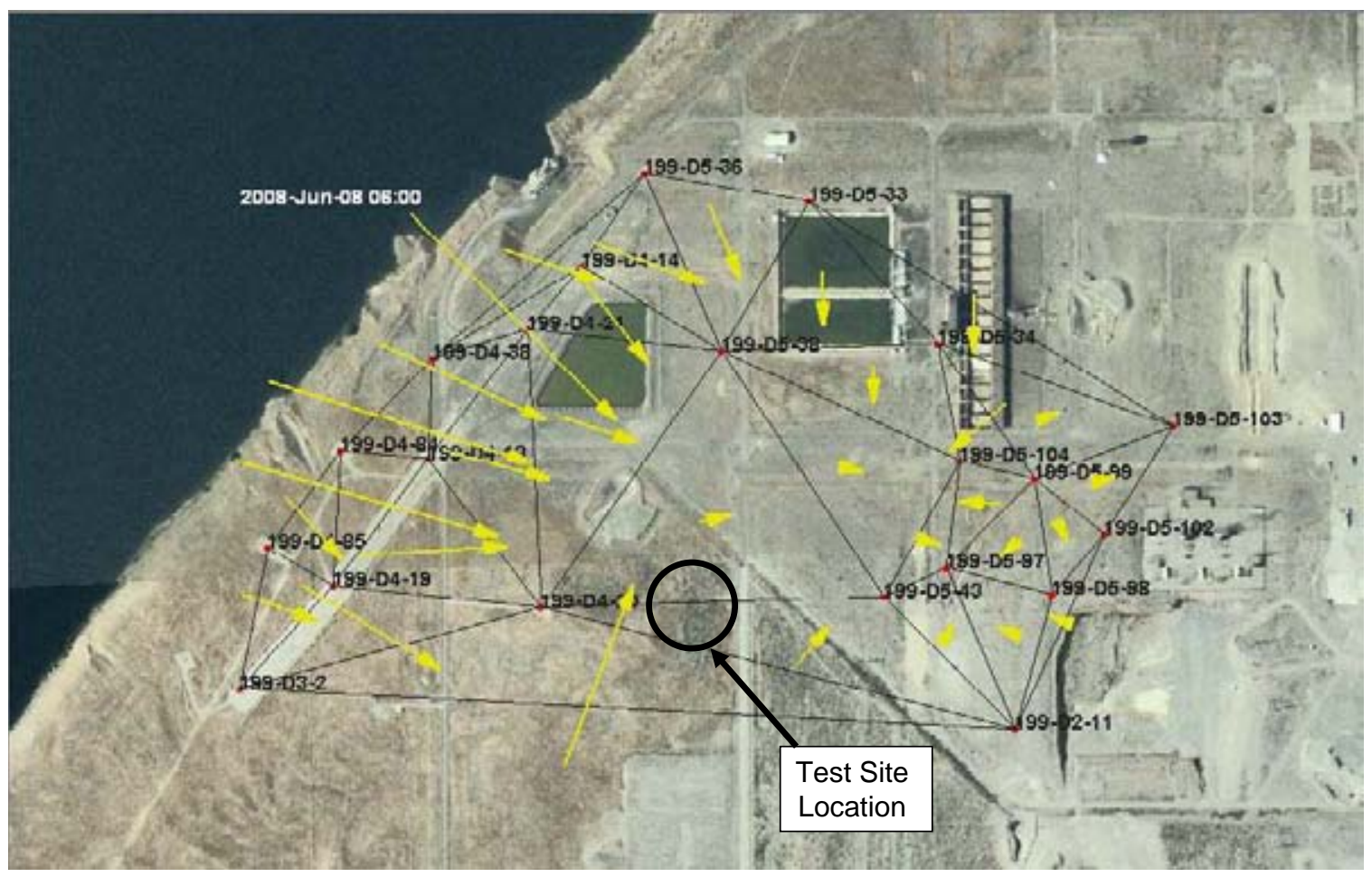

Figure B.10. Gradient Direction and Relative Magnitude in the 100-D Chromate Plume for June 2008

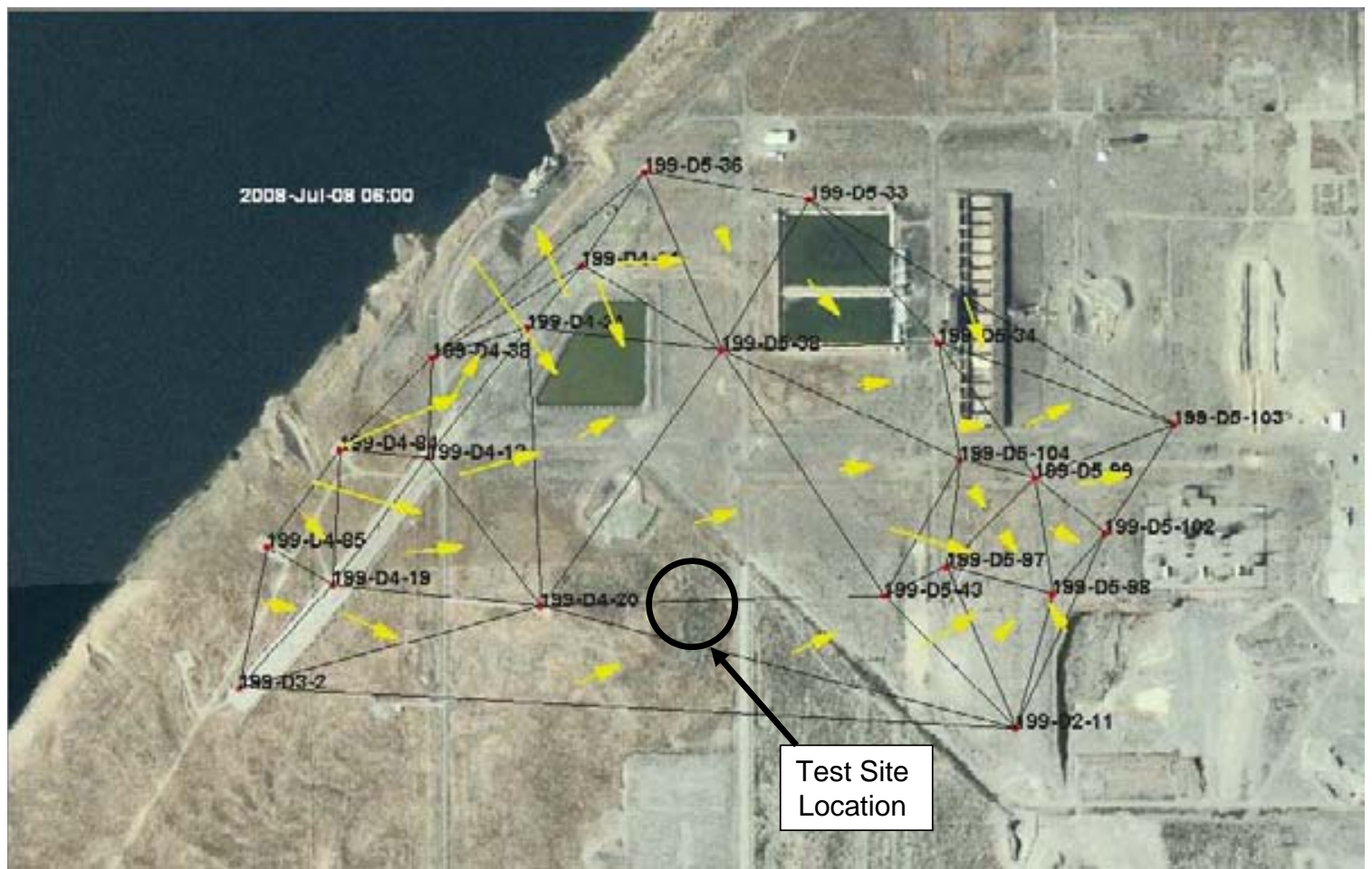

Figure B.11. Gradient Direction and Relative Magnitude in the 100-D Chromate Plume for July 2008 


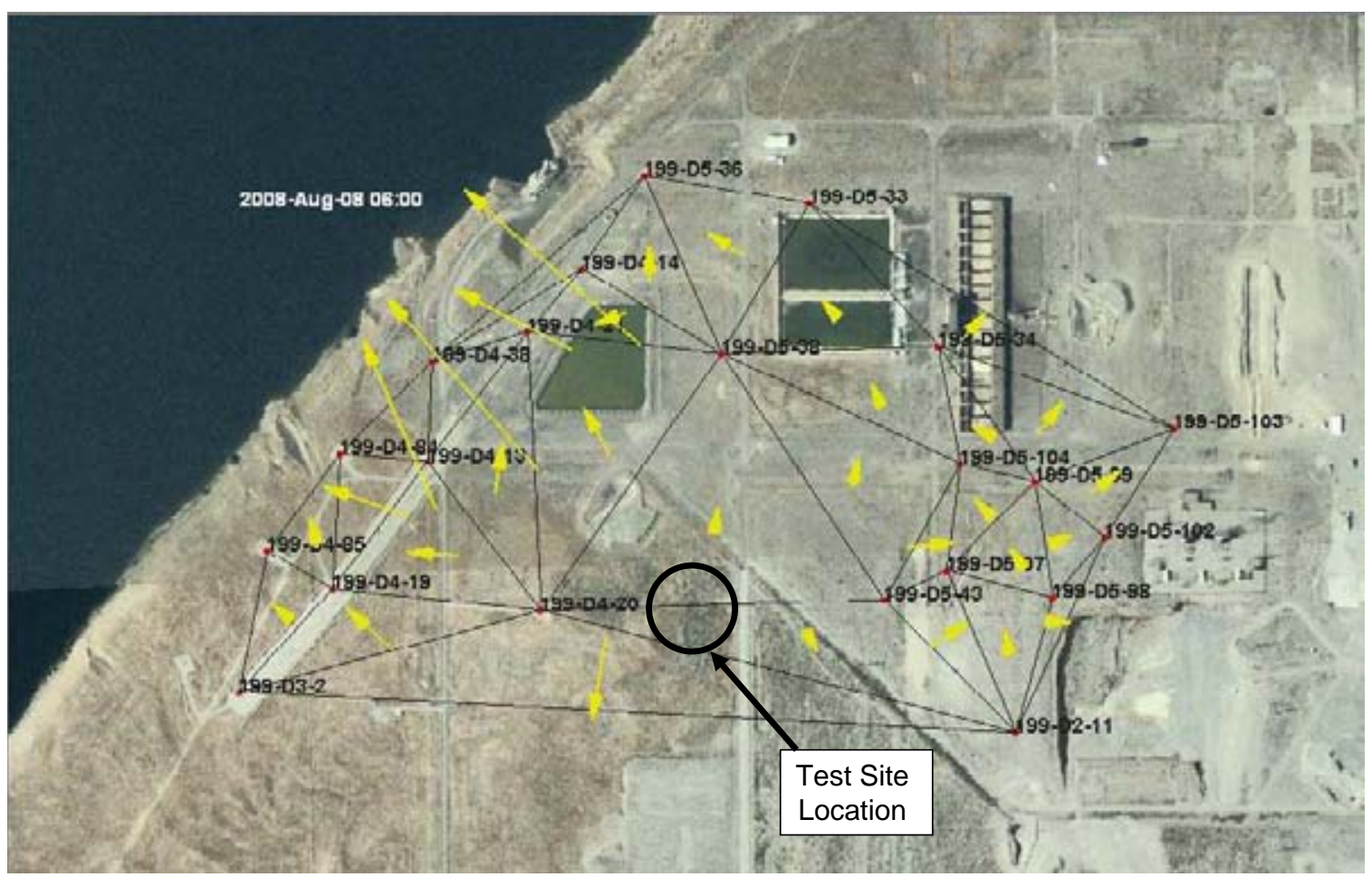

Figure B.12. Gradient Direction and Relative Magnitude in the 100-D Chromate Plume for August 2008

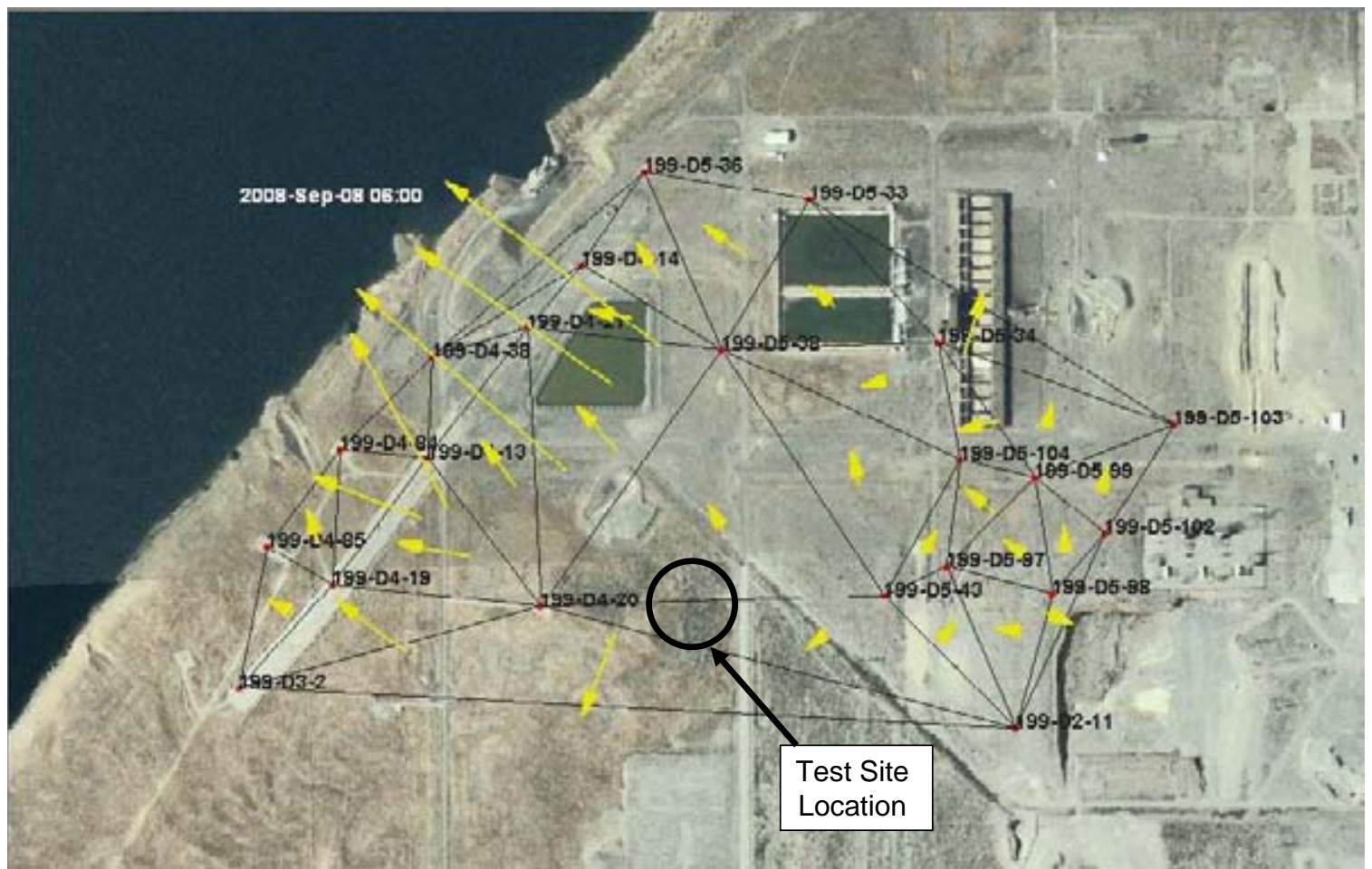

Figure B.13. Gradient Direction and Relative Magnitude in the 100-D Chromate Plume for September 2008 


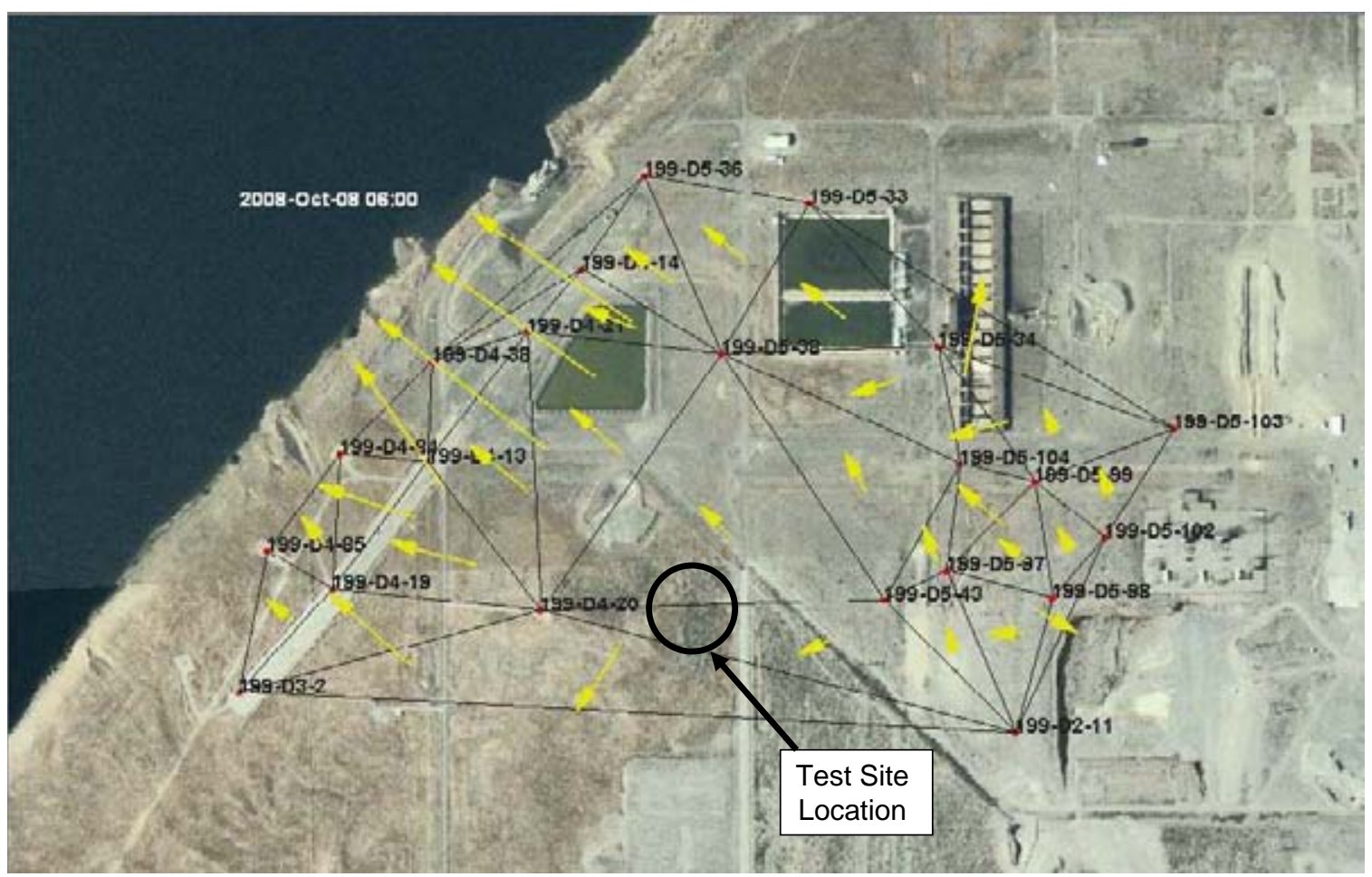

Figure B.14. Gradient Direction and Relative Magnitude in the 100-D Chromate Plume for October 2008

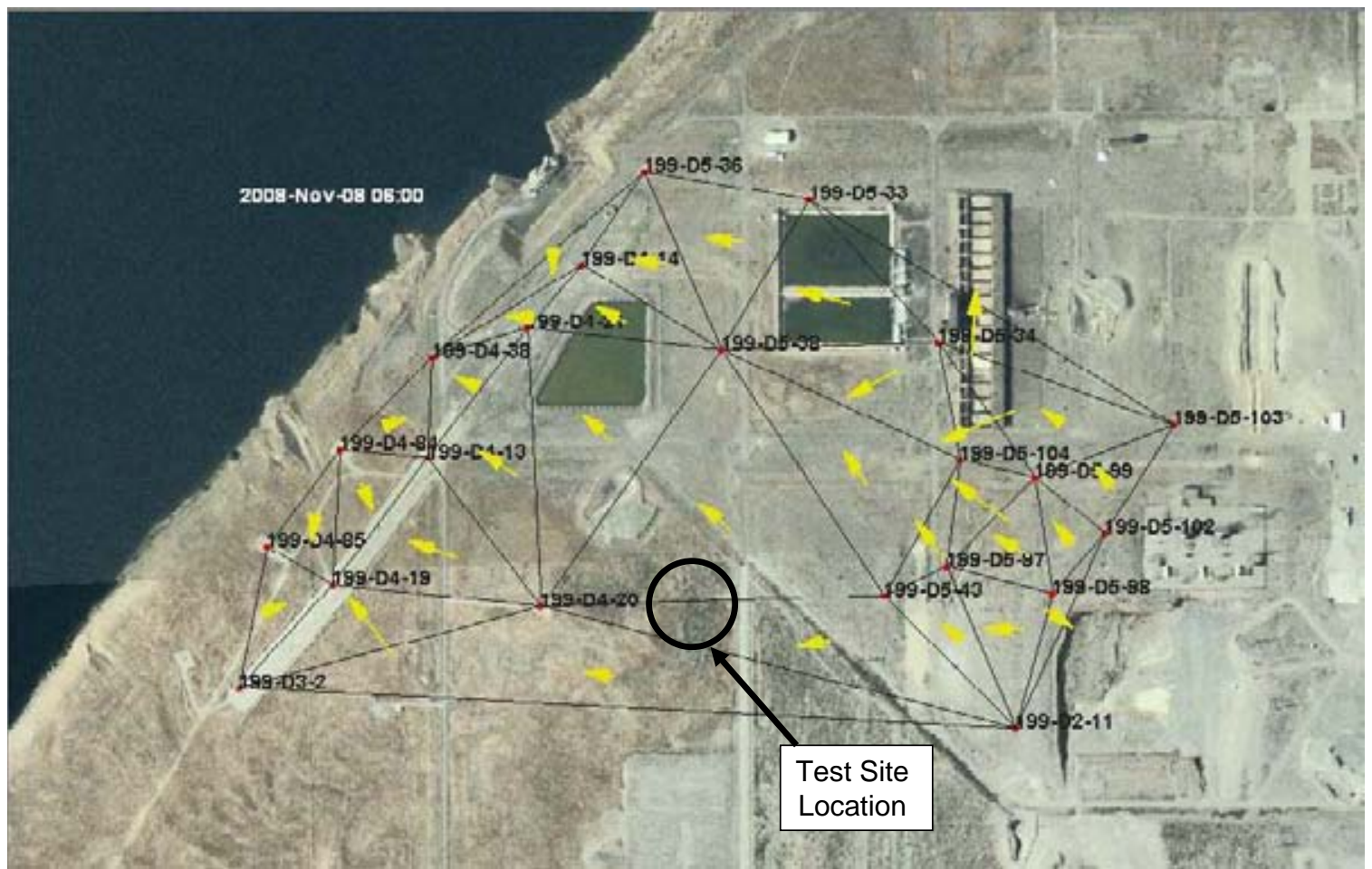

Figure B.15. Gradient Direction and Relative Magnitude in the 100-D Chromate Plume for November 2008 


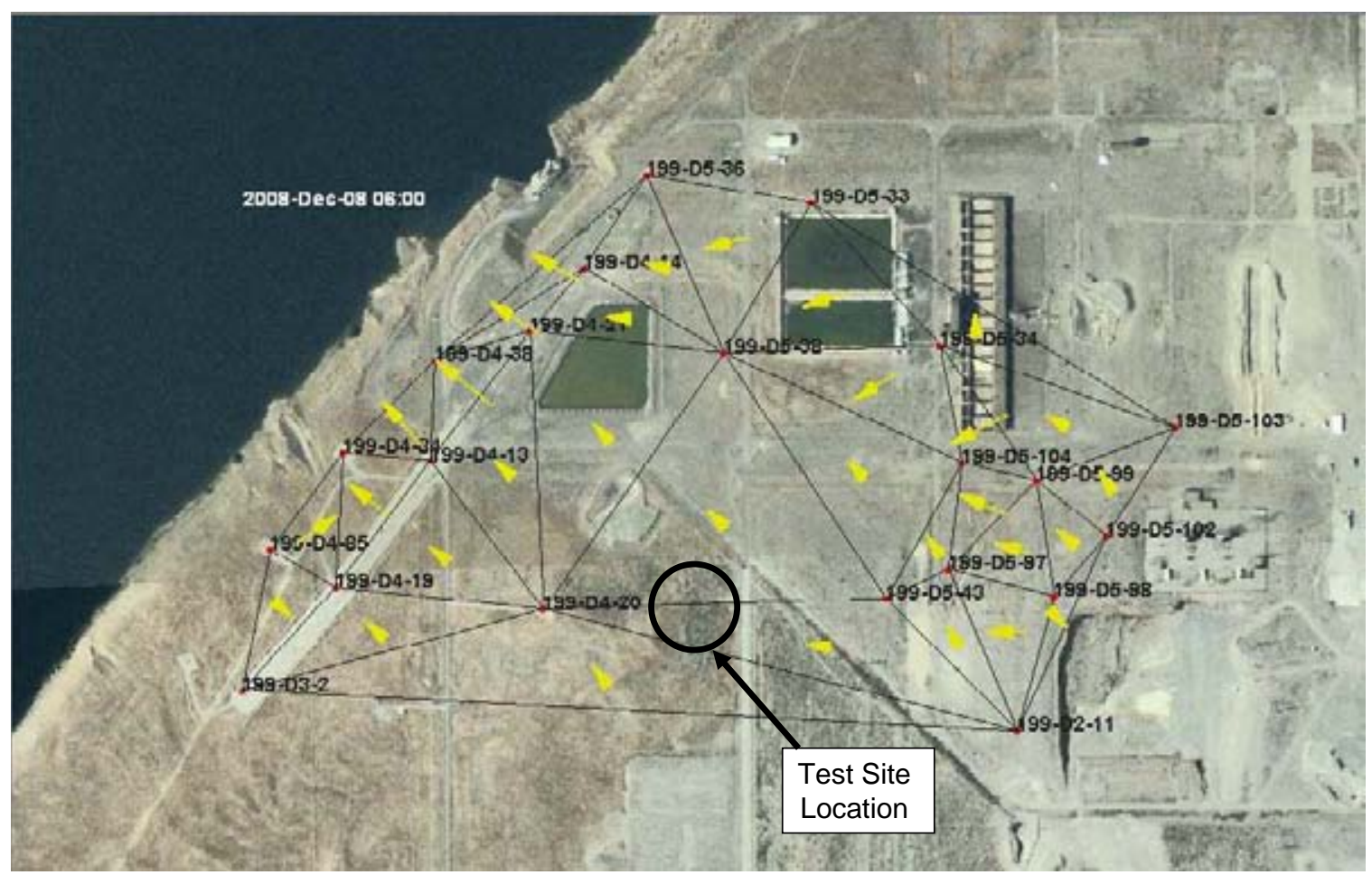

Figure B.16. Gradient Direction and Relative Magnitude in the 100-D Chromate Plume for December 2008

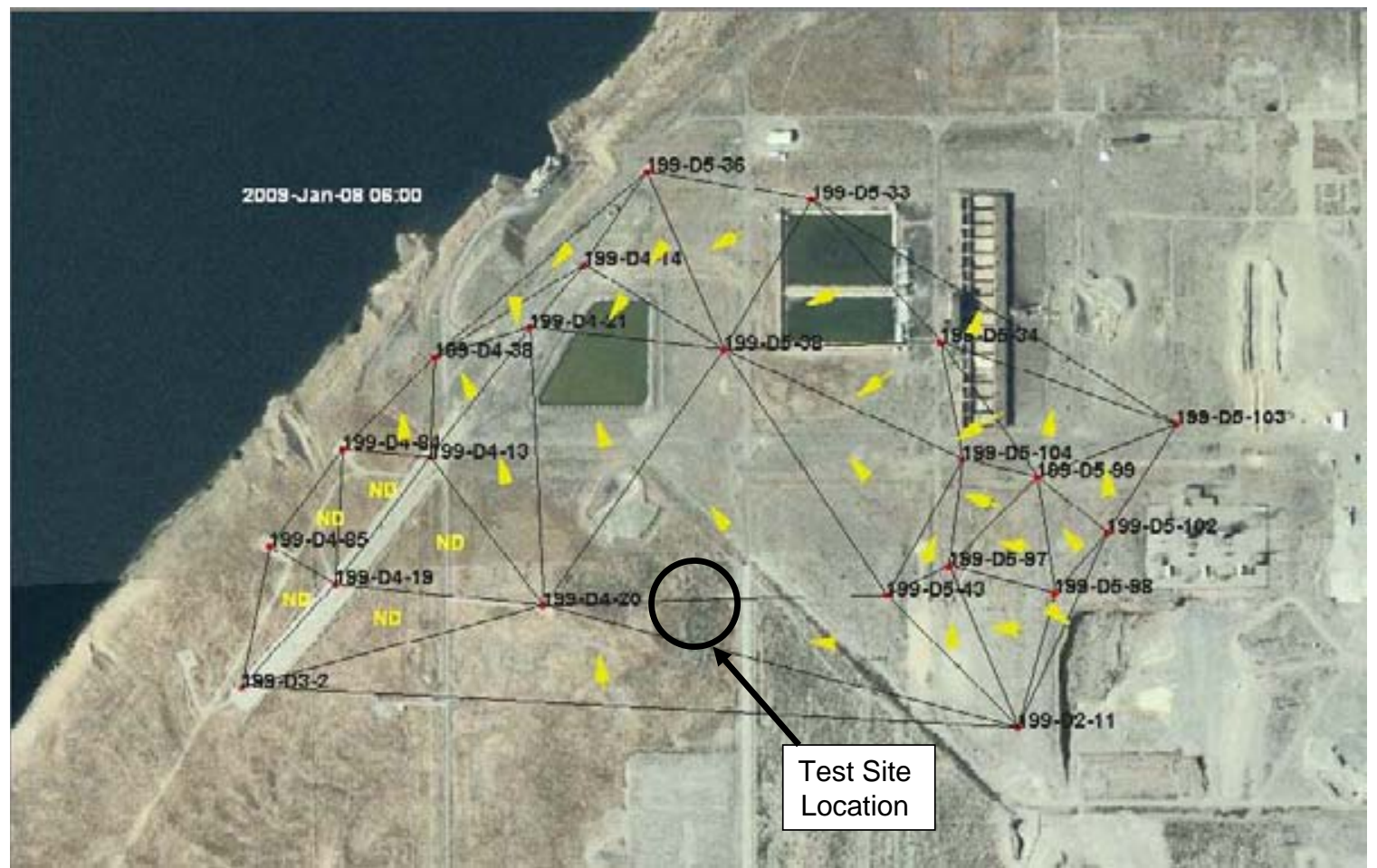

Figure B.17. Gradient Direction and Relative Magnitude in the 100-D Chromate Plume for January 2009 


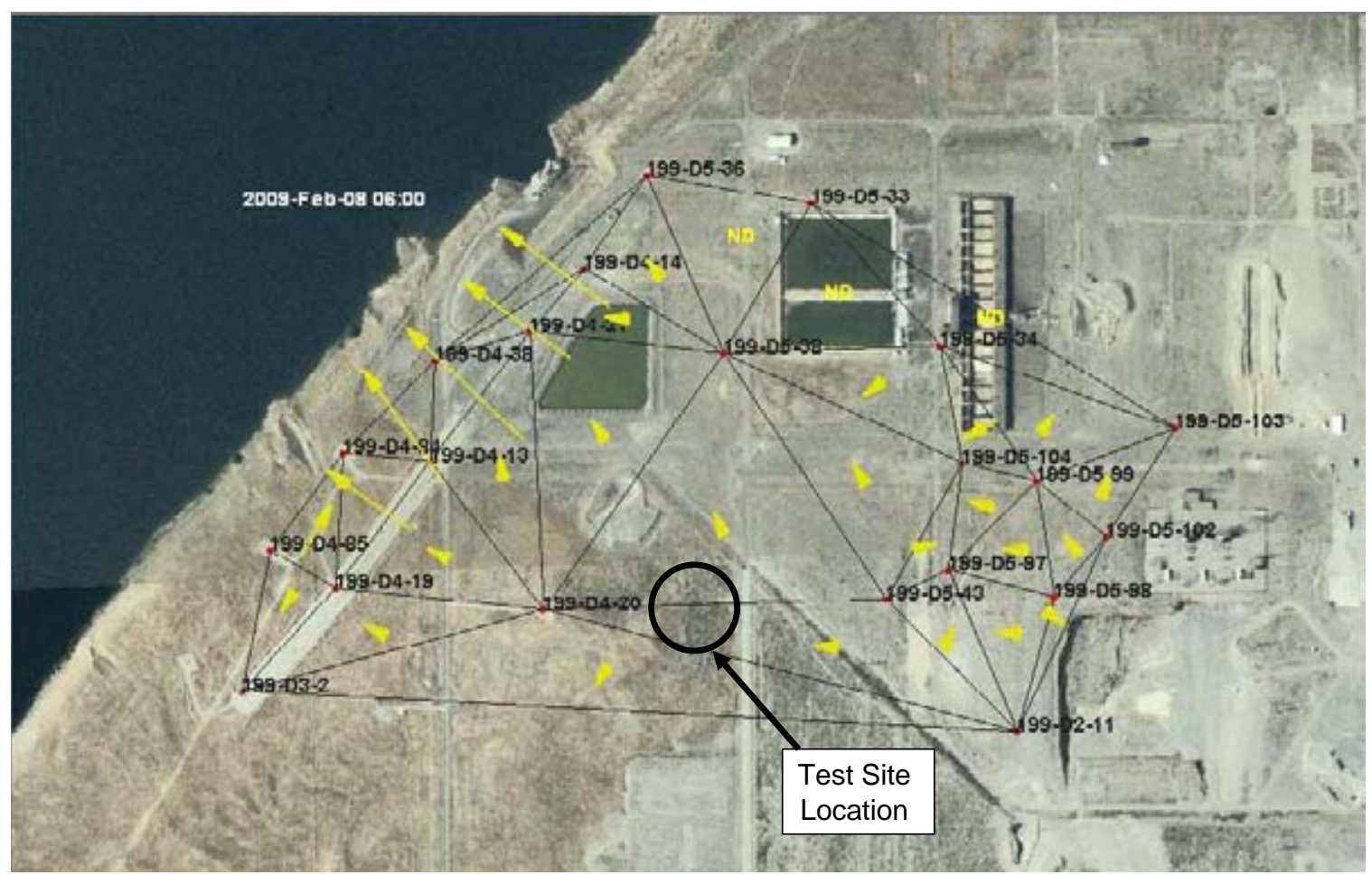

Figure B.18. Gradient Direction and Relative Magnitude in the 100-D Chromate Plume for February 2009

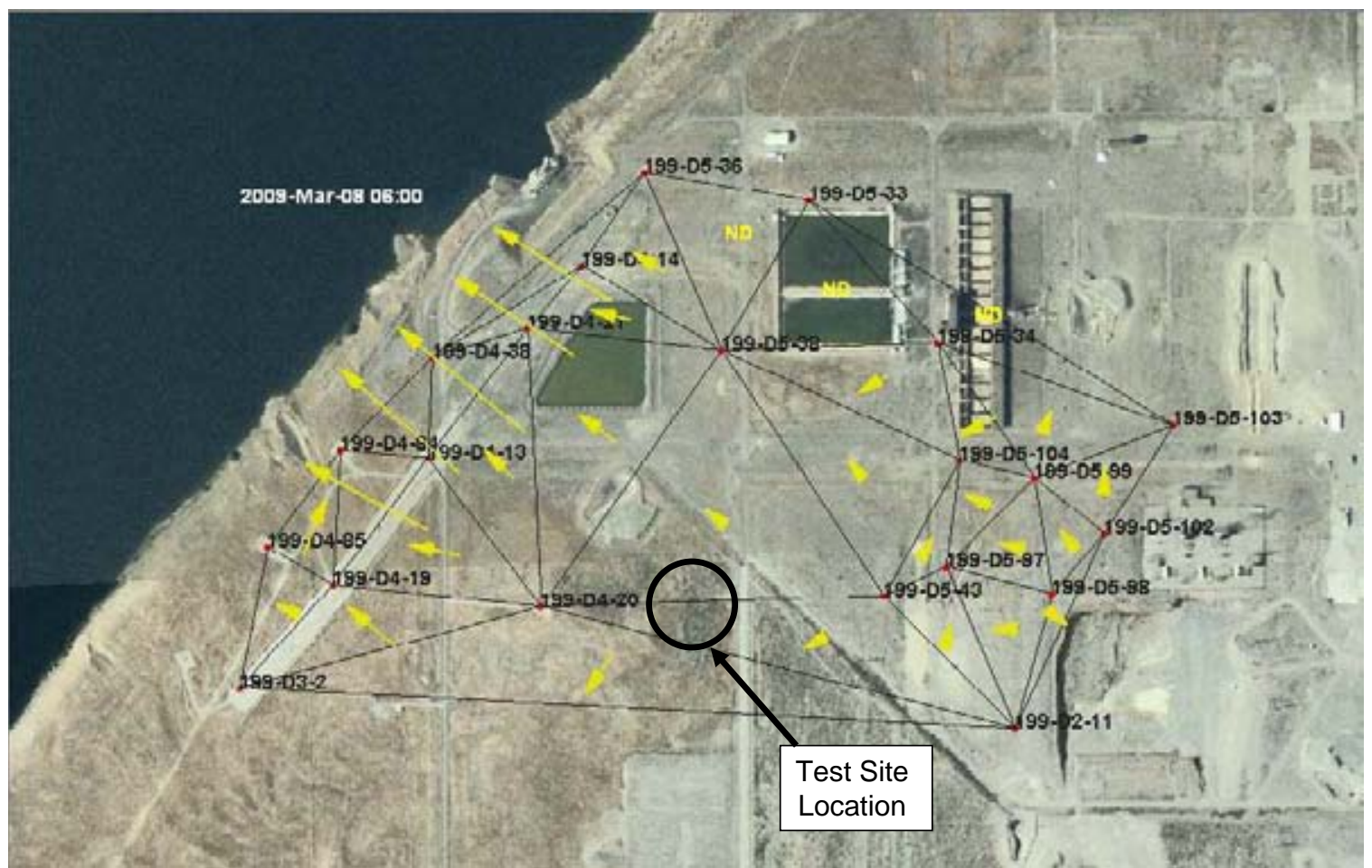

Figure B.19. Gradient Direction and Relative Magnitude in the 100-D Chromate Plume for March 2009 


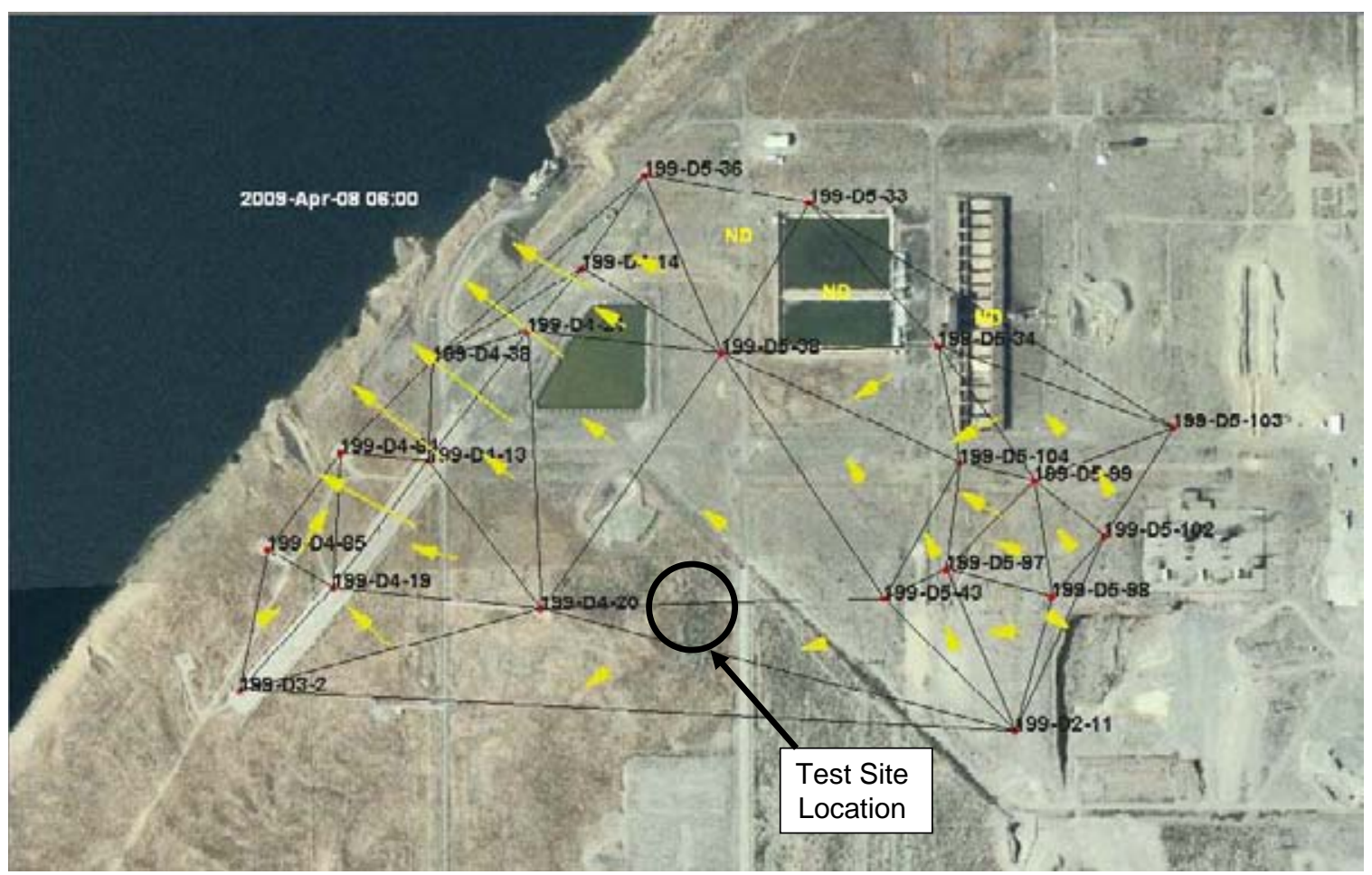

Figure B.20. Gradient Direction and Relative Magnitude in the 100-D Chromate Plume for April 2009

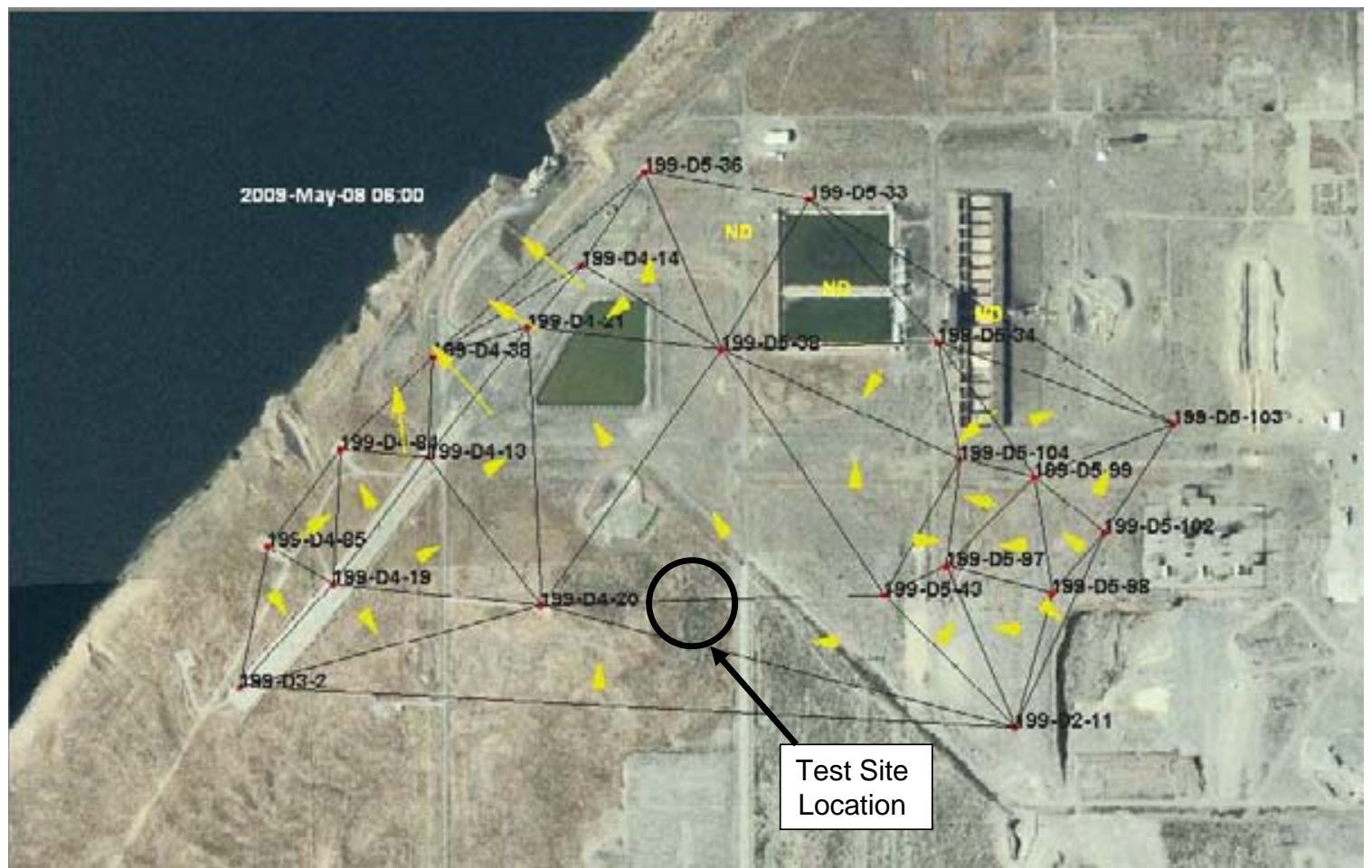

Figure B.21. Gradient Direction and Relative Magnitude in the 100-D Chromate Plume for May 2009 


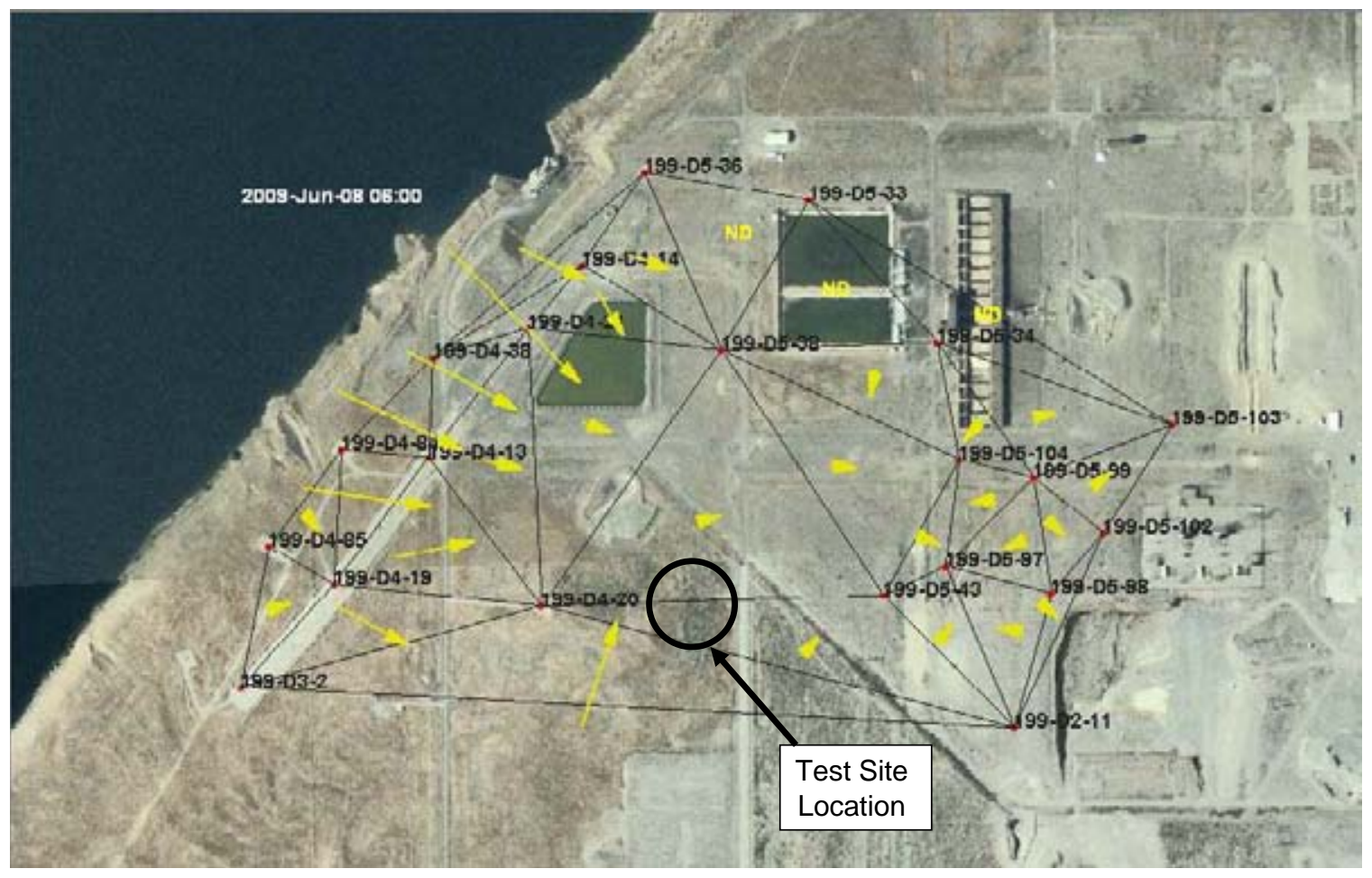

Figure B.22. Gradient Direction and Relative Magnitude in the 100-D Chromate Plume for June 2009 


\section{Appendix C}

\section{Geophysical Methods Background}




\section{Appendix C}

\section{Geophysical Methods Background}

\section{C.1 Complex Electrical Methods}

The complex electrical method was used to measure frequency-dependent electrical responses over the range of 0.1-1000 Hz using non-polarizing Ag/AgCl electrodes. This method involves injecting current of different frequencies into a sample volume and measuring the responses relative to a reference resistor to yield the phase and electrical conductivity as function of frequency. Typically, the obtained electrical conductivity estimate is used to provide information about pore space variations (water content, total dissolved solids) whereas the phase is used to infer information about interactions occurring near the interface of the grains and pore fluids (Binley and Kemna 2005). Archie's Law (Archie 1942) is commonly used to relate the measured effective conductivity $\left(\sigma_{\text {eff }}\right)$ to porosity $(\boldsymbol{n})$, the electrical conductivity of the pore water $\left(\sigma_{w}\right)$, and the electrical conductivity associated with surface conduction $\left(\sigma_{\text {surface }}\right)$ as

$$
\sigma_{\text {eff }}=\sigma_{w} n^{m}+\sigma_{\text {surface }}
$$

where $m$ is Archie's exponent. Neglecting changes associated with surface conduction, cementation and porosity, equation (1) suggests that if an amendment having a higher electrical conductivity replaces pore water, the effective electrical conductivity will increase.

Because theoretically based models for predicting spectral induced polarization (SIP) signatures are lacking or difficult to parameterize, phenomenological formulations such as the Cole-Cole relaxation model (Cole and Cole 1941) are often used to model the complex response. Inversion of the complex resistivity data yields estimates of the Cole-Cole parameters chargeability and time constant (e.g., Chen et al. 2008), which can in turn be related to pore and grain geometric characteristics. Interpretation of complex resistivity measurements and obtained parameters in terms of near subsurface biogeochemical properties and processes is a relatively new area of biogeophysical research. Although recent research has interpreted these measurements in terms of remediation-induced end-products such as precipitates (Williams et al. 2005; Chen et al. 2008) and biofilms, to our knowledge the complex resistivity response of pore fluid replacement by remedial amendments has not been documented.

\section{C.2 Radar Methods}

Time-domain reflectometer (TDR) methods were used at the laboratory scale, and tomographic ground-penetrating radar (GPR) methods were used at the field scale to measure electromagnetic wave propagation characteristics over the $\sim 100-1000 \mathrm{MHz}$ range. TDR methods involve propagating an electromagnetic signal along waveguides inserted into the material of interest and measuring the velocity and amplitude of the traveling wave (Topp et al. 1980). Tomographic radar data acquisition consists of placing a transmitter and a receiver in separate boreholes, and moving them successively until many 
transmitter and receiver locations have been occupied. The travel time of the direct arrival and associated amplitude information is extracted from the recorded waveforms, and inversion algorithms are used to transform this information into estimations of velocity and attenuation between the boreholes (Peterson 2001).

At the frequency of operation for TDR and radar systems, the separation (polarization) of opposite electric charges within a material subjected to an external electric fielddominates the electrical response. The dielectric constant $(\boldsymbol{\kappa})$, which used to describe these high-frequency electrical properties; can be approximated from the velocity ( $V$ ) of the radar signal (Davis and Annan 1989) by

$$
\kappa \approx\left(\frac{C}{V}\right)^{2}
$$

where $c$ is the propagation velocity of electromagnetic waves in free space. The dielectric constant obtained from travel times is often used within dielectric mixing models to explore the dielectric contribution from a variety of components (Wharton et al. 1980) such as the idealistic expression for a three-component, soil-water-air system:

$$
\kappa=\left(S n \kappa_{w}^{\gamma}+(1-n) \kappa_{g}^{\gamma}+n(1-S) \kappa_{a}^{\gamma}\right)^{\frac{1}{\gamma}}
$$

In Equation (3), $S$ is water saturation; $n$ is the soil porosity; $\kappa_{w}, \kappa_{g}$ and $\kappa_{a}$ are the unitless dielectric constant values of pore water, soil grains, and air, respectively; and $\chi$ is a factor that accounts for the orientation of the electrical field with respect to the geometry of the medium (which is commonly assumed to be 0.5 for an isotropic medium). Given that the dielectric constant of water (80) is high relative to typical values for grains (4-8) and air (1), the mixing formula shown in (3) is commonly used for moisture content estimation. Under saturated conditions and assuming constant porosity, Equation (3) suggests that if a lower dielectric constant amendment replaces the pore water, that the effective dielectric constant will decrease.

\section{C.3 Seismic Methods}

Seismic methods use sensitive geophones to measure disturbances that propagate outward from the source as a series of wavefronts. Seismic velocity and attenuation are related to the bulk elastic properties of the sediment and pore fluids, which in turn depend on mineralogy, fluid chemistry, and intergranular structure (Pride 2005). As such, simple expressions, such as those given in (1) and (3), are not available to relate seismic attributes to pore fluid properties. However, as P-wave velocity increases with both fluid viscosity and density, this attribute might be sensitive to pore water replacement by a more viscous or dense amendment.

\section{C.4 References}

Archie GE. 1942. "The Electrical Resistivity Log as an Aid in Determining Some Reservoir Characteristics.” Trans. Amer. Inst. Mining Metallurgical and Petroleum Engineers 146:54-62. 
Binley A and A Kemna. 2005. "DC Resistivity and Induced Polarization Methods.” Chapter 5 in Hydrogeophysics, Y Rubin and S Hubbard (eds.), pp. 129-156. Springer, Netherlands.

Chen J, A Kemna, and S Hubbard 2008. “A Comparison Between Gauss-Newton and Markov-Chair Monte Carlo-Based Methods for Inverting Spectral Induced-Polarization Data for Cole-Cole Parameters. Geophysics 73(6):F247-F259, DOI 10.1190/1.2976115.

Cole KS and RH Cole. 1941. "Dispersion and Absorption in Dielectrics I: Alternating Current Field. Journal of Chemical Physics 1341-351.

Davis JL and AP Annan. 1989. "Ground Penetrating Radar for High Resolution Mapping of Soil and Rock Stratigraphy.” Geophysical Prospecting 37(5):531-551.

Peterson JE. 2001. "Pre-Inversion Processing and Analysis of Tomographic Radar Data. Journal of Environ. Engin. Geop, 6 (1):1-18.

Pride S. 2005. "Relationships Between Seismic and Hydrological Properties.” Chapter 9 in Hydrogeophysics, Y Rubin and S Hubbard (eds), pp. 253-290. Springer, Netherlands.

Topp CG, JL Davis, and AP Annan. 1980. "Electromagnetic Determination of Soil Water Content: Measurements in Coaxial Transmission Lines.” Water Resources Research 16(3):574-582.

Wharton RP, GA Hazen, R Rau, and DL Best. 1980. Electromagnetic Propagation Logging, Advances in Technique and Interpretation.” SPE Paper 9267, Society of Petroleum Engineers, Dallas, Texas.

Williams KH, D Ntarlagiannis, LD Slater, A Dohnalkova, SS Hubbard, and JF Banfield. 2005. “Geophysical Imaging of Stimulated Microbial Biomineralization.” Environ. Sci. Technol. 39(19):75927600; DOI: 10.1021/es0504035. 
Appendix D

Field Test Data 


\section{Appendix D}

\section{Field Test Data}

The field test data are provided on the compact disk bound inside the back cover of the printed copies of this report. 


\section{Appendix E}

\section{Organic Compound Concentration Data Plots for the Soluble}

Substrate Test 


\section{Appendix E}

\section{Organic Compound Concentration Data Plots for the Soluble Substrate Test}

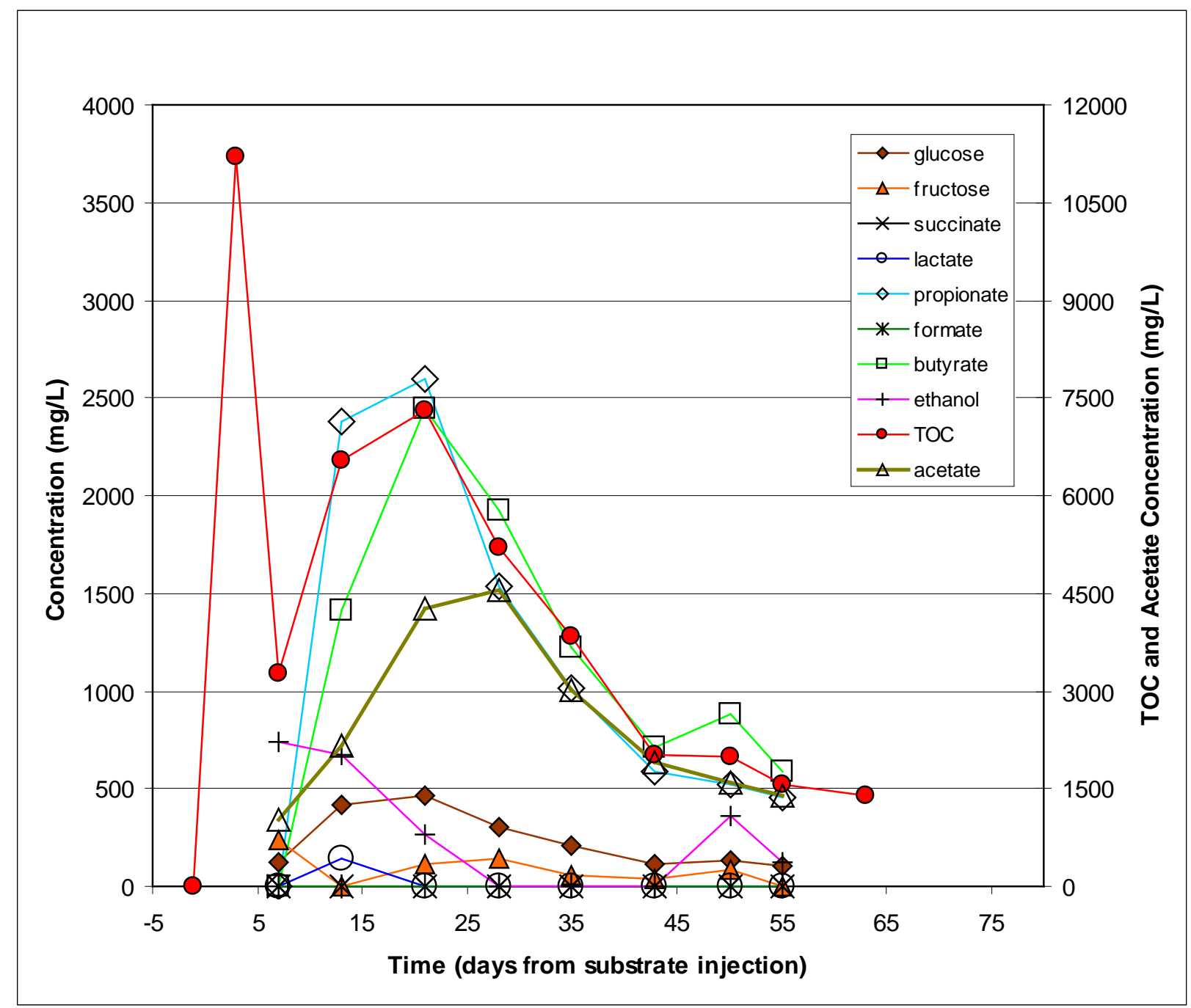

Figure E.1. Organic Compound Concentrations During the Process Monitoring Phase at the Injection Well 199-D5-107 


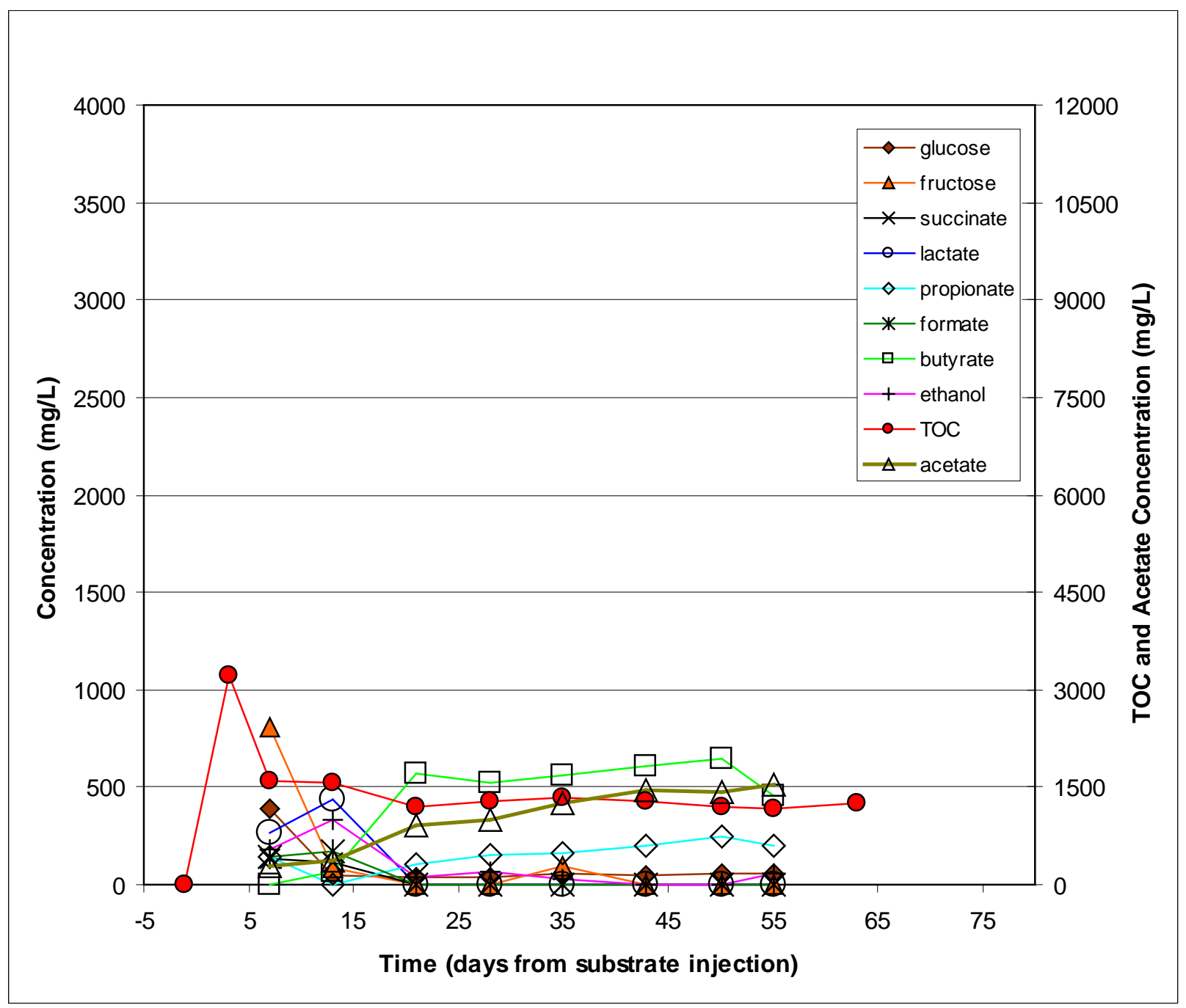

Figure E.2. Organic Compound Concentrations During the Process Monitoring Phase at Monitoring Well 199-D5-109 


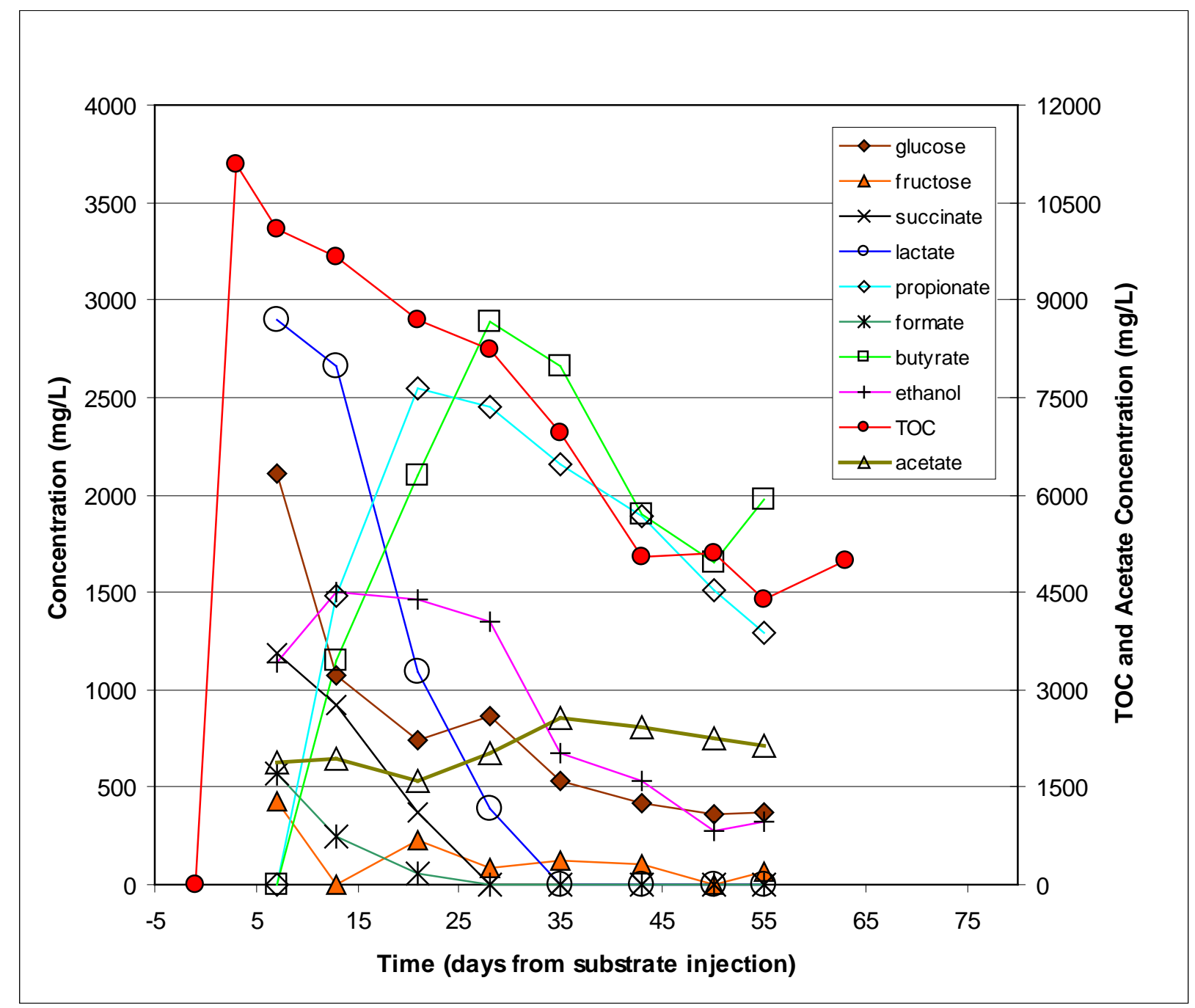

Figure E.3. Organic Compound Concentrations During the Process Monitoring Phase at Monitoring Well 199-D5-110 


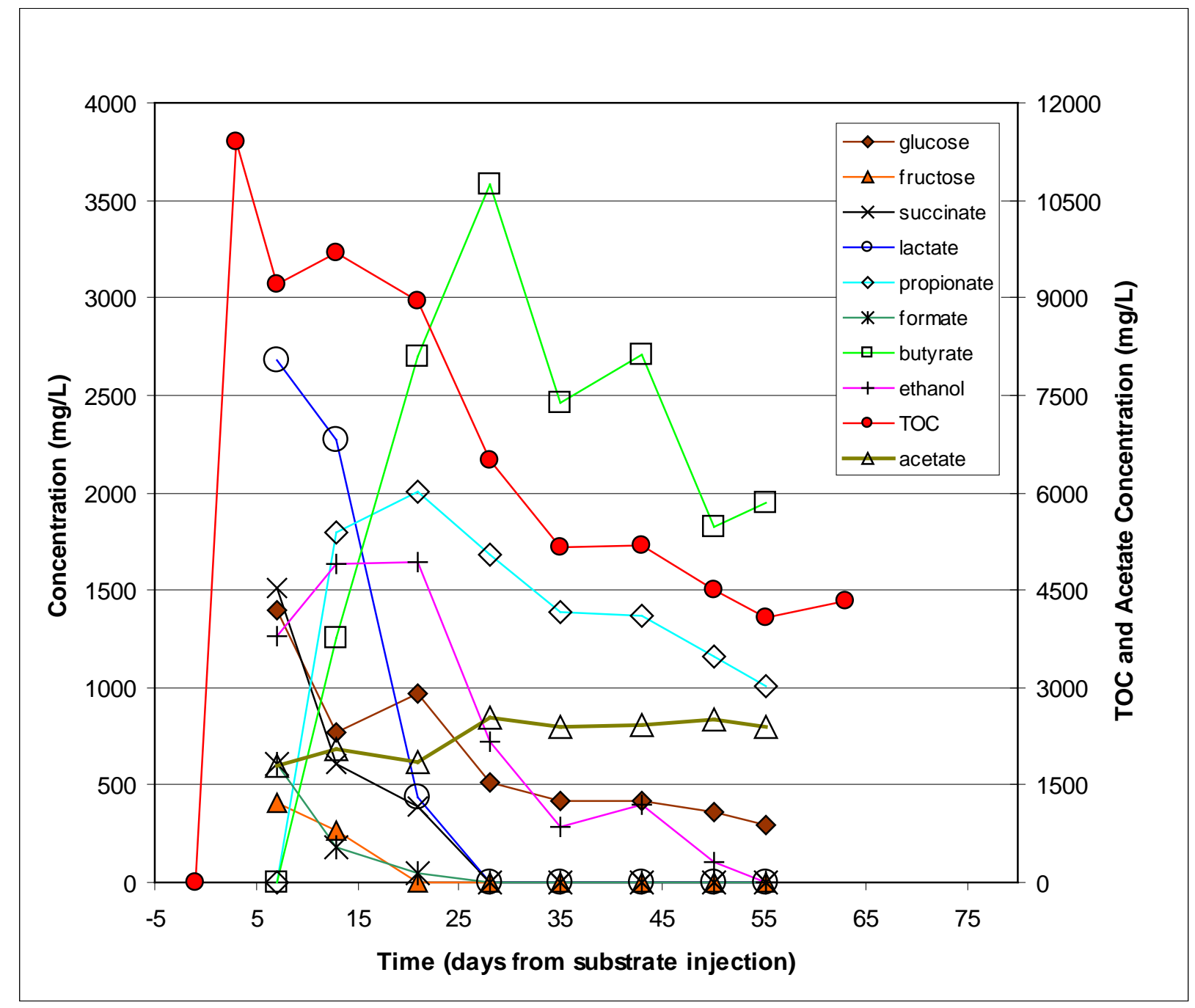

Figure E.4. Organic Compound Concentrations During the Process Monitoring Phase at Monitoring Well 199-D5-111 


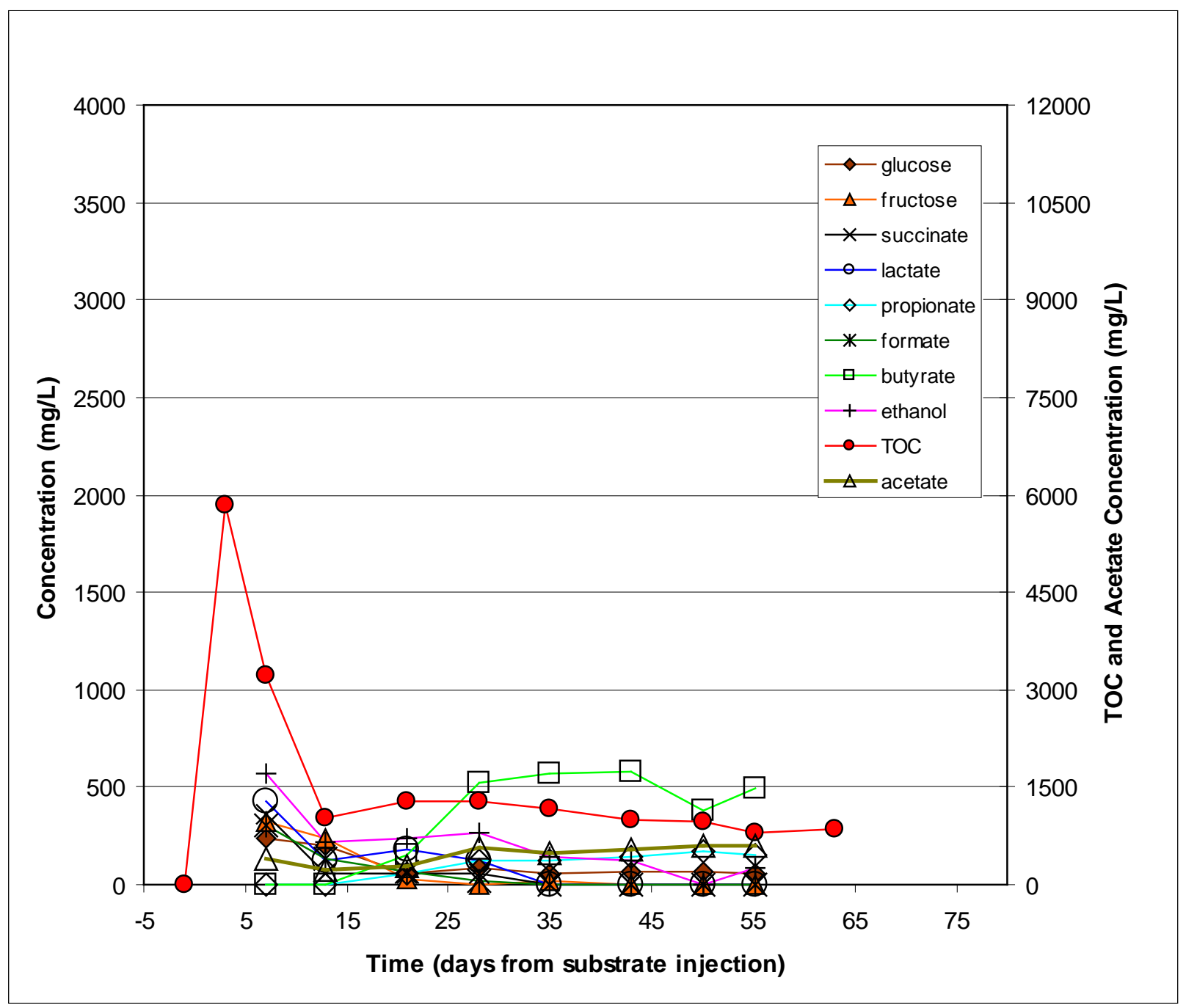

Figure E.5. Organic Compound Concentrations During the Process Monitoring Phase at Monitoring Well 199-D5-112 


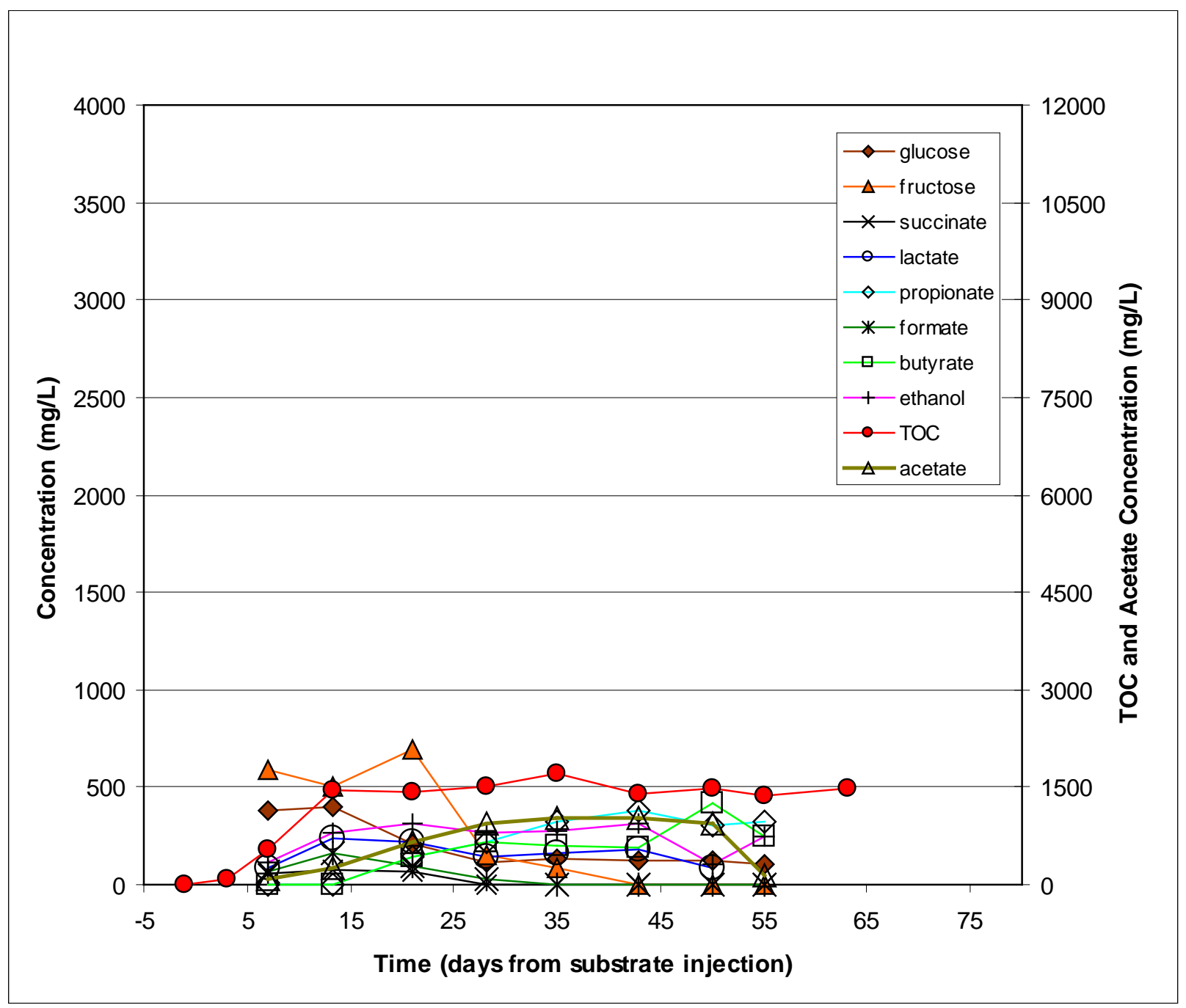

Figure E.6. Organic Compound Concentrations During the Process Monitoring Phase at Monitoring Well 199-D5-113 


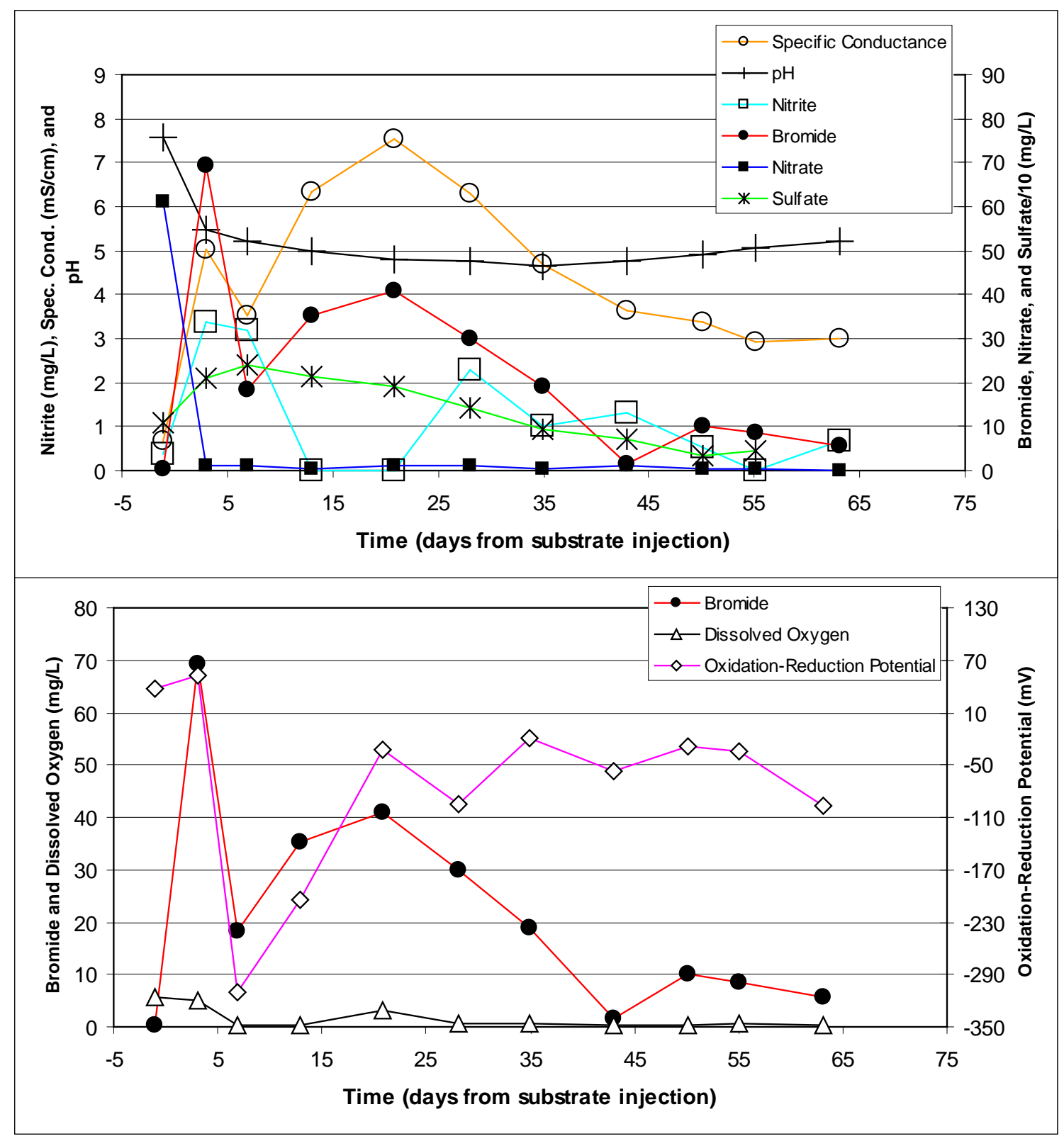

Figure E.7. Process Monitoring Phase Data at Injection Well 199-D5-107 


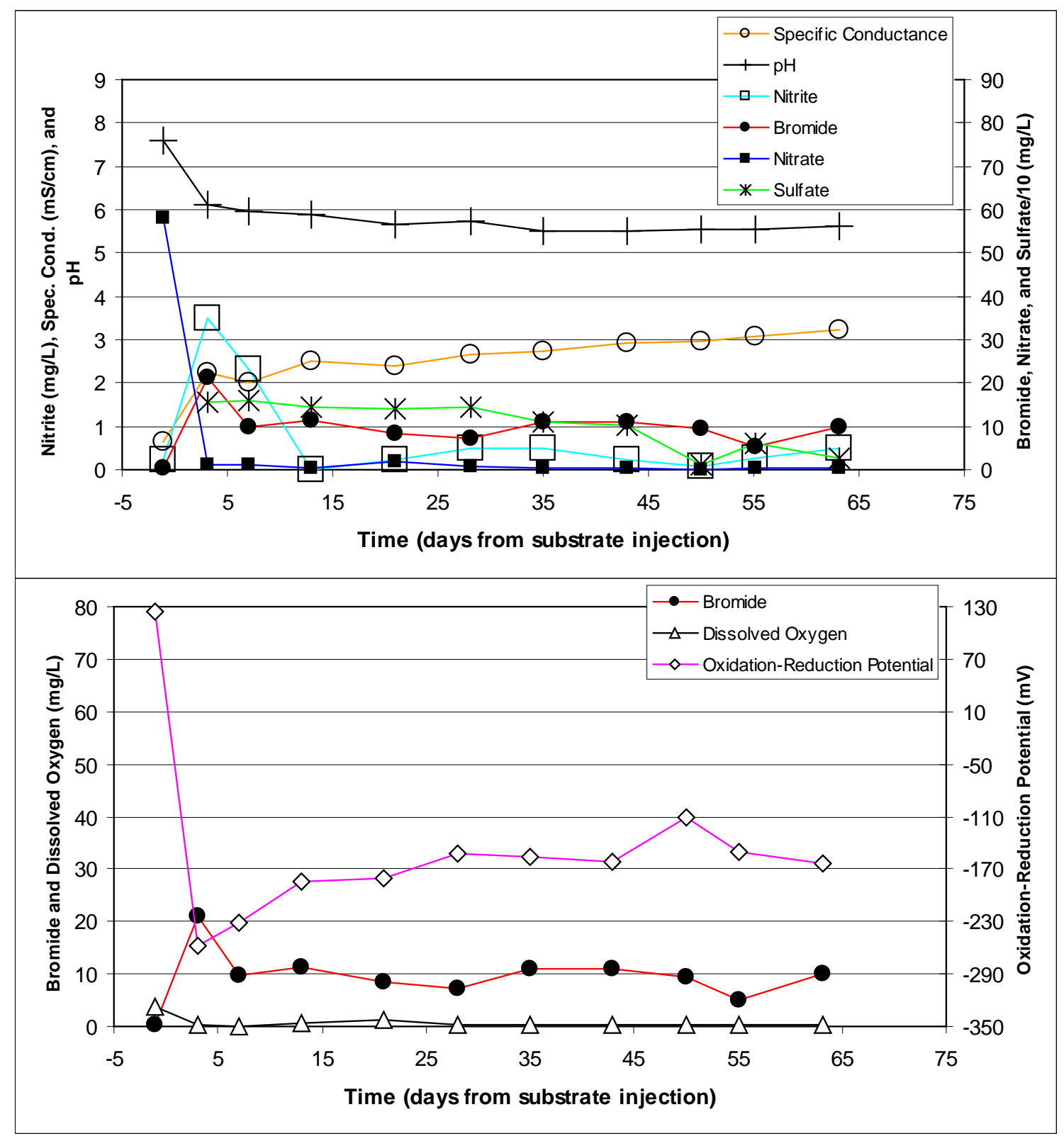

Figure E.8. Process Monitoring Phase Data at Monitoring Well 199-D5-109 


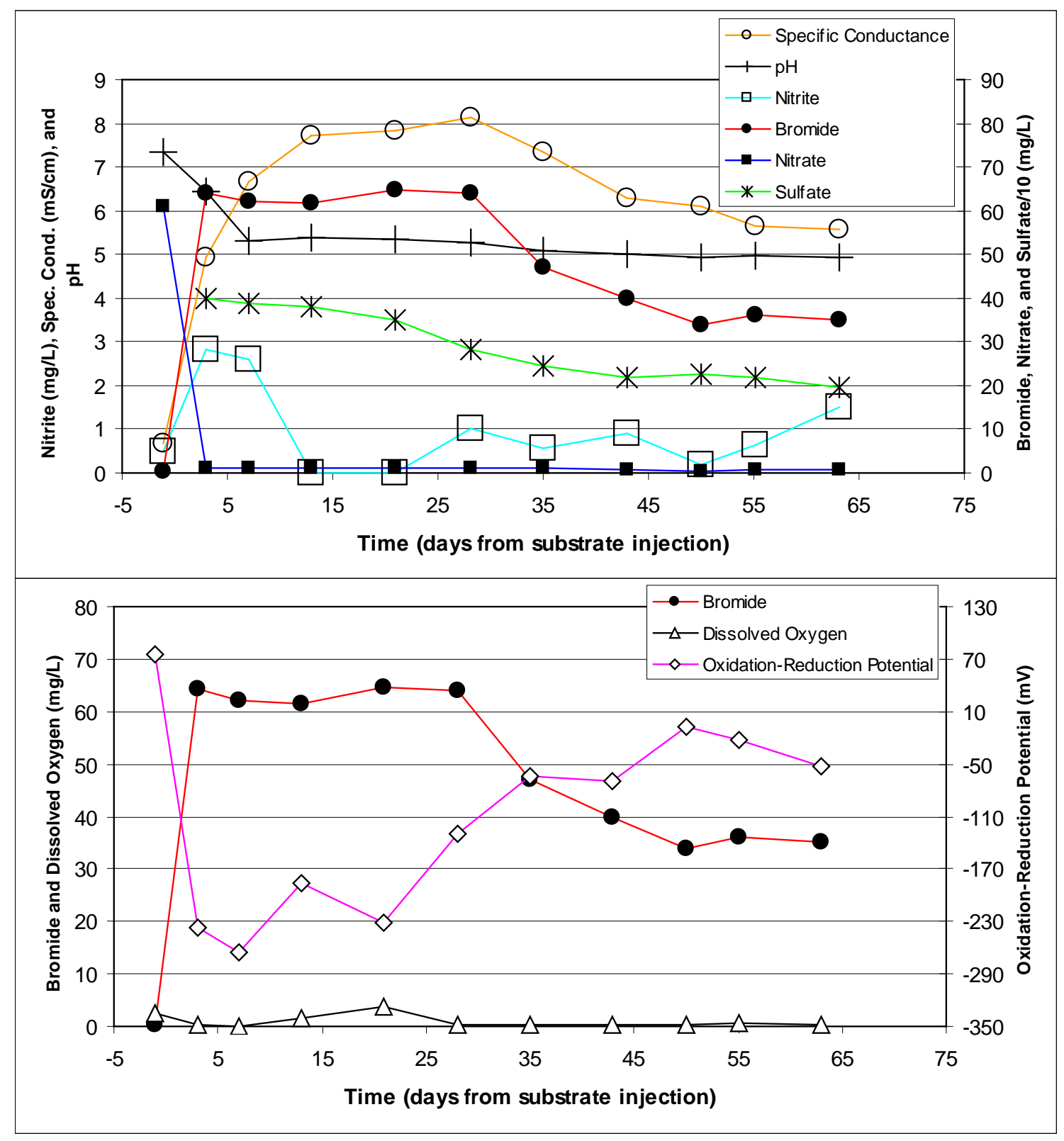

Figure E.9. Process Monitoring Phase Data at Monitoring Well 199-D5-110 


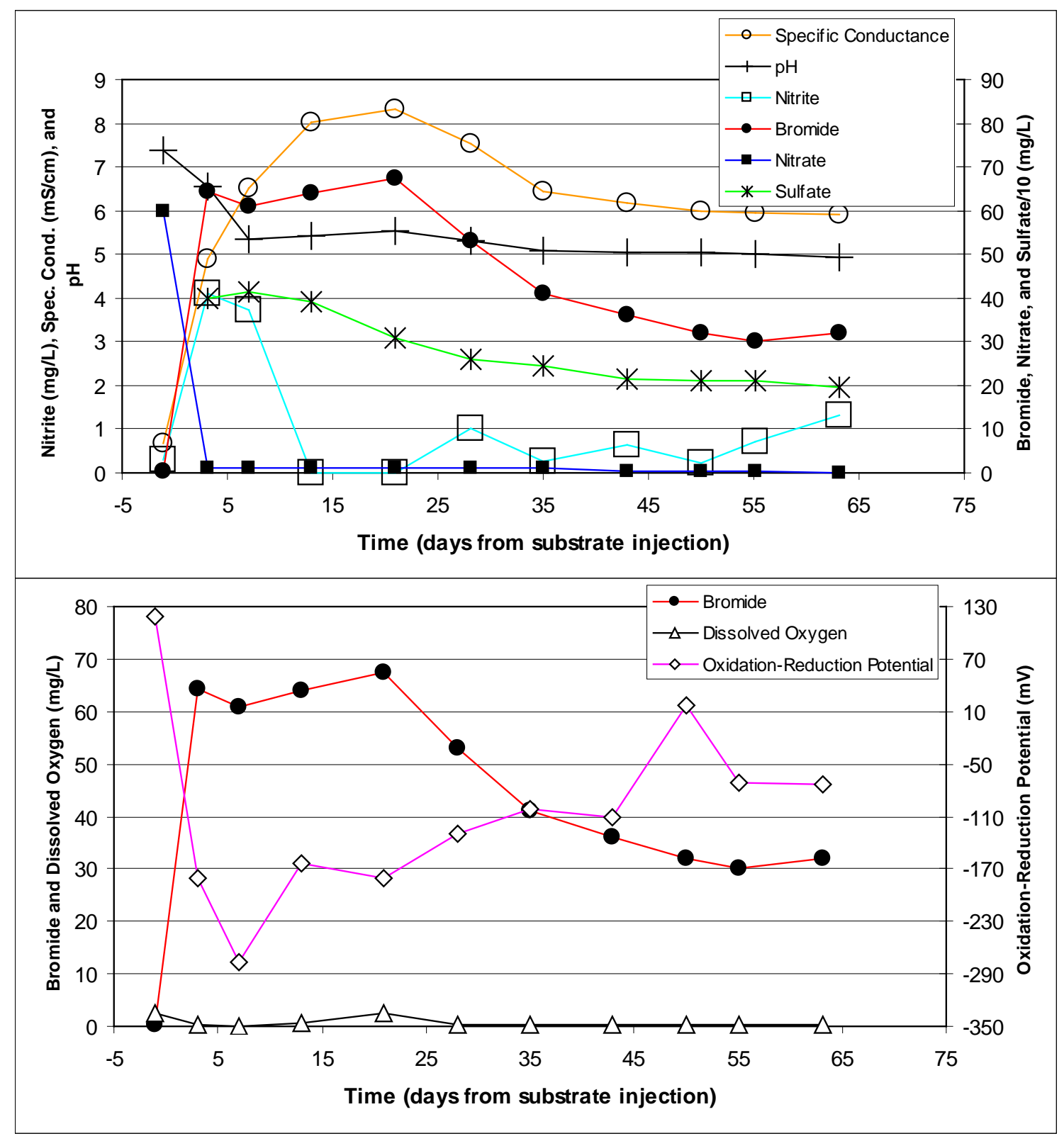

Figure E.10. Process Monitoring Phase Data at Monitoring Well 199-D5-111 


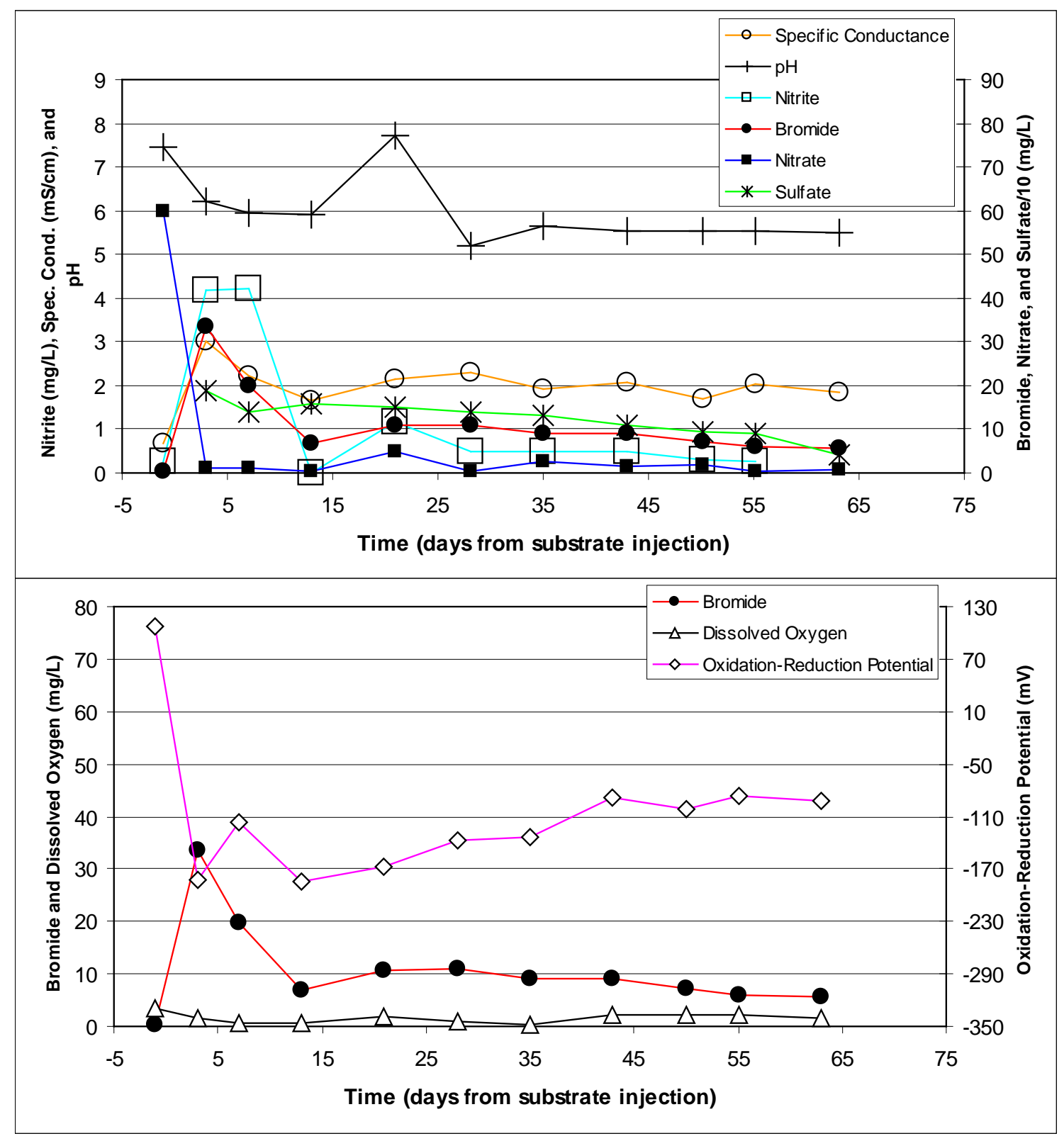

Figure E.11. Process Monitoring Phase Data at Monitoring Well 199-D5-112 


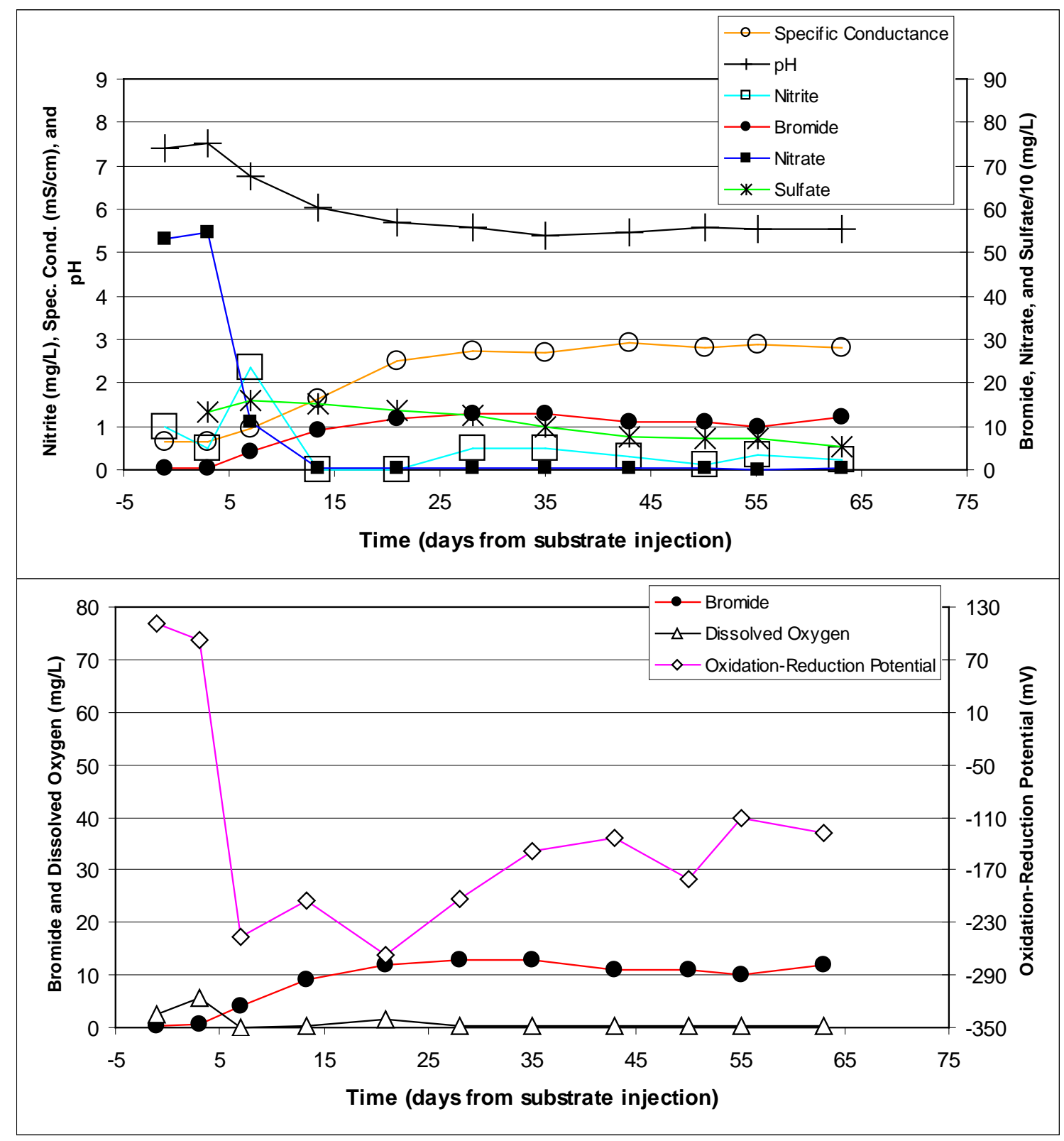

Figure E.12. Process Monitoring Phase Data at Monitoring Well 199-D5-113

The following data plots are the same as Figures 6.1 through 6.6 in the text except that the scale of the vertical axis has been changed to provide for additional interpretation of the data. 


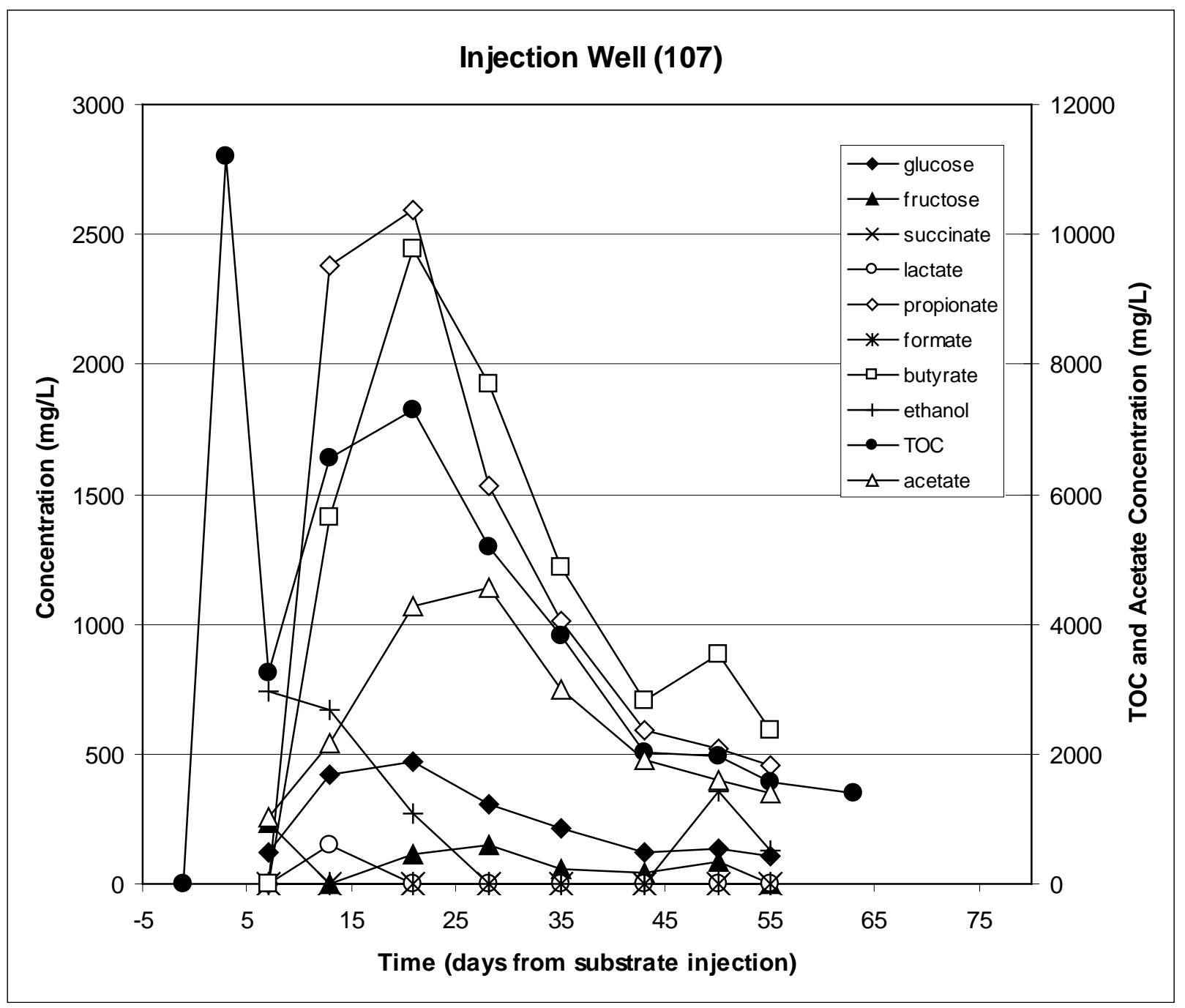

Figure E.13. Organic Compound Concentrations During the Process Monitoring Phase at Injection Well 199-D5-107 


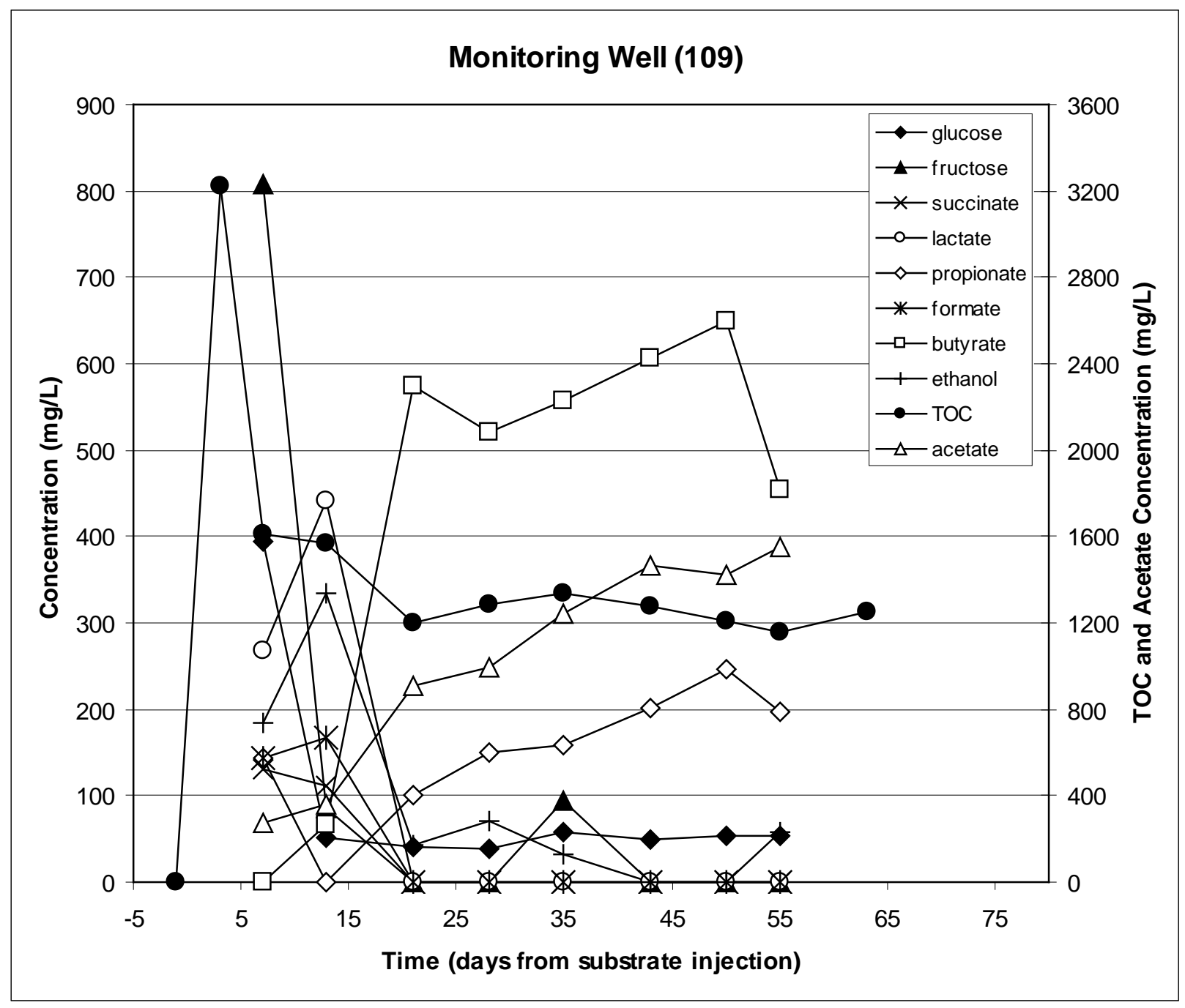

Figure E.14. Organic Compound Concentrations During the Process Monitoring Phase at Process Monitoring Well 199-D5-109 


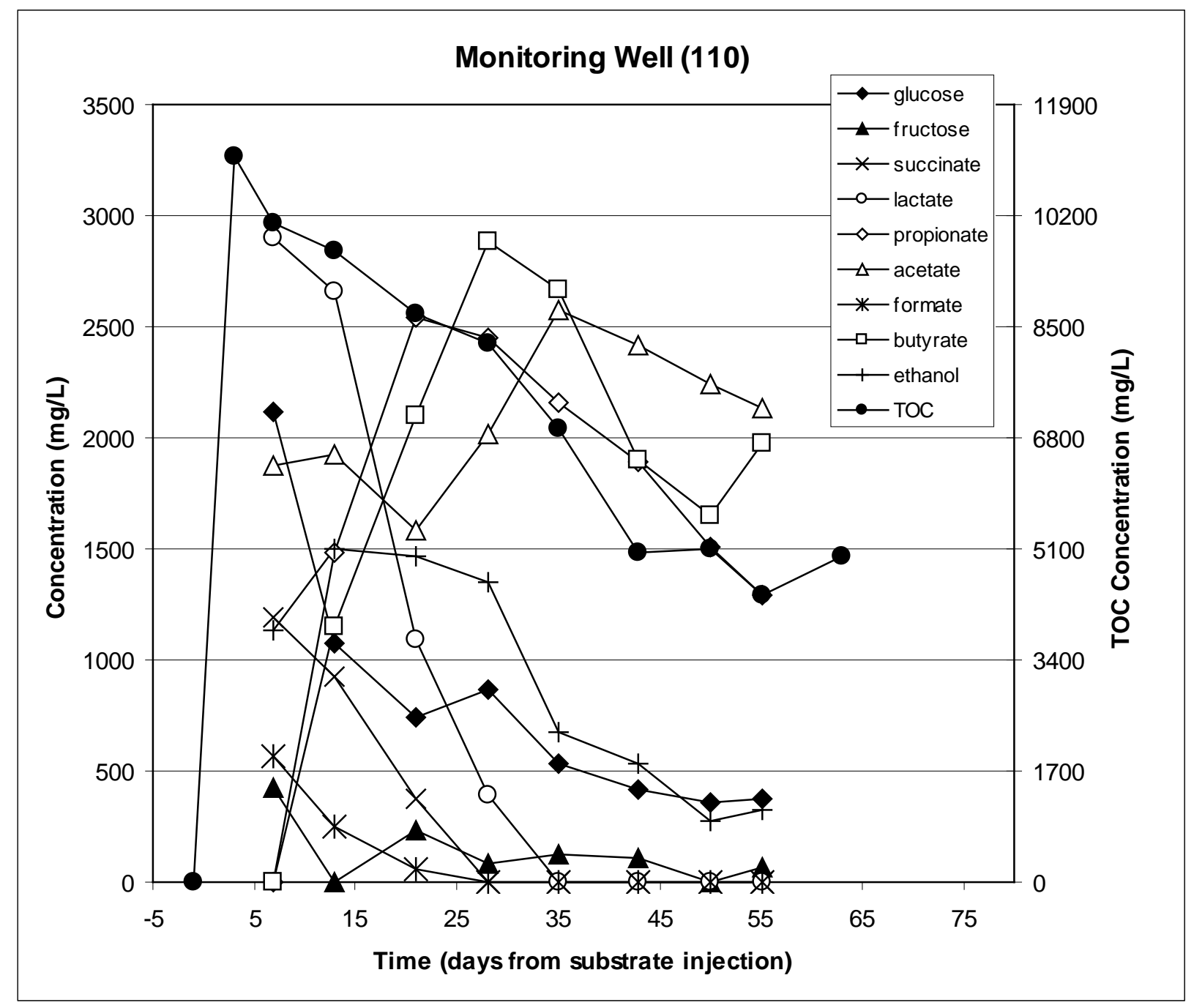

Figure E.15. Organic Compound Concentrations During the Process Monitoring Phase at Process Monitoring Well 199-D5-110 


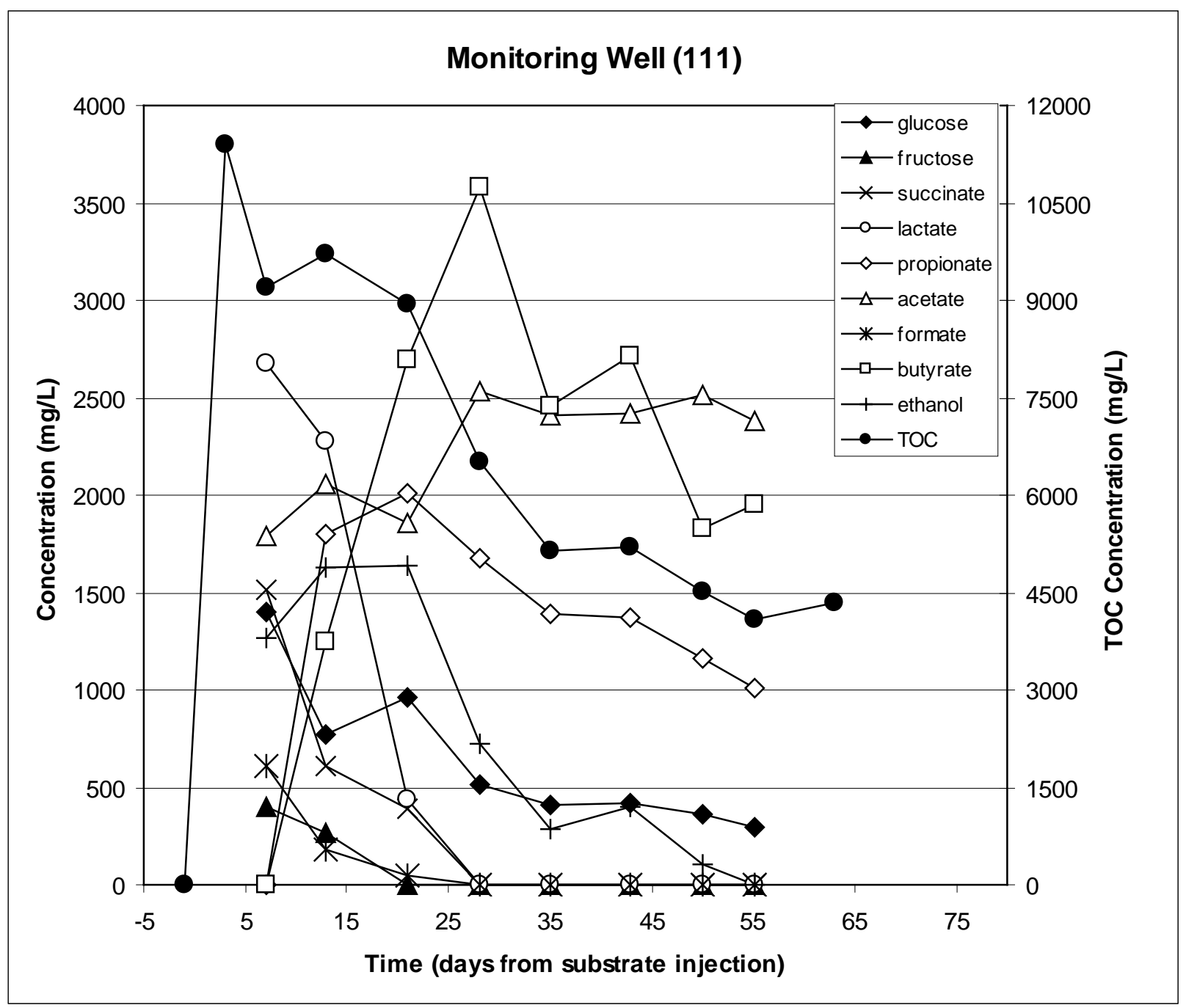

Figure E.16. Organic Compound Concentrations During the Process Monitoring Phase at Process Monitoring Well 199-D5-111 


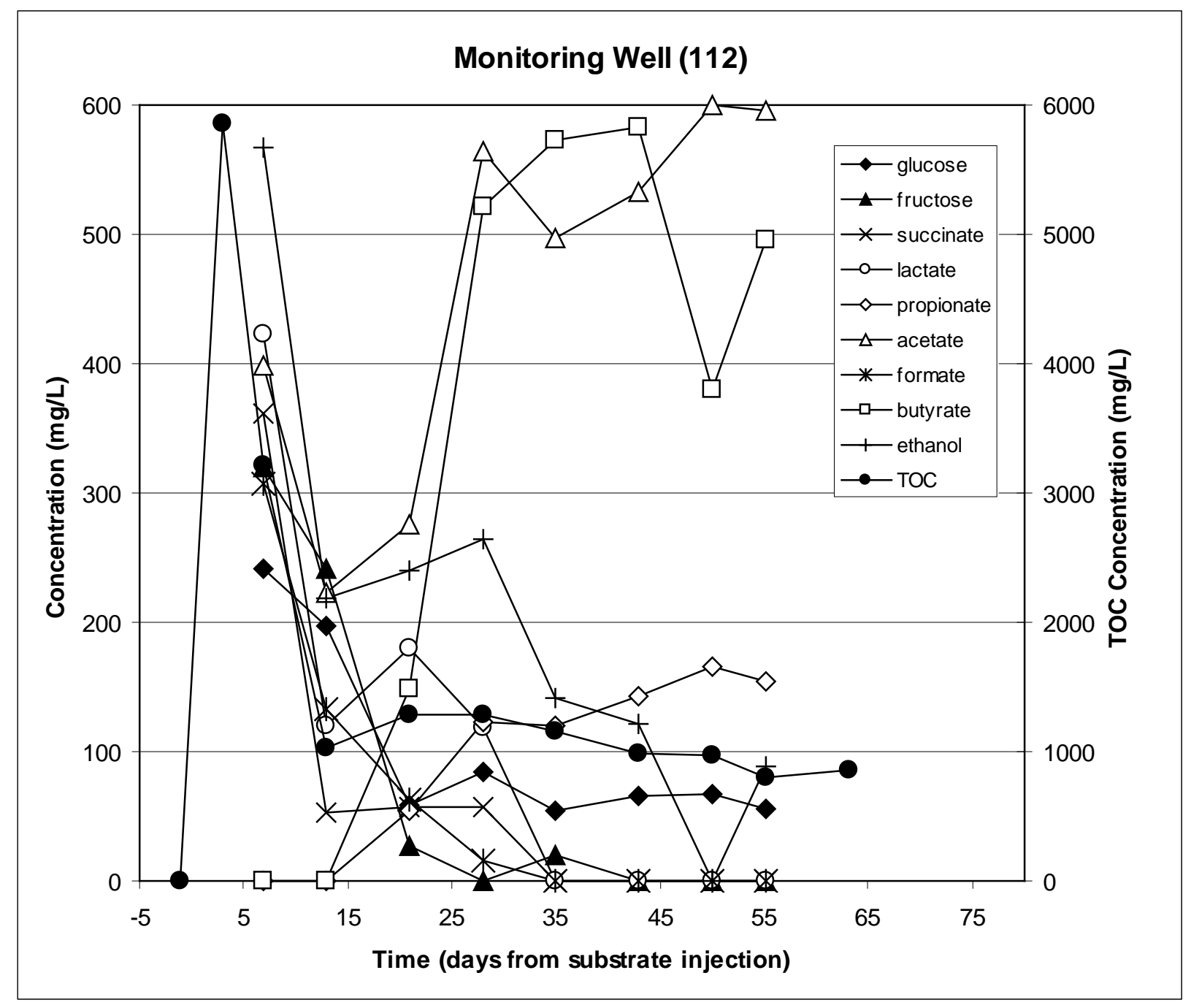

Figure E.17. Organic Compound Concentrations During the Process Monitoring Phase at Process Monitoring Well 199-D5-112 


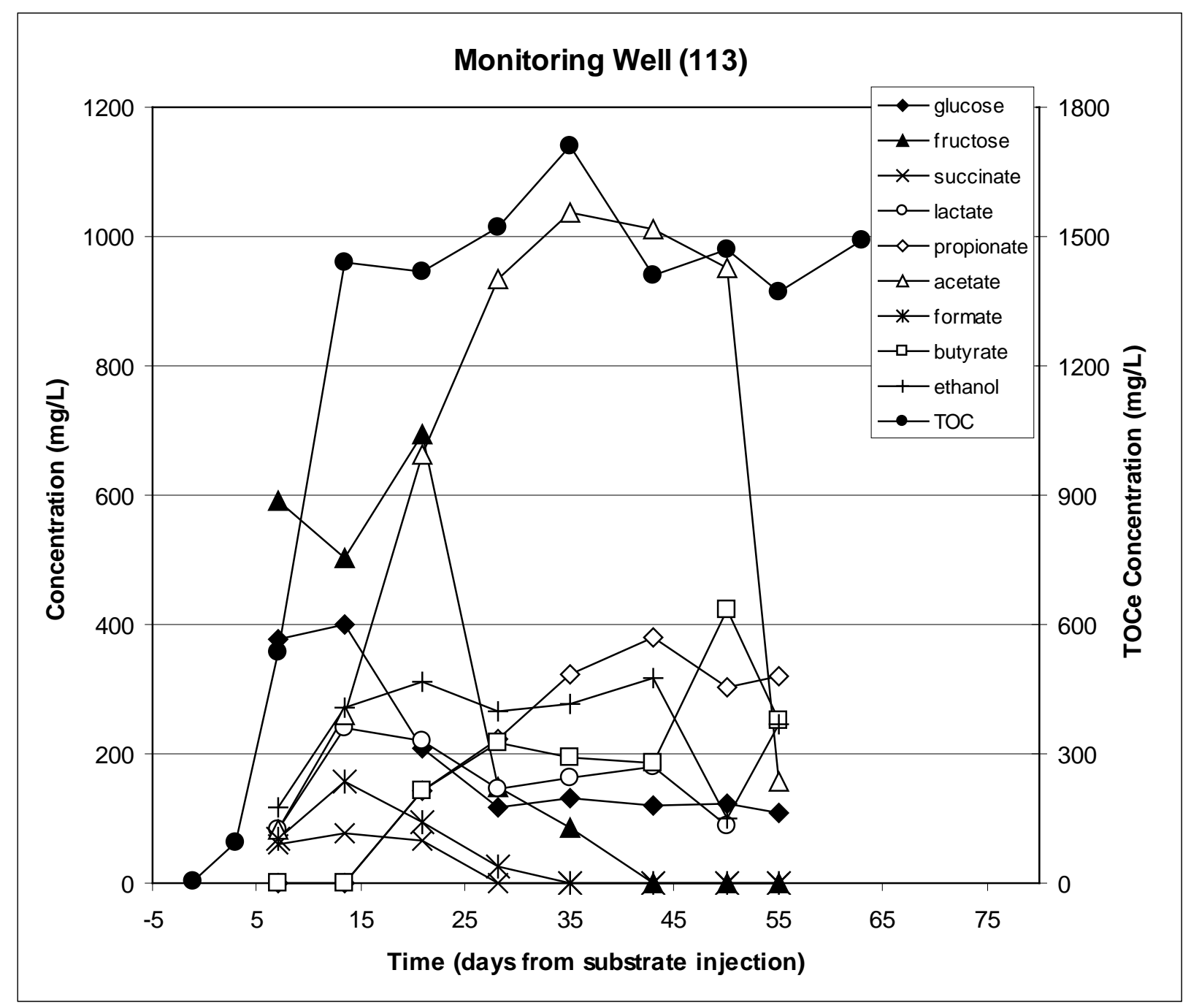

Figure E.18. Organic Compound Concentrations During the Process Monitoring Phase at Process Monitoring Well 199-D5-113 


\section{Appendix F}

\section{Detailed Slug Testing Results}




\section{Appendix F}

\section{Detailed Slug Testing Results}

A series of slug tests were performed to evaluate potential reduction in permeability in the aquifer associated with the bioremediation treatment activities. Slug test responses were analyzed using multiple analytical methods in order to provide a more complete and comparative analysis.

Table F.1 contains the results from all of the analysis methods; however, it should be noted that only those results obtained using the most appropriate analytical method and representative portions of the responses were selected for use in the permeability reduction calculations. Except for one well (discussed below) estimates obtained using the KGS (Hyder et al. 1994; Butler 1998) are preferred. For the critically-damped responses observed in well 199-D5-109, the Springer and Gelhar (1991) model was deemed most appropriate. Heterogeneous responses were analyzed as inner- and outer-zone responses separately. Both are included here, but the outer-zone estimates are more representative of the undisturbed formation (Bouwer 1989).

Table F.1. Detailed Hydraulic Conductivity Estimates from Pre- and Post-Treatment Slug Tests

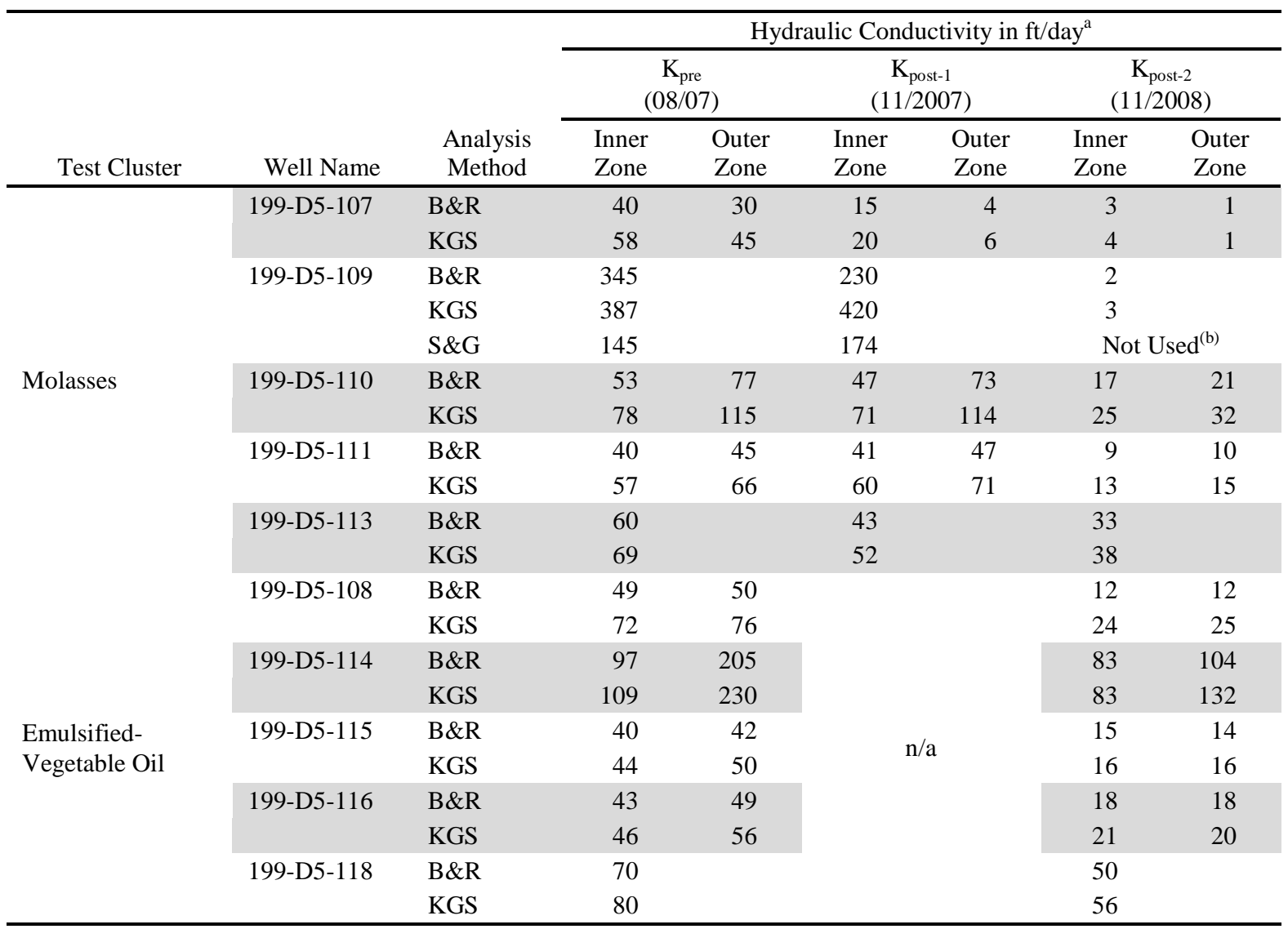

(a) Best estimates of $\mathrm{K}$ for the aquifer used in calculations of permeability change are highlighted in BOLD.

(b) Response for well 199-D5-109 in 11/2008 was overdamped, unlike previous responses.

Abbreviations.

$\mathrm{ft}=$ feet, B\&R = Bouwer and Rice (1979) straight-line method, KGS = KGS type-curve model (Hyder et al. 1994; Butler 1998), S\&G = Springer and Gelhar (1991, pp. 36-40) inertial model. 
Table F.2 contains a summary of the calculated permeability change based on the best estimates of hydraulic conductivity for pre- and post-treatment tests. Permeability change was defined as the ratio of post-treatment $\mathrm{K}$ to the pre-treatment $\mathrm{K}\left(\mathrm{K}_{\text {post }} / \mathrm{P}_{\text {pre }}\right)$.

TableF.2. Permeability Change Results Based on Slug Test Best Estimates

\begin{tabular}{|c|c|c|c|c|c|c|}
\hline \multirow[b]{2}{*}{ Test Cluster } & \multirow[b]{2}{*}{ Well Name } & \multirow{2}{*}{$\begin{array}{c}\mathrm{K}_{\text {pre }} \\
(08 / 07) \\
\mathrm{ft} / \text { day }\end{array}$} & \multirow{2}{*}{$\begin{array}{c}\mathrm{K}_{\text {post-1 }} \\
(11 / 2007) \\
\mathrm{ft} / \text { day }\end{array}$} & \multirow{2}{*}{$\begin{array}{c}\mathrm{K}_{\text {post-2 }} \\
(11 / 2008) \\
\mathrm{ft} / \text { day }\end{array}$} & \multicolumn{2}{|c|}{$\begin{array}{c}\text { Permeability Change } \\
\left(\mathrm{K}_{\text {post }} / \mathrm{K}_{\text {pre }}\right)\end{array}$} \\
\hline & & & & & Post 1 & Post 2 \\
\hline \multirow{5}{*}{ Molasses } & 199-D5-107 & 45 & 6 & 1 & 0.13 & 0.02 \\
\hline & 199-D5-109 & 145 & 174 & 3 & 1.20 & 0.02 \\
\hline & 199-D5-110 & 115 & 114 & 32 & 0.99 & 0.28 \\
\hline & 199-D5-111 & 66 & 71 & 15 & 1.08 & 0.23 \\
\hline & 199-D5-113 & 69 & 52 & 38 & 0.75 & 0.55 \\
\hline \multirow{5}{*}{$\begin{array}{l}\text { Emulsified- } \\
\text { Vegetable } \\
\text { Oil }\end{array}$} & 199-D5-108 & 76 & \multirow{5}{*}{$\mathrm{n} / \mathrm{a}$} & 25 & \multirow{5}{*}{$\mathrm{n} / \mathrm{a}$} & 0.33 \\
\hline & 199-D5-114 & 230 & & 132 & & 0.57 \\
\hline & 199-D5-115 & 50 & & 16 & & 0.32 \\
\hline & 199-D5-116 & 56 & & 20 & & 0.36 \\
\hline & 199-D5-118 & 80 & & 56 & & 0.70 \\
\hline
\end{tabular}

Figures F.1 through F.25 contain the slug test responses, analytical model fits to the data, and accompanying analytical parameters. They are organized by well, test date, inner/outer zone, and analytical method, in that order. 

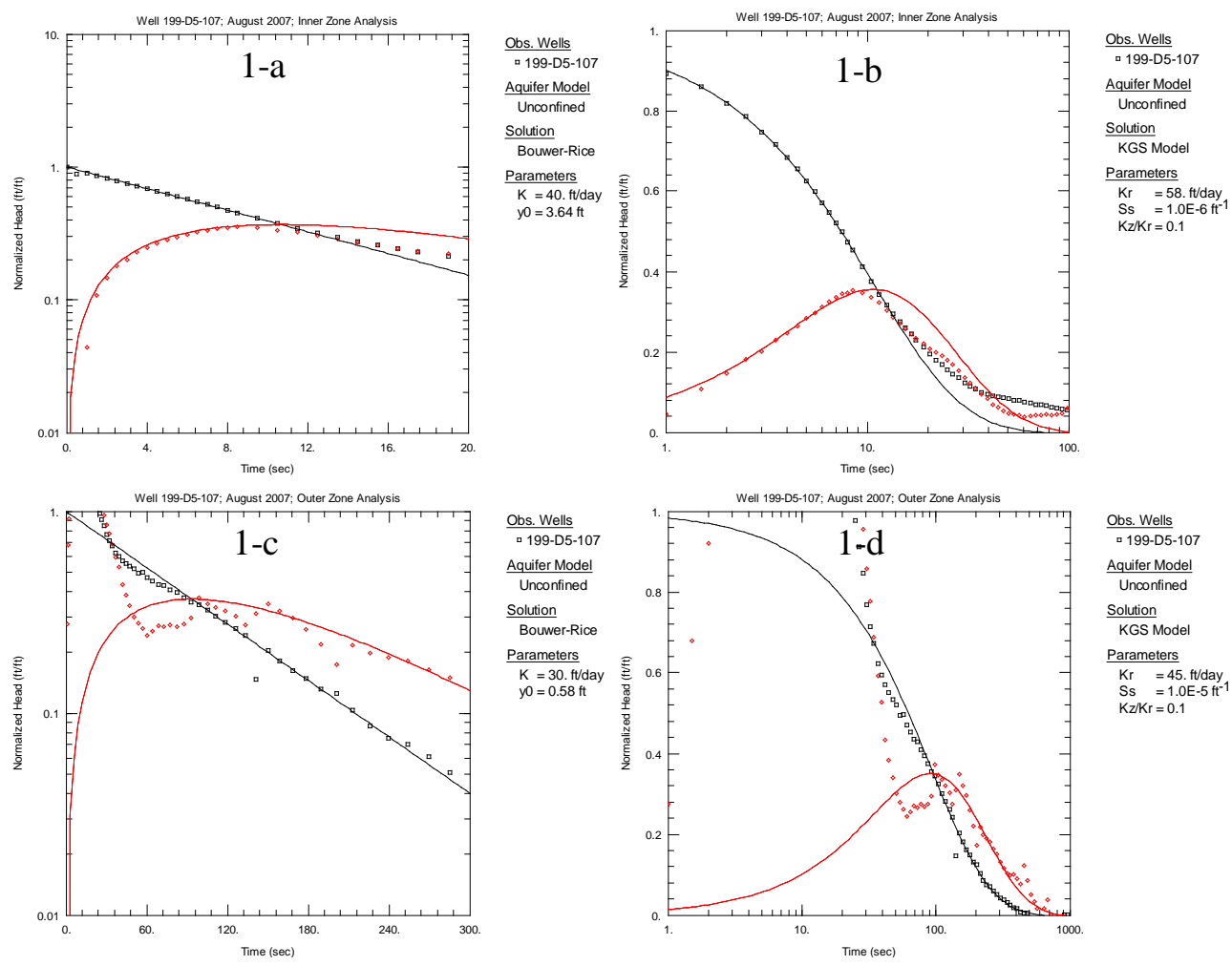

Figure F.1. Responses for Well 199-D5-107 from 11/2007 Tests (derivative shown in red)
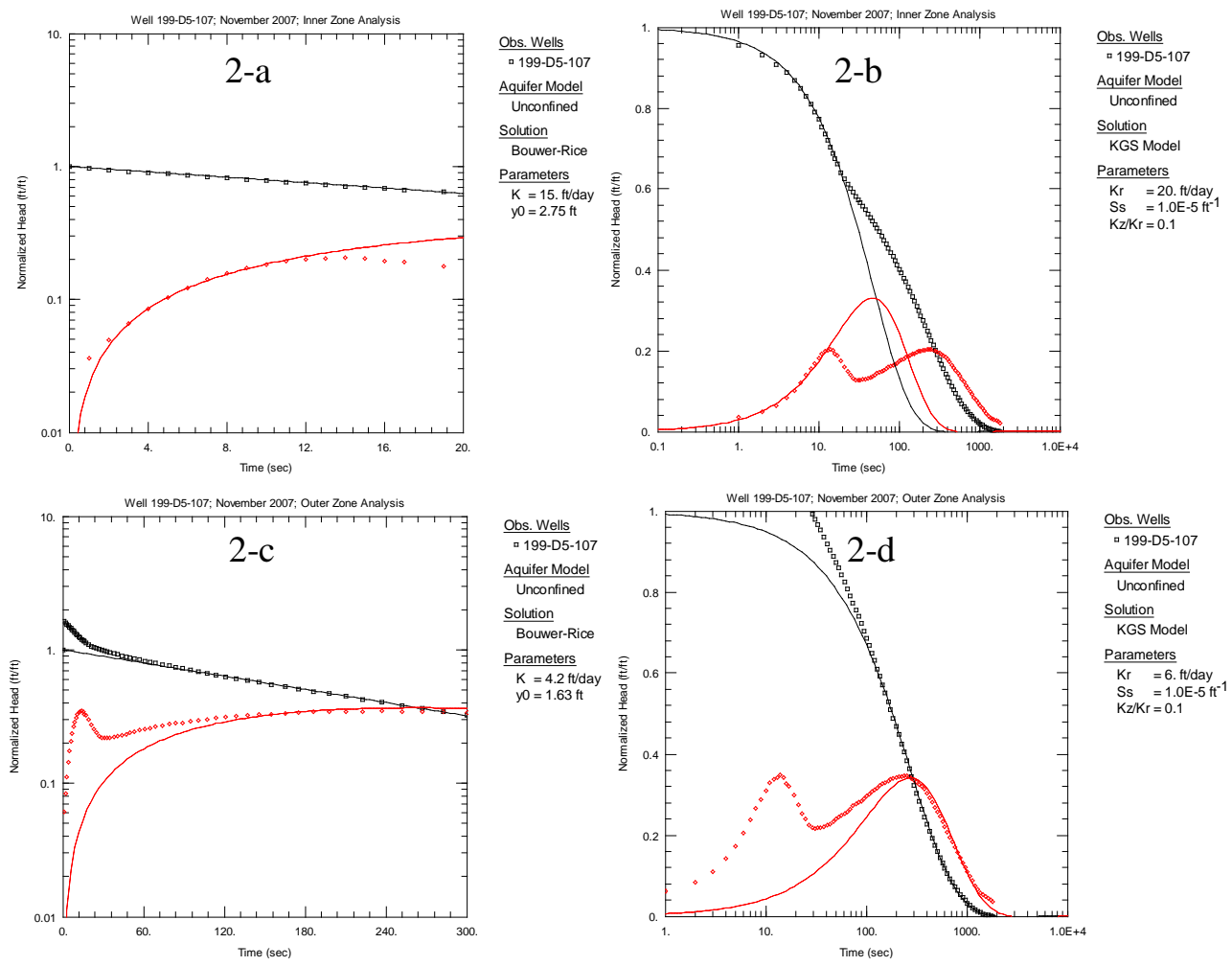

Figure F.2. Responses for Well 199-D5-107 from 11/2007 Tests (derivative shown in red) 

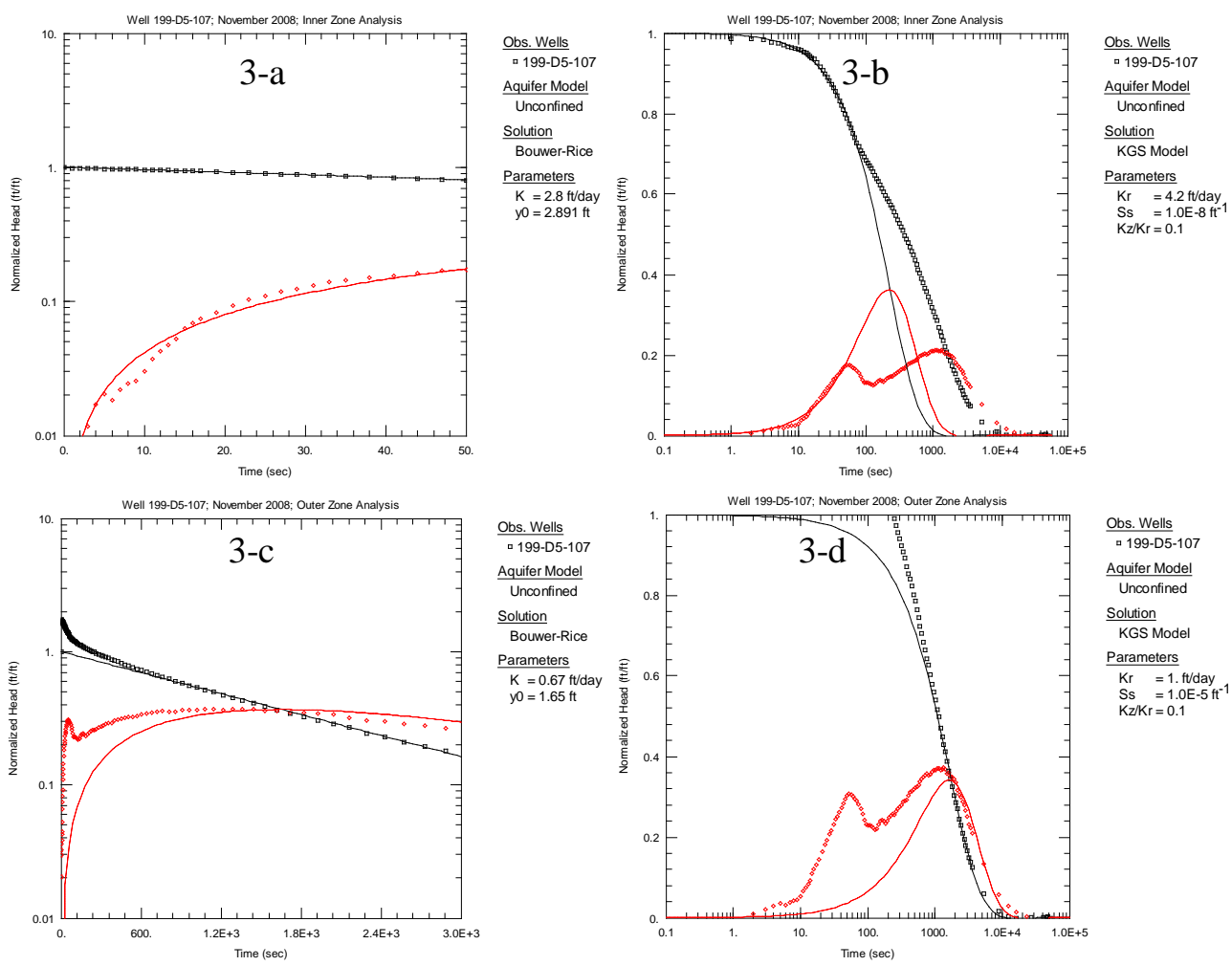

Figure F.3. Responses for Well 199-D5-107 from 11/2008 Tests (derivative shown in red) Well 199-D5-108
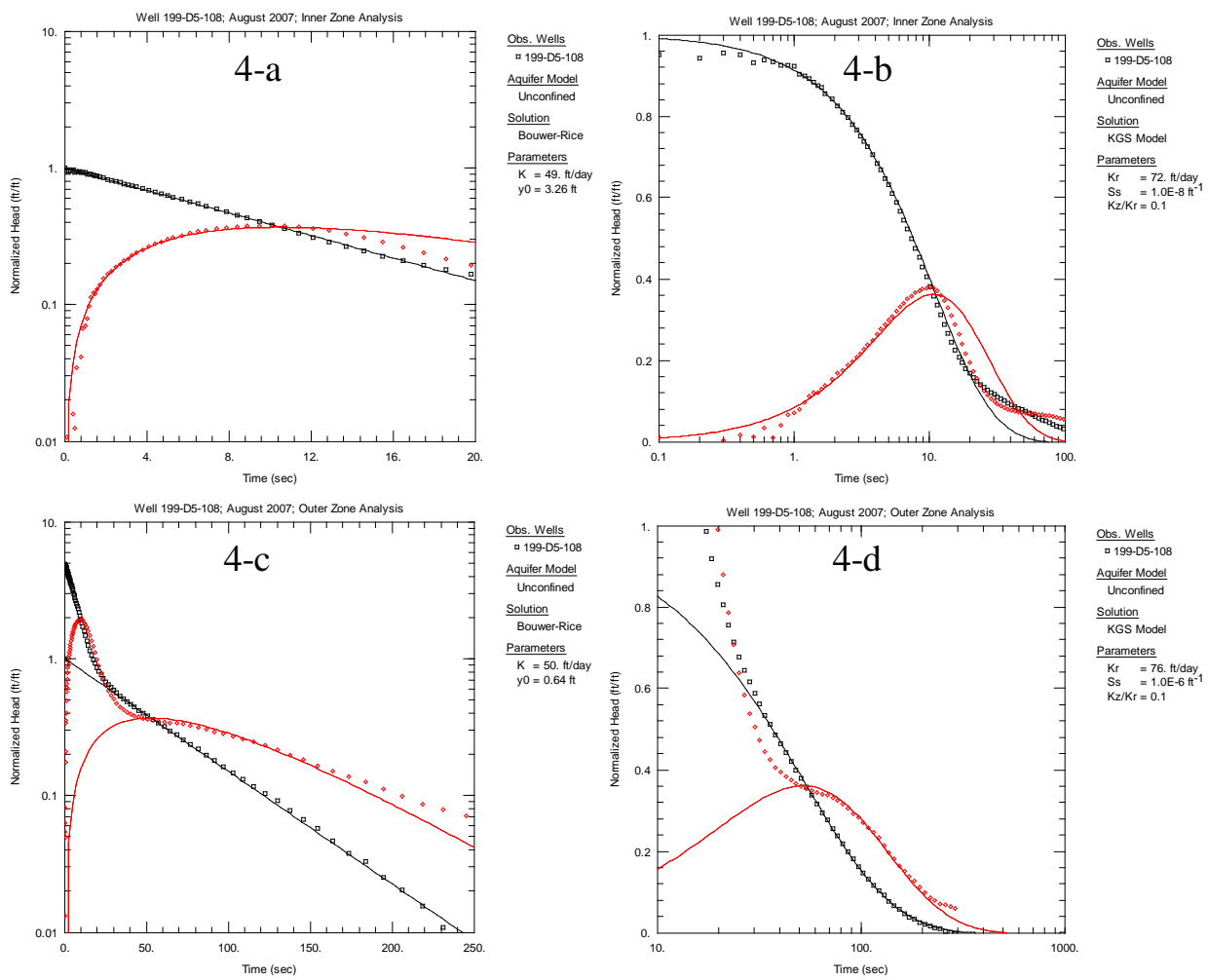

Figure F.4. Responses for Well 199-D5-108 from 08/2007 Tests (derivative shown in red) 

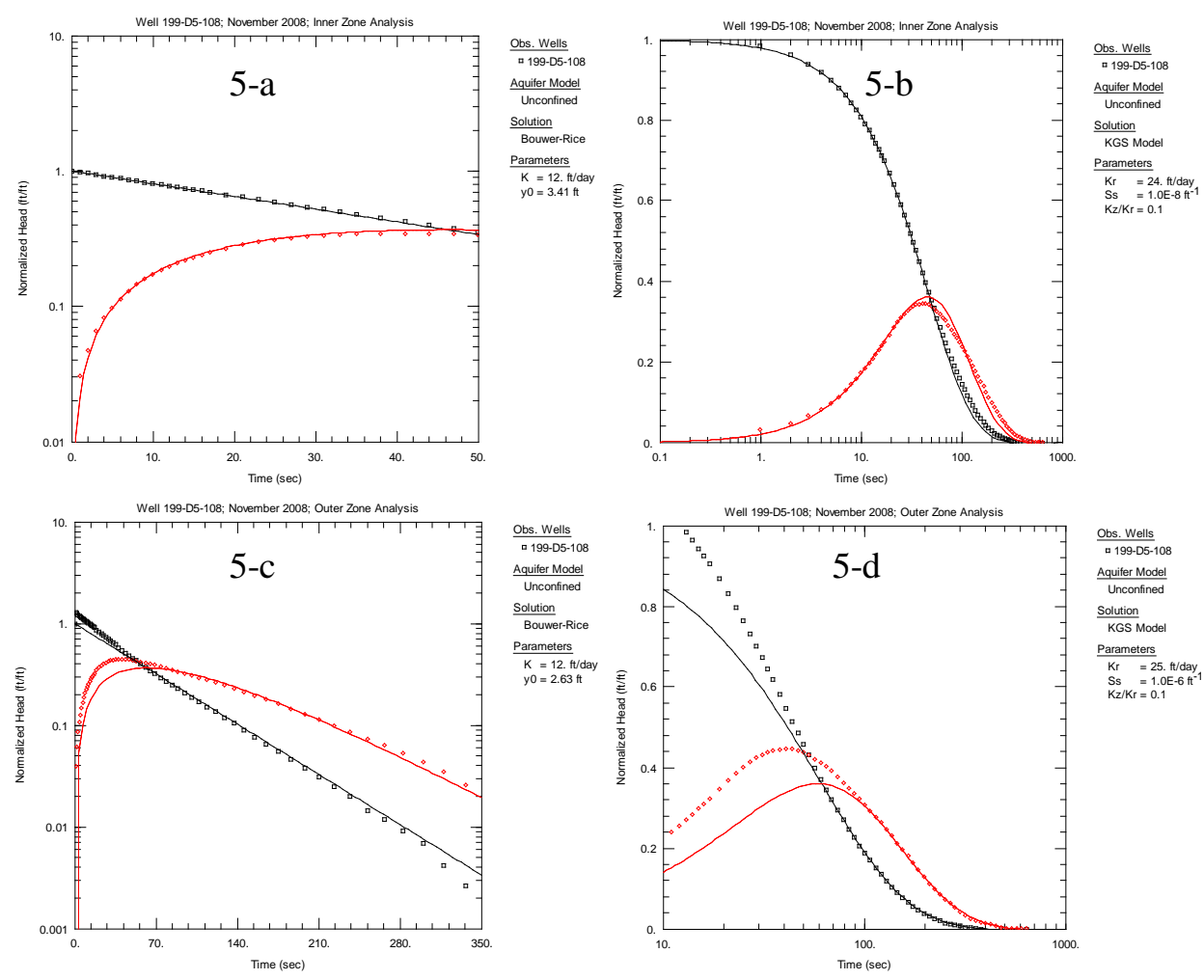

Figure F.5. Responses for Well 199-D5-108 from 11/2007 Tests (derivative shown in red) Well 199-D5-109
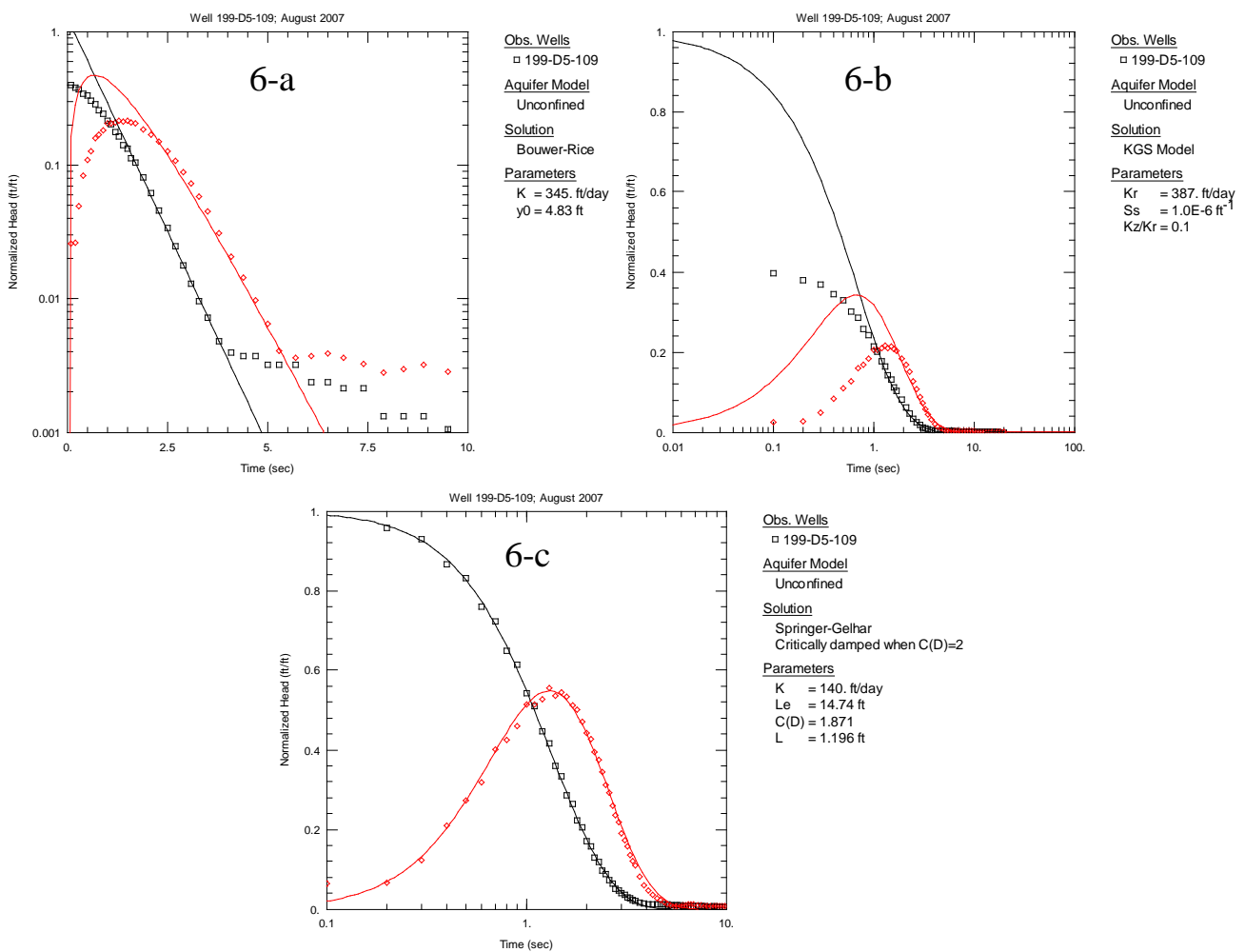

$\frac{\text { Obs. Wells }}{\text { 口 199-D5-10 }}$ $\frac{\text { Aquifer Model }}{\text { Unconfined }}$

Solution

Springer-Gelhar

Springer-Gelhar
Critically damped when $C(D)=2$

Parameters

$\begin{aligned} \mathrm{K} & =140 . \mathrm{ft} / \mathrm{day} \\ \mathrm{Le} & =14.74 \mathrm{ft}\end{aligned}$

$C(D)=1.871$

Figure F.6. Responses for Well 199-D5-109 from 08/2007 Tests (derivative shown in red) 

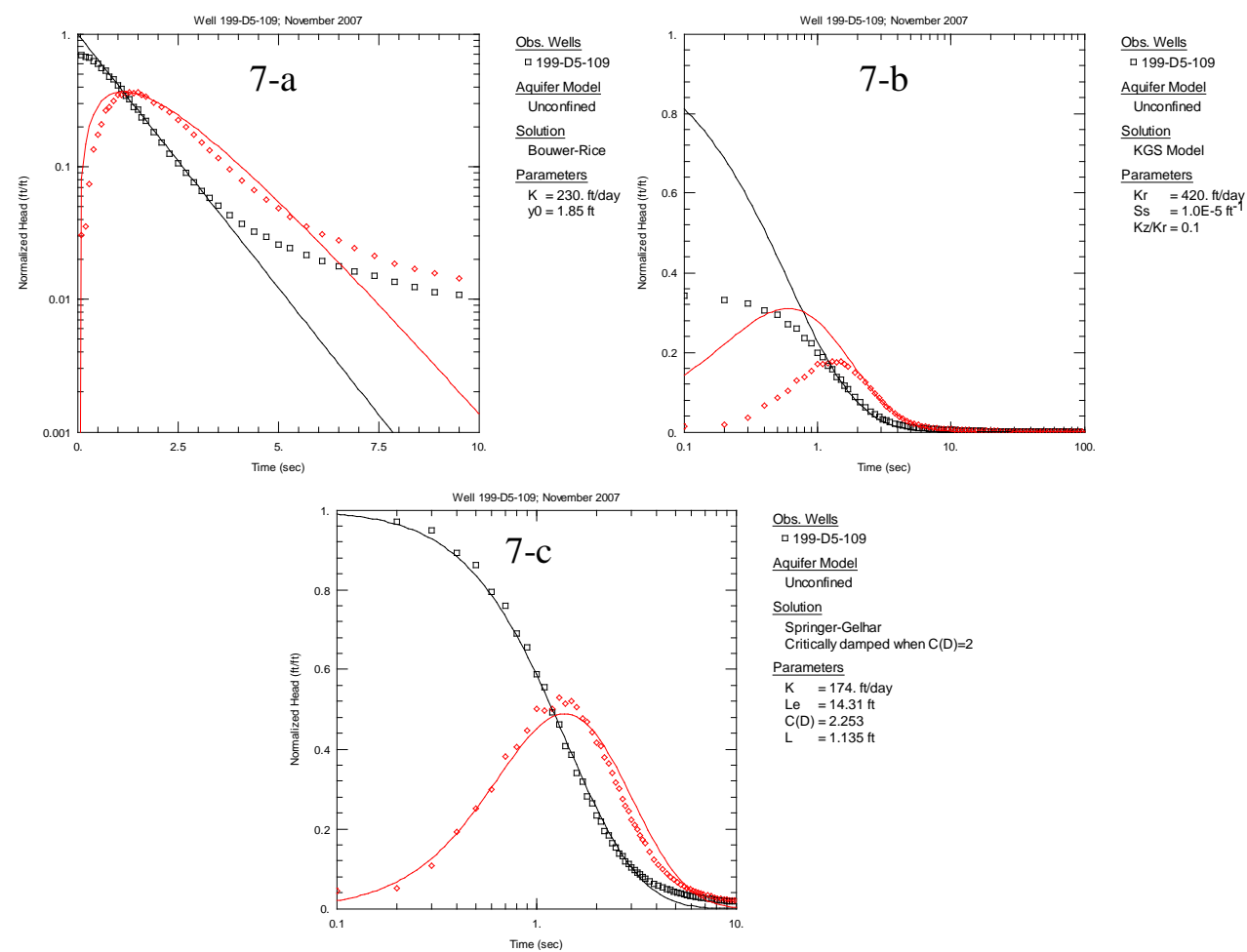

Figure F.7. Responses for Well 199-D5-109 from 11/2007 Tests (derivative shown in red)
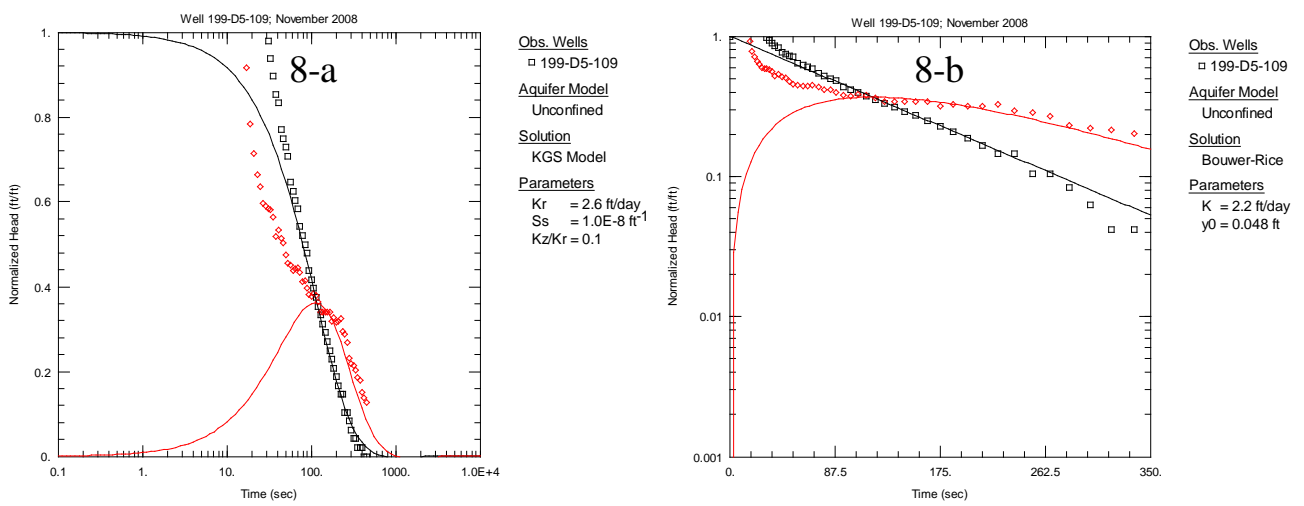

Figure F.8. Responses for Well 199-D5-109 from 11/2008 Tests (derivative shown in red) 
Well 199-D5-110
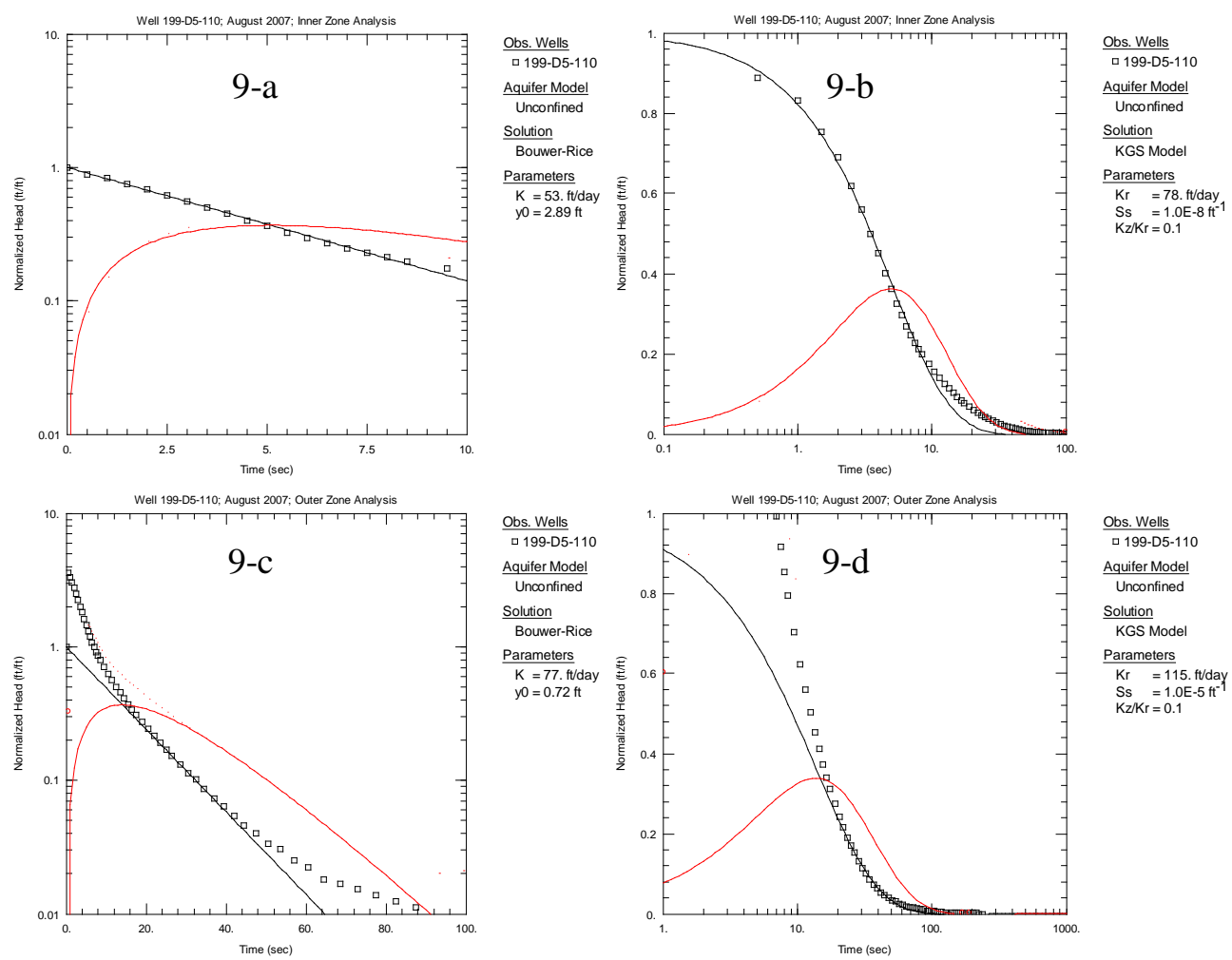

Figure F.9. Responses for Well 199-D5-110 from 08/2007 Tests (derivative shown in red)
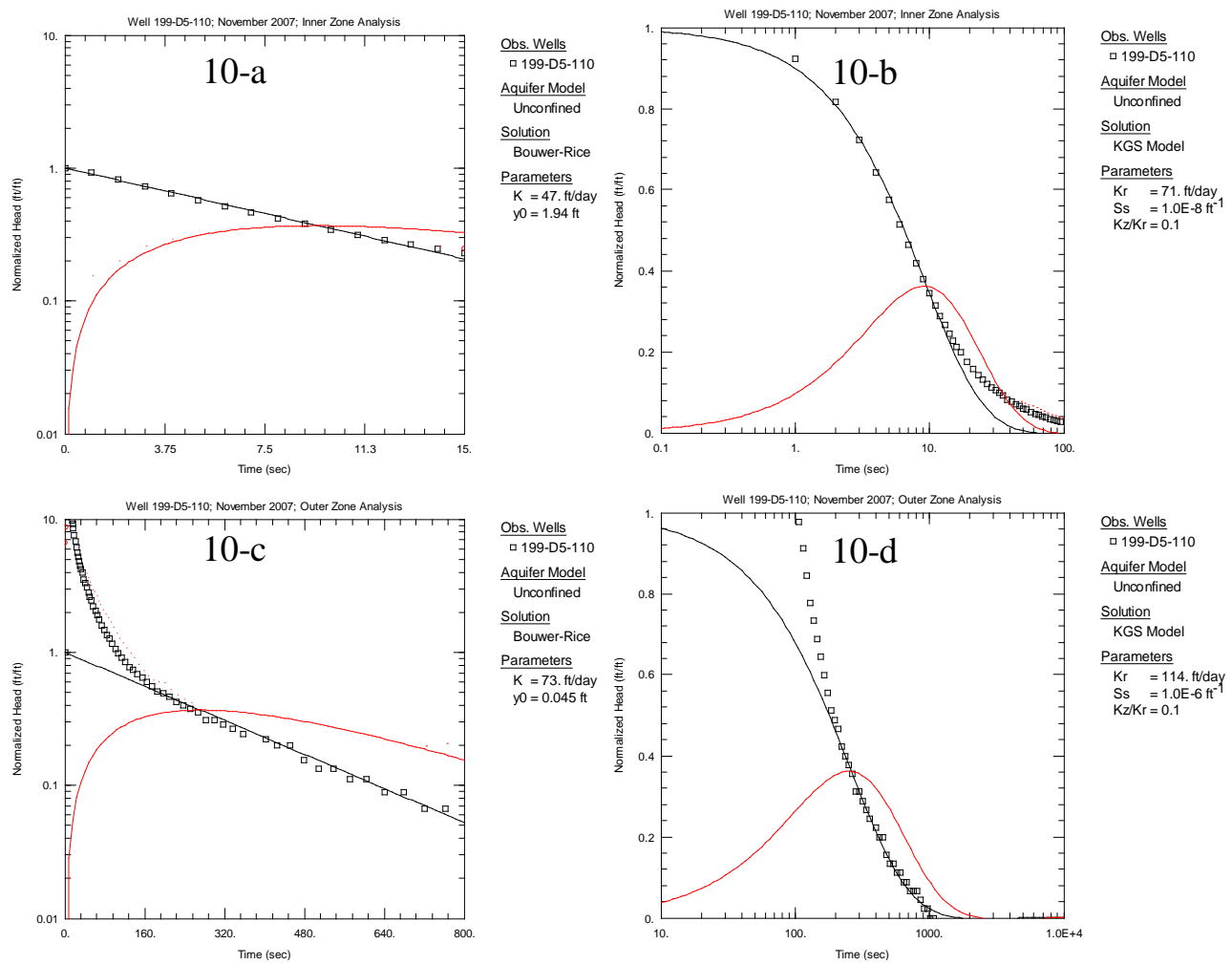

Figure F.10. Responses for Well 199-D5-110 from 11/2007 Tests (derivative shown in red) 

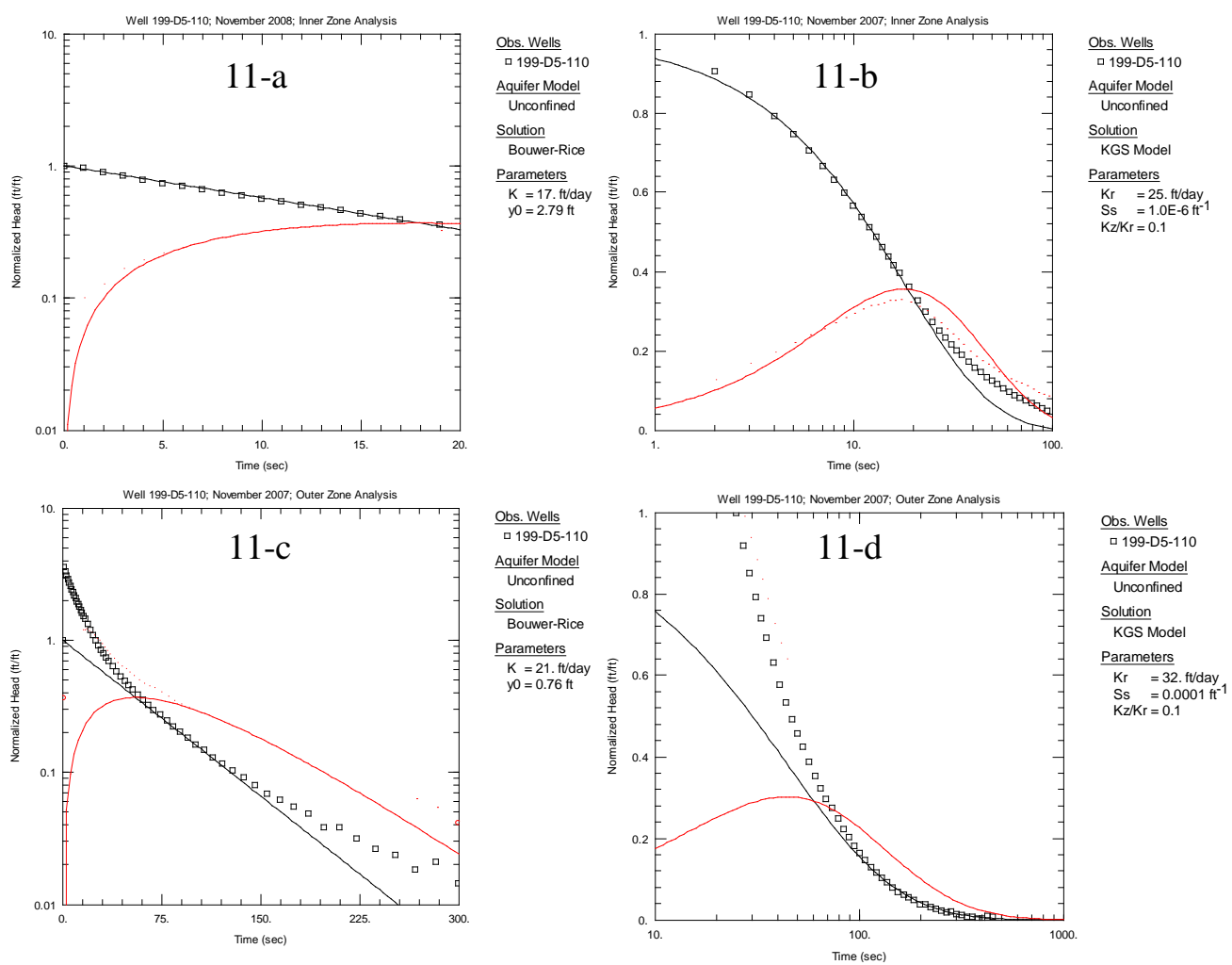

Figure F.11. Responses for Well 199-D5-110 from 11/2008 Tests (derivative shown in red) Well 199-D5-111
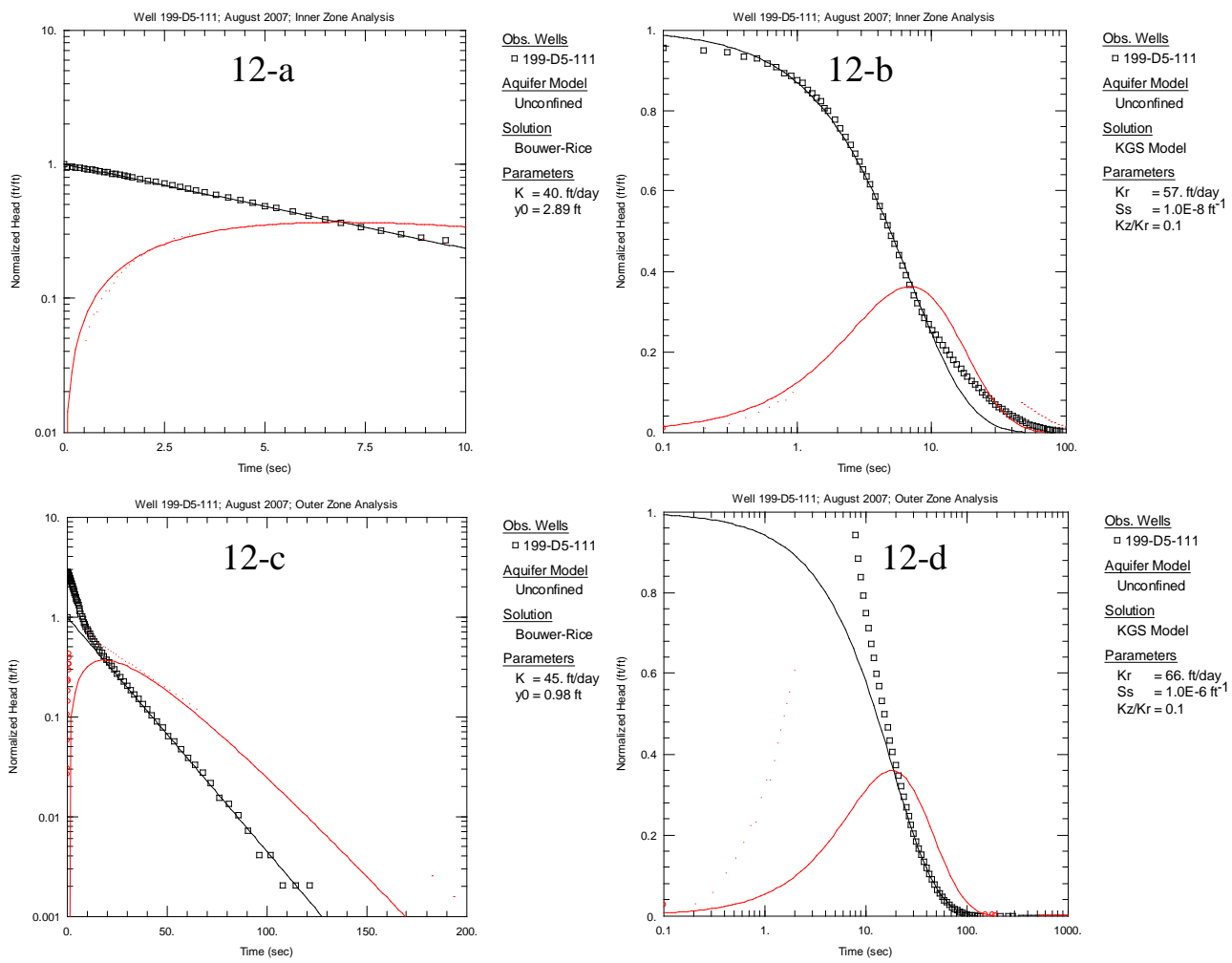

Figure F.12. Responses for Well 199-D5-111 from 08/2007 Tests (derivative shown in red) 

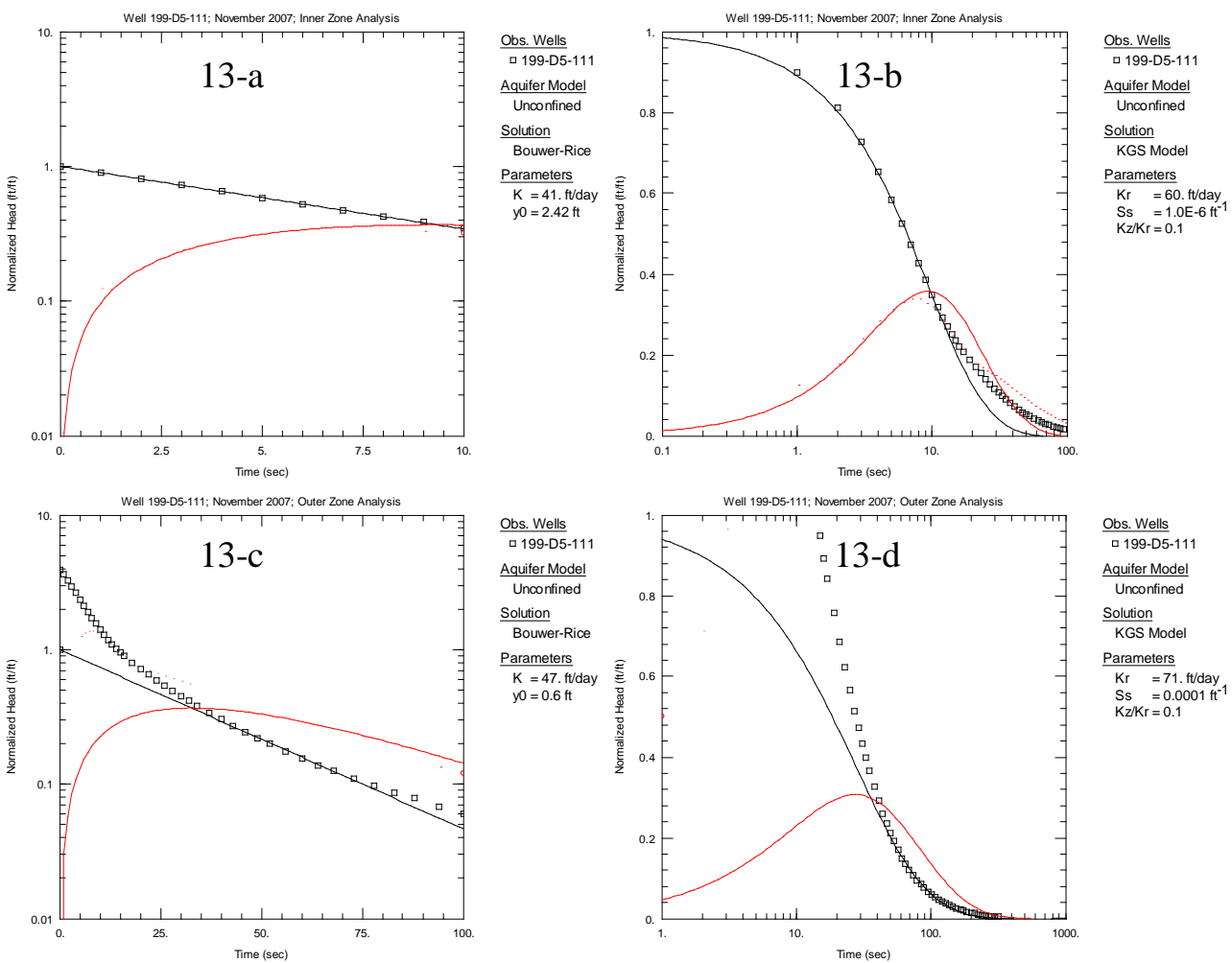

Figure F.13. Responses for Well 199-D5-111 from 11/2007 Tests (derivative shown in red)
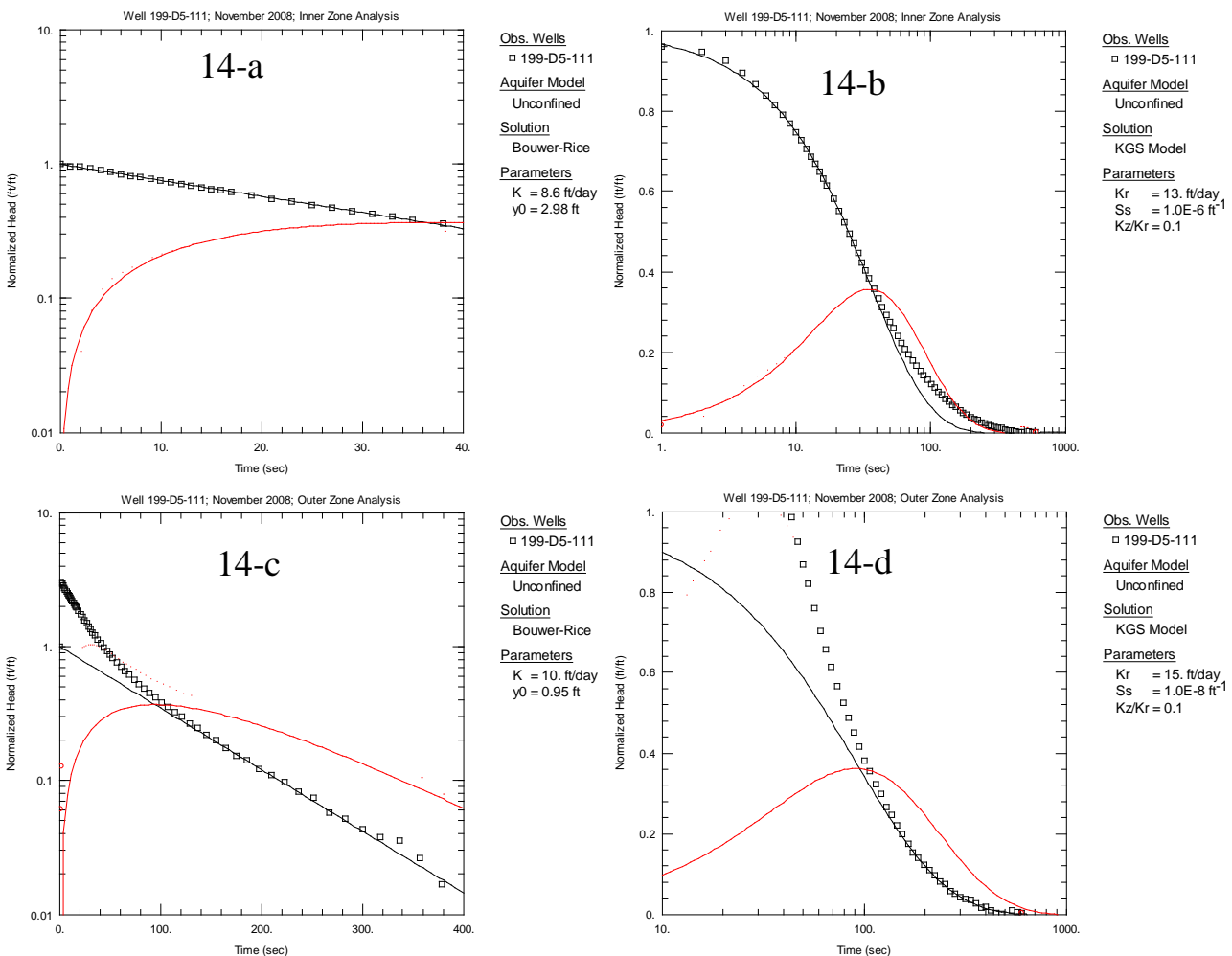

Figure F.14. Responses for Well 199-D5-111 from 11/2008 Tests (derivative shown in red) 


\section{Well 199-D5-113}
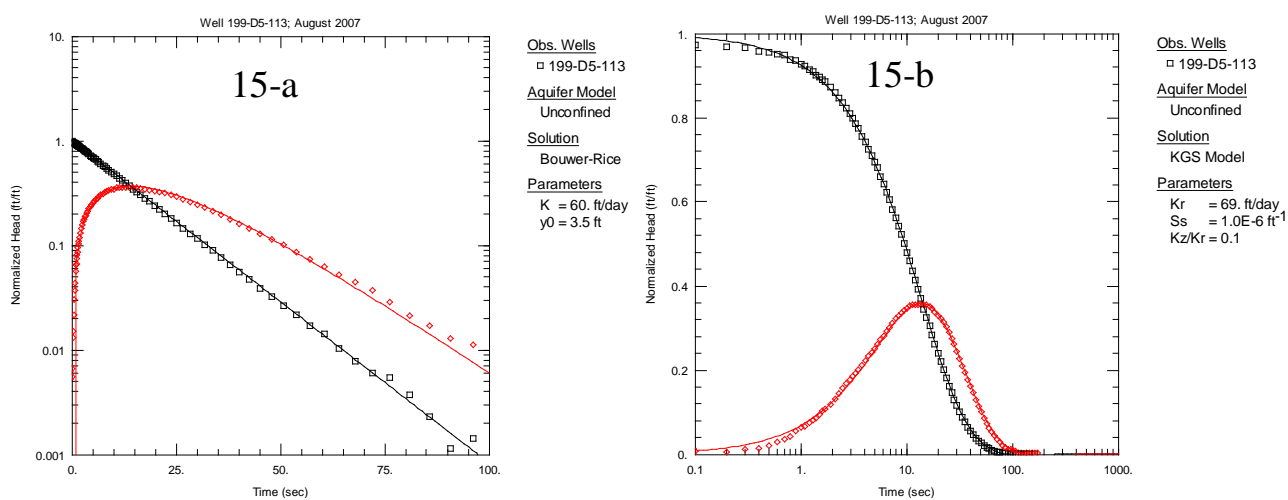

Figure F.15. Responses for Well 199-D5-113 from 08/2007 Tests (derivative shown in red)
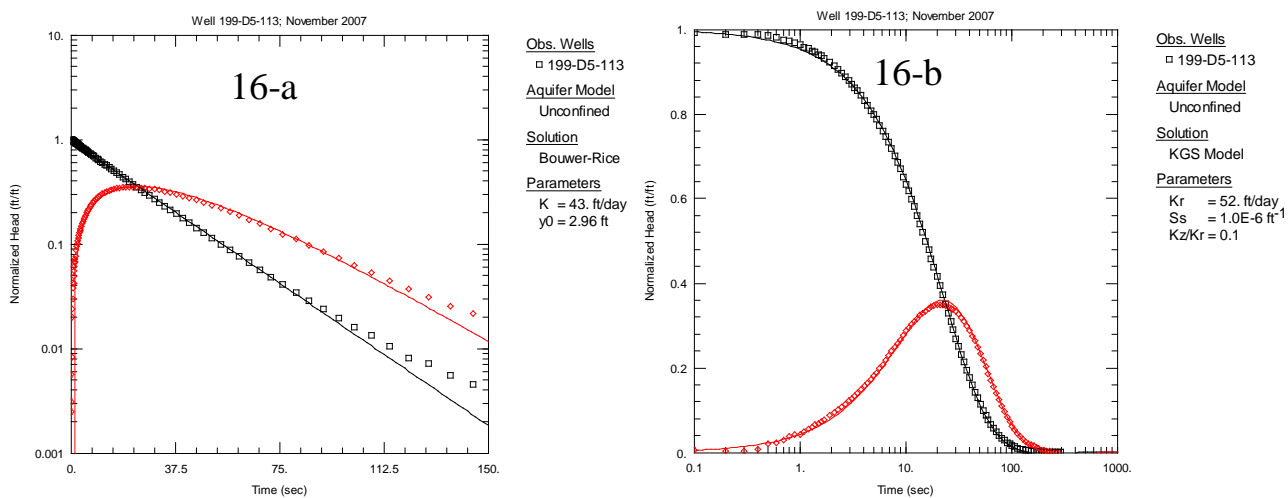

Figure F.16. Responses for Well 199-D5-113 from 11/2007 Tests (derivative shown in red)
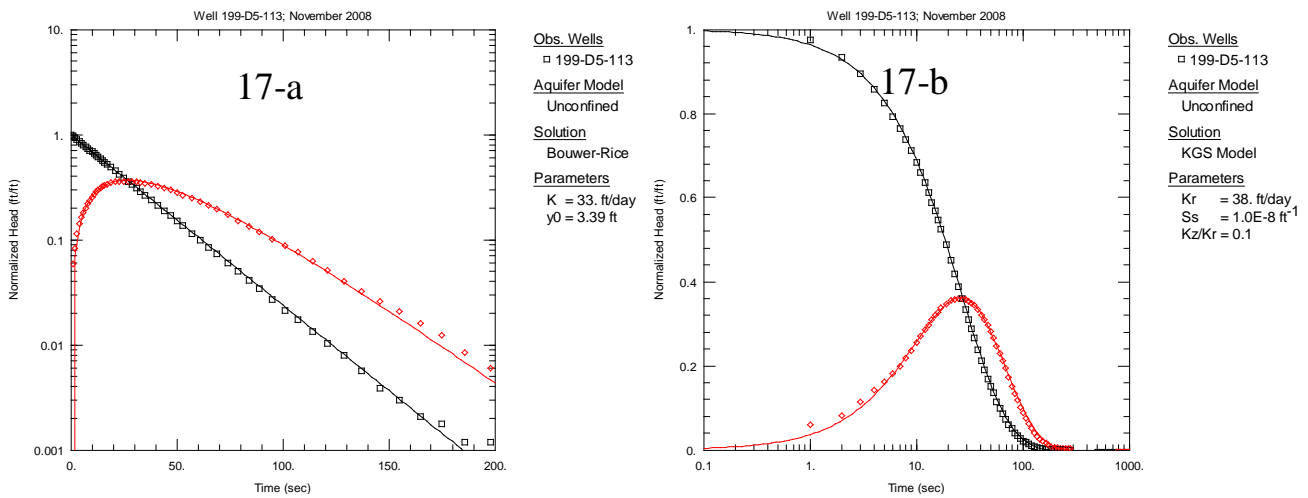

Figure F.17. Responses for Well 199-D5-113 from 11/2008 Tests (derivative shown in red) 
Well 199-D5-114
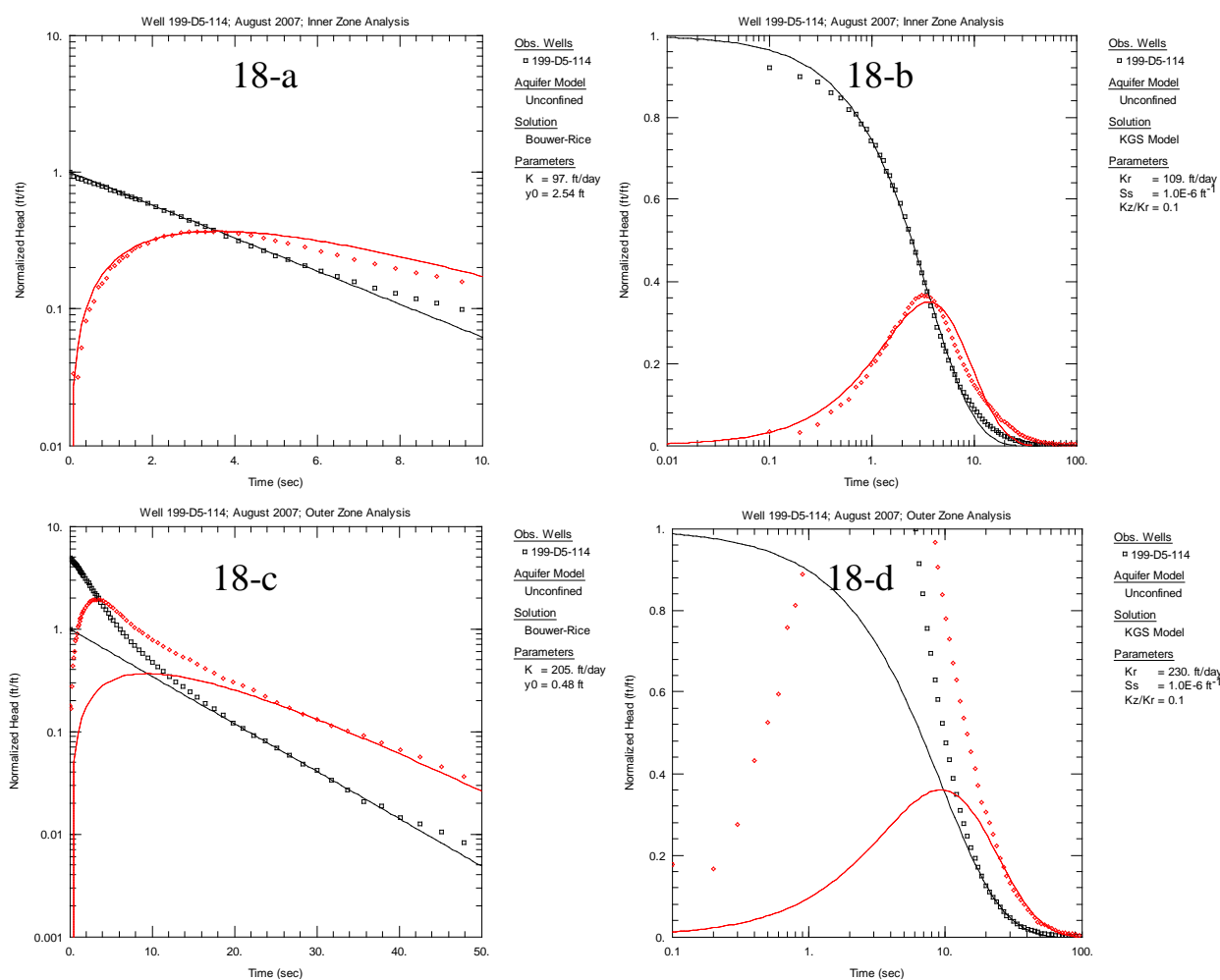

Figure F.18. Responses for Well 199-D5-114 from 11/2007 Tests (derivative shown in red)
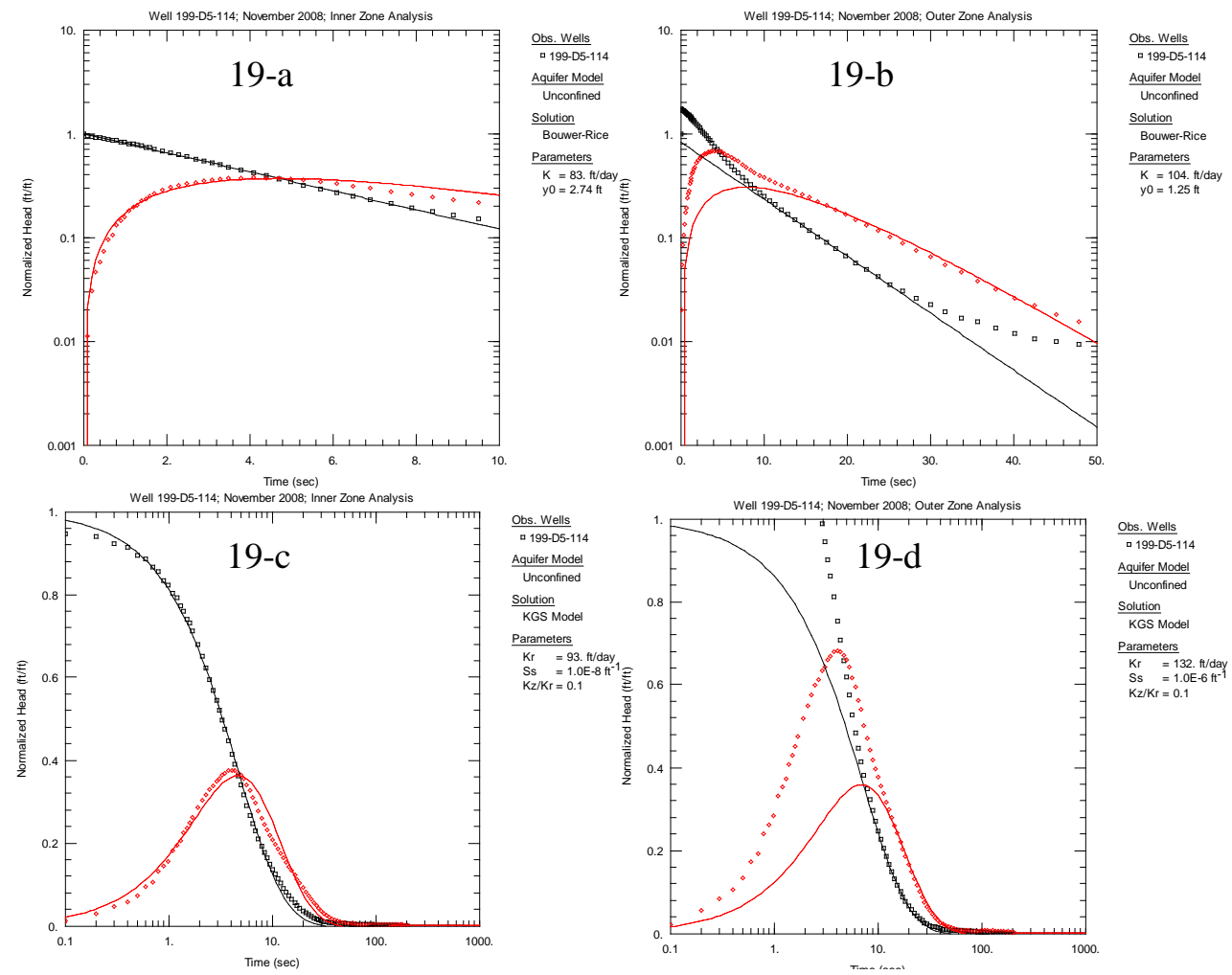

Figure F.19. Responses for Well 199-D5-114 from 11/2008 Tests (derivative shown in red) 

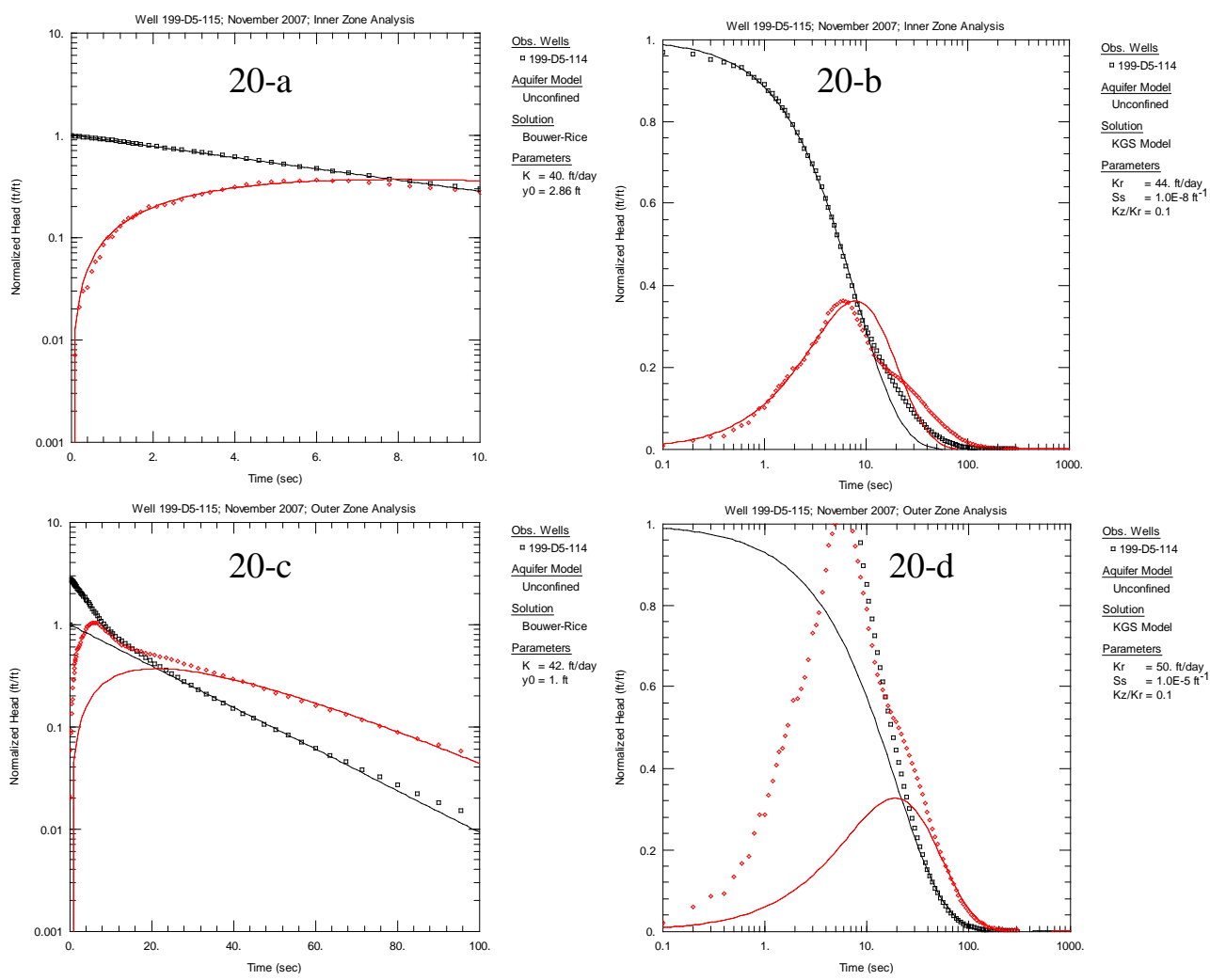

Figure F.20. Responses for Well 199-D5-115 from 11/2007 Tests (derivative shown in red)
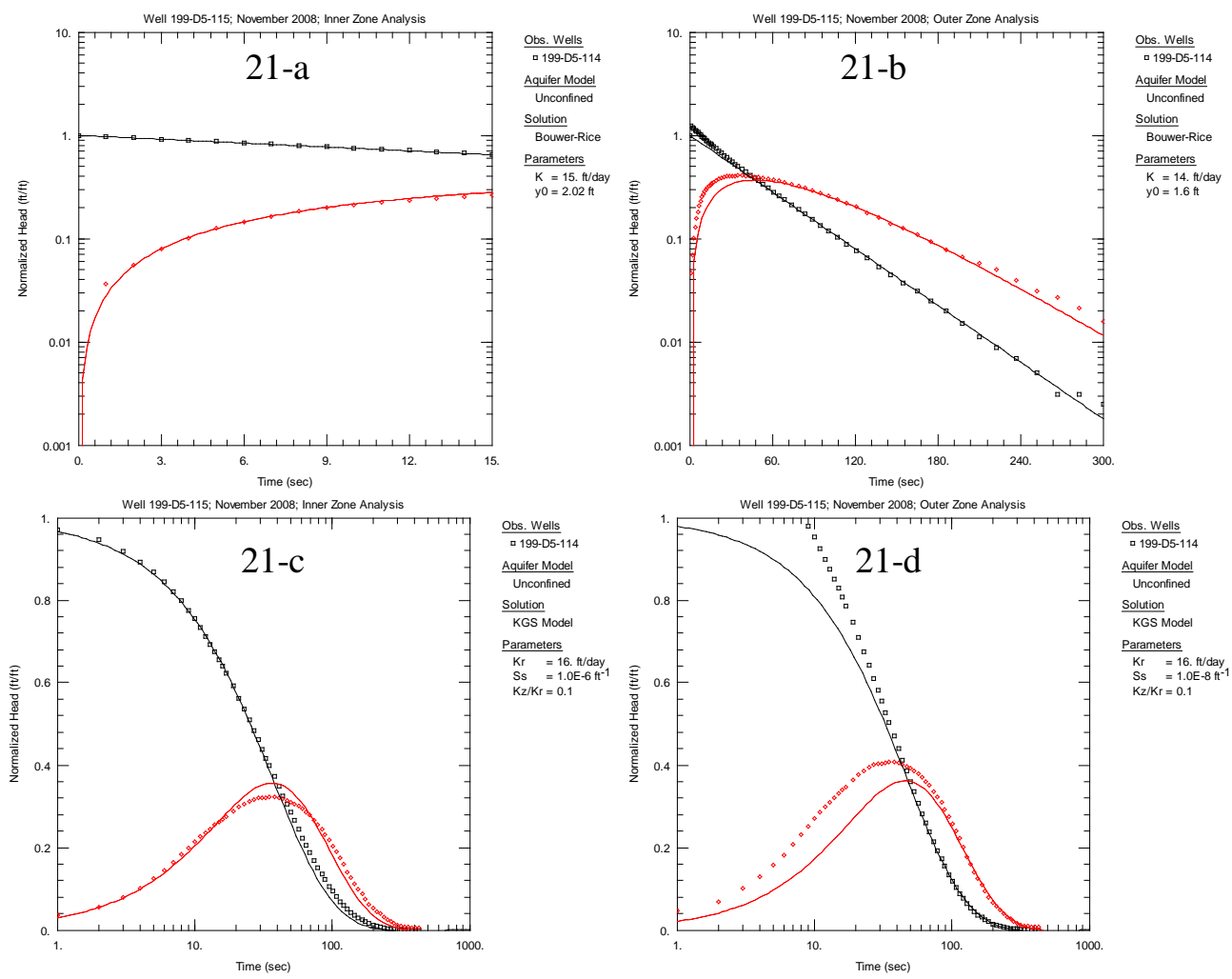

Figure F.21. Responses for Well 199-D5-115 from 11/2008 Tests (derivative shown in red) 

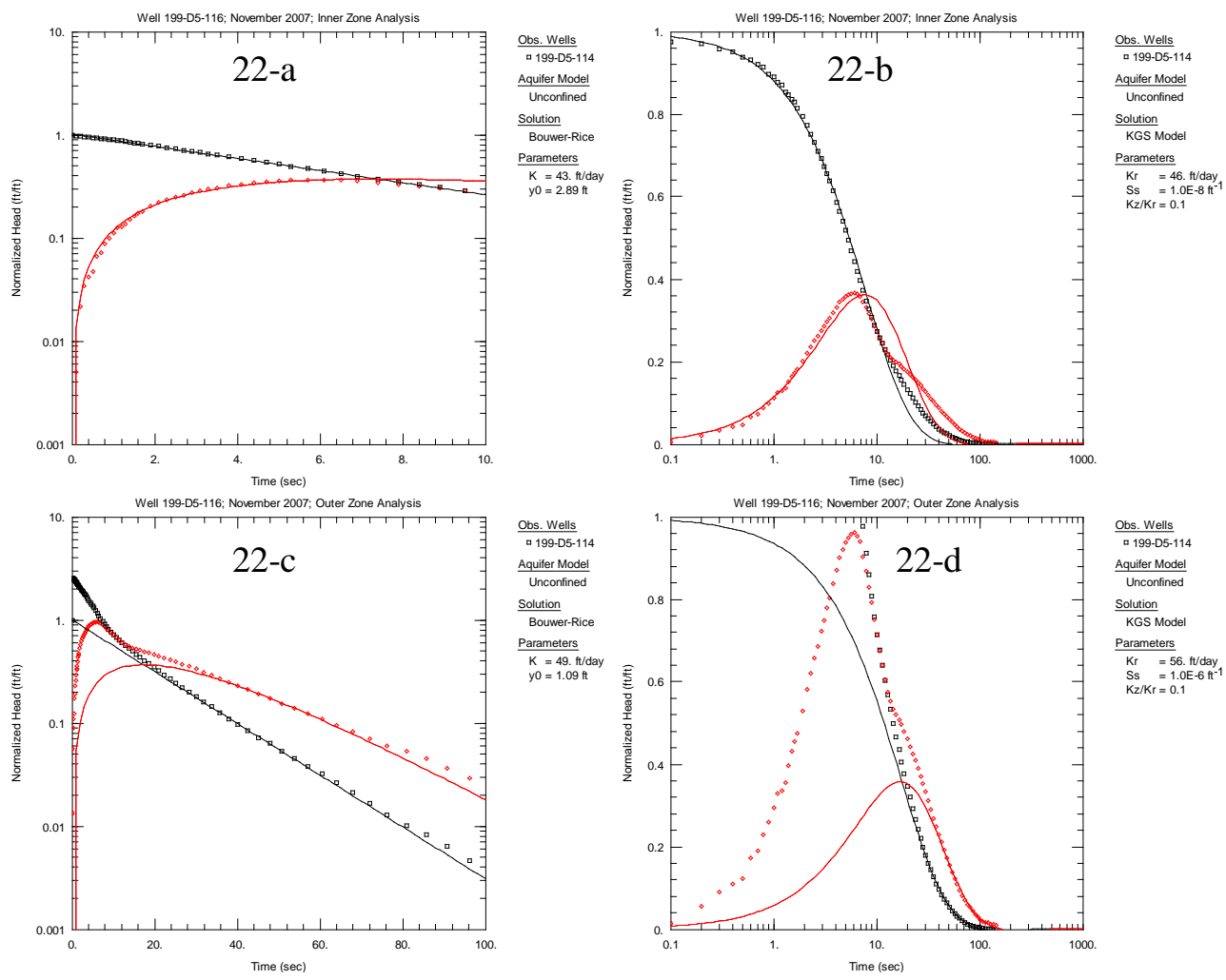

Figure F.22. Responses for Well 199-D5-116 from 11/2007 Tests (derivative shown in red)
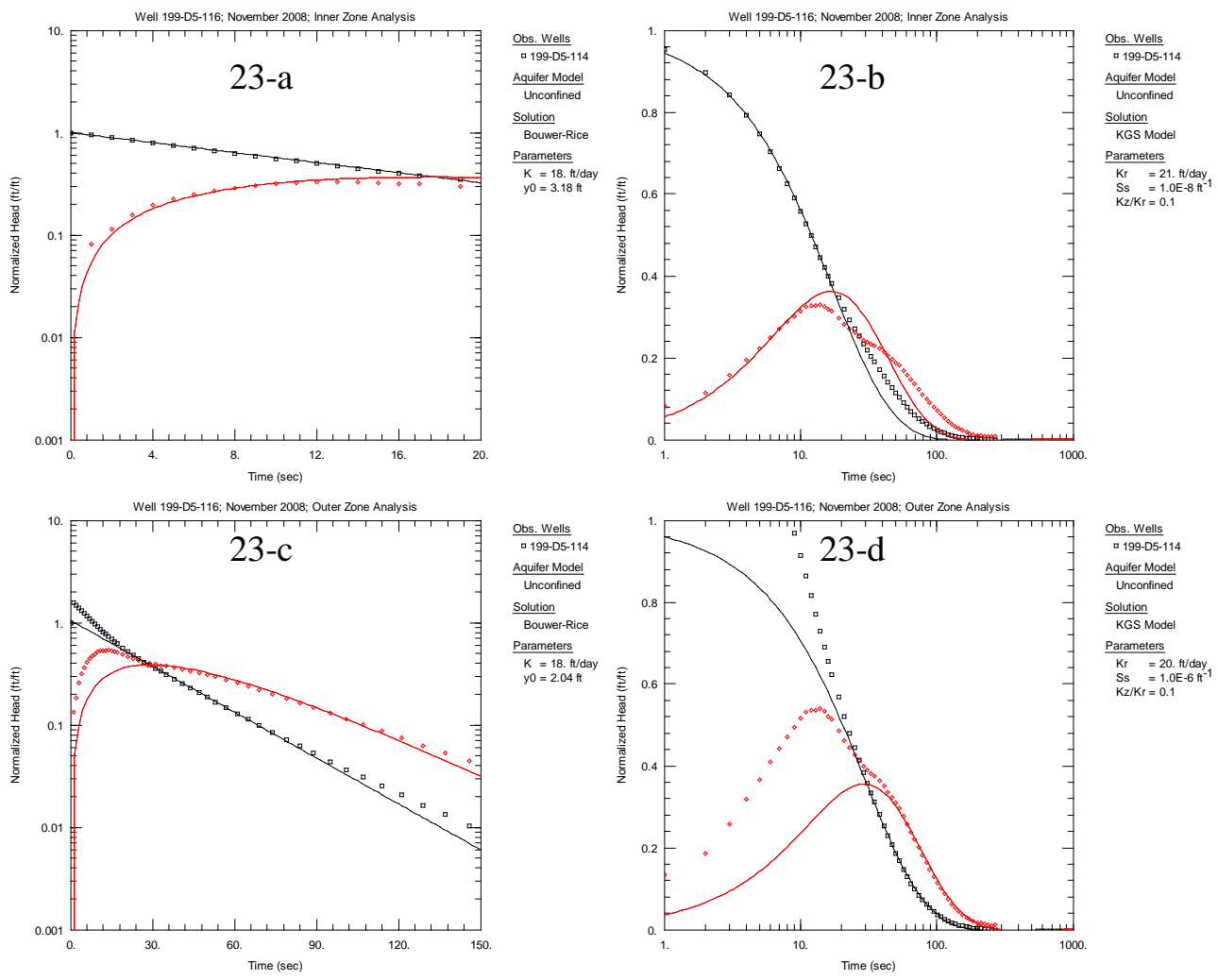

Figure F.23. Responses for Well 199-D5-116 from 11/2008 Tests (derivative shown in red) 


\section{Well 199-D5-118}
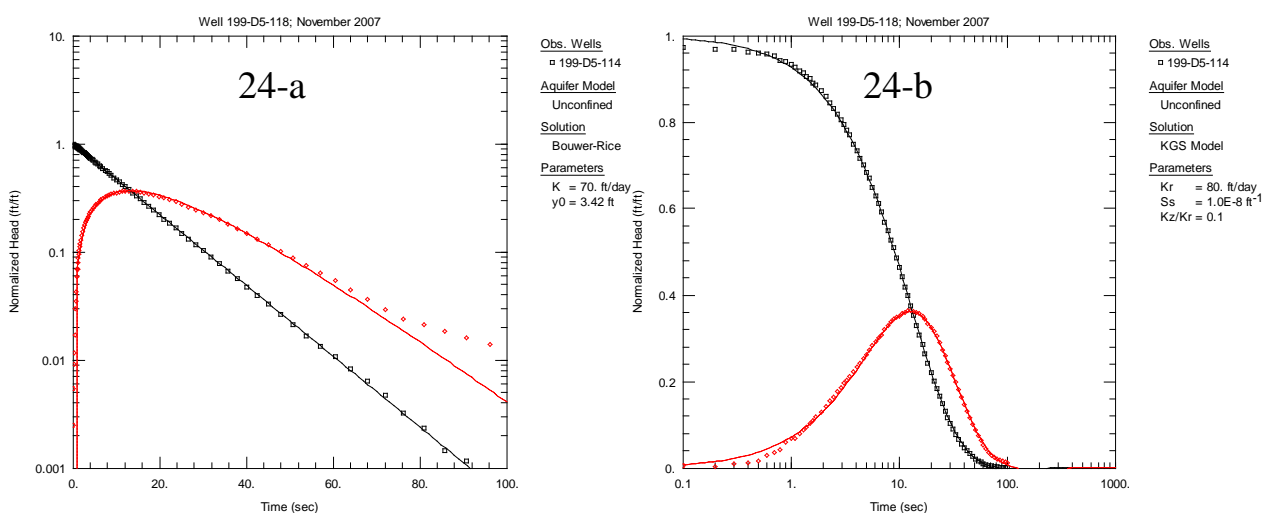

Figure F.24. Responses for Well 199-D5-118 from 11/2007 Tests (derivative shown in red)
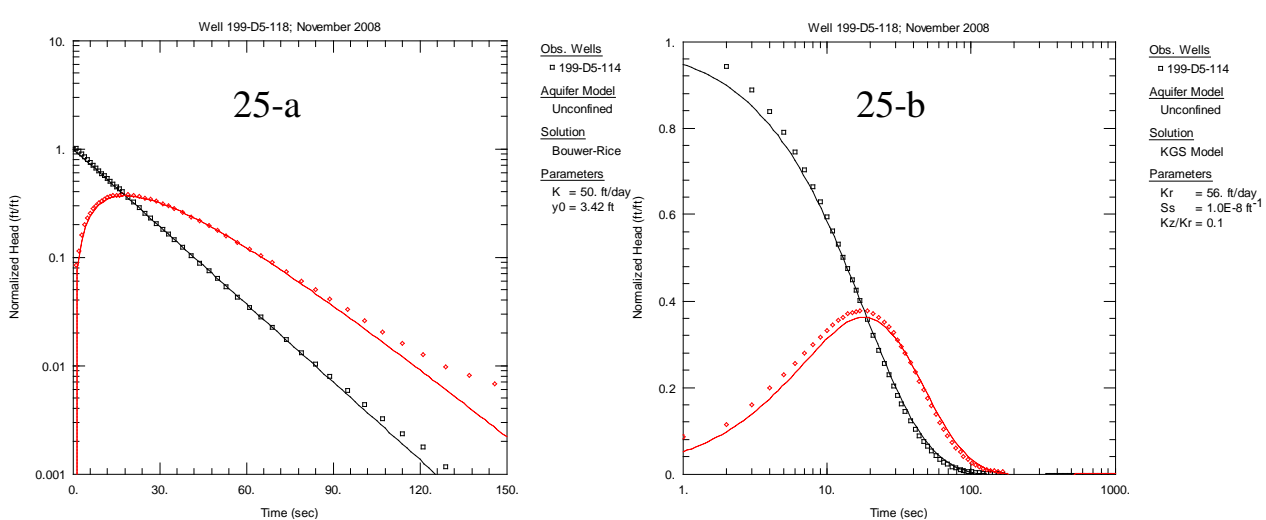

Figure F.25. Responses for Well 199-D5-118 from 11/2008 Tests (derivative shown in red)

\section{References}

Bouwer H. 1989. “The Bouwer and Rice Slug Test - An Update.” Ground Water 27(3):304-309.

Bouwer H and RC Rice. 1976. “A Slug Test Method for Determining Hydraulic Conductivity of Unconfined Aquifers with Completely or Partially Penetrating Wells.” Water Resources Research 12(3):423-428.

Butler JJ Jr. 1998. The Design, Performance, and Analysis of Slug Tests. Lewis Publishers, Boca Raton, Florida.

Hyder Z, JJ Butler Jr., CD McElwee, and W Liu. 1994. “Slug Tests in Partially Penetrating Wells.” Water Resources Research 30(11):2945-2957.

Springer RK and LW Gelhar. 1991. Characterization of Large-Scale Aquifer Heterogeneity in Glacial Outwash by Analysis of Slug Tests with Oscillatory Response. U.S. Geological Survey Water Resources Investigation Report 91-4034, Cape Cod, Massachusetts. 


\section{Distribution}

No. of

Copies

\section{OFFSITE}

G. Chamberlain, EM-22

U.S. Department of Energy

Office of Environmental Management

1000 Independence Avenue, S.W.

Washington, D.C. 20585

\section{ONSITE}

\section{DOE Richland Operations Office}

J. P. Hanson

K. M. Thompson
No. of

Copies

3 CH2M HILL Plateau Remediation Company

J. G. Blount

H3-21

S. W. Petersen H3-21

J. L. Smoot R3-50

6 Pacific Northwest National Laboratory

J. S. Fruchter (2)

K6-96

M. J. Truex

K6-96

V. R. Vermeul

K6-96

Hanford Technical Library (2)

P8-55 


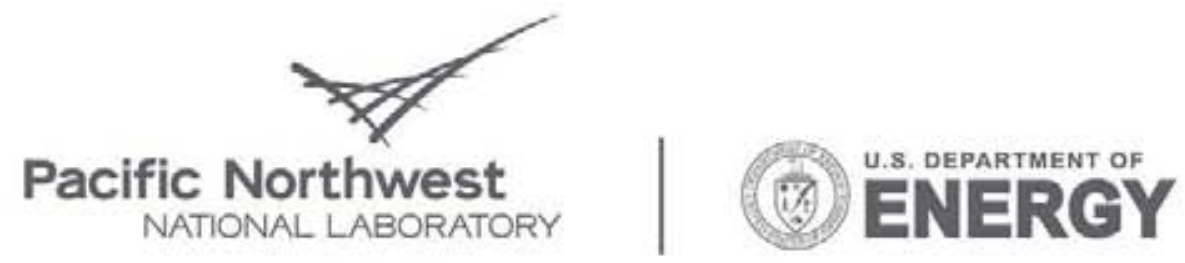

Proudly Operated by Banelle Since 1965

902 Battelle Boulevard

P.O. Box 999

Richland, WA 99352

1-888-375-PNNL (7665)

www.pnl.gov 